\title{
Tracer Gas Exposure of Human Subjects Doing Simulated Work at a Benchtop Enclosing Hood in a Wind Tunnel
}

Rolando A. Carreno-Chavez

West Virginia University

Follow this and additional works at: https://researchrepository.wvu.edu/etd

\section{Recommended Citation}

Carreno-Chavez, Rolando A., "Tracer Gas Exposure of Human Subjects Doing Simulated Work at a Benchtop Enclosing Hood in a Wind Tunnel" (2013). Graduate Theses, Dissertations, and Problem Reports. 3649.

https://researchrepository.wvu.edu/etd/3649

This Dissertation is protected by copyright and/or related rights. It has been brought to you by the The Research Repository @ WVU with permission from the rights-holder(s). You are free to use this Dissertation in any way that is permitted by the copyright and related rights legislation that applies to your use. For other uses you must obtain permission from the rights-holder(s) directly, unless additional rights are indicated by a Creative Commons license in the record and/ or on the work itself. This Dissertation has been accepted for inclusion in WVU Graduate Theses, Dissertations, and Problem Reports collection by an authorized administrator of The Research Repository @ WVU.

For more information, please contact researchrepository@mail.wvu.edu. 


\title{
TRACER GAS EXPOSURE OF HUMAN SUBJECTS DOING SIMULATED WORK AT A BENCHTOP ENCLOSING HOOD IN A WIND TUNNEL
}

\section{Rolando A. Carreño-Chávez}

\author{
Dissertation submitted to the \\ College of Engineering and Mineral Resources \\ at West Virginia University \\ in partial fulfillment of the requirements \\ for the degree of
}

\author{
Doctor of Philosophy \\ in \\ Mechanical Engineering \\ Steven Guffey, Ph.D., Chair \\ Ismail Celik, Ph.D., Co-Chair \\ Wafik Iskander, Ph.D. \\ Gary Morris, Ph.D. \\ Kenneth Means, Ph.D. \\ Mechanical and Aerospace Engineering Department \\ Morgantown, West Virginia \\ 2013
}

Keywords: Benchtop Enclosing Hood; Wind Tunnel; Human Subject and Manikin Exposure Assessment; Comparison Human-Manikin Exposure; Air Sampling; Face Velocity; Cross-Draft Velocity; Subject Body Temperature 


\title{
ABSTRACT \\ Tracer Gas Exposure of Human Subjects Doing Simulated Work at a Benchtop Enclosing Hood in a Wind Tunnel
}

\author{
Rolando A. Carreño-Chávez
}

Local exhaust ventilation devices (LEV) are critical in protecting workers from harmful airborne contaminants. The aim of this study is to investigate the factors that affect the performance of a benchtop enclosing hood. A Freon 134ahelium mixture was released from a 9" diameter pie-pan placed on the floor of a 30 " high by 36 " wide hood at 2 " from the hood face. Freon 134a was measured close to the nose and mouth for a simple manikin (unheated and not breathing), a complex manikin (heated and breathing), and ten human subjects at different times while they stood at the face of the hood in a wind tunnel. Air was drawn from probe openings at the manikin and human subjects' faces at $0.20 \mathrm{lpm}$ into 5 liter sampling bags for 20 minutes each. In a factorial study design, the manikins and the human subjects were tested at hood face velocity $\left(V_{\text {face }}\right)$ levels from 100 to 220 fpm and wind tunnel cross-draft velocity $\left(V_{\text {cross }}\right)$ levels from 14 to $63 \mathrm{fpm}$. The temperature difference $(\Delta T)$ between the subject's body and the environment was also recorded.

The results show that $V_{\text {face }}$ plays an important role on subjects' exposure. In general, the exposures decreased as $V_{\text {face }}$ increased. A statistically significant effect $(\mathrm{p}<0.001)$ of $V_{\text {face }}$ on $\log$-transformed exposure at the nose and mouth $\left(\log C_{\text {nose }}\right.$ and $\log C_{\text {mouth }}$ ) was found for both the simple manikin and the human subjects; in contrast, this effect was only found on $\log C_{\text {mouth }}$ for the complex manikin. Cross- 
draft velocity $\left(V_{\text {cross }}\right)$ showed a highly significant effect $(\mathrm{p}<0.001)$ on $\log C_{\text {nose }}$ and $\log C_{\text {mouth }}$ for the simple manikin. However, for the complex manikin and the human subjects, $V_{\text {cross }}$ presented no significant effects $(\mathrm{p}>0.05)$ on exposures $(\log$ $C_{\text {nose }}$ and $\left.\log C_{\text {mouth }}\right)$. In addition, $\Delta T$ showed no statistically significant effect on $\log C_{\text {nose }}$ and $\log C_{\text {mouth }}(\mathrm{p}>0.90)$ for either the complex manikin or the human subjects. At low Reynolds numbers $(<7000), C_{\text {nose }}$ increased as $\Delta T$ increased.

For this study, it was observed that the distance between the breathing zone and the face of the hood had a large impact on exposure. Exposures dropped dramatically for the complex manikin and the humans $\left(C_{\text {nose }}=0.0 \mathrm{ppm}\right)$ when the subjects' breathing zones were just outside of the hood face. For the human subjects, the exposure increased radically from tests where the subject aligned with the hood face $\left(C_{\text {mouth }}=2.8 \mathrm{ppm}\right)$ to the back of the head face location $\left(C_{\text {mouth }}=93.3\right.$ ppm). In addition, the human subjects' body dimensions such as height, weight, and width of the shoulders had a highly significant effect on exposure $(\mathrm{p}<0.0001)$. The comparisons of the results between each of the manikins and the ten human subjects found that the two manikins did not differ significantly from the three human subjects with greatest exposures and were not consistently different from each other. 


\section{DEDICATION}

To my parents for their endless love and support 


\section{ACKNOWLEDGMENTS}

This dissertation was made possible by the love and constant support of all my family members. I feel so lucky to have them in my life. I would like to thank my parents Tomás and Doris, my brothers Wilmer and Edgardo, my sister Yliana, and my nieces Yanira and Issely for their unconditional love, support, and continuous encouragement during my studies at West Virginia University.

I would like to give my sincere gratitude to my research advisor and committee chair Dr. Steven Guffey for his encouragement, support, and invaluable guidance through the different stages of this project. I learned many things from his expertise in the area during many hours of conversation. I would also like to thank my research co-advisor, Dr. Ismail Celik, for his initial support for the project and his insights and encouragement in this study.

I wish to express my sincere appreciation and thanks to Dr. Wafik Iskander, Dr. Gary Morris, and Dr. Kenneth Means for taking time to serve as my committee members. Especially, I would like to thank Dr. Iskander for his helpful advice in the statistical analysis of the results. In addition, I would like to thank Dr. Alain Lui and Kevin He for their help in the data collection, and all the human subjects who were willing to participate in this study. Finally, I would like to thank the WVU

Writing Center, especially Natalie Carpini and Julia Kurtz for the proofreading of my dissertation. 


\section{TABLE OF CONTENTS}

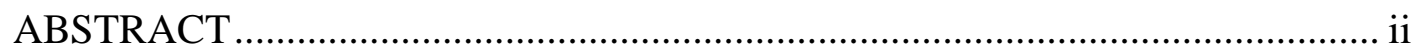

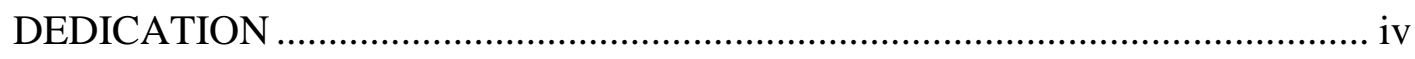

ACKNOWLEDGMENTS ......................................................................

TABLE OF CONTENTS ........................................................................ vi

LIST OF SYMBOLS .........................................................................

LIST OF TABLES ......................................................................... xvi

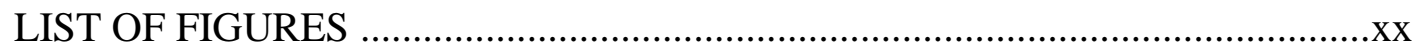

CHAPTER 1. INTRODUCTION ..........................................................

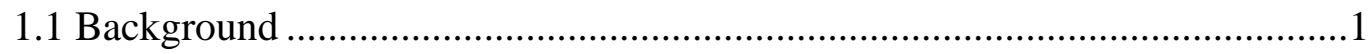

1.2 Protection efficiency for enclosing hood ...............................................

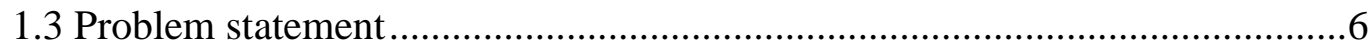

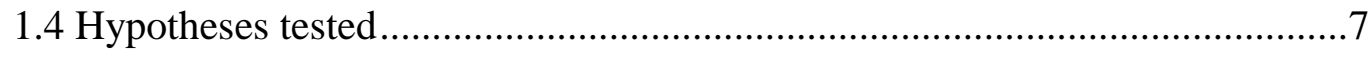

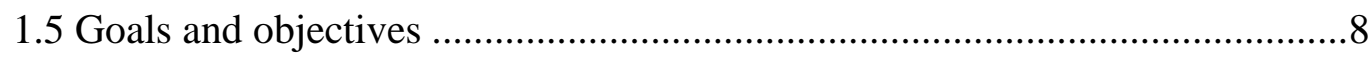

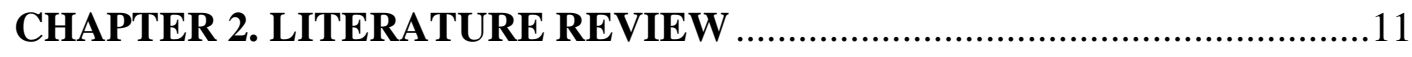

2.1 Manikin in free-stream studies....................................................... 11

2.2 Manikin at plain hood studies ......................................................... 13

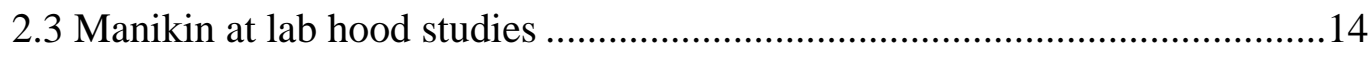

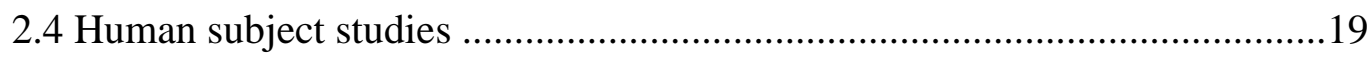

2.5 Computational fluid dynamics studies (CFD) ........................................22 


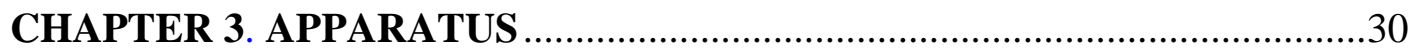

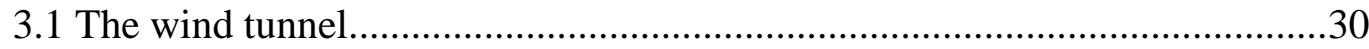

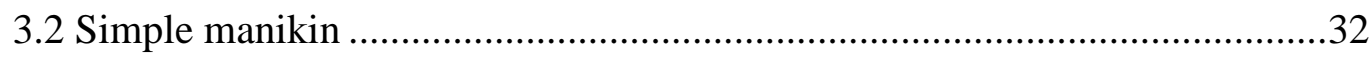

3.3 Anthropometrically-correct manikin.................................................................3

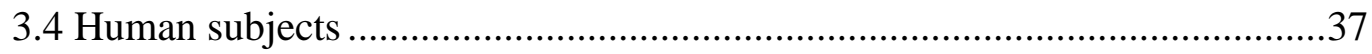

3.5 Benchtop enclosing hood .............................................................................. 38

3.6 Tracer gas mixture system ………………………………….....................40

3.7 Pitot traverse measurements.........................................................................41

3.8 Tracer gas sampling apparatus ....................................................................42

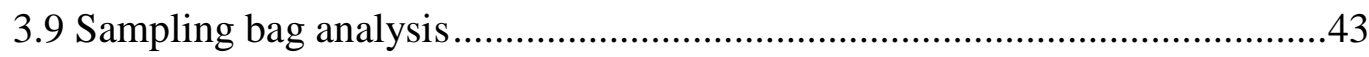

3.10 Temperature, humidity, and barometric pressure …………………….........44

CHAPTER 4. RESEARCH DESIGN, METHODS, AND PROCEDURES .....46

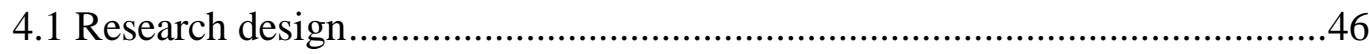

4.2 Research methods....................................................................................4

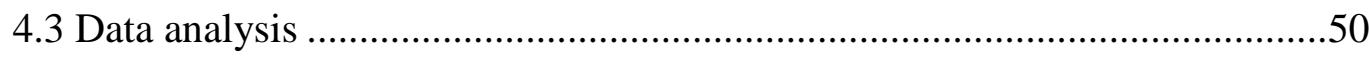

4.4 Enclosing hood experimental test procedures...............................................51

4.4.1 Equipment preparation prior to experimental runs .................................52

4.4.2 Procedures during the experimental runs ...............................................54

4.4.3 Procedures after the experimental runs ....................................................55

4.4.4 Calibration of the FTIR gas analyzer ...................................................56

4.4.5 SKC low-flow sampling pumps calibration ..........................................57 
CHAPTER 5. SIMPLE MANIKIN STUDY ............................................. 58

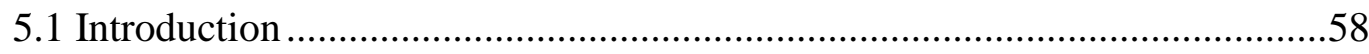

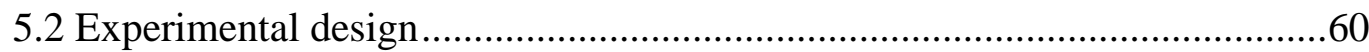

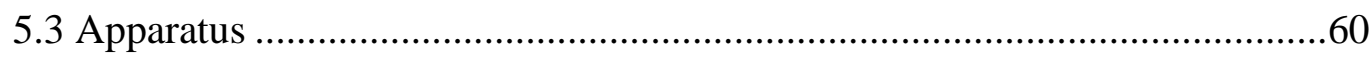

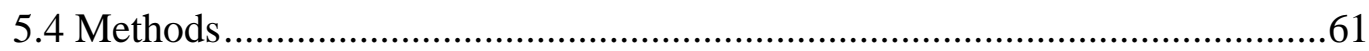

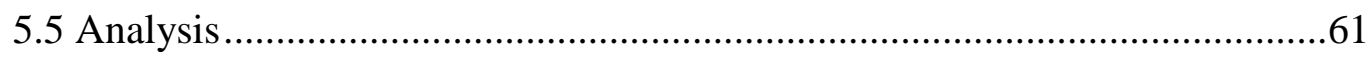

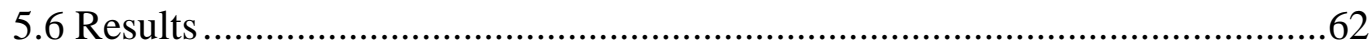

5.6.1 Fluid dynamics considerations .................................................64

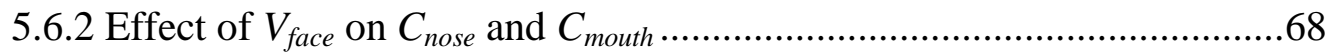

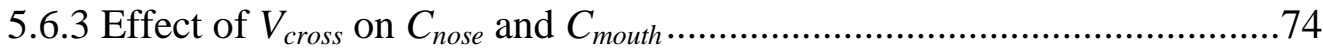

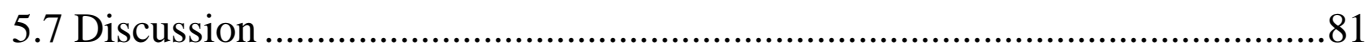

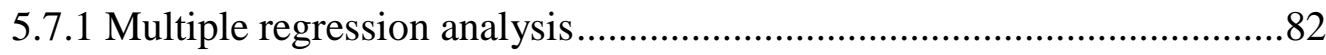

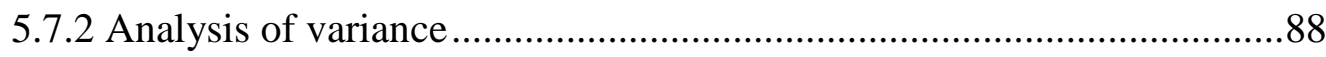

5.7.3 Effectiveness of the enclosing hood................................................91

CHAPTER 6. ANTHROPOMETRIC MANIKIN STUDY ............................93

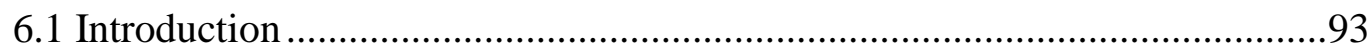

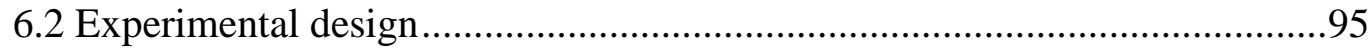

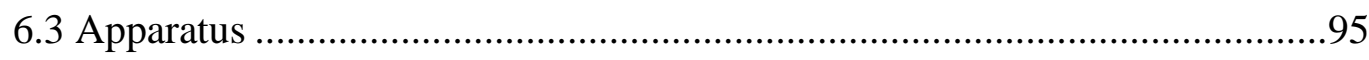

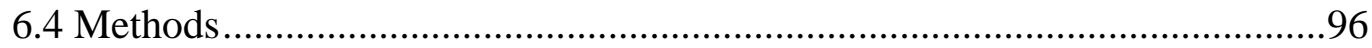

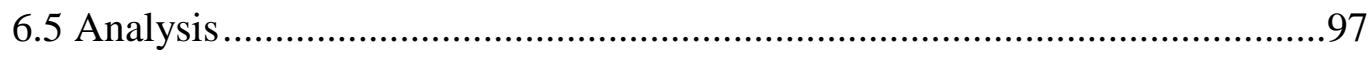

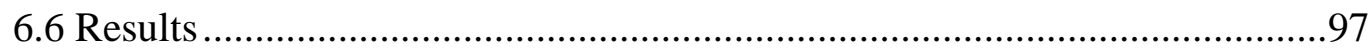

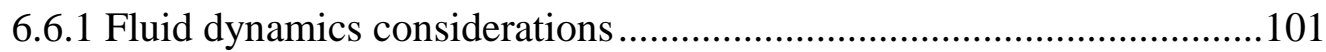




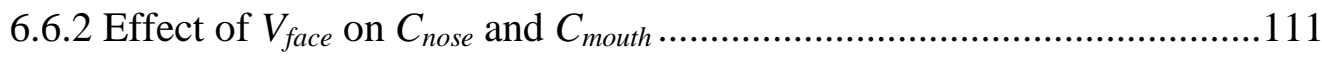

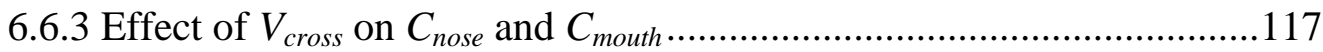

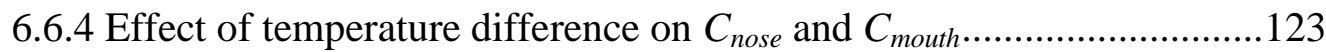

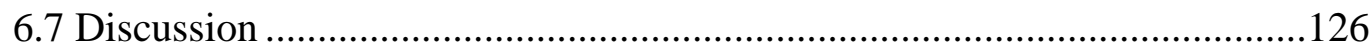

6.7.1 Analysis of covariance ......................................................................128

6.7.2 Effectiveness of the enclosing hood.....................................................132

6.7.3 Complex manikin's body temperature and heat transfer .......................135

6.7.4 Effect of thermocouple on manikin's face ............................................139

6.7.5 Effect of face location on exposure ......................................................147

6.7.6 Effect of the distance between the breathing zone and the source.........149

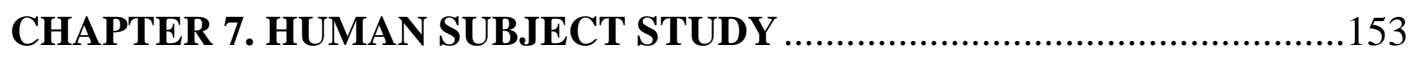

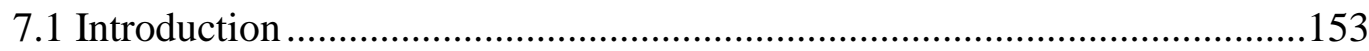

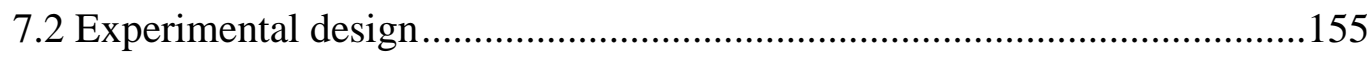

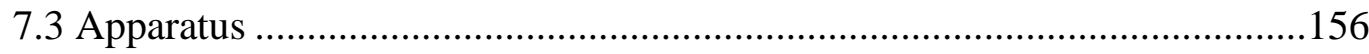

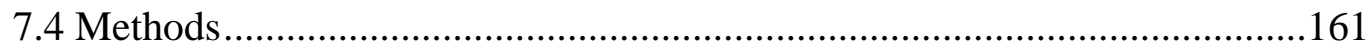

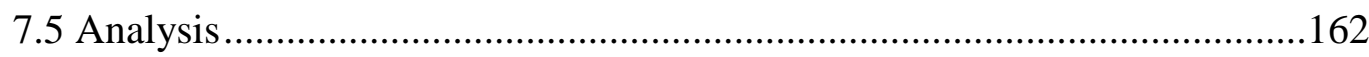

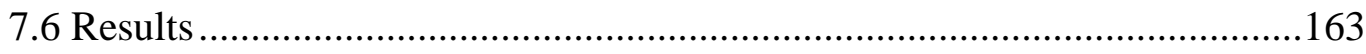

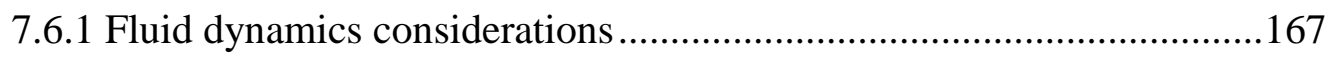

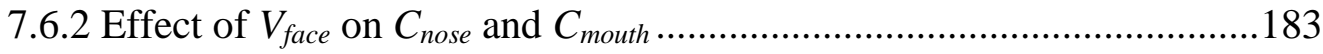

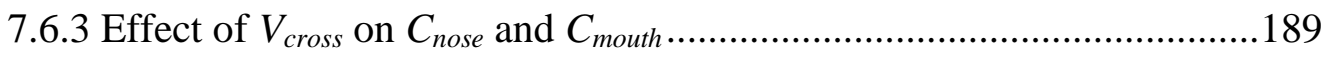

7.6.4 Effect of humans' temperature on $C_{\text {nose }}$ and $C_{\text {mouth }} \ldots \ldots \ldots \ldots \ldots \ldots \ldots \ldots \ldots \ldots \ldots . . . . . . . . . .194$

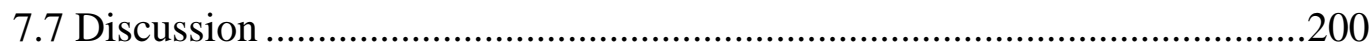


7.7.1 Analysis of covariance.....

7.7.2 Effect of human subjects' body dimensions .....................................206

7.7.3 Effectiveness of the enclosing hood.................................................209

7.7.4 Effect of face location on exposure ..............................................211

7.7.5 Effect of the distance between the breathing zone and the source........213

\section{CHAPTER 8. COMPARISONS OF EXPOSURE FOR THE SIMPLE}

MANIKIN, THE COMPLEX MANIKIN, AND THE HUMAN SUBJECTS 217

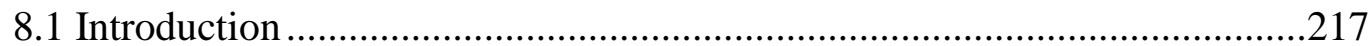

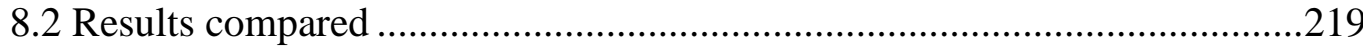

8.2.1 Comparison of the effect of $V_{\text {face }}$ on exposure ..................................222

8.2.2 Comparison of the effect of $V_{\text {cross }}$ on exposure ...............................227

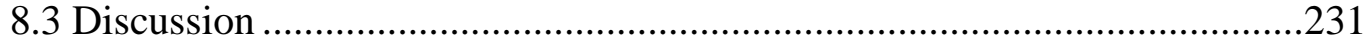

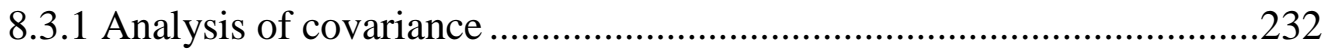

CHAPTER 9. CONCLUSIONS AND RECOMMENDATIONS ..................237

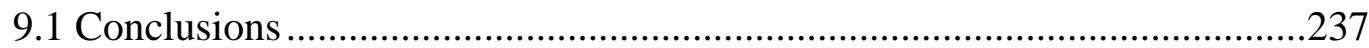

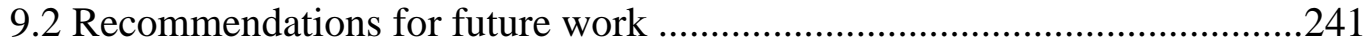

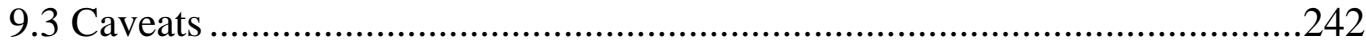

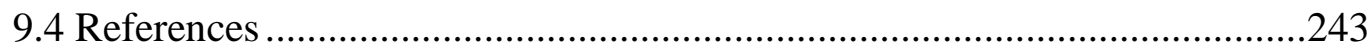

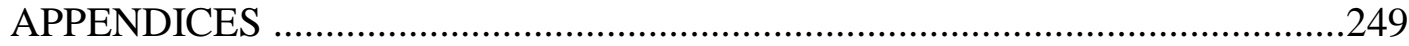

APPENDIX A: Basic statistic relationships .................................................249

APPENDIX B: Cross-draft velocity and face velocity equations.....................250

APPENDIX C: Simple manikin .................................................................252 
APPENDIX D: Anthropometrically-correct manikin

APPENDIX E: Human subjects

APPENDIX F: Calibration curve of Gasmet FTIR gas analyzer .264

APPENDIX G: Calibration of SKC ${ }^{\circledR}$ low flow sample pump .........................265

APPENDIX H: Calibration of Airflow PVM 100 micromanometer .................266 APPENDIX I: Themometers calibration with a standard ASTM thermometer 268 APPENDIX J: Hydraulic diameter $\left(D_{h}\right)$ .270

APPENDIX K: Thermocouples' temperature .272 


\section{LIST OF SYMBOLS}

\section{Roman Symbols}

$\begin{array}{ll}C_{\text {ambientAvg }} & \text { Average concentration of ambient right and left location, [ppm] } \\ C_{\text {ambient }} & \text { Concentration at ambient left location, [ppm] } \\ C_{\text {ambient }} & \text { Concentration at ambient right location, [ppm] } \\ C_{\text {downstream }} & \text { Concentration at downstream location, [ppm] } \\ C_{\text {duct }} & \text { Concentration at the exhaust duct location, [ppm] } \\ C_{\text {mouth }} & \text { Corrected concentration at mouth location, [ppm] } \\ C_{\text {mouthMeas }} & \text { Measured concentration at mouth location, [ppm] } \\ C_{\text {nose }} & \text { Corrected concentration at nose location, [ppm] } \\ C_{\text {noseMeas }} & \text { Measured concentration at nose location, [ppm] } \\ C_{r e f} & \text { Maximum concentration at the nose or mouth, [ppm] } \\ g & \text { Acceleration of gravity, [m/s }{ }^{2} \text { ] } \\ G r & \text { Grashof number, [-] } \\ H_{\text {man }} & \text { Vertical distance from the hood table to the manikin's top of the head, } \\ & \text { [in] } \\ H_{\text {human }} & \text { Vertical distance from the hood table to the human's top of the head, } \\ R e & \text { Reynolds number, [-] } \\ R i & \text { Richardson number, [-] } \\ R_{\text {adj }}^{2} & \text { Adjusted coefficient of determination, [-] }\end{array}$




$\begin{array}{ll}R^{2} & \text { Coefficient of determination, [-] } \\ T_{\text {ambient }} & \text { Dry bulb ambient' temperature, [deg F] } \\ T_{\text {humanAvg }} & \text { Average human' temperature, [deg F] } \\ T_{\text {manAvg }} & \text { Average manikin' temperature, [deg F] } \\ T_{o} & \text { Ambient temperature, [deg F] } \\ U & \text { Approach velocity, [fpm] } \\ V_{\text {cross }} & \text { Wind tunnel cross-draft velocity, [fpm] } \\ V_{\text {face }} & \text { Hood face velocity, [fpm] } \\ V_{\text {crossm }} & \text { Wind tunnel cross-draft velocity subtracted from its mean, [fpm] } \\ V_{\text {facem }} & \text { Hood face velocity subtracted from its mean, [fpm] } \\ \Delta T & \text { Human subjects' and manikins' temperature differences, [deg F] } \\ \Delta T_{\text {human }} & \text { Human subjects' temperature difference, [deg F] } \\ \Delta T_{\text {man }} & \text { (delTmanRoom) Manikins' temperature difference, [deg F] }\end{array}$

\section{Greek Symbols}

$\beta \quad$ Thermal expansion coefficient, $[1 / \mathrm{K}]$

$\mu_{h s} \quad$ Human subject mean, [ppm]

$\mu_{m k} \quad$ Manikin sample mean, [ppm]

$v \quad$ Kinematic viscosity, $\left[\mathrm{m}^{2} / \mathrm{s}, \mathrm{ft}^{2} / \mathrm{s}\right]$

\section{Subscripts}

$\begin{array}{ll}\text { cross } & \text { Cross-draft } \\ \text { face } & \text { Face }\end{array}$




\begin{tabular}{|c|c|}
\hline \multicolumn{2}{|c|}{ Abbreviations } \\
\hline ACGIH & American conference of governmental industrial hygiene \\
\hline ANOVA & Analysis of variance \\
\hline ASHRAE & American society of heating, refrigeration, and air-conditioning \\
\hline & engineers \\
\hline $\mathrm{BZ}$ & Breathing zone \\
\hline CFD & Computational fluid dynamics \\
\hline CTA & Constant temperature anemometer \\
\hline $\mathrm{CV}$ & Coefficient of variation \\
\hline Fpm & Feet per minute \\
\hline I.D. & Internal diameter, [in] \\
\hline LEV & Local exhaust ventilation \\
\hline $1 \mathrm{pm}$ & Liters per minute \\
\hline Max & Maximum value \\
\hline Min & Minimum value \\
\hline NIOSH & National institute for occupational safety and health \\
\hline OSHA & Occupational safety and health administration \\
\hline Ppm & Parts per million \\
\hline RANS & Reynolds average Navier-Stokes \\
\hline RNG & Renormalization group \\
\hline S & Standard deviation \\
\hline SSE & Error sum of squares \\
\hline
\end{tabular}


SST Shear stress transport

TairDB Ambient air temperature, [deg F]

TLV Threshold limit value 


\section{LIST OF TABLES}

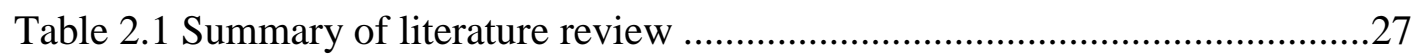

Table 4.1 Description of sampling locations .........................................................48

Table $5.1 C_{\text {nose }}$ for the simple manikin study in ppm..............................................63

Table $5.2 C_{\text {mouth }}$ for the simple manikin study in ppm ...........................................64

Table 5.3 Reynolds numbers for the simple manikin experiments ...........................65

Table 5.4 Log $C_{\text {nose }}$ regression model for the simple manikin..................................84

Table 5.5 $\log C_{\text {mouth }}$ regression model for simple manikin ......................................86

Table 5.6 Log $C_{\text {nose }}$ ANOVA for the simple manikin ...............................................89

Table 5.7 Log $C_{\text {mouth }}$ ANOVA for the simple manikin ............................................89

Table $6.1 C_{\text {nose }}$ for the complex manikin study in ppm.........................................98

Table 6.2 Summary statistics of $C_{\text {nose }}$ for the complex manikin..............................99

Table $6.3 C_{\text {mouth }}$ for the complex manikin study in ppm .......................................100

Table 6.4 Summary statistics of $C_{\text {mouth }}$ for the complex manikin ..........................101

Table 6.5 Reynolds numbers for complex manikin experiments...........................102

Table 6.6 Richardson numbers for the complex manikin experiments..................107

Table 6.7 Temperature difference data $\left(\Delta T_{\operatorname{man}}\right)$ for the complex manikin in ${ }^{\circ} \mathrm{F} \ldots . .123$

Table 6.8 No-interaction $\log C_{\text {nose }}$ ANCOVA for the complex manikin ................130

Table 6.9 No-interaction $\log C_{\text {mouth }}$ ANCOVA for the complex manikin ..............131

Table $6.10 \log C_{\text {nose }}$ ANCOVA for the complex manikin ...................................132

Table 6.11 Log $C_{\text {mouth }}$ ANCOVA for the complex manikin .................................132 
Table 6.12 Complex manikin's temperature distribution and heat transfer..... 135

Table 6.13 Humans' heat transfer distribution (Kilic and Sevilgen, 2008) ...........136

Table 6.14 Humans' total heat transfer (Kilic and Sevilgen, 2008)

138

Table 6.15 Concentrations at the nose (ppm) with and without thermocouple for the complex manikin

140

Table 6.16 Concentrations at the mouth (ppm) with and without thermocouple for

the complex manikin

Table 6.17 Summary statistic for complex manikin with and without thermocouple

Table $6.18 C_{\text {nose }}$ ANOVA for the complex manikin with and without thermocouple

Table $6.19 C_{\text {mouth }}$ ANOVA for complex manikin with and without thermocouple

Table 6.20 Log $C_{\text {nose }}$ ANOVA for the complex manikin with and without

thermocouple 146

Table 6.21 Log $C_{\text {mouth }}$ ANOVA for the complex manikin with and without thermocouple 146

Table 6.22 Complex manikin's face location exposure ....................................148

Table 6.23 Complex manikin's distance from the hood face exposure .................151

Table 7.1 Human subjects' physical measures .................................................161

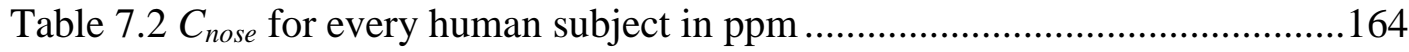

Table $7.3 C_{\text {mouth }}$ for every human subject in $\mathrm{ppm}$.............................................165 
Table 7.4 Human subjects' summary statistic for $C_{\text {nose }}$..........................................166

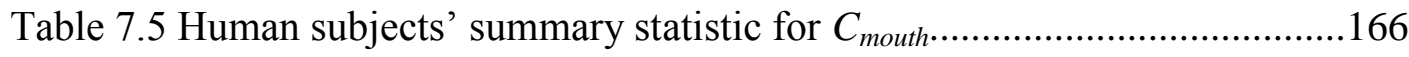

Table 7.6 Human subjects’ Reynolds numbers..................................................168

Table 7.7 Human subjects' Richardson numbers.................................................175

Table 7.8 Human subjects' temperature differences with the ambient temperature

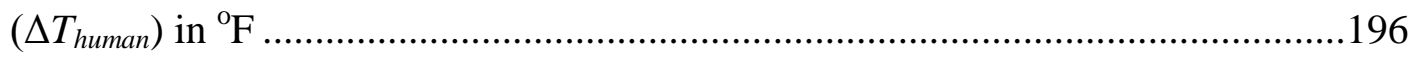

Table 7.9 Log $C_{\text {nose }}$ ANCOVA for the human subjects ........................................204

Table 7.10 Log $C_{\text {mouth }}$ ANCOVA for the human subjects ......................................204

Table 7.11 Log Cmouth ANCOVA for the human subjects without the highest

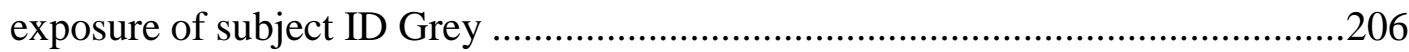

Table 7.12 Log $C_{\text {nose }}$ ANCOVA for the human subjects' body dimensions...........207

Table 7.13 Log $C_{\text {mouth }}$ ANCOVA for the human subjects' body dimensions ........207

Table 7.14 Human subject's face location exposure.............................................212

Table 7.15 Human subject's intervention exposure …………………...................215

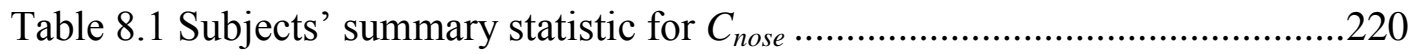

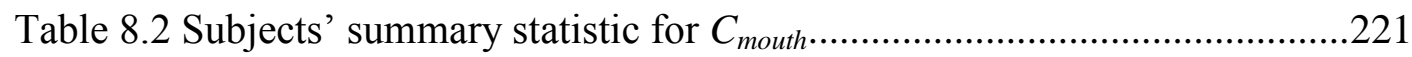

Table 8.3 Subjects' body dimensions and exposure ……....................................221

Table 8.4 Log $C_{\text {nose }}$ ANCOVA for both manikins and the human subjects...........233

Table 8.5 $\log C_{\text {mouth }}$ ANCOVA for both manikins and the human subjects .........234

Table 8.6 $\log C_{\text {nose }}$ Bonferroni post hoc tests for both manikins and the human

subjects 
Table 8.7 Log $C_{\text {mouth }}$ Bonferroni post hoc test for both manikins and the human

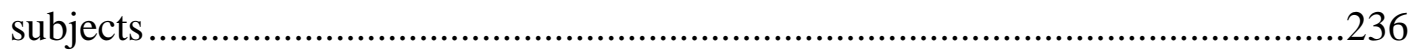




\section{LIST OF FIGURES}

Figure 1.1 Custom-made benchtop enclosing hood ........................................

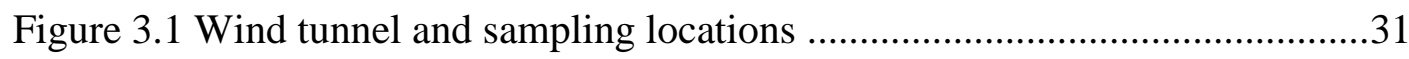

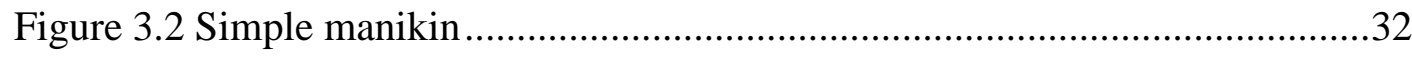

Figure 3.3 Sampling locations on the simple manikin head ..................................33

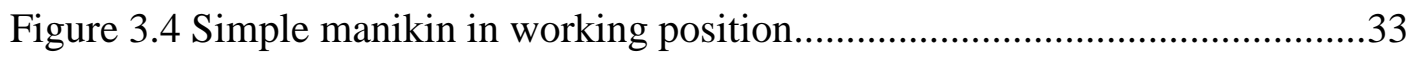

Figure 3.5 Anthropometrically-correct manikin in working posture ...................... 34

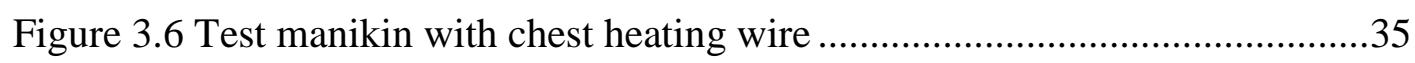

Figure 3.7 Anthropometric manikin breathing system .....................................

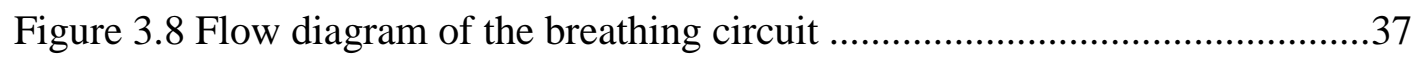

Figure 3.9 Human subject in front of the hood doing a light task ........................38

Figure 3.10 Benchtop enclosing hood position inside the wind tunnel ..................39

Figure 3.11 Tracer gas flow rate release system ..........................................40

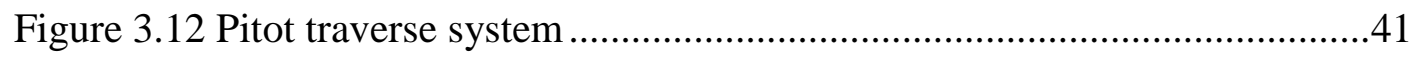

Figure 3.13 Sampling pumps and sampling bags setup ....................................43

Figure 3.14 Sampling bag gas analysis system ...........................................44

Figure 4.1 Simple manikin, anthropometric manikin, and human sampling locations . .48

Figure 5.1 Comparison of $C_{\text {nose }}$ and $C_{\text {mouth }}$ for simple manikin ..........................62

Figure 5.2 Effect of $\operatorname{Re}$ on $C_{n o s e} / C_{r e f}$ for the simple manikin, $C_{r e f}=30.0 \mathrm{ppm} \ldots \ldots . .66$ 
Figure 5.3 Effect of $R e$ on average $C_{n o s e} / C_{r e f}$ for the simple manikin, $C_{r e f}=30.0$

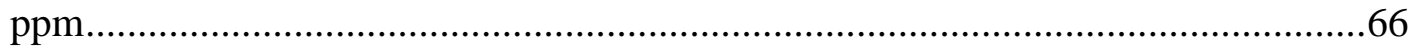

Figure 5.4 Effect of $R e$ on $C_{\text {mouth }} / C_{r e f}$ for the simple manikin, $C_{r e f}=23.7 \mathrm{ppm}$......67

Figure 5.5 Effect of $R e$ on average $C_{m o u t h} / C_{r e f}$ for the simple manikin, $C_{r e f}=23.7$

ppm.

.67

Figure 5.6 Effect of $V_{\text {face }}$ on $C_{\text {nose }}$ for the simple manikin .................................69

Figure 5.7 Effect of $V_{f a c e}$ on $C_{\text {mouth }}$ for the simple manikin................................69

Figure 5.8 Effect of $V_{\text {face }}$ on average $C_{\text {nose }}$ for the simple manikin ........................70

Figure 5.9 Effect of $V_{\text {face }}$ on average $C_{\text {mouth }}$ for the simple manikin ......................70

Figure 5.10 Effect of Vface on Log Cnose for the simple manikin ........................72

Figure 5.11 Effect of $V_{\text {face }}$ on $\log C_{\text {mouth }}$ for the simple manikin ........................73

Figure 5.12 Effect of $V_{\text {face }}$ on average Log $C_{\text {nose }}$ for the simple manikin ................73

Figure 5.13 Effect of $V_{\text {face }}$ on average $\log C_{\text {mouth }}$ for the simple manikin ..............74

Figure 5.14 Effect of $V_{\text {cross }}$ on $C_{\text {nose }}$ for the simple manikin ...............................75

Figure 5.15 Effect of $V_{\text {cross }}$ on $C_{\text {mouth }}$ for the simple manikin .............................76

Figure 5.16 Effect of $V_{\text {cross }}$ on average $C_{\text {nose }}$ for the simple manikin.....................76

Figure 5.17 Effect of $V_{\text {cross }}$ on average $C_{\text {mouth }}$ for the simple manikin ...................77

Figure 5.18 Effect of $V_{\text {cross }}$ on Log $C_{\text {nose }}$ for the simple manikin .........................78

Figure 5.19 Effect of $V_{\text {cross }}$ on $\log C_{\text {mouth }}$ for the simple manikin ........................79

Figure 5.20 Effect of $V_{\text {cross }}$ on average Log $C_{\text {nose }}$ for the simple manikin................79

Figure 5.21 Effect of $V_{\text {cross }}$ on average $\log C_{\text {mouth }}$ for the simple manikin..............80 
Figure 5.22 Effect of $V_{\text {face }} / V_{\text {cross }}$ on average $C_{\text {nose }} / C_{\text {ref }}$ at constant $V_{\text {face }}$ for the simple manikin, $C_{r e f}=30.0 \mathrm{ppm}$.

Figure 5.23 Effect of $V_{\text {face }} / V_{\text {cross }}$ on average $C_{\text {mouth }} / C_{\text {ref }}$ at constant $V_{\text {face }}$ for the simple manikin, $C_{r e f}=23.7 \mathrm{ppm}$

Figure 5.24 Residuals against Predicted $\log C_{\text {nose }}$ for the simple manikin .84 Figure 5.25 Normal probability plot of Residuals Log $C_{\text {nose }}$ against Nscores for the simple manikin .85

Figure 5.26 Residuals against Predicted $\log C_{\text {mouth }}$ for the simple manikin .87

Figure 5.27 Normal probability plot of Residuals $\log C_{\text {mouth }}$ against Nscores for the simple manikin

Figure 5.28 Effect of $V_{\text {face }}$ on the average protection efficiency at fixed $V_{\text {cross }}$ for the simple manikin .92

Figure 5.29 Effect of $V_{\text {cross }}$ on the average protection efficiency at fixed $V_{\text {face }}$ for the simple manikin .92

Figure 6.1 Effect of $R e$ on $C_{n o s e} / C_{r e f}$ for the complex manikin, $C_{r e f}=26.8 \mathrm{ppm} \ldots 104$ Figure 6.2 Effect of $R e$ on average $C_{n o s e} / C_{r e f}$ for the complex manikin, $C_{r e f}=26.8$ ppm 104

Figure 6.3 Effect of $R e$ on $C_{\text {mouth }} / C_{r e f}$ for the complex manikin, $C_{r e f}=19.4 \mathrm{ppm} .105$ Figure 6.4 Effect of $R e$ on average $C_{m o u t h} / C_{r e f}$ for the complex manikin, $C_{r e f}=19.4$ ppm 105

Figure 6.5 Schematic representations of the approach velocity and buoyancy around a heated complex manikin. 108 
Figure 6.6 Effect of $R i$ on $C_{n o s e} / C_{r e f}$ for the complex manikin, $C_{r e f}=26.8 \mathrm{ppm}$ (No highest exposure value) 108

Figure 6.7 Effect of $R i$ on average $C_{n o s e} / C_{r e f}$ for the complex manikin, $C_{r e f}=26.8$

ppm (No highest exposure value)

Figure 6.8 Effect of $R i$ on $C_{\text {mouth }} / C_{\text {ref }}$ for the complex manikin, $C_{r e f}=19.4 \mathrm{ppm}$ (No highest exposure value)

Figure 6.9 Effect of $R i$ on average $C_{\text {mouth }} / C_{r e f}$ for the complex manikin, $C_{r e f}=19.4$

ppm (No highest exposure value)

Figure 6.10 Effect of $V_{\text {face }}$ on $C_{\text {nose }}$ for the complex manikin

Figure 6.11 Effect of $V_{\text {face }}$ on $C_{\text {mouth }}$ for complex manikin

Figure 6.12 Effect of $V_{\text {face }}$ on average $C_{\text {nose }}$ for the complex manikin

Figure 6.13 Effect of $V_{\text {face }}$ on average $C_{\text {mouth }}$ for the complex manikin 114

Figure 6.14 Effect of $V_{\text {face }}$ on $\log C_{\text {nose }}$ for the complex manikin......................115

Figure 6.15 Effect of $V_{\text {face }}$ on $\log C_{\text {mouth }}$ for the complex manikin .....................116

Figure 6.16 Effect of $V_{\text {face }}$ on average Log $C_{\text {nose }}$ for complex manikin 116

Figure 6.17 Effect of $V_{\text {face }}$ on average $\log C_{\text {mouth }}$ for complex manikin........

Figure 6.18 Effect of $V_{\text {cross }}$ on $C_{\text {nose }}$ for the complex manikin 118

Figure 6.19 Effect of $V_{\text {cross }}$ on $C_{\text {mouth }}$ for the complex manikin 118

Figure 6.20 Effect of $V_{\text {cross }}$ on average $C_{\text {nose }}$ for the complex manikin. 119

Figure 6.21 Effect of $V_{\text {cross }}$ on average $C_{\text {mouth }}$ for the complex manikin 119

Figure 6.22 Effect of $V_{\text {cross }}$ on $\log C_{\text {nose }}$ for the complex manikin.

Figure 6.23 Effect of $V_{\text {cross }}$ on Log $C_{\text {mouth }}$ for the complex manikin..... 121 
Figure 6.24 Effect of $V_{\text {cross }}$ on average Log $C_{\text {nose }}$ for the complex manikin 122

Figure 6.25 Effect of $V_{\text {cross }}$ on average $\log C_{\text {mouth }}$ for the complex manikin 122

Figure 6.26 Effect of $\Delta T_{\text {man }}$ on $C_{\text {nose }}$ at constant $V_{\text {face }}$ for the complex manikin....125

Figure 6.27 Effect of $\Delta T_{\text {man }}$ on $C_{\text {mouth }}$ at constant $V_{\text {face }}$ for the complex manikin..125 Figure 6.28 Effect of $V_{\text {face }}$ on the average protection efficiency at each level of $V_{\text {cross }}$ for the complex manikin 133

Figure 6.29 Effect of $V_{\text {cross }}$ on the average protection efficiency at each level of $V_{\text {face }}$ for the complex manikin

Figure 6.30 Complex manikin a) with thermocouple on face b) without thermocouple on face 140

Figure 6.31 Effect of $V_{\text {face }}$ on $C_{\text {nose }}$ for the complex manikin with and without thermocouple on the face 142 Figure 6.32 Effect of $V_{\text {face }}$ on $C_{\text {mouth }}$ for the complex manikin with and without thermocouple on the face 142

Figure 6.33 Effect of $V_{\text {cross }}$ on $C_{\text {nose }}$ for the complex manikin with and without thermocouple on the face 143

Figure 6.34 Effect of $V_{\text {cross }}$ on $C_{\text {mouth }}$ for the complex manikin with and without thermocouple on the face

Figure 6.35 Complex manikin's face location a) vertical b) sideburn c) ear .........148 Figure 6.36 Complex manikin's padded belly 150

Figure 6.37 Complex manikin's distance from the hood face a) without padded belly b) padded belly 1 " c) padded belly 4 " 
Figure 7.1 Human subject ID Orange in a working posture 156

Figure 7.2 Human subject ID Red in a working posture 157

Figure 7.3 Human subject ID Yellow in a working posture 157

Figure 7.4 Human subject ID Green in a working posture 158

Figure 7.5 Human subject ID Brown in a working posture 158

Figure 7.6 Human subject ID Gray in a working posture 159

Figure 7.7 Human subject ID Cyan in a working posture. 159

Figure 7.8 Human subject ID Purple in a working posture 160

Figure 7.9 Human subject ID Black in a working posture 160

Figure 7.10 Human subject ID Magenta in a working posture 161

Figure 7.11 Effect of $R e$ on $C_{n o s e} / C_{r e f}$ for the human subjects, $C_{r e f}=26.4$ ppm ....169

Figure 7.12 Human subjects' effect of $R e$ on average $C_{\text {nose }} / C_{\text {ref }}$ at $V_{\text {face }}=100 \mathrm{fpm}$,

$C_{r e f}=26.4 \mathrm{ppm}$

Figure 7.13 Human subjects' effect of $R e$ on average $C_{\text {nose }} / C_{\text {ref }}$ at $V_{\text {face }}=160 \mathrm{fpm}$,

$C_{r e f}=26.4 \mathrm{ppm}$ 170

Figure 7.14 Human subjects' effect of $R e$ on average $C_{\text {nose }} / C_{\text {ref }}$ at $V_{\text {face }}=220 \mathrm{fpm}$,

$C_{r e f}=26.4 \mathrm{ppm}$

Figure 7.15 Effect of $R e$ on $C_{\text {mouth }} / C_{r e f}$ for the human subjects, $C_{r e f}=108.2 \mathrm{ppm} .172$

Figure 7.16 Human subject' effect of $R e$ on average $C_{\text {mouth }} / C_{\text {ref }}$ at $V_{\text {face }}=100 \mathrm{fpm}$,

$C_{\text {ref }}=108.2 \mathrm{ppm}$

Figure 7.17 Human subject' effect of $R e$ on average $C_{\text {mouth }} / C_{\text {ref }}$ at $V_{\text {face }}=160 \mathrm{fpm}$,

$C_{r e f}=108.2 \mathrm{ppm}$ 173 
Figure 7.18 Human subject' effect of $R e$ on average $C_{\text {mouth }} / C_{r e f}$ at $V_{\text {face }}=220 \mathrm{fpm}$,

$C_{\text {ref }}=108.2 \mathrm{ppm}$

Figure 7.19 Approach velocity and buoyancy representations around a human

subject

Figure 7.20 Human subjects' effect of $R i$ on $C_{n o s e} / C_{r e f}, C_{r e f}=26.4 \mathrm{ppm}$ (No highest exposure values)

Figure 7.21 Human subjects' effect of $R i$ on $C_{\text {mouth }} / C_{r e f}, C_{r e f}=108.2 \mathrm{ppm}$ (No highest exposure value) 177

Figure 7.22 Effect of $R i$ on $C_{n o s e} / C_{r e f}$ for subjects Brown, Gray, and Black, $C_{r e f}=$ $26.4 \mathrm{ppm}$ (No highest exposure values) 178

Figure 7.23 Effect of $R i$ on $C_{\text {nose }} / C_{\text {ref }}$ at $V_{\text {face }}=100 \mathrm{fpm}$ for human subjects, $C_{\text {ref }}=$ 26.4 ppm (No highest exposure value) 179

Figure 7.24 Effect of Ri on $C_{\text {nose }} / C_{r e f}$ at $V_{\text {face }}=160 \mathrm{fpm}$ for human subjects, $C_{r e f}=$ 26.4 ppm (No highest exposure value..... 179

Figure 7.25 Effect of Ri on $C_{n o s e} / C_{r e f}$ at $V_{\text {face }}=220 \mathrm{fpm}$ for human subject, $C_{r e f}=$ $26.4 \mathrm{ppm}$ (No highest exposure value) 180

Figure 7.26 Effect of $R i$ on $C_{m o u t h} / C_{r e f}$ for subjects Brown, Gray, and Black, $C_{r e f}=$ 108.2 ppm (No highest exposure value) 180

Figure 7.27 Effect of $R i$ on $C_{\text {mouth }} / C_{r e f}$ at $V_{\text {face }}=100 \mathrm{fpm}$ for human subjects, $C_{r e f}=$ 108.2 ppm (No highest exposure value) 181

Figure 7.28 Effect of $R i$ on $C_{\text {mouth }} / C_{\text {ref }}$ at $V_{\text {face }}=160 \mathrm{fpm}$ for human subjects, $C_{r e f}=$ 108.2 ppm (No highest exposure value) 181 
Figure 7.29 Effect of $R i$ on $C_{\text {mouth }} / C_{\text {ref }}$ at $V_{\text {face }}=220 \mathrm{fpm}$ for human subjects, $C_{r e f}=$

108.2 ppm (No highest exposure value) …………..............................................182

Figure 7.30 Comparison of $C_{\text {nose }}$ among the human subjects.................................183

Figure 7.31 Comparison of $C_{\text {mouth }}$ among the human subject .................................184

Figure 7.32 Effect of $V_{\text {face }}$ on $C_{\text {nose }}$ for the human subjects ..................................184

Figure 7.33 Effect of $V_{\text {face }}$ on $C_{\text {mouth }}$ for the human subjects ..................................185

Figure 7.34 Effect of $V_{\text {face }}$ on average $C_{\text {nose }}$ for the human subjects .....................185

Figure 7.35 Effect of $V_{\text {face }}$ on average $C_{\text {mouth }}$ for the human subjects ....................186

Figure 7.36 Effect of $V_{\text {face }}$ on average $\log C_{\text {nose }}$ for the human subjects ................187

Figure 7.37 Effect of $V_{\text {face }}$ on average $\log C_{\text {mouth }}$ for the human subjects ..............188

Figure 7.38 Effect of $V_{\text {cross }}$ on $C_{\text {nose }}$ for the human subjects ..................................190

Figure 7.39 Effect of $V_{\text {cross }}$ on $C_{\text {mouth }}$ for the human subjects ................................190

Figure 7.40 Effect of $V_{\text {cross }}$ on average $C_{\text {nose }}$ for the human subjects.....................191

Figure 7.41 Effect of $V_{\text {cross }}$ on average $C_{\text {mouth }}$ for the human subjects ...................192

Figure 7.42 Effect of $V_{\text {cross }}$ on average $\log C_{\text {nose }}$ for the human subjects...............192

Figure 7.43 Effect of $V_{\text {cross }}$ on average $\log C_{\text {mouth }}$ for the human subjects .............193

Figure $7.44 C_{\text {nose }}$ vs $\Delta T_{\text {human }}$ for the human subjects............................................197

Figure $7.45 C_{\text {mouth }}$ vs $\Delta T_{\text {human }}$ for the human subjects ...........................................197

Figure 7.46 Effect of $\Delta T_{\text {human }}$ on average $C_{\text {nose }}$ for the human subjects .................198

Figure 7.47 Effect of $\Delta T_{\text {human }}$ on average $C_{\text {mouth }}$ for the human subjects ...............198

Figure 7.48 Effect of $V_{\text {face }}$ on the average protection efficiency at each level of $V_{\text {cross }}$

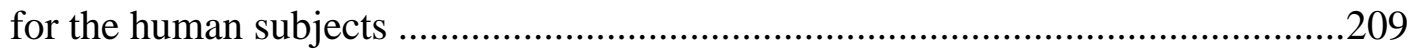


Figure 7.49 Effect of $V_{\text {cross }}$ on the average protection efficiency at each level of $V_{\text {face }}$

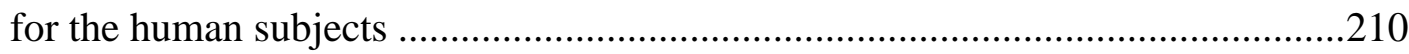
Figure 7.50 Human subject's face location a) sideburn b) back of the head .........212 Figure 7.51 Human subject's padded belly .........................................................214 Figure 7.52 Human subject's intervention a) without padded belly b) padded belly c) ) padded chest 214

Figure 8.1 Subjects' working posture a) simple manikin b) complex manikin c) human subject. 217

Figure $8.2 C_{n o s e}$ for both manikins and all 10 human subjects (average exposure in parenthesis) 219

Figure $8.3 C_{\text {mouth }}$ for both manikins and all 10 human subjects (average exposure in parenthesis) 220

Figure 8.4 Comparison of the effect of $V_{\text {face }}$ on average $C_{\text {nose }}$ for all subjects at $V_{\text {cross }}$ $=14 \mathrm{fpm}$

Figure 8.5 Comparison of the effect of $V_{\text {face }}$ on average $C_{\text {mouth }}$ for all subjects at $V_{\text {cross }}=14 \mathrm{fpm}$ 224

Figure 8.6 Comparison of the effect of $V_{\text {face }}$ on average $C_{\text {nose }}$ for all subjects at $V_{\text {cross }}$ $=46 \mathrm{fpm}$ 224

Figure 8.7 Comparison of the effect of $V_{\text {face }}$ on average $C_{\text {mouth }}$ for all subjects at $V_{\text {cross }}=46 \mathrm{fpm}$ 225

Figure 8.8 Comparison of the effect of $V_{\text {face }}$ on average $C_{\text {nose }}$ for all subjects at $V_{\text {cross }}$ $=63 \mathrm{fpm}$ (No simple manikin results) .225 
Figure 8.9 Comparison of the effect of $V_{\text {face }}$ on average $C_{\text {mouth }}$ for all subjects at $V_{\text {cross }}=63 \mathrm{fpm}$ (No simple manikin results)

Figure 8.10 Comparison of the effect of $V_{\text {cross }}$ on average $C_{n o s e}$ for all subjects at $V_{\text {face }}=100 \mathrm{fpm}$ 228

Figure 8.11 Comparison of the effect of $V_{\text {cross }}$ on average $C_{\text {mouth }}$ for all subjects at

$V_{\text {face }}=100 \mathrm{fpm}$ 228

Figure 8.12 Comparison of the effect of $V_{\text {cross }}$ on average $C_{\text {nose }}$ for all subjects at $V_{\text {face }}=160 \mathrm{fpm}$ 229

Figure 8.13 Comparison of the effect of $V_{\text {cross }}$ on average $C_{\text {mouth }}$ for all subjects at $V_{\text {face }}=160 \mathrm{fpm}$ .229

Figure 8.14 Comparison of the effect of $V_{\text {cross }}$ on average $C_{n o s e}$ for all subjects at $V_{\text {face }}=220 \mathrm{fpm}$ 230

Figure 8.15 Comparison of the effect of $V_{\text {cross }}$ on average ${ }_{\text {Cmouth }}$ for all subjects at $V_{\text {face }}=220 \mathrm{fpm}$ 230 


\section{CHAPTER 1}

\section{INTRODUCTION}

\subsection{Background}

Benchtop enclosing hoods (Figure 1.1) are deemed the most effective type to protect workers from airborne contaminants in industrial processes $\left(\mathrm{ACGIH}^{\circledR}\right.$ Industrial Ventilation Committee, 2010). These simple enclosing hoods are an important tool for local exhaust ventilation (Guffey and Barnea, 1994). However, little has been published on factors affecting the effectiveness of benchtop enclosing hoods most used in industry. Even though most studies have been devoted to laboratory fume hoods, their results may not apply to benchtop enclosing hoods (Figure 1.1) because of their differences in design and use.
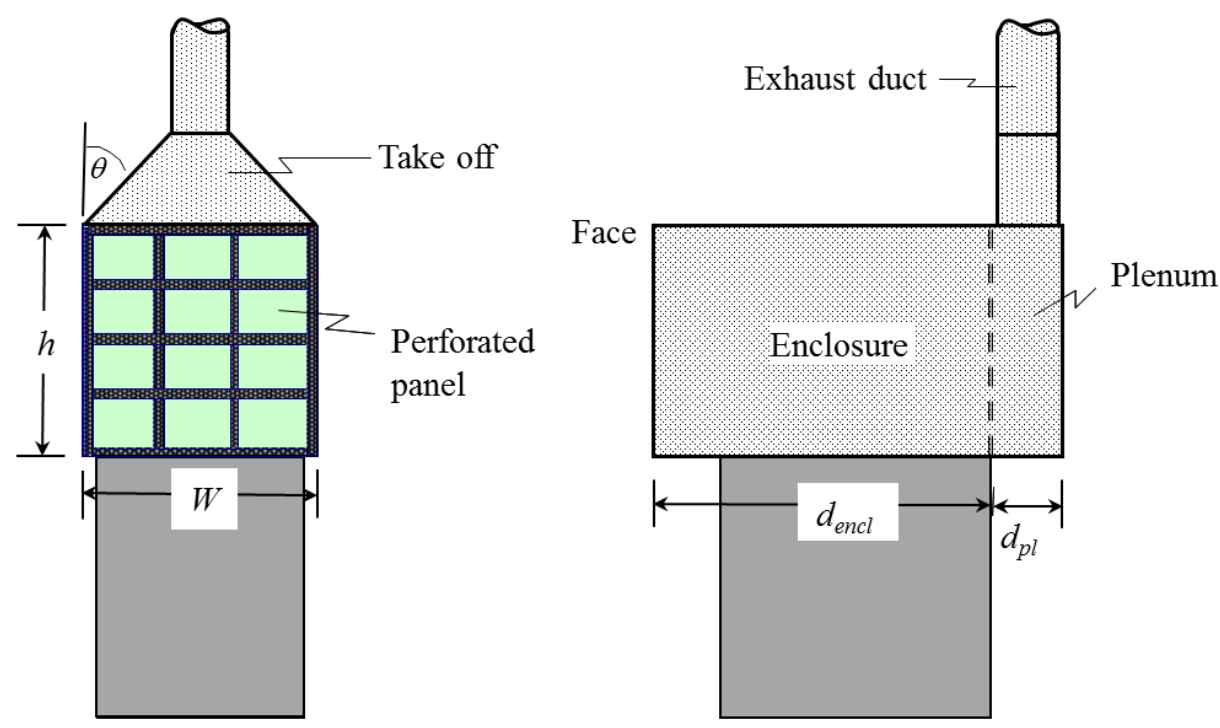

Figure 1.1 Custom-made benchtop enclosing hood 
Plain ("reach-in") enclosing hoods typically are boxes with a plenum at the back leading air into a tapered takeoff and then to the exhaust duct (see Figure 1.1). The plenum section at the back of the hood is created by a wall of baffles, mesh, or perforated metal to achieve adequately spatially uniform velocities at the open face of the hood. Benchtop enclosing hoods generally have plain sides and thus are likely to have larger separation zones $\left(\mathrm{ACGIH}^{\circledR}\right.$ Industrial Ventilation Committee, 2010). Since the hood face has no sash, a worker can lean his or her body and head into the enclosing hood to perform any task.

By contrast, laboratory fume hoods have a moveable sash at the hood face and a dome inside. To minimize the separation zone generated by the momentum of the flow around the perimeter of the hood, lab hoods have aerodynamically shaped entries (ACGIH ${ }^{\circledR}$ Industrial Ventilation Committee, 2010). The sash at the hood face may prevent leakage of contaminants from the hood. However, recirculation of air in front of the worker, called eddy currents might transport contaminants up to the worker's breathing zone. It is possible that higher $V_{\text {face }}$ values do not necessarily provide greater worker protection as might be thought (ACGIH $^{\circledR}$ Industrial Ventilation Committee, 2010).

Many factors affect hood performance, such as hood design elements, ambient air and worker temperature, hood face velocity $\left(V_{\text {face }}\right)$, cross-draft velocity $\left(V_{\text {cross }}\right)$, worker activities, and work practices (Altemose et al., 1998; Caplan and Knutson, 1982). Hood face velocity was shown to be an important factor in 
controlling worker exposure to pollutant contaminants in an enclosing hood (Guffey and Barnea, 1994) and it is often treated as a reliable guide to hood effectiveness (ACGIH ${ }^{\circledR}$ Industrial Ventilation Committee, 2010). However, the practice of using only $V_{\text {face }}$ as factor to assess the lab hood's performance has been repeatedly questioned and thought as an inadequate criterion by Caplan and Knutson (1982). They point out that $V_{\text {cross }}$ and other factors mentioned above should be considered.

Cross-draft velocity might be caused by opening doors, by people passing in front of the hood and by the room air supply. For most hood studies, it is clear that cross-draft velocities affected the containment ability of lab hoods (Greenley et al., 2000; Altemose et al., 1998; DiBerardinis, 2003; Caplan and Knutson, 1982) but no comprehensible guidance exists other than recommendation that the velocity of diffusers should be less than $25 \%$ the face velocity as asserted by Caplan and Knutson (1982).

Improper design of the supply air system influences the performance of lab hoods (Caplan and Knutson, 1982a). Wall grilles' $V_{\text {cross }}$ at the face of the hood should be less than $1 / 2$ the hood $V_{\text {face }}$ and a lower concentration on the worker breathing zone is achieved when the supply air jet is above the top of the hood opening. Perforated ceiling panels are considered to provide a better supply system because they are simpler and easy to apply (Caplan and Knutson, 1982a) and the panel velocity should not be greater than $2 / 3$ of hood $V_{\text {face }}$. Those results are just 
valid under the specific conditions of this study and cannot be generalized (Caplan and Knutson, 1982a).

Experimental tests have shown that $V_{\text {face }}$ and $V_{\text {cross }}$ have significant effects on concentrations at the nose and mouth $\left(C_{\text {nose }}\right.$ and $\left.C_{\text {mouth }}\right)$ for a heated and breathing anthropometric manikin standing at the face of a benchtop enclosing hood but no attention has been paid to the effects of the manikin's body temperature on benchtop enclosing hood exposure (He, 2010). The thermal effect of the subject body may play an important role on hood leakage. This leakage concentration increased $60 \%$ when a heated manikin or a human subject was placed in front of a lab hood (Johnson and Fletcher, 1996).

For human body temperatures between 29 to $33{ }^{\circ} \mathrm{C}$, a maximum airflow velocity of $0.23 \mathrm{~m} / \mathrm{s}$ is reached over the head due to buoyancy effect produced by the temperature gradient between the subject body and the environment (Murakami et al., 2000; Kilic et al., 2008). On the other hand, the metabolic heat (100 W/m²) produced by the human body is released through convection (29\%), radiation (38.1\%), evaporation (24.2\%), and respiration (8.7\%). A numerical method with a naked manikin was used (Murakami et al., 2000; Tanabe et al., 2002; Kilic et al., 2008). However, the heat release to the environment is strongly influenced by the level of insulation of clothing (Voelker et al., 2009).

Work practice is deemed an important factor that affects the performance of LEV devices (Mikell and Fuller, 1988). The distance of the contaminant source from the breathing zone affects the effectiveness of lab hoods (Mikell and Hobbs, 
1981; Mikell and Fuller, 1988; Ivany et al., 1989). A minimum distance of 6" from the emitting source to the hood face and 6" or 7" from the hood face to the worker breathing zone is suggested to reduce leakage. Therefore, a distance of 12 " or 13 " between the source and worker is considered a good work practice to keep leakage under control (Mikell and Hobbs, 1981; Mikell and Fuller, 1988; Ivany et al., 1989).

More research is needed about the factors affecting the performance of benchtop enclosing hoods. Despite a diligent search, two experimental studies, Guffey and Barnea (1994) and He (2010), and two numerical studies, Dunnett (1994) and Karaismail and Celik (2010) are the only published studies about plain enclosing hood performance. They studied the effects of $V_{\text {face }}, V_{\text {cross }}$, worker orientation, flanges (He, 2010; Guffey and Barnea; 1994), recirculating flow and airflow patterns on the performance of plain hoods (Dunnett, 1994; and Karaismail and Celik, 2010). However, although the effects of these factors on the performance of benchtop enclosing hoods were demonstrated with these studies, these results have not been validated with human subjects.

In the present study the effects of enclosing hood face velocity $\left(V_{\text {face }}\right)$, the wind tunnel cross-draft velocity $\left(V_{\text {cross }}\right)$, and the temperature difference between the worker body and the environment $\left(\Delta T_{\text {man }}\right)$ on exposures to manikins and human subjects are experimentally investigated. In addition, the effect of body dimensions and the distance between the breathing zone and the source on exposure to human 
subjects were studied. For comparison purposes, both the manikins and the human subjects were standing at the face of a custom-made benchtop enclosing hood.

\subsection{Protection efficiency for enclosing hood}

The concept of protection efficiency $\left(\eta_{\text {prot }}\right)$ is proposed in order to quantify the enclosing hood performance. Protection efficiency measures the ability of the enclosing hood to reduce a worker's exposure. It is simply defined as

$$
\eta_{p r o t}=\left[1-\frac{C_{B Z}}{(G / Q)}\right] * 100
$$

Where:

$$
\begin{aligned}
C_{B Z}= & \text { breathing zone concentration. Average concentration at the user's } \\
& \text { nose and mouth, } \mathrm{ppm} \\
G= & \text { rate of contaminant generation, } \mathrm{lpm} \\
Q= & \text { hood exhaust airflow rate, } 1 \mathrm{pm}
\end{aligned}
$$

The amount $G / Q$ can be considered as total concentration of contaminants

released by the source. However, $\eta_{\text {prot }}$ results could be misleading due to the fact that when $C_{B Z}$ reach the minimum value and $Q$ is increased, $\eta_{\text {prot }}$ decreased. In other words, no always increasing $Q$ produces lowest $\eta_{\text {prot }}$.

\subsection{Problem statement}

As mentioned above, many factors such as $V_{\text {face }}, V_{\text {cross }}$, work practices (e.g., arm and body movements), worker position, distance between the breathing zone 
and the emitting source, and body temperature, affect the effectiveness on the performance of lab hoods $\left(\eta_{\text {prot }}\right)$. However, these results might be completely misleading if applied to plain enclosing hood studies due to the difference in design and use. In addition, there is clearly a gap on the two experimental studies (manikin) reported to the date (Guffey and Barnea, 1994; He, 2010) and the present study, because previous manikin results were not validated with human subjects experiments.

The effects of $V_{\text {face }}, V_{\text {cross }}$, the temperature difference between the subject's body and the ambient air $\left(\Delta T_{m a n}\right)$, human subjects' body dimensions, factor interactions, and the distance of the subjects' breathing zone to the hood face on the performance of a benchtop enclosing hood are the primary focus of this research. A simple manikin, an anthropometrically-correct manikin, and ten human subjects were used as subjects. They were exposed to a contaminant released from a source inside the hood. Finally, this study will compare results from the two manikins to results from the human subjects to determine which best represent humans.

\subsection{Hypotheses tested}

The main hypothesis of this research is that the independent variables of $V_{\text {face }}, V_{\text {cross }}$, and $\Delta T_{\text {man }}$ affect the dependent variables of $C_{\text {nose }}$ and $\mathrm{C}_{\text {mouth }}$ of ten human subjects, an anthropometric manikin, and a simple manikin. For a fixed effect model, the statistical models can be written as:

Analysis of variance (ANOVA) for the simple manikin,

$$
Y_{i j k}=\mu+\alpha_{i}+\beta_{j}+(\alpha \beta)_{i j}+\varepsilon_{i j k}
$$


Analysis of covariance (ANCOVA) for the complex manikin,

$$
Y_{i j k}=\mu+\alpha_{i}+\beta_{j}+\gamma x_{i j k}+\varepsilon_{i j k}
$$

Analysis of covariance (ANCOVA) for the human subjects,

$$
Y_{i j k l}=\mu+\alpha_{i}+\beta_{j}+\psi_{k}+\gamma x_{i j k l}+(\alpha \beta)_{i j}+\varepsilon_{i j k l}
$$

and the hypotheses can be stated as,

$$
\begin{array}{ll}
H_{o}: \alpha_{1}=\alpha_{2}=\ldots=\alpha_{a}=0 ; & H_{1}: \text { any } \alpha_{i} \neq 0 ; \\
H_{o}: \beta_{1}=\beta_{2}=\ldots=\beta_{b}=0 ; & H_{1}: \text { any } \beta_{j} \neq 0 \\
H_{o}: \gamma_{1}=\gamma_{2}=\ldots=\gamma_{b}=0 ; & H_{1}: \text { any } \gamma_{j} \neq 0 \\
H_{o}: \psi_{1}=\psi_{2}=\ldots=\psi_{b}=0 ; & H_{1}: \text { any } \psi_{j} \neq 0
\end{array}
$$

Where:

$\alpha, \beta, \gamma$, and $\psi$ : represent the effects of independent variables such as $V_{\text {face }}, V_{\text {cross }}$, $\Delta T_{m a n}$ and different subjects (including manikins and humans) on exposure.

$H_{o}$ : represent no effects of independent variables on dependent variables or null hypothesis.

$H_{1}$ : represent the effects of independent variables on dependent variables or alternative hypothesis.

\subsection{Goals and objectives}

The experiments with both manikins and human subjects can suggest whether a simple manikin and a complex manikin experience the same exposure. It can also reveal whether either manikin is an adequate surrogate for human subjects.

The goal of this research is to evaluate the performance of a benchtop enclosing hood in protecting workers of airborne contaminants using manikins and 
human subjects exposed to a tracer gas at different combinations of $V_{\text {face }}$ and $V_{\text {cross }}$. To carry out this goal, the strategy chosen comprises the following specific steps:

1. Determine the effects of $V_{\text {face }}$ and $V_{\text {cross }}$ on $C_{\text {nose }}$ and $C_{\text {mouth }}$ for a simple manikin standing in front of the hood face of a custom-made benchtop enclosing hood.

2. Repeat No. 1 for a heating and breathing anthropometrically-correct manikin.

3. Repeat No. 1 for ten human subjects standing in front of the hood face doing a simple, non-energetic task inside the hood.

4. Compare $C_{\text {nose }}$ and $C_{\text {mouth }}$ for human subjects under the same conditions, with the results for manikin tests (both simple and anthropometricallycorrect) to determine whether one or both manikins were adequate surrogates for human subjects.

5. Evaluate if the effect of $\Delta T_{\operatorname{man}}$ is significant on $C_{\text {nose }}$ and $C_{\text {mouth }}$ for the results for manikins and human subjects.

6. Investigate the effect of different body dimensions (height, shoulder, and weight) on $C_{\text {nose }}$ and $C_{\text {mouth }}$ for human subjects.

For all experimental tests, the following conditions were fixed:

- Manikin and human subject tests were carried out inside the same wind tunnel and benchtop enclosing hood.

- All subjects stood at the same position and posture in front of the hood. 
- The volume flow rate of the contaminant source was a mix of Freon 134a (3.0 lpm) and Helium (4.9 lpm).

- The hood and all subjects (both manikins and humans) were at a side orientation to $V_{\text {cross }}$.

The contaminant source was at waist level for the manikins:

- Both manikins were stationary and their limbs did not move.

- The anthropometrically-correct manikin was heated and it "breathed." Its hands were inside the hood on each side of the source.

For human subjects:

- Both hands were inside the hood doing a task with a simple, slow motion.

- All human subjects performed the same task. 


\section{CHAPTER 2}

\section{LITERATURE REVIEW}

There is limited published experimental research done on the parameters affecting the effectiveness of the plain enclosing hoods commonly used in industry. Most enclosing hood research studies to date have been devoted to the performance and the factors affecting the containment ability of lab fume hoods. The most relevant published research in free-stream studies, plain hood studies, lab hood studies, human subject studies, and computational fluid dynamic studies are discussed next.

\subsection{Manikin in free-stream studies}

Although LEV devices were not used in these studies, the results of these publications help to understand the effects of several factors important to controlling worker exposure in ventilated environments. For example, Kim and Flynn (1991) studied the airflow around a person immersed in a uniform freestream. Three subjects were used: an anthropometric manikin, a circular cylinder, and an elliptical cylinder. The heights of the subjects were 41,48 , and 60 in respectively. Each was 8 in wide at the shoulders. Smoke-wire techniques were used to visualize the three-dimensional airflow around the manikins. In addition, hot-film anemometry and flow visualization videos were used to determine the

vortex shedding frequency and the dimensions of the reverse flow region. The 
average Strouhal numbers (describe the oscillating flow mechanisms) at $150 \mathrm{fpm}$ for both elliptical and circular cylinder were roughly the same (0.20).

Measurements of velocity vectors, using laser Doppler anemometer (LDA), were carried out around a worker in a low-speed flow field by Johnson et al. (1996). Two- and three-dimensional, heated and unheated, manikins (1.73 $\mathrm{m}$ in height and $40 \mathrm{~cm}$ in chest) were used and the results were compared with those of human subject $(1.68 \mathrm{~m}$ in height and $97 \mathrm{~cm}$ in chest) experiments. They found that a thermal boundary layer is produced by the heated manikin with a layer moving upward at $0.2 \mathrm{~m} / \mathrm{s}$. The heated three-dimensional manikin was clothed and it was found to be the better representative of human subject tests. They also reported that breathing effects did not influence the general flow field.

Guffey et al. (2001) studied the effects of worker orientation related to the free-stream airflow in a wind tunnel. An unheated and nonbreathing, child-size, manikin was used. The manikin held the source at waist height in front of its body at all times. They reported that the concentrations at the nose $\left(C_{\text {nose }}\right)$ when air flowed towards the manikin's back was ten times higher than when the airflow flowed towards the manikin's front or side at wind tunnel cross-draft velocities $\left(V_{\text {cross }}\right)$ of $10,22,47$, and $80 \mathrm{fpm}$. For the backflow orientation, the exposure concentrations increased with increasing values of $V_{\text {cross. }}$. However, caution must be taken in extrapolating to human subjects because the manikin's lack of breathing and body heat do not represent real humans. Undiluted $\mathrm{SF}_{6}$ (a very dense gas) was used as tracer gas. 
For many years, it was believed that concentrations anywhere in the breathing zone (BZ) would be more or less equal to the inhaled concentration. The breathing zone is supposed to be a volume throughout which concentrations are all equal to the inhaled concentrations. Different concentrations at different points in what would be considered in the "breathing zone" were reported by Elnahas (2005). The tested sample locations were the right collar, left collar, right lapel, left lapel, mouth, nose, forehead, center chest, and neck. A heated, breathing anthropometric manikin standing in a free-stream flow was used as the subject. For every test condition, the neck and the forehead location were found to better represent the exposure at the mouth location .They represented only $20 \%$ of the exposure at the mouth. For that reason, in the present study all subjects (manikins and humans) were sampled at the nose and mouth.

\subsection{Manikin at plain hood studies}

Benchtop enclosing hoods are deemed the most effective LEV device to control worker exposure (Guffey and Barnea, 1994). However, little has been published about the factors that affect its performance. To the best of the author's knowledge and in spite of a diligent search, just two experimental studies were found involving plain enclosing hoods. The findings of these two experimental studies are briefly summarized.

One of the pioneering works on the effectiveness of a benchtop enclosing hood considering the manikin's posture, flange design, and face velocity was carried out by Guffey and Barnea (1994). They reported that the hood face velocity 
was the main factor controlling concentrations near the nose and mouth of a manikin standing at the face of a plain enclosing hood. They found that at face velocities $\left(V_{\text {face }}\right)$ above $0.51 \mathrm{~m} / \mathrm{s}(100 \mathrm{fpm})$, exposures were low for all experiments. They also found that exposures were lowest without flanges.

The effects of $V_{\text {face }}, V_{\text {cross }}$, and interventions on the performance of a plain, benchtop enclosing hoods were studied by He (2010). Both the anthropometric manikin (heated and breathing) and the hood were at side orientation to $V_{\text {cross }}$. He reported that $V_{\text {face }}, V_{\text {cross }}$ and its interaction had significant effects on the performance of an enclosing hood. At $V_{\text {cross }}=14 \mathrm{fpm}$, the concentrations at the nose and mouth $\left(C_{\text {nose }}\right.$ and $\left.C_{\text {mouth }}\right)$ showed their highest values. As $V_{\text {face }}$ and $V_{\text {cross }}$ increased, $C_{\text {nose }}$ and $C_{\text {mouth }}$ decreased but at $V_{\text {face }}>170 \mathrm{fpm}$ and $V_{\text {cross }}>36 \mathrm{fpm}$ concentrations did not further decline significantly. Also, a 45 degree inclined sash at the hood face was shown to reduce $C_{\text {nose }}$ and $C_{\text {mouth }}$ considerably. However, little attention has been paid to the influence of the body temperature on the performance of the enclosing hood and the comparison with the results of human subjects as the present study does.

\subsection{Manikin at lab hood studies}

Most studies carried out on LEV concern lab hoods and the factors that affect their performance. The distance of the subject's breathing zone to contaminant source is deemed one of the most important factors to control worker exposure. Several authors (Mikell and Hobbs, 1981; Mikell and Fuller, 1988; Fuller, 1990) reported that worker exposures were less than the "standard" value 
$(<0.1 \mathrm{ppm})$ if the distance from the emitting source to the sash door was 6 " or greater. Experiments have been performed with and without a subject, and some used human subjects. It was concluded that the user received better protection if he kept the sash door as low as possible, among others. Hood face velocity levels of 40 to $150 \mathrm{fpm}$ were tested.

A performance test for laboratory fume hoods was developed by Caplan and Knutson (1982). They stated that $V_{\text {face }}$ is an inadequate criterion to assess laboratory hood performance. Their test method, which became the basis for ANSI/ASHRAE 110 , includes parameters such as the room ventilation and the hood condition. A manikin is stood in front of the hood with its nose near the plane of the hood sash when known amounts of tracer gas mixed with air are released in the hood. They concluded that many factors other than hood design (e.g., airflow patterns near the hood face) might influence hood performance. They also concluded that their proposed method is practical for field use.

Using that test, the effect of the supply air system on the performance of laboratory fume hood was assessed by Caplan and Knutson (1982a). Three types of supply air were studied, wall grilles, ceiling diffusers, and perforated ceiling panels. A manikin was placed in front of the hood face and a sample probe was located between them. They found that the wall grilles terminal velocity $\left(V_{\text {terminal }}\right)$ at the face of the hood should be less than $1 / 2$ of the hood face velocity. For ceiling diffusers, $V_{\text {terminal }}$ should be less than the hood face velocity and the terminals should be located well away from the hood face. Because they are simpler and easy 
to apply, perforated ceiling panels were considered a better supply air system. They recommended that $V_{\text {terminal }}$ should not exceed $2 / 3$ of the hood face velocity $\left(V_{\text {face }}\right)$.

Abrams et al. (1986) reported an evaluation of the effectiveness of a recirculating laboratory hood. Face velocity, flow profile, ability to retain vapors, sorptive capacity of the filter media, and the overall worker protection were evaluated at sash openings of 18,37 , and $68 \mathrm{~cm}$. The results indicated that there was a poor ability to retain contaminant when the sash was opened to $37 \mathrm{~cm}$. When the sash was opened $68 \mathrm{~cm}$, there was not observable $V_{\text {face }}$. For the lowest sash opening $(18 \mathrm{~cm}), V_{\text {face }}=54 \mathrm{fpm}$ was close to that claimed by the manufacturer $(60$ fpm) but could not be considered acceptable because of the laboratory activity. The authors concluded that the hood did not meet the general accepted criteria for fume hood performance.

Smoke visualization techniques to study the air movement and the dispersion of pollutants in a lab hood were used by Ljungqvist (1987). He observed a large difference in leakage between tests for which a manikin and a human subject stood in front of the hood face. He noted that results of the former may give a false sense of safety in the work environment. Since the movements of arms and hands of the living person generated an unstable process where the pollutants may be discharged outwards and reach the subject breathing zone. He speculated that the wake formation and the unstable vortices created in front of the human subject could destroy the beneficial effect of the ventilation system. Experiments were 
carried out with a hood's exhaust flow rate of $600 \mathrm{~m}^{3} / \mathrm{h}$ and sash door that was $2 / 3$ open.

The influence of face velocity on hood leakage as a function of the distance of the contaminant source from the hood face was studied by Ivany et al. (1989). They showed an exponential decline of concentrations at manikin's breathing zone when a centrifuging task was carried out in the hood with the source at $10 \mathrm{~cm}$ and $20 \mathrm{~cm}$ from the hood face inside the hood. Face velocities from 0.3 to $0.7 \mathrm{~m} / \mathrm{s}$ were tested. Other tasks such as pipetting, thermal load and lack of activity showed very low and almost constant leakage. For $V_{\text {face }}>0.6 \mathrm{~m} / \mathrm{s}$ a slight increase in leakage was observed which was associated with the turbulence generated at high face velocities. When the source was placed at $20 \mathrm{~cm}$ from the hood face, even lower leakage was reported by the authors.

The thermal effect of the body of a heated manikin and a human subject was studied by Johnson and Fletcher (1996). The bottom of the fume cupboard's sash was $390 \mathrm{~mm}$ high to obtain relatively high leakage, and the emitting source was located $150 \mathrm{~mm}$ inside the hood from the plane of the sash. They reported a $60 \%$ higher leakage concentration for a human operator than they found for an unheated manikin, mainly due to the thermal effects of the human body. However, a close agreement on concentration values was found when the human subject and a heated $\left(30{ }^{\circ} \mathrm{C}\right)$ three-dimensional manikin were compared. In addition, they reported that at a distance of $0.6 \mathrm{~m}$ or more between the operator and the hood face, the leakage 
was greatly lower and the thermal effects were negligible. Face velocities from 0.2 to $1.4 \mathrm{~m} / \mathrm{s}$ were tested.

Maupins and Hitchings (1998) found serious deficiencies in the adequacy of laboratory fume hoods in protecting workers from exposure to hazardous chemicals in an aging laboratory facility. They found that most fume hoods met neither the industry consensus standard for containment $\left(C_{n o s e}<0.1 \mathrm{ppm}\right)$ nor the industry face velocity specification $\left(V_{\text {face }}=80\right.$ to $\left.120 \mathrm{fpm}\right)$. They applied the ASHRAE 110 method for testing the performance of laboratory fume hoods as part of a mitigation plan that consisted of low and high-volume of smoke test, face velocity test, and tracer gas tests. The average concentration level was reduced from $24.2 \mathrm{ppm}$ to $0.13 \mathrm{ppm}$ after mitigation efforts. They recommended that face velocity testing should be discontinued as the sole test for laboratory fume hoods in favor of the ASHRAE 110 method.

The contaminant leakage of a laboratory fume hood was studied using a multipoint sample method by Tseng et al. (2006). They divided the hood face in upper, middle, and lower level with four sample points for each level. For the experiments, the sash door was open to a height of $600 \mathrm{~mm}$ and the hood face velocity was $0.5 \mathrm{~m} / \mathrm{s}$. Factors of hood geometry and the presence of a manikin were evaluated. They found higher leakage of contaminants around the doorsill and side poles at the lower level of the hood face. For example, at the right lower level, the average concentrations were $1.88 \mathrm{ppm}$ for an unoccupied hood and $77.65 \mathrm{ppm}$ when a manikin stood in front of the hood. It was stated by the authors that a 
multipoint strategy is a more realistic evaluation of the hood effectiveness than the ANSI/ASHRAE 110-1995 single point method.

A summary review of quantitative experimental studies on factors affecting the performance of laboratory fume hood was presented by Ahn et al. (2008). The presence of a manikin or a human subject in front of the lab hood, the distance of the contaminant source to the breathing zone, and the height and area of the sash opening door were reported as the most important factors that affect the performance of lab hood. Face velocity was found to be the most investigated factor but if it is not too low $(<0.30 \mathrm{~m} / \mathrm{s})$ and not too high $(>0.76 \mathrm{~m} / \mathrm{s})$, it appears that other factors are more important to hood performance. Therefore, face velocity is not sufficient to evaluate hood performance. In addition, there are many other factors that affect the containment ability of lab hoods, such as cross-draft velocities, worker practice factors (hand movement, trunk movement, posture), and hood design elements.

\subsection{Human subject studies}

A few published studies have used human subjects to test the performance of general ventilation and LEV in minimizing contaminants in workers' breathing zones. The National Institute of Occupational Safety and Health (NIOSH) defined a "breathing zone" as a distance up to three feet from the nose and mouth (NIOSH, 1973). On the other hand, the Occupational Safety and Health Administration (OSHA) defined this breathing zone to be a hemisphere of roughly 6-9 inches around the head. As a result, to represent worker exposure, sampling was carried 
out at different locations in the breathing zone (Martinelli et al., 1983; Cohen et al., 1984; Van Del Wal and Moerkerken, 1984; Elnahas, 2005).

Martinelli et al. (1983) monitored and recorded the aerosol concentrations at the forehead, nose, and lapel during the process of melting and casting in a beryllium refinery. They also show that dust deposited on the worker's clothing may be released and then collected by a lapel sampler. In the present study, concentration samples were collected near the worker's nose and mouth while they performed a light task in front of the hood face.

Cohen et al. (1984) found no significant differences in beryllium (Be) air concentrations measured at the same time with mini hi-volume samplers and those measured using personal monitors on workers in a beryllium production facility. They also found that work clothing may be a source of personal exposure because a surprisingly large quantity of Be was found on the workers' clothes.

The performance of passive diffusion monitors for organic vapors were assessed by Van Del Wal and Moerkerken (1984). They reported that local vapor concentrations at left and right lapels of painters could differ considerably. The tests carried out in a room with natural ventilation showed that the concentration on the right lapel sampler of right-handed painter was sometimes over $50 \%$ more than the left lapel samplers.

The performance of a horizontal sash laboratory fume hoods was investigated by Altemose et al. (1998). Their tracer gas test was performed with the human subject standing in front of the hood. They found that $V_{\text {face }}$, variability of 
$V_{\text {face }}$, and $V_{\text {cross }}$ were important parameters in determining hood leakage. The door of the fume hood opening at the center position was shown to produce the best containment ability at $V_{\text {face }}=80$ to $120 \mathrm{fpm}$. Results from both the human subject and manikin were inconsistent, suggesting that a static manikin (unheated and not breathing) did not represent the human subjects. Although the present study was performed using a plain enclosing hood without a sash door, $V_{\text {face }}$, and $V_{\text {cross }}$ were also important parameters on the hood containment ability.

Tan et al. (1999) evaluated MIT students' exposures to chemicals in a teaching laboratory and a research laboratory. The sampled chemicals were cobalt, styrene, and formaldehyde. They reported that chemical exposures in both academic laboratories were well under the standard ACGIH threshold limit value (TLV- 8 hrs exposure) or short-term exposure limit (STEL under 15 minutes exposure). The ACGIH- TLV or STEL standard exposures values are $0.02 \mathrm{mg} / \mathrm{m}^{3}$ for cobalt, $100 \mathrm{ppm}$ for styrene, and $0.3 \mathrm{ppm}$ for formaldehyde. They also found that chemical exposures in the teaching laboratory were higher than in the research laboratory.

Tracer gas tests using sulfur hexafluoride $\left(\mathrm{SF}_{6}\right)$ with a manikin and then with a human subject performing a phenol-chloroform (PC) extraction were reported by Greenley et al. (2000). They reported that PC levels were not detectable in the breathing zone of 12 workers $(<0.1 \mathrm{ppm})$. Simultaneously sampled $\mathrm{SF}_{6}$ concentrations were also minimal $($ average $=0.06 \mathrm{ppm})$. As expected, $\mathrm{SF}_{6}$ leakage was greater when the sash height was above the breathing zone and 
lower when the sash height was below the breathing zone. In addition, none of the hoods tested meet the recommended ASHRAE 110 criteria of $0.10 \mathrm{ppm}$ with a fully opened sash. They concluded that face velocity is not the only factor that influences containment. They suggested that other factors that may influence containment include $V_{\text {cross }}$, user activities, hood design, back baffle adjustment, and sash height.

El-Sotouhy (2008) compared human subjects' experimental results with Elnahas's (2005) anthropometrically-correct manikin results under free-stream conditions. In both studies the subjects hold the source in their hands. Although there were strong similarities, the manikin's inhaled concentrations were usually higher than those of human subjects. For human subjects, the results at the lower chest were somewhat different from those of the manikin's tests.

\subsection{Computational fluid dynamics studies (CFD)}

To understand the effectiveness of ventilation system in reducing the worker's exposure to airborne pollutants many numerical studies have been carried out in the past two decades. Numerical modeling is an important tool that serves to guide the experiments in the selection of the best factors and levels of these that affect the containment ability of exhaust ventilation equipments.

One of the few numerical investigations to deal with the airflow behavior obstructed by a worker in front of an exhaust opening was done by Dunnett (1994). The worker was simulated by an elliptical cylinder standing in front of the exhaust opening. For both the laminar and turbulent regimes, he reported that if the cylinder 
was far away of the opening, then an unsteady flow field occurs with the formation of vortex shedding in the worker's wake. However, if the worker was close to the exhaust opening, the flow field between the person and the opening was steady just with small recirculating flow in the wake of the worker. Although it was a twodimensional study, he stated the numerical model could be extended to investigate the three-dimensional effects of the flow field.

Kulmala et al. (1996) studied experimentally and numerically the exposure of workers due to a recirculating airflow in a free-stream flow. The airflow field was determined using a $k-\varepsilon$ turbulence model. They found that the breathing zone concentration decreased as the distance of the contaminant source increased. They also found significant contaminant transport toward the breathing zone occurred above hip level.

Worker exposure and body shape were studied numerically by Li et al. (2005). They compared the Eulerian transport model and the Lagrangian trajectory tracking method. It was observed that the Eulerian method has a more diffusive nature than the Lagrangian method. However, both methods suggest that concentrations measured at the lapel could be very different from those concentrations measured near the mouth. They also show that their predictions using a rounded body (closest approximation to human body) resulted in much lower concentration levels. However, the results of this study cannot be generalized to humans because the simulations were carried out with a simulated unheated manikin. 
Li et al. (2007) reported the results of their CFD simulations to predict worker exposure to airborne contaminants in a wind tunnel. The airflow came behind the worker and the source was immediately downstream at waist height. They investigated the effects of $V_{\text {cross }}$, body heat, and free-stream turbulent intensity on worker exposure levels. The results were in good agreement with experiments at the same conditions. Results for an unheated and heated manikin were reported. When the manikin was unheated, the exposure levels were inversely related to $V_{\text {cross }}$, but for a heated manikin exposure levels had an inverted V relationship with $V_{\text {cross }}(46 \mathrm{fpm})$.

The performance of different RANS models, such as the standard $k$ - $\varepsilon$, the RNG $k-\varepsilon$, and the SST $k-\omega$ at high, moderate, and low Reynolds numbers were tested by Karaismail and Celik, (2010). They performed two- and threedimensional, unsteady, laminar and turbulent computations for Reynolds numbers of $1.0 \times 10^{3}, 1.0 \times 10^{4}$, and $1.0 \times 10^{5}$. It was found that the SST $k$ - $\omega$ model predicted a more realistic three-dimensional simulation of both steady and unsteady recirculatory flow patterns in the wake of the worker standing at the face of a plain enclosing hood. They also found that the standard and the RNG $k-\varepsilon$ model failed to predict the unsteadiness at low Reynolds numbers.

The heat released from the human body plays an important role on concentrations inhaled by the workers and in the design of air-conditioned in buildings. Although there are no experimental plain enclosing hoods studies regarding the buoyancy effects produced by the temperature difference between the 
worker's skin and the surrounding environment, there is plenty of published research, especially numerical models, dealing with the heat transfer and thermal impact of workers in air-conditioned environments.

For example, Murakami et al. (2000) studied the heat released from a naked human body (manikin) to the environment through convection, radiation, evaporation, and respiration. These account for $29.1 \mathrm{~W} / \mathrm{m}^{2}, 38.3 \mathrm{~W} / \mathrm{m}^{2}, 24.3 \mathrm{~W} / \mathrm{m}^{2}$, and $8.7 \mathrm{~W} / \mathrm{m}^{2}$ of the total metabolic heat production of $100.4 \mathrm{~W} / \mathrm{m}^{2}$ (ASHRAE handbook, 1993). The numerical model simulated a manikin with $1.651 \mathrm{~m}$ of height, $65.5 \mathrm{~kg}$ of weight, and $1.698 \mathrm{~m}^{2}$ of body surface. The temperature distribution of the manikin skin surface ranged from $29{ }^{\circ} \mathrm{C}$ at the feet to $34{ }^{\circ} \mathrm{C}$ at the neck and shoulders. Consequently, the vertical air velocity increased due to the buoyancy effects of free convection, reaching the maximum velocity of $0.23 \mathrm{~m} / \mathrm{s}$ over the head of the manikin.

The human body's temperature distribution was studied using a thermal manikin and a 65-node thermoregulation model by Tanabe et al. (2002). The CFD model divided the thermal manikin into 16 body segments, each consisting of four layers such as core, muscle, fat, and skin. The clothing insulation was also derived from the experiments. In a simplified model, the thermal manikin represented an average person with a height of $1.70 \mathrm{~m}$, body weight of $74.4 \mathrm{~kg}$, and body surface area of $1.53 \mathrm{~m}^{2}$. Two subjects were tested, subject A in front of the window and subject $\mathrm{B}$ behind the subject $\mathrm{A}$. They found that the air temperature around the body was $29.9{ }^{\circ} \mathrm{C}$ for subject $\mathrm{A}$ in front of the window and $28.8{ }^{\circ} \mathrm{C}$ for subject $\mathrm{B}$. In 
addition, the skin temperatures were $35.2{ }^{\circ} \mathrm{C}$ and $34.4{ }^{\circ} \mathrm{C}$ for subjects $\mathrm{A}$ and $\mathrm{B}$, respectively.

Like free convection on a vertical flat plate, the air raises from the lower part of the human body at a low velocity and up to the head at higher velocity. Kilic et al. (2008) reported a maximum velocity above of the head of $0.26 \mathrm{~m} / \mathrm{s}$. They also reported the heat transfer of the simulated human body with the surrounding environment of $35.72 \mathrm{~W} / \mathrm{m}^{2}$ by convention, $35.28 \mathrm{~W} / \mathrm{m}^{2}$ by radiation, $20.4 \mathrm{~W} / \mathrm{m}^{2}$ by evaporation, and $8.6 \mathrm{~W} / \mathrm{m}^{2}$ by respiration, for a total metabolic heat production of $100 \mathrm{~W} / \mathrm{m}^{2}$. Under somewhat similar simulation conditions, this numerical model shows smaller variations than that of Murakami et al.'s (2000) reported results.

Humans mainly wear clothing all day long. Since the human body is largely covered with clothing, the skin's heat release to the environment is strongly influenced by the level of insulation of clothing. Voelker et al. (2009) used a CFD thermal comfort model, which includes the clothing layer in the calculations of heat release and moisture to the surrounding environment. The heat transfer from the skin to the clothing occurs through convection and evaporation. As a result, the moisture transferred from skin to clothing will change the humidity of the garment. Finally, the heat exchange between the surface of the clothing and the ambient air take place through convective heat transfer, long and short wave radiation, and evaporative heat loss. 
Table 2.1 Summary of literature review

\begin{tabular}{|c|c|c|c|}
\hline Author & $\begin{array}{c}\text { Type of } \\
\text { ventilation }\end{array}$ & $\begin{array}{c}\text { Type of } \\
\text { work }\end{array}$ & Factor/Contribution \\
\hline $\begin{array}{l}\text { Mikell and Hobbs } \\
\text { (1981) }\end{array}$ & Lab hood & Experimental & $\begin{array}{c}\text { Distance breathing zone } \\
\text { to emitting source, } \\
\text { manikin/human }\end{array}$ \\
\hline $\begin{array}{c}\text { Caplan and Knutson } \\
\text { (1982) }\end{array}$ & Lab hood & Experimental & $\begin{array}{l}\text { Face velocity, air supply, } \\
\text { hood condition, manikin }\end{array}$ \\
\hline $\begin{array}{l}\text { Caplan and Knutson } \\
\qquad(1982 a)\end{array}$ & Lab hood & Experimental & $\begin{array}{l}\text { Types of supply air, cross- } \\
\text { draft velocity, face } \\
\text { velocity, manikin }\end{array}$ \\
\hline $\begin{array}{l}\text { Martinelli et al. } \\
\text { (1983) }\end{array}$ & General & Experimental & $\begin{array}{l}\text { Sample location, worker } \\
\text { activity, breathing zone, } \\
\text { human subject }\end{array}$ \\
\hline Cohen et al. (1984) & General & Experimental & $\begin{array}{l}\text { Type of samplers, } \\
\text { worker's clothes, human }\end{array}$ \\
\hline $\begin{array}{c}\text { Van Del Wal and } \\
\text { Moerkerken (1984) }\end{array}$ & General & Experimental & $\begin{array}{c}\text { Passive monitor, sample } \\
\text { location, human }\end{array}$ \\
\hline Abrams et al. (1986) & Lab hood & Experimental & $\begin{array}{l}\text { Face velocity, flow } \\
\text { profile, sash opening }\end{array}$ \\
\hline Ljungqvist (1987) & Lab hood & Experimental & $\begin{array}{l}\text { Smoke visualization, } \\
\text { human arm/hand } \\
\text { movement, manikin }\end{array}$ \\
\hline $\begin{array}{l}\text { Mikell and Fuller } \\
\text { (1988) }\end{array}$ & Lab hood & Experimental & $\begin{array}{l}\text { Face velocity, sash door } \\
\text { to source distance, sash } \\
\text { opening }\end{array}$ \\
\hline Ivany et al. (1989) & Lab hood & Experimental & $\begin{array}{c}\text { Source to hood face } \\
\text { distance, face velocity, } \\
\text { manikin }\end{array}$ \\
\hline Fuller (1990) & Lab hood & Experimental & $\begin{array}{l}\text { Source to breathing zone } \\
\text { distance, face velocity, } \\
\text { manikin/human }\end{array}$ \\
\hline $\begin{array}{l}\text { Kim and Flynn } \\
\text { (1991) }\end{array}$ & Free-Stream & Experimental & $\begin{array}{l}\text { Smoke-wire technique, } \\
\text { vortex shedding, manikin }\end{array}$ \\
\hline $\begin{array}{l}\text { Guffey and Barnea } \\
\text { (1994) }\end{array}$ & Plain hood & Experimental & $\begin{array}{l}\text { Face velocity, posture, } \\
\text { flange design, manikin }\end{array}$ \\
\hline Dunnett (1994) & Plain hood & Numerical & $\begin{array}{c}\text { Worker to hood face } \\
\text { distance, vortex shedding, } \\
\text { manikin }\end{array}$ \\
\hline $\begin{array}{l}\text { Johnson et al. } \\
\text { (1996) }\end{array}$ & Free-Stream & Experimental & $\begin{array}{l}\text { Velocity vector, thermal } \\
\text { boundary layer, breathing, } \\
\text { manikin/human }\end{array}$ \\
\hline
\end{tabular}


Table 2.1 Summary of literature review (Continued)

\begin{tabular}{|c|c|c|c|}
\hline Author & $\begin{array}{c}\text { Type of } \\
\text { ventilation }\end{array}$ & $\begin{array}{l}\text { Type of } \\
\text { work }\end{array}$ & Factor/Contribution \\
\hline $\begin{array}{c}\text { Johnson and Fletcher } \\
\text { (1996) }\end{array}$ & $\begin{array}{l}\text { Fume } \\
\text { cupboard }\end{array}$ & Experimental & $\begin{array}{c}\text { Manikin/human body } \\
\text { thermal effect, operator to } \\
\text { hood face distance, face } \\
\text { velocity }\end{array}$ \\
\hline $\begin{array}{l}\text { Kulmala et al. } \\
\text { (1996) }\end{array}$ & Free-stream & $\begin{array}{l}\text { Experimental/ } \\
\text { Numerical }\end{array}$ & $\begin{array}{l}\text { Wake region, breathing } \\
\text { zone to source distance }\end{array}$ \\
\hline $\begin{array}{c}\text { Maupins and } \\
\text { Hitchings (1998) }\end{array}$ & Lab hood & Experimental & $\begin{array}{l}\text { Face velocity, smoke test, } \\
\text { hood condition }\end{array}$ \\
\hline $\begin{array}{l}\text { Altemose et al. } \\
\quad \text { (1998) }\end{array}$ & Lab hood & Experimental & $\begin{array}{l}\text { Face velocity, cross-draft } \\
\text { velocity, horizontal sash } \\
\text { lab hood, human }\end{array}$ \\
\hline Tan et al. (1999) & General & Experimental & $\begin{array}{l}\text { Research lab, chemical } \\
\text { exposure, human }\end{array}$ \\
\hline $\begin{array}{l}\text { Greenley et al. } \\
\quad(2000)\end{array}$ & Lab hood & Experimental & $\begin{array}{l}\text { Face velocity, breathing } \\
\text { zone, sash opening, } \\
\text { manikin/human }\end{array}$ \\
\hline $\begin{array}{l}\text { Murakami et al. } \\
\text { (2000) }\end{array}$ & Free-stream & Numerical & $\begin{array}{c}\text { Body heat release, } \\
\text { buoyancy effect, } \\
\text { velocity/temperature } \\
\text { profile, skin temperature }\end{array}$ \\
\hline Guffey et al. (2001) & Free-stream & Experimental & $\begin{array}{l}\text { Worker orientation, cross- } \\
\text { draft velocity, manikin }\end{array}$ \\
\hline Tanabe et al. (2002) & Free-stream & Numerical & $\begin{array}{l}\text { Temperature distribution, } \\
\text { clothing, thermal manikin, } \\
\text { skin temperature }\end{array}$ \\
\hline Elnahas (2005) & Free-stream & Experimental & $\begin{array}{c}\text { Sample location, } \\
\text { breathing zone, manikin }\end{array}$ \\
\hline Li et al. (2005) & Free-stream & Numerical & $\begin{array}{l}\text { Worker body shade, } \\
\text { transport model, sample } \\
\text { location }\end{array}$ \\
\hline Tseng et al. (2006) & Lab hood & Experimental & $\begin{array}{l}\text { Face velocity, hood } \\
\text { geometry, manikin }\end{array}$ \\
\hline Li et al. (2007) & Free-stream & Numerical & $\begin{array}{l}\text { Worker body heat, cross- } \\
\text { draft velocity, } \\
\text { unheated/heated manikin }\end{array}$ \\
\hline Ahn et al. (2008) & Lab hood & $\begin{array}{l}\text { Experimental- } \\
\text { Review }\end{array}$ & $\begin{array}{l}\text { Source to breathing zone } \\
\text { distance, face velocity, } \\
\text { sash opening, cross-draft } \\
\text { velocity, manikin/human }\end{array}$ \\
\hline
\end{tabular}


Table 2.1 Summary of literature review (Continued)

\begin{tabular}{|c|c|c|c|}
\hline Author & $\begin{array}{c}\text { Type of } \\
\text { ventilation }\end{array}$ & $\begin{array}{c}\text { Type of } \\
\text { work }\end{array}$ & Factor/Contribution \\
\hline El-Sotouhy (2008) & Free-stream & Experimental & $\begin{array}{l}\text { Sample location, } \\
\text { breathing zone, human }\end{array}$ \\
\hline Kilic et al. (2008) & Free-stream & Numerical & $\begin{array}{l}\text { Velocity profile, body } \\
\text { heat transfer }\end{array}$ \\
\hline Voelker et al. (2009) & Free-stream & Numerical & $\begin{array}{l}\text { Clothing, skin's heat } \\
\text { release, humidity }\end{array}$ \\
\hline He (2010) & Plain hood & Experimental & $\begin{array}{l}\text { Face velocity, cross-draft } \\
\text { velocity, flanges, manikin }\end{array}$ \\
\hline $\begin{array}{l}\text { Karaismail and Celik } \\
\qquad(2010)\end{array}$ & Plain hood & Numerical & $\begin{array}{l}\text { RANS models, wake of } \\
\text { the worker, } \\
\text { steady/unsteady flow }\end{array}$ \\
\hline This work & Plain hood & Experimental & $\begin{array}{l}\text { Face velocity, cross-draft } \\
\text { velocity, temperature, } \\
\text { manikins/humans } \\
\text { exposure }\end{array}$ \\
\hline
\end{tabular}




\title{
CHAPTER 3
}

\begin{abstract}
APPARATUS
To assess the effectiveness of a benchtop enclosing hood in protecting workers from airborne contaminants, this study employed a simple manikin, an anthropometric manikin, and ten human subjects were used as subjects. It also employed an experimental hood and wind tunnel, a tracer gas releases system, a pitot traverse system, a sampling system, a gas analysis system, and temperature, humidity, and barometric pressure apparatus.
\end{abstract}

\subsection{The wind tunnel}

The WVU wind tunnel for ventilation and worker exposure research is $32 \mathrm{ft}$ long, $12 \mathrm{ft}$ wide, and $9 \mathrm{ft}$ high (See Figure 3.1). Velocity uniformity is enhanced by the upstream and downstream HEPA filters, and the downstream activated charcoal filter panels. Constant temperature anemometry (CTA) measurements taken at 6" intervals vertically and 12 " intervals horizontally found a coefficient of variation of $10 \%$ for velocity along the axis of the wind tunnel. The turbulence intensity was generally around $15-20 \%$ near the ceiling and was $3-5 \%$ in the middle section where the manikin and human subjects stood. The wind tunnel fan was controlled by a variable frequency drive to produce a range of wind tunnel velocities from 10 to $155 \mathrm{fpm}$. 


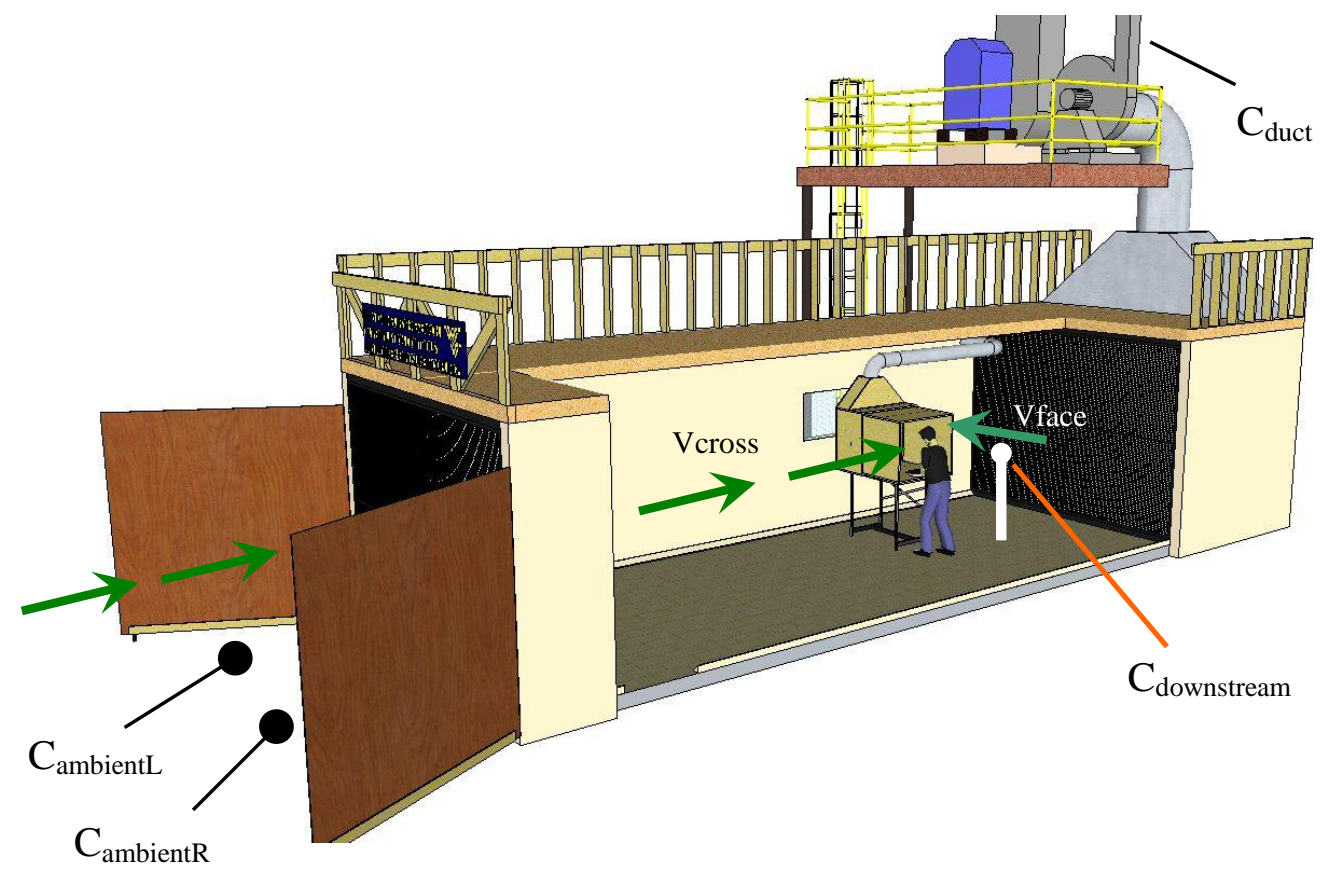

Figure 3.1 Wind tunnel and sampling locations

The wind tunnel is large enough that the enclosing hood and subject together do not block more than $15 \%$ of its cross-sectional area. To reduce thermal buoyancy effects due to the difference in temperatures between the floor and the ceiling of the wind tunnel, the floor is covered by 0.75 " styrene foam insulating sheets, which are overlaid by 1" plywood sheets and a linoleum floor covering. The temperature difference between the walls (lateral walls, ceiling, and floor) and the ambient air inside the wind tunnel was found to be always less than $2{ }^{\circ} \mathrm{C}$. 


\subsection{Simple manikin}

The simple manikin is a rounded acrylic plastic body 63 " tall that served as an experimental surrogate for a worker. The head is a sphere of 8 " diameter, the manikin's torso is an elliptical cylinder of 17.5 " wide without arms, and its legs are represented by two circular cylinders (see Figure 3.2). This static simple manikin was unheated and did not breathe.

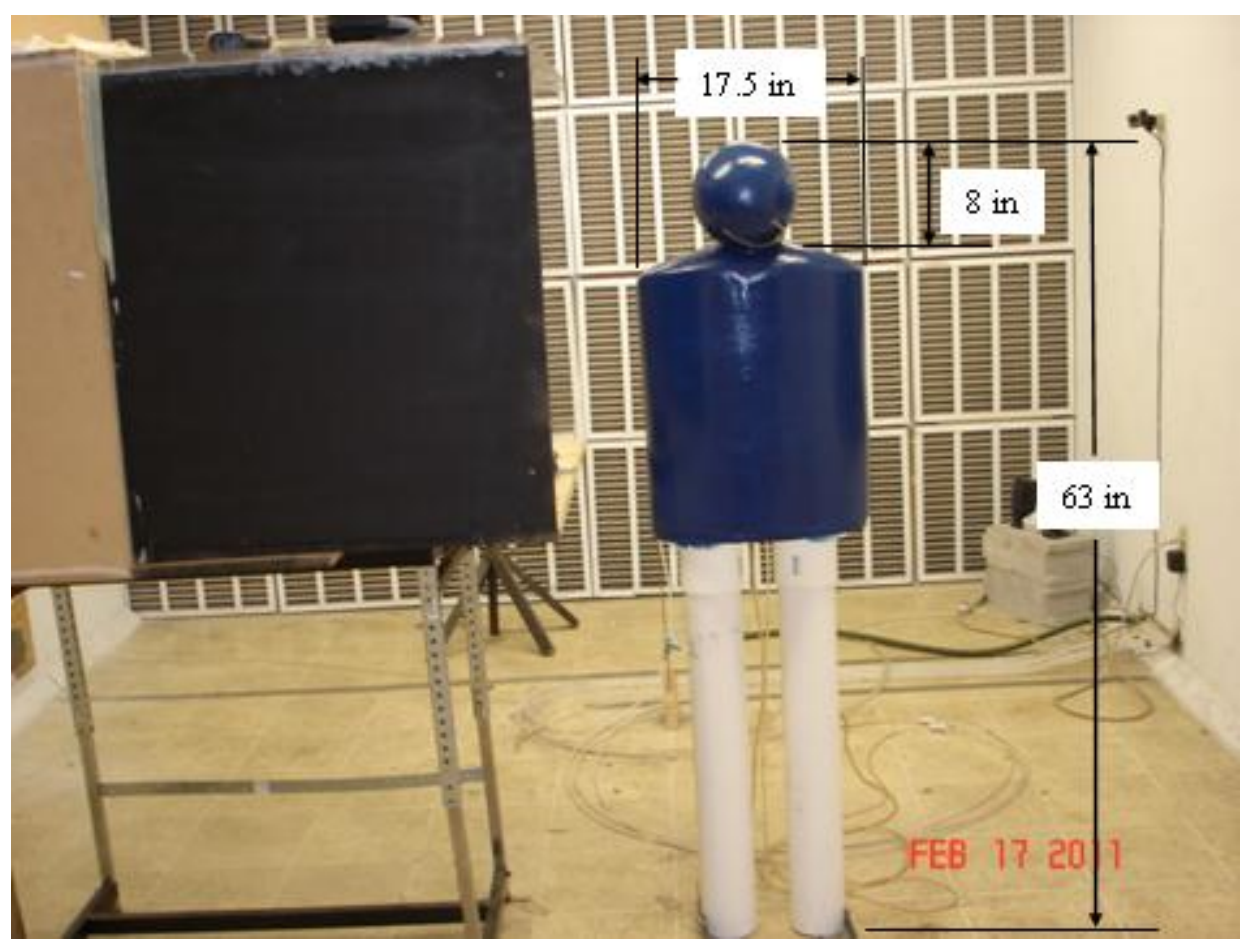

Figure 3.2 Simple manikin

Sampler probes were placed on the spherical head of the manikin on the left side of the nose and the right side of the mouth with a separation distance between them of approximately 3.5" (see Figure 3.3). For the experimental test, the manikin 
stood in a straight position at 1 " in front of the hood face with its waist at height of the 9" diameter pie-pan source (see Figure 3.4).

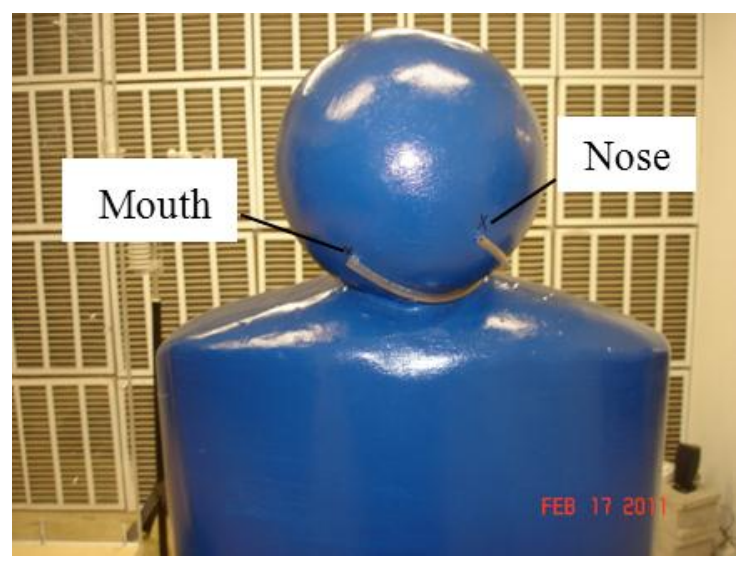

Figure 3.3 Sampling locations on the simple manikin head

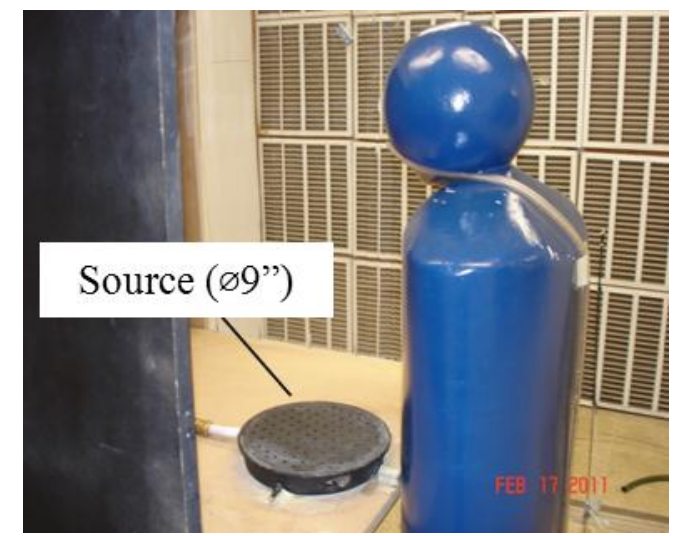

Figure 3.4 Simple manikin in working position

\subsection{Anthropometrically-correct manikin}

This manikin is a 66" high "male", anthropometrically-scaled manikin (see Figure 3.5) with molded facial features and molded short hair, with hollow cavities in the nose, ear, mouth, legs, and arms. It has rubber skin that feels similar to real human skin. The joints in the shoulders, hips, and knees allow the manikin to be 
posed to stand, to sit, and to bend at the torso and neck. The manikin's dimensions match with $50^{\text {th }}$ percentile for women and $5^{\text {th }}$ percentile for men (Kroemer and Grandjean, 1997).

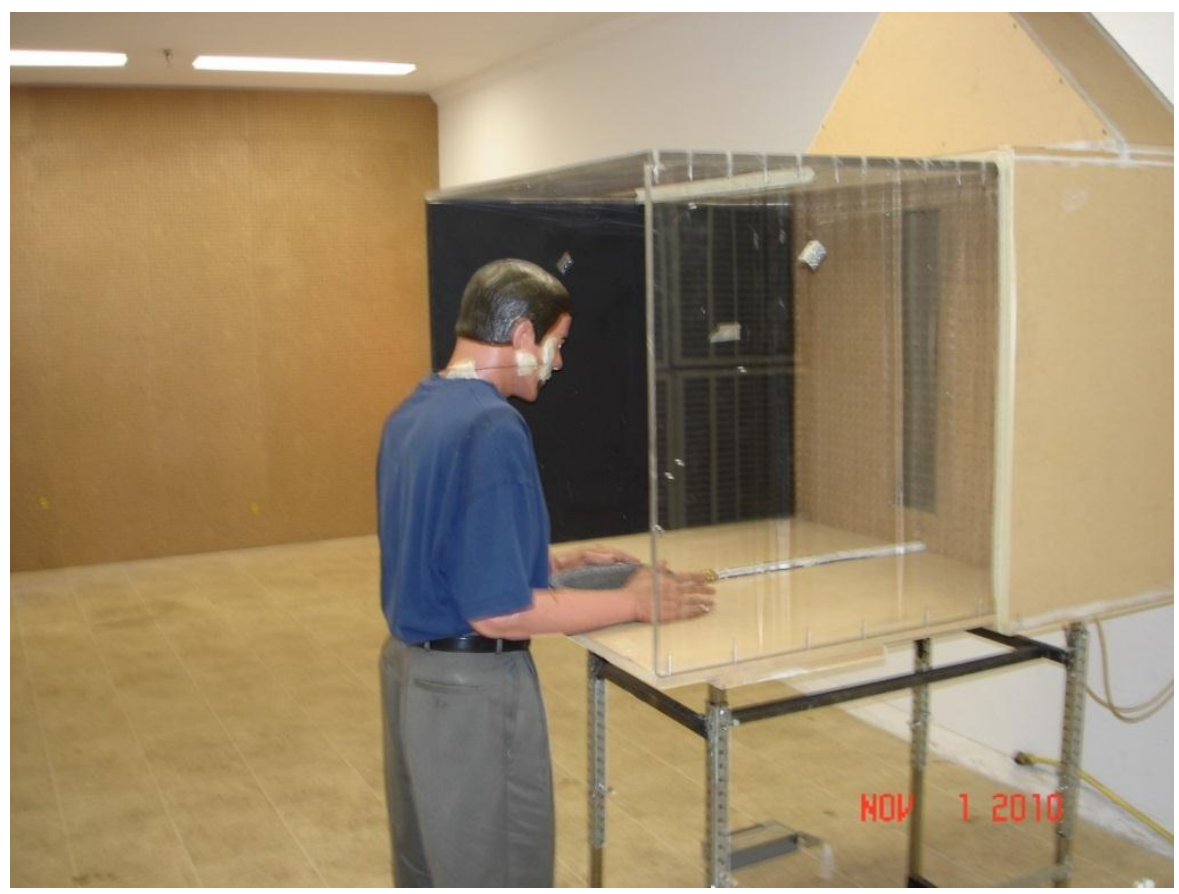

Figure 3.5 Anthropometrically-correct manikin in working posture

To produce a human body skin temperature, the manikin head and torso were heated by placing a length of small light bulbs (see Figure 3.6) for a total of 20 watts inside cavities in the torso, groin, and head of the manikin. To achieve a reasonably uniform temperature, the light bulbs were adjusted and insulation was placed at selected locations within cavities by trial and error. As a result, the skin temperature ranged from $27^{\circ}$ to $33^{\circ} \mathrm{C}$. 
To monitor the skin temperature, thermocouples were placed on the face and back of the manikin. To obtain and log the temperature data, a program was written using LabView software (National Instruments Corp., Austin, TX, 2007). The manikin was garbed in loose-fitting pants and a summer weight short-sleeved shirt (see Figure 3.5). The typical values of clothing insulation are 0 clo for a naked person, 0.5 clo for a person using summer clothes and 1 clo for a person using winter clothes (Brohus, 1997). Thus, the manikin's clothing insulation was assumed 0.5 clo.

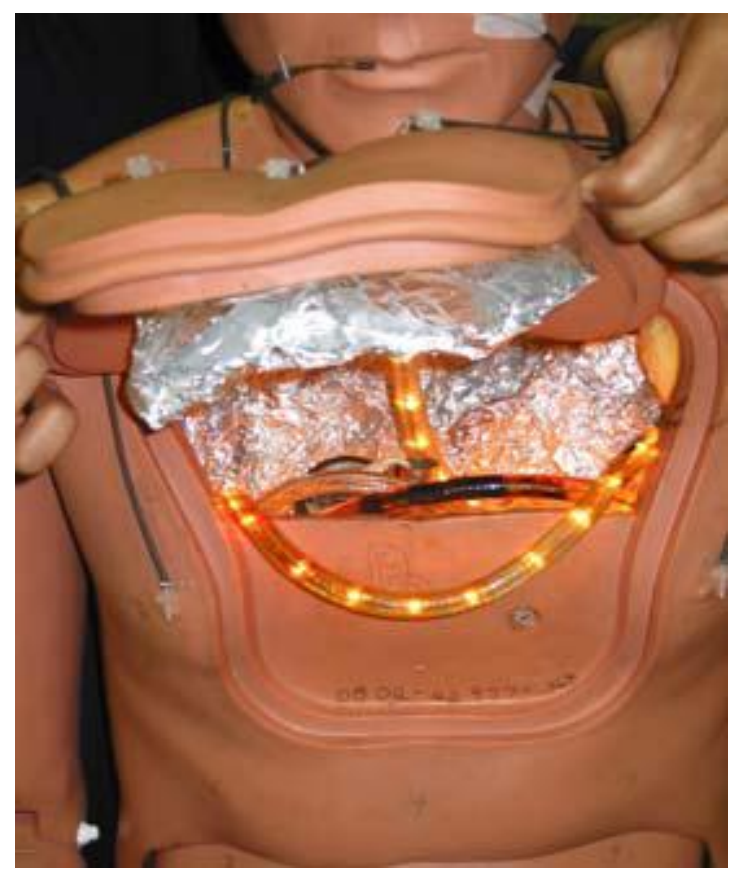

Figure 3.6 Test manikin with chest heating wire

An artificial lung (see Figure 3.7) was provided to simulate breathing by the manikin. An compressed air piston drew air and expelled the same air through the 
nasal openings. Compressed air ran from the breathing bellows which were connected to 1 " I.D. Tygon tubing, then to 0.5 " I.D. tubing, and from this to both nostrils (1/8" I.D. plastic tubing from each one) inside the manikin's head. As the breathing air entered the chamber inside the torso, it was heated by the body's heat to $35-37{ }^{\circ} \mathrm{C}$. Throughout the experiments, the motorized bellows outside the wind tunnel provided a sinusoidal pattern that produced a pulmonary ventilation rate from 16 to $18 \mathrm{lpm}$, which matches the lung ventilation for a low workload ranging from 11 to 20 lpm (Christensen, 1964, cited in Kroemer and Grandjean, 1997). Figure 3.8 shows a schematic diagram of the breathing circuit.

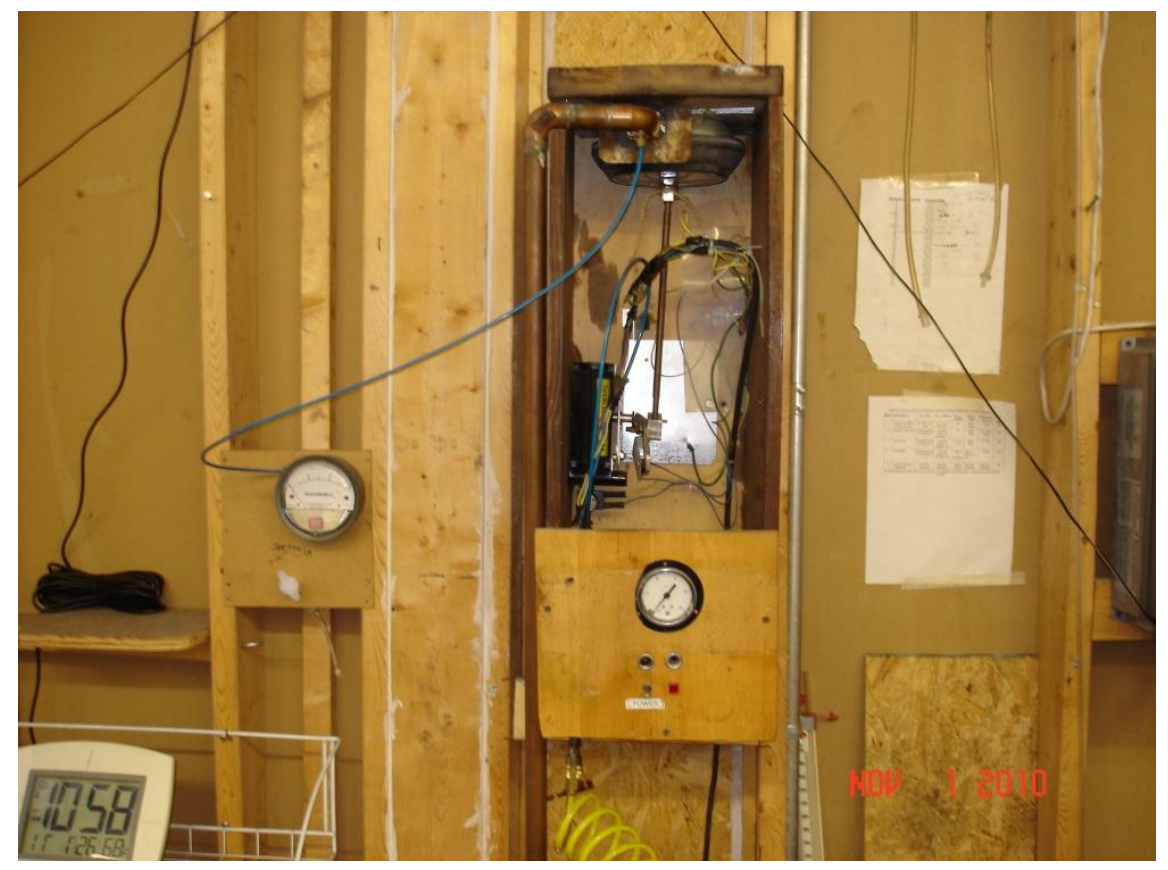

Figure 3.7 Anthropometric manikin breathing system 


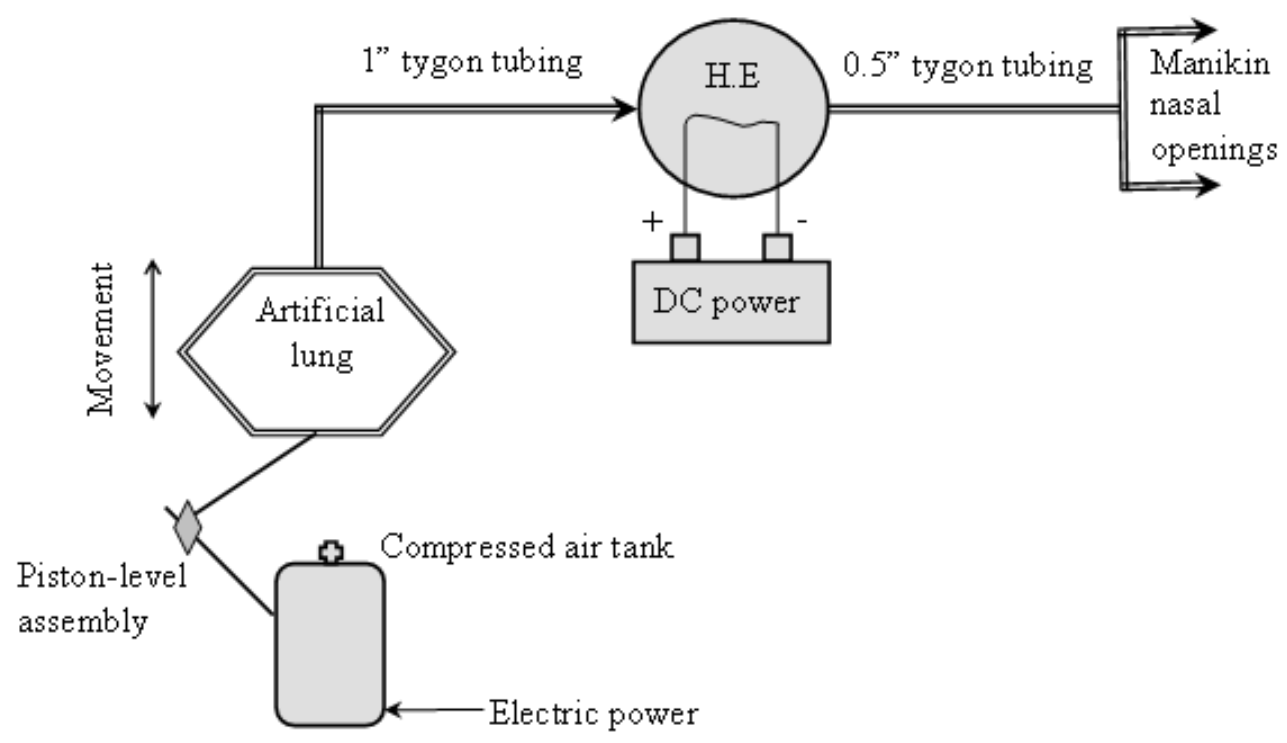

Figure 3.8 Flow diagram of the breathing circuit

\subsection{Human subjects}

Ten of the twelve human subjects, who were recruited through posted advertisements, completed the entire set of experimental trials. All ten subjects were male students with different ethnic backgrounds: four Hispanics, two white American, two black Americans, one black African, and one Asian student. They had different body sizes (see Table 7.1) and an average age lower than 30 years.

Tracer gas exposure tests were done to investigate the effects of hood face velocity and cross-draft velocity on benchtop enclosing hood containment ability. Human subjects stood in front of the enclosing hood (see Figure 3.9). The subjects moved small children's blocks back and forth over the contaminant source using both hands one at the time. The rate of block movement was controlled with metronome software ( $\mathrm{NCH}$ free software) at 40 to 60 beats per minute. 


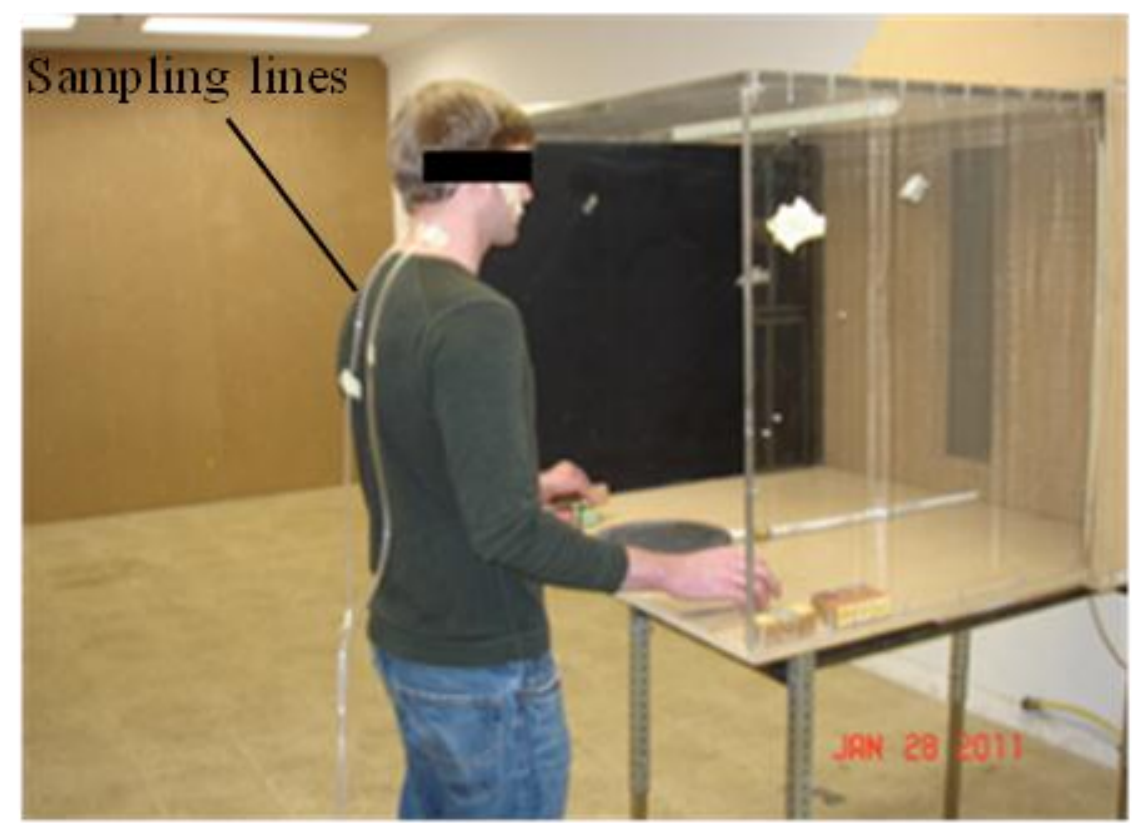

Figure 3.9 Human subject in front of the hood doing a light task

Sampling probes were placed near the left nasal opening and near the mouth on the right side (see Table 4.1) and fixed on the face with hypoallergenic paper tape. The sampling lines were spread and taped over the ears and back of the subjects to avoid any distortion to the airflow at the subjects' faces.

\subsection{Benchtop enclosing hood}

The experimental custom-made benchtop enclosing hood is 36 " wide, 30 " high and 48 " deep with transparent plastic sides to allow visualization inside (see Figures 3.9 and 3.10). For both manikins and human subject experiments, the hood was located 88 " from the downstream plenum of the wind tunnel and mounted on a table so that the bottom of the hood was 38 " from the floor. It was located such that the subject was near the midline of the long dimension of the wind tunnel. The subject stood at the center of the width of the hood facing the front of the enclosing 
hood face (see Figure 3.10). The separation between the waist of the subject and the forward edge of the hood was $2 "$. The source was fixed in place on the table at the center of the width of the hood at $2 "$ from the hood face.

In addition, to enhance the uniformity of the airflow velocity at the face and inside the hood, a perforated plastic glass with $95 \%$ opacity was placed at the back of the hood plenum face. The plenum section is 10 " deep and has a take-off taper angle of $45^{\circ}$ to guide the converging air to the exhaust duct.

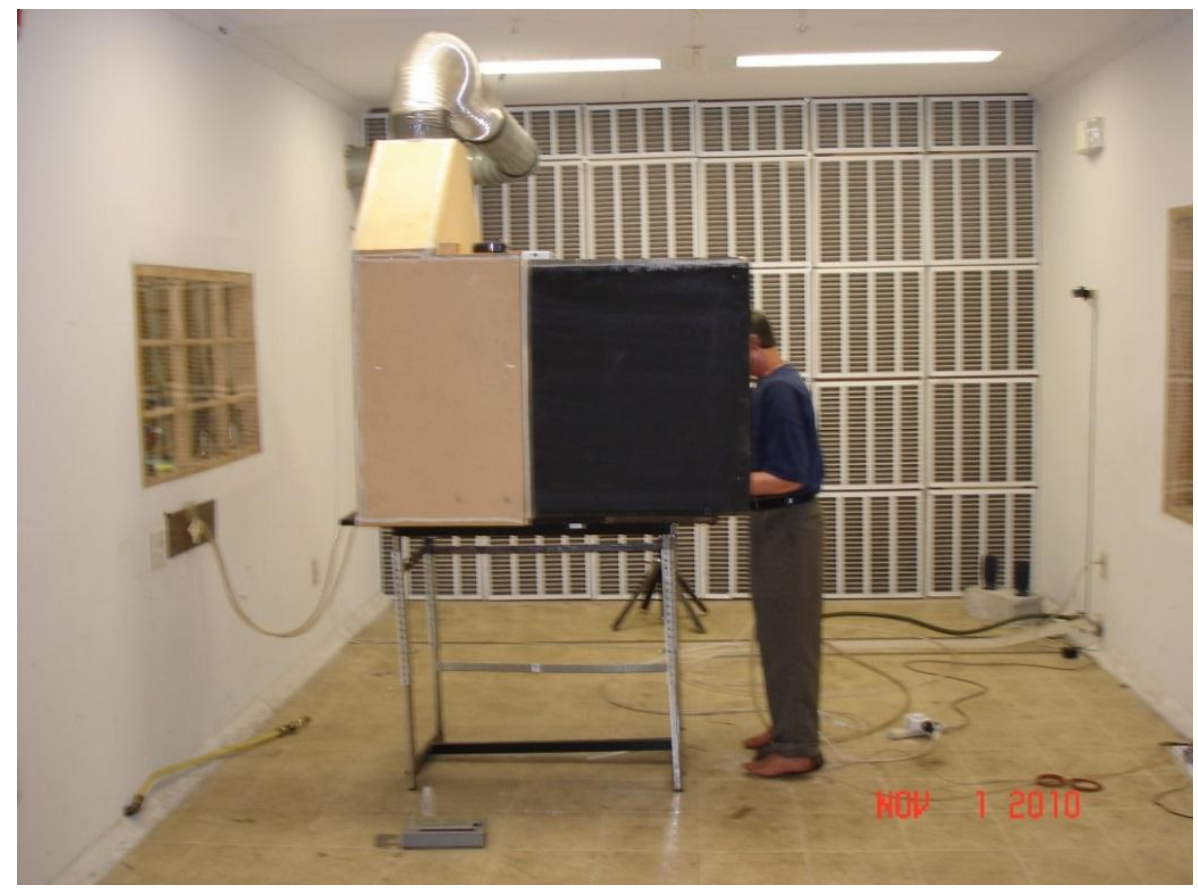

Figure 3.10 Benchtop enclosing hood position inside the wind tunnel 


\subsection{Tracer gas mixture system}

Three liters per minute $(3.0 \mathrm{lpm})$ of Freon $134 \mathrm{a}$ and $4.9 \mathrm{lpm}$ of helium were mixed to produce a neutrally-buoyant mixture for all hood tests. The Freon 134a and helium flow rates were regulated and measured by digital mass flow controllers (Aalborg GFC37 for Freon 134a and Aalborg GFC37 for helium) as shown in Figure 3.11. The mixture was carried by $1 / 2$ " I.D. plastic tubing to a 9" diameter, 1" deep aluminum pie-pan that served as the contaminant source. A plastic cover was glued to the pie-pan and drilled with 99 one-eighth inch diameter holes that were uniformly dispersed across the plastic cover (see Figures 3.4, 3.5, and 3.9). The velocity of the contaminant through these small holes was less than $1 \mathrm{fpm}$.

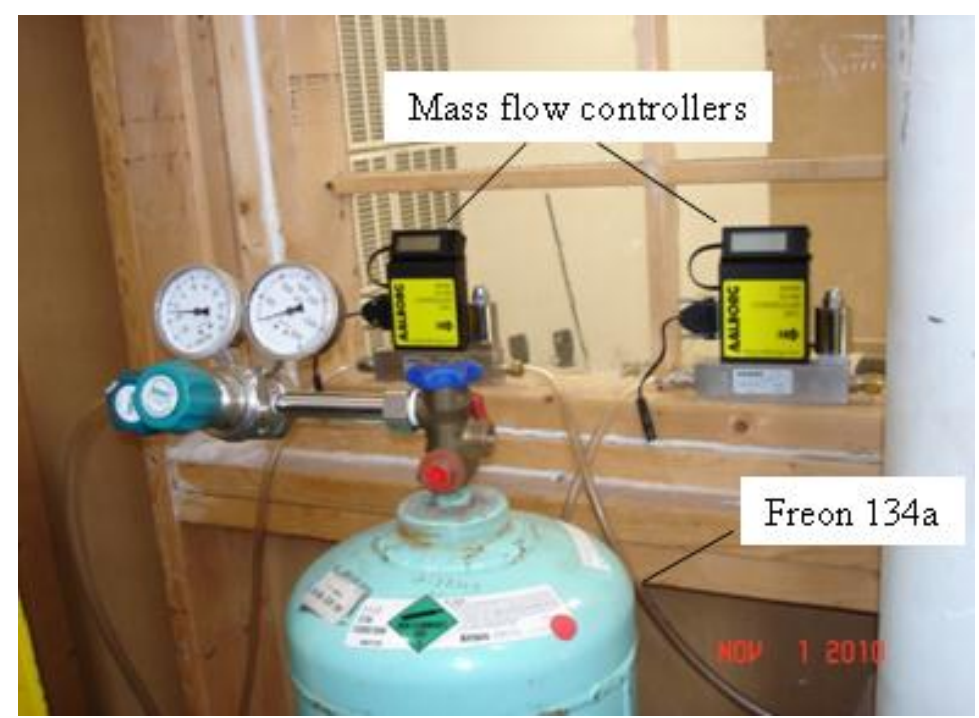

Figure 3.11 Tracer gas flow rate release system 


\subsection{Pitot traverse measurements}

Values of the enclosing hood $V_{\text {face }}$ were determined from the averages of two perpendicular 10-point pitot traverses taken for each test (see Figure 3.12). Values of $V_{\text {cross }}$ were determined from a pitot traverse based calibration of the wind tunnel fan output as a linear function of rotation rate. Velocity pressures were measured using a digital micromanometer (PVM 100, Airflow ${ }^{\mathrm{TM}}$ Buckinghamshire, UK). The digital manometer was calibrated with a hook gage (Dwyer Instruments Inc., Series 1425, Michigan City, Indiana, USA). Air density factors were determined from the static pressure measured at the same location as the velocity pressure traverses and from dry bulb temperature, wet bulb temperature, and barometric pressures measured with standard laboratory apparatus. Ventilation measurement software (Heavent Measurement) was used to capture and analyze micromanometer data.

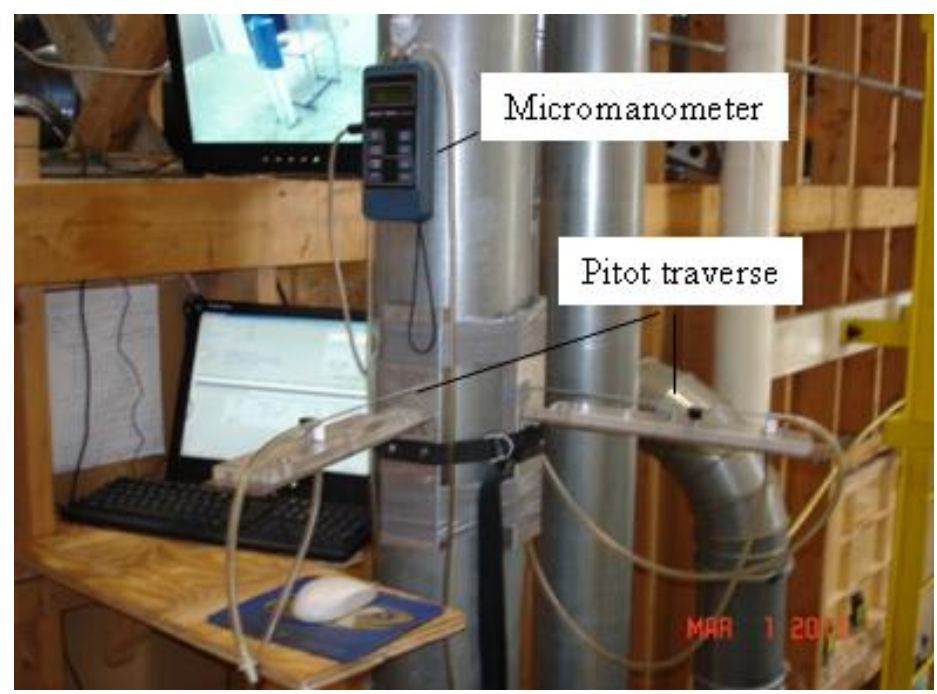

Figure 3.12 Pitot traverse system 


\subsection{Tracer gas sampling apparatus}

To draw samples from locations on the manikin or human subjects, $1 / 8$ " I.D. Tygon ${ }^{\circledR}$ sampling lines were used. On the face of human subjects, these sampling lines were taped using non-allergic skin tape. The inlets were close to the tip of the left nasal orifice and close to the right lip of the mouth. The sampling lines ran over the ears and down the back of the human subjects. Each 1/8" tube connected to $1 / 4$ " Tygon ${ }^{\circledR}$ tubing. The latter terminated at the inlet port of a SKC (Series 222-3, Eighty Four, PA, USA) low-flow sampling pump calibrated to 0.20 lpm using a DryCal pump calibrator (Defender 500 series, Butler, NJ, USA) and from the pump's outlet port to a 5 liter SKC Tedlar ${ }^{\circledR}$ sampling bag (Series 231, Eighty Four, PA, USA). Figure 3.13 shows the sampling pumps and sampling bags setup.

Samples were drawn downstream of the hood in the wind tunnel, from the exhaust duct, and from outside upstream of the wind tunnel at two locations, ambient left and ambient right (see Figure 3.1). All samples for a given test were drawn concurrently. For this research, all locations were sampled for 20 minutes into the 5-liter bags at $200 \mathrm{ml} / \mathrm{min}$ each. 


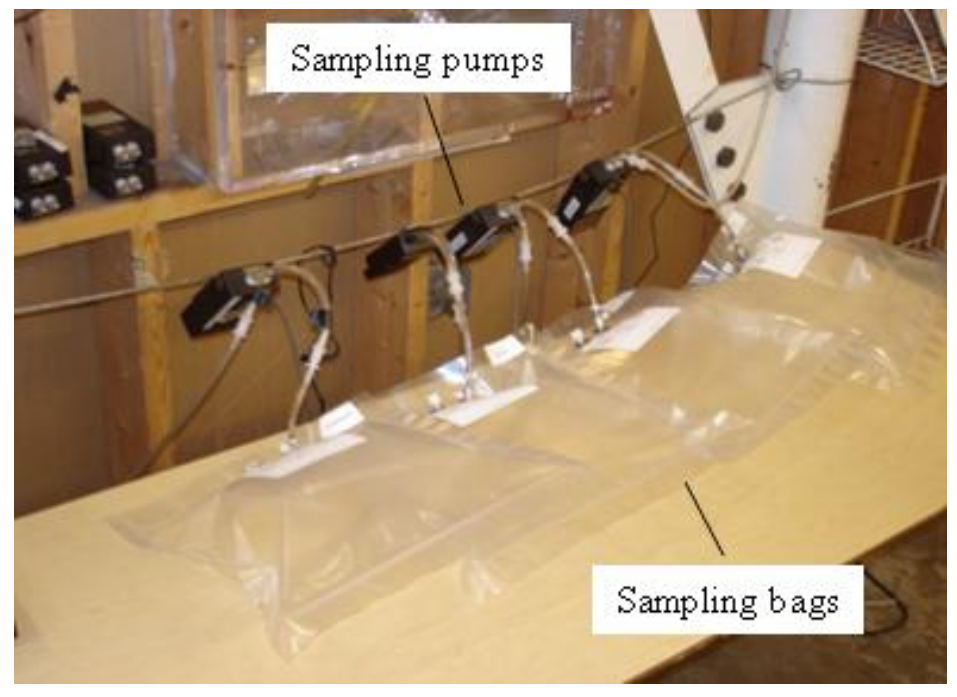

Figure 3.13 Sampling pumps and sampling bags setup

\subsection{Sampling bag analysis}

Analysis of the air inside the sampling bags was performed using a Gasmet $^{\mathrm{TM}}$ gas analyzer, model DX-4015 (see Figure 3.14), whose measuring principle is Fourier Transformed Infrared (FTIR). After each test, sample bags' valves were tightly closed and carried to the FTIR. The analysis of each bag took 2 minutes: 1 minute to pump the sample inside the FTIR and 1 minute to process the result (detailed description of the procedure in Chapter 4). To detect sampling bag leaks, bags were often filled with air and left for several hours or were placed under water. 


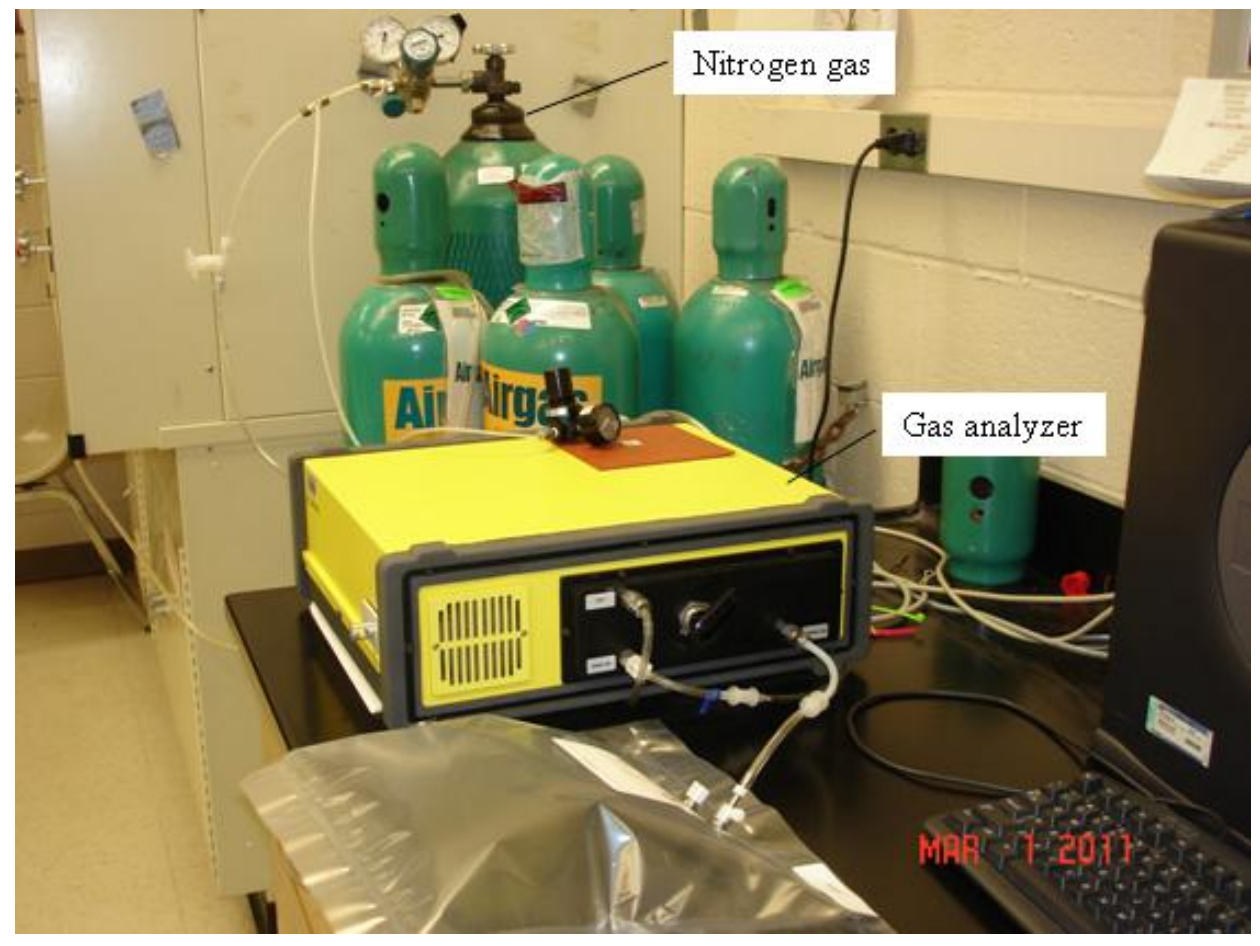

Figure 3.14 Sampling bag gas analysis system

\subsection{Temperature, humidity, and barometric pressure}

Temperatures of the lateral walls, ceiling, and floor of the wind tunnel were measured with an infrared thermometer (Oakton, model number EW-35629) with accuracy $\pm 1 \%$ of the reading or $\pm 1{ }^{\circ} \mathrm{C}( \pm 2 \mathrm{~F})$. The cheek and the back temperatures of the manikins and human subjects were also measured with the infrared thermometer. Wind tunnel dry bulb temperature (i.e., the ambient temperature) and wet bulb temperature were measured with a battery-powered psychrometer (Industrial Instruments and Supplies, model 22012, Southampton, PA)

The relative humidity and dew point temperature were read from the psychrometric chart on the psychrometer. These temperatures and humidity 
measurements were corroborated by a digital "weather station" (Tycon Power Systems, Draper, Utah, USA) installed outside the wind tunnel. Barometric pressures were measured with a standard laboratory mercury barometer 


\section{CHAPTER 4}

\section{RESEARCH DESIGN, METHODS, AND PROCEDURES}

The aim of the present experimental study is to evaluate the performance of a custom-made benchtop enclosing hood. A simple manikin, an anthropometric manikin, and ten human subjects were used for this purpose. This chapter describes the research design and methods, and the calibration procedures of the main equipments.

\subsection{Research design}

Experiments were carried out in a completely randomized factorial design with 2 replications for each condition. The dependent variables were concentrations at the nose and mouth $\left(C_{\text {nose }}\right.$ and $\left.C_{\text {mouth }}\right)$. While the independent variables or main factors were the hood face velocity $\left(V_{\text {face }}\right)$ and the wind tunnel cross-draft velocity $\left(V_{\text {cross }}\right)$. For the simple manikin experiments, five levels of $V_{\text {face }}(100,140,160,190$, and $220 \mathrm{fpm}$ ) and five levels of $V_{\text {cross }}(14,24,36,46$, and $57 \mathrm{fpm})$ were chosen. These levels of $V_{\text {face }}$ overlap the range of recommended values (100-200 fpm) by the Industrial Ventilation Manual $\left(\mathrm{ACGIH}^{\circledR}\right.$ Industrial Ventilation Committee, 2010). The $V_{\text {face }}$ of $220 \mathrm{fpm}$ was the maximum value that the exhaust fan allows to set up. The range $V_{\text {cross }}$ was chosen because it is deem likely to occur in an industrial workplace. Thus, this range is well enough to show the effects of $V_{\text {cross }}$ on exposure. For the anthropometric manikin and the human subjects, three levels of $V_{\text {face }}(100,160$, and $220 \mathrm{fpm})$ and three levels of $V_{\text {cross }}(14,46$, and $63 \mathrm{fpm})$ were 
selected. It was also proved in previous enclosing hood experimental study (Guffey and Barnea, 1994) that $V_{\text {face }}<100 \mathrm{fpm}$ always produces higher worker's exposure. Thus, the present study focuses its attention to $V_{\text {face }}$ in the range of 100-220 fpm.

In addition to the controlled independent variables $\left(V_{\text {face }}\right.$ and $\left.V_{\text {cross }}\right)$, the temperature difference between the subjects and the environment $\left(\Delta T_{\text {man }}\right)$ was deemed as an uncontrolled independent variable. Also, the different human subjects' body dimensions such as the width of the shoulders, the height, and the weight were considered as independent variables to assess the effect on exposure. The effect on exposure of the distance between the subject breathing zone and the hood face was also assessed. Finally, all subjects (including both manikins and the ten human subjects) were considered as independent variables to investigate their effects on $C_{\text {nose }}$ and $C_{\text {mouth }}$.

\subsection{Research methods}

Data was collected in the WVU exposure assessment wind tunnel, which includes the benchtop enclosing hood, a tracer gas releases system, a pitot traverse system, a sampling system, a gas analysis system, and the temperature, humidity, and barometric pressure apparatus (detailed apparatus description in Chapter 3). Samples of contaminated air were collected from Tygon probes located on the subjects' faces at roughly 0.2 inch from the nose $\left(C_{n o s e}\right)$ and 0.5 inch from the mouth $\left(C_{\text {mouth }}\right)$. Those locations were deemed the most reliable ones to capture the actual worker's exposure (Figure 4.1). Samples were also taken downstream of the 
hood in the wind tunnel $\left(C_{\text {downstream }}\right)$, upstream outside the wind tunnel $\left(C_{a m b i e n t R}\right.$, $\left.C_{\text {ambientL }}\right)$, and in the duct exhaust $\left(C_{d u c t}\right)$ outside the wind tunnel (Table 4.1).

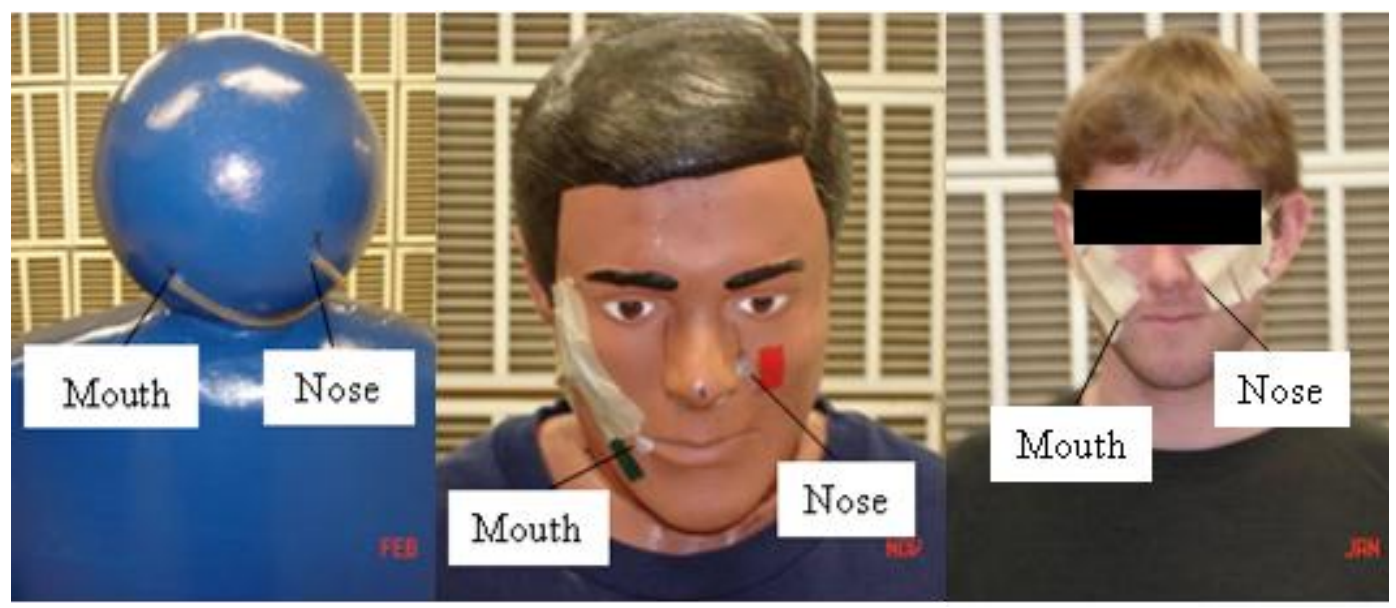

Figure 4.1 Simple manikin, anthropometric manikin, and human sampling locations

Table 4.1 Description of sampling locations

\begin{tabular}{|c|l|c|}
\hline Symbol & \multicolumn{1}{|c|}{ Description } & Location \\
\hline$C_{\text {nose }}$ & 0.2 inch laterally from the left nasal orifice & Nose \\
\hline$C_{\text {mouth }}$ & 0.5 inch from the right lip & Mouth \\
\hline$C_{\text {downstream }}$ & $\begin{array}{l}4.0 \text { feet before the wind tunnel outlet, between } \\
\text { the enclosing hood and wind tunnel outlet }\end{array}$ & Downstream \\
\hline$C_{\text {duct }}$ & At 6.0 feet downstream of the duct exhaust fan & Duct \\
\hline$C_{\text {ambient }}$ & At 6.0 feet outside of the wind tunnel inlet & $\begin{array}{c}\text { Ambient } \\
\text { right and left }\end{array}$ \\
\hline
\end{tabular}

Sample probes were glued over the simple manikin's spherical head at roughly the nose and mouth location with a separation of 3.5 inches between them. In addition, the simple manikin was unheated, non-breathing and without arms. Its 
body was always in a rigidly vertical posture without clothes during the sample tests. The heating and breathing anthropometric manikin kept a forward leaning "working" posture with both hands placed at each side of the tracer gas source (9" pie-pan). For all tests, the anthropometric manikin was wearing summer clothes. On the other hand, human subjects simulated a working task moving children's blocks back and forth over the contaminant source.

Prior to each experimental test, after $V_{\text {face }}$ and $V_{\text {cross }}$ were set up and before sampling, temperatures on the manikins' and humans' cheeks and backs were taken. The average of these two values was considered the subject's average body temperature $\left(T_{\text {manAvg }}\right.$ and $\left.T_{\text {humanAvg }}\right)$. Subjects' chest temperatures would have better represented the average body temperature, but this surface of the body was inaccessible for infrared measurement because subjects leaned against the hood face. Instead, back temperatures were taken because of the ease of infrared instrument access. In any case, to obtain the temperature differences between the subject's body and the ambient air, the dry bulb ambient temperature $\left(T_{\text {ambient }}\right)$ was subtracted from these average body temperatures, as shown in Equations 4.1 and 4.2. In addition, temperatures on the lateral walls, the ceiling and the floor were also recorded.

For the complex manikin, thermocouples were fixed on the right side of the face and the back of the manikin to control the temperature $\left(27-33^{\circ} \mathrm{C}\right)$ in real time during the 20 minutes of each experiment. To find out whether or not the thermocouple affects the head airflow pattern, and therefore the exposure, 
experiments were carried out with and without thermocouple on the manikin's face. Results are discussed in the next chapters.

$$
\begin{aligned}
& \Delta T_{\text {man }}=T_{\text {manAvg }}-T_{\text {ambient }} \\
& \Delta T_{\text {human }}=T_{\text {humanAvg }}-T_{\text {ambient }}
\end{aligned}
$$

To calculate the fluid mechanics dimensionless numbers such as the Reynolds number $(R e)$ and the Richardson number $(R i)$, a free stream velocity $(U)$ or approach velocity is needed. Approach velocities were calculated by Karaismail (2011) in his numerical simulations of the benchtop enclosing hood at different combinations of $V_{\text {face }}$ and $V_{\text {cross }}$. Therefore, a regression approach velocity $(U)$ equation was obtained using the numerical data of Karaismail (2011) for all studies in this work (see Equation C.1 in Appendix C). The numerical simulated enclosing hood was of the same characteristics and dimensions that the experimental hood of this study.

\subsection{Data analysis}

The reliability of the measured concentrations in the FTIR gas analyzer can be tested by the difference between the measured dimensionless absorbance spectrum and the instrument settings absorbance spectrum for each component, which is called residuals. The residuals analysis must be below 0.02 to be considered successful. Otherwise, the sample bag analysis result was incorrect and should not be considered (Gasmet ${ }^{\mathrm{TM}}$ Technology Oy, 2005). Therefore, incorrect results were omitted from the data analysis. 
Prior to statistical data analysis, an average of the ambient concentrations at the right and the left location $\left(C_{\text {ambientAvg }}\right)$, outside the wind tunnel, was calculated. If the $C_{\text {ambientAvg }}$ was less than the measured values of $C_{\text {noseMeas }}$ and $C_{\text {mouthMeas }}$, corrected concentrations at the nose $\left(C_{\text {nose }}\right)$ and mouth $\left(C_{\text {mouth }}\right)$ were calculated to reflect the actual subjects' exposures (Equations 4.3 and 4.4). Otherwise, a value of $0.0001 \mathrm{ppm}$ was set. In addition, these values were log-transformed for statistical analysis to have a roughly linear model. Statistical analyses were performed for all experimental data using Data Desk commercial software (Data Description Inc. Ithaca, NY) at $5 \%$ level of significance.

$$
\begin{aligned}
& C_{\text {nose }}=C_{\text {noseMeas }}-C_{\text {ambientAvg }} \\
& C_{\text {mouth }}=C_{\text {mouthMeas }}-C_{\text {ambientAvg }}
\end{aligned}
$$

For the simple manikin data, analysis of variance (ANOVA) was performed because the controlled factors of $V_{\text {face }}$ and $V_{\text {cross }}$ were considered discrete variables. On the other hand, analyses of covariance (ANCOVA) were carried out for the complex manikin and the human subjects' data, because an uncontrolled continuous variable $\left(\Delta T_{\text {man }}\right.$ and $\left.\Delta T_{\text {human }}\right)$ was included in the statistical model. The significance of these variables and their interaction were analyzed using Data Desk (Data Description Inc. Ithaca, NY) software.

\subsection{Enclosing hood experimental test procedures}

The following are the procedures for benchtop enclosing hood exposure sampling experiments. 


\subsubsection{Equipment preparation prior to experimental runs}

1. The FTIR gas analyzer was turned on at least 1 hour prior to the analysis of sampling bags. Nitrogen gas was injected into the FTIR.

2. The mass flow controllers were turned on 30 minutes before any experimental test was started.

3. All SKC low-flow sampling pumps were activated and their flow rates were checked to ensure that flows were approximately $200 \mathrm{ml} / \mathrm{min}$.

4. Labeled SKC sampling bags were connected with their valves in closed position to their respective SKC sampling pumps' outlet ports.

5. The wind tunnel variable frequency drive and the hood fan variable frequency drive were switched on and adjusted to produce the scheduled flow values of $V_{\text {face }}$ and $V_{\text {cross }}$.

6. Inside the wind tunnel the following tasks were carried out

- The sampling line tubing was checked visually for correct connections.

- For the anthropometrically-correct manikin, its heating system was switched on at least 3 hours prior to the experimental tests. Time delays were not needed for the unheated simple manikin or human subjects.

- Sampling probes were glued in a roughly nose and mouth location on the simple manikin's spherical head. For the anthropometric manikin, sampling probes were coming out from 
inside the body through two small holes near the nose and mouth.

- Non-allergenic skin tape was used to fix the tubing sampling line near the nose and mouth of the human subject, if any was tested that day.

- Position of the manikins or human subjects at the center of the hood face was verified. The tracer gas source was placed at 2" from the hood face. For the anthropometric manikin and the human subjects, the contaminant source was between the subjects' hands.

- The LabView system was activated to obtain temperatures from the thermocouples on the sample wall and on the ceiling of the wind tunnel and on the anthropometric manikin's face and back. Temperatures were not recorded on the face and back of the simple manikin and human subjects using LabView.

- To verify LabView's temperatures, the wind tunnel walls, ceiling, floor, and manikins or human subjects' face and back were measured using an infrared digital thermometer.

- The dry bulb and wet bulb ambient temperature were read using a standard psychrometer.

7. After completing the setup inside the wind tunnel, the door was closed tightly. 
8. For the anthropometrically-correct manikin experiments, the breathing machine was switched on outside the wind tunnel.

9. The barometric pressure in the test lab was recorded.

10. The helium tank valve and the Freon 134a tank valve were opened and the time was recorded. The contaminant mixture was allowed to stabilize for 5 minutes before experimental sampling started.

11. The experimental exposure test was started. The valves of the SKC sampling bags were opened and the LabView program was initiated to record temperatures from thermocouples.

\subsubsection{Procedures during the experimental runs}

1. If present, the human subject was signaled for the start of the experiment. The subject started moving small children blocks from one side of the source to the other for 20 minutes while the sampling was carried out.

2. Twenty values of velocity pressure were measured using the pitot tubes traverse and the PVM 100 digital micromanometer. The Heavent Measurement software calculated and recorded the $V_{\text {face }}$ and the duct average velocity.

3. Human subjects were observed frequently using a web camera and by viewing through the glass windows to check if they were keeping the right position in front of the hood. If not, a suggestion was made through the microphone. 
4. When the 20 minutes sampling period expired, the valves of the SKC sampling bags were closed and disconnected from the SKC sampling pumps' outlet ports.

\subsubsection{Procedures after the experimental runs}

1. The valves of Freon 134a and helium cylinders were closed and the human subject, if present, was signaled to stop "work."

2. The SKC sampling pump was left running to purge the contaminants remaining in the sampling line tubing and the wind tunnel door was opened to ventilate it.

3. SKC sampling bags were thoroughly taken to the FTIR gas analyzer.

4. Before the sampling bags were analyzed, the FTIR was filled with nitrogen gas and then purged until the desired zero calibration (background) was achieved.

5. The first SKC sampling bag was connected to the inlet port of the FTIR gas analyzer using plastic tubing. Its valve was open and sample was drawn into the analyzer for one minute.

6. The concentration of the Freon 134a was displayed on the computer screen and logged to a text file. The investigator also logged the concentration to a data collection sheet.

7. The sample bag was removed from the gas analyzer and Steps 5 and 6 were repeated for the next sample bag. 
8. After all sampling bags were finished, the analyzer was left running for about 15 minutes to purge the nitrogen and the injected contaminants.

9. The sampling bags were filled with air and then manually rolled and pressed to empty them. This procedure was repeated twice and then their valves were closed.

10. The SKC sampling bags were ready for the next experiment.

\subsubsection{Calibration of the FTIR gas analyzer}

1. Repeated Step 4 from Section 4.2.3.

2. Using a calibration syringe, two liters of clean ambient air were injected into a sampling bag.

3. Fifty micro liters of Freon 134a were injected in the same sampling bag, filled previously with ambient air, using a small syringe.

4. The sampling bag was shaken a few times to ensure uniformity in the mixture.

5. The sampling bag was connected to the gas analyzer, and for one minute, sample was drawn into it.

6. The concentration of Freon 134a was displayed on the screen and recorded.

7. The expected concentration of Freon 134a was computed from the volume of the air injected into the bag and the volume of Freon 134a injected into the same bag. This value was compared with the gas 
analyzer result. If necessary, new calibration coefficients were computed by linear regression.

\subsubsection{SKC low-flow sampling pumps calibration}

1. The SKC low-flow sample pump was switched on.

2. The sample pump dial was setup to different levels (i.e. 0, 30, 50, 80, and $100 \%$ of the flow rate).

3. For each level, the sample pump outlet port was connected to the inlet port of a Bios DryCal flow meter and the flow rate was recorded.

4. A graph of the flow rate $(\mathrm{ml} / \mathrm{min})$ and the sampling pump dial level (\%) was constructed.

5. A calibration curve was developed using linear regression (see Appendix G).

6. The linear regression equation $\left(\mathrm{R}^{2}=0.9916\right)$ was used to predict flow rates (see Appendix G).

7. The same procedure was followed for each of the SKC low-flow sampling pumps. 


\section{CHAPTER 5}

\section{SIMPLE MANIKIN STUDY}

\subsection{Introduction}

There is a continuing interest in replacing human subjects with manikins in all types of experiments, including local exhaust ventilation (LEV) experiments. Thus, manikin studies to assess the performance of LEV devices are widely used. It is not clear to what degree a manikin must be like a human in shape, respirator, and body heat. By comparing results for manikins with different features, it is possible to determine their importance.

This portion of the overall study investigated the performance of the hood when the simple manikin was the subject. In addition, the simple manikin data can be compared with those of CFD simulations because both used the same simple volume shapes as body parts (sphere and cylinders). Most importantly, the simple manikin and the human subjects' data can be also compared to determine if this type of manikin is enough to represent human exposures.

Despite a diligent search, Guffey and Barnea (1994) and He (2010) were the only two experimental studies about the performance of a benchtop enclosing hood to capture and to remove contaminants of the manikin breathing zone. Both used an anthropometric manikin, Guffey and Barnea (1994) used a child-size anthropometric manikin (40") and $\mathrm{He}$ (2010) an average adult anthropometric manikin (66"). Unlike Guffey and Barnea (1994), He (2010) carried out its 
experimental work in the same with tunnel and hood that the present study. They studied the effect of controlled face velocity $\left(V_{\text {face }}\right)$ and cross-draft velocity $\left(V_{\text {cross }}\right)$ on manikin's exposure using an enclosing hood. However, no experimental studies were found on factors affecting the performance of the benchtop enclosing hood using a simple manikin (unheated and non-breathing) as a surrogate of a human subject.

Limited studies about the factors affecting the performance of benchtop enclosing hoods have been done (Guffey and Barnea, 1994; He, 2010; Karaismail and Celik, 2010). Face velocity is the most important factor that affects worker exposure (Guffey and Barnea, 1994; He, 2010). At $V_{\text {face }}=100 \mathrm{fpm}$ and higher, concentrations were always lower in the breathing zone (Guffey and Barnea, 1994). He (2010) found that the simultaneous effects of $V_{\text {face }}$ and $V_{\text {cross }}$ had a significant effect in the performance of enclosing hoods using a heated and breathing anthropometric manikin. In addition, the wake region formation was predicted downstream of a simple manikin using numerical simulation (Karaismail and Celik, 2010).

The importance of the airflow direction relative to the worker orientation was pointed out in several studies (Flynn and Miller, 1991; Guffey et al. 2001). Flynn and Miller (1991) simulated the boundary layer separation in a twodimensional elliptical cylinder (worker) to study the effects on contaminant exposure. Even though there was a CFD simulation and different manikin, they agreed with our study that side orientation was the better worker position to reduce 
pollutant exposure in the breathing zone. Guffey et al. 2001 studied airflow patterns for three different orientations (back, front, and side) and determined experimentally that side orientation gives lower concentration values than the other ones.

The present study investigated the effects of hood face velocity $\left(V_{\text {face }}\right)$, cross-draft velocity $\left(V_{\text {cross }}\right)$, and the temperature difference between the manikin's body and the ambient air $\left(\Delta T_{\operatorname{man}}\right)$ in the performance of a custom-made benchtop enclosing hood to capture and to remove contaminants of the manikin environment.

\subsection{Experimental design}

The effect of two controlled factors, hood face velocity $\left(V_{\text {face }}\right)$ and crossdraft velocity $\left(V_{\text {cross }}\right)$, on the concentrations at the nose $\left(C_{\text {nose }}\right)$ and mouth $\left(C_{\text {mouth }}\right)$ were investigated. In addition, the effect of one uncontrolled factor such as the temperature difference of manikin's surface and ambient air $\left(\Delta T_{\text {man }}\right)$ on $C_{\text {nose }}$ and $C_{\text {mouth }}$ was also assessed.

To this end, five levels of $V_{\text {face }}(100,140,160,190$, and $220 \mathrm{fpm})$ and five levels of $V_{\text {cross }}(14,24,36,46$, and $57 \mathrm{fpm})$ were tested in a completely randomized factorial design. Every treatment combination of $V_{\text {face }}$ and $V_{\text {cross }}$ were replicated twice. The $\Delta T_{\operatorname{man}}$ was recorded and observed passively.

\subsection{Apparatus}

The simple manikin was unheated, non-breathing, built of basic geometric forms (see Figures 3.2), and it was without clothes. In addition, the manikin has no arms. Unlike the complex manikin, the simple manikin was a static rigid body and 
cannot be posed in front of the hood face. The simple manikin's head does not break the hood face. Detailed manikin description and experimental apparatus are given in Chapter 3.

\subsection{Methods}

Samples of concentrations at the nose and mouth $\left(C_{\text {nose }}\right.$ and $\left.C_{\text {mouth }}\right)$ were collected from probes glued at roughly nose and mouth locations on the manikin's head (Detailed description on Chapter 4). In addition, temperatures on the manikin's cheek and back were also collected. Similar to the complex manikin and the human subjects, the simple manikin was exposed to a mixture of $3.0 \mathrm{lpm}$ of Freon 134a and $4.9 \mathrm{lpm}$ of Helium, which was released from a contaminant source just inside the hood on the hood floor (see Figure 3.4). Also, similar to the other subjects, the simple manikin and the hood were positioned perpendicular to the long dimension of the wind tunnel so that the flow through the wind tunnel (crossdraft) impacted the sides of the manikin and hood (i.e. "side orientation").

\subsection{Analysis}

Detailed description of data analysis for all subjects, including simple manikin can be seen in Chapter 4. However, it is worthy to mention again that the effect of $V_{\text {face }}, V_{\text {cross }}$ and their interaction was analyzed using analysis of variance (ANOVA). Though $\Delta T_{\operatorname{man}}$ was collected, those were not analyzed because the manikin was unheated and breathless. 


\subsection{Results}

Simultaneous samples were collected near the manikin's nose $\left(C_{n o s e}\right)$ and mouth $\left(C_{\text {mouth }}\right)$. One would expect small differences between these two locations because they are close each other. Figure 5.1 shows a strong coefficient of determination $\left(R^{2}=0.85\right)$ and a slope of 1.07 for the linear relationship of $C_{n o s e}$ and $C_{\text {mouth }}$. In addition, the normality of residuals showed an $R^{2}=0.94$ (see Figure C.2 in Appendix C). Values of $C_{\text {nose }}$ and $C_{\text {mouth }}$ are presented in Tables 5.1 and 5.2. For the statistical analyses, exposure values were log-transformed to reduce the variability of the data.

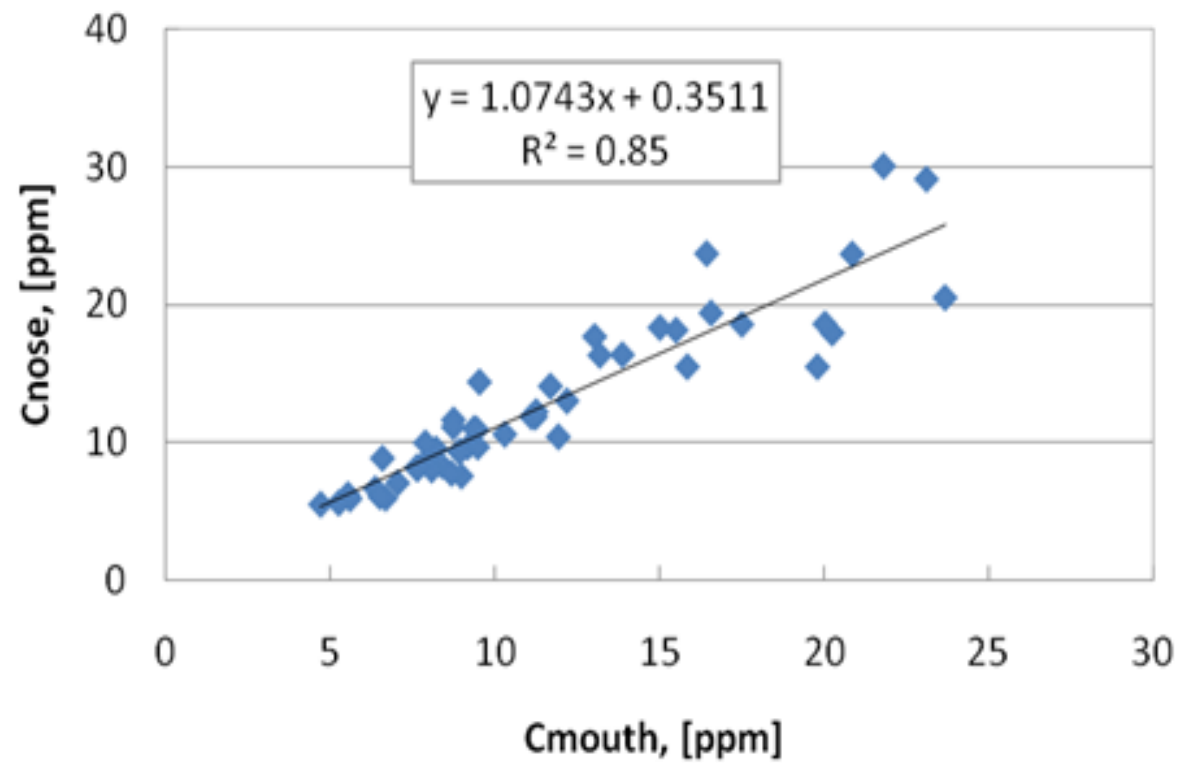

Figure 5.1 Comparison of $C_{\text {nose }}$ and $C_{\text {mouth }}$ for simple manikin 
Table 5.1 $C_{\text {nose }}$ for the simple manikin study in ppm

\begin{tabular}{|c|c|c|c|c|c|c|}
\hline \multirow{2}{*}{$\begin{array}{c}V_{\text {face }}, \\
{[\mathbf{f p m}]}\end{array}$} & \multicolumn{5}{|c|}{$V_{\text {cross }},[\mathrm{fpm}]$} & \multirow[b]{2}{*}{ Mean } \\
\hline & 14 & 24 & 36 & 46 & 57 & \\
\hline \multirow{3}{*}{100} & 18.0 & 30.0 & 19.4 & 6.3 & 7.6 & \multirow[b]{3}{*}{16} \\
\hline & 23.7 & 15.5 & 23.6 & 6.7 & 6.0 & \\
\hline & 21 & 23 & 22 & 6 & 7 & \\
\hline \multirow{3}{*}{140} & 20.5 & 17.7 & 16.4 & 15.5 & 11.9 & \multirow[b]{3}{*}{17} \\
\hline & 14.4 & 29.1 & 18.2 & 18.6 & 11.9 & \\
\hline & 17 & 23 & 17 & 17 & 12 & \\
\hline \multirow{3}{*}{160} & 13.0 & 18.3 & 18.6 & 7.1 & 8.8 & \multirow[b]{3}{*}{13} \\
\hline & 11.7 & 16.3 & 14.1 & 9.7 & 9.6 & \\
\hline & 12 & 17 & 16 & 8 & 9 & \\
\hline \multirow{3}{*}{190} & 10.4 & 11.2 & 9.4 & 6.0 & 6.1 & \multirow[b]{3}{*}{9} \\
\hline & 9.7 & 11.0 & 8.3 & 8.1 & 7.8 & \\
\hline & 10 & 11 & 9 & 7 & 8 & \\
\hline \multirow{3}{*}{220} & 8.1 & 11.0 & 8.3 & 5.7 & 10.6 & \multirow[b]{3}{*}{9} \\
\hline & 8.9 & 10.0 & 12.3 & 5.6 & 9.4 & \\
\hline & 8 & 10 & 10 & 6 & 10 & \\
\hline Mean & 14 & 17 & 15 & 9 & 9 & 13 \\
\hline
\end{tabular}


Table 5.2 $C_{\text {mouth }}$ for the simple manikin study in ppm

\begin{tabular}{cc|c|c|c|cc}
\hline $\begin{array}{c}\boldsymbol{V}_{\text {face}}, \\
{[\mathbf{f p m}]}\end{array}$ & $\mathbf{1 4}$ & $\mathbf{2 4}$ & $\mathbf{3 6}$ & $\mathbf{4 6}$ & $\mathbf{5 7}$ & Mean \\
\cline { 2 - 6 } $\mathbf{3} \mathbf{1 0 0}$ & 20.2 & 21.8 & 16.6 & 5.5 & 9.0 & \\
& 16.4 & 19.8 & 20.8 & 6.3 & 6.7 & \\
\cline { 2 - 6 } & 18 & 21 & 19 & 6 & 8 & 14 \\
\hline \multirow{3}{*}{$\mathbf{1 4 0}$} & 23.7 & 13.0 & 13.9 & 15.8 & 11.1 & \\
& 9.5 & 23.1 & 15.5 & 20.0 & 11.2 & \\
\cline { 2 - 6 } & 17 & 18 & 15 & 18 & 11 & 16 \\
\hline \multirow{3}{*}{$\mathbf{1 6 0}$} & 12.2 & 15.0 & 17.5 & 7.0 & 7.9 & \\
& 8.7 & 13.2 & 11.7 & 9.2 & 8.2 & \\
& 10 & 14 & 15 & 8 & 8 & 11 \\
\hline \multirow{3}{*}{$\mathbf{1 9 0}$} & 11.9 & 8.7 & 8.9 & 5.6 & 6.5 & \\
& 9.5 & 9.4 & 8.4 & 7.6 & 8.7 & \\
\cline { 2 - 6 } & 11 & 9 & 9 & 7 & 8 & 9 \\
\hline \multirow{2}{*}{$\mathbf{2 2 0}$} & 8.1 & 9.4 & 7.6 & 5.2 & 10.3 & \\
& 6.6 & 7.9 & 11.2 & 4.7 & 8.9 & \\
\hline \multirow{2}{*}{ Mean } & 7 & 9 & 9 & 5 & 10 & 8 \\
\hline
\end{tabular}

\subsubsection{Fluid dynamics considerations}

The presence of a simple manikin in front of the enclosing hood face obstructing the suction flow inside the hood can be treated with the theory of flow around bluff bodies. One of the most important parameters to assess the flow behavior at different velocity levels is the Reynolds number (Young et al., 2007; White, 2006). Reynolds number $(R e)$ is the ratio between inertial forces and viscous forces ( $R e=U D / v)$. Those were calculated using an approach velocity $(U)$ to the simple manikin and the width of the manikin's shoulders $(D=17.5$ "). Approach velocities were obtained as a linear function of both the hood face 
velocity $\left(V_{\text {face }}\right)$ and the cross-draft velocity $\left(V_{\text {cross }}\right)$. Table C.1 in Appendix C shows $U$ for every combination of $V_{\text {face }}$ and $V_{\text {cross. }}$.

Table 5.3 Reynolds numbers for the simple manikin experiments

\begin{tabular}{|c|c|c|c|c|c|c|}
\hline \multirow[b]{2}{*}{$V_{\text {face }},[\mathbf{f p m}]$} & \multicolumn{5}{|c|}{$V_{\text {cross }},[\mathrm{fpm}]$} & \multirow[b]{2}{*}{ Mean } \\
\hline & 14 & 24 & 36 & 46 & 57 & \\
\hline \multirow{3}{*}{100} & 4032 & 5853 & 8093 & 10023 & 11867 & \multirow[b]{3}{*}{7980} \\
\hline & 4037 & 5877 & 8106 & 10025 & 11888 & \\
\hline & 4034 & 5865 & 8100 & 10024 & 11877 & \\
\hline \multirow{3}{*}{140} & 4526 & 6367 & 8617 & 10470 & 12338 & \multirow[b]{3}{*}{8468} \\
\hline & 4538 & 6378 & 8621 & 10478 & 12350 & \\
\hline & 4532 & 6372 & 8619 & 10474 & 12344 & \\
\hline \multirow{3}{*}{160} & 5020 & 6869 & 9130 & 11015 & 12904 & \multirow[b]{3}{*}{9000} \\
\hline & 5057 & 6870 & 9159 & 11061 & 12915 & \\
\hline & 5039 & 6870 & 9144 & 11038 & 12910 & \\
\hline \multirow{3}{*}{190} & 5505 & 7344 & 9555 & 11451 & 13390 & \multirow[b]{3}{*}{9457} \\
\hline & 5509 & 7393 & 9564 & 11466 & 13391 & \\
\hline & 5507 & 7369 & 9559 & 11459 & 13391 & \\
\hline \multirow{3}{*}{220} & 6050 & 7866 & 10146 & 12087 & 13849 & \multirow[b]{3}{*}{10013} \\
\hline & 6068 & 7928 & 10153 & 12094 & 13884 & \\
\hline & 6059 & 7897 & 10150 & 12090 & 13867 & \\
\hline Mean & 5034 & 6874 & 9114 & 11017 & 12878 & 8984 \\
\hline
\end{tabular}

For the approach velocity range of 26 to $90 \mathrm{fpm}$, Reynolds number is between 4000 and 14000 (see Table 5.3), which is in the subcritical and transitional range suggesting that most probably the turbulent boundary layer does not exist before the separation of the fluid from the manikin's body (Ingham and Yuan, 1992). The onset of turbulent flow behind a smooth bluff body occurs at Reynolds number of $2 \times 10^{5}$ (Mills, 1999), which is roughly twenty times the level of the experimental values. Figures 5.2 to 5.5 show the effect of $R e$ on the dimensionless $C_{\text {nose }}$ and $C_{\text {mouth }}$. 


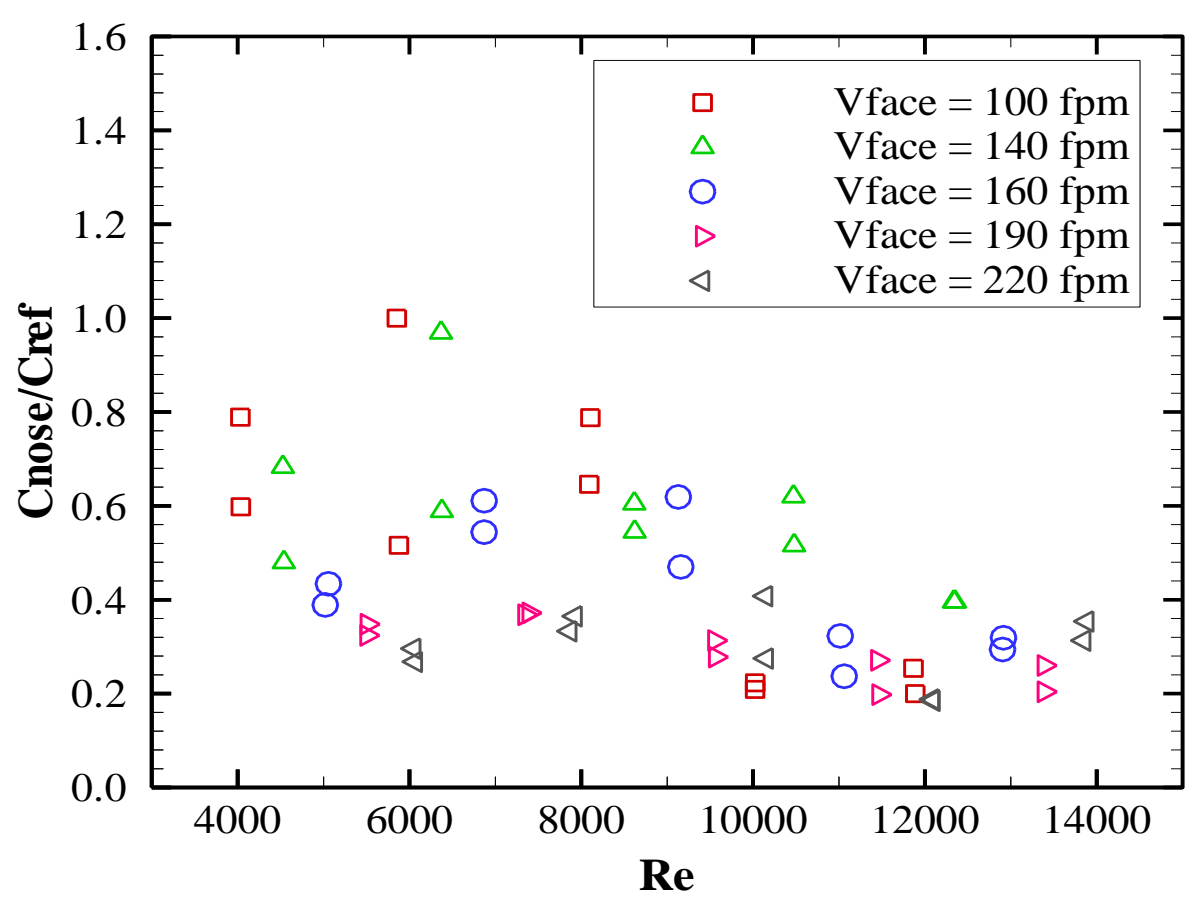

Figure 5.2 Effect of $\operatorname{Re}$ on $C_{n o s e} / C_{r e f}$ for the simple manikin, $C_{r e f}=30.0 \mathrm{ppm}$

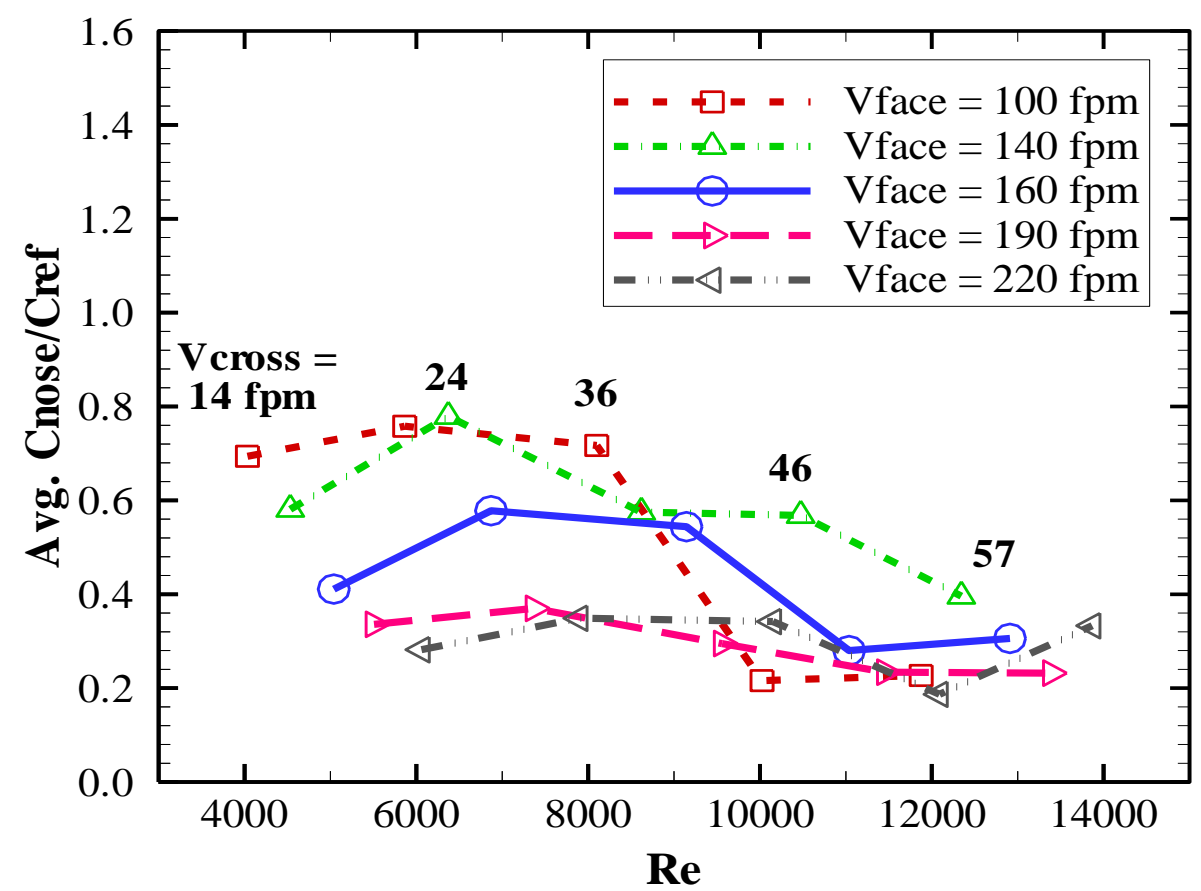

Figure 5.3 Effect of $R e$ on average $C_{n o s e} / C_{r e f}$ for the simple manikin, $C_{r e f}=30.0$ ppm 


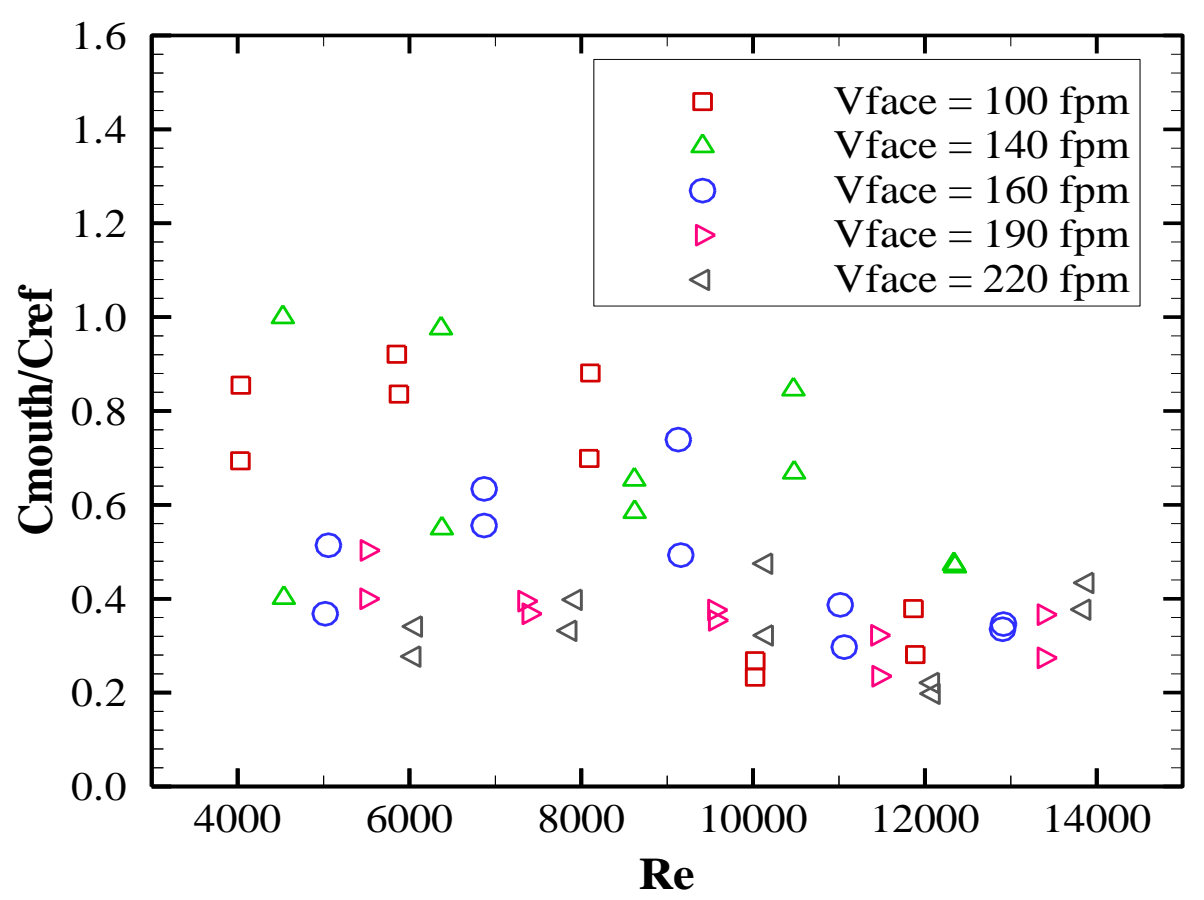

Figure 5.4 Effect of $\operatorname{Re}$ on $C_{\text {mouth }} / C_{r e f}$ for the simple manikin, $C_{r e f}=23.7 \mathrm{ppm}$

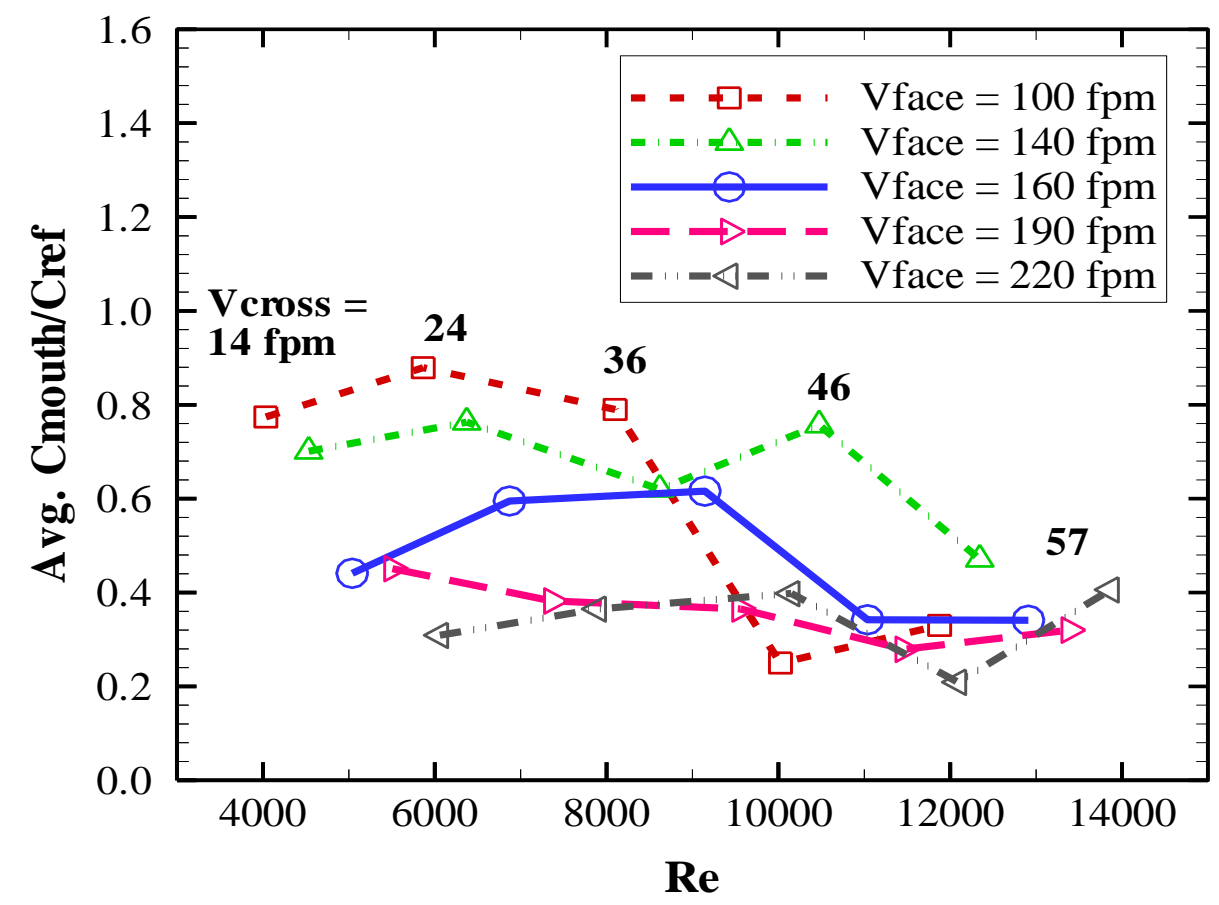

Figure 5.5 Effect of $R e$ on average $C_{m o u t h} / C_{r e f}$ for the simple manikin, $C_{r e f}=23.7$ ppm 
A more clear pattern of the effect of $R e$ on $C_{\text {nose }}$ and $C_{m o u t h}$ than those of scatter plots (Figures 5.2 and 5.4) can be observed in Figures 5.3 and 5.5. Figure 5.3 shows the effect of $R e$ on the average non-dimensional concentrations $\left(C_{\text {nose }}\right)$ $\left.C_{r e f}\right) . C_{r e f}$ is the maximum exposure value for either $C_{\text {nose }}$ or $C_{\text {mouth }}$. At $R e$ between 4000 and 8000 , higher and more variable values of $C_{n o s e}$ can be observed. However, at $R e>8000$, all concentration patterns but one come together in decreasing concentrations, as can be seen in Figures 5.3 and 5.5. At fixed $V_{\text {face }}=$ $140 \mathrm{fpm}$, a striking behavior occurs at $R e>8000$ when $C_{\text {mouth }}$ reached a higher value before decreasing at higher values of $R e$ (Figure 5.5). For this unheated manikin, the temperature difference between the manikin and the air was too small $\left(\Delta T_{\text {man }}<0.5^{\circ} \mathrm{C}\right)$ that those were not considered in this study.

\subsubsection{Effect of $V_{\text {face }}$ on $C_{\text {nose }}$ and $C_{\text {mouth }}$}

At fixed levels of cross-draft velocity $\left(V_{\text {cross }}\right)$, the effect of hood face velocity $\left(V_{\text {face }}\right)$ on the concentrations at the nose and mouth $\left(C_{\text {nose }}\right.$ and $\left.C_{\text {mouth }}\right)$ can be seen in Figures 5.6 and 5.7. Note the wider spread of $C_{\text {nose }}$ and $C_{\text {mouth }}$ values at $V_{\text {face }}$ $=100 \mathrm{fpm}$ and the monotonically decreased dispersion as $V_{\text {face }}$ increased. At $V_{\text {face }}=$ $100 \mathrm{fpm}$, the lowest $C_{\text {nose }}$ and $C_{\text {mouth }}$ values can be observed at $V_{\text {cross }}=46$ and 57 fpm. However, higher exposure was obtained at $V_{\text {cross }}=14,24$ and $36 \mathrm{fpm}$. A reasonable explanation is that at higher values of $V_{\text {cross }}$, the strength of the contaminant flow rate and the wake region behind the manikin were overcome for the combination of higher $V_{\text {cross }}$ and low $V_{\text {face }}$. 


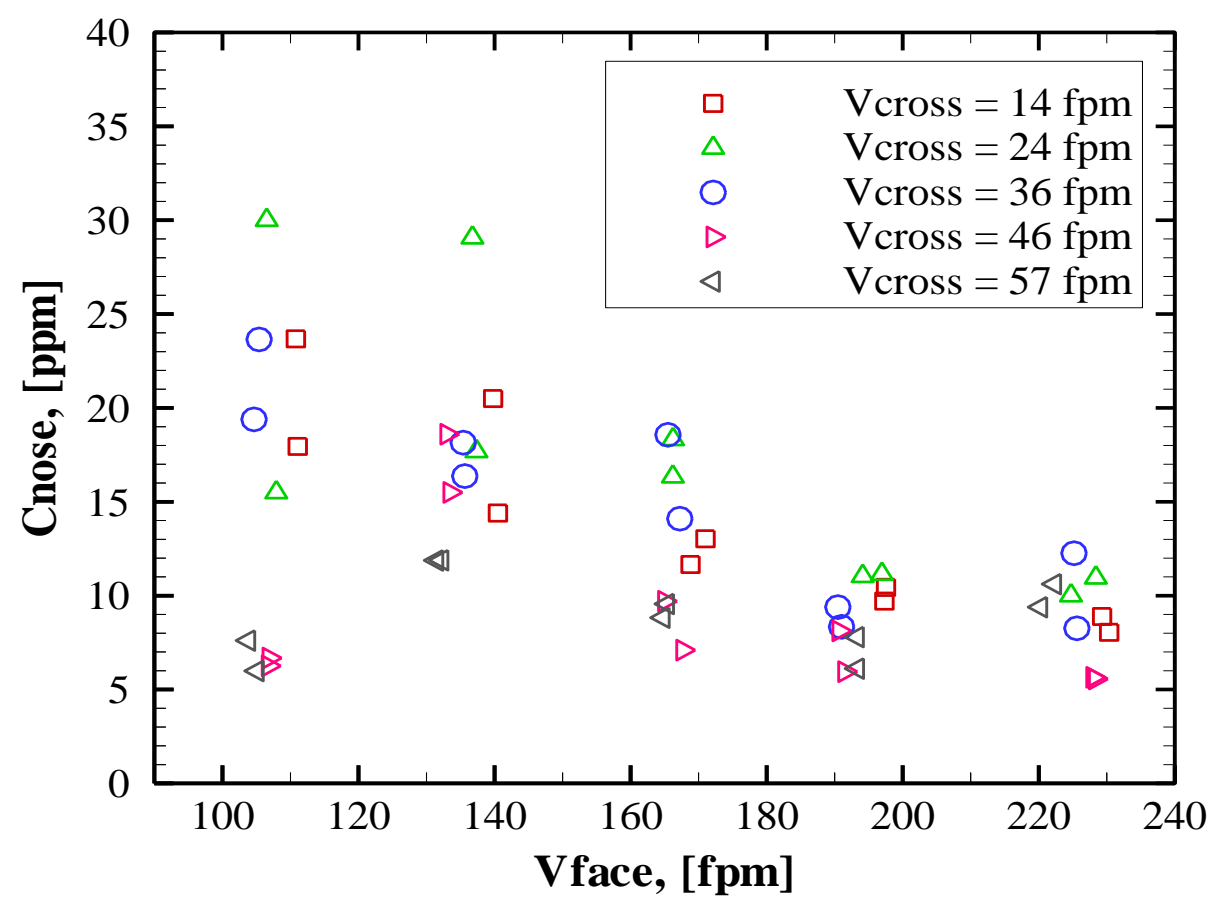

Figure 5.6 Effect of $V_{\text {face }}$ on $C_{\text {nose }}$ for the simple manikin

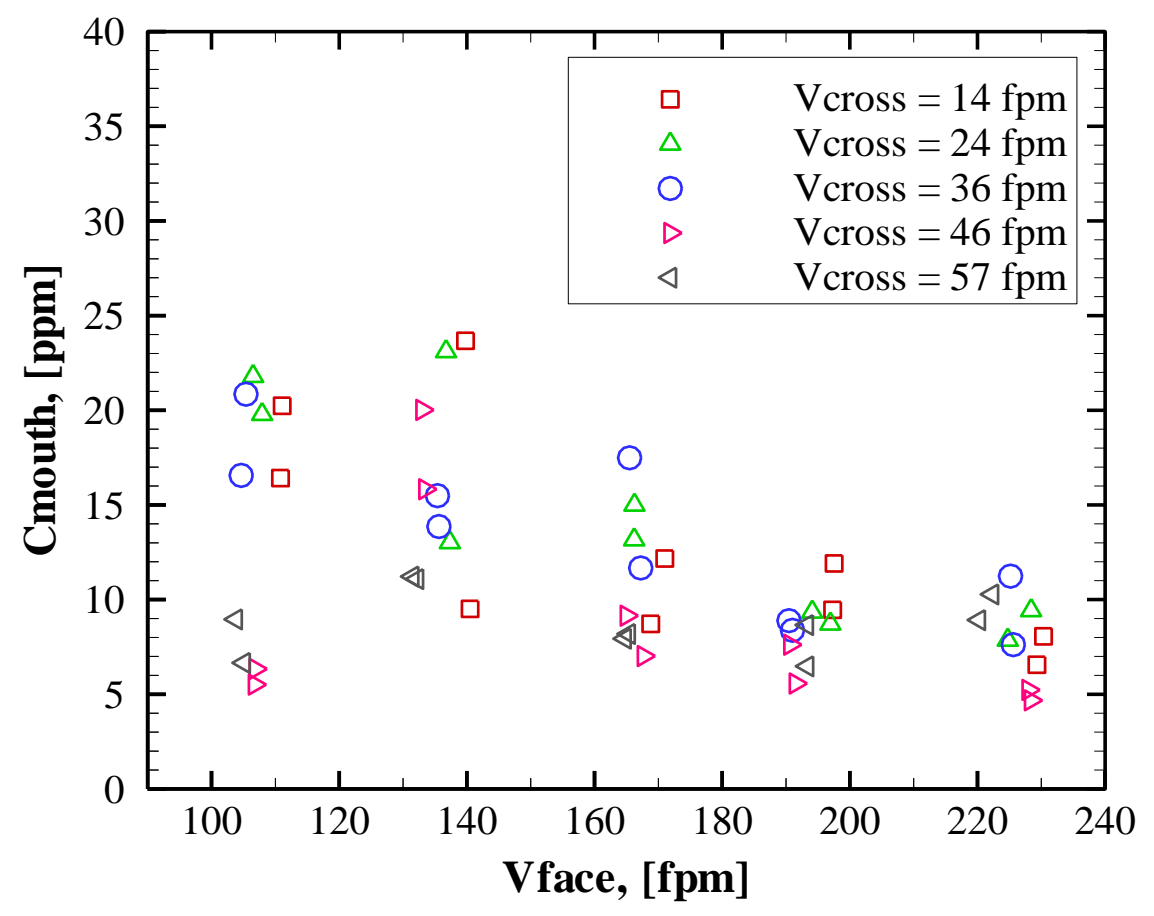

Figure 5.7 Effect of $V_{\text {face }}$ on $C_{\text {mouth }}$ for the simple manikin 


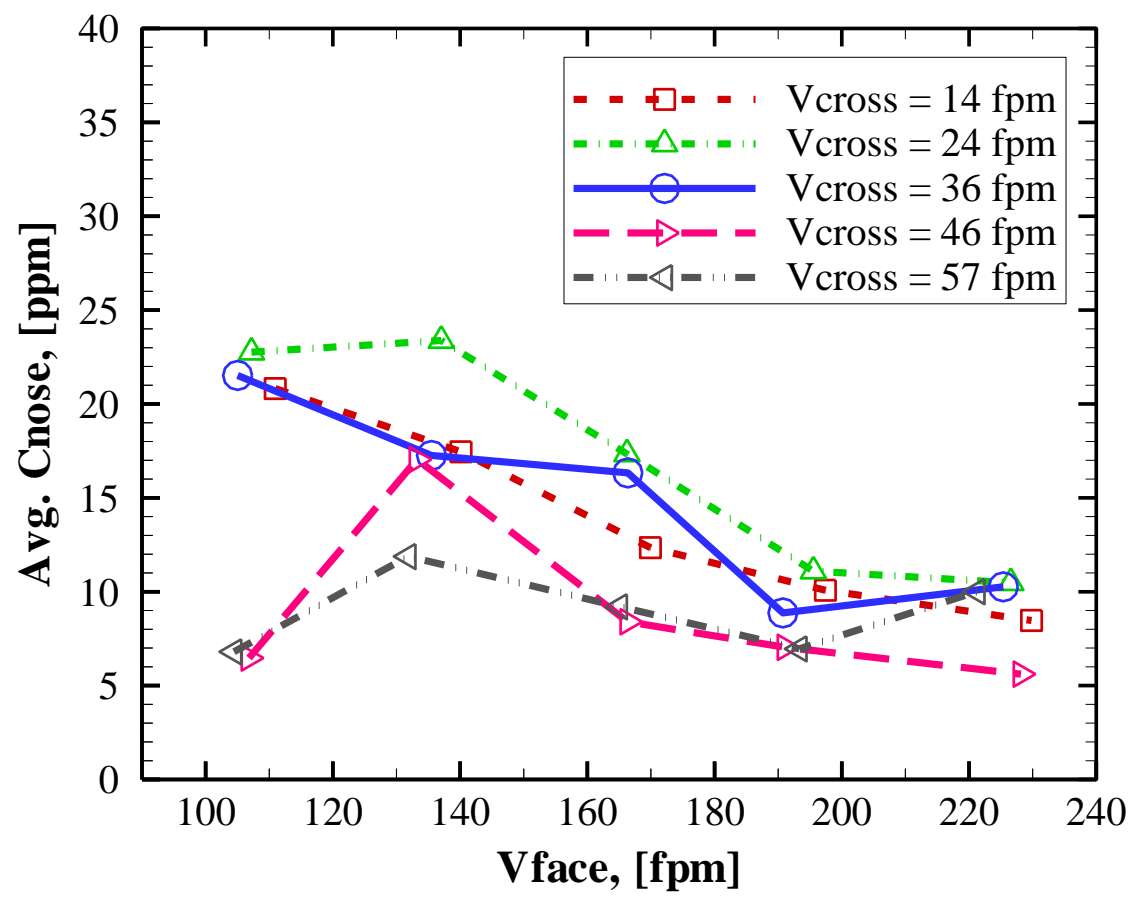

Figure 5.8 Effect of $V_{\text {face }}$ on average $C_{\text {nose }}$ for the simple manikin

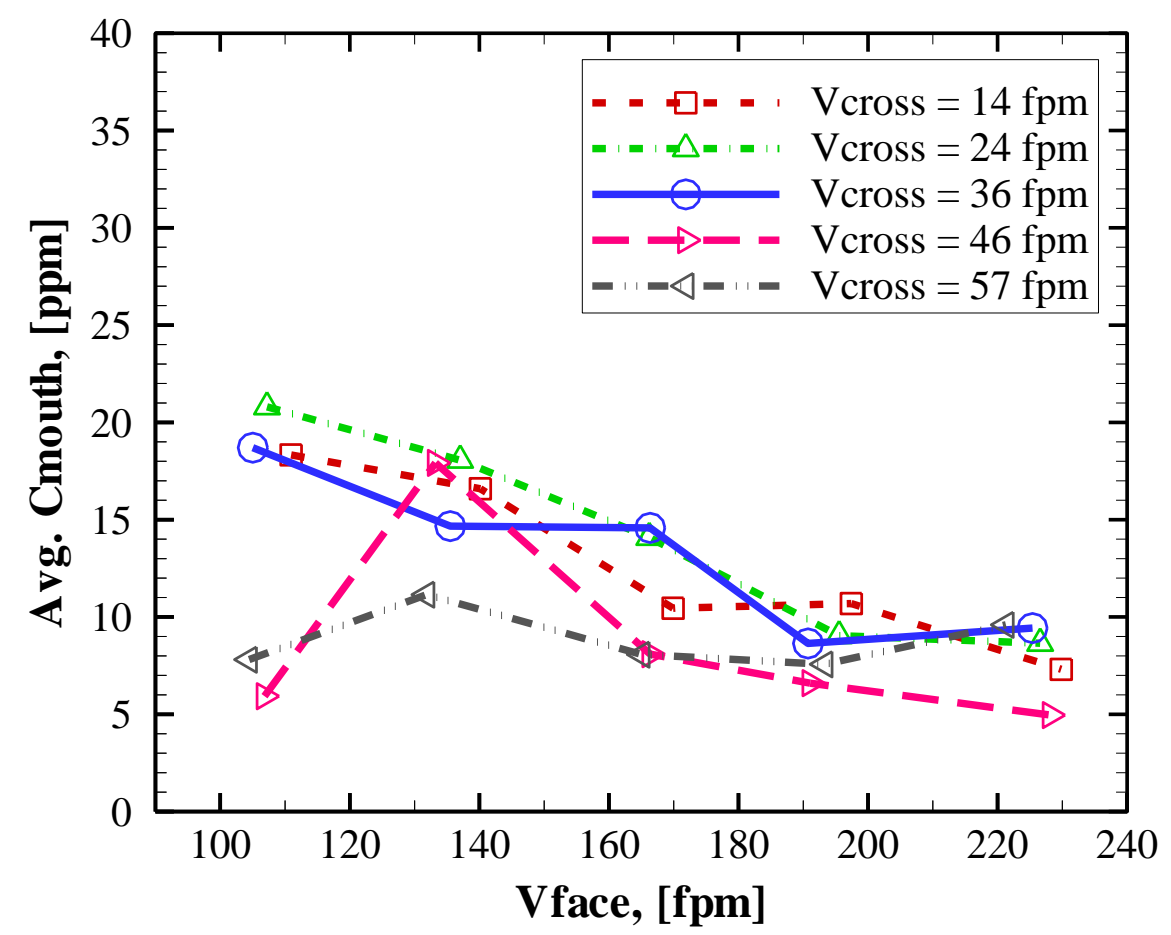

Figure 5.9 Effect of $V_{\text {face }}$ on average $C_{\text {mouth }}$ for the simple manikin 
Since $C_{\text {nose }}$ and $C_{\text {mouth }}$ were correlated each other, the effects of $V_{\text {face }}$ on average $C_{\text {nose }}$ (Figure 5.8) were very similar to the effects of $V_{\text {face }}$ on average $C_{\text {mouth }}$ (Figure 5.9). For the range of $V_{\text {face }}=100$ to $220 \mathrm{fpm}, C_{\text {nose }}$ and $C_{\text {mouth }}$ dropped consistently as $V_{\text {face }}$ increased, which is in general agreement with previous studies (Li et al., 2007; Elnahas, 2005; Guffey and Barnea, 1994; He, 2010). This agreement suggests that $V_{\text {face }}$ is an important factor affecting levels of airborne contaminants in the breathing zone for the simple manikin. Figures 5.8 and 5.9 show clearly the decreasing concentration pattern as $V_{\text {face }}$ increased. However, a noticeable peak in concentration is seen at $V_{\text {face }}=140 \mathrm{fpm}$ and $V_{\text {cross }}=46 \mathrm{fpm}$ (Figures 5.8 and 5.9), which could be explained using the concepts of fluid mechanics and boundary layer theory.

At levels of $V_{\text {face }}=140 \mathrm{fpm}$ and $V_{\text {cross }}=46 \mathrm{fpm}$, an average approach velocity $(U)$ of $68 \mathrm{fpm}$ was calculated, which produced an average $R e=10474$. It is suggested from this Reynolds number that a transitional, subcritical flow existed and that the heat transfer, if any, is basically due to forced convection because the temperature difference $\left(\Delta T_{m a n}\right)$ was near zero (Ingham and Yuan, 1992; Mills, 1999; Oosthuizen and Madan, 1971; Schlichting, 1949). In addition, it seems likely that the formation of the wake region behind the manikin due to the boundary layer separation may have caused these sharp concentrations at the nose and mouth.

When air flows around a body such as this manikin, a separated boundary layer is generated because of the adverse pressure gradient. This produced a reverse flow zone (wake zone) downstream of body, which in this case would tend to 
increase the manikin's exposure due to the recirculation of contaminants near the breathing zone (Flynn and Ljungqvist, 1995). These results agree with the front and the side orientation concentrations of previous studies (Guffey et. al., 2001), even though they used higher levels of cross-draft velocity.

In order to reduce the appearance of variability of concentrations and obtain a roughly linear relationship between dependent and independent variables, $C_{\text {nose }}$ and $C_{\text {mouth }}$ were log-transformed as shown in Figures 5.10 to 5.11. Except for $V_{\text {cross }}$ $=46 \mathrm{fpm}$, all other curves exhibit an almost linear pattern when the average of logtransformed exposures were plotted against $V_{\text {face }}$ (see Figures 5.12 and 5.13).

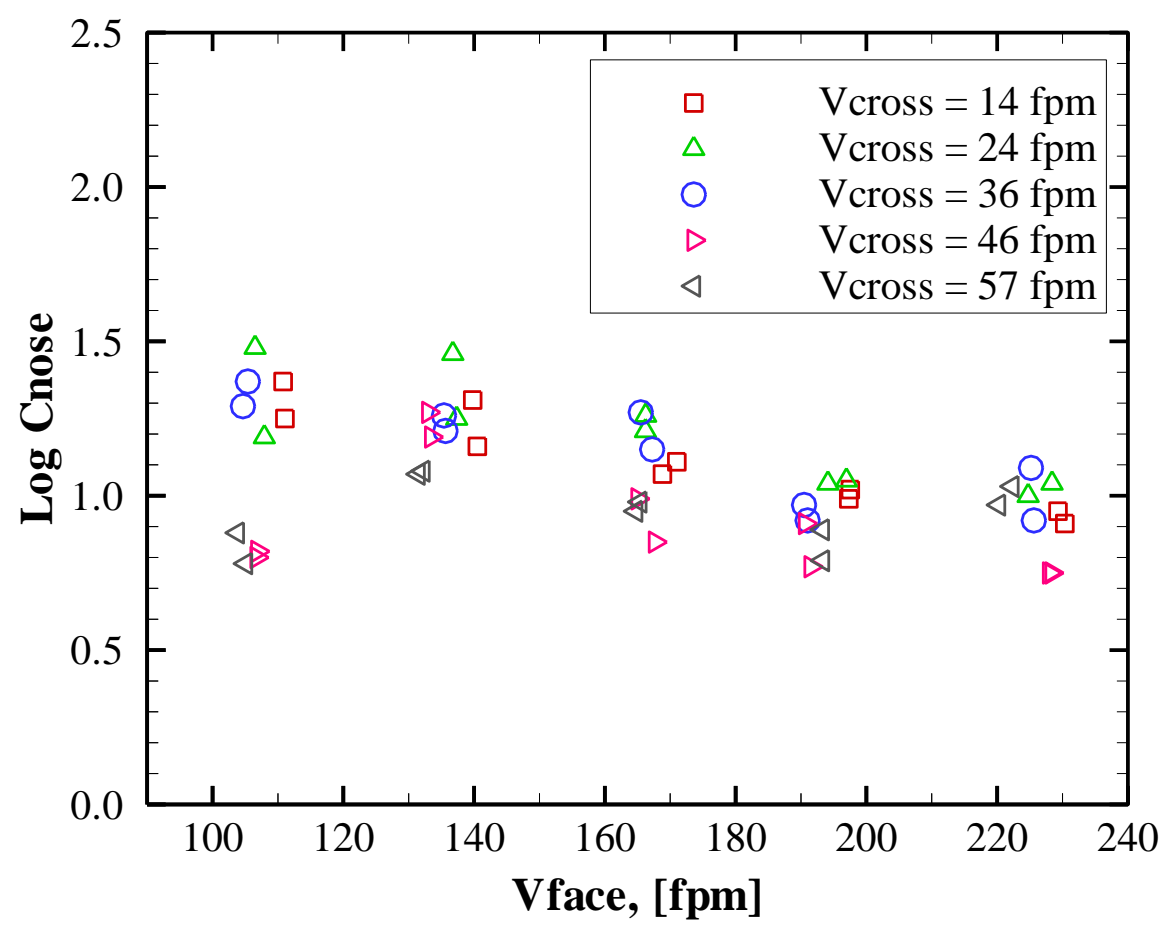

Figure 5.10 Effect of Vface on Log Cnose for the simple manikin 


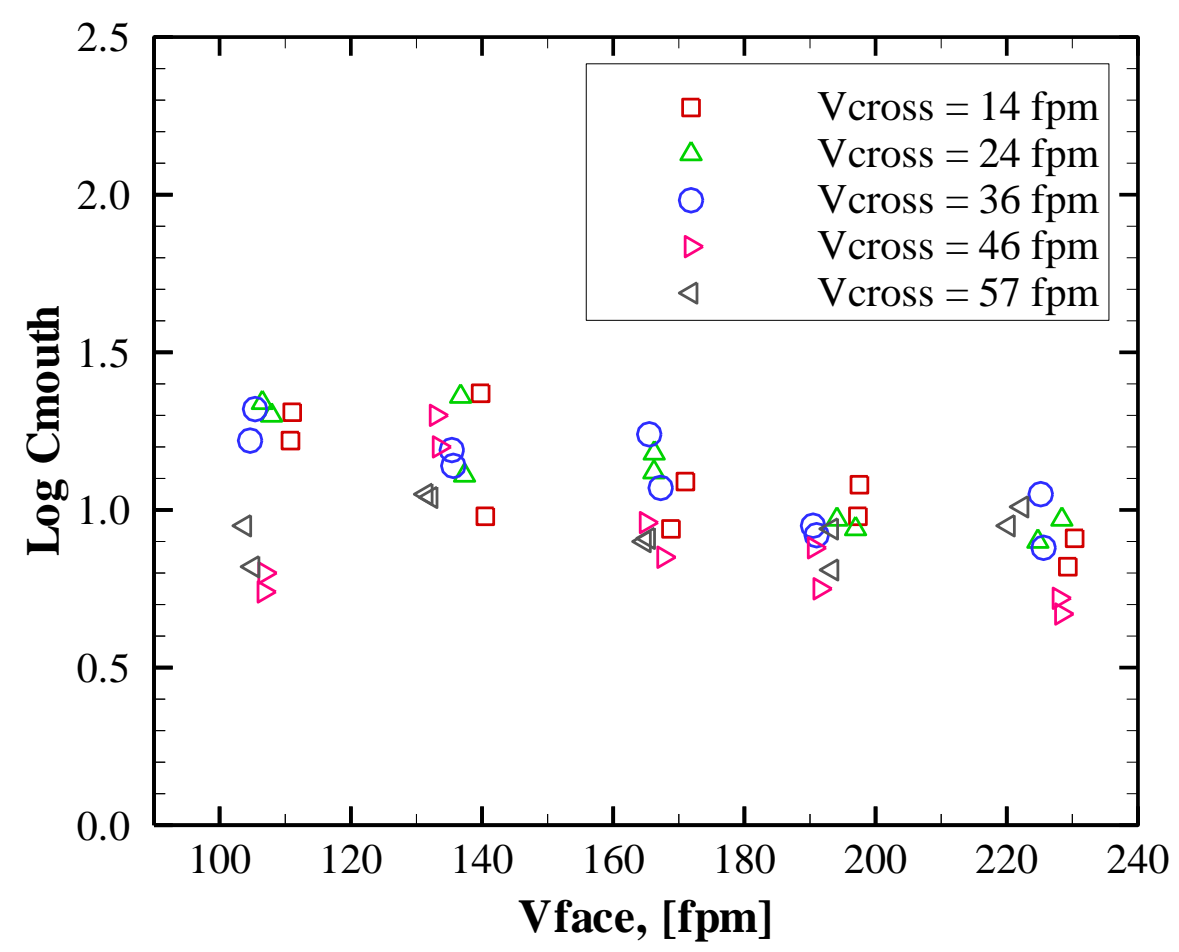

Figure 5.11 Effect of $V_{\text {face }}$ on $\log C_{\text {mouth }}$ for the simple manikin

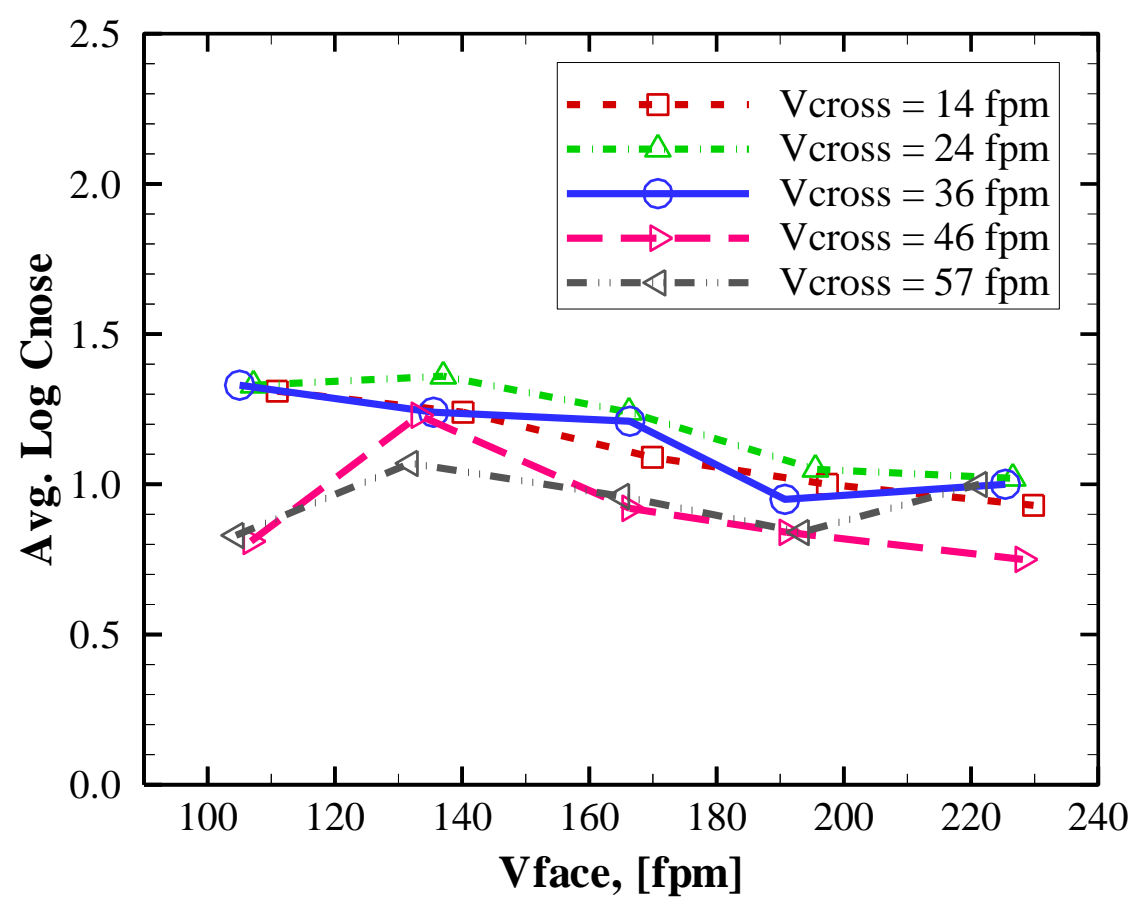

Figure 5.12 Effect of $V_{\text {face }}$ on average $\log C_{\text {nose }}$ for the simple manikin 


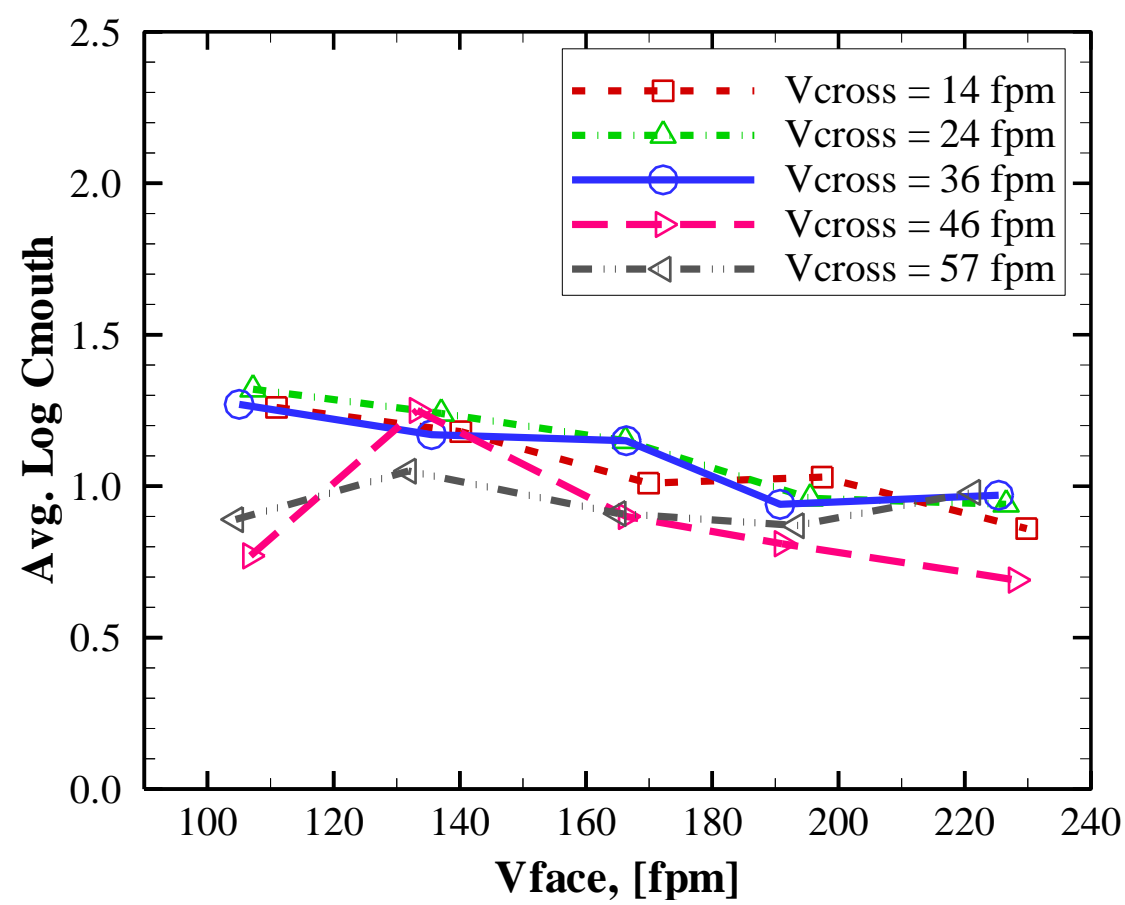

Figure 5.13 Effect of $V_{\text {face }}$ on average $\log C_{\text {mouth }}$ for the simple manikin

\subsubsection{Effect of $V_{\text {cross }}$ on $C_{\text {nose }}$ and $C_{\text {mouth }}$}

Figures 5.14 and 5.15 illustrate the effect of $V_{\text {cross }}$ on $C_{\text {nose }}$ and $C_{m o u t h}$ at different levels of $V_{\text {face }}$. As is seen in both figures, a marked peak exists at $V_{\text {cross }}=$ 24, which can be better appreciated on average plots (Figures 5.16 and 5.17). Figure 5.16 clearly shows this average peak exposure at the nose at combined levels of $V_{\text {face }}=140 \mathrm{fpm}$ and $V_{\text {cross }}=24 \mathrm{fpm}$. However, a slight increase at the average $C_{\text {mouth }}$ can be seen at the same velocity levels in Figure 5.17. Instead, the peak exposure at the mouth can be seen at $V_{\text {face }}=140 \mathrm{fpm}$ and $V_{\text {cross }}=46 \mathrm{fpm}$ (Figure 5.17). As mentioned before, these peak concentrations could be due to the formation of reverse flow and turbulence mixing produced by the boundary layer 
separation in the near wake downstream of the manikin (Kim and Flynn, 1992; Kim and Flynn, 1991a, 1991b; George et al., 1990; Ingham and Yuan, 1992).

After a wider spread of concentrations at $V_{\text {cross }}$ between 14 and $36 \mathrm{fpm}$, all but one concentration comes closer together at $V_{\text {cross }}=57 \mathrm{fpm}$. As was explained before, this sharp exposure far from the rest occurs at $V_{\text {face }}=140 \mathrm{fpm}$ and $V_{\text {cross }}=$ $46 \mathrm{fpm}$ and then all exposure values dropped together to concentrations under 12 ppm at $V_{\text {cross }}=46 \mathrm{fpm}$ (Figures 5.16 and 5.17). It should be noted that exposure at $V_{\text {face }} \geq 190$ fpm shows a roughly linear pattern for the entire range of $V_{\text {cross }}$. More clearly, exposure was not affected for $V_{\text {cross }}$ when $V_{\text {face }} \geq 190 \mathrm{fpm}$. This finding is in general agreement with $\mathrm{Li}$, et al., 2007 even though they used a different experimental setup.

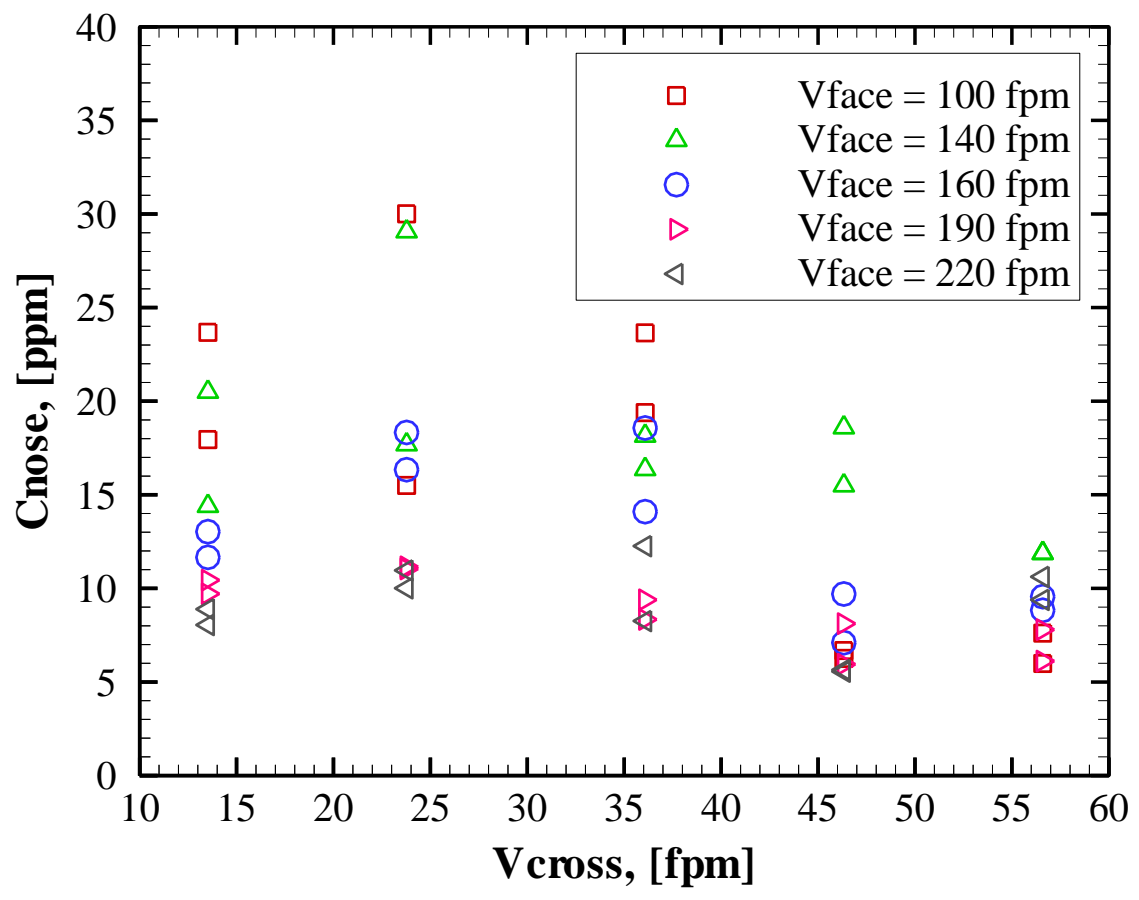

Figure 5.14 Effect of $V_{\text {cross }}$ on $C_{\text {nose }}$ for the simple manikin 


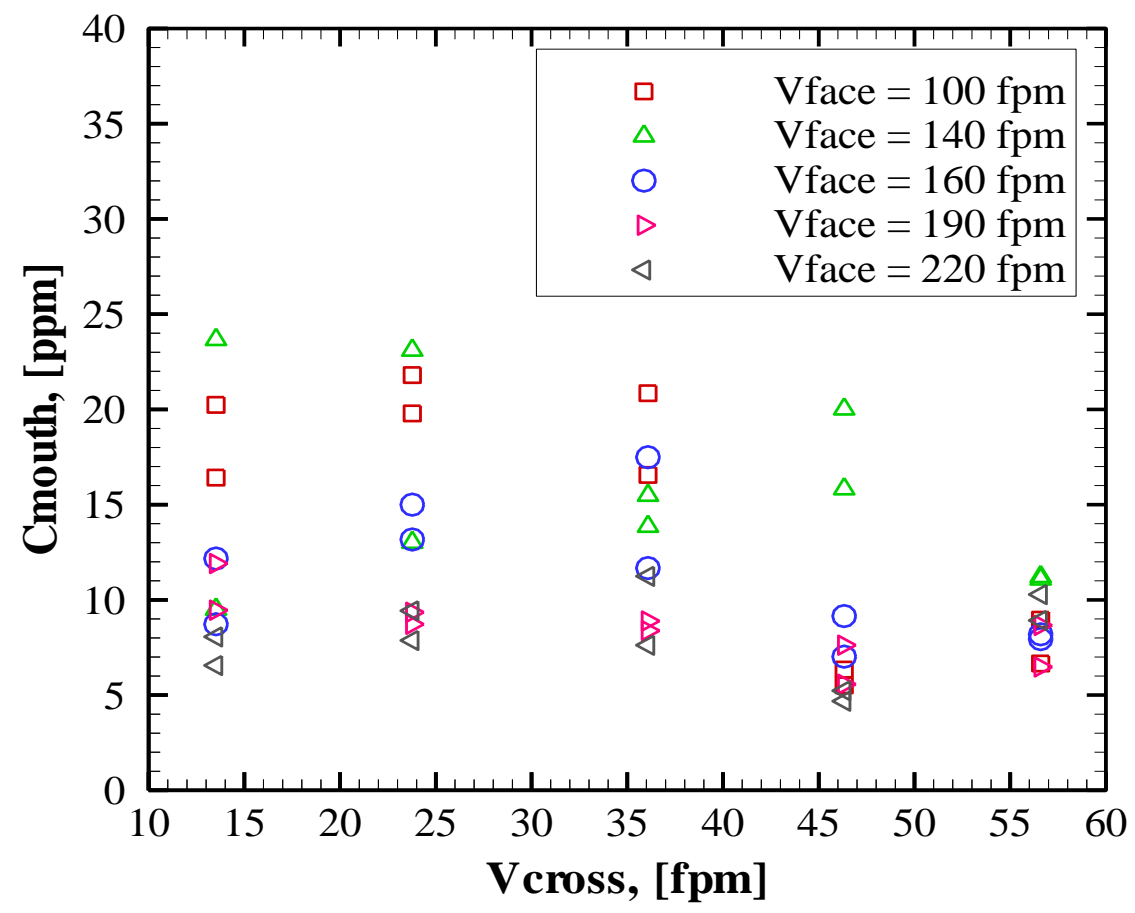

Figure 5.15 Effect of $V_{\text {cross }}$ on $C_{\text {mouth }}$ for the simple manikin

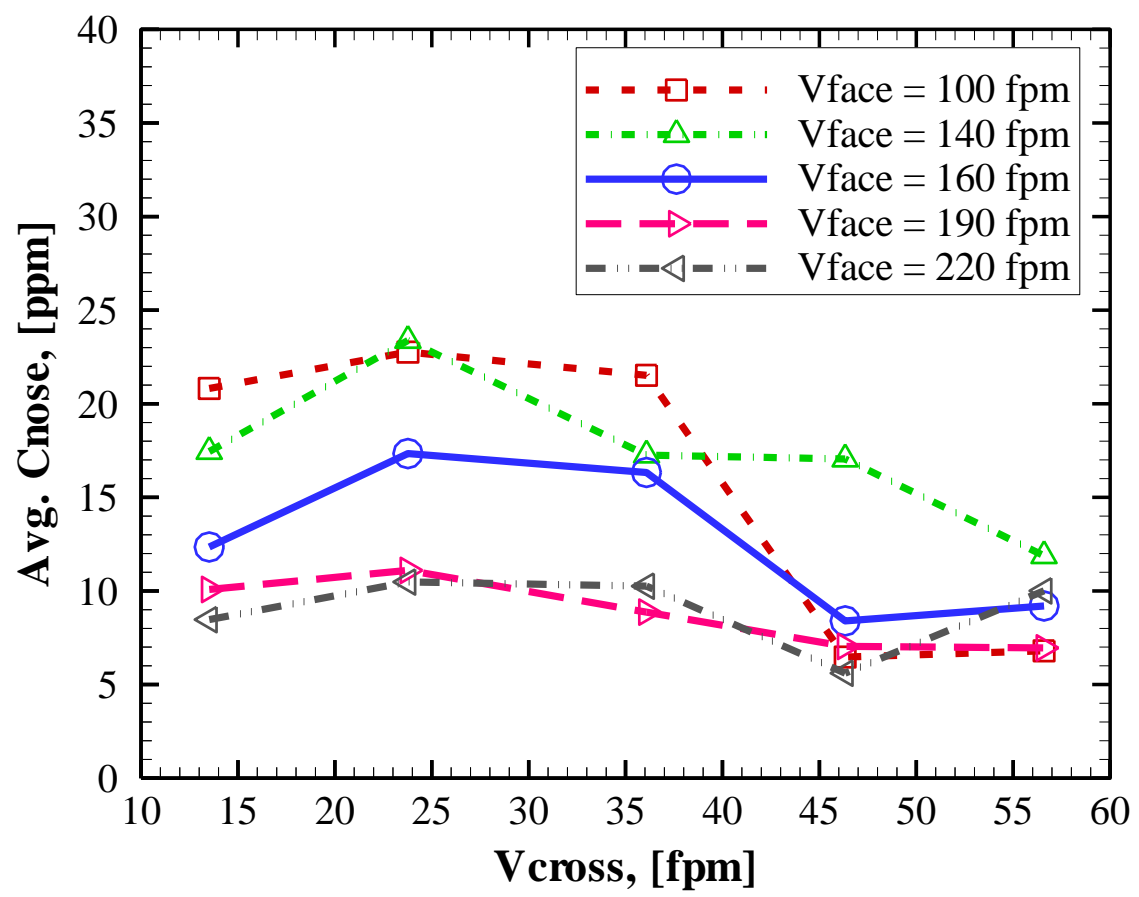

Figure 5.16 Effect of $V_{\text {cross }}$ on average $C_{\text {nose }}$ for the simple manikin 


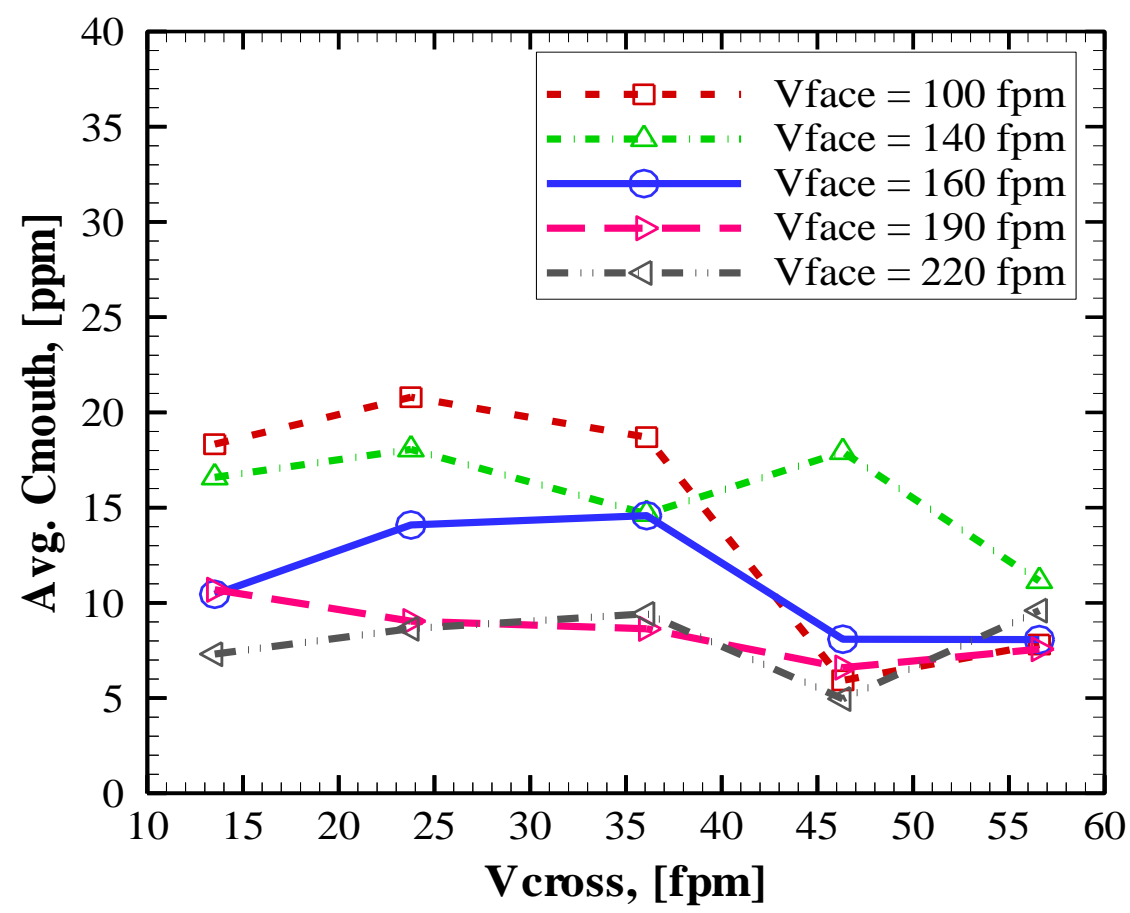

Figure 5.17 Effect of $V_{\text {cross }}$ on average $C_{\text {mouth }}$ for the simple manikin

Even though there was a roughly linear pattern for $C_{\text {nose }}$ and $C_{\text {mouth }}$ at $V_{\text {face }}=$ $220 \mathrm{fpm}$, a smaller V-shape can be seen for $C_{\text {nose }}$ and $C_{\text {mouth }}$ at $V_{\text {cross }}=46 \mathrm{fpm}$. These smaller concentrations could be due to the strength of the hood suction flow $\left(V_{\text {face }}\right)$ and $V_{\text {cross }}$ to remove most of the contaminant, trapped in the reverse flow, before this gets into the manikin's breathing zone. There is a fair agreement between this finding and the previous work of Guffey and Barnea (1994), which stated that $V_{\text {face }}$ is the predominant factor to control worker exposure.

To reduce the appearance of variability among concentration values and to obtain a roughly linear model, $C_{\text {nose }}$ and $C_{\text {mouth }}$ were log-transformed, as is shown in Figures 5.18 and 5.19. A narrow spread of concentrations is better appreciated in the average plots of $\log C_{\text {nose }}$ and $\log C_{\text {mouth }}$ (Figures 5.20 and 5.21). However, a 
smaller decreasing exposure after $V_{\text {cross }}=36 \mathrm{fpm}$ is still observed. On the other hand, dimensionless $C_{\text {nose }}$ and $C_{\text {mouth }}$ were plotted against the $V_{\text {face }} / V_{\text {cross }}$ ratio (Figures 5.22 and 5.23). The higher $C_{\text {nose }}$ and $C_{\text {mouth }}$ values (reference concentrations) were used to obtained dimensionless $C_{\text {nose }}$ and $C_{\text {mouth }}$. Pattern shows a rapid increase of average dimensionless $C_{\text {nose }}$ and $C_{\text {mouth }}$ followed by a gradual decline with increasing $V_{\text {face }} / V_{\text {cross }}$ ratio. Then exposures dropped as the ratio became greater than 8 . Important to note there is a family of $V_{\text {face }}$ lines rather than a single curve that incorporates all velocities. These results were in line with the previous work of Karaismail (2011) even though those were numerically simulated.

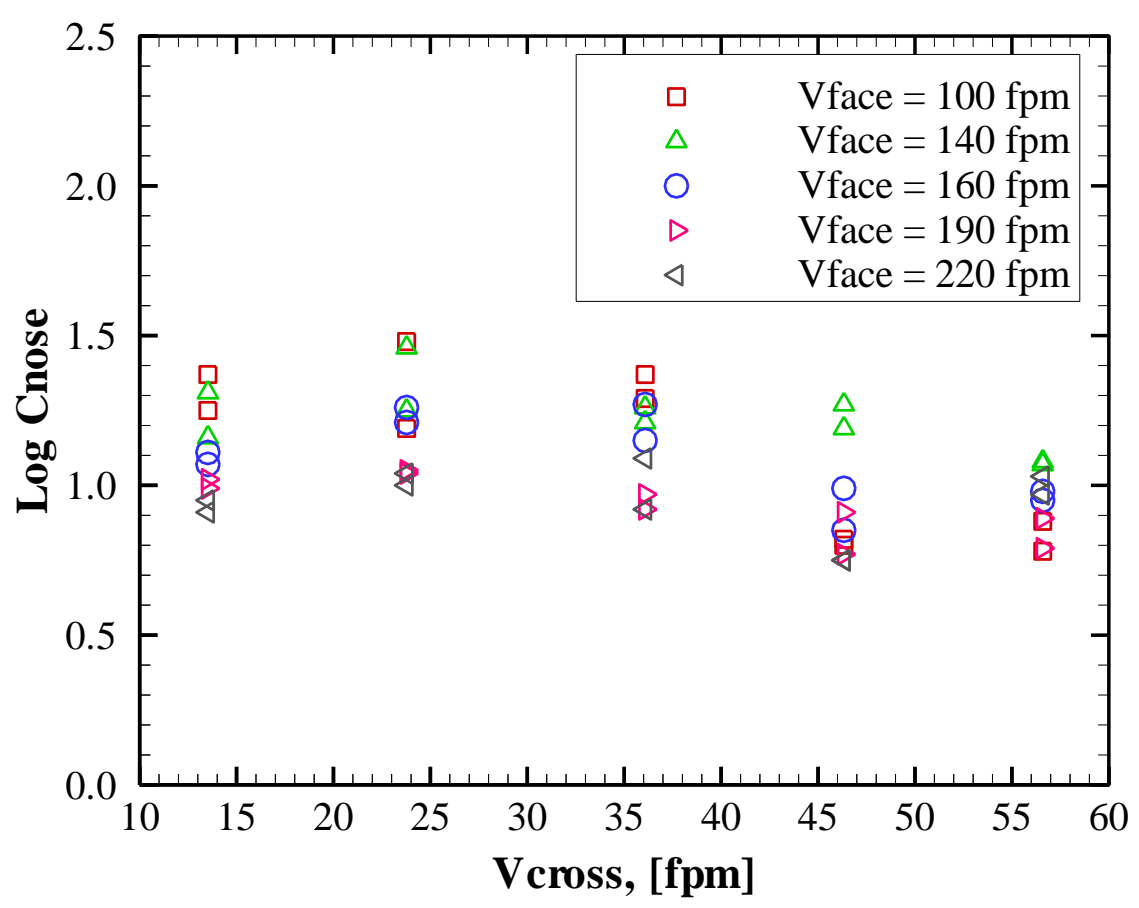

Figure 5.18 Effect of $V_{\text {cross }}$ on $\log C_{\text {nose }}$ for the simple manikin 


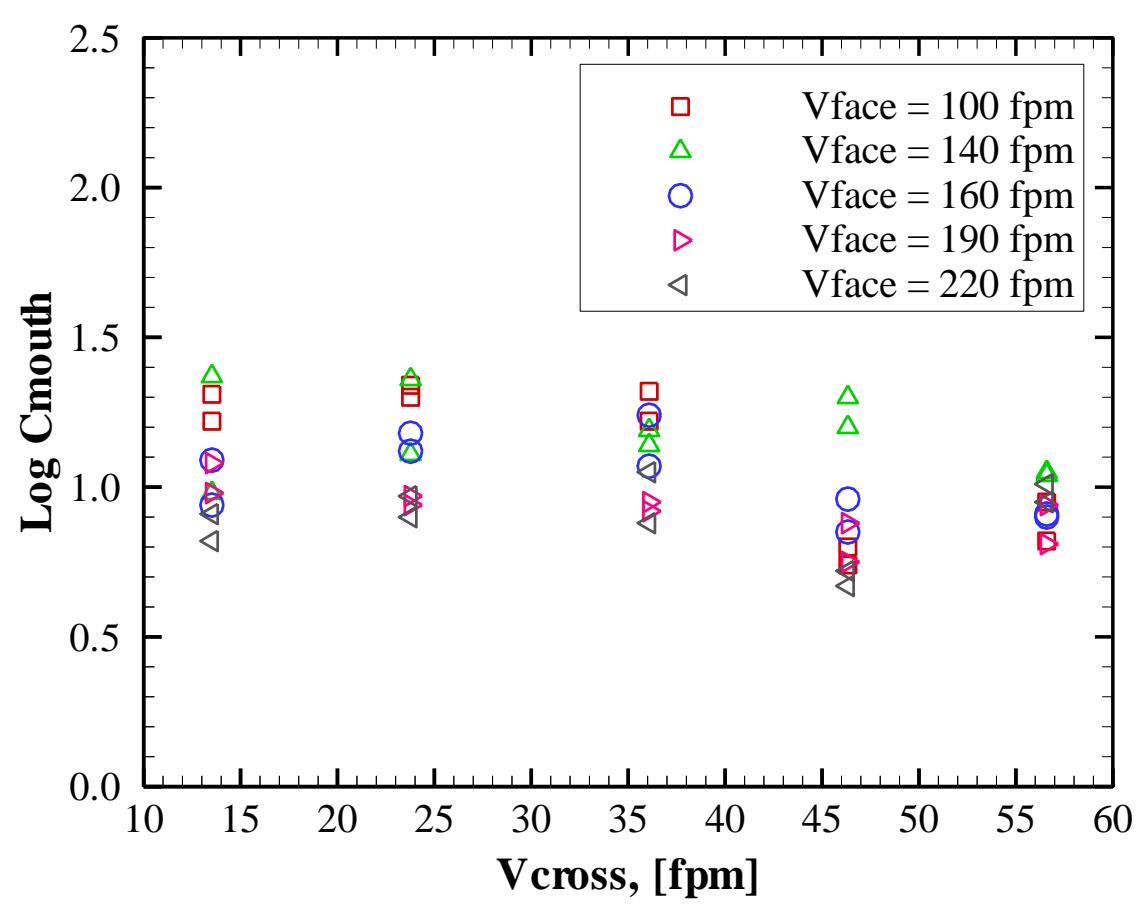

Figure 5.19 Effect of $V_{\text {cross }}$ on $\log C_{\text {mouth }}$ for the simple manikin

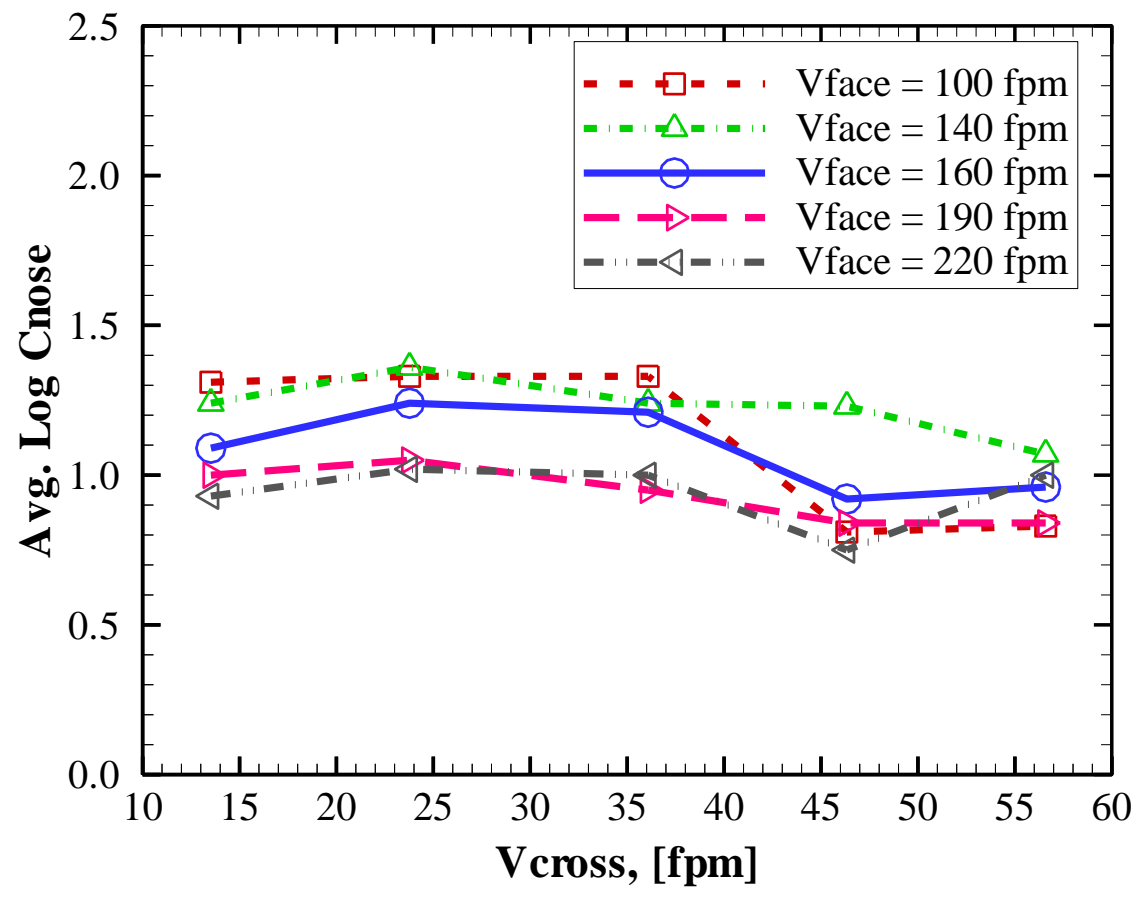

Figure 5.20 Effect of $V_{\text {cross }}$ on average $\log C_{\text {nose }}$ for the simple manikin 


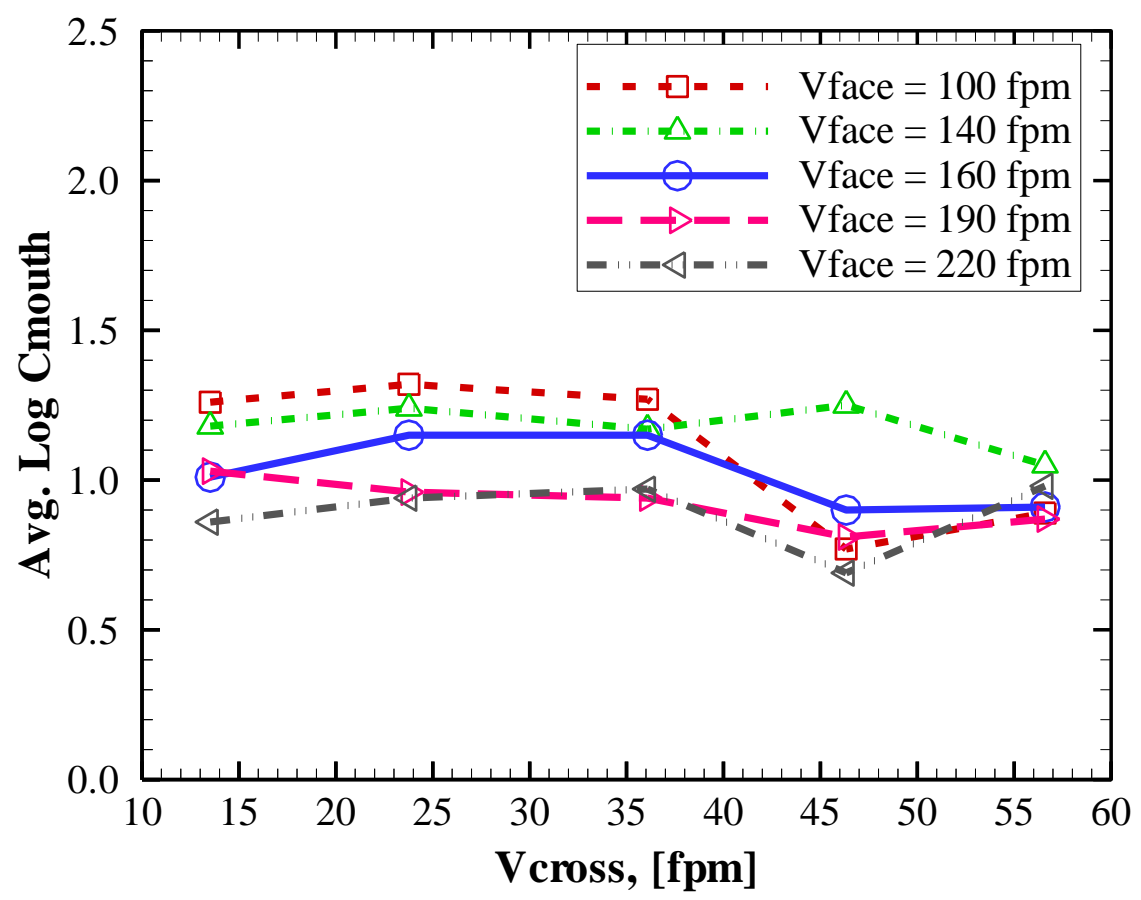

Figure 5.21 Effect of $V_{\text {cross }}$ on average $\log C_{\text {mouth }}$ for the simple manikin

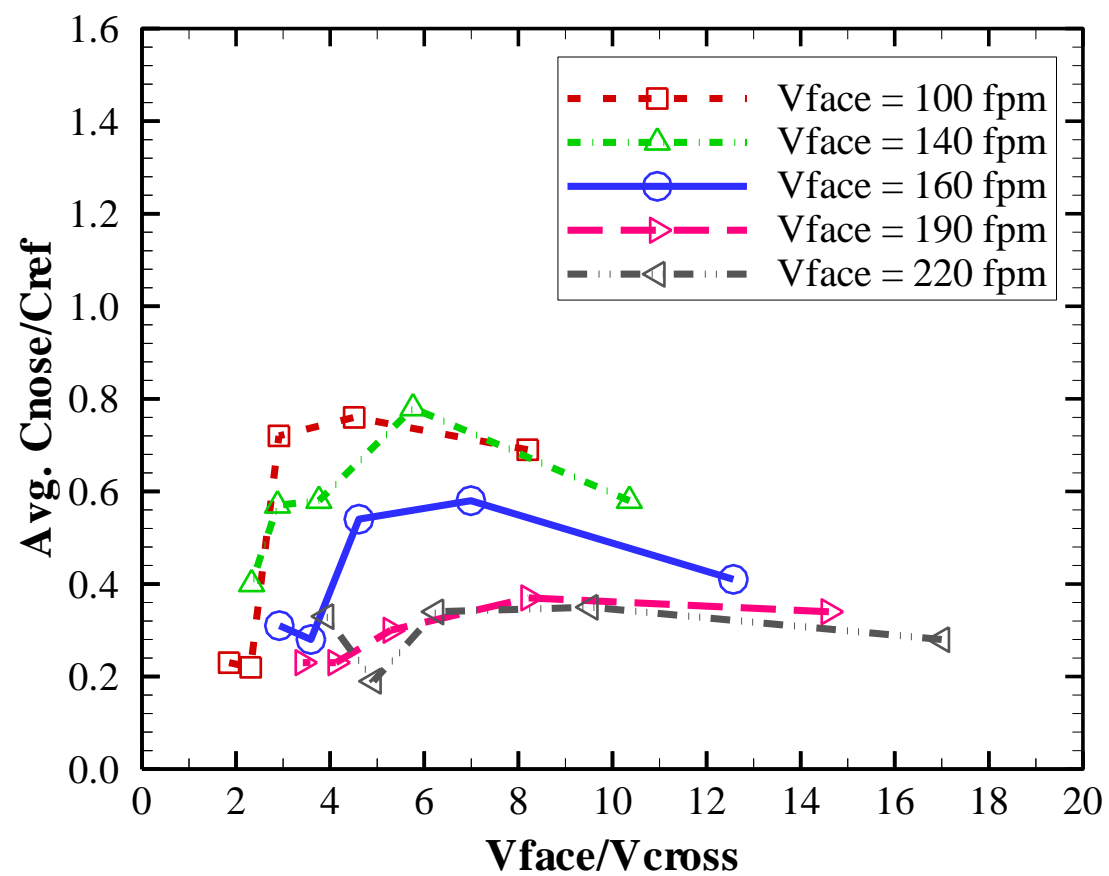

Figure 5.22 Effect of $V_{\text {face }} / V_{\text {cross }}$ on average $C_{\text {nose }} / C_{\text {ref }}$ at constant $V_{\text {face }}$ for the simple manikin, $C_{r e f}=30.0 \mathrm{ppm}$ 


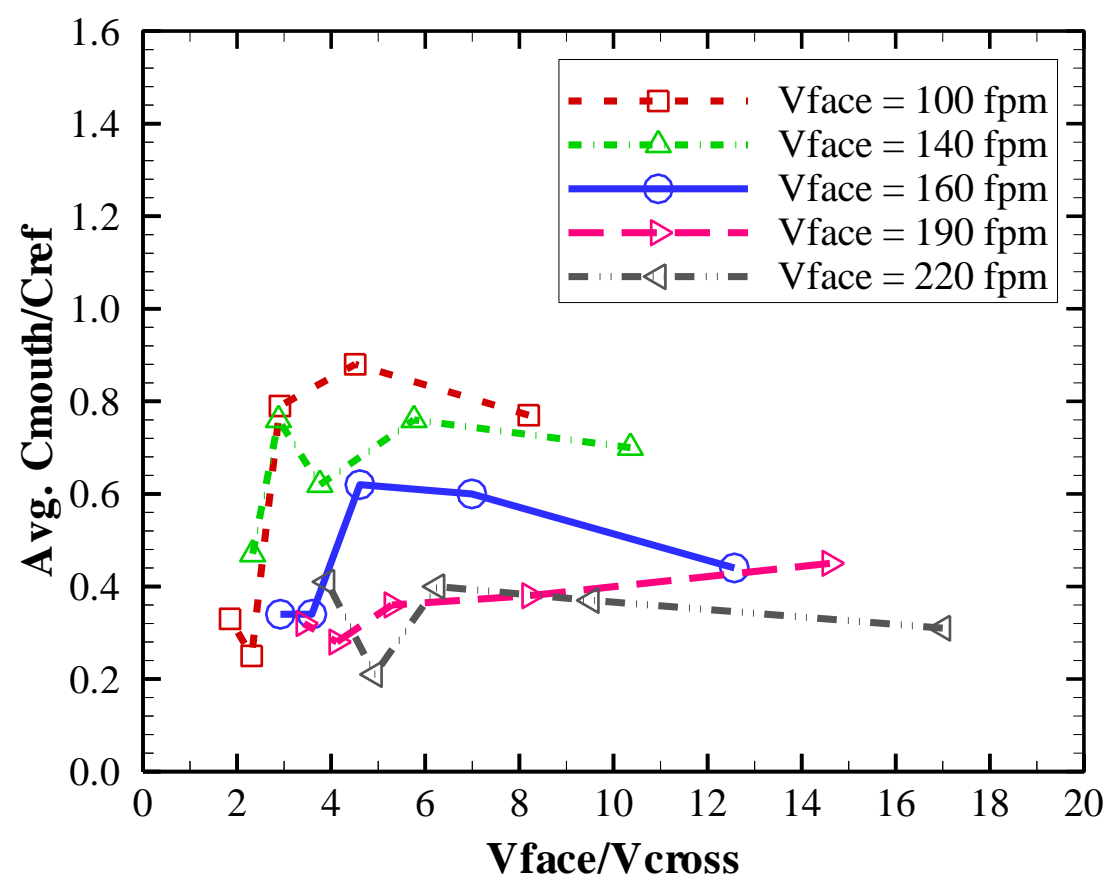

Figure 5.23 Effect of $V_{\text {face }} / V_{\text {cross }}$ on average $C_{\text {mout }} / C_{\text {ref }}$ at constant $V_{\text {face }}$ for the simple manikin, $C_{r e f}=23.7 \mathrm{ppm}$

\subsection{Discussion}

Previous experimental and numerical studies have shown the effects of $V_{\text {face }}$ and $V_{\text {cross }}$ on worker exposure (Guffey et al., 2001; Guffey and Barnea, 1994; Karaismail, 2011; He, 2010). However, the experimental conditions in those studies were quite different from the present study. For instance, they use different levels of velocities and different experimental setups. A static simple manikin without arms, built from basic geometric forms, was used in this study; hence, results can be compared with simulations studies with similar figures (Karaismail, 2011; Li, 2005).

This study found strong evidence of the importance of $V_{\text {face }}$ and $V_{\text {cross }}$ to control worker exposure (see Figures 5.6 to 5.23). In general, agreement with 
previous studies (Karaismail, 2011; Li, 2005) was found. For instance, when velocity increased $\left(V_{\text {face }} \geq 140 \mathrm{fpm}\right), C_{\text {nose }}$ and $C_{\text {mouth }}$ on the manikin decreased. However, peak concentrations were found at $V_{\text {face }}=140 \mathrm{fpm}$ and $V_{\text {cross }}=46$ and 57 fpm $\left(R e_{a v g}=10474\right.$ and 12344), which is an interesting finding not found by Li, (2007) in his numerical simulation using an unheated manikin. As it was mentioned before, this behavior could be explained by the boundary layer separation and the formation of the recirculation region between the manikin and the hood face or it could be an artifact of a single test condition. In addition, it is worth mentioning that a free stream wind tunnel exposure simulation was used by Li (2005) in the range of velocities of 10 to $150 \mathrm{fpm}$. Simple manikin results will be later compared to human subject results to determine how manikin represents worker exposure.

\subsubsection{Multiple regression analysis}

In the next sections, the linear relationship between dependent variables $\left(C_{\text {nose }}\right.$ and $\left.C_{\text {mouth }}\right)$ and independent variables $\left(V_{\text {face }}\right.$ and $\left.V_{\text {cross }}\right)$ were analyzed using multiple regression analysis and the analysis of variance (ANOVA). In addition, the effectiveness of the enclosing hood is discussed. For the regression analysis and analysis of variance, the temperature difference between the manikin and the ambient air $\left(\Delta T_{\text {man }}\right)$ was not considered due to the lack of complete temperature data for the entire experimental design. However, it is highly possible that the effect of temperature differences would not be significant because an unheated manikin was used as subject. Data Desk (Data Description Inc. Ithaca, NY) software was used for all the statistical results presented. 
A linear regression model can be carried out for a rough estimation of the response variable coefficients within the range of the studied conditions. For this study, the dependent variables or response variables $\left(C_{\text {nose }}\right.$ and $\left.C_{\text {mouth }}\right)$ are related to the independent variables or predictor variables $\left(V_{\text {face }}\right.$ and $\left.V_{\text {cross }}\right)$, which can be modeled through the linear regression equation. To fit the sample data to a nearly linear regression model, the dependent variables were log-transformed to reduce the variability of the concentration values and to produce residuals that were normally distributed. In addition, the independent variables were subtracted from their means to reduce multicollinearity among them with exception of the square root terms of these variables to avoid the square root of negative values (see Tables 5.4 and 5.5).

For $\log C_{\text {nose }}$ and $\log C_{\text {mouth }}$, a $R^{2}=0.98$ and 0.99 were found for the regression analysis of the normality of residuals (see normality of residuals in Figures 5.25 and 5.27). The regression model must satisfy the assumption of normal distribution of the residuals to be considered a lineal model. In addition, other assumptions must be satisfied, such as the constancy of the error variance (Figures 5.24 and 5.26 for $\log C_{\text {nose }}$ and $\log C_{\text {mouth }}$ ) and the randomness and independence of the errors (Montgomery et al., 2001; Neter and Wasserman, 1974). 
Table 5.4 Log $C_{\text {nose }}$ regression model for the simple manikin

\begin{tabular}{|c|c|c|c|c|}
\hline \multicolumn{5}{|c|}{$\begin{array}{l}\text { Dependent variable is: } \log C_{\text {nose }} \\
\mathrm{R} \text { squared }=77.1 \% \quad \mathrm{R} \text { squared (adjusted) }=73.3 \% \\
\mathrm{~s}=0.09914 \text { with } 50-8=42 \text { degrees of freedom }\end{array}$} \\
\hline Variable & Coefficient & s.e. of Coeff & t-ratio & prob \\
\hline Constant & -93.99 & 20.04 & -4.69 & $<0.0001$ \\
\hline$V_{\text {facem }}$ & -0.30 & 0.07 & -4.29 & 0.0001 \\
\hline$V_{\text {crossm }}$ & -0.16 & 0.04 & -4.09 & 0.0002 \\
\hline$V_{\text {facem }} * V_{\text {crossm }}$ & 8.70E-05 & $2.21 \mathrm{E}-05$ & 3.93 & 0.0003 \\
\hline Sqrt $V_{\text {face }}$ & 7.03 & 1.65 & 4.26 & 0.0001 \\
\hline Sqrt $V_{\text {cross }}$ & 1.75 & 0.45 & 3.89 & 0.0004 \\
\hline $\mathrm{Sq} V_{\text {facem }}$ & 4.38E-04 & $1.08 \mathrm{E}-04$ & 4.06 & 0.0002 \\
\hline $\mathrm{Sq} V_{\text {crossm }}$ & 8.13E-04 & 2.69E-04 & 3.03 & 0.0042 \\
\hline
\end{tabular}

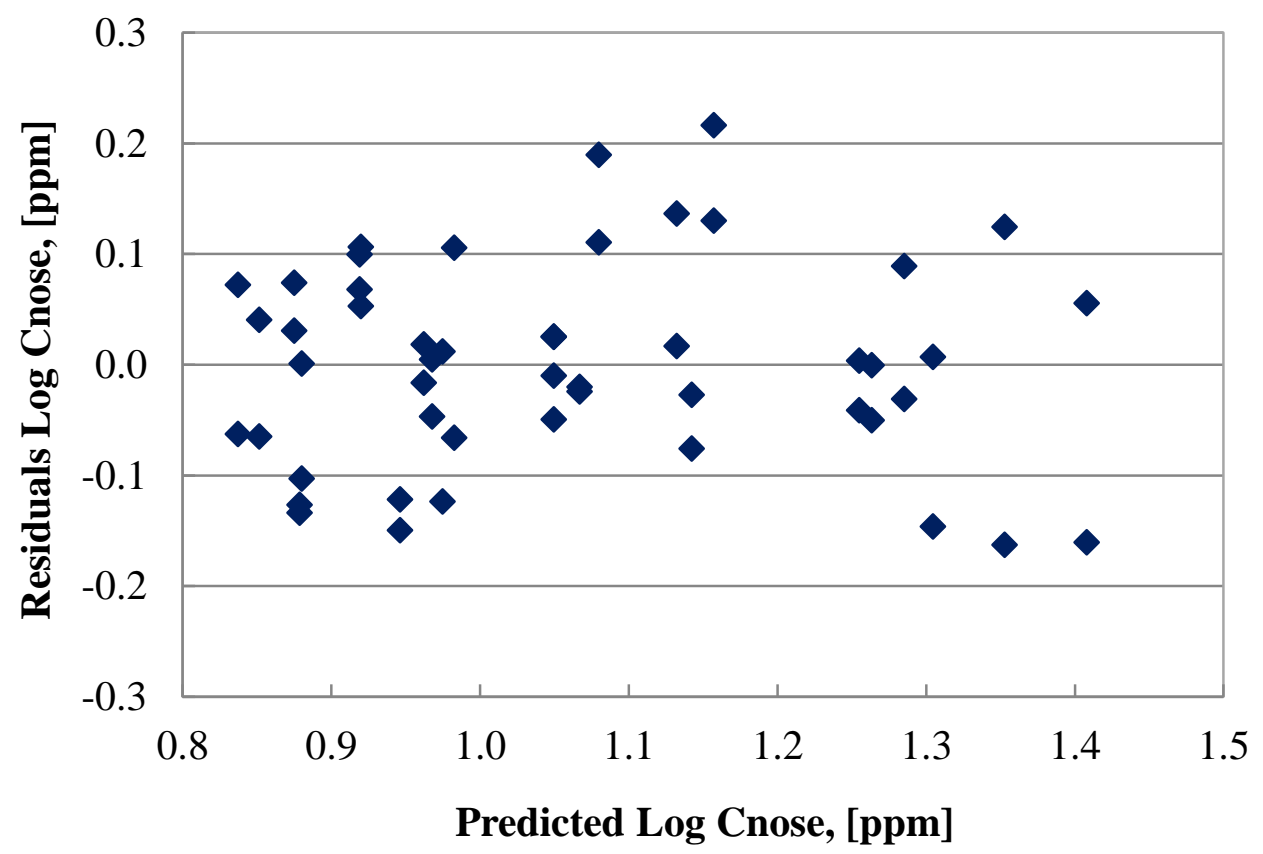

Figure 5.24 Residuals against Predicted $\log C_{\text {nose }}$ for the simple manikin 


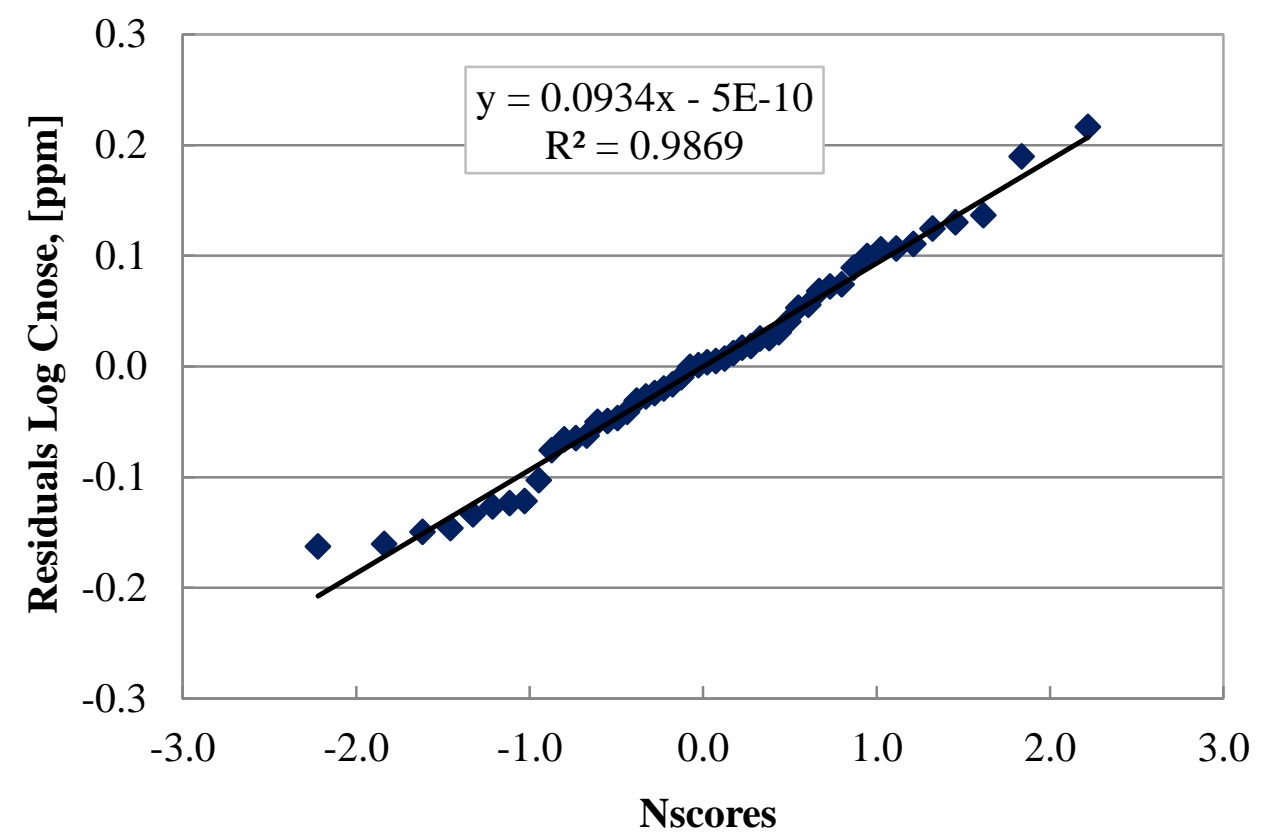

Figure 5.25 Normal probability plot of Residuals $\log C_{\text {nose }}$ against Nscores for the simple manikin

Every predictor variable added to the model contributed to obtain a better coefficient of multiple determination $\left(R^{2}\right)$ of the entire regression model. Table 5.4 shows the linear regression model $\log C_{\text {nose }}$ obtained using stepwise regression $(\alpha=$ 0.05). As can be seen $R^{2}$ and $R_{A d j}^{2}$ (adjusted coefficient of multiple determination) are $77.1 \%$ and $73.3 \%$, respectively. A $R^{2}=100 \%$ indicates that the linear model perfectly fits the entire experimental data. This $R^{2}$ increases as predictor variables are added to the model regardless of whether they are significant or not. Conversely, the adjusted coefficient of multiple determination $\left(R_{A d j}^{2}\right)$ takes into account the number of predictor variables, the sample size, and only increases if the added variable improves the model. 
Table 5.4 shows that all predictor variables added to the model are statistically significant $(\mathrm{p}<0.05)$. The same is true for the regression analysis of $\log C_{\text {mouth }}$ (Table 5.5), where the $R^{2}$ and $R_{\text {Adj }}^{2}$ are $64.7 \%$ and $58.8 \%$, respectively (Table 5.5). Only statistically significant predictor variables that improve the $R_{A d j}^{2}$ were added to the linear regression models (Tables 5.4 and 5.5) and all other nonsignificant predictor variables were removed.

Table 5.5 Log $C_{\text {mouth }}$ regression model for simple manikin

\begin{tabular}{|c|c|c|c|c|}
\hline \multicolumn{5}{|c|}{$\begin{array}{l}\text { Dependent variable is: } \log C_{\text {mouth }} \\
\mathrm{R} \text { squared }=64.7 \% \quad \mathrm{R} \text { squared (adjusted) }=58.8 \% \\
\mathrm{~s}=0.1175 \text { with } 50-8=42 \text { degrees of freedom }\end{array}$} \\
\hline Variable & Coefficient & s.e. of Coeff & t-ratio & prob \\
\hline Constant & -72.69 & 23.75 & -3.06 & 0.0038 \\
\hline$V_{\text {facem }}$ & -0.23 & 0.08 & -2.79 & 0.0080 \\
\hline$V_{\text {crossm }}$ & -0.13 & 0.05 & -2.85 & 0.0067 \\
\hline$V_{\text {facem }}{ }^{*} V_{\text {crossm }}$ & 7.96E-05 & $2.62 \mathrm{E}-05$ & 3.03 & 0.0041 \\
\hline Sqrt $V_{\text {face }}$ & 5.41 & 1.96 & 2.77 & 0.0084 \\
\hline Sqrt $V_{\text {cross }}$ & 1.45 & 0.53 & 2.72 & 0.0095 \\
\hline $\mathrm{Sq} V_{\text {facem }}$ & $3.35 \mathrm{E}-04$ & $1.28 \mathrm{E}-04$ & 2.62 & 0.0123 \\
\hline $\mathrm{Sq} V_{\text {crossm }}$ & 7.04E-04 & $3.18 \mathrm{E}-04$ & 2.21 & 0.0324 \\
\hline
\end{tabular}




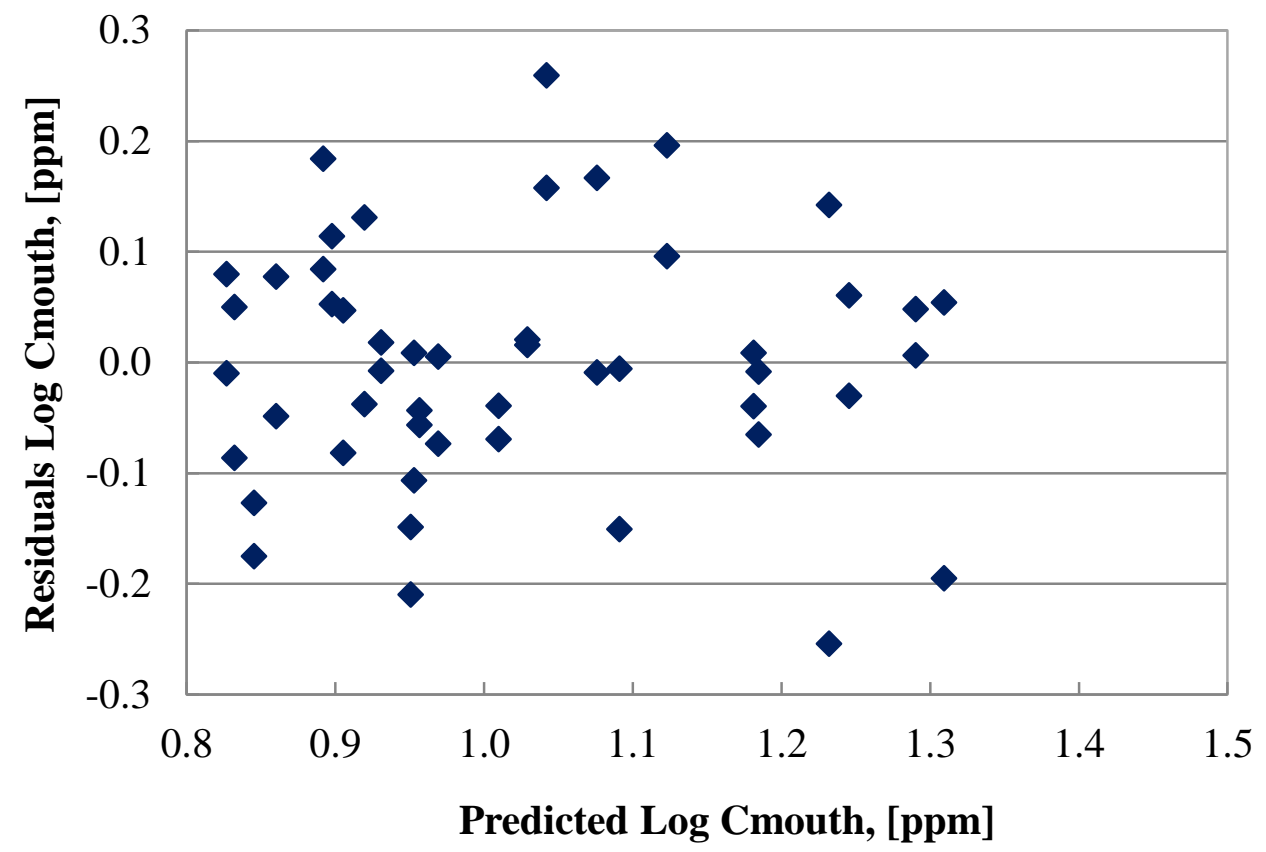

Figure 5.26 Residuals against Predicted $\log C_{\text {mouth }}$ for the simple manikin

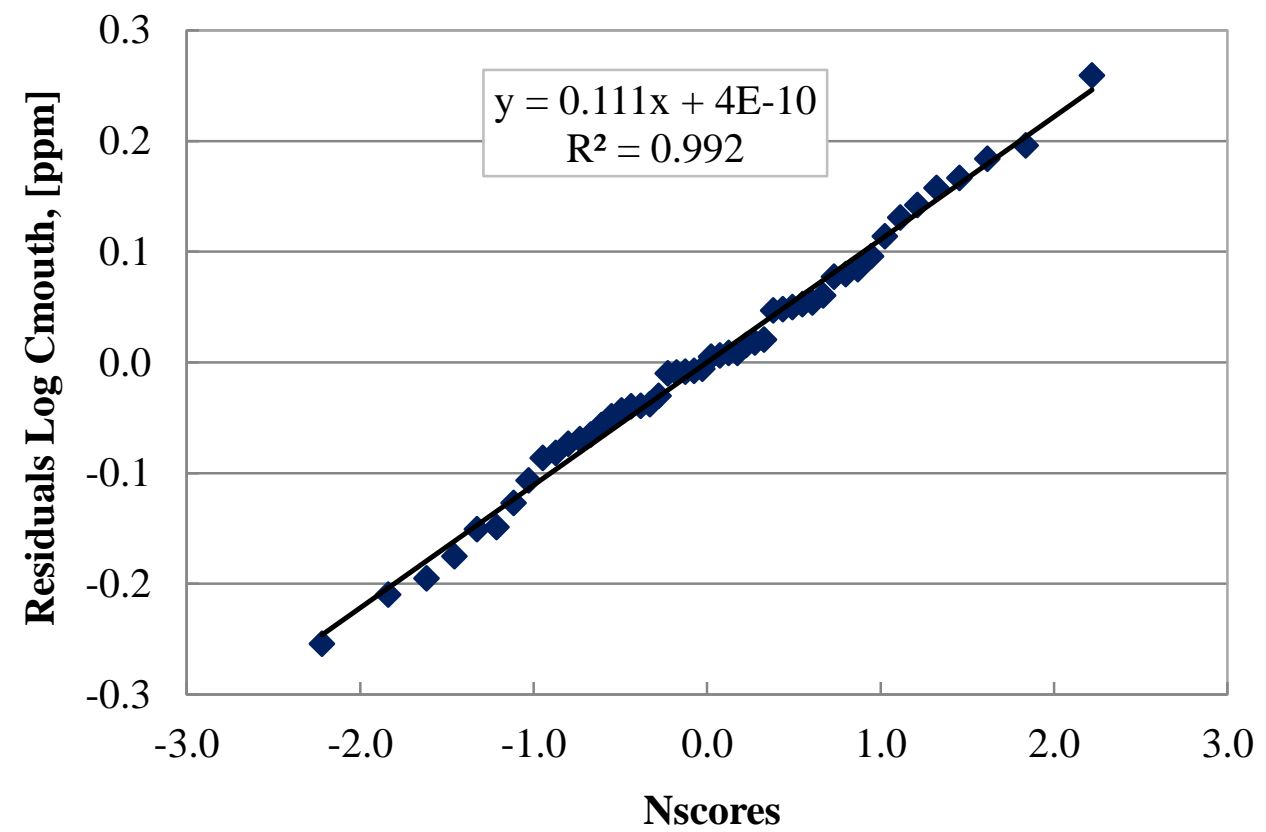

Figure 5.27 Normal probability plot of Residuals $\log C_{\text {mouth }}$ against Nscores for the simple manikin 


\subsubsection{Analysis of variance}

Analysis of variance (ANOVA) fixed effects model was performed for five levels of $V_{\text {face }}$ and five levels $V_{\text {cross }}$ (see Tables 5.1 and 5.2). The levels of $V_{\text {face }}$ and $V_{\text {cross }}$ were intentionally chosen because this study is interested in the effects of these specific levels on the response variable. This is the well known fixed factors effects model (Montgomery, 2009; Montgomery et al., 2001; Neter and Wasserman, 1974; Mason et al., 2003). For two-factor ANOVA, the fixed effects analysis of variance statistical model with interaction can be recalled for Eq. 1.2,

$$
Y_{i j k}=\mu+\alpha_{i}+\beta_{j}+(\alpha \beta)_{i j}+\varepsilon_{i j k}
$$

Where $\mu$ is a constant, $\alpha_{i}$ represents the effect of $V_{\text {face }}$ at the $i$ level treatment $(i=1,2,3,4,5), \beta_{j}$ represents the effect of $V_{\text {cross }}$ at the $j$ level treatment $(j=1,2,3,4,5)$, $(\alpha \beta)_{i j}$ represents the interaction effect of $V_{\text {face }}$ at the $i$ level and $V_{\text {cross }}$ at the $j$ level, and $\varepsilon_{i j k}$ represents the random error.

In order to obtain a better linear model, logarithmic transformations of the dependent variables $\left(C_{\text {nose }}\right.$ and $\left.C_{\text {mouth }}\right)$ were used for the ANOVA calculations. Analysis of variance was performed for the main factors or independent variables $\left(V_{\text {face }}\right.$ and $\left.V_{\text {cross }}\right)$ and its interaction between them. Due to that only a handful of $V_{\text {face }}$ and $V_{\text {cross }}$ levels were chosen for this study, those were treated as discrete variables. Partial sum of squares (Type 3) was used for the ANOVA model. A summary of the results are showed in Tables 5.6 and 5.7. 
Table 5.6 Log $C_{\text {nose }}$ ANOVA for the simple manikin

\begin{tabular}{lccccc}
\hline \multicolumn{1}{c}{ Source } & df & Sums of Squares & Mean Square & F-ratio & Prob \\
\hline Constant & 1 & 56.371 & 56.371 & 9342.30 & $<0.0001$ \\
$V_{\text {face }}$ & 4 & 0.624 & 0.156 & 25.83 & $<0.0001$ \\
$V_{\text {cross }}$ & 4 & 0.659 & 0.165 & 27.31 & $<0.0001$ \\
$V_{\text {face }} * V_{\text {cross }}$ & 16 & 0.369 & 0.023 & 3.82 & 0.0014 \\
Error & 25 & 0.151 & 0.006 & & \\
Total & 49 & 1.803 & & & \\
\hline
\end{tabular}

Table 5.7 Log $C_{\text {mouth }}$ ANOVA for the simple manikin

\begin{tabular}{lccccc}
\hline \multicolumn{1}{c}{ Source } & df & Sums of Squares & Mean Square & F-ratio & Prob \\
\hline Constant & 1 & 52.249 & 52.249 & 6000.10 & $<0.0001$ \\
$V_{\text {face }}$ & 4 & 0.582 & 0.145 & 16.70 & $<0.0001$ \\
$V_{\text {cross }}$ & 4 & 0.424 & 0.106 & 12.17 & $<0.0001$ \\
$V_{\text {face }} * V_{\text {cross }}$ & 16 & 0.422 & 0.026 & 3.03 & 0.0065 \\
Error & 25 & 0.218 & 0.009 & & \\
Total & 49 & 1.645 & & & \\
\hline
\end{tabular}

For each ANOVA table, the sum of the squares column was composed for the sum of squares of factors and interactions, the sum of square error, and the sum of square total. The total sum of squares represent the total variability of the ANOVA model. The sum of squares that remains unexplained is attributed to error.

The variance of every factor and interaction was represented by the mean square which was found by dividing the sum of squares (variation) by their degrees of freedom. The F-test statistic is obtained by dividing the mean square by the mean square error. Finally, the last column of the analysis of variance table is the probability (Prob), or p-value. Factors and interactions are statistically significant if their $p$-values are less than the specified level of significance $(\alpha=0.05)$. 
As listed in Tables 5.6 and 5.7, the effects of independent variables ( $V_{\text {face }}$ and $\left.V_{\text {cross }}\right)$ on the dependent variables ( $\log C_{\text {nose }}$ and $\left.\log C_{\text {mouth }}\right)$ were highly significant $(\mathrm{p}<0.0001)$. Likewise, the interaction of factors $\left(V_{\text {face }} * V_{\text {cross }}\right)$ was also statistically significant in both cases $(\mathrm{p}<0.05)$. Thus, the null hypothesis of no effects was rejected at the alpha level of significance of 0.05 . On the other hand, the coefficient of multiple determination $\left(R^{2}\right)$ and the adjusted coefficient of multiple determination $\left(R_{A d j}^{2}\right)$ of the ANOVA linear model were $91.6 \%$ and $91.1 \%$ for $\log$ $C_{\text {nose }}$ and $86.7 \%$ and $85.9 \%$ for $\log C_{\text {mouth }}$, respectively; indicating that the variance is largely explained by the model.

The findings of this study agree well with published studies of the effects of $V_{\text {face }}$ and $V_{\text {cross }}$ in hood effectiveness even though either lab hoods were used (Caplan and Knutson, 1982; 1982a) or an enclosing hood was studied in the absence of $V_{\text {cross }}$ (Guffey and Barnea, 1994). The experimental results of this study show that $V_{\text {cross }}, V_{\text {face }}$, and their interaction were all important in modelling the exposure to the simple manikin. This agrees well with the finding of Caplan and Knutson (1982) which pointed out that $V_{\text {cross }}$ is as important as $V_{\text {face }}$ on worker levels of exposure. However, statistically significant does not mean the factors effects on exposure are important or meaningful (Montgomery, 2009; Neter and Wasserman, 1974; Mason et al., 2003). It means that there is significant evidence to reject the null hypothesis (no effects). 


\subsubsection{Effectiveness of the enclosing hood}

The effectiveness of the enclosing hood in protecting workers from potentially hazardous airborne contaminants $\left(\eta_{\text {prot }}\right)$ was computed from measured values. Protection efficiency $\left(\eta_{\text {prot }}\right)$ is a function of the level of exposure in the manikin's breathing zone and the maximum exposure to the contaminant source (Eq. 1.1). To the author's knowledge no prior publication exist related to the performance of enclosing hood using the protection efficiency as the main parameter. However, most previous publications show the importance of hood face velocity $\left(V_{\text {face }}\right)$ and cross draft velocity $\left(V_{\text {cross }}\right)$ on worker exposure (Guffey and Barnea, 1994; Guffey et al., 2001; He, 2010; Li et al., 2005).

This study shows greater $\eta_{\text {prot }}(\sim 90 \%)$ at $V_{\text {face }}=100 \mathrm{fpm}$ and $V_{\text {cross }}=46$ and $57 \mathrm{fpm}$, and lower $\eta_{\text {prot }}$ at $V_{\text {face }}=100 \mathrm{fpm}$ and $V_{\text {cross }}=14,24$ and $36 \mathrm{fpm}$. In other words, higher $V_{\text {cross }}$ contributed to have better worker protection from airborne contaminants even though $V_{\text {face }}$ was at the lowest level (Fig. 5.28). It is better appreciated in Figure 5.29, which shows the effects of $V_{\text {cross }}$ on the average $\eta_{\text {prot }}$.

However, at $V_{\text {face }}=220 \mathrm{fpm}$ and $V_{\text {cross }}=57 \mathrm{fpm}$, the $\eta_{\text {prot }}$ showed a lower value $(\sim 70 \%)$ if compared to others $V_{\text {face }}$ at the same $V_{\text {cross. }}$ This possibly could be explained due to the increasing turbulence in front of the manikin at these higher velocities. 


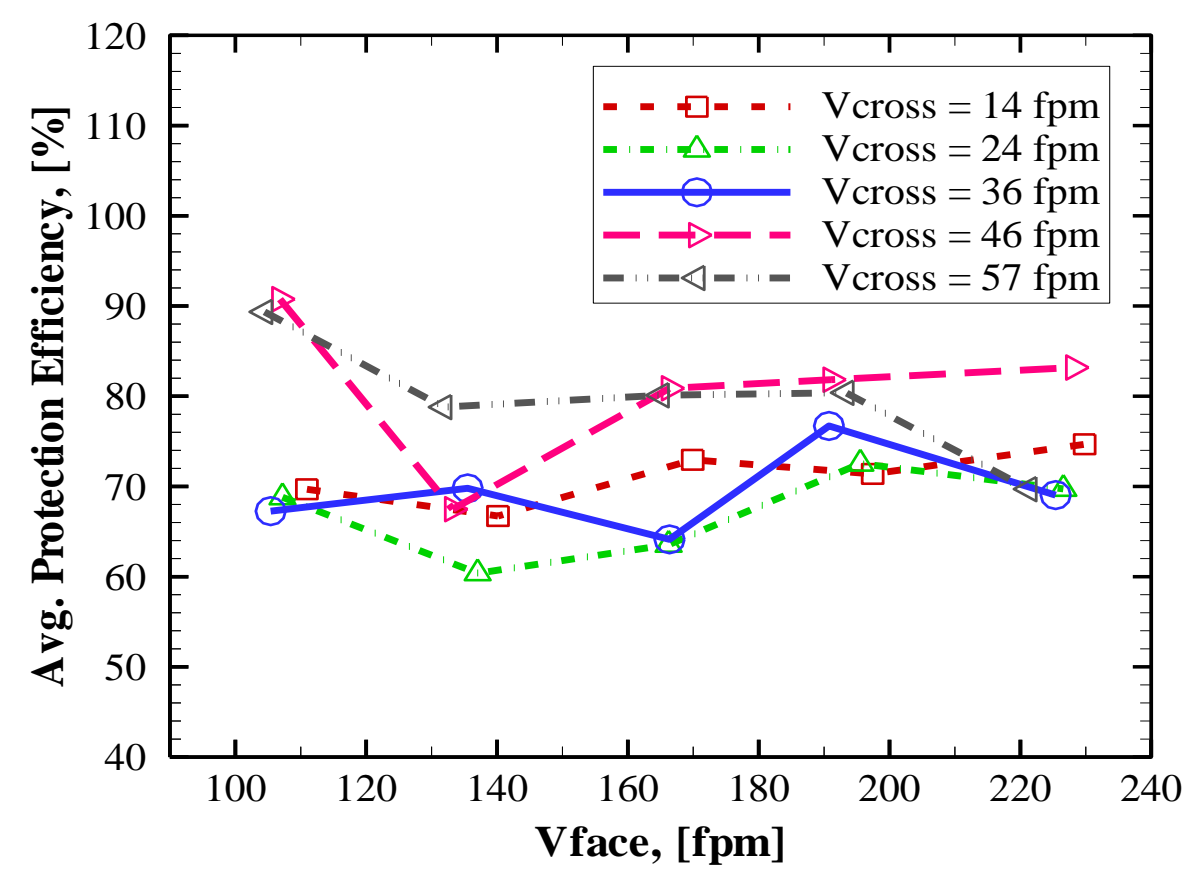

Figure 5.28 Effect of $V_{\text {face }}$ on the average protection efficiency at fixed $V_{\text {cross }}$ for the simple manikin

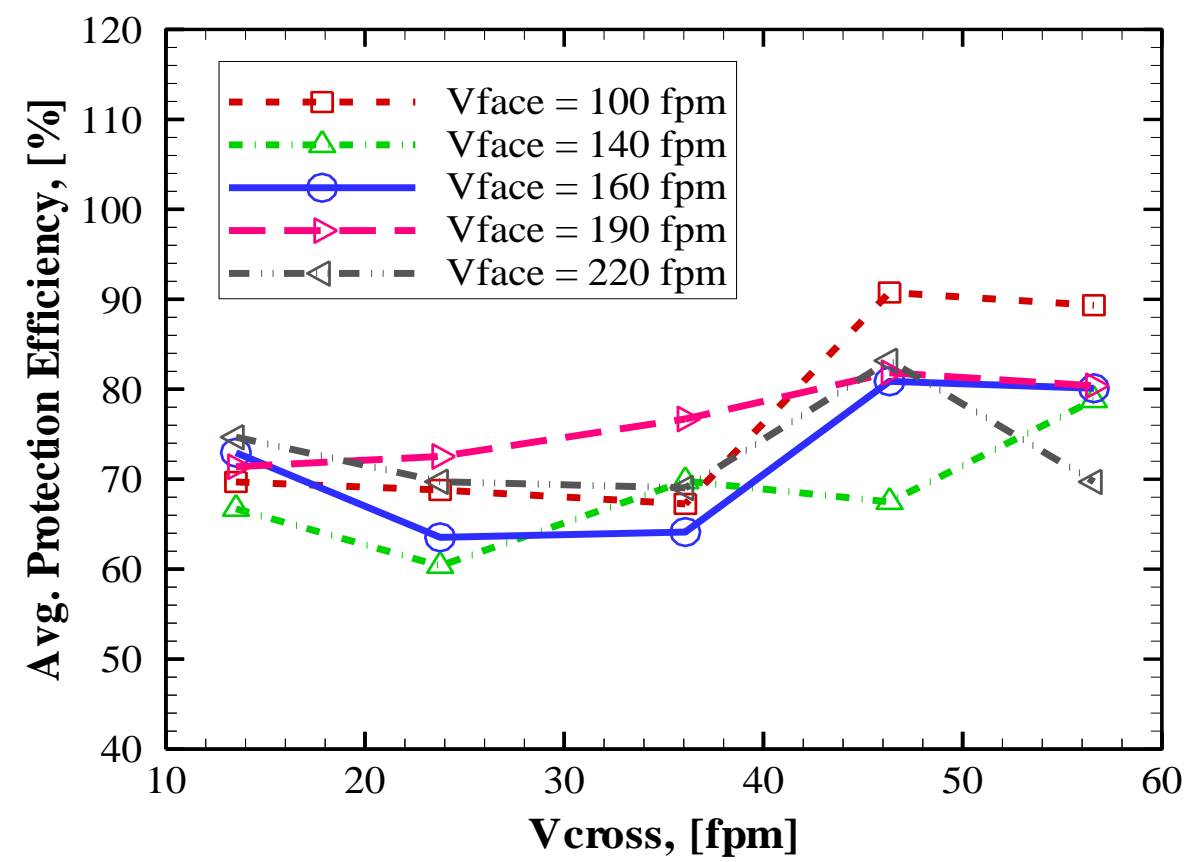

Figure 5.29 Effect of $V_{\text {cross }}$ on the average protection efficiency at fixed $V_{\text {face }}$ for the simple manikin 


\section{CHAPTER 6}

\section{ANTHROPOMETRIC MANIKIN STUDY}

\subsection{Introduction}

It is expected that testing the performance of an enclosing hood using an anthropometric or complex manikin would likely be more representative of human exposure than simple manikin because it is more similar to a human in relevant ways. Several published studies were carried out using complex manikins to test the performance of local exhaust ventilation (He, 2010; Guffey and Barnea, 1994; Brohus, 1997). The tested variables in these studies included hood face velocity $\left(V_{\text {face }}\right)$ and cross-draft velocity $\left(V_{\text {cross }}\right)$.

This study used a heated and breathing complex manikin to simulate a real human being. To obtain a skin temperature between $27^{\circ} \mathrm{C}$ and $33^{\circ} \mathrm{C}$, a string of small light bulbs inside the torso, groin, and head of the manikin for a total of $20 \mathrm{~W}$ was used (Figure 3.6). The breathing was achieved using a bellows arrangement to draw and to expel the same air through the nasal openings (Figure 3.7). The complex manikin was tested under the same experimental conditions as the simple manikin. Samples of contaminants concentrations (Freon 134a) were taken at the nose $\left(C_{\text {nose }}\right)$ and mouth $\left(C_{\text {mouth }}\right)$ of the manikin.

The performance of a benchtop enclosing hood was assessed by Guffey and Barnea (1994) and He (2010). Guffey and Barnea (1994) used an unheated anthropometric child size manikin in the absence of cross-draft velocity $\left(V_{\text {cross }}\right)$ and 
He (2010) used the same complex manikin and experimental setup that this study. Both studies found the relevant importance of hood face velocity $\left(V_{\text {face }}\right)$ to control worker exposure. In addition, there has been extensive research regarding the effect of body temperature in the vertical acceleration of the air near the body surface $(\mathrm{Hu}$ and Koochesfahani, 2011; Kilic and Sevilgen, 2008; Li et al., 2007; Mills, 1999). However, to the author's knowledge no literature was found describing experimental studies of the effects of $\Delta T_{\text {man }}$ on the performance of benchtop enclosing hoods. Even when a heated and breathing complex manikin was used to assess the performance of a benchtop enclosing hood, the effect of the temperature difference between the manikin and the surrounding environment $\left(\Delta T_{\text {man }}\right)$ on worker exposure was not considered an important factor; thus, it was neglected in the analysis by He (2010).

Numerical simulation studies were also carried out taking into account the effect of manikin body temperature on subject's exposure (Karaismail, 2011; Li et $a l .$, 2007). Karaismail (2011) pointed out that at low values of $V_{\text {cross }}$ and $V_{\text {face }}$, the aiding buoyancy $\left(T_{\text {man }}>T_{o}\right)$ increases the workers' exposures, while at higher flow rates this effect is not significant on exposure when testing the performance of a simulated enclosing hood. This effect is in general agreement with this study even though the numerical simulation was performed using a heated simple manikin. In addition, the effect of the body heat on concentration in the breathing zone was studied by Li et al. (2007) in a simulated free stream airflow. 
The aim of this study is to elucidate whether or not the use of a heated and breathing complex manikin better represents a human subject contaminant exposure than does a simple manikin. To this end, the effect of $V_{\text {face }}, V_{\text {cross }}$, and $\Delta T_{\text {man }}$ on concentrations at the nose and mouth will be assessed.

\subsection{Experimental design}

The experimental trials to test the effectiveness of a custom-made benchtop enclosing hood were carried out in a wind tunnel under controlled hood face velocities $\left(V_{\text {face }}\right)$ and wind tunnel cross-draft velocities $\left(V_{\text {cross }}\right)$. Concentration at the nose $\left(C_{\text {nose }}\right)$ and mouth $\left(C_{\text {mouth }}\right)$ were taken simultaneously throughout the duration of each experiment (20 minutes). The temperature difference between the manikin and its surrounding environment $\left(\Delta T_{\text {man }}\right)$ was recorded before every test. An average of the measured manikin's face temperature and back temperature was deemed the manikin's temperature.

Three levels of $V_{\text {face }}(100,160$, and $220 \mathrm{fpm})$ and three levels of $V_{\text {cross }}(14$, 46, and $63 \mathrm{fpm}$ ) were used in a completely randomized factorial design. This design became an unbalance design because several experimental results were discarded because their residuals were greater than 0.02 as it was explained in Section 4.3 of Chapter 4.

\subsection{Apparatus}

The heated and breathing complex manikin was 66" high male manikin. It had physical features like a human being and it was clothed with a sport t-shirt and pants. Its hands were positioned on both sides of the contaminant source during all 
experimental trials (see Figure 3.5). Unlike the simple manikin, the complex manikin can be posed and his head can break the hood face.

To heat the manikin, strings of small light bulbs were placed in hollowed cavities for a total power of roughly $20 \mathrm{~W}$. There were no hollow cavities in the arms and legs. The power of $20 \mathrm{~W}$ was due to efforts to keep surface temperature to less than $35^{\circ} \mathrm{C}$ and the inability to heat the arms and legs. In addition, thermocouples were placed on the manikin's face and back, and also on the wind tunnel's ceiling and wall. Detailed description of the manikin and all related apparatus are given in Chapter 3.

\subsection{Methods}

Sample probes were coming out from inside the manikin's head at locations near the nose and mouth. Thus, samples of concentrations at the nose and mouth $\left(C_{\text {nose }}\right.$ and $\left.C_{\text {mouth }}\right)$ were collected at those locations when the manikin was in the sideburn posture in from of the hood face (Detailed description on Chapter 4). In addition, temperatures on the manikin's cheek and back were also collected. Similar to the other subjects, the complex manikin was exposed to a mixture of 3.0 lpm of Freon 134a and $4.9 \mathrm{lpm}$ of Helium, which was released from a contaminant source just inside the hood on the hood floor (see Figure 3.4). All subjects, including the complex manikin, were positioned perpendicular to the long dimension of the wind tunnel so that the flow through the wind tunnel (cross-draft) impacted the sides of the manikin and hood (i.e. "side orientation"). 


\subsection{Analysis}

Corrected values of concentrations at the nose and mouth $\left(C_{\text {nose }}\right.$ and $\left.C_{\text {mouth }}\right)$ were analyzed as dependent variables (see Equations 4.3 and 4.4). Detailed description of data analysis for all subjects can be seen in Section 4.3 of Chapter 4 . However, it is noteworthy to mention again that in addition to the discrete variables $V_{\text {face }}$ and $V_{\text {cross }}$, the continuous variable of $\Delta T_{\text {man }}$ was also included in the model. These variables and their interactions were analyzed using the analysis of covariance (ANCOVA).

\subsection{Results}

Table 6.1 and 6.3 shows an unbalanced design for the results of $C_{n o s e}$ and $C_{\text {mouth }}$ for every level combination of $V_{\text {face }}$ and $V_{\text {cross }}$. The missing values are cases with excessive FTIR residuals (see Section 4.3 in Chapter 4). The summary statistics for $C_{n o s e}$ and $C_{\text {mouth }}$ are displayed in Tables 6.2 and 6.4. As can be seen from these tables, the minimum coefficient of variation $(\mathrm{CV}=0.16)$ occurs at $V_{\text {face }}$ $=160 \mathrm{fpm}$ and $V_{\text {cross }}=46 \mathrm{fpm}$ for $C_{\text {mouth }}$ (Table 6.4). A maximum value of $\mathrm{CV}$ (2.36) is seen at $V_{\text {face }}=220 \mathrm{fpm}$ and $V_{\text {cross }}=63 \mathrm{fpm}$ for $C_{\text {nose }}$ (Table 6.2). In addition, error bars were plotted on the average of the exposure data to indicate how closely the means are likely to represent the true exposure values. 
Table $6.1 C_{\text {nose }}$ for the complex manikin study in ppm

\begin{tabular}{|c|c|c|c|c|c|c|c|}
\hline \multirow[b]{2}{*}{$V_{\text {face }},[\mathbf{f p m}]$} & \multicolumn{6}{|c|}{$V_{\text {cross }},[\mathrm{fpm}]$} & \multirow[b]{2}{*}{ Mean } \\
\hline & \multicolumn{2}{|c|}{14} & \multicolumn{2}{|c|}{46} & \multicolumn{2}{|c|}{63} & \\
\hline \multirow{5}{*}{100} & 4.5 & 1.6 & 0.8 & 0.6 & 14.8 & 0.4 & \\
\hline & 0.8 & 4.1 & 5.4 & 2.0 & 1.0 & 0.5 & \\
\hline & 0.6 & 4.2 & 1.4 & 2.7 & 4.1 & 0.3 & \\
\hline & & & 1.3 & & 3.8 & & \\
\hline & 2.6 & & 2.0 & & 3.6 & & 2.7 \\
\hline \multirow{4}{*}{160} & 0.2 & 0.3 & 2.6 & 2.6 & 0.9 & 10.3 & \\
\hline & 1.3 & 26.8 & 2.7 & 4.4 & 0.5 & 0.4 & \\
\hline & 0.0 & & & & & & \\
\hline & 5.7 & & 3.1 & & 3.0 & & 3.9 \\
\hline \multirow{5}{*}{220} & 0.0 & 0.0 & 22.7 & 0.1 & 17.3 & 0.3 & \\
\hline & 3.0 & 0.1 & 7.7 & 0.4 & 0.1 & 0.7 & \\
\hline & 2.4 & 0.1 & 0.2 & 0.1 & 0.3 & 0.2 & \\
\hline & 0.0 & & 0.2 & & 0.1 & & \\
\hline & 0.8 & & 4.5 & & 2.7 & & 2.7 \\
\hline Mean & 3.1 & & 3.2 & & 3.1 & & 3.0 \\
\hline
\end{tabular}


Table 6.2 Summary statistics of $C_{\text {nose }}$ for the complex manikin

\begin{tabular}{|c|c|c|c|c|c|c|}
\hline \multirow[b]{2}{*}{$V_{\text {face }},[\mathbf{f p m}]$} & \multicolumn{5}{|c|}{$V_{\text {cross }},[\mathrm{fpm}]$} & \multirow[b]{2}{*}{ Average } \\
\hline & & 14 & 46 & 63 & Total & \\
\hline \multirow{6}{*}{100} & Total & 15.8 & 14.0 & 24.9 & 54.7 & \multirow{6}{*}{2.7} \\
\hline & Min & 0.6 & 0.6 & 0.3 & & \\
\hline & Max & 4.5 & 5.4 & 14.8 & & \\
\hline & $\mathrm{S}$ & 1.8 & 1.6 & 5.2 & & \\
\hline & Average & 2.6 & 2.0 & 3.6 & & \\
\hline & $\mathrm{CV}$ & 0.7 & 0.8 & 1.5 & & \\
\hline \multirow{6}{*}{160} & Total & 28.5 & 12.3 & 12.2 & 53.1 & \multirow{6}{*}{3.9} \\
\hline & Min & 0.0 & 2.6 & 0.4 & & \\
\hline & Max & 26.8 & 4.4 & 10.3 & & \\
\hline & $\mathrm{S}$ & 11.8 & 0.9 & 4.9 & & \\
\hline & Average & 5.7 & 3.1 & 3.0 & & \\
\hline & $\mathrm{CV}$ & 2.1 & 0.3 & 1.6 & & \\
\hline \multirow{8}{*}{220} & Total & 5.7 & 31.4 & 19.1 & 56.2 & \multirow{6}{*}{2.7} \\
\hline & Min & 0.0 & 0.1 & 0.1 & & \\
\hline & Max & 3.0 & 22.7 & 17.3 & & \\
\hline & $S$ & 1.3 & 8.5 & 6.4 & & \\
\hline & Average & 0.8 & 4.5 & 2.7 & & \\
\hline & $\mathrm{CV}$ & 1.6 & 1.9 & 2.4 & & \\
\hline & Total & 50.0 & 57.8 & 56.2 & 164.0 & \\
\hline & Average & 3.1 & 3.2 & 3.1 & & 3.1 \\
\hline
\end{tabular}


Table $6.3 C_{\text {mouth }}$ for the complex manikin study in ppm

\begin{tabular}{|c|c|c|c|c|c|c|c|}
\hline \multirow[b]{2}{*}{$V_{\text {face }},[\mathrm{fpm}]$} & \multicolumn{6}{|c|}{$V_{\text {cross }},[\mathrm{fpm}]$} & \multirow[b]{2}{*}{ Mean } \\
\hline & \multicolumn{2}{|c|}{14} & \multicolumn{2}{|c|}{46} & \multicolumn{2}{|c|}{63} & \\
\hline \multirow{5}{*}{100} & 6.7 & 1.9 & 2.1 & 2.0 & 1.4 & 1.4 & \\
\hline & 1.0 & 2.8 & 7.5 & 1.3 & 6.0 & 1.1 & \\
\hline & 0.7 & 3.2 & 1.6 & 3.0 & 6.1 & 1.0 & \\
\hline & & & 2.0 & 2.9 & & & \\
\hline & 2.7 & & 2.8 & & 2.8 & & 2.8 \\
\hline \multirow{3}{*}{160} & 0.2 & 0.2 & 3.4 & 3.0 & 1.7 & 19.4 & \\
\hline & 1.4 & 0.3 & 3.7 & 4.4 & 0.6 & 0.5 & \\
\hline & 0.5 & & 3.6 & & 5.6 & & 3.2 \\
\hline \multirow{5}{*}{220} & 0.1 & 0.1 & 12.7 & 0.3 & 0.3 & 0.8 & \\
\hline & 3.4 & 0.1 & 0.5 & 0.9 & 0.3 & 1.1 & \\
\hline & 2.9 & 0.2 & 0.4 & 0.3 & 0.3 & 0.8 & \\
\hline & 0.1 & & & & & & \\
\hline & 1.0 & & 2.5 & & 0.6 & & 1.4 \\
\hline Mean & 1.4 & & 3.0 & & 3.0 & & 2.4 \\
\hline
\end{tabular}


Table 6.4 Summary statistics of $C_{\text {mouth }}$ for the complex manikin

\begin{tabular}{|c|c|c|c|c|c|c|}
\hline \multirow[b]{2}{*}{$V_{\text {face }},[\mathbf{f p m}]$} & \multicolumn{5}{|c|}{$V_{\text {cross, }}[\mathbf{f p m}]$} & \multirow[b]{2}{*}{ Average } \\
\hline & & 14 & 46 & 63 & Total & \\
\hline \multirow{6}{*}{100} & Total & 16.3 & 22.5 & 17.0 & 55.8 & \multirow{6}{*}{2.8} \\
\hline & Min & 0.7 & 1.3 & 1.0 & & \\
\hline & Max & 6.7 & 7.5 & 6.1 & & \\
\hline & $\mathrm{S}$ & 2.2 & 2.0 & 2.5 & & \\
\hline & Average & 2.7 & 2.8 & 2.8 & & \\
\hline & $\mathrm{CV}$ & 0.8 & 0.7 & 0.9 & & \\
\hline \multirow{6}{*}{160} & Total & 2.1 & 14.5 & 22.3 & 38.8 & \multirow{6}{*}{3.2} \\
\hline & Min & 0.2 & 3.0 & 0.5 & & \\
\hline & Max & 1.4 & 4.4 & 19.4 & & \\
\hline & $\mathrm{S}$ & 0.6 & 0.6 & 9.3 & & \\
\hline & Average & 0.5 & 3.6 & 5.6 & & \\
\hline & $\mathrm{CV}$ & 1.2 & 0.2 & 1.7 & & \\
\hline \multirow{8}{*}{220} & Total & 6.9 & 15.0 & 3.5 & 25.4 & \multirow{6}{*}{1.4} \\
\hline & Min & 0.1 & 0.3 & 0.3 & & \\
\hline & Max & 3.4 & 12.7 & 1.1 & & \\
\hline & S & 1.5 & 5.0 & 0.3 & & \\
\hline & Average & 1.0 & 2.5 & 0.6 & & \\
\hline & $\mathrm{CV}$ & 1.5 & 2.0 & 0.6 & & \\
\hline & Total & 25.3 & 52.0 & 42.8 & 120.0 & \\
\hline & Average & 1.4 & 3.0 & 3.0 & & 2.5 \\
\hline
\end{tabular}

\subsubsection{Fluid dynamics considerations}

The understanding of fluid dynamics theory is a key factor to explain the variability of worker exposure at different combinations of $V_{\text {face }}$ and $V_{\text {cross. }}$. The complex manikin standing in front of the enclosing hood in a working position has two competing velocities over its body, the suction velocity of the hood face $\left(V_{\text {face }}\right)$ and the air velocity of the wind tunnel ( $\left.V_{\text {cross }}\right)$ hitting the side of the manikin. However, to calculate the Reynolds number $(R e)$ and determine the regime of the 
flow, a free stream velocity $(U)$ or approach velocity was needed, which was calculated from the empirical relationship (Equation C.1) showed in Appendix C (Detailed explanation in Section 4.2 of Chapter 4). Approach velocity ranged between 25 and $97 \mathrm{fpm}$ as showed in Table D.1 (Appendix D). Reynolds numbers were calculated based in the diameter of the manikin's shoulders $\left(D=17.5^{\prime \prime}\right)$. Both $V_{\text {face }}$ and $V_{\text {cross }}$ had an effect on Reynolds numbers (Table 6.5). It can be seen that the effect of $V_{\text {cross }}$ on $U$ (Table D.1) and, therefore, the Reynolds numbers (Table 6.5) are higher than the effect of $V_{\text {face }}$.

Table 6.5 Reynolds numbers for complex manikin experiments

\begin{tabular}{|c|c|c|c|c|c|c|c|}
\hline \multirow[b]{2}{*}{$V_{\text {face }},[\mathbf{f p m}]$} & \multicolumn{6}{|c|}{$V_{\text {cross }},[\mathrm{fpm}]$} & \multirow[b]{2}{*}{ Mean } \\
\hline & \multicolumn{2}{|c|}{14} & \multicolumn{2}{|c|}{46} & \multicolumn{2}{|c|}{63} & \\
\hline \multirow{5}{*}{100} & 3918 & 3998 & 9889 & 9974 & 12873 & 12945 & \\
\hline & 3932 & 3998 & 9908 & 9986 & 12885 & 12956 & \\
\hline & 3985 & 4016 & 9911 & 10010 & 12912 & 12965 & \\
\hline & & & 9960 & 10014 & 12913 & & \\
\hline & 3974 & & 9957 & & 12921 & & 8951 \\
\hline \multirow{4}{*}{160} & 4887 & 4898 & 10891 & 10916 & 13871 & 13900 & \\
\hline & 4888 & 4911 & 10893 & 10955 & 13891 & 13906 & \\
\hline & 4894 & & & & & & \\
\hline & 4895 & & 10913 & & 13892 & & 9900 \\
\hline \multirow{5}{*}{220} & 5851 & 5963 & 11843 & 12008 & 14837 & 14992 & \\
\hline & 5852 & 5990 & 11873 & 12010 & 14850 & 15000 & \\
\hline & 5856 & 5994 & 11911 & 12033 & 14854 & 15008 & \\
\hline & 5858 & & 11920 & & 14857 & & \\
\hline & 5909 & & 11943 & & 14914 & & 10922 \\
\hline Mean & 4926 & & 10938 & & 13909 & & 9924 \\
\hline
\end{tabular}

The Reynolds numbers for the complex manikin experiments ranged between 3900 and 15000 (Table 6.5), both of which fall in the transitional and 
unstable regime (Mills, 1999; Hu and Koochesfahani, 2011). This range of Reynolds numbers is well below the onset of turbulent flow $\left(\operatorname{Re}>2 \times 10^{5}\right)$ for a vertical cylinder considered as bluff body. To reach the turbulent regime, the approach velocity on the manikin should be $1300 \mathrm{fpm}$, which would be extraordinarily high for an indoor environment.

A wider spread of average dimensionless $C_{n o s e} / C_{\text {ref }}$ can be seen at Reynolds numbers between 4000 and 6000, which could be due to an unstable flow regime and the wake region formation in front of the manikin (Figure 6.2). However, a narrow and lower spread of worker's exposure can be seen at Reynolds numbers greater than 10000 at the three levels of $V_{\text {face }}$, which shows the effect of higher $V_{\text {cross }}$ in control exposure (Figure 6.2). At $V_{\text {face }}=220 \mathrm{fpm}$ and the Reynolds number of roughly 12000 , a peak exposure is observed but soon after it dropped at higher Reynolds number. A possible explanation could be that the recirculation of airflow and contaminants got into the breathing zone of the manikin increasing the exposure, but then it fell possibly because higher $V_{\text {cross }}$ overcomes the strength of the recirculation region. A scatter plot of the dimensionless $C_{n o s e}$ against the Reynolds number is displayed in Figure 6.1.

The same pattern can be seen in plots of $C_{\text {mouth }} / C_{\text {ref }}$ against Reynolds numbers (Figures 6.3 and 6.4). However, at the end of the curve at $V_{\text {face }}=160 \mathrm{fpm}$, $C_{\text {mouth }}$ is higher than $C_{\text {nose }}$ (Figure 6.4). One would reasonably expect to have similar average concentrations values since the nose and mouth are near each other. 


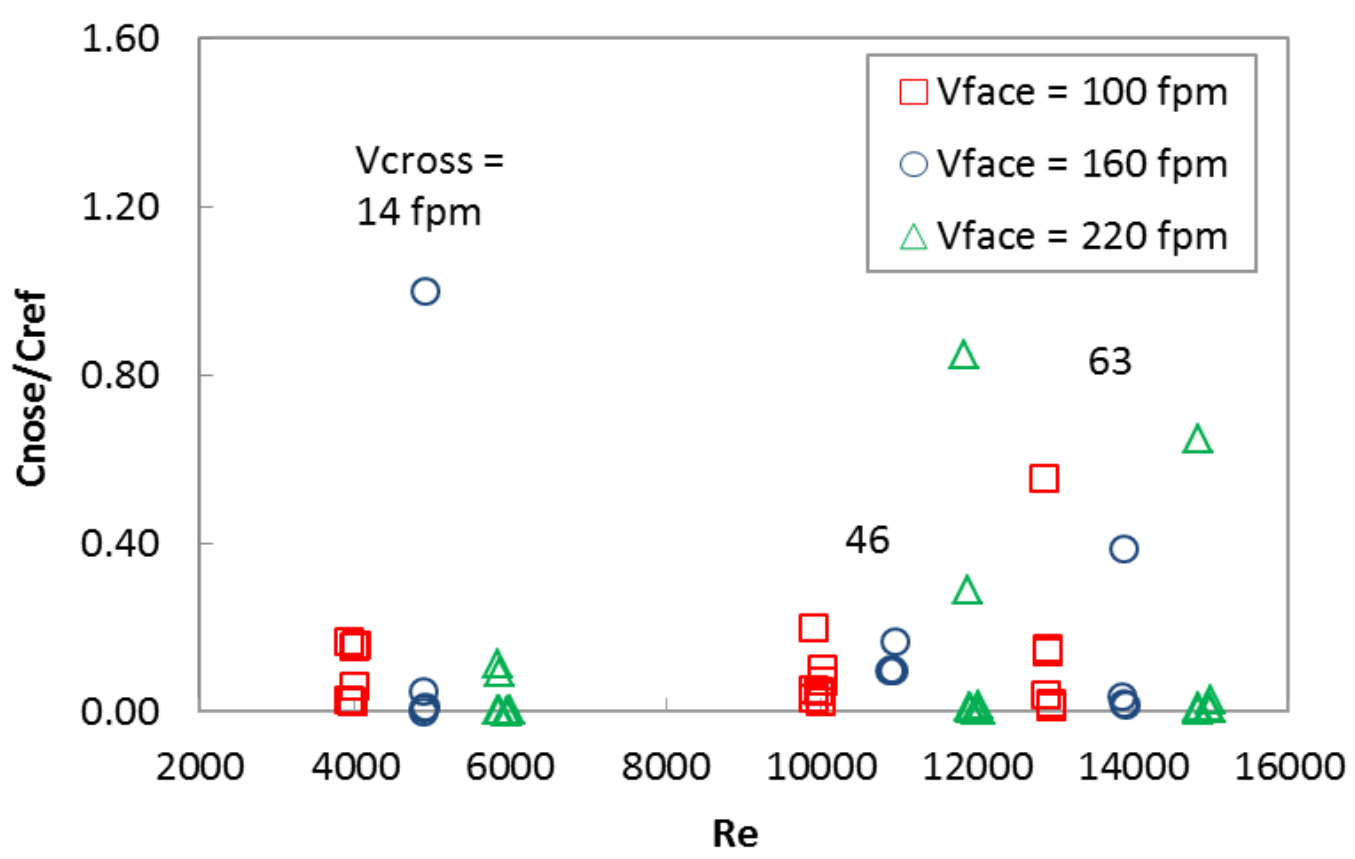

Figure 6.1 Effect of $R e$ on $C_{n o s e} / C_{r e f}$ for the complex manikin, $C_{r e f}=26.8 \mathrm{ppm}$

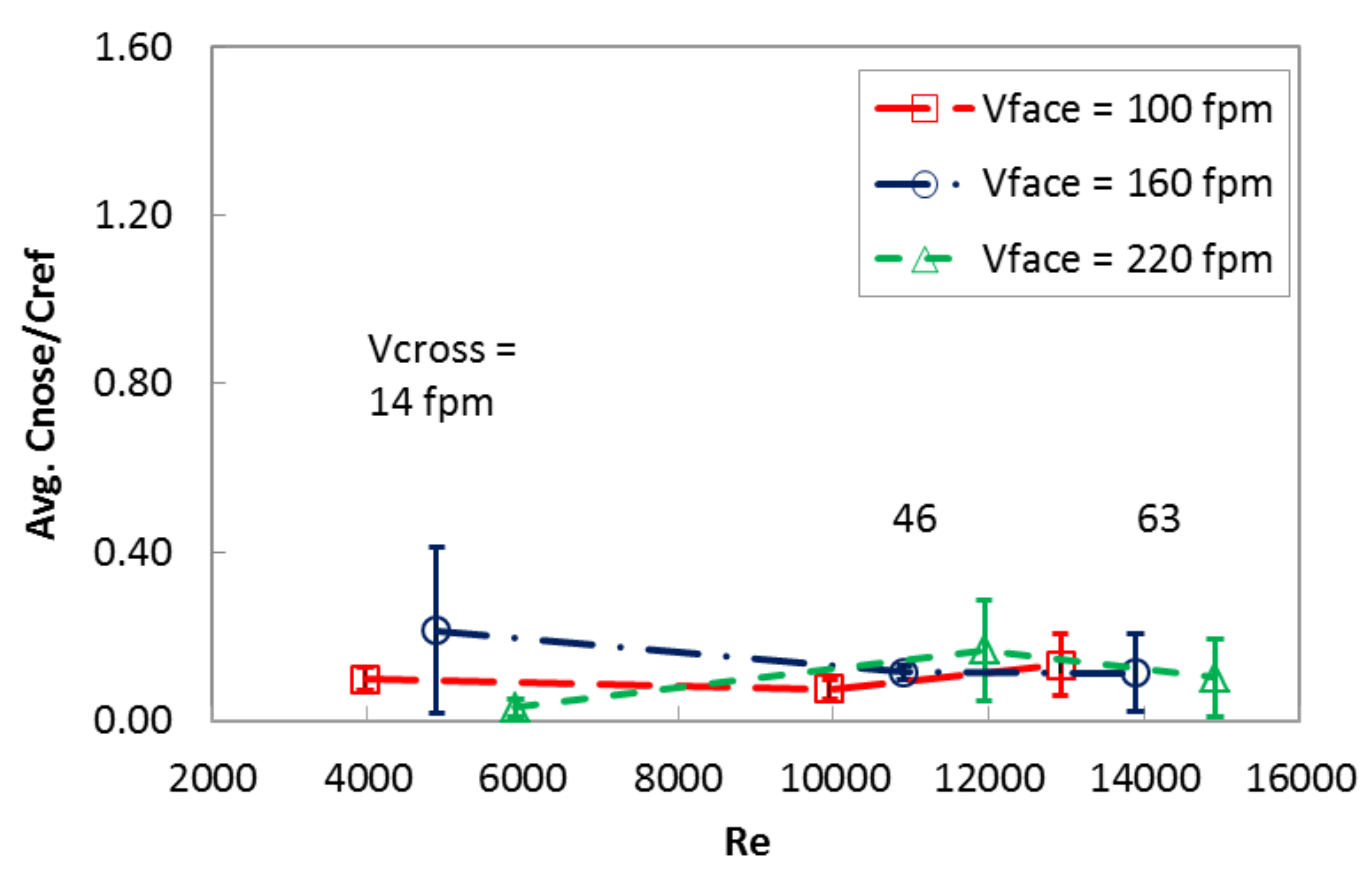

Figure 6.2 Effect of $R e$ on average $C_{n o s e} / C_{r e f}$ for the complex manikin, $C_{r e f}=26.8$ ppm 


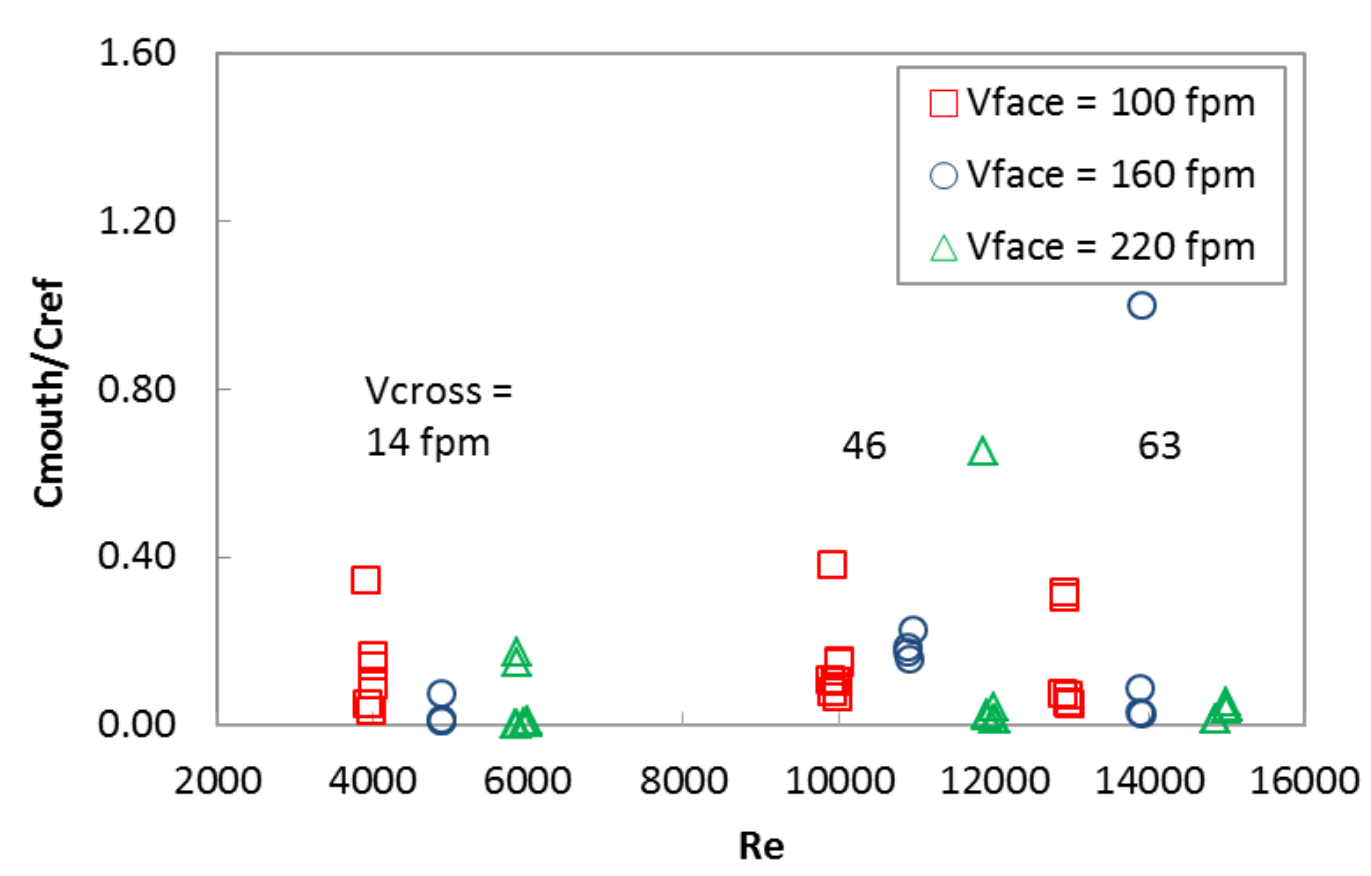

Figure 6.3 Effect of $R e$ on $C_{\text {mouth }} / C_{r e f}$ for the complex manikin, $C_{r e f}=19.4 \mathrm{ppm}$

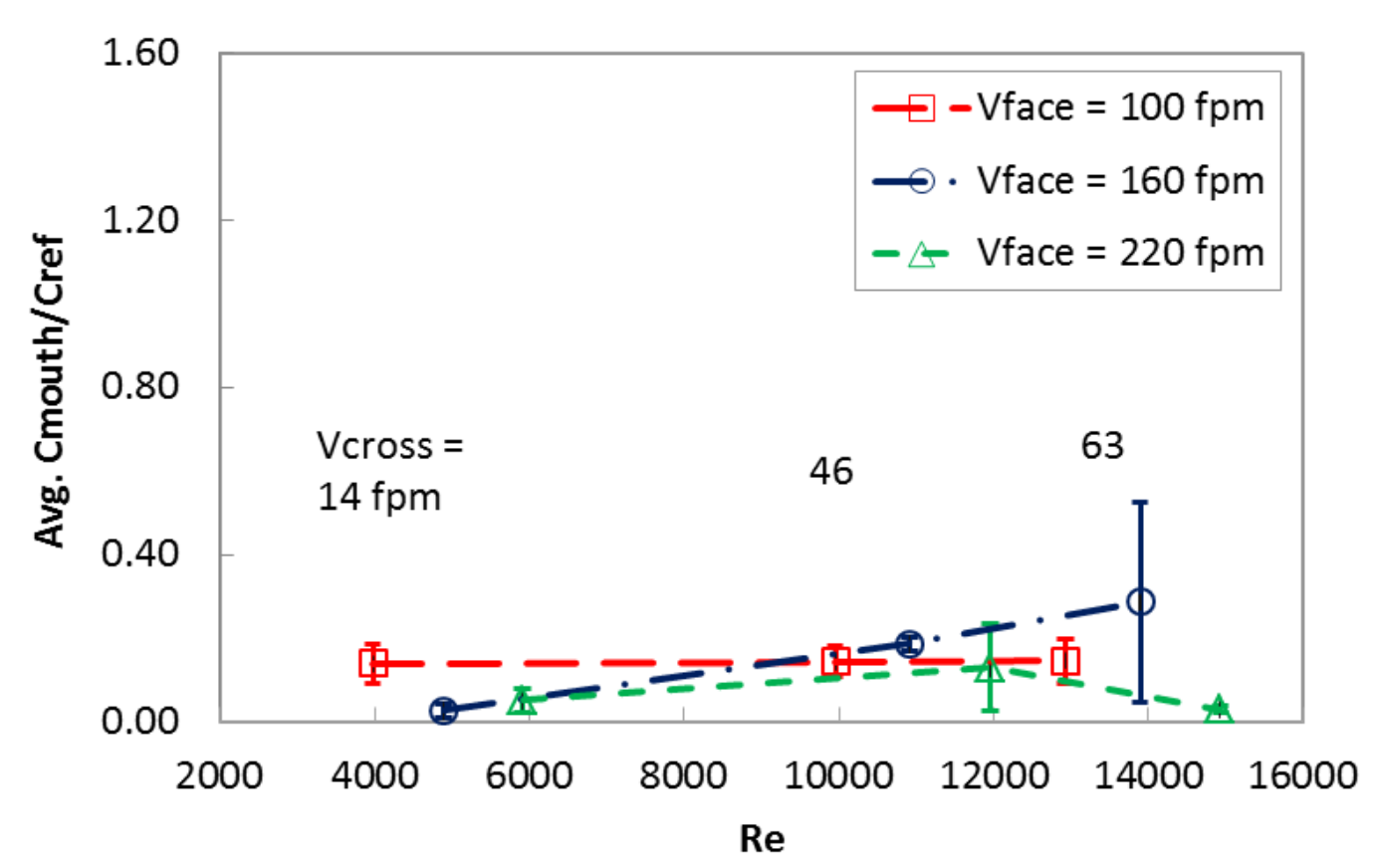

Figure 6.4 Effect of $R e$ on average $C_{m o u t h} / C_{r e f}$ for the complex manikin, $C_{r e f}=19.4$ ppm 
Another important dimensionless parameter is the Grashof number $(G r)$. It is the ratio between buoyancy force and viscous force $\left(G r=g \beta \Delta T_{\operatorname{man}} H_{\text {man }}{ }^{3} / v^{2}\right)$. The key factor of the buoyancy force is the temperature difference of the manikin's body and the ambient air $\left(\Delta T_{\text {man }}\right)$. Thus, at greater temperature differences, the contaminants trapped in the reverse flow between the manikin and the hood face are transported at a higher velocity to the breathing zone from the lower half of the worker. Temperatures on the manikin surface and the ambient air were taken after $V_{\text {face }}$ and $V_{\text {cross }}$ were set up in the wind tunnel and before sampling began (see Table 6.7). An ambient temperature of $297 \mathrm{~K}$ was considered for the calculation of the thermal expansion coefficient $(\beta)$. Grashof number are based on the vertical distance from the hood table to the manikin's top of the head $\left(H_{m a n}\right)$. The calculated Grashof numbers are shown in Table D.2 of Appendix D.

On the other hand, the effect of body heat makes the analysis more complex and at the same time more interesting due to the fact that the temperature difference between the manikin and his surrounding environment is always greater than zero $\left(\Delta T_{\text {man }}>0\right)$. This positive temperature gradient generates an upward movement of heated air due to buoyancy (Mills, 1999; Srinivas et al., 2009; $\mathrm{Hu}$ and Koochesfahani, 2011). The importance of the buoyancy force can be tested through the calculation of the Richardson number $(R i)$. The buoyancy affects the way heat is transported to the environment, which could be due to force, free, or mixed convection (force and free). Richardson number is the ratio between buoyancy 
force and inertial force $\left(R i=G r / R e^{2}\right)$. Table 6.6 shows the Richardson numbers for every combination of $V_{\text {face }}$ and $V_{\text {cross }}$ for which the manikin was tested. Figure 6.5 shows the schematic representations of the approach velocity and buoyancy.

Table 6.6 Richardson numbers for the complex manikin experiments

\begin{tabular}{|c|c|c|c|c|c|c|c|}
\hline \multirow[b]{2}{*}{$V_{\text {face }},[\mathbf{f p m}]$} & \multicolumn{6}{|c|}{$V_{\text {cross }},[\mathbf{f p m}]$} & \multirow{3}{*}{ Mean } \\
\hline & \multicolumn{2}{|c|}{14} & \multicolumn{2}{|c|}{46} & \multicolumn{2}{|c|}{63} & \\
\hline \multirow{5}{*}{100} & 10.32 & 7.27 & 2.00 & 1.33 & 1.05 & 0.79 & \\
\hline & 7.86 & 6.94 & 1.34 & 1.64 & 0.83 & 1.42 & \\
\hline & 6.98 & 5.24 & 1.24 & 1.32 & 0.32 & 1.16 & \\
\hline & & & 1.76 & 1.79 & 0.51 & & \\
\hline & 7.43 & & 1.55 & & 0.87 & & 3.28 \\
\hline \multirow{4}{*}{160} & 3.10 & 5.50 & 1.42 & 1.24 & 0.49 & 0.66 & \\
\hline & 6.41 & 7.23 & 1.11 & 1.36 & 0.82 & 0.57 & \\
\hline & 5.95 & & & & & & \\
\hline & 5.64 & & 1.29 & & 0.64 & & 2.52 \\
\hline \multirow{5}{*}{220} & 4.47 & 2.23 & 0.79 & 0.44 & 0.50 & 0.61 & \\
\hline & 2.78 & 3.68 & 1.42 & 1.03 & 0.50 & 0.40 & \\
\hline & 3.08 & 3.97 & 0.41 & 0.66 & 0.60 & 0.61 & \\
\hline & 4.77 & & 0.56 & & 0.79 & & \\
\hline & 3.57 & & 0.76 & & 0.57 & & 1.63 \\
\hline Mean & 5.55 & & 1.20 & & 0.69 & & 2.48 \\
\hline
\end{tabular}




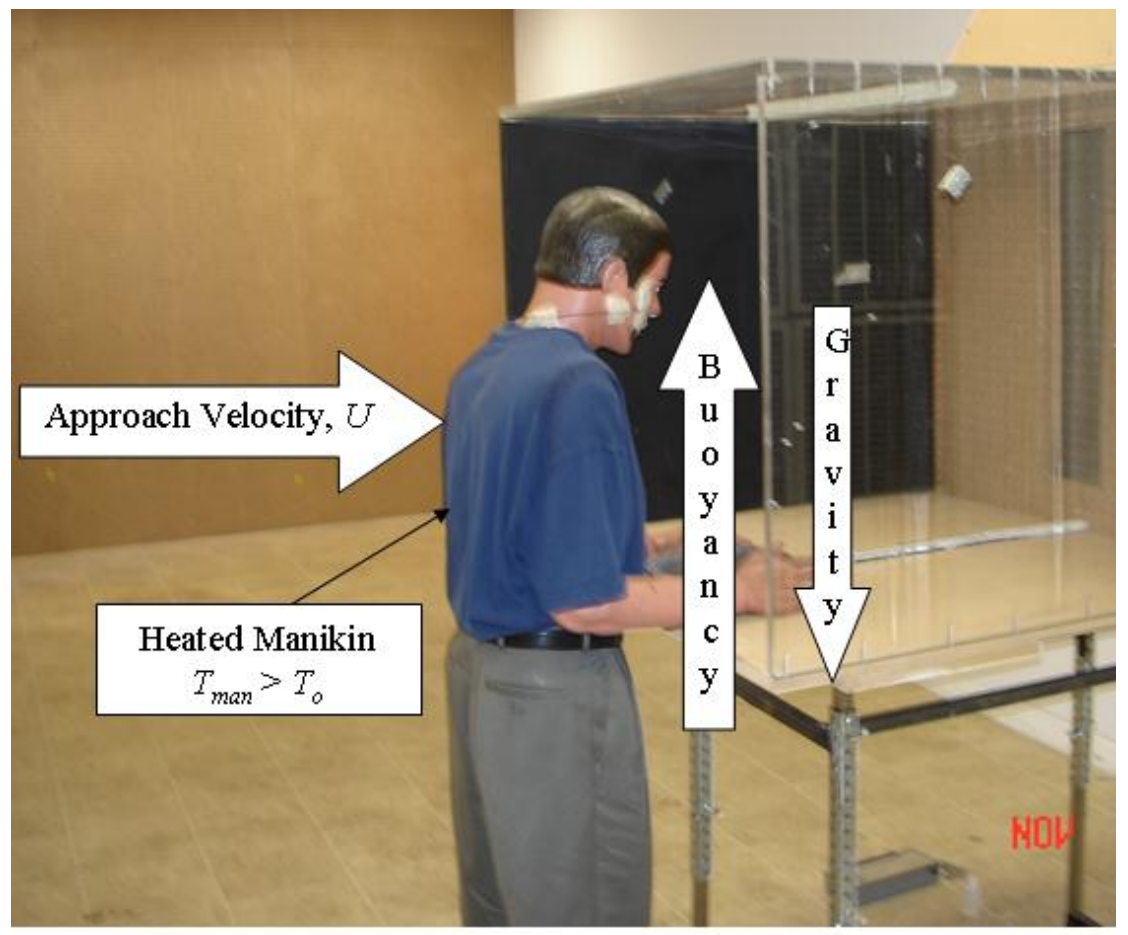

Figure 6.5 Schematic representations of the approach velocity and buoyancy around a heated complex manikin

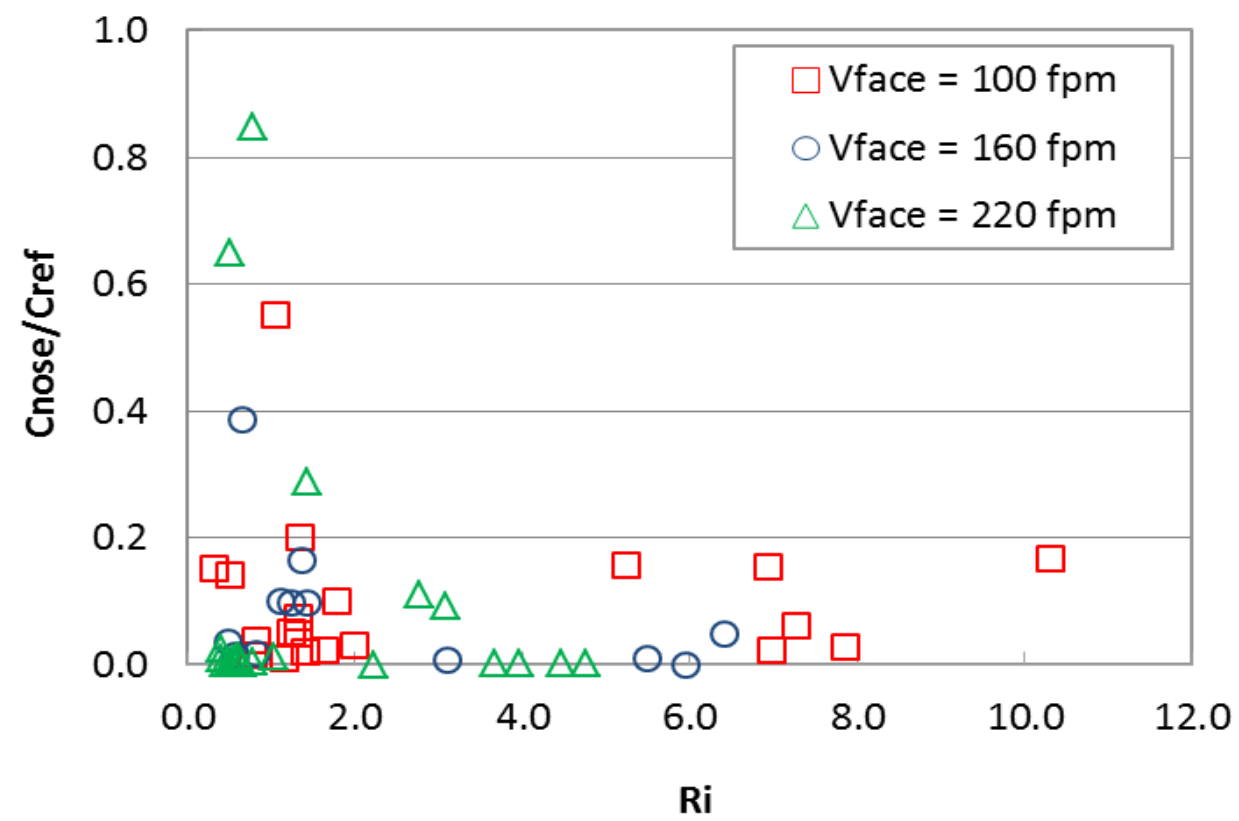

Figure 6.6 Effect of $R i$ on $C_{n o s e} / C_{r e f}$ for the complex manikin, $C_{r e f}=26.8 \mathrm{ppm}$ (No highest exposure value) 


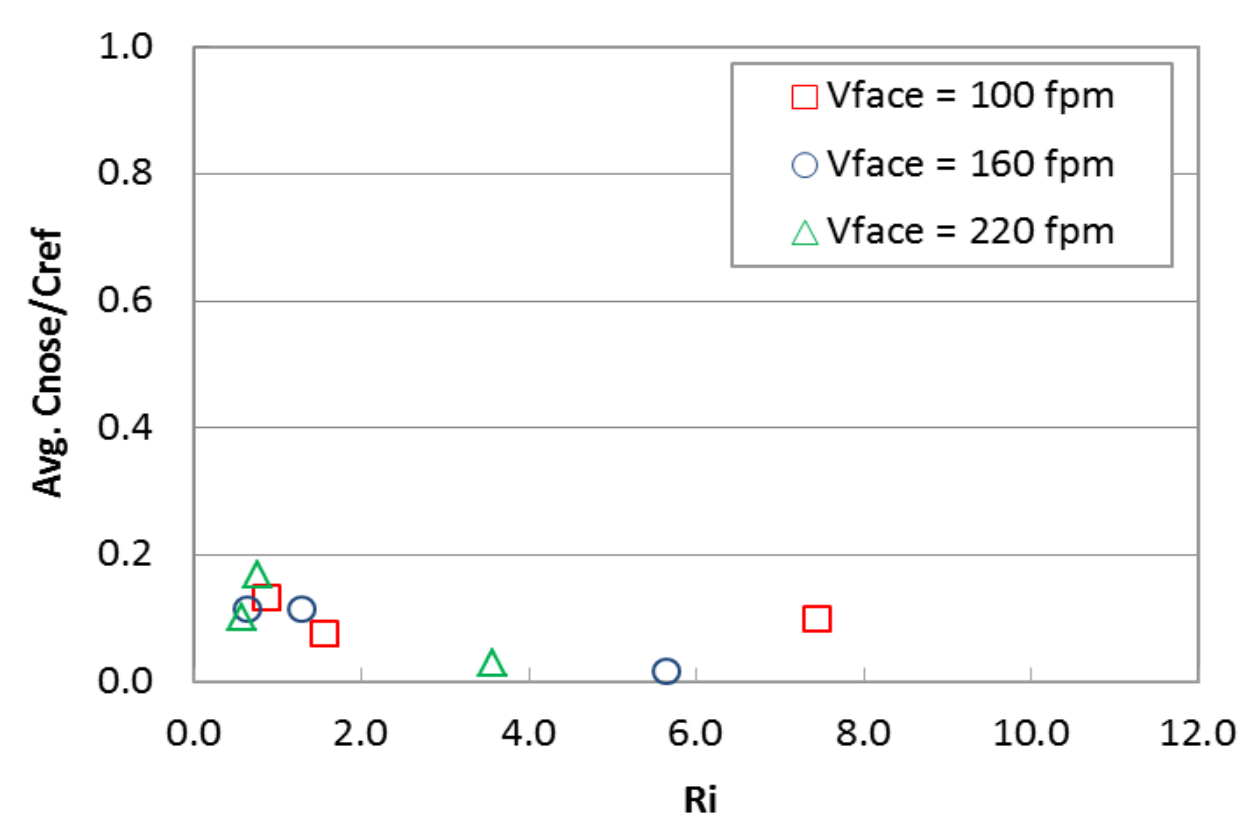

Figure 6.7 Effect of $R i$ on average $C_{n o s e} / C_{r e f}$ for the complex manikin, $C_{r e f}=26.8$ ppm (No highest exposure value)

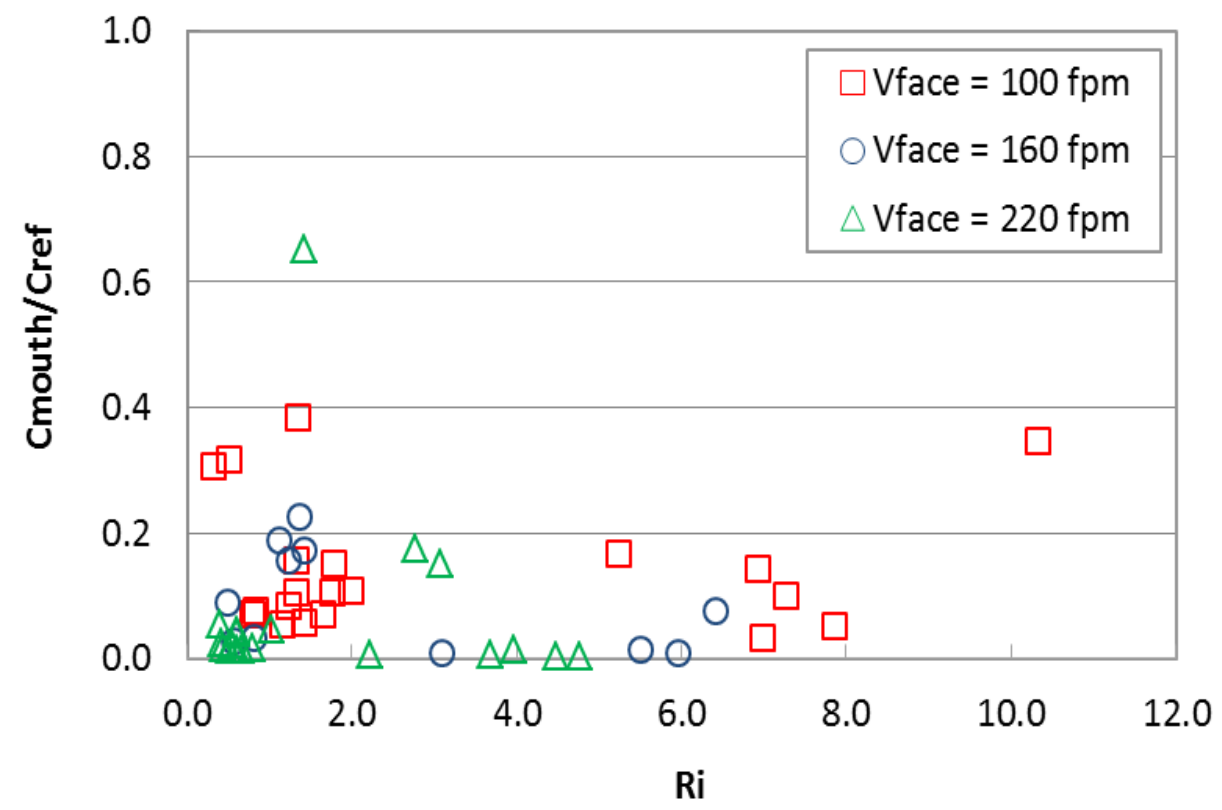

Figure 6.8 Effect of $R i$ on $C_{m o u t h} / C_{r e f}$ for the complex manikin, $C_{r e f}=19.4 \mathrm{ppm}$ (No highest exposure value) 


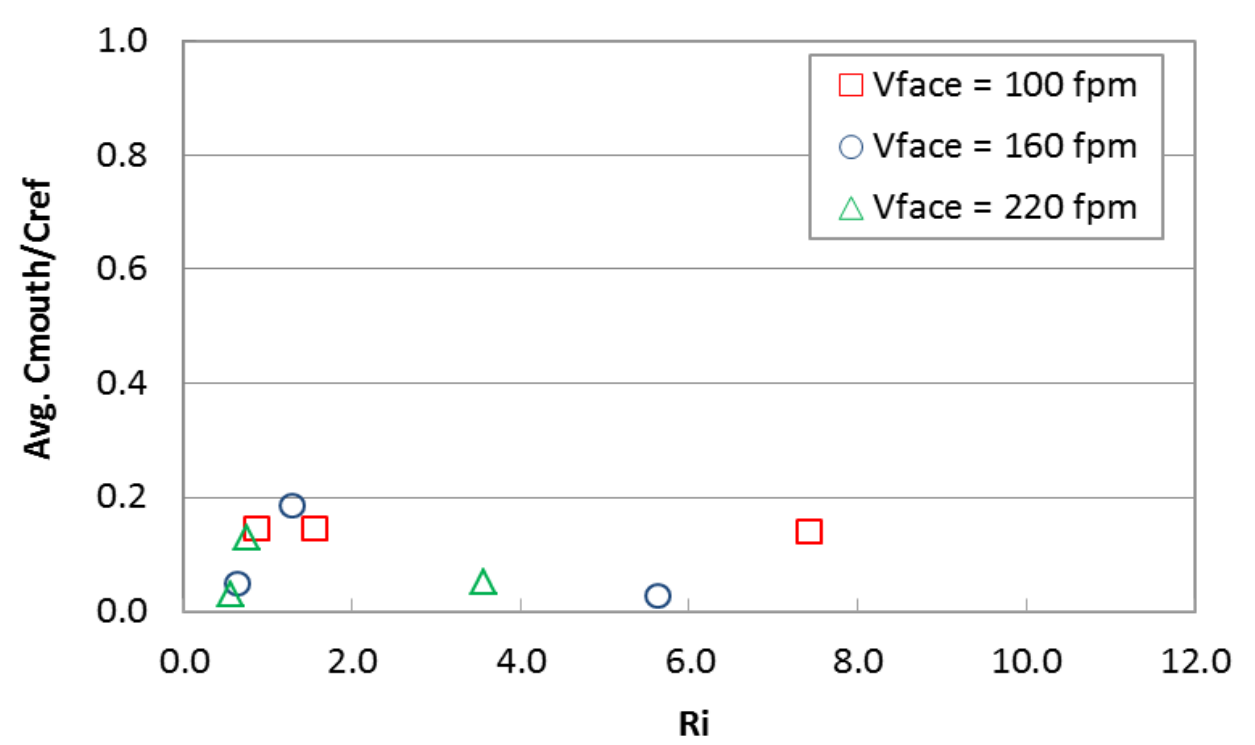

Figure 6.9 Effect of $R i$ on average $C_{\text {mouth }} / C_{r e f}$ for the complex manikin, $C_{r e f}=19.4$ ppm (No highest exposure value)

In this study, the approach velocity is perpendicular to the buoyancy and to the acceleration of gravity. Also, the Richardson number is always greater than zero $(R i>0)$. Heat is transported to the environment purely by force convection if the Richardson number is lower than 0.53 (Oosthuizen and Madan, 1971). For Richardson numbers greater than $16(R i>16)$, heat is released from the manikin mainly by natural convection; force convection is deemed negligible (Brohus, 1997). The range between these two Richardson numbers is called "mixed convection" where in both forced and free convection are relevant in the heat transfer process.

As can be seen in Table 6.6, heat transfer is predominantly by mixed convection $(0.53<R i<16)$ at all levels of $V_{\text {face }}$ and $V_{\text {cross }}$. A few $R i$ values were in 
the forced convection regime at $V_{\text {cross }}=46$ and $63 \mathrm{fpm}(R i<0.53)$, as it is shown in Table 6.6. Table 6.6 shows that buoyancy is more important in heat releases from the manikin and in worker exposures at low $V_{\text {cross }}\left(V_{\text {cross }}=14 \mathrm{fpm}\right)$. In other words, buoyancy is important at low approach velocities or low Reynolds numbers $(R e<$ 6000). For the average of $R i$, heat transfer is purely due to mixed convection with higher values at low $V_{\text {cross }}$, as can be seen in Table 6.6. This finding is consistent with previous studies ( $\mathrm{Li}$ et al, 2007; Karaismail, 2011) even though a free stream experimental numerical simulation was performed by Li et al., 2007.

The effect of Richardson numbers on dimensionless worker exposure at the nose and mouth can also be observed in Figures 6.6 to 6.9. These plots suggest that a critical Richardson number $\left(R i_{c r}\right)$ exists at $R i$ greater than 0.5 and lower than 1.5 $(0.5<R i<1.5)$. From Figures 6.7 and $6.9, R i_{c r}$ possibly would be around 1.0 $\left(R i_{c r} \sim 1.0\right)$. As can be seen in Figures 6.7 and 6.9 , for $R i<R i_{c r}$ turbulent mixing occurs and the subject's exposure increased, demonstrating that turbulent mixing is an effective mechanism to transport contaminants to the breathing zone. When $R i>$ $R i_{c r}$, turbulence and exposure decrease. However, at $R i>10$ flow can be unstable as well (see Figure 6.8 at $V_{\text {face }}=100 \mathrm{fpm}$ ). For clarity, the maximum dimensionless values (1.0) were removed from the figures.

\subsubsection{Effect of $V_{\text {face }}$ on $C_{\text {nose }}$ and $C_{\text {mouth }}$}

As many as $90 \%$ of the values of $C_{\text {nose }}$ and $96 \%$ of the results of $C_{\text {mouth }}$ are under $10 \mathrm{ppm}$, as can be seen in Figures 6.10 and 6.11. These complex manikin results are far below those obtained with the simple manikin. It is reasonable to 
suppose that the fact of using an anthropometric, heated, and breathing manikin caused these lower concentrations. This agrees with previous study by Li et al. (2007), which showed a decreasing exposure when a heated manikin was used in a free stream experimental setup, but disagree with Karaismail (2011), which showed the opposite outcome.

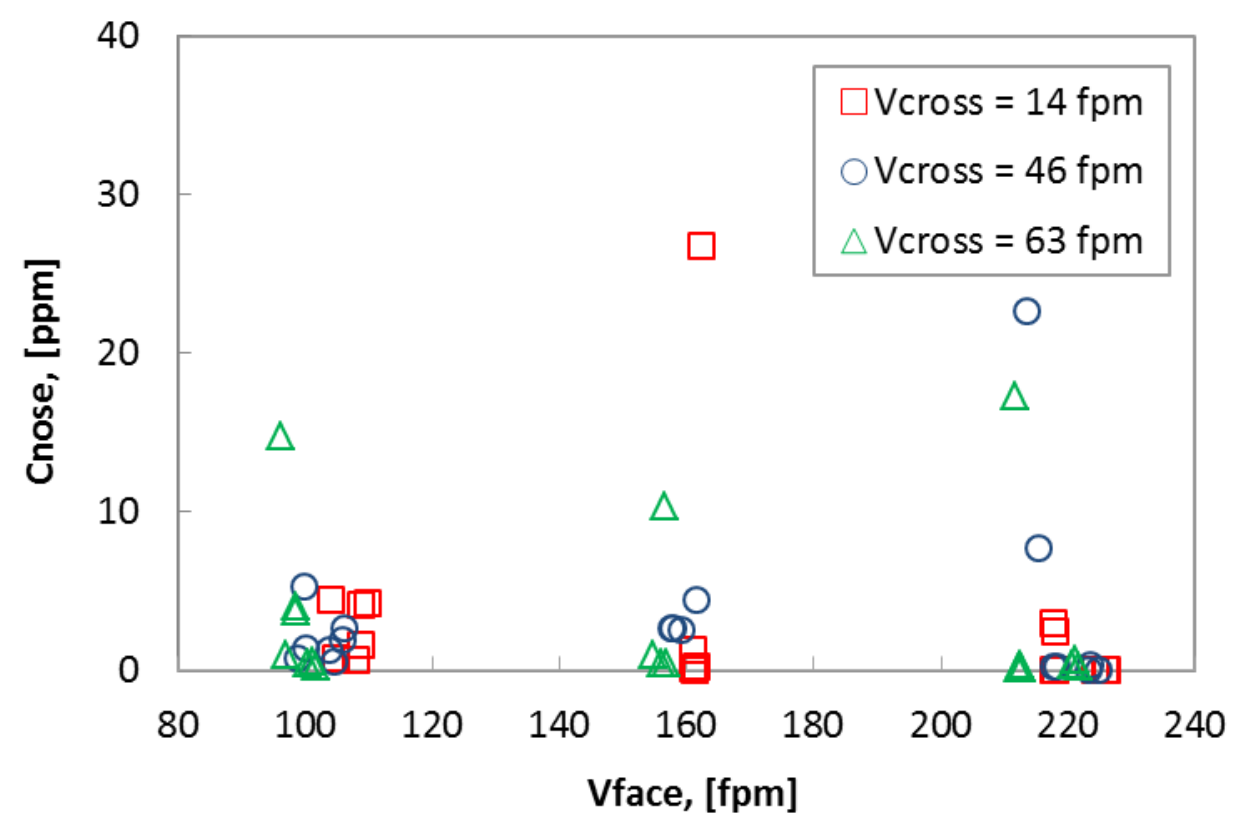

Figure 6.10 Effect of $V_{\text {face }}$ on $C_{\text {nose }}$ for the complex manikin 


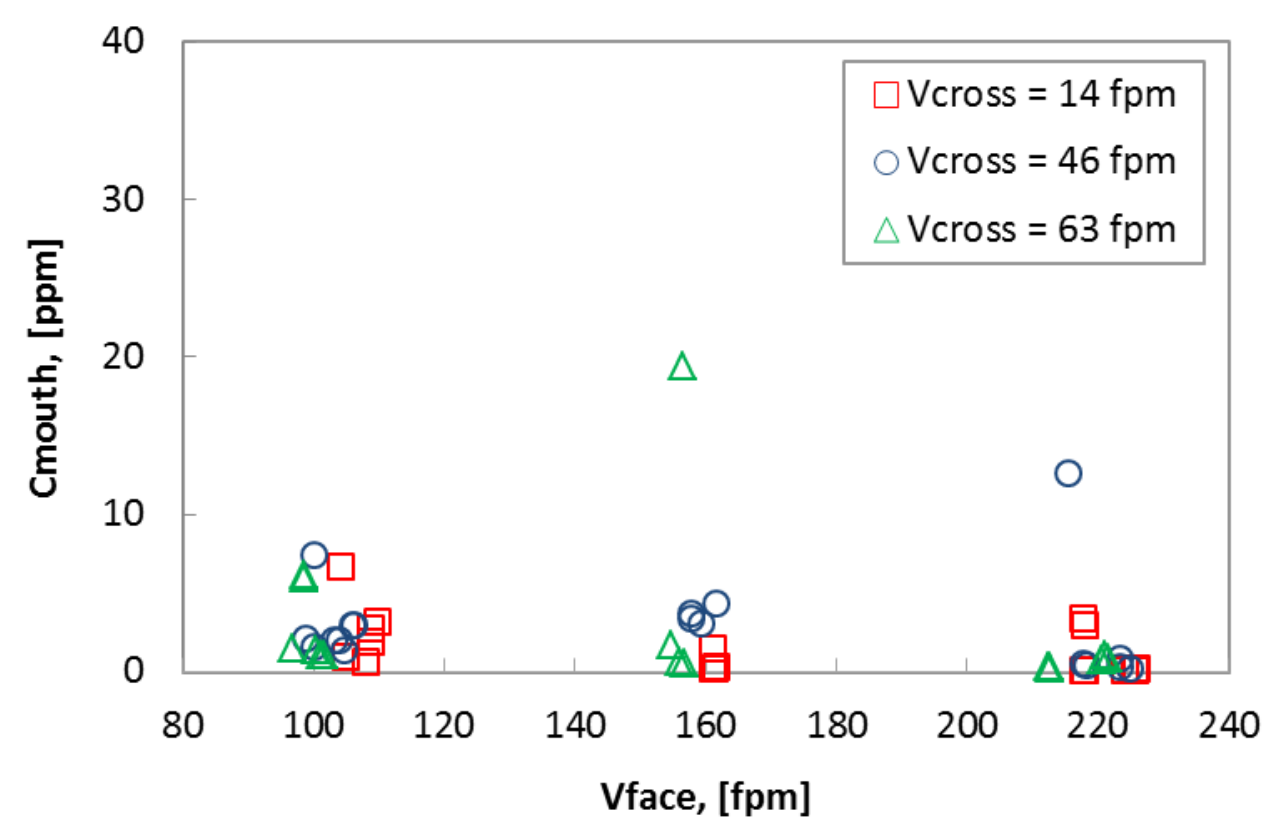

Figure 6.11 Effect of $V_{\text {face }}$ on $C_{\text {mouth }}$ for complex manikin

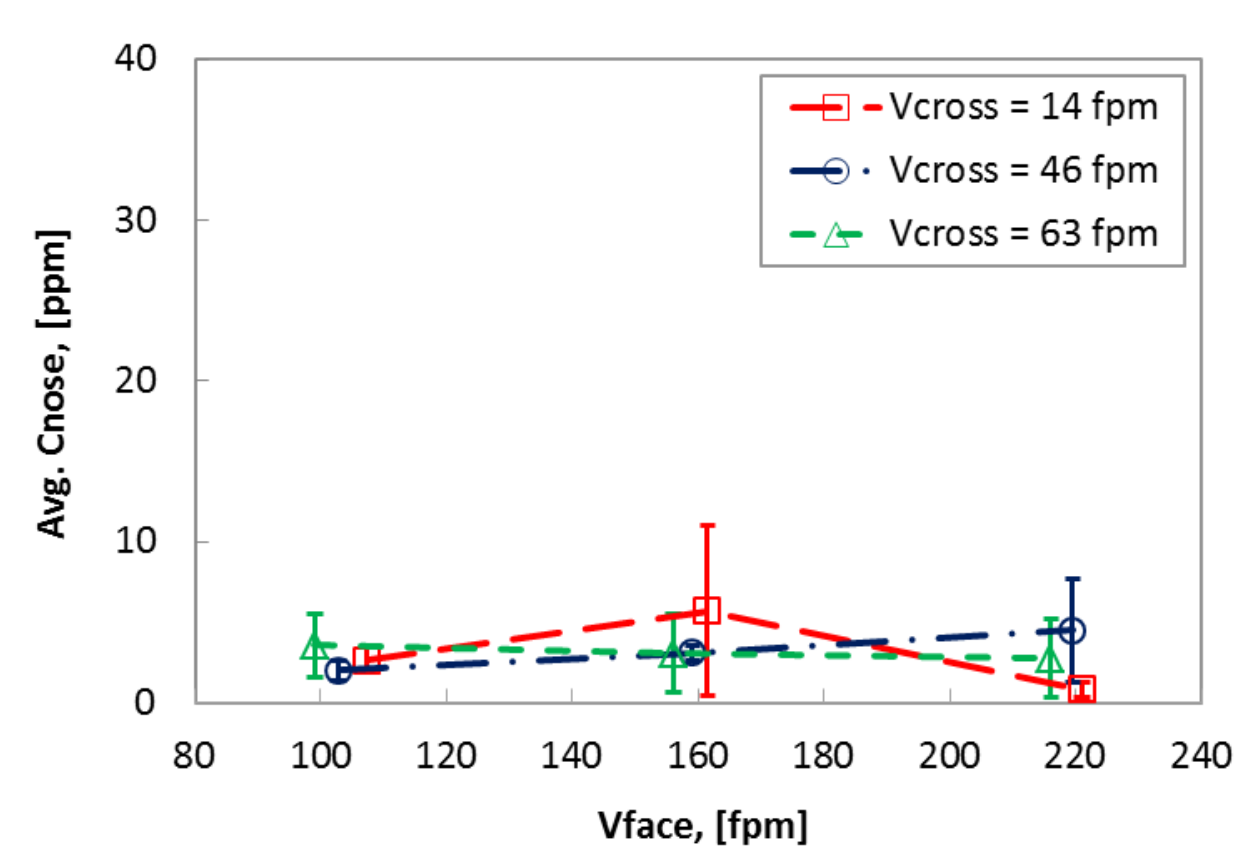

Figure 6.12 Effect of $V_{\text {face }}$ on average $C_{\text {nose }}$ for the complex manikin 


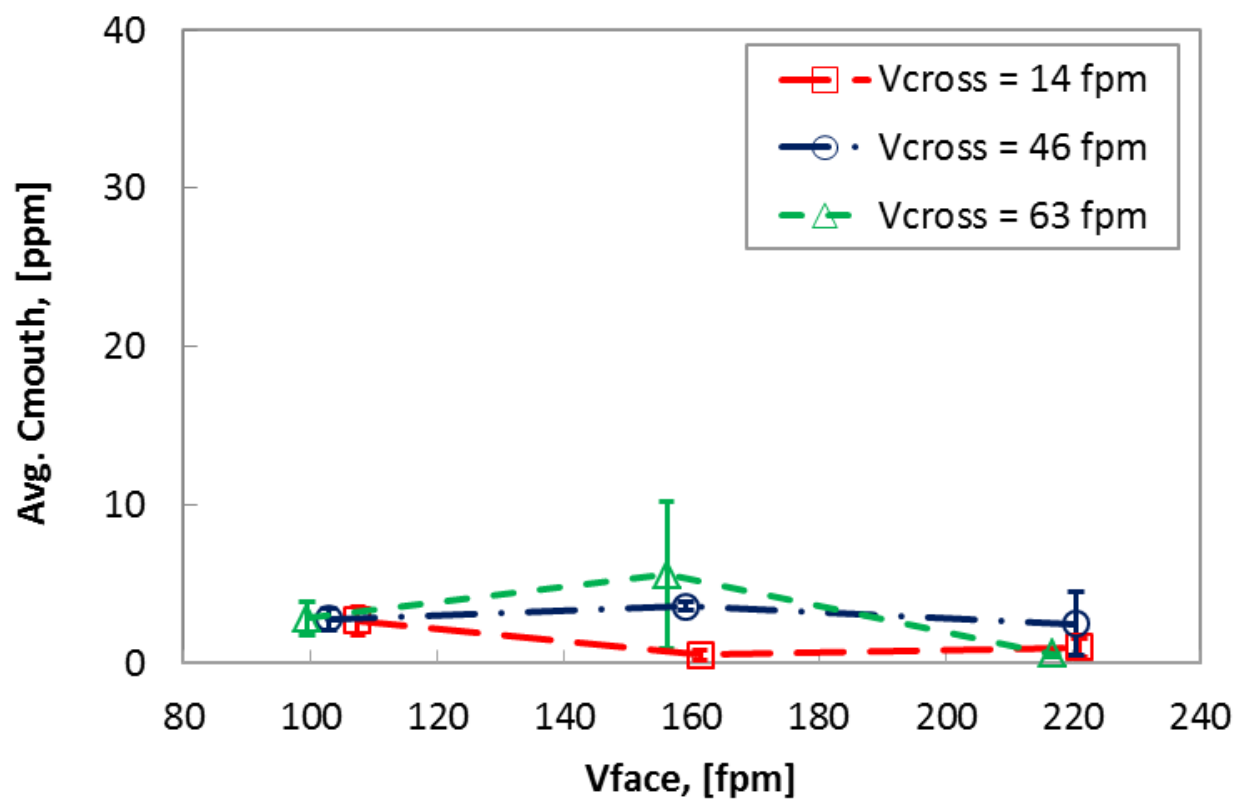

Figure 6.13 Effect of $V_{\text {face }}$ on average $C_{\text {mouth }}$ for the complex manikin

A clear pattern of the effect of $V_{\text {face }}$ on the average $C_{\text {nose }}$ is shown in Figure 6.12. At $V_{\text {face }}=160 \mathrm{fpm}$ and $V_{\text {cross }}=14 \mathrm{fpm}$, a peak exposure at the nose is observed, possibly due to the recirculation flow and the heat transfer from the manikin to the surrounding environment through mixed convection $(R i=5.64)$. It appears that buoyancy contributed to the transport of contaminants to the breathing zone, increasing the worker's exposure. At $V_{\text {face }}>160 \mathrm{fpm}$, the exposure dropped considerably, reaching its lowest value at $V_{\text {face }}=220 \mathrm{fpm}$ and $V_{\text {cross }}=14 \mathrm{fpm}$, which is possibly explained by the increased forced convection into the hood $(R i=$ 3.57).

However, the effect of $V_{\text {face }}$ on the average $C_{\text {mouth }}$ (Figure 6.13) shows the lowest exposure at the same combination of velocities $\left(V_{\text {face }}=160 \mathrm{fpm}\right.$ and $V_{\text {cross }}=$ $14 \mathrm{fpm})$. This result perhaps can be explained by the random behavior of 
contaminants in the breathing zone. In addition, a peak exposure for $C_{\text {mouth }}$ is displayed at $V_{\text {face }}=160 \mathrm{fpm}$ and $V_{\text {cross }}=63 \mathrm{fpm}$ (Figure 6.13). At this combination of velocities, the heat transfer is carried out by free and forced convection $(R i=$ 0.64). It is very likely that the recirculation zone in the wake of the manikin affects the breathing zone, thereby increasing the manikin's exposure.

Logarithmic transformations of exposure data were done to obtain a roughly linear model with model errors normally distributed (Figures 6.14 and 6.15). In addition, a roughly linear pattern can be seen for $V_{\text {face }}$ in both $\log C_{\text {nose }}$ and $\log$ $C_{\text {mouth }}$ (Figures 6.16 and 6.17). It appears that at $V_{\text {face }}=160 \mathrm{fpm}$ and $V_{\text {cross }}=14,46$, and $63 \mathrm{fpm}$, there is a slight spread of log exposure, possibly due to the effects of heat release from the manikin to the environment through mixed convection $(0.53<$ $R i>16.0)$.

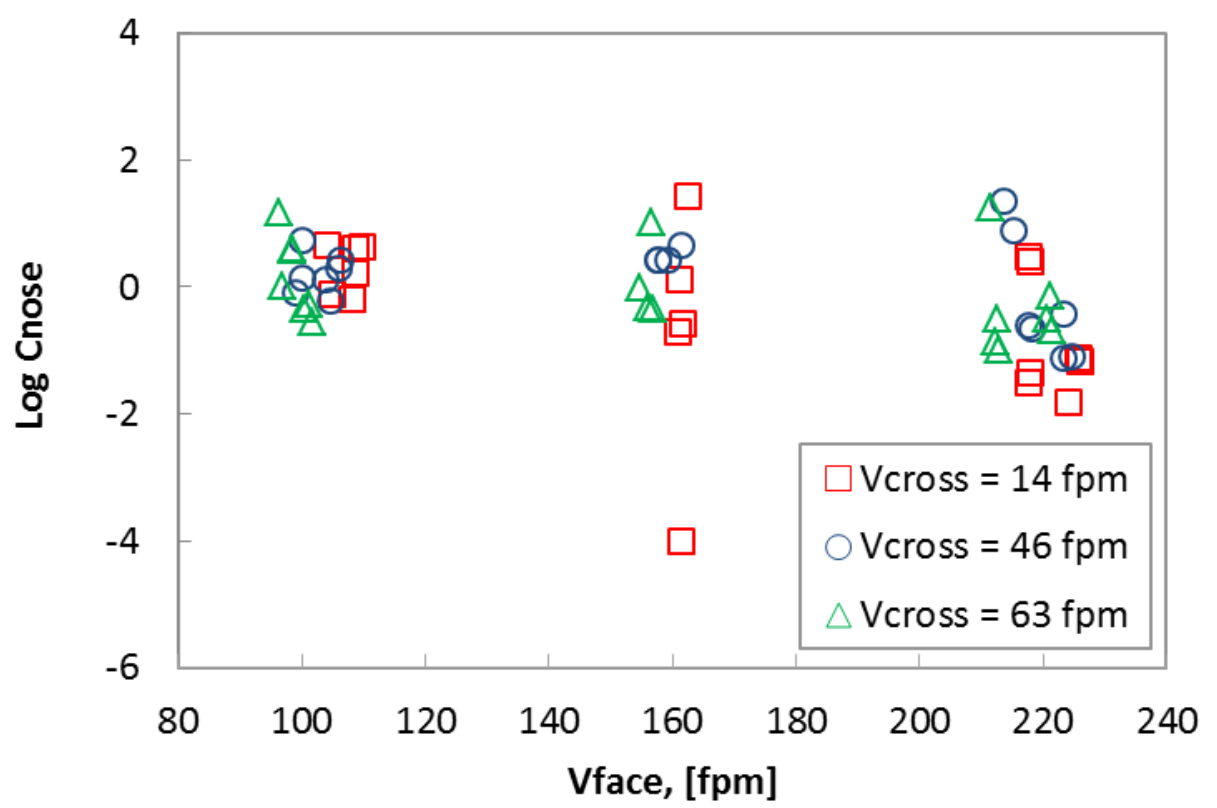

Figure 6.14 Effect of $V_{\text {face }}$ on $\log C_{\text {nose }}$ for the complex manikin 


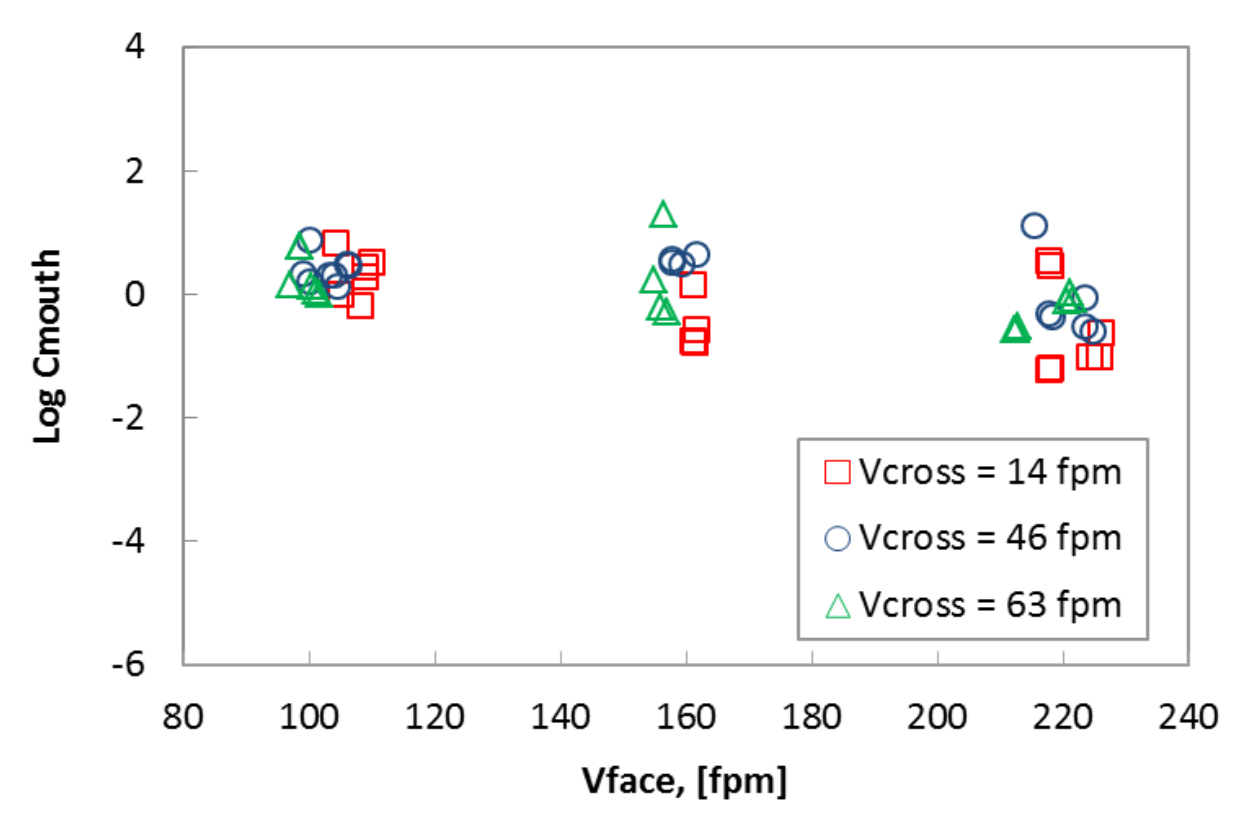

Figure 6.15 Effect of $V_{\text {face }}$ on Log $C_{\text {mouth }}$ for the complex manikin

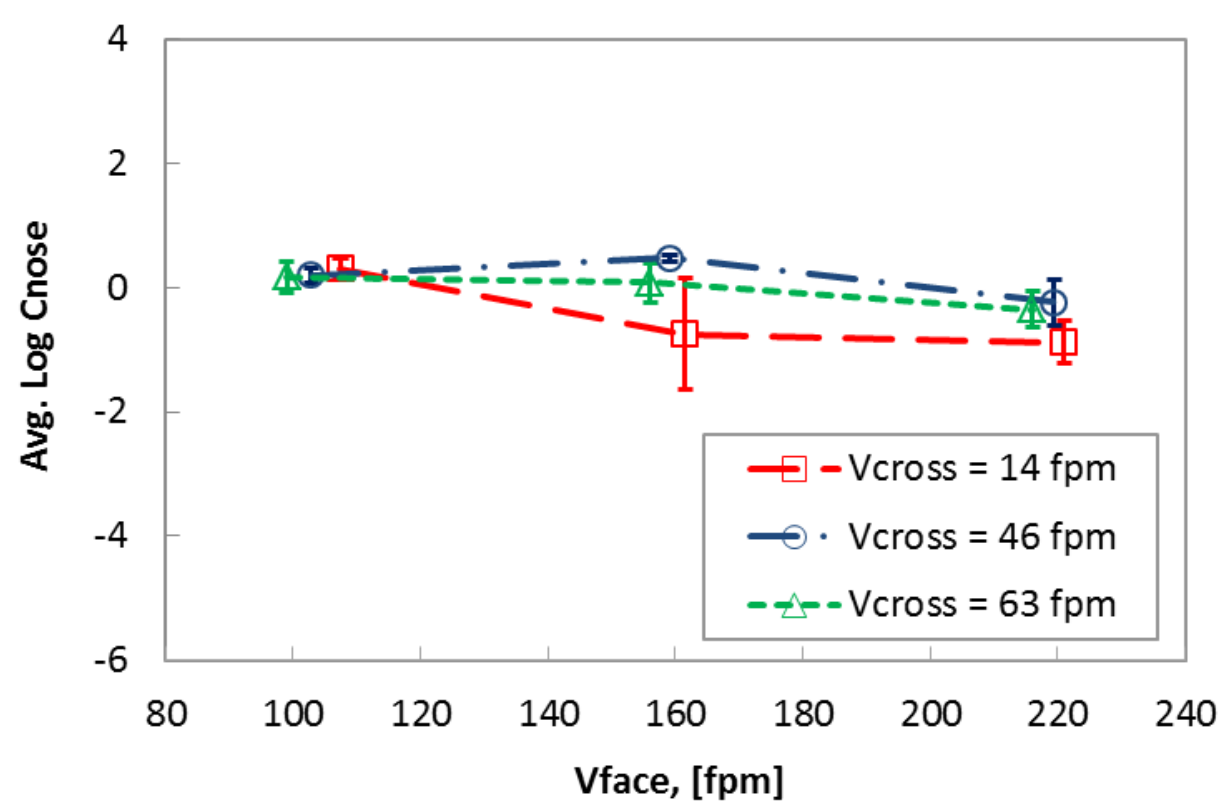

Figure 6.16 Effect of $V_{\text {face }}$ on average Log $C_{\text {nose }}$ for complex manikin 


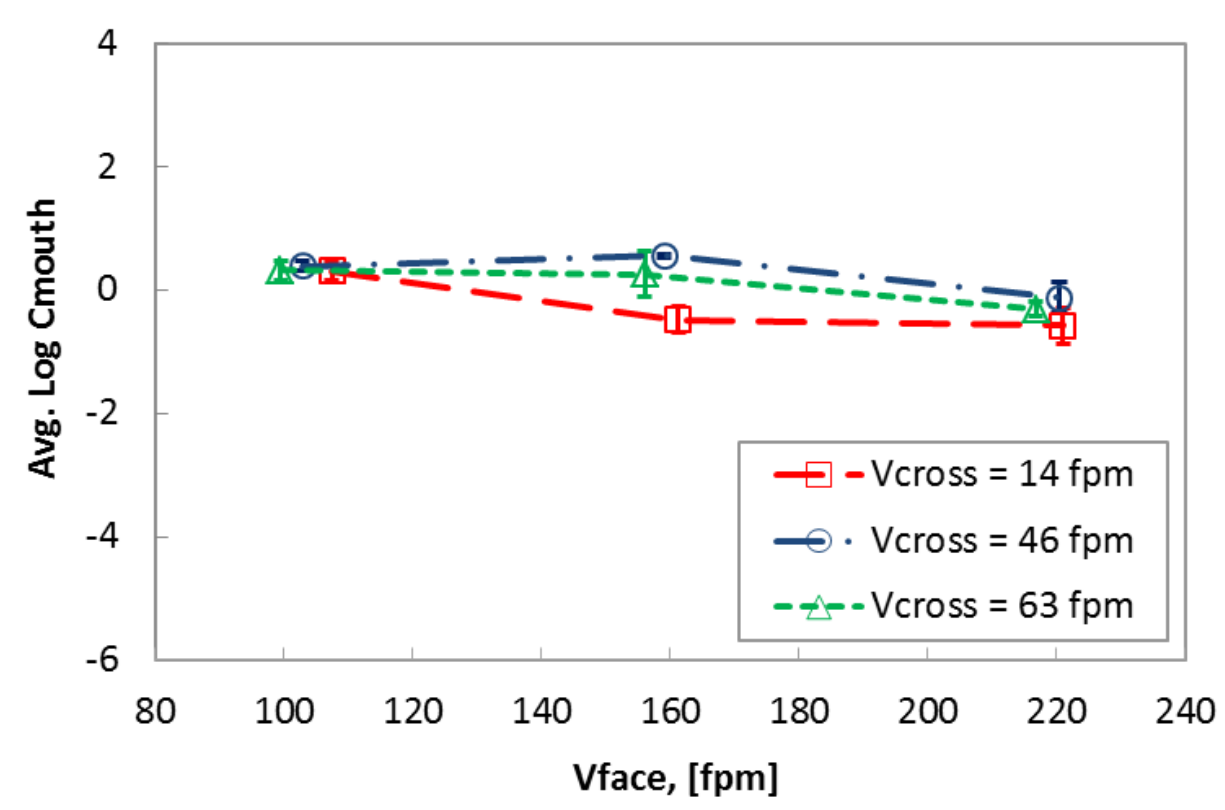

Figure 6.17 Effect of $V_{\text {face }}$ on average $\log C_{\text {mouth }}$ for complex manikin

\subsubsection{Effect of $V_{\text {cross }}$ on $C_{\text {nose }}$ and $C_{\text {mouth }}$}

Even though previous research established that $V_{\text {cross }}$ increased workers' exposures (Guffey et al., 2001; Caplan and Knutson, 1982a), the present study found that it is not completely true when the performance of a benchtop enclosing hood was tested using a complex manikin. This behavior was also found in previous enclosing hood studies by He (2010) and Karaismail (2011). In an experimental study using the same apparatus as this study, He (2010) found that when $V_{\text {cross }}$ increased, the worker's exposure decreased. Likewise, Karaismail (2011) using a CFD study of the same apparatus found an exposure reduction when $V_{\text {cross }}$ hit the side orientation of the manikin rather than the back orientation. Scatter plots of the effect of $V_{\text {cross }}$ on $C_{\text {nose }}$ and $C_{\text {mouth }}$ are shown in Figure 6.18 and 6.19. 


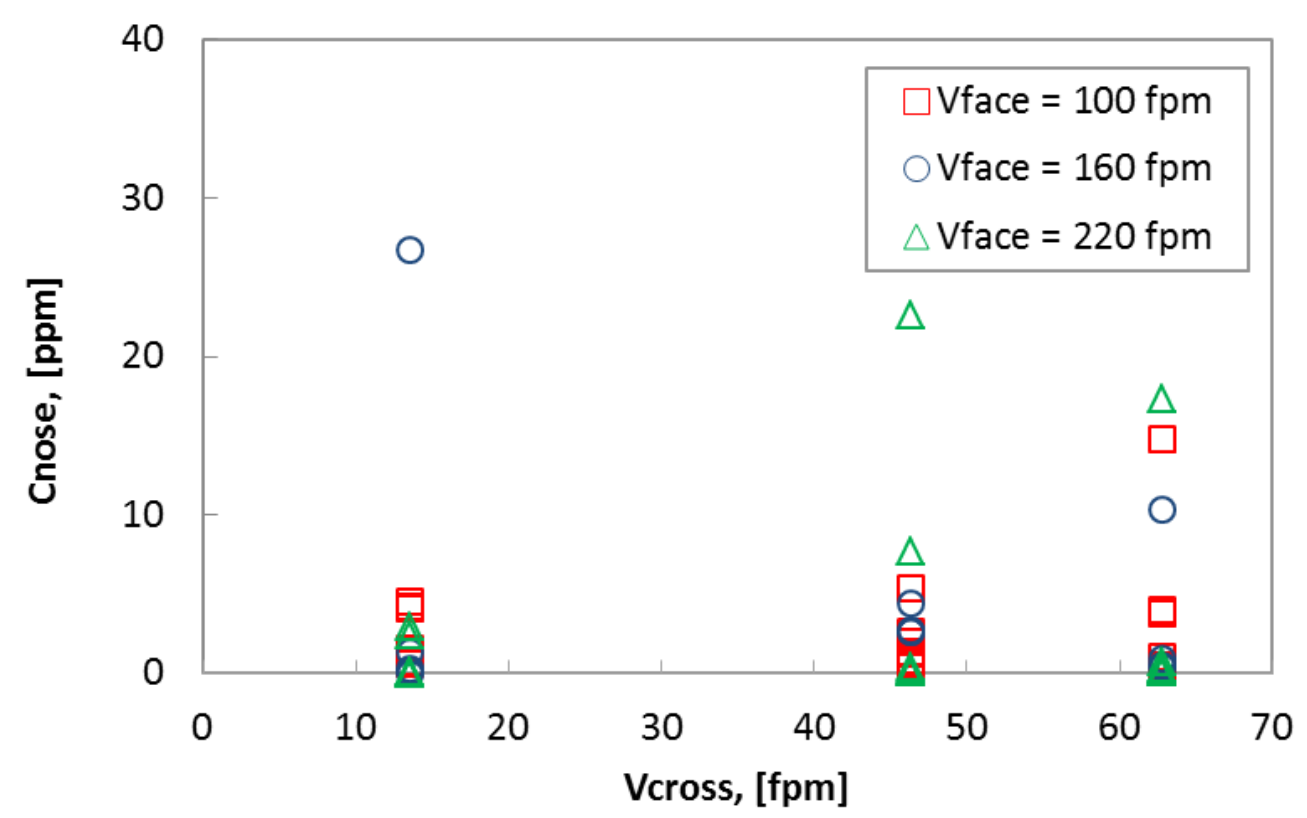

Figure 6.18 Effect of $V_{\text {cross }}$ on $C_{\text {nose }}$ for the complex manikin

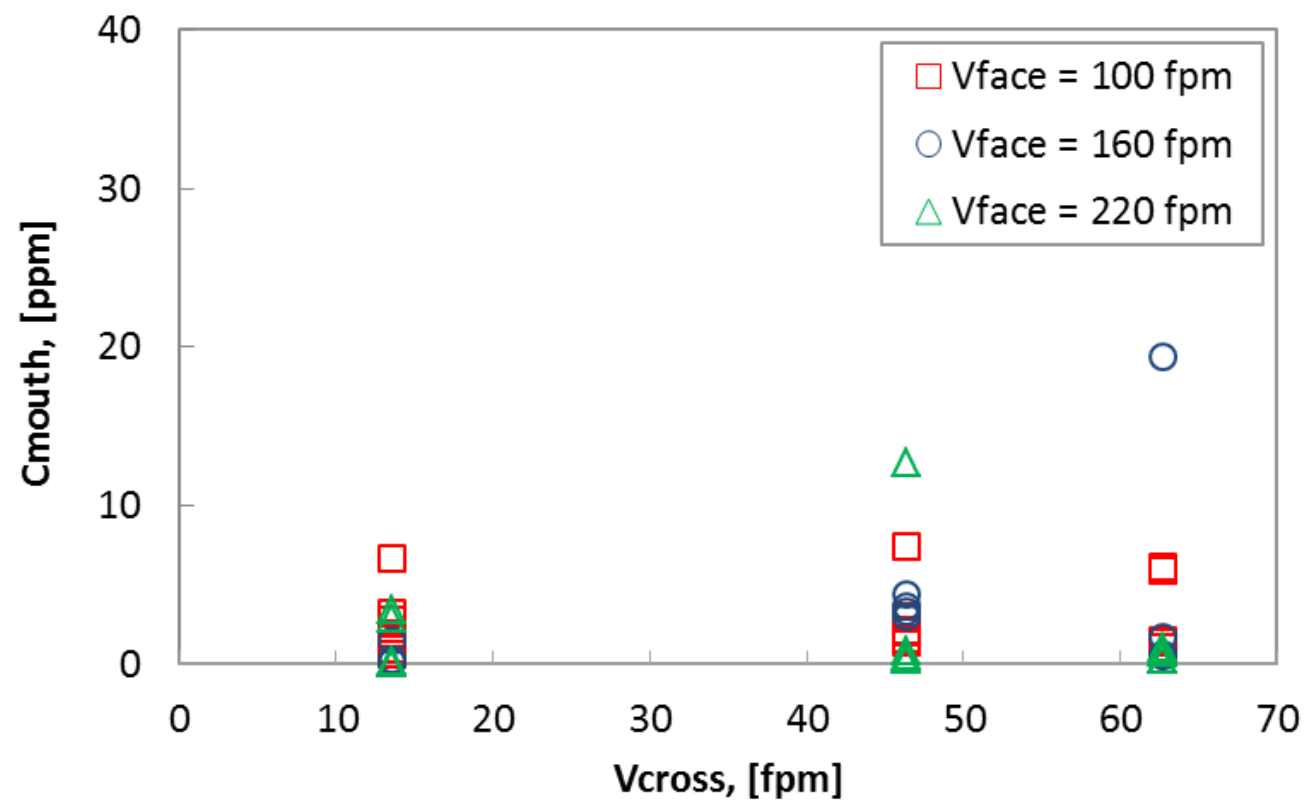

Figure 6.19 Effect of $V_{\text {cross }}$ on $C_{\text {mouth }}$ for the complex manikin 


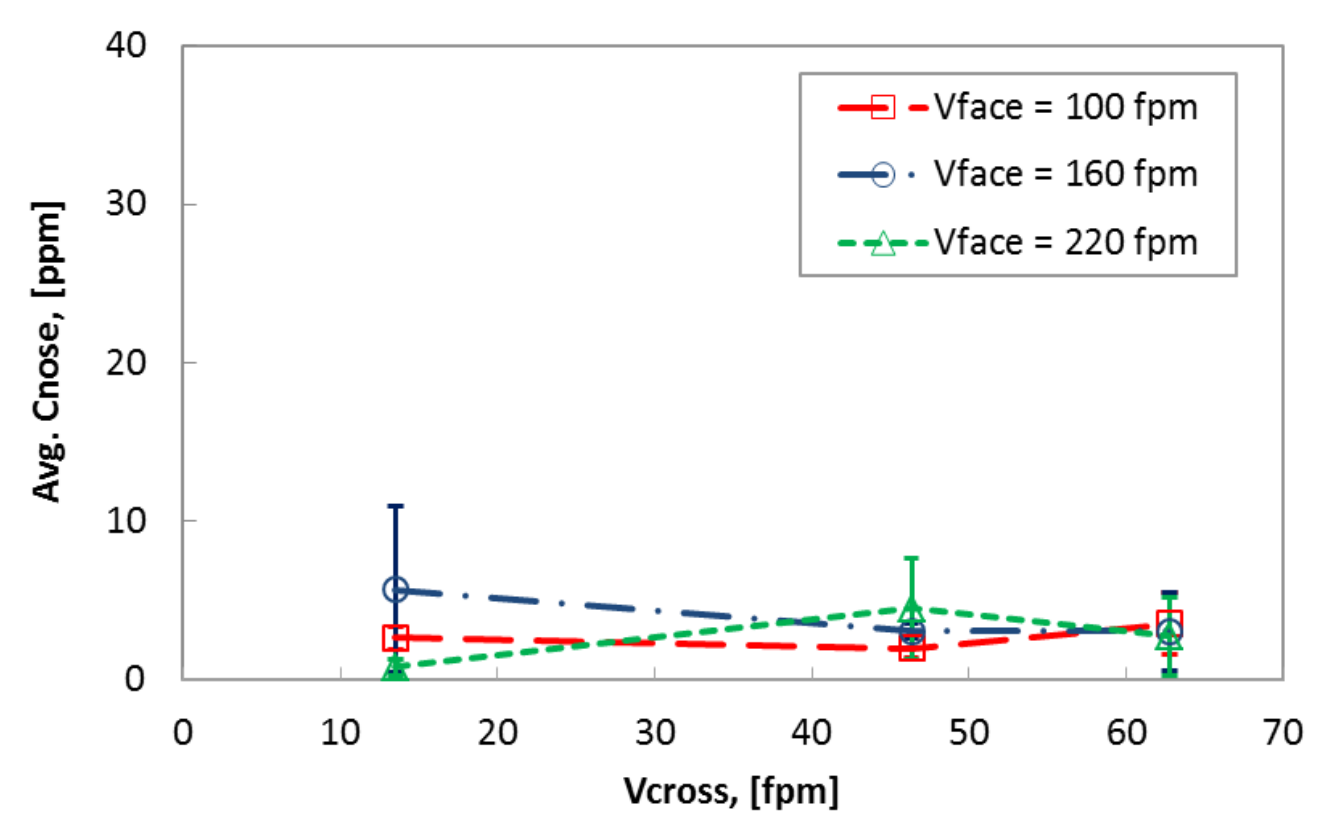

Figure 6.20 Effect of $V_{\text {cross }}$ on average $C_{\text {nose }}$ for the complex manikin

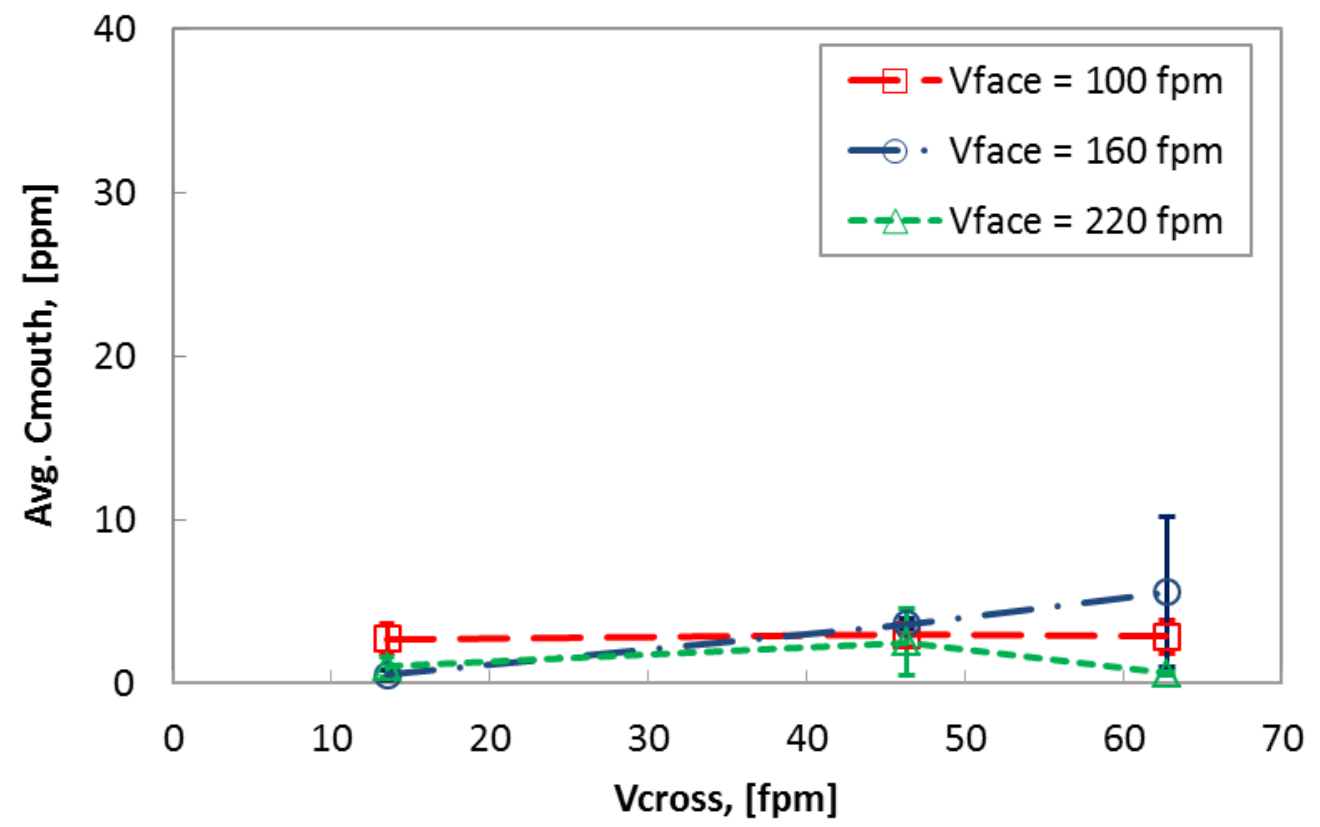

Figure 6.21 Effect of $V_{\text {cross }}$ on average $C_{\text {mouth }}$ for the complex manikin 
After an initial wide spread of average $C_{\text {nose }}$ at the lowest tested $V_{\text {cross }}(14$ fpm), all concentrations converge at lower values at the higher tested $V_{\text {cross }}$ (63 fpm), as it is displayed in Figure 6.20. This improvement in average $C_{\text {nose }}$ as $V_{\text {cross }}$ increases agrees with previous studies by He (2010) and Karaismail (2011). At $V_{\text {cross }}=46 \mathrm{fpm}$ and $V_{\text {face }}=220 \mathrm{fpm}$, a peak exposure can be seen, possibly due to the recicurlation flow in the wake of the manikin (Figure 6.20). Heat is released from the manikin to the environment mainly through mixed convection $(R i=0.76)$ at this velocity combination. However, the manikin's exposures $\left(C_{\text {mouth }}\right)$ spread out at a higher $V_{\text {cross }}(63 \mathrm{fpm})$. It seems likely that not just the unstable flow in the wake of the manikin affect the exposure but also the unbalanced desing (Figure 6.21).

The logarithmic transformation of the exposures at the nose and mouth shows a roughly linear pattern with concentration values at both sides of 0 value (Figures 6.22 and 6.23). These almost linear behaviors are better appreciated in the average plots of log transformations (Figures 6.24 and 6.25). It can be seen that the effect of $V_{\text {cross }}$ at fixed $V_{\text {face }}=220 \mathrm{fpm}$ are negative values because the log exposures were calculated from concentrations lower than the unit (Figures 6.24 and 6.25). 


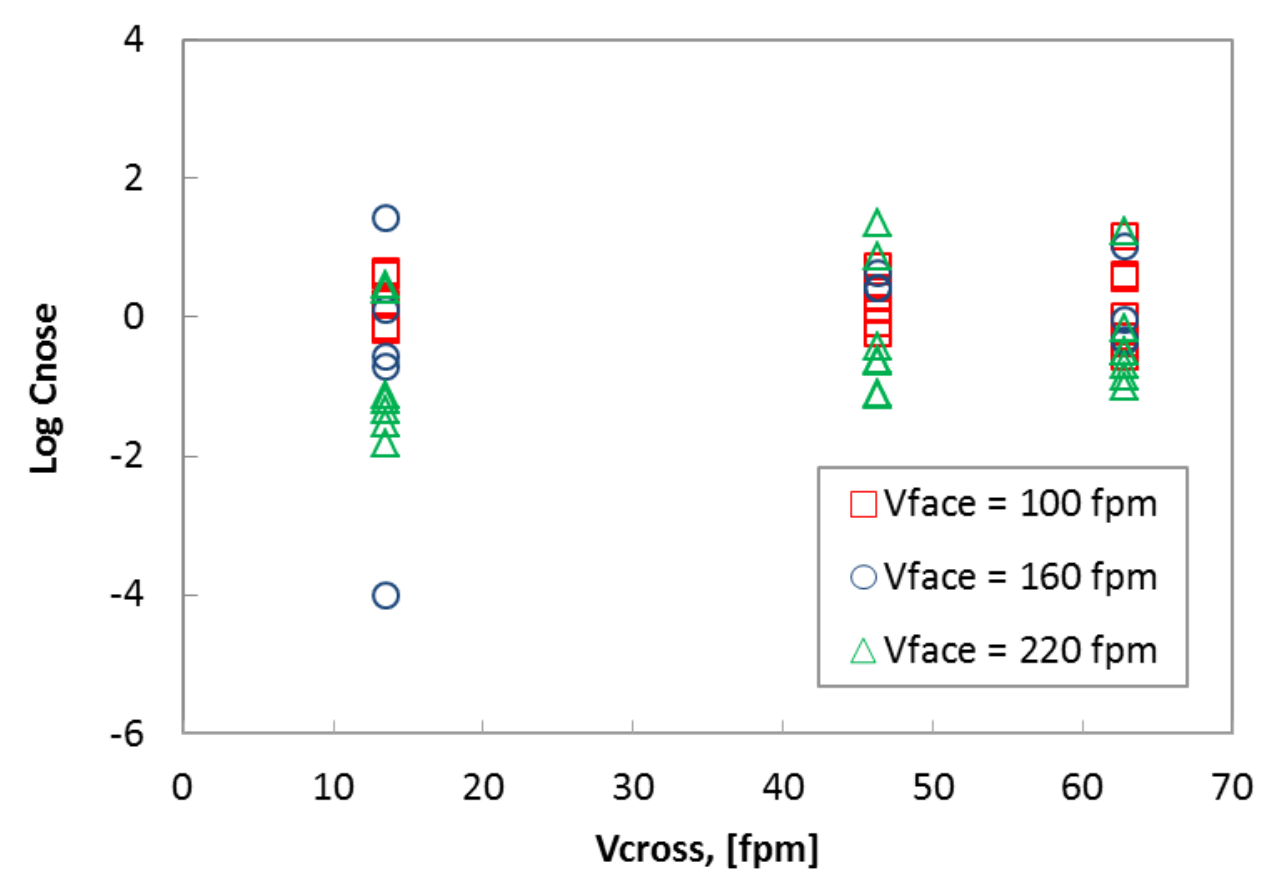

Figure 6.22 Effect of $V_{\text {cross }}$ on $\log C_{\text {nose }}$ for the complex manikin

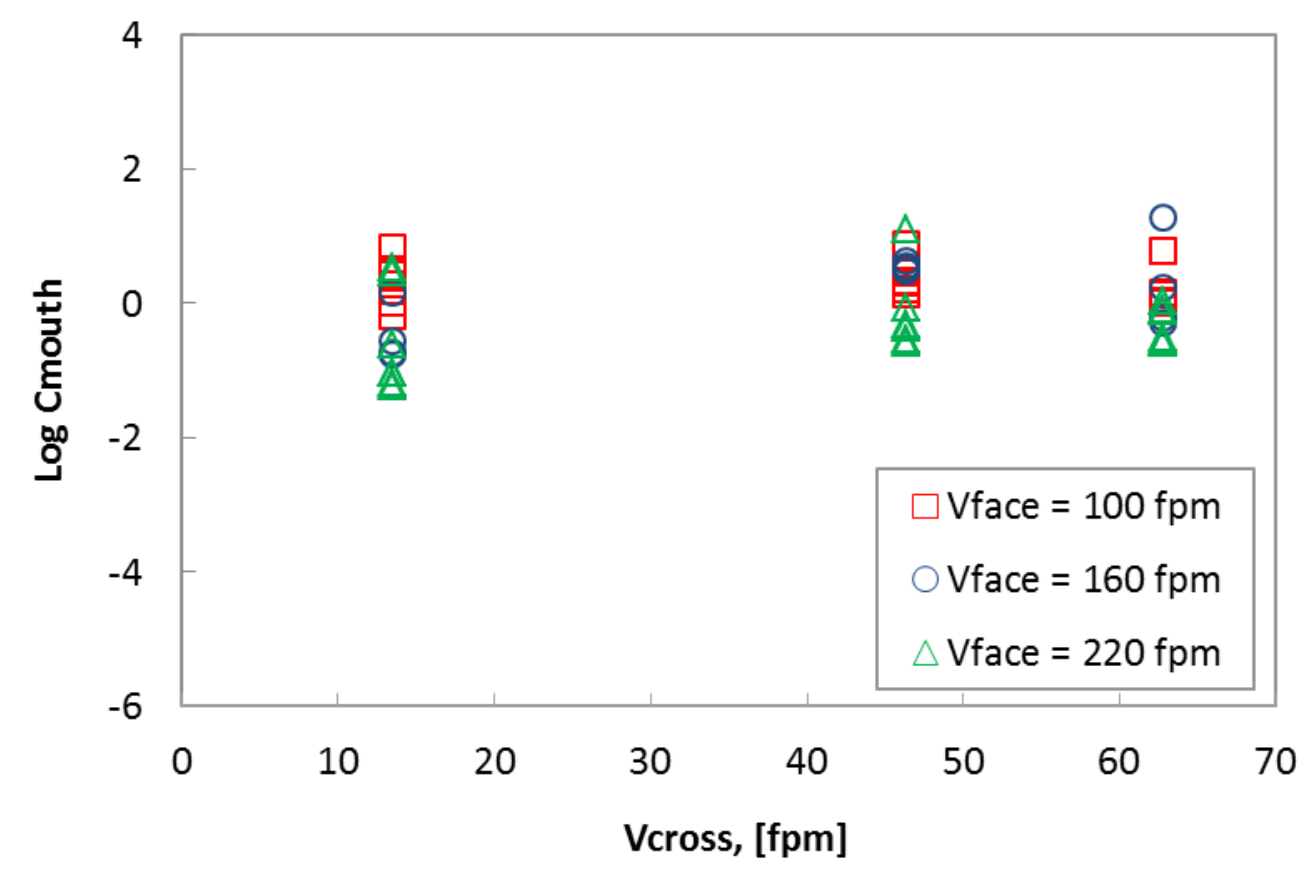

Figure 6.23 Effect of $V_{\text {cross }}$ on $\log C_{\text {mouth }}$ for the complex manikin 


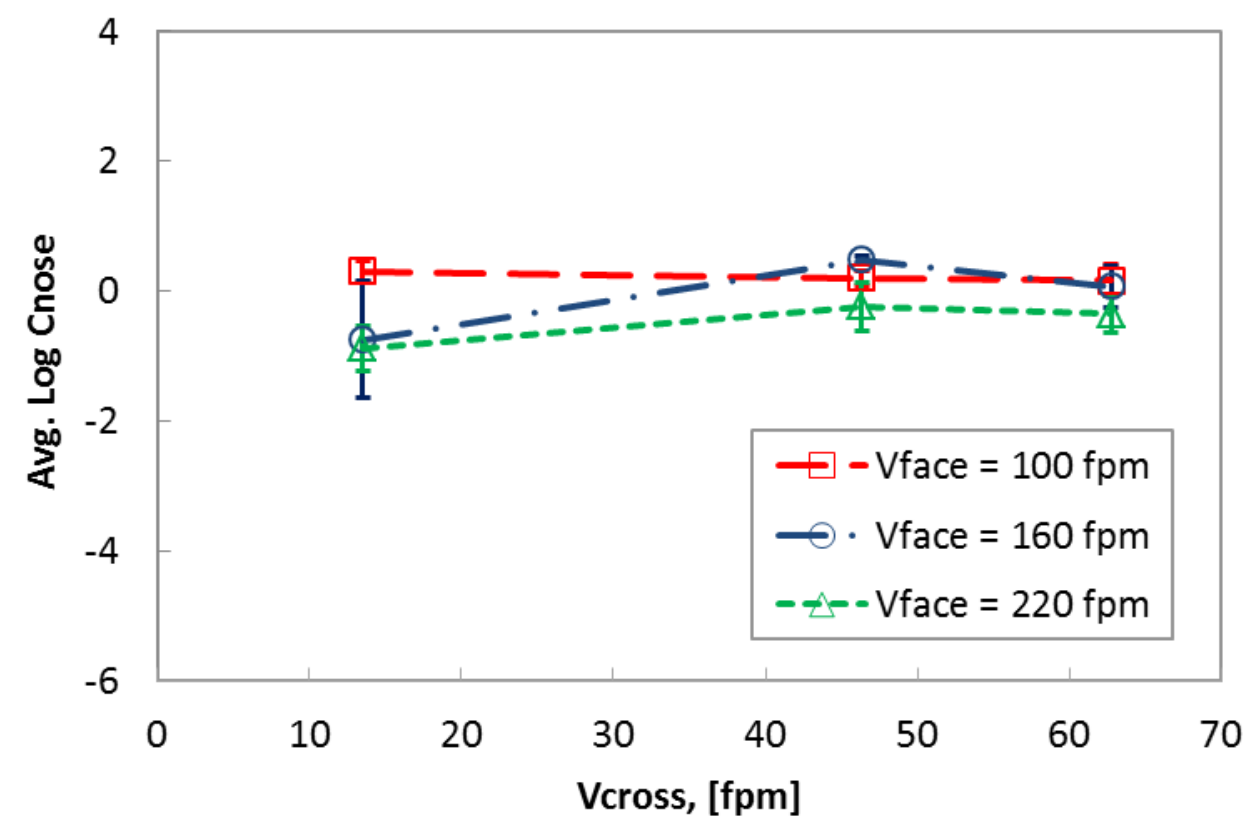

Figure 6.24 Effect of $V_{\text {cross }}$ on average $\log C_{\text {nose }}$ for the complex manikin

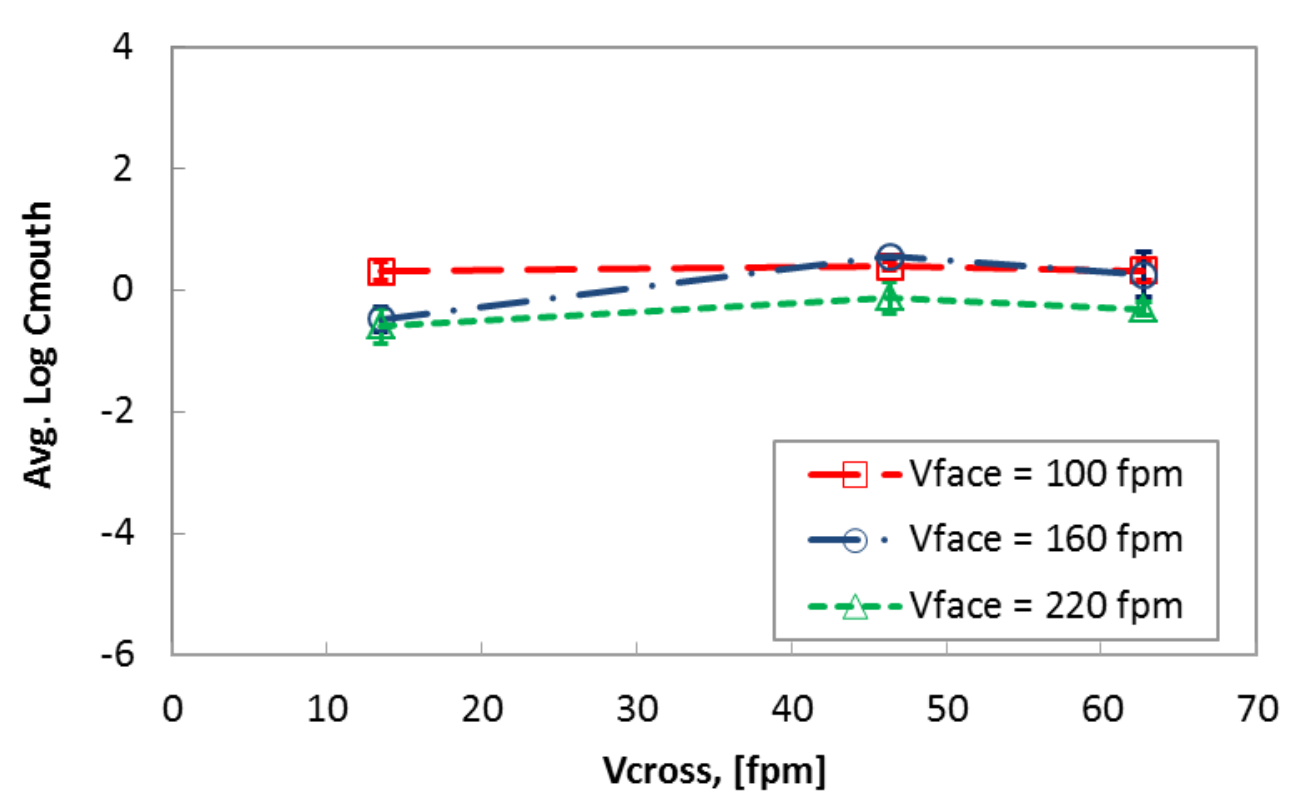

Figure 6.25 Effect of $V_{\text {cross }}$ on average $\log C_{\text {mouth }}$ for the complex manikin 


\subsubsection{Effect of temperature difference on $C_{\text {nose }}$ and $C_{\text {mouth }}$}

Previous studies pointed out the relevant effect of the temperature difference between the worker's body and the surrounding environment (see Equation 4.1 for $\Delta T_{\operatorname{man}}$ ) on levels of exposure (Li et al., 2007; Karaismail, 2011, $\mathrm{Hu}$ and Koochesfahani, 2011; Mills, 1999; Srinivas et al., 2009). The heat released from the heated manikin could affect the inhalation of contaminants because the bouyancy along the manikin body could transport contaminants from its lower part to the manikin's breathing zone.

Table 6.7 Temperature difference data $\left(\Delta T_{\operatorname{man}}\right)$ for the complex manikin in ${ }^{\circ} \mathrm{F}$

\begin{tabular}{|c|c|c|c|c|c|c|c|}
\hline \multirow{2}{*}{$V_{\text {face }},[\mathbf{f p m}]$} & \multicolumn{6}{|c|}{$V_{\text {cross }},[\mathrm{fpm}]$} & \multirow{2}{*}{ Mean } \\
\hline & \multicolumn{2}{|c|}{14} & \multicolumn{2}{|c|}{46} & \multicolumn{2}{|c|}{63} & \\
\hline \multirow{5}{*}{100} & 5.4 & 4.0 & 6.7 & 4.5 & 5.9 & 4.5 & \\
\hline & 4.1 & 3.8 & 4.5 & 5.6 & 4.7 & 8.1 & \\
\hline & 3.8 & 2.9 & 4.1 & 4.5 & 1.8 & 6.7 & \\
\hline & & & 5.9 & 6.1 & 2.9 & & \\
\hline & 4.0 & & 5.2 & & 4.9 & & 4.7 \\
\hline \multirow{4}{*}{160} & 2.5 & 4.5 & 5.8 & 5.0 & 3.2 & 4.3 & \\
\hline & 5.2 & 5.9 & 4.5 & 5.6 & 5.4 & 3.8 & \\
\hline & 4.9 & & & & & & \\
\hline & 4.6 & & 5.2 & & 4.2 & & 4.7 \\
\hline \multirow{5}{*}{220} & 5.2 & 2.7 & 3.8 & 2.2 & 3.8 & 4.7 & \\
\hline & 3.2 & 4.5 & 6.8 & 5.0 & 3.8 & 3.1 & \\
\hline & 3.6 & 4.9 & 2.0 & 3.2 & 4.5 & 4.7 & \\
\hline & 5.6 & & 2.7 & & 5.9 & & \\
\hline & 4.2 & & 3.7 & & 4.3 & & 4.1 \\
\hline Mean & 4.3 & & 4.7 & & 4.5 & & 4.5 \\
\hline
\end{tabular}


Heat is transferred to the environment from the worker's skin through conduction and convection. Conduction heat transfer occurs from the manikin's skin to the clothes and convection heat transfer takes place from the clothes to the environment (Brohus, 1997; Kilic and Sevilgen, 2008; Murakami et al., 2000; Voelker; 2009). Heat transfer through conduction from the skin to the environment can be neglected because it represents a small part of the heat releases through convection (Brohus, 1997).

Temperature difference is an important factor in the rate of heat transfer flow to the enviroment, which could be due to free, forced, and mixed convection as it was mentioned before. As can be seen in Table 6.7 and Figures 6.26 and 6.27, most values of $\Delta T_{\operatorname{man}}$ are in the range of 2 to $6 \mathrm{~F}$, which possibly could affect the worker's exposure levels. Figures 6.26 and 6.27 showed that at $V_{\text {face }}=220 \mathrm{fpm}$, most concentration values were near zero, which suggests that the strength of the suction exhaust airflow (forced convection) overcame the effect of $\Delta T_{\operatorname{man}}$ on exposure (natural convection), as can be seen in Table 6.6. 


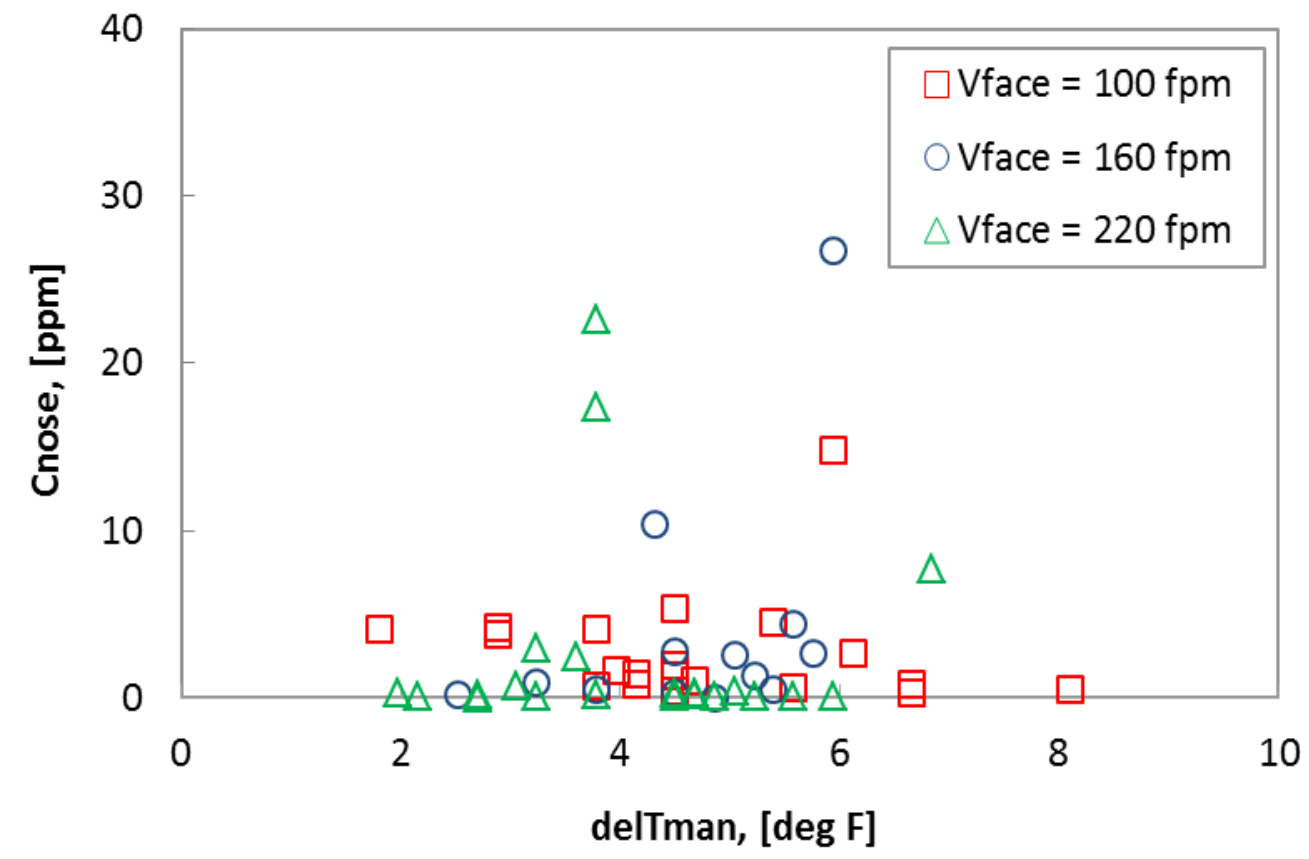

Figure 6.26 Effect of $\Delta T_{\text {man }}$ on $C_{\text {nose }}$ at constant $V_{\text {face }}$ for the complex manikin

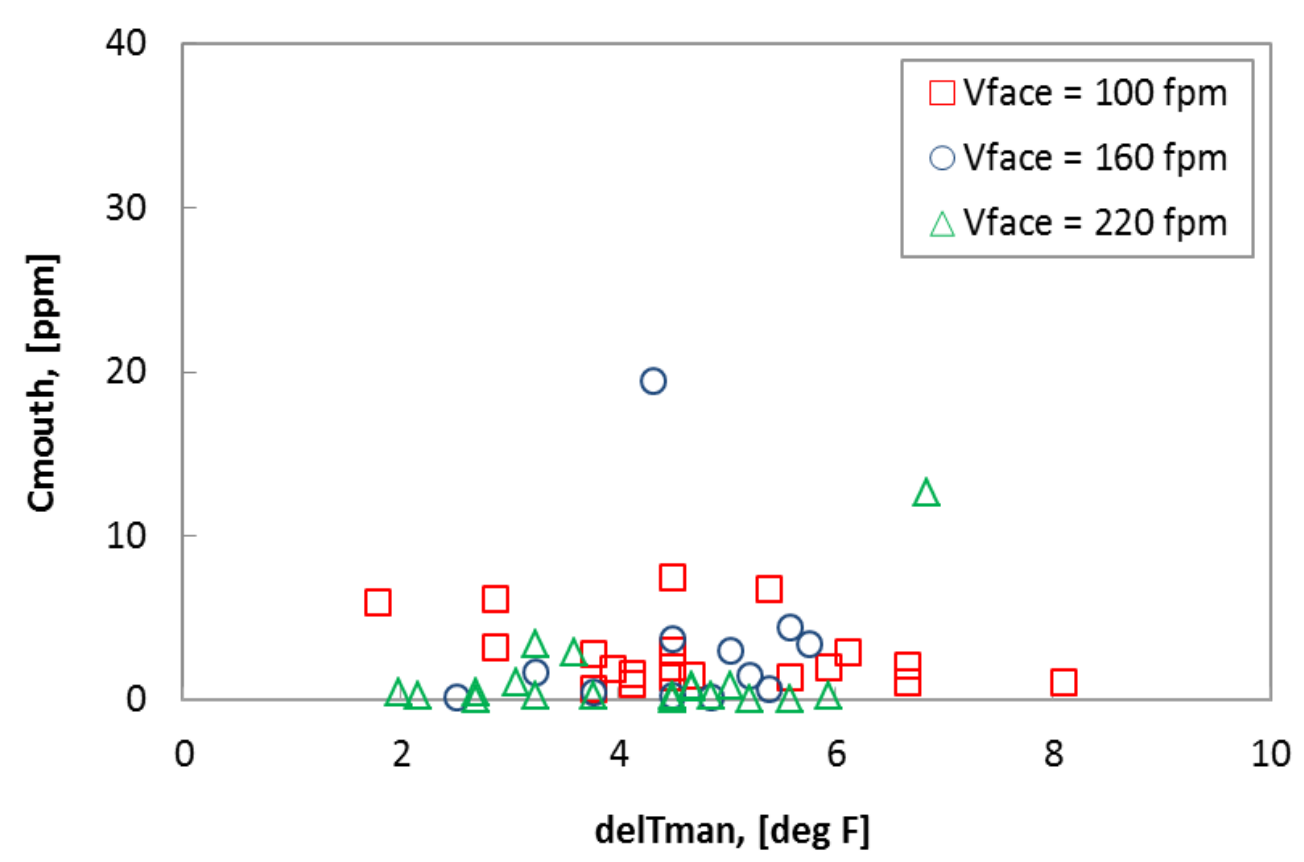

Figure 6.27 Effect of $\Delta T_{\text {man }}$ on $C_{\text {mouth }}$ at constant $V_{\text {face }}$ for the complex manikin 


\subsection{Discussion}

Prior experimental and numerical studies (Guffey and Barnea, 1994; He, 2010; Karaismail, 2011) have shown significant effects of hood face velocity $\left(V_{\text {face }}\right)$ and cross-draft velocity $\left(V_{\text {cross }}\right)$ on the performance of an enclosing hood in reducing $C_{\text {nose }}$ and $C_{\text {mouth }}$. In addition, other research tested the performance of a free stream wind tunnel $V_{\text {cross }}$ to reduce worker's exposure in a simulated industrial workplace (Li et al., 2007; Brohus, 1997; Elnahas, 2005; Guffey et al., 2001). However, these studies in most cases just assessed the effect of $V_{\text {face }}$ and $V_{\text {cross }}$ in personal exposures and did not focus on the effect of the uncontrolled variable, $\Delta T_{m a n}$

Even though the same heated, breathing complex manikin was used by $\mathrm{He}$ (2010), the influence of temperature difference was not assessed in his study. This study tested the extent to which $V_{\text {face }}, V_{\text {cross }}$, and $\Delta T_{\text {man }}$ affected the exposure of a heated, breathing complex manikin. For this study $V_{\text {face }}$ and $V_{\text {cross }}$, in most cases, decreased the level of exposure, which agrees with previous studies (Guffey and Barnea, 1994; He, 2010; Karaismail, 2011).

The effects of temperature difference $\left(\Delta T_{\text {man }}\right)$ on personal exposure can be seen in Figures 6.26 and 6.27. Though a random pattern of the effects of $\Delta T_{\text {man }}$ on $C_{\text {nose }}$ and $C_{\text {mouth }}$ is showed in these figures, a wide spread of concentrations values can be seen at $V_{\text {face }}=100$ fpm for $\Delta T_{\text {man }}$ between 2 and $6{ }^{\circ} \mathrm{F}$ (Figures 6.26 and 6.27). Grashof numbers increased as $\Delta T_{\text {man }}$ increased. However, all Grashof numbers were below the turbulent flow regime $\left(<10^{9}\right)$ for this study. The significance of $\Delta T_{\text {man }}$ on 
buoyancy and on the heat transfer flow regime was evaluated using the Richardson number $(R i)$. From the results shown before, $R i$ is a better scaling parameter than Grashof number. For most values of $C_{\text {nose }}$ and $C_{\text {mouth }}$, heat was released to the environment through mixed convection $(0.53<R i<16)$ as can be seen in Figures 6.6 to 6.9 .

Although $V_{\text {face }}$ most strongly affected Reynolds numbers $(R e)$ for the manikin, this study demostrated the effect of $V_{\text {cross }}$ on $R e$, increasing $V_{\text {cross }}$ at fixed values of $V_{\text {face }}$ produced higher $R e$ than increasing $V_{\text {face }}$ at fixed values of $V_{\text {cross }}$ (Table 6.5). Approach velocity $(U)$ is very sensitive to change in $V_{\text {cross. }}$. This velocity $(U)$ was used to calculate the $R e$. At $R e$ between 4000 and 6000, a wider spread of average dimensionless $C_{n o s e} / C_{r e f}$ and $C_{m o u t h} / C_{r e f}$ can be seen (Figures 6.2 and 6.4), which could be due to an unstable flow regime and the wake region formation in front of the manikin. However, a narrow and lower spread of worker's exposure can be seen at $R e$ greater than 10000 for $C_{\text {nose }} / C_{\text {ref }}$ but a different outcome is seen for $C_{\text {mouth }} / C_{\text {ref }}$ (see Figures 6.2 and 6.4). This shows the effect of higher $V_{\text {cross }}$ in control exposure.

This study found that at the lowest value of $V_{\text {cross }}(14 \mathrm{fpm})$ and the entire range of $V_{\text {face }}(100,160$, and $220 \mathrm{fpm})$, heat is release from the manikin's body through mixed convection (free and forced convection), as it is showed in Table 6.6. For the rest of velocity combinations heat is also transferred from the manikin to the environment, in most cases, through mixed convection (see Table 6.6). The fact that heat was released through mixed convection suggests that temperature 
differences played an important role in the upward buoyancy along the manikin's body. This, in turn, may have helped to transport contaminants from the manikin's lower part to its breathing zone. This effect can be appreciated in Figure 6.20, where for $V_{\text {cross }}=14 \mathrm{fpm}$ and all face velocities, values of $C_{\text {nose }}$ show higher variance. Smaller variance at $V_{\text {cross }}=14 \mathrm{fpm}$ for values of $C_{\text {mouth }}$ can be seen at Figure 6.21. This finding is consistent with Li et al. (2007) but contradicts that of Karaismail (2011).

The analyses of covariance were done to determine the effects of independent variables $\left(V_{\text {face }}, V_{\text {cross }}\right.$, and $\left.\Delta T_{\text {man }}\right)$ on $C_{\text {nose }}$ and $C_{\text {mouth }}$. In addition, the performance of the plain enclosing hood is evaluated through the calculation of protection efficiencies at different velocity combinations. Finally, the manikin heat transfer and the effect of the manikin's face thermocouple on exposure are discussed.

\subsubsection{Analysis of covariance}

The analysis of experimental data with both controlled ( $V_{\text {face }}$ and $\left.V_{\text {cross }}\right)$ and uncontrolled $\left(\Delta T_{\operatorname{man}}\right)$ variables called analysis of covariance or ANCOVA (Montgomery, 2009; Montgomery et al., 2001; Neter and Wasserman, 1974; Mason et al., 2003) is used in this study.

The uncontrolled variable or covariate $\left(\Delta T_{\operatorname{man}}\right)$ affected the response variables of $\log C_{\text {nose }}$ and $\log C_{\text {mouth }}$, but it was unaffected by the controlled factors such as $V_{\text {face }}$ and $V_{\text {cross }}$ (Mason et al., 2003). Analysis of the same manikin's data showed that there is no significant linear relationship ( $\mathrm{p}>0.05)$ between $\Delta T_{\text {man }}$ and 
the controlled factors of $V_{\text {face }}$ and $V_{\text {cross. }}$. For this study, the three levels of $V_{\text {face }}(100$, 160, and $220 \mathrm{fpm})$ and the three levels of $V_{\text {cross }}(14,46$, and $63 \mathrm{fpm})$ were intentionally chosen for later comparison with the results of simple manikin and human subject studies. This way of choosing the factor levels is better known as the fixed factors effects model (Montgomery, 2009; Mason et al., 2003). However, there are no levels for the uncontrolled factor $\left(\Delta T_{\text {man }}\right)$; their random values were observed and recorded. In addition, the experiments were an unbalanced, randomized factorial design (Tables 6.1 and 6.3) whose ANCOVA model for two factors of interest and one covariate can be recalled from Eq. 1.3 as:

$$
Y_{i j k}=\mu+\alpha_{i}+\beta_{j}+\gamma x_{i j k}+\varepsilon_{i j k}
$$

where $\mu$ is a constant, $\alpha_{i}$ represents the effect $V_{\text {face }}$ at the $i$ level treatment $(i=1,2,3), \beta_{j}$ represents the effect of $V_{\text {cross }}$ at the $j$ level treatment $(j=1,2,3)$. In addition, $x_{i j k}$ represent the measurements of the covariate $\left(\Delta T_{\text {man }}\right)$ at the $i j k$ run, $\gamma$ is the covariate regression analysis coefficient, and $\varepsilon_{i j k}$ represent the random error term.

For the ANCOVA model, $V_{\text {face }}$ and $V_{\text {cross }}$ were treated as discrete variables, and $\Delta T_{\text {man }}$ as a continuous variable. The number of degrees of freedom was the number of levels minus one for any main factor. Partial (Type 3) sum of squares were computed for the model because the controlled and uncontrolled variables were analyzed simultaneously. In addition, the ANCOVA mean squares were calculated as the sum of squares divided by the degrees of freedom of each source 
of variation. Also, the F-test value was computed as the mean square divided by the mean square error.

Response or dependent variables were $\log$-transformed $\left(\log C_{\text {nose }}\right.$ and $\log$ $\left.C_{m o u t h}\right)$ to obtain a roughly linear model and a normal distributed error terms. The covariate influences the response variable and, therefore, its inclusion to the model helps to reduce the experimental error. In addition, the ANCOVA without interactions for $\log C_{\text {nose }}$ and $\log C_{\text {mouth }}$ shows different outcomes. For $\log C_{\text {nose }}$, all variables were not significant and for $\log C_{\text {mouth }}$, the controlled variables were significant $(\mathrm{p}<0.05)$ and the covariate was not significant (Tables 6.8 and 6.9).

The fact that the covariate $\left(\Delta T_{\text {man }}\right)$ was not statistically significant in both cases does not mean it was not important and did not influence the response variable. It could mean that insufficient data was collected due to the few levels for each factor or that the significance was affected by the unbalanced design. A better adjusted coefficient of determination and mean square error was obtained for log $C_{\text {mouth }}\left(R_{A d j}^{2}=30.4 \%, \mathrm{MSE}=0.243\right)$ than for $\log C_{\text {nose }}\left(R_{A d j}^{2}=8.3 \%, \mathrm{MSE}=0.790\right)$ as can be seen from the results in Tables 6.8 and 6.9.

Table 6.8 No-interaction $\log C_{\text {nose }}$ ANCOVA for the complex manikin

\begin{tabular}{lccccc}
\hline Source & df & Sums of Squares & Mean Square & F-ratio & Prob \\
\hline Constant & 1 & 1.037 & 1.037 & 1.311 & 0.2578 \\
$V_{\text {face }}$ & 2 & 4.851 & 2.426 & 3.069 & 0.0557 \\
$V_{\text {cross }}$ & 2 & 2.656 & 1.328 & 1.680 & 0.1972 \\
$\Delta T_{\text {man }}$ & 1 & 0.034 & 0.034 & 0.043 & 0.8369 \\
Error & 48 & 37.942 & 0.790 & & \\
Total & 53 & 45.701 & & & \\
\hline
\end{tabular}


Table 6.9 No-interaction $\log C_{\text {mouth }}$ ANCOVA for the complex manikin

\begin{tabular}{lccccc}
\hline Source & df & Sums of Squares & Mean Square & F-ratio & Prob \\
\hline Constant & 1 & 0.048 & 0.048 & 0.195 & 0.6606 \\
$V_{\text {face }}$ & 2 & 4.293 & 2.147 & 8.820 & 0.0006 \\
$V_{\text {cross }}$ & 2 & 1.747 & 0.874 & 3.589 & 0.0358 \\
$\Delta T_{\text {man }}$ & 1 & 0.025 & 0.025 & 0.102 & 0.7509 \\
Error & 45 & 10.953 & 0.243 & & \\
Total & 50 & 17.483 & & & \\
\hline
\end{tabular}

The significance of hood face velocity $\left(V_{\text {face }}\right)$ for $\log C_{\text {mouth }}$ ANCOVA agreed with Guffey and Barnea (1994), who also found that $V_{\text {face }}$ was the most important factor in explained $C_{\text {mouth }}$. They found that incresed levels of $V_{\text {face }}$ decreased the manikin's exposure. They used a lower range of $V_{\text {face }}(60-170 \mathrm{fpm})$ than this study, had no $V_{\text {cross }}$, and used a child size manikin. Table 6.9 shows that $V_{\text {face }}$ and $V_{\text {cross }}$ both significantly affected values of $\log C_{\text {mouth }}$, and $\Delta T_{\text {man }}$ had no significant effect ( $\mathrm{p}>0.05)$ on $\log C_{\text {nose }}$ and $\log C_{\text {mouth }}$ (Tables 6.8 and 6.9).

In addition, the full model ANCOVA for $\log C_{\text {nose }}$ and $\log C_{\text {mouth }}$ (Tables 6.10 and 6.11) shows that the interaction term was nonsignificant $(p>0.05)$ and the models had no significant improvement $\left(R_{A d j}^{2}=6.7 \%\right.$ for $\log C_{n o s e}$ and $R_{A d j}^{2}=32.2 \%$ $\log C_{\text {mouth }}$ ) compared to the no interaction models of Tables 6.8 and 6.9. Though this complex manikin mimics the lifelike conditons for human subjects with its heating, breathing, and human physical features, exposure results should be taken with caution and may not be directly extrapolated to human subjects because this manikin was in a static position without moving its hands and torso during the experiments. 
Table 6.10 Log $C_{\text {nose }}$ ANCOVA for the complex manikin

\begin{tabular}{lccccc}
\hline Source & df & Sums of Squares & Mean Square & F-ratio & Prob \\
\hline Constant & 1 & 1.037 & 1.037 & 1.291 & 0.2621 \\
$V_{\text {face }}$ & 2 & 4.916 & 2.458 & 3.061 & 0.0569 \\
$V_{\text {cross }}$ & 2 & 3.081 & 1.540 & 1.918 & 0.159 \\
$V_{\text {face }}{ }^{*} V_{\text {cross }}$ & 4 & 2.604 & 0.651 & 0.811 & 0.5252 \\
$\Delta T_{\text {man }}$ & 1 & $7.68 \mathrm{E}-04$ & $7.68 \mathrm{E}-04$ & $9.56 \mathrm{E}-04$ & 0.9755 \\
Error & 44 & 35.338 & 0.803 & & \\
Total & 53 & 45.701 & & & \\
\hline
\end{tabular}

Table 6.11 Log $C_{\text {mouth }}$ ANCOVA for the complex manikin

\begin{tabular}{lccccc}
\hline \multicolumn{1}{c}{ Source } & df & Sums of Squares & Mean Square & F-ratio & Prob \\
\hline Constant & 1 & 0.048 & 0.048 & 0.201 & 0.6566 \\
$V_{\text {face }}$ & 2 & 4.373 & 2.186 & 9.222 & 0.0005 \\
$V_{\text {cross }}$ & 2 & 2.245 & 1.122 & 4.734 & 0.0141 \\
$V_{\text {face }} V_{\text {cross }}$ & 4 & 1.233 & 0.308 & 1.300 & 0.2859 \\
$\Delta T_{\text {man }}$ & 1 & 0.006 & 0.006 & 0.024 & 0.8784 \\
Error & 41 & 9.720 & 0.237 & & \\
Total & 50 & 17.483 & & & \\
\hline
\end{tabular}

\subsubsection{Effectiveness of the enclosing hood}

Previous experimental works have not evaluated the effectiveness of an enclosing hood to protect workers of hazardous airborne contaminants. They tested the effects of controlled variables $\left(V_{\text {face }}\right.$ and $\left.V_{\text {cross }}\right)$ on worker exposure without quantifying the protection efficiency of the enclosing hood (He, 2010; Guffey and Barnea, 1994). In this study, protection efficiency (Eq. 1.1) was calculated to assess the hood's performance using the heated and breathing complex manikin. 


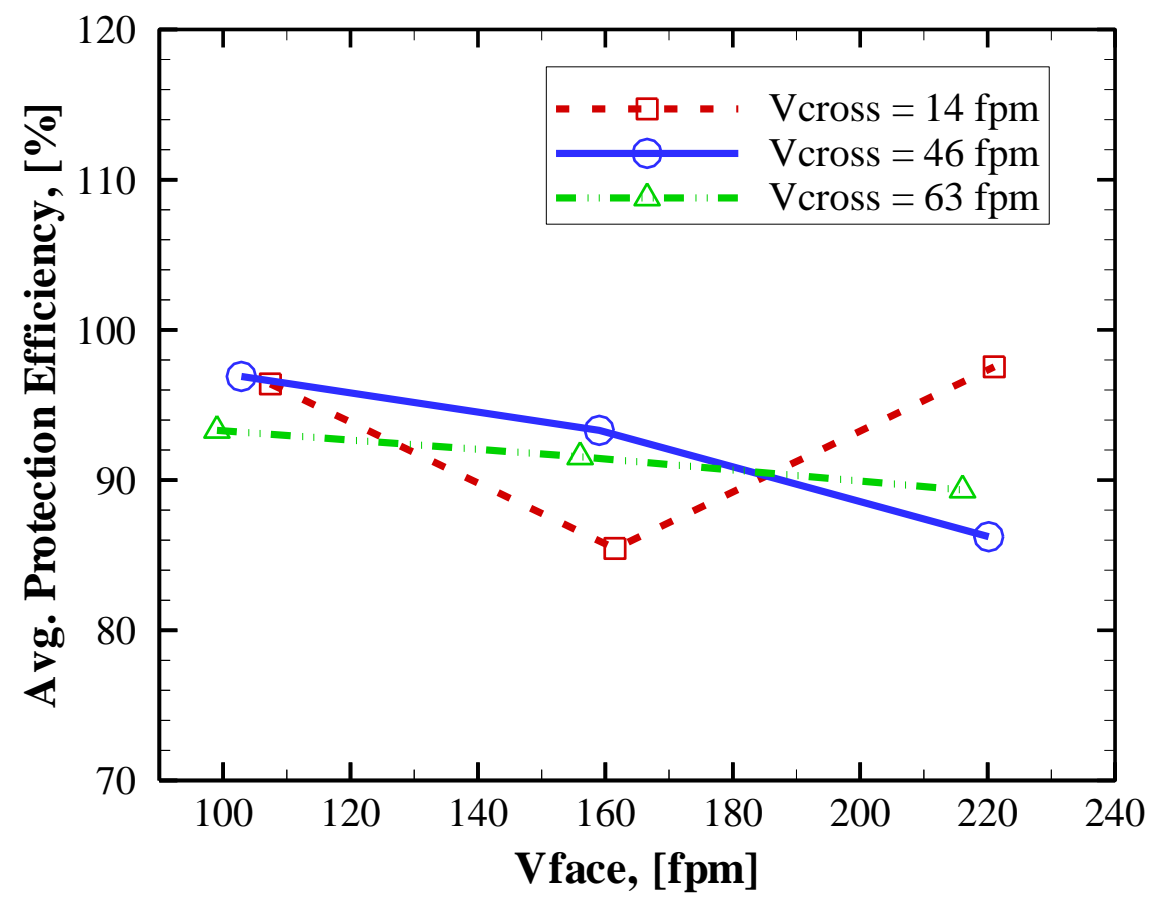

Figure 6.28 Effect of $V_{\text {face }}$ on the average protection efficiency at each level of $V_{\text {cross }}$ for the complex manikin

The average protection efficiency $\left(\eta_{\text {prot }}\right)$ showed a slight decrease as $V_{\text {face }}$ increased at fixed $V_{\text {cross }}=46$ and $63 \mathrm{fpm}$ (Figure 6.28). However, at $V_{\text {face }}=220 \mathrm{fpm}$ and $V_{\text {cross }}=14 \mathrm{fpm}$, the $\eta_{\text {prot }}$ increased (Figure 6.28), which suggets that the manikin's exposure decreased considerably (see Tables 6.1 and 6.3). In addition, at these velocity levels, the heat from the manikin's body is released due to mixed convection (free and forced convection, $R i=3.57$ ) as showed in Table 6.6. 


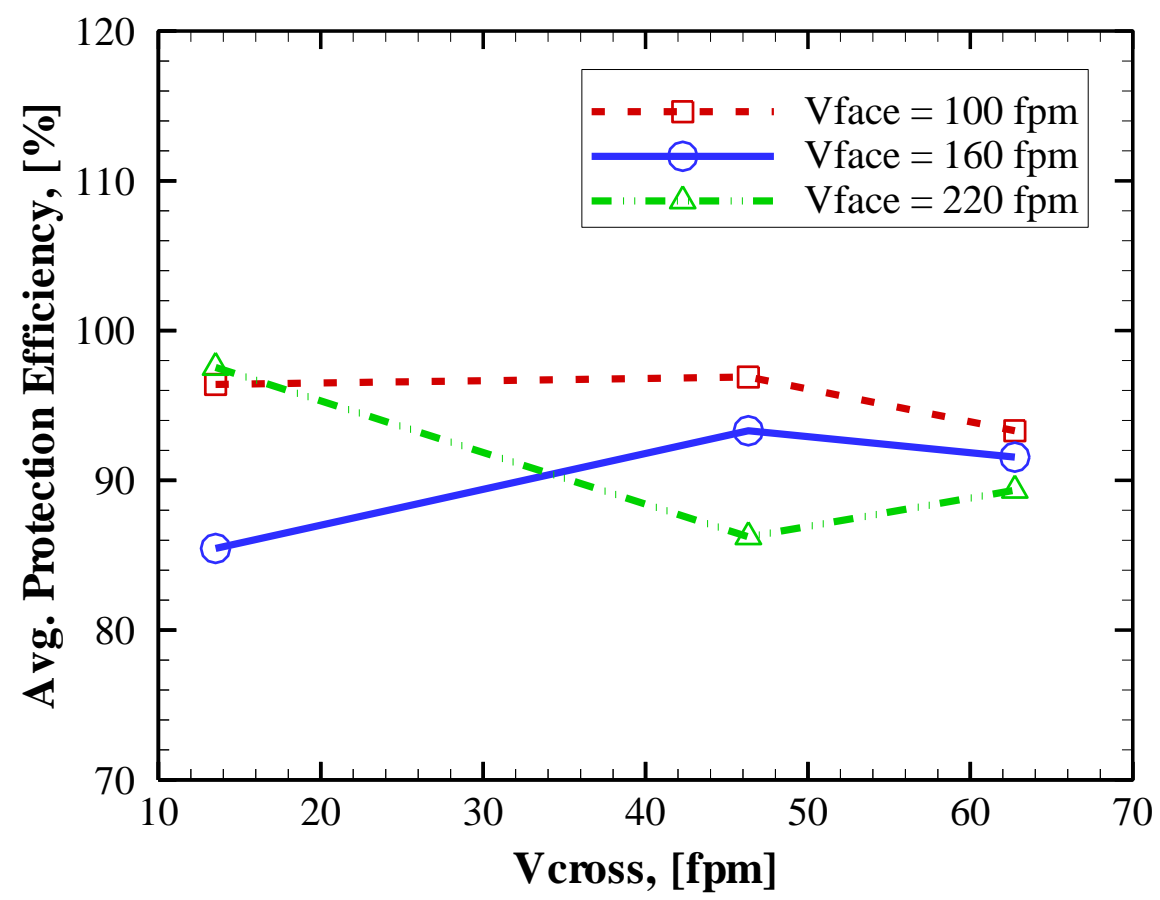

Figure 6.29 Effect of $V_{\text {cross }}$ on the average protection efficiency at each level of $V_{\text {face }}$ for the complex manikin

At the lowest cross-draft velocity $\left(V_{\text {cross }}=14 \mathrm{fpm}\right)$ and $V_{\text {face }}=100,160$, and $220 \mathrm{fpm}$ there is higher concentration variability and, therefore, higher protection efficiency variability, as is shown in Figure 6.29. At $V_{\text {cross }}=14 \mathrm{fpm}$ and at all hood face velocities, buoyancy and forced convection were important, which means heat is transferred from the manikin to the ambient through mixed convection. However, other factors, such as the breathing, head position, distance between the manikin and the hood face, and the topology of the manikin may have played an important role in the protection efficiency of the benchtop enclosing hood. In addition, at $V_{\text {cross }}=63 \mathrm{fpm}$ and $V_{\text {face }}=100,160$, and $220 \mathrm{fpm}$, it appears that $\eta_{\text {prot }}$ comes together at roughly equal values, which may have been due to the predominant 
strength of the contracted and accelerated suction flow (forced flow) into the hood (Figure 6.29).

\subsubsection{Complex manikin's body temperature and heat transfer}

Previous studies, mostly numerical simulations, have determined the temperature distribution and heat transfer of the human body (Kilic and Sevilgen, 2008; Murakami et al., 2000; Tanabe et al., 2002). For a standing posture, the temperature of the human body ranges between 29 to $33^{\circ} \mathrm{C}$ and $100 \mathrm{~W} / \mathrm{m}^{2}$ of metabolic heat production (ASHRAE handbook, 1993). In general, these simulations were carried out with a naked human body in a controlled environment without considering the effect of clothes in the heat transfer from the body to the ambient. However, this study was performed with a partially heated, clothed manikin, which, of course, represents a lower heat transfer to the surroundings.

Table 6.12 Complex manikin's temperature distribution and heat transfer

\begin{tabular}{|c|c|c|c|c|c|}
\hline \multirow[t]{2}{*}{ Surface name } & \multirow{2}{*}{$\begin{array}{c}* \text { Area, } \\
{\left[\mathbf{m}^{2}\right]}\end{array}$} & \multicolumn{2}{|c|}{ Temperature, $\left[{ }^{\circ} \mathrm{C}\right]$} & \multicolumn{2}{|c|}{$\begin{array}{c}\text { Calculated heat } \\
\text { transfer, }[\mathrm{W}]\end{array}$} \\
\hline & & Clothed & Naked & Clothed & Naked \\
\hline Head & 0.130 & 27.3 & $* *$ & 2.03 & \\
\hline Neck & 0.019 & 30.7 & $* *$ & 0.55 & \\
\hline Chest & 0.280 & 28.7 & 29.5 & 5.94 & 6.83 \\
\hline Back & 0.140 & 28.0 & 29.4 & 2.55 & 3.33 \\
\hline Pelvis & 0.018 & 26.6 & 29.9 & 0.23 & 0.47 \\
\hline Right shoulder & 0.023 & 26.4 & 28.8 & 0.28 & 0.50 \\
\hline Left shoulder & 0.023 & 26.2 & 28.8 & 0.26 & 0.50 \\
\hline Total & 0.633 & & & 11.83 & 11.63 \\
\hline
\end{tabular}


Table 6.13 Humans' heat transfer distribution (Kilic and Sevilgen, 2008)

\begin{tabular}{|c|c|c|}
\hline Surface name & $\begin{array}{c}\text { Area, } \\
{\left[\mathrm{m}^{2}\right]}\end{array}$ & Power, $[\mathrm{W}]$ \\
\hline Head & 0.130 & 4.64 \\
\hline Neck & 0.019 & 0.68 \\
\hline Chest & 0.280 & 10.00 \\
\hline Back & 0.140 & 5.00 \\
\hline Pelvis & 0.018 & 0.64 \\
\hline Right shoulder & 0.023 & 0.82 \\
\hline Left shoulder & 0.023 & 0.82 \\
\hline Total & 0.633 & 22.61 \\
\hline
\end{tabular}

The complex manikin was heated from the pelvis to the head, excluding the arms, hands, legs, and feet (Table 6.12). Strings of small light bulbs were placed in hollowed cavities for a total power of roughly $20 \mathrm{~W}$. There were no hollow cavities in the arms and legs. The low power value here was due to efforts to keep surface temperature to less than $35^{\circ} \mathrm{C}$ and the inability to heat the arms and legs. For a normal human of this size, the body heat flux would be over 100 watts (Kilic and Sevilgen, 2008). The author was very careful in the distribution of the light bulbs to obtain reasonable body temperature. In general, a warmer experimental manikin produces higher exposure (Johnson and Fletcher, 1996). Hence, the lower heat rate for this manikin may substantially underestimate convection effects. Table 6.12 shows the temperature distribution for the clothed and naked complex manikins in those specific locations where light bulbs were placed. The ambient temperature was $23.4^{\circ} \mathrm{C}$ when those were recorded.

Heat released through convection for a manikin that was clothed and not clothed was calculated from recorded manikin's temperatures (Table 6.12). A 
coefficient of heat transfer of $4.0 \mathrm{~W} / \mathrm{m}^{2} \mathrm{~K}$ for velocities between 0 and $0.15 \mathrm{~m} / \mathrm{s}$ for standing person was used (ASHRAE, 2001). Temperatures at the head and neck of the naked manikin were not recorded (Table 6.12). However, the heat delivered to the manikin must be the same $(11.83 \mathrm{~W})$ whether it is clothed or not, these temperatures should be roughly around $23.6{ }^{\circ} \mathrm{C}$ and $24.7{ }^{\circ} \mathrm{C}$ in order to balance the heat delivered to the naked manikin (Table 6.12). The heat released through the chest, back, pelvis, right and left shoulders of the naked manikin $(11.63 \mathrm{~W})$ was greater than the heat released for the same surfaces of the clothed manikin $(9.25$ W). So, the difference of heat transferred to the environment $(2.38 \mathrm{~W})$ may be released through the head and neck of the clothed manikin to satisfy the principle of conservation of energy.

For a standard person of $1.70 \mathrm{~m}$ height, $1.81 \mathrm{~m}^{2}$ total surface area, and 70 $\mathrm{kg}$ weight, the overall heat transfer to the environment is $181 \mathrm{~W}$ (Kilic and Sevilgen, 2008). In this study, however, 20W was enough to obtain the temperature distribution shown in Table 6.12. For the manikin heating surfaces in this study, Table 6.13 shows the numerical heat transfer to the ambient due to convection performed by Kilic and Sevilgen (2008) for a simulated human being. As can be seen in this table, the heat transfer $(22.61 \mathrm{~W})$ to the ambient was greater than the calculated in this study $(11.83 \mathrm{~W})$. In addition, the present experimental manikin does not have the ability to release heat through sweating.

However, the results of the numerical study should not be directly extrapolated to the present study because important factors were not included in the 
numerical simulation, such as the effect of clothes, and different sizes and body shapes comparable to the manikin in this study. Volker et al. (2009) pointed out the effect of clothing on heat releases; he stated that heat is released from the skin to the clothing and from the clothing to the environment.

Table 6.14 Humans' total heat transfer (Kilic and Sevilgen, 2008)

\begin{tabular}{lc}
\hline Type & Value, $\left[\mathbf{W} / \mathbf{m}^{\mathbf{2}}\right]$ \\
\hline Convection & 35.72 \\
Radiation & 35.28 \\
Evaporation & 20.40 \\
Respiration & 8.60 \\
\hline Total & 100.00 \\
\hline
\end{tabular}

Previous works have utilized $90 \mathrm{~W}$ as the partial heat released from the pelvis to the head by their simulated manikins (Karaismail, 2011; Li et al., 2007). However, neither a clear explanation of this choice nor references were presented that support the 90W heat released selection. It was very clear by the author based in the experimental work and by previous studies (Johnson and Fletcher, 1996; Kilic and Sevilgen, 2008; Murakami et al., 2000; Tanabe et al., 2002) that increased temperature (increased heat release) above the normal range can be the cause of higher exposure due to the higher velocity of the upward buoyancy flow that can transport contaminants from the lower part of the body to the breathing zone at a higher rate. On the other hand, Table 6.14 shows the total heat release for a simulated naked human body through convection, radiation, evaporation, and 
respiration (Kilic and Sevilgen, 2008). As can be seen from this table, heat transfer through convection represents the highest rate $\left(35.72 \mathrm{~W} / \mathrm{m}^{2}\right)$.

\subsubsection{Effect of thermocouple on manikin's face}

Earlier experimental studies have used either thermocouples or thermistor probes to monitor and to record the temperature of the skin and clothes of their heated manikins (Johnson and Fletcher, 1996; Johnson et al., 1996; Brohus, 1997; Welling et al., 2001). In this study, in addition to the temperatures taken with the infrared thermometer prior to the experimental test, temperature was monitored and recorded using thermocouples during each test. Thermocouples were placed on the manikin's face and back, and also on the wind tunnel's ceiling and wall.

It was a concern whether the thermocouple on the manikin's face affects the airflow pattern over the head and therefore the exposure. To answer this question, experiments were carried out with and without a thermocouple on the manikin in a completely randomized design. The manikin was in a working posture with the thermocouple on the right side of his face (see Figure 6.30). After subtracting the background concentrations of Freon 134a from the measured values of $C_{\text {noseMeas }}$ and $C_{\text {mouthMeas }}$, corrected concentrations were found $\left(C_{\text {nose }}\right.$ and $\left.C_{\text {mouth }}\right)$, as it is showed in Equations 4.3 and 4.4. Results showed a relatively lower exposure with the thermocouple on the manikin's face than without it (Tables 6.15, 6.16 and 6.17). The mean exposure of the manikin with the thermocouple was roughly $50 \%$ lower than the mean exposure of the manikin without it at both sampling locations (nose 
and mouth). In addition, the median exposure with the thermocouple was nearly 96\% lower than the median exposure without the thermocouple (Table 6.17).
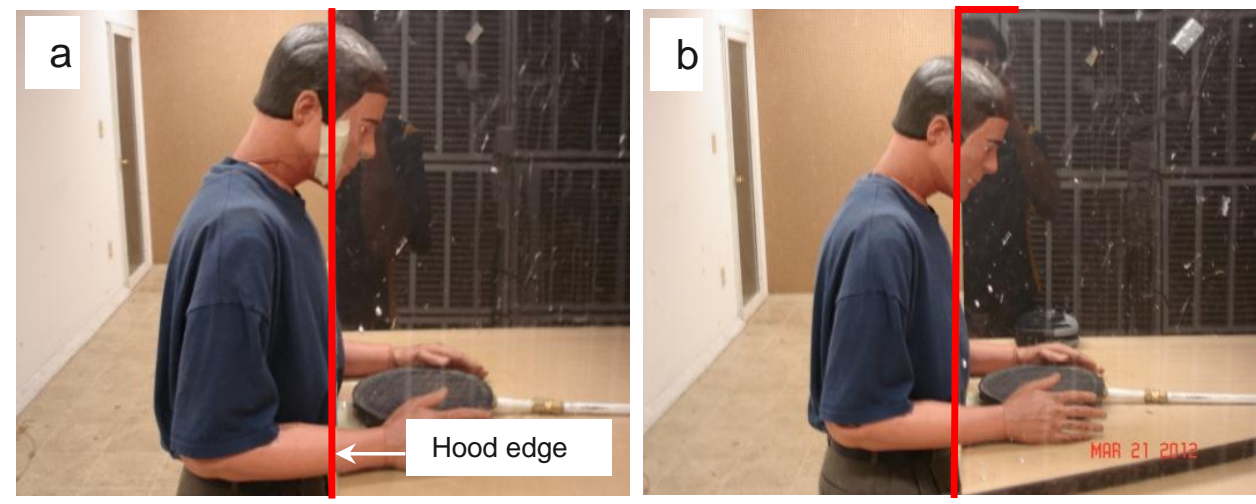

Figure 6.30 Complex manikin a) with thermocouple on face b) without thermocouple on face

Table 6.15 Concentrations at the nose (ppm) with and without thermocouple for the complex manikin

\begin{tabular}{c|c|c|c|c|c|c|c|c}
\hline \multirow{2}{*}{$\begin{array}{c}V_{\text {face},} \\
{[\mathbf{f p m}]}\end{array}$} & \multicolumn{4}{|c|}{ With thermocouple } & \multicolumn{4}{c}{ Without thermocouple } \\
\cline { 2 - 9 } & \multicolumn{3}{|c|}{$\boldsymbol{V}_{\text {cross }},[\mathbf{f p m}]$} & \multicolumn{4}{c}{$\boldsymbol{V}_{\text {cross }}$ [fpm] } \\
\cline { 2 - 9 } & $\mathbf{1 4}$ & $\mathbf{4 6}$ & $\mathbf{6 3}$ & Mean & $\mathbf{1 4}$ & $\mathbf{4 6}$ & $\mathbf{6 3}$ & Mean \\
\hline \multirow{2}{*}{$\mathbf{1 0 0}$} & 1.1 & 1.7 & 0.8 & & 0.7 & 1.8 & 2.7 & \\
& 0.1 & 2.5 & & & 0.8 & 4.9 & 3.6 & \\
\hline Mean & 0.6 & 2.1 & 0.8 & 1.2 & 0.7 & 3.3 & 3.1 & 2.4 \\
\hline \multirow{2}{*}{$\mathbf{1 6 0}$} & 0.0 & 0.1 & 1.4 & & 0.0 & 0.9 & 0.0 & \\
& 0.0 & 0.0 & 0.4 & & 0.0 & 1.6 & 1.7 & \\
\hline Mean & 0.0 & 0.1 & 0.9 & 0.3 & 0.0 & 1.3 & 0.9 & 0.7 \\
\hline \multirow{2}{*}{$\mathbf{2 2 0}$} & 0.0 & 0.0 & 0.0 & & 0.0 & 0.3 & 0.0 & \\
\hline Mean & 0.0 & 0.00 & 0.0 & & 0.0 & 0.0 & 0.0 & \\
\hline Mean & 0.0 & 0.0 & 0.0 & 0.0 & 0.0 & 0.2 & 0.0 & 0.1 \\
\hline
\end{tabular}


Table 6.16 Concentrations at the mouth (ppm) with and without thermocouple for the complex manikin

\begin{tabular}{c|c|c|c|c|c|c|c|c}
\hline \multirow{2}{*}{$\begin{array}{c}\boldsymbol{V}_{\text {face, }} \\
{[\mathbf{f p m}]}\end{array}$} & \multicolumn{4}{|c|}{ With thermocouple } & \multicolumn{5}{c}{ Without thermocouple } \\
\cline { 2 - 9 } & \multicolumn{3}{|c|}{$\boldsymbol{V}_{\text {cross }},[\mathbf{f p m}]$} & \multicolumn{4}{c}{$\boldsymbol{V}_{\text {cross }},[\mathbf{f p m}]$} \\
\hline & $\mathbf{1 4}$ & $\mathbf{4 6}$ & $\mathbf{6 3}$ & $\mathbf{M e a n}$ & $\mathbf{1 4}$ & $\mathbf{4 6}$ & $\mathbf{6 3}$ & Mean \\
\hline \multirow{2}{*}{$\mathbf{1 0 0}$} & 1.8 & 3.1 & 1.6 & & 1.2 & 3.5 & 4.6 & \\
& 0.2 & 3.1 & 4.0 & & 1.0 & 8.7 & 6.1 & \\
\hline Mean & 1.0 & 3.1 & 2.8 & 2.3 & 1.1 & 6.1 & 5.4 & 4.2 \\
\hline \multirow{3}{*}{$\mathbf{1 6 0}$} & 0.0 & 0.1 & 2.2 & & 0.1 & 2.3 & 0.2 & \\
& 0.0 & 0.0 & & & 0.0 & 1.5 & 2.5 & \\
& & & & & & 2.0 & & \\
\hline Mean & 0.0 & 0.1 & 2.2 & 0.8 & 0.1 & 1.9 & 1.4 & 1.1 \\
\hline $\mathbf{2 2 0}$ & 0.0 & 0.0 & 0.0 & & 0.0 & 0.8 & 0.0 & \\
& 0.0 & 0.0 & 0.0 & & 0.0 & 0.0 & 0.0 & \\
\hline Mean & 0.0 & 0.0 & 0.0 & 0.0 & 0.0 & 0.4 & 0.0 & 0.1 \\
\hline Mean & 0.4 & 1.0 & 1.7 & 1.0 & 0.4 & 2.8 & 2.2 & 1.8 \\
\hline
\end{tabular}

Table 6.17 Summary statistic for complex manikin with and without thermocouple

\begin{tabular}{cccccccc}
\hline Variable & Data & Count & Mean & Median & StdDev & Min & Max \\
\hline \multirow{4}{*}{$C_{\text {nose }}$} & Thermocouple & 17 & 0.5 & 0.0 & 0.8 & 0.0 & 2.5 \\
& No-thermocouple & 18 & 1.1 & 0.5 & 1.4 & 0.0 & 4.9 \\
& Total & 35 & 0.8 & 0.1 & 1.2 & 0.0 & 4.9 \\
\hline \multirow{3}{*}{$C_{\text {mouth }}$} & Thermocouple & 17 & 1.0 & 0.0 & 1.4 & 0.0 & 4.0 \\
& No-thermocouple & 19 & 1.8 & 1.0 & 2.4 & 0.0 & 8.7 \\
& Total & 36 & 1.4 & 0.2 & 2.0 & 0.0 & 8.7 \\
\hline
\end{tabular}




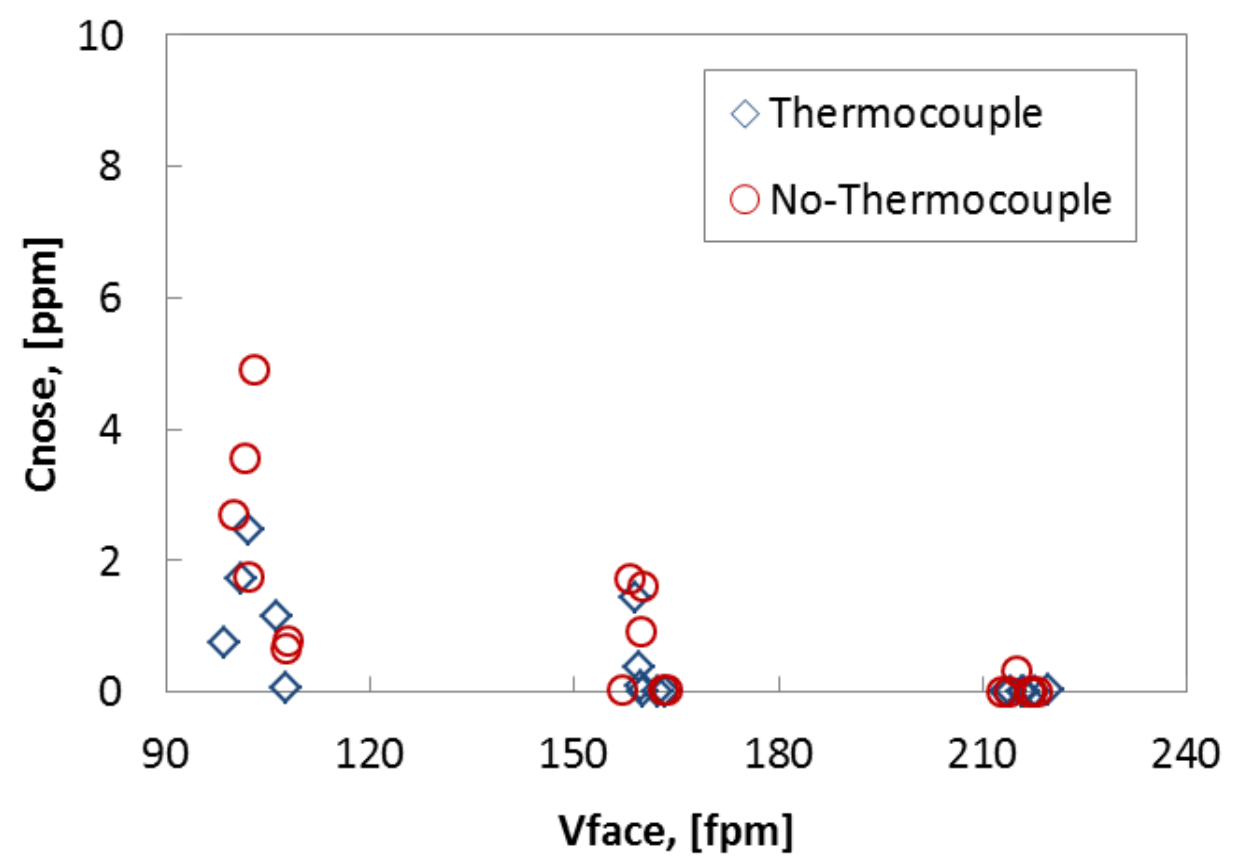

Figure 6.31 Effect of $V_{\text {face }}$ on $C_{\text {nose }}$ for the complex manikin with and without thermocouple on the face

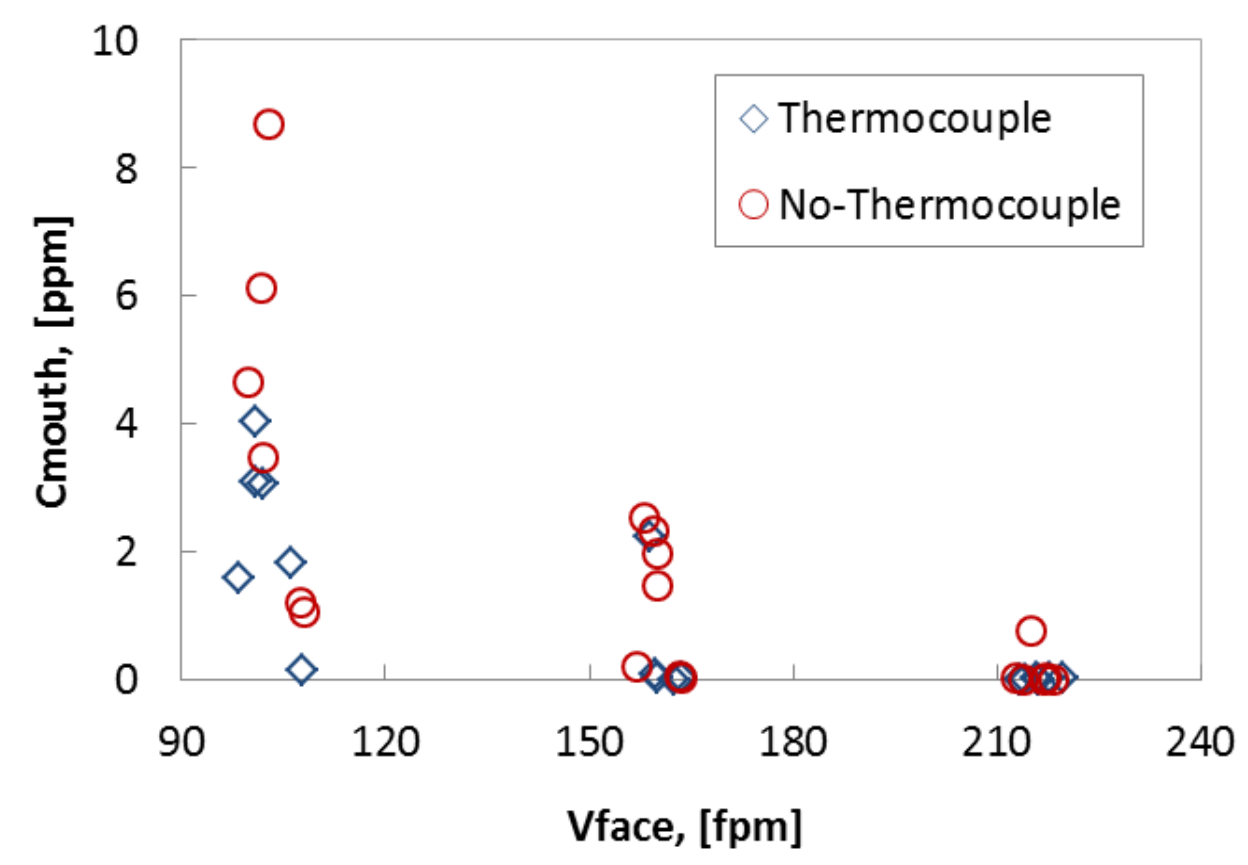

Figure 6.32 Effect of $V_{\text {face }}$ on $C_{\text {mouth }}$ for the complex manikin with and without thermocouple on the face 


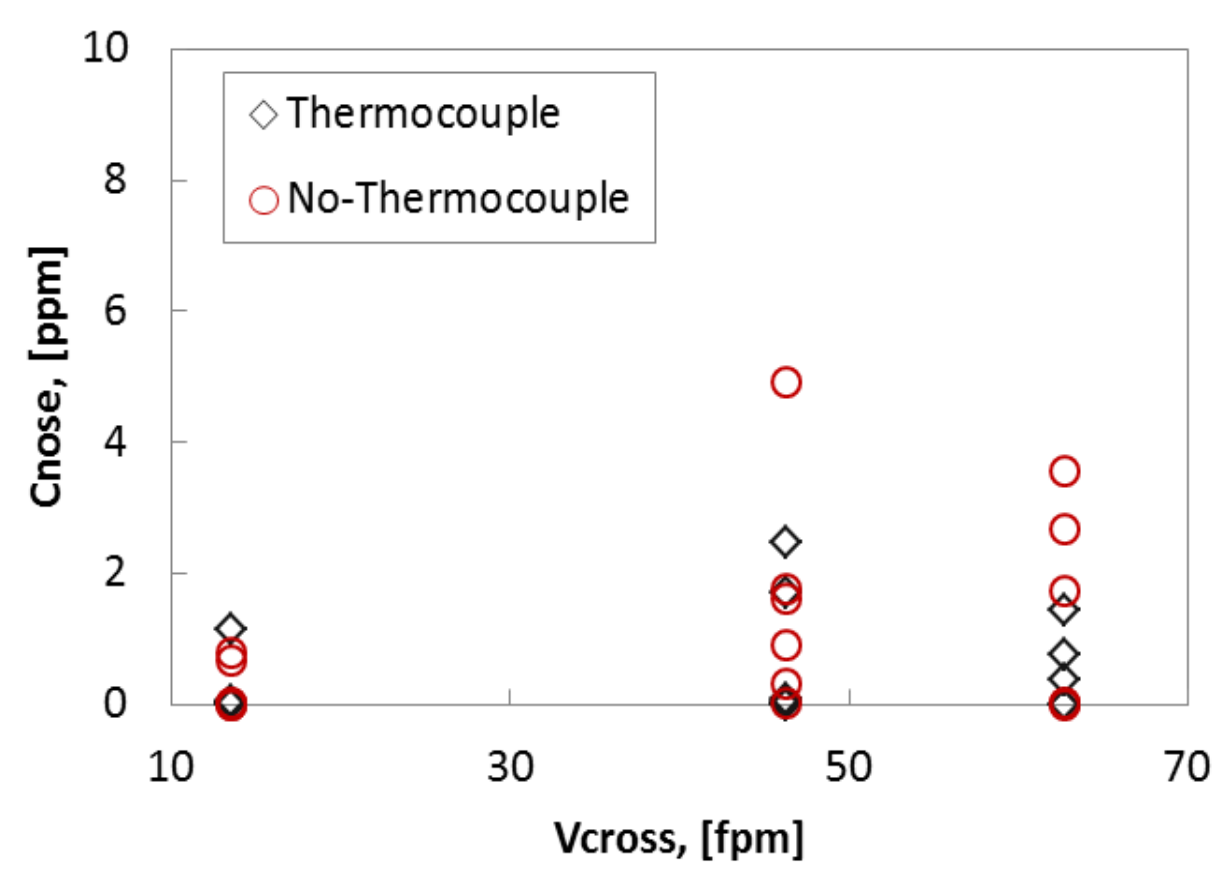

Figure 6.33 Effect of $V_{\text {cross }}$ on $C_{\text {nose }}$ for the complex manikin with and without thermocouple on the face

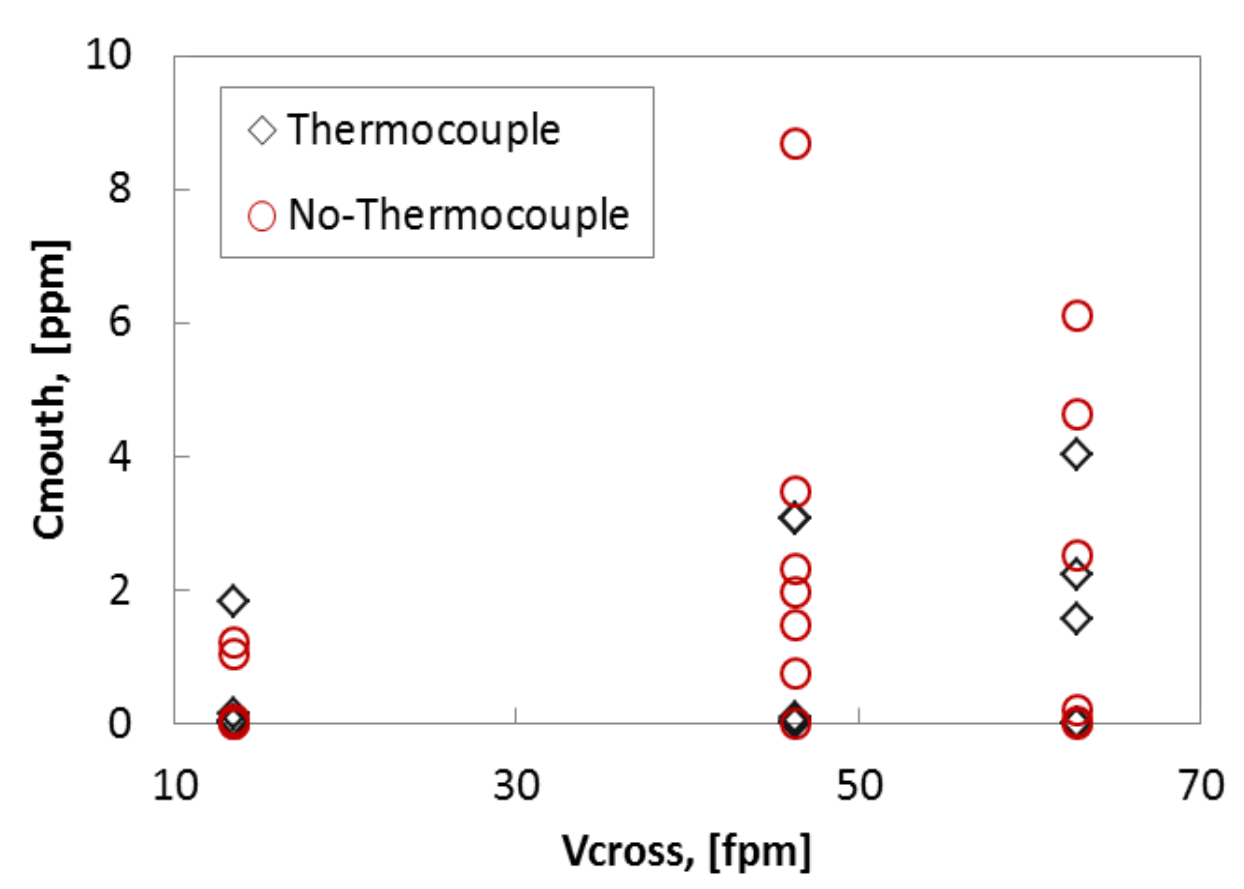

Figure 6.34 Effect of $V_{\text {cross }}$ on $C_{\text {mouth }}$ for the complex manikin with and without thermocouple on the face 
A wider spread of values of $C_{\text {nose }}$ with and without the thermocouple can be seen at $V_{\text {face }}=100 \mathrm{fpm}$ and $V_{\text {cross }}=14,46$, and $63 \mathrm{fpm}$ (Figure 6.31). It is clear that at this level of $V_{\text {face }}$, exposures without the thermocouple are higher than those with the thermocouple (Figure 6.31). Then exposure dropped as $V_{\text {face }}$ increased. The same exposure pattern can be appreciated, for both cases, when $C_{\text {mouth }}$ is plotted against $V_{\text {face }}$ (Figure 6.32). It seems that an inverted $\mathrm{V}$ shape is displayed at $V_{\text {cross }}=$ $14 \mathrm{fpm}$ and all levels of $V_{\text {face }}$ because of the higher exposure of the manikin without the thermocouple (Figure 6.33 and 6.34).

Table $6.18 C_{\text {nose }}$ ANOVA for the complex manikin with and without thermocouple

\begin{tabular}{lccccc}
\hline Source & df & $\begin{array}{c}\text { Sums of } \\
\text { Squares }\end{array}$ & $\begin{array}{c}\text { Mean } \\
\text { Square }\end{array}$ & F-ratio & Prob \\
\hline Constant & 1 & 21.061 & 21.061 & 42.30 & $<0.0001$ \\
$V_{\text {face }}$ & 2 & 19.178 & 9.589 & 19.26 & $<0.0001$ \\
$V_{\text {cross }}$ & 2 & 5.805 & 2.903 & 5.83 & 0.0097 \\
$V_{\text {face }} V_{\text {cross }}$ & 4 & 4.648 & 1.162 & 2.33 & 0.0890 \\
Thermocouple & 1 & 2.386 & 2.386 & 4.79 & 0.0400 \\
$V_{\text {face }}{ }^{*}$ Thermocouple & 2 & 1.662 & 0.831 & 1.67 & 0.2124 \\
$V_{\text {cross }}{ }^{\text {Thermocouple }}$ & 2 & 1.103 & 0.551 & 1.11 & 0.3489 \\
Error & 21 & 10.456 & 0.498 & & \\
Total & 34 & 46.676 & & & \\
\hline
\end{tabular}


Table 6.19 $C_{\text {mouth }}$ ANOVA for complex manikin with and without thermocouple

\begin{tabular}{lccccc}
\hline Source & df & $\begin{array}{c}\text { Sums of } \\
\text { Squares }\end{array}$ & $\begin{array}{c}\text { Mean } \\
\text { Square }\end{array}$ & F-ratio & Prob \\
\hline Constant & 1 & 71.657 & 71.657 & 59.87 & $<0.0001$ \\
$V_{\text {face }}$ & 2 & 64.666 & 32.333 & 27.02 & $<0.0001$ \\
$V_{\text {cross }}$ & 2 & 18.950 & 9.475 & 7.92 & 0.0026 \\
$V_{\text {face }} V_{\text {cross }}$ & 4 & 15.091 & 3.773 & 3.15 & 0.0343 \\
Thermocouple & 1 & 6.280 & 6.280 & 5.25 & 0.0319 \\
$V_{\text {face }}{ }^{*}$ Thermocouple & 2 & 5.269 & 2.634 & 2.20 & 0.1345 \\
$V_{\text {cross }} *$ Thermocouple & 2 & 4.699 & 2.350 & 1.96 & 0.1642 \\
Error & 22 & 26.331 & 1.197 & & \\
Total & 35 & 141.789 & & & \\
\hline
\end{tabular}

In most velocity treatment combinations, this study found that exposures without the thermocouple were higher than those with the thermocouple on the manikin's face. Therefore, analyses of variance (ANOVA) of the response variables $\left(C_{\text {nose }}\right.$ and $\left.C_{\text {mouth }}\right)$ were carried out to determine whether or not these differences are statistically significant. Tables 6.18 and 6.19 showed that the thermocouple on the manikin's face had statistically significant effects on both $C_{\text {nose }}$ and $C_{\text {mouth }}(\mathrm{p}$-value $<0.05)$. The hypothesis of the thermocouple effect on exposure was supported statistically. 
Table 6.20 Log $C_{\text {nose }}$ ANOVA for the complex manikin with and without thermocouple

\begin{tabular}{lccccc}
\hline Source & df & $\begin{array}{c}\text { Sums of } \\
\text { Squares }\end{array}$ & $\begin{array}{c}\text { Mean } \\
\text { Square }\end{array}$ & F-ratio & Prob \\
\hline Constant & 1 & 48.343 & 48.343 & 83.44 & $<0.0001$ \\
$V_{\text {face }}$ & 2 & 39.766 & 19.883 & 34.32 & $<0.0001$ \\
$V_{\text {cross }}$ & 2 & 2.322 & 1.161 & 2.00 & 0.1598 \\
$V_{\text {face }} V_{\text {cross }}$ & 4 & 8.499 & 2.125 & 3.67 & 0.0204 \\
Thermocouple & 1 & 2.671 & 2.671 & 4.61 & 0.0436 \\
$V_{\text {face }}{ }^{\text {Thermocouple }}$ & 2 & 0.234 & 0.117 & 0.20 & 0.8190 \\
$V_{\text {cross }} *$ Thermocouple & 2 & 1.577 & 0.788 & 1.36 & 0.2781 \\
Error & 21 & 12.166 & 0.579 & & \\
Total & 34 & 67.948 & & & \\
\hline
\end{tabular}

Table 6.21 Log $C_{\text {mouth }}$ ANOVA for the complex manikin with and without thermocouple

\begin{tabular}{lccccc}
\hline Source & df & $\begin{array}{c}\text { Sums of } \\
\text { Squares }\end{array}$ & $\begin{array}{c}\text { Mean } \\
\text { Square }\end{array}$ & F-ratio & Prob \\
\hline Constant & 1 & 28.970 & 28.970 & 32.29 & $<0.0001$ \\
$V_{\text {face }}$ & 2 & 44.457 & 22.228 & 24.77 & $<0.0001$ \\
$V_{\text {cross }}$ & 2 & 1.241 & 0.621 & 0.69 & 0.5114 \\
$V_{\text {face }}{ }^{*} V_{\text {cross }}$ & 4 & 7.012 & 1.753 & 1.95 & 0.1372 \\
Thermocouple & 1 & 1.278 & 1.278 & 1.42 & 0.2454 \\
$V_{\text {face }} *$ Thermocouple & 2 & 0.503 & 0.251 & 0.28 & 0.7583 \\
$V_{\text {cross }} *$ Thermocouple & 2 & 1.213 & 0.607 & 0.68 & 0.5189 \\
Error & 22 & 19.741 & 0.897 & & \\
Total & 35 & 76.546 & & & \\
\hline
\end{tabular}

For comparison with the ANOVA for $C_{\text {nose }}$ and $C_{\text {mouth }}$ (Tables 6.18 and 6.19), ANOVA of the $\log$-transformed concentrations response variables $\left(\log C_{\text {nose }}\right.$ and $\log C_{\text {mouth }}$ ) were performed (Tables 6.20 and 6.21). Results showed that the thermocouple had significant effect on $\log C_{\text {nose }}$ (p-value $\left.<0.05\right)$ but no in $\log C_{\text {mouth }}$ (p-value > 0.05). Face velocity explain much of the variability of the data in both $\log C_{\text {nose }}$ and $\log C_{\text {mouth }}$ and the thermocouple barely contribute to the sum of 
squares (see Tables 6.20 and 6.21). Future works should either reassess the analysis with a larger sample or relocate the thermocouple.

\subsubsection{Effect of face location on exposure}

Others have proved experimentally that proper work practices can dramatically increase the effectiveness of fume hoods (Mikell and Hobbs, 1981; Mikell and Fuller, 1988; Johnson and Fletcher, 1996; Ivany et al., 1989). Good work practice in lab fume hoods is defined as keeping the contaminant source at least 6 in from the hood sash, the worker standing in front of the hood with his face outside of the sash and the sash being closed as much as possible. In contrast, bad work practices in fume hoods are working with the body and head against the sash, the emission source being at 2-3 in from the hood sash, and the sash being inadequately closed. However, no study was found about good or bad work practices in benchtop enclosing hoods. Therefore, this study specifically investigated, using a manikin, how the worker's face location affects the performance of an enclosing hood. 


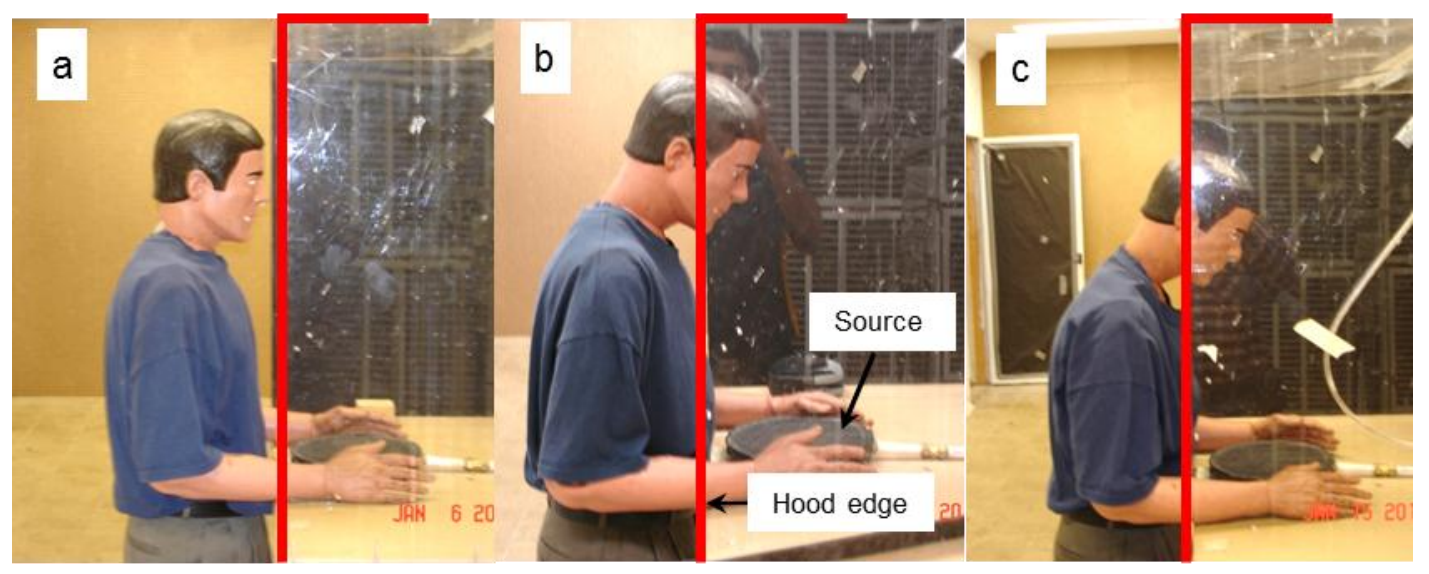

Figure 6.35 Complex manikin's face location a) vertical b) sideburn c) ear

Table 6.22 Complex manikin's face location exposure

\begin{tabular}{|c|c|c|c|c|c|c|c|}
\hline & & \multicolumn{6}{|c|}{ Face location exposure, [ppm] } \\
\hline \multicolumn{2}{|c|}{ Velocity, [fpm] } & \multicolumn{2}{|c|}{ Vertical } & \multicolumn{2}{|c|}{ Sideburn } & \multicolumn{2}{|c|}{ Ear } \\
\hline$V_{\text {face }}$ & $V_{\text {cross }}$ & $C_{\text {nose }}$ & $C_{\text {mouth }}$ & $C_{\text {nose }}$ & $C_{\text {mouth }}$ & $C_{\text {nose }}$ & $C_{\text {mouth }}$ \\
\hline 100 & 14 & 0.1 & 0.1 & 10.1 & 9.2 & & \\
\hline 100 & 63 & & 3.4 & $3.1 *$ & $5.4 *$ & 10.4 & 25.6 \\
\hline 160 & 46 & 0.0 & 0.1 & 6.5 & 7.3 & 14.5 & 18.9 \\
\hline 220 & 63 & 0.0 & 0.0 & 6.9 & 7.3 & 8.4 & 9.2 \\
\hline Mean & & 0.0 & 0.9 & 7.9 & 8.0 & 11.1 & 17.9 \\
\hline
\end{tabular}

*Average of two values

Experiments were carried out with the manikin standing at almost 1 in from the table edge at waist level and the contaminant source at a fixed location (2 in from the hood face), as is shown in Figures 6.35. Three face working locations were investigated: vertical, sideburn, and ear (Figure 6.35). For the first, the manikin kept a "Vertical" working posture (body and head) at roughly 1 in from the hood face (Figure 6.35a). The manikin leaned his body and placed his face inside the hood at a "Sideburn" working posture for the second location (Figure 
$6.35 \mathrm{~b}$ ), and for the third location, the manikin moved his face further inside the open hood face until the ear and the hood edge overlapped, "Ear" location (Figure $6.35 c)$.

The experimental results show evidence of the effects of face location on the performance of a plain hood. Some values were omitted because their residuals were greater than the 0.02 criterion. It can be seen on Table 6.22 that $C_{\text {nose }}$ and $C_{\text {mouth }}$ are almost neglegible for the vertical face position when every velocity combinations were tested. The average of $C_{\text {nose }}$ and $C_{\text {mouth }}$ was 0.0 and $0.9 \mathrm{ppm}$ (see Table 6.22). As can be seen as the face is moved further inside the hood, there are remarkable increases in exposure for $C_{\text {nose }}$ and $C_{\text {mouth }}$ at the sideburn face location and even higher exposures at the ear face location (Table 6.22). This agrees with previous studies (Mikell and Hobbs, 1981; Johnson and Fletcher, 1996; Ivany et al., 1989). It should also be noted that in most cases exposure decreased as both $V_{\text {face }}$ and $V_{\text {cross }}$ increased.

\subsubsection{Effect of the distance between the breathing zone and the source}

The distance between the breathing zone and the contaminant source is an important factor in a lab fume hood performance, even more important than face velocity and cross-draft velocity (Mikell and Hobbs, 1981; Mikell and Fuller, 1988;

Johnson and Fletcher, 1996). For that reason, this study describes experiments using a manikin at different distances from the plain enclosing hood (Figure 6.37). To the author's knowledge no previous published studies exist that investigated the 
effect of the distance of the breathing zone to the emission source on the performance of a benchtop enclosing hood.

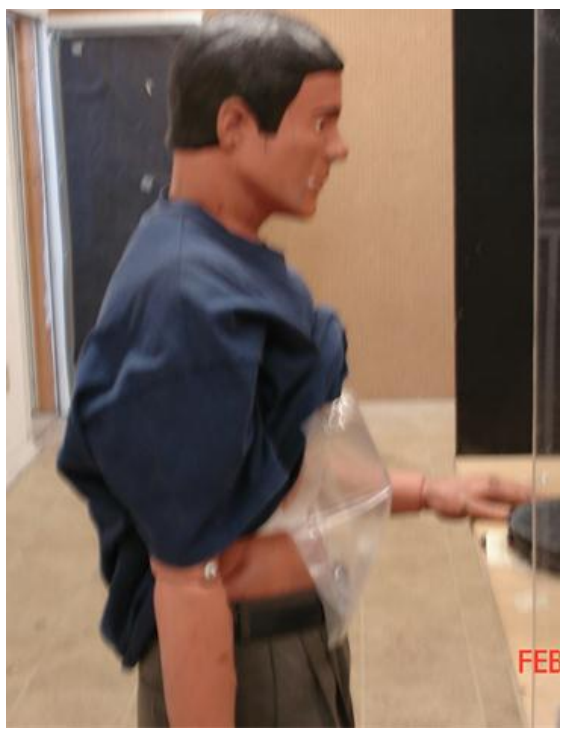

Figure 6.36 Complex manikin's padded belly

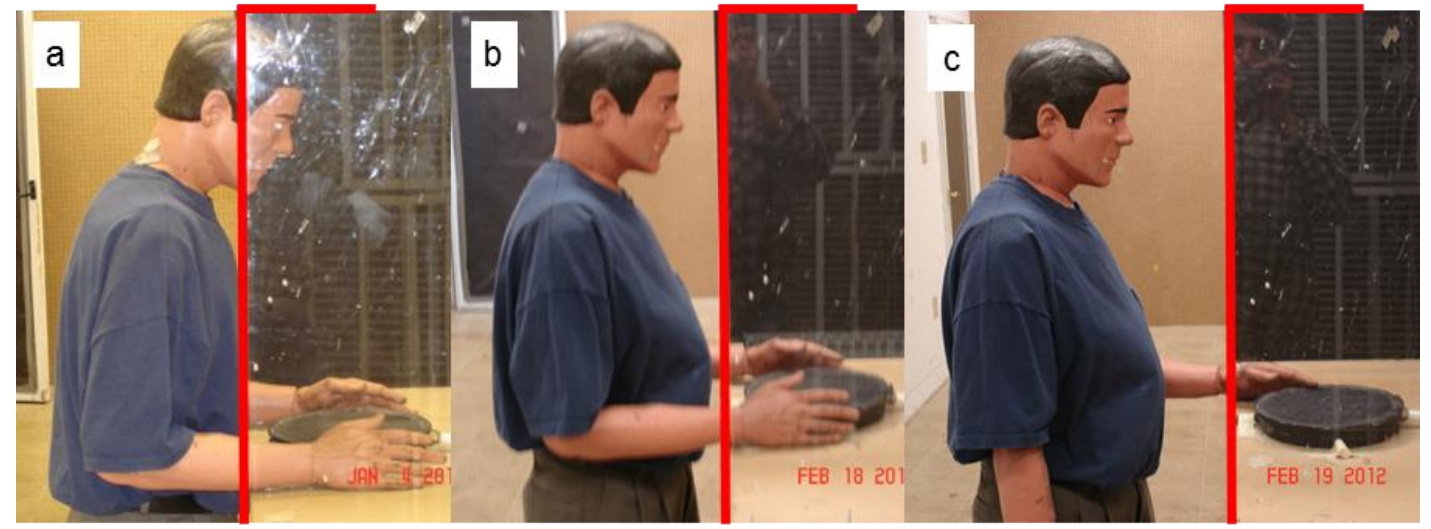

Figure 6.37 Complex manikin's distance from the hood face a) without padded belly b) padded belly 1" c) padded belly 4" 
Table 6.23 Complex manikin's distance from the hood face exposure

\begin{tabular}{cc|cc|cc|cc}
\hline & \multicolumn{5}{|c}{ Distance from the hood face exposure, [ppm] } \\
\hline $\begin{array}{c}\text { Velocity, } \\
{[\mathbf{f p m}]}\end{array}$ & \multicolumn{2}{|c|}{ Without padded belly, 1" } & \multicolumn{2}{c}{ Padded belly, 1" } & \multicolumn{2}{c}{ Padded belly, 4" } \\
\hline $\boldsymbol{V}_{\text {face }}$ & $\boldsymbol{V}_{\text {cross }}$ & $\boldsymbol{C}_{\text {nose }}$ & $\boldsymbol{C}_{\text {mouth }}$ & \multicolumn{2}{c|}{$\boldsymbol{C}_{\text {nose }}$} & $\boldsymbol{C}_{\text {mouth }}$ & \multicolumn{2}{c}{$\boldsymbol{C}_{\text {nose }}$} & $\boldsymbol{C}_{\text {mouth }}$ \\
\hline \multirow{2}{*}{600} & 2.7 & 4.6 & 0.0 & 0.0 & 0.0 & 0.1 \\
& 3.6 & 6.1 & 0.0 & 0.0 & 0.0 & 0.1 \\
\hline Mean & 3.1 & 5.4 & 0.0 & 0.0 & 0.0 & 0.1 \\
\hline \multirow{2}{*}{160} & 0.9 & 1.5 & 0.0 & 0.0 & 0.0 & 0.0 \\
& 1.6 & 2.0 & 0.0 & 0.0 & 0.0 & 0.0 \\
\hline Mean & 1.3 & 1.7 & 0.0 & 0.0 & 0.0 & 0.0 \\
\hline Mean & 2.2 & 3.6 & 0.0 & 0.0 & 0.0 & 0.0 \\
\hline
\end{tabular}

As in previous experiments, the contaminant source was fixed inside the hood at 2 inches from the hood face edge. The complex manikin was tested at three different distances from the hood face with and without the use of a padded belly. To simulate the manikin's padded belly, a sample bag was filled with 2.5 liters of air and then fixed to his belly (see Figures 6.36). This increased in 3.5 inches width the manikin's belly (see Figures $6.37 \mathrm{~b}$ and $6.37 \mathrm{c}$ ). For all experimental tests, the manikin's head was in the Sideburn posture. In addition, for each distances from the hood face, different sets of experiments were considered. Replications were carried out in a random order.

For the first set of experiments, the manikin wore no padding and the distance between the hood face and the manikin's waist was roughly 1 in for the control condition (see Figure 6.37a). For the other two sets of experiments, the plastic padded belly of 3.5 in width was added to the manikin belly as it is shown in Figures $6.37 \mathrm{~b}$ and $6.37 \mathrm{c}$. The distance between the manikin's padded belly and the 
hood face was 1 in during the second set of experiments. Thus, the manikin's face was outside the enclosing hood due to the padded belly (Figure 6.37b). For the third set of experiments, the distance between the manikin's padded belly and the hood face was increased to 4 in (Figure 6.37c).

As can be seen in Table 6.23, $C_{\text {nose }}$ and $C_{\text {mouth }}$ substantially decreased in the manikin's exposure to almost negligible levels when the manikin distance between the breathing zone and the hood face was increased. There was more than a hundredfold decrease between the manikin without a padded belly (average $C_{n o s e}=$ $2.2 \mathrm{ppm}$ and average $C_{\text {mouth }}=3.6 \mathrm{ppm}$ ) and the manikin with a padded belly 1 in from the hood face (average $C_{\text {nose }}=0.0 \mathrm{ppm}$ and average $C_{\text {mouth }}=0.0 \mathrm{ppm}$ ). In addition, almost no difference in exposure was observed when the distance between the manikin's padded belly and the hood face was further increased to 4 in (see Table 6.23).

It is suggested from the results that at separation distances greater than 1 in from the hood face, the exposure to the manikin is effectively zero (see Table 6.23). This finding agrees with previous studies (Johnson and Fletcher, 1996; Mikell and Hobbs, 1981; Mikell and Fuller, 1988), even though they tested an experimental fume hood. 


\section{CHAPTER 7}

\section{HUMAN SUBJECT STUDY}

\subsection{Introduction}

Other portions of this study investigated the effectiveness of a small, benchtop enclosing hood using manikins as surrogates of human operators. However, given the paucity of studies done to determine how well manikins represent human working in front of a hood, the results of manikin studies is of unknown value until the use of manikins is validated. This portion of the study determines the performance of the hood when humans serve as subject. When results are later compared to results from the manikin studies, the adequacy of the manikins as surrogates can be determine.

Most research studies in which human subjects were used have focused either on factors affecting the performance of lab fume hoods (Altemose et al., 1998; Greenley et al., 2000; Johnson and Fletcher, 1996; Mikell and Hobbs, 1981; Tan et al., 1999) or measurement of concentrations at the worker's breathing zone in a free-stream environment (Cohen et al., 1984; Johnson et al., 1996; Martinelli et al., 1983; Van Der Wal and Moerkerken, 1984). Despite a diligent search, no studies were found in which factors affecting the performance of benchtop enclosing hoods using human subjects were tested.

Many factors affect the performance of a lab hood, such as the height of sash opening, the distance between the source and the breathing zone, user posture, 
body movement, hand movement, body temperature, face velocity $\left(V_{\text {face }}\right)$, and cross-draft velocity ( $V_{\text {cross }}$ ), among others (Ahn et al., 2008; Altemose et al., 1998; Greenley et al., 2000; Johnson and Fletcher, 1996; Mikell and Hobbs, 1981). The interactions between $V_{\text {face }}$ and $V_{\text {cross }}$ as well as the spatial and temporal variability are important in determining the hood performance (Altemose et al., 1998). In addition, the presence of a human operator increases the leakage of contaminants up to $60 \%$ than an unobstructed fume cupboard, possibly due to the thermal effects of the operator's body (Johnson and Fletcher, 1996). However, findings from lab hoods cannot be directly extrapolated to plain enclosing hoods because of the difference in hood designs. To the author's knowledge, no published study to the date has investigated the effect of these factors on a benchtop enclosing hood using humans as subjects.

Previous studies have shown that the effect of the distance between the source and the breathing zone, the thermal load of the worker, and work practices may be even more important than $V_{\text {face }}$ and $V_{\text {cross }}$ on the effectiveness of local exhaust ventilation (LEV) devices (Johnson and Fletcher, 1996; Johnson et al., 1996; Mikell and Hobbs, 1981). A minimum distance of 6 in from the plane of the sash to the source is recommended to minimize leakage of contaminants from the hood while keeping adequate space from the sash door to the operator (Mikell and Hobbs, 1981). In addition, the human subject breathing exhalation pattern does not affect the flow in the wake of the worker and therefore does not contribute to the operator's exposure (Johnson et al., 1996). 
The effect of work practices plays an important role on workers' exposure to airborne contaminants. It was experimentally demonstrated that operators have a higher exposure when the workers lean with their foreheads against the sash of a laboratory hood (Johnson and Fletcher, 1996; Mikell and Hobbs, 1981). On the other hand, in a field study, high variability of concentrations was found for breathing zone samples taken on the lapel and near the nose and mouth. This variability may be due to the resuspended dust collected on the workers' clothes (Martinelli et al., 1983; Cohen et al., 1984).

Effect of factors on $C_{\text {nose }}$ and $C_{\text {mouth }}$ such as $V_{\text {face }}$, $V_{\text {cross }}$, temperature differences between the human and the environment $\left(\Delta T_{\text {human }}\right)$, and subjects' body size were explored with ten different human subjects in this study. Finally, the effect of face location and the distance between the workers' breathing zone and the hood face on $C_{\text {nose }}$ and $C_{\text {mouth }}$ were also investigated.

\subsection{Experimental design}

Tests for each human subject were carried in a completely randomized factorial design. The dependent variables were $C_{\text {nose }}$ and $C_{\text {mouth }}$, and the independent variables were $V_{\text {face }}, V_{\text {cross }}$, and $\Delta T_{\text {human }}$. Three levels of $V_{\text {face }}(100,160$, and $220 \mathrm{fpm})$ and three levels of $V_{\text {cross }}(14,46$, and $63 \mathrm{fpm})$ were tested with two replications for every experimental trial. This completes a set of 18 experimental tests for each subject. However, several extra replications were carried out due to incorrect results or equipment malfunction. Every test took 35 to 40 minutes, including the 20 minutes of sampling and apparatus setup. 


\subsection{Apparatus}

Human subject experiments were carried out to test the performance of the custom-made benchtop enclosing hood to minimize exposure to the subjects. All tests were done inside a wind tunnel (see Figure 3.1) with ten different human subjects. The subjects were of different ethnic backgrounds (two black Americans, two white Americans, four Hispanics, one black African, and one Asian), and different physical features (Table 7.1), as shown in Figures 7.1 to 7.10. Subjects who did not complete all trials were not included. They were casually clothed and stood in front of the hood in a working posture. Human subjects and both manikins' tests used the same apparatus. Thus, detailed description of apparatus is given in Chapter 3.

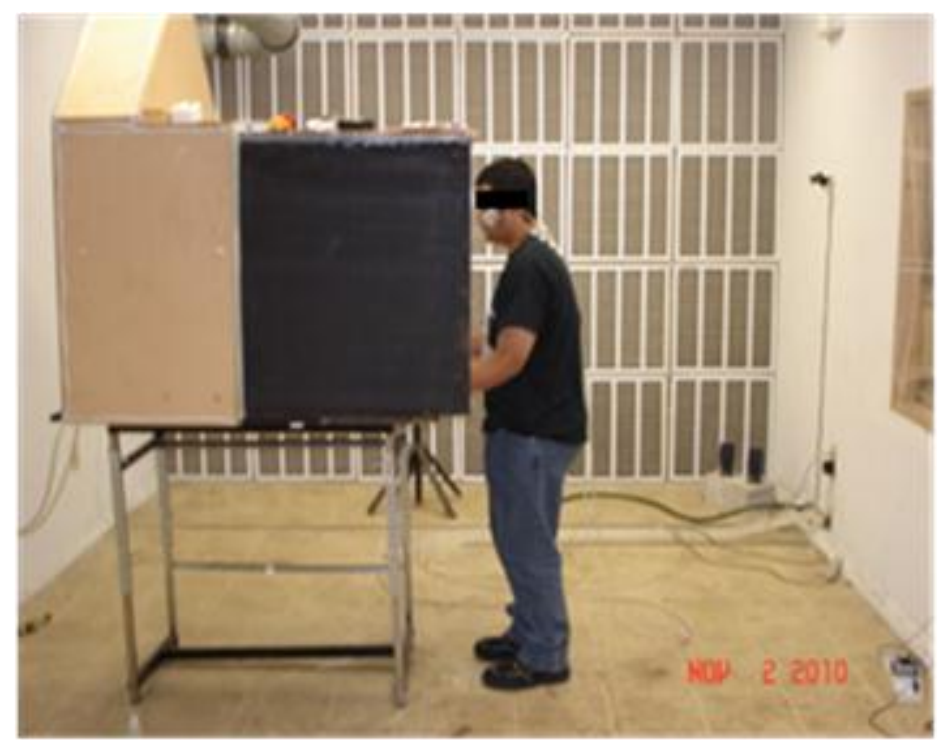

Figure 7.1 Human subject ID Orange in a working posture 


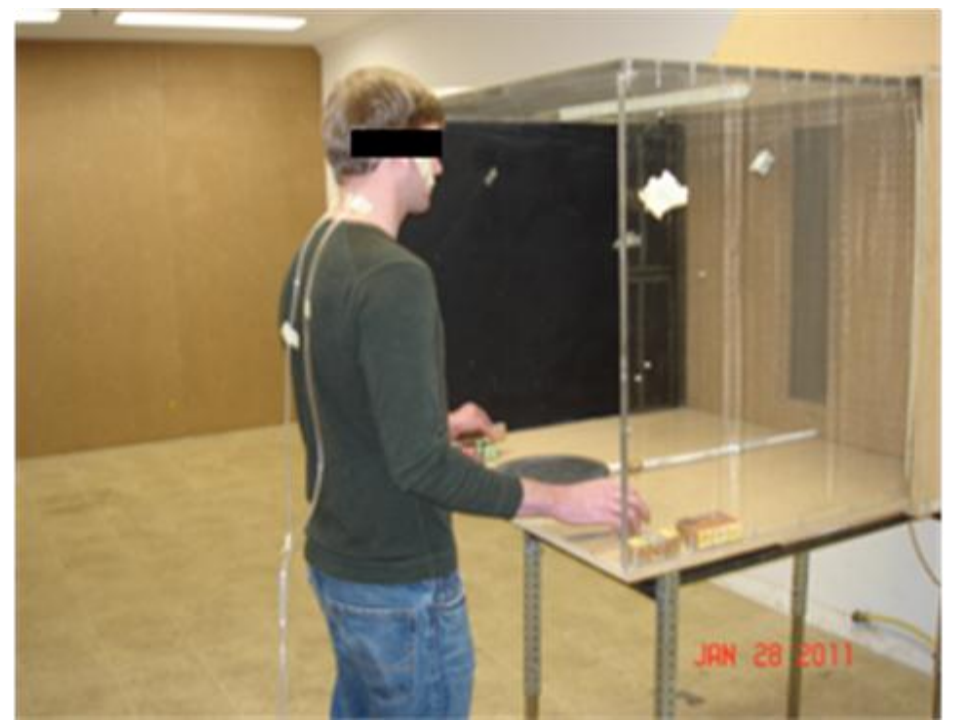

Figure 7.2 Human subject ID Red in a working posture

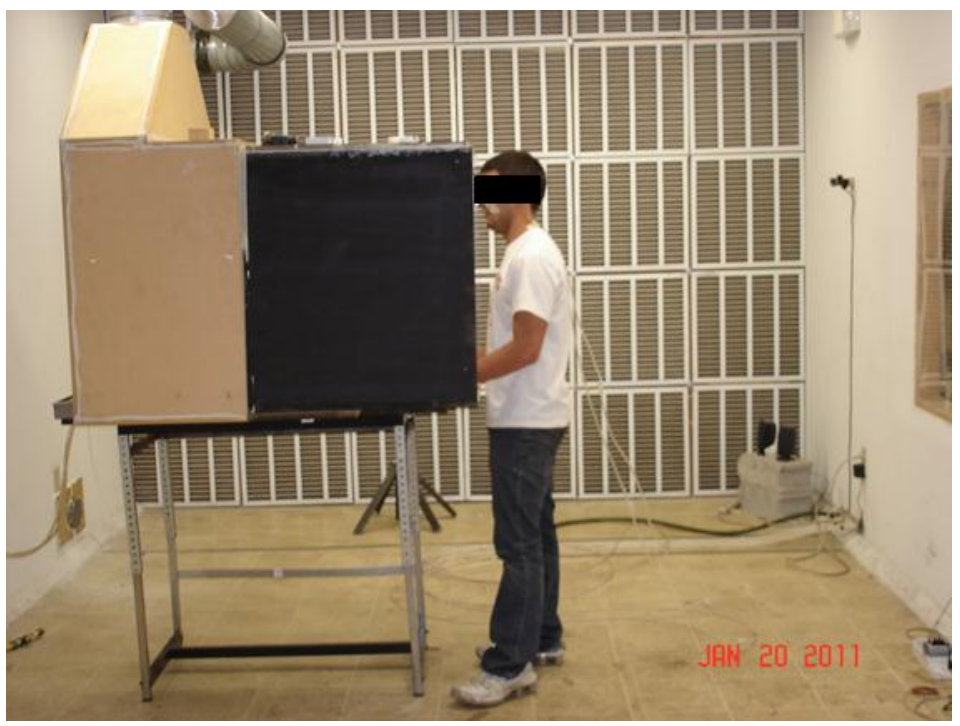

Figure 7.3 Human subject ID Yellow in a working posture 


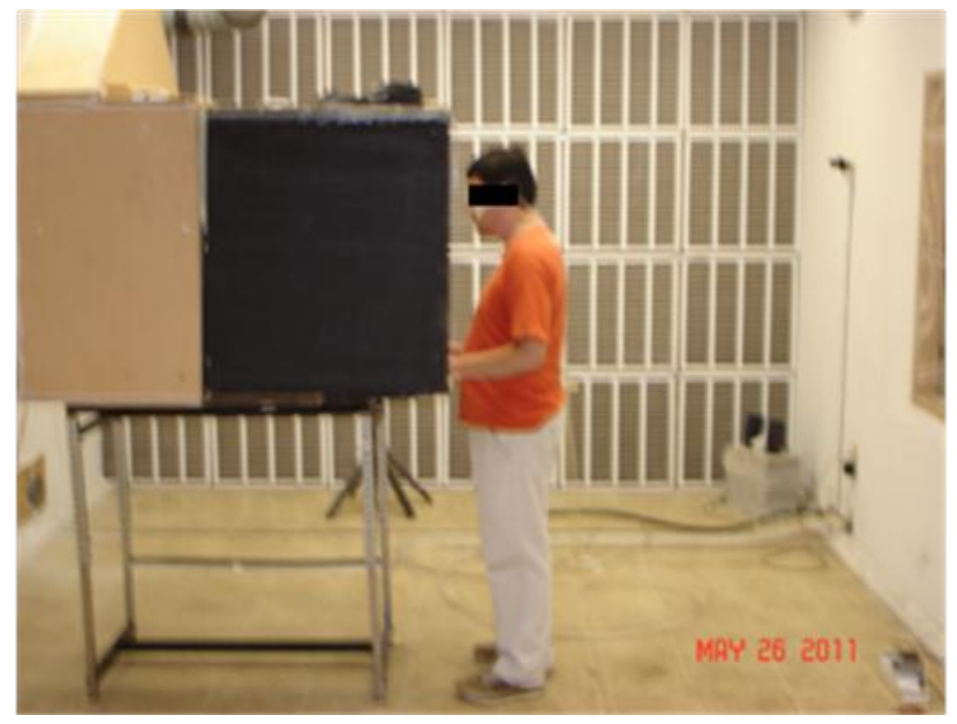

Figure 7.4 Human subject ID Green in a working posture

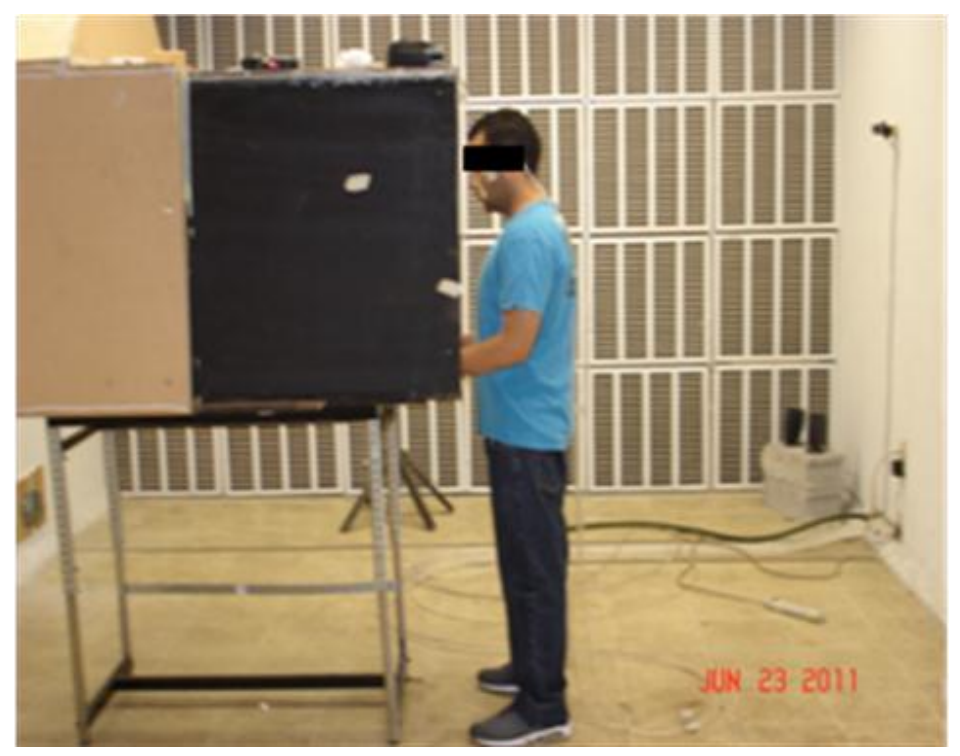

Figure 7.5 Human subject ID Brown in a working posture 


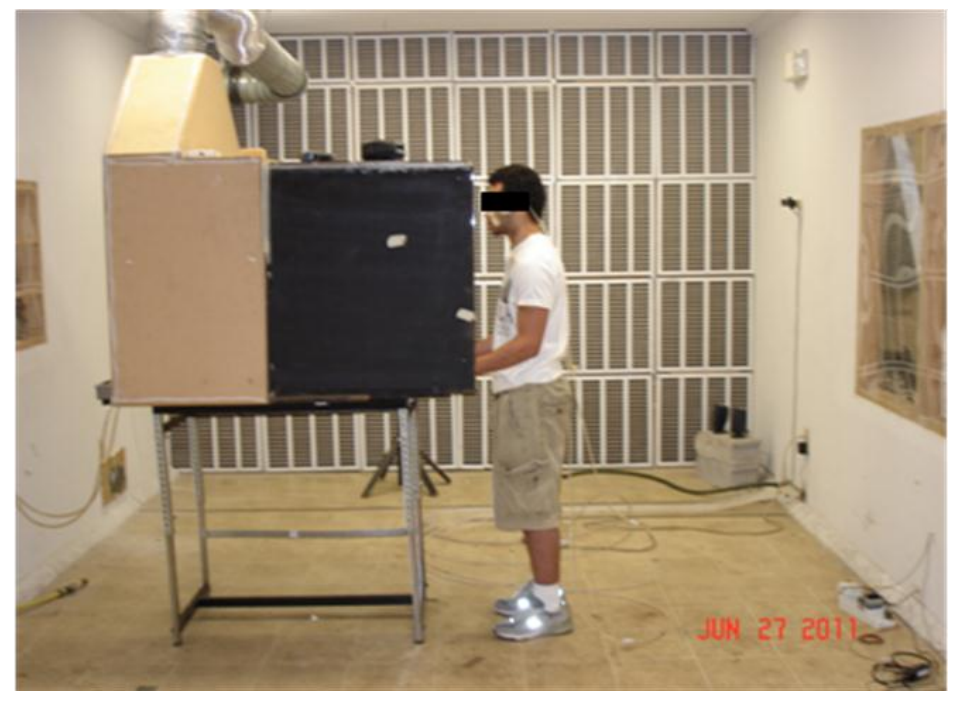

Figure 7.6 Human subject ID Gray in a working posture

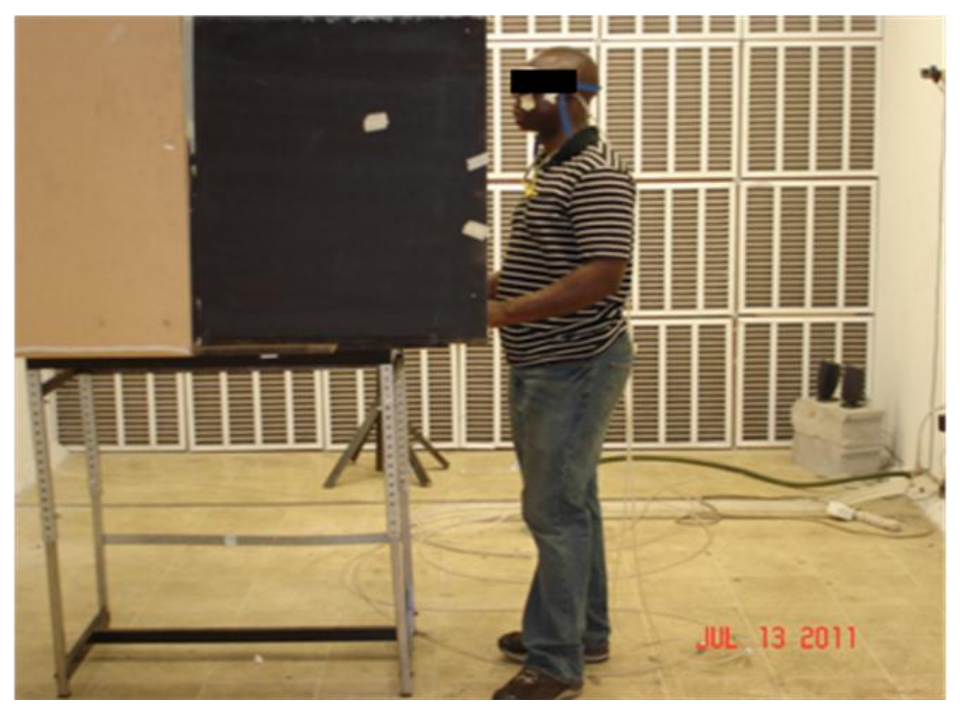

Figure 7.7 Human subject ID Cyan in a working posture 


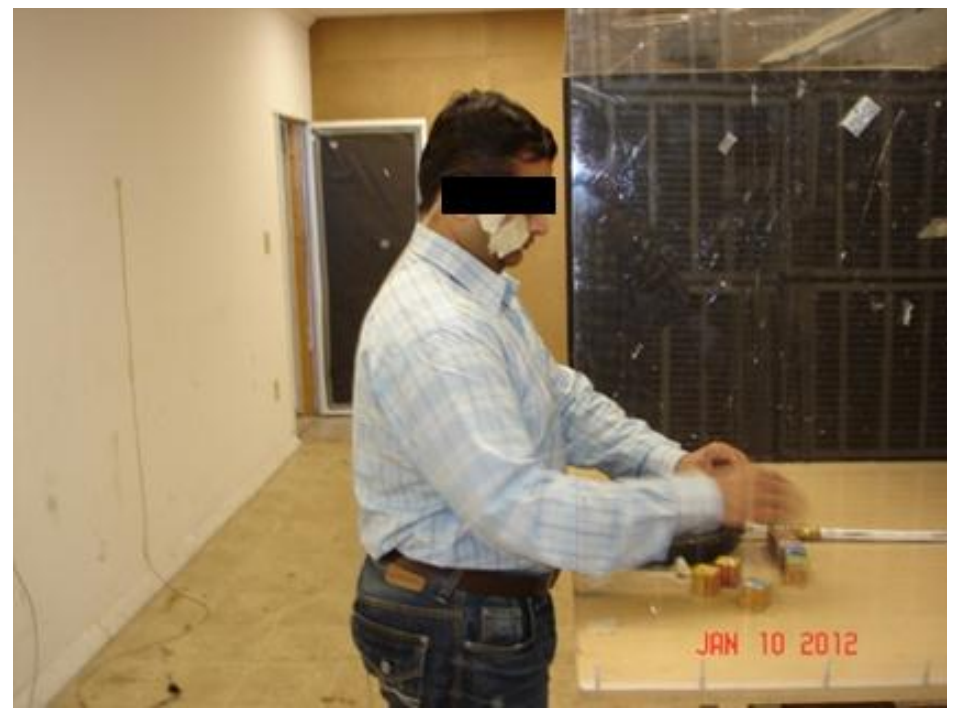

Figure 7.8 Human subject ID Purple in a working posture

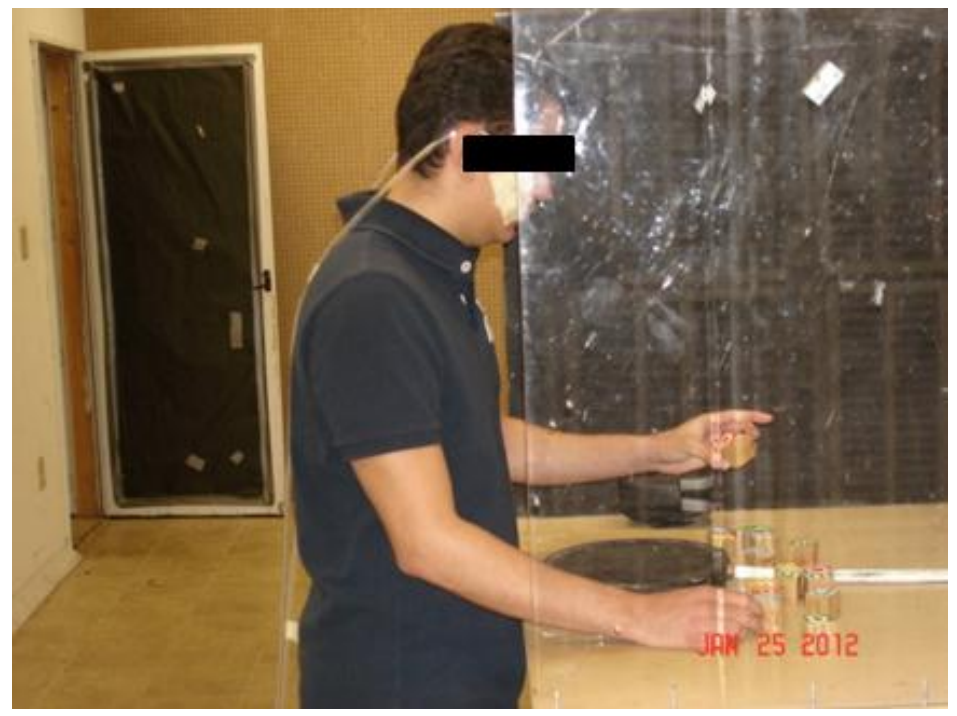

Figure 7.9 Human subject ID Black in a working posture 


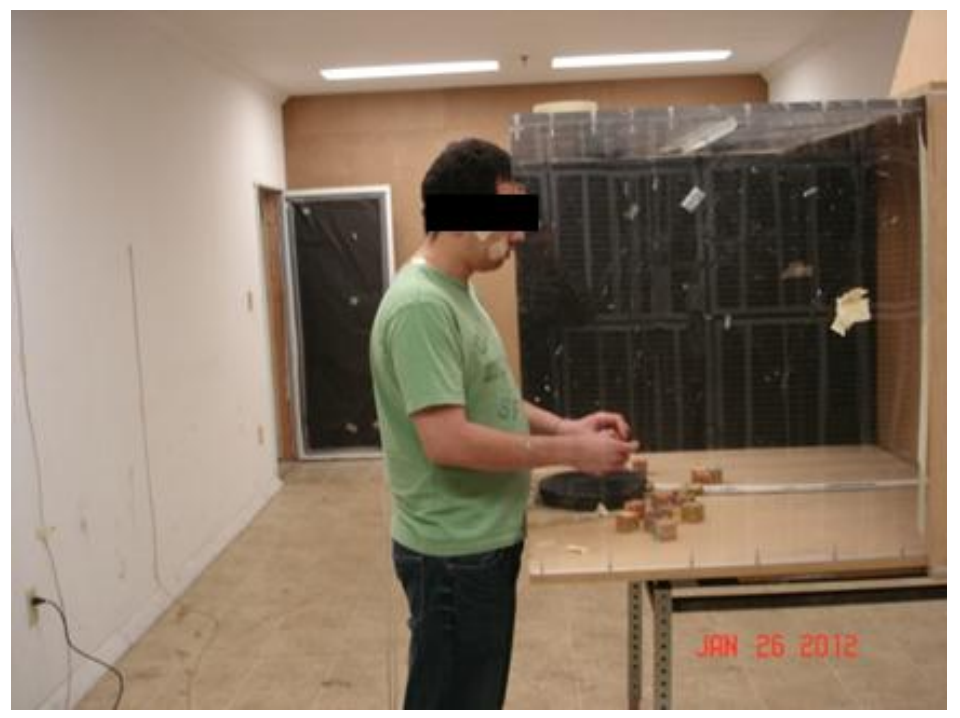

Figure 7.10 Human subject ID Magenta in a working posture

Table 7.1 Human subjects' physical measures

\begin{tabular}{lcccc}
\hline Subject & Height & Shoulder, [in] & Weight, [lb] & Head perim., [in] \\
\hline Orange & $5^{\prime} 8^{\prime \prime}$ & 20.0 & 203.0 & 22.5 \\
Red & $5^{\prime} 10^{\prime \prime}$ & 17.0 & 160.0 & 22.5 \\
Yellow & $5^{\prime} 10^{\prime \prime}$ & 18.0 & 180.0 & 21.5 \\
Green & $5^{\prime} 7^{\prime \prime}$ & 17.5 & 169.4 & 21.5 \\
Brown & $5^{\prime} 7^{\prime \prime}$ & 18.0 & 156.5 & 23.5 \\
Gray & $5^{\prime} 10^{\prime \prime}$ & 18.0 & 170.0 & 21.5 \\
Cyan & $5^{\prime} 8^{\prime \prime}$ & 17.5 & 180.0 & 22.5 \\
Purple & $5^{\prime} 7^{\prime \prime}$ & 18.0 & 175.0 & 22.5 \\
Black & $5^{\prime} 8^{\prime \prime}$ & 17.5 & 140.0 & 20.5 \\
Magenta & $5^{\prime} 11^{\prime \prime}$ & 18.5 & 183.0 & 23.0 \\
\hline
\end{tabular}

\subsection{Methods}

Throughout the experiments, human subjects stood in front of the enclosing hood in a working posture moving small children's blocks back and forth with both hands, one at a time, over the source. The rate of the hand movement followed the 
sound of a metronome software ( $\mathrm{NCH}$ free software) at 40 to 60 beats per minute. For comparison purposes, humans and both manikins all had the same working posture in front of the enclosing hood.

The released contaminant source was placed at the center edge of the table on the hood face at waist height of the subject. Sampling probes (1/8" I.D. Tygon tubing) were placed near the left side of the nose and near the right side of the mouth to assess the inhaled contaminants $\left(C_{\text {nose }}\right.$ and $\left.C_{\text {mouth }}\right)$. Sampling probes were fixed to the human subject's face using a non-allergenic tape during the experiments. In addition, samples of leaked contaminants (Freon 134a) were also taken inside the wind tunnel $\left(C_{\text {downstream }}\right)$, upstream outside of the wind tunnel on the right and left locations $\left(C_{\text {ambientR }}\right.$ and $\left.C_{\text {ambient }}\right)$, and in the exhaust duct outside the wind tunnel $\left(C_{d u c t}\right)$. See Chapter 4 for detailed description of methods.

\subsection{Analysis}

Data analyses of human experiments follow the same procedure as for both manikins. Detailed description is given in the data analysis section of Chapter 4. However, it is important to mention again that due to the fact that two discrete variables $\left(V_{\text {face }}\right.$ and $\left.V_{\text {cross }}\right)$ and a continuous variable $\left(\Delta T_{\text {human }}\right)$ were set as independent variables, the analysis of covariance (ANCOVA) was used for the logtransformed concentrations at the nose and mouth of the dependent variables (log $C_{\text {nose }}$ and $\left.\log C_{\text {mouth }}\right)$. 


\subsection{Results}

Between November 2010 and February 2012, 188 samples were collected at the nose $\left(C_{\text {nose }}\right)$ and 186 at the mouth $\left(C_{\text {mouth }}\right)$, as shown in Tables 7.4 and 7.5. Concentrations at the nose and mouth $\left(C_{\text {nose }}\right.$ and $\left.C_{\text {mouth }}\right)$ are the corrected concentrations (Tables 7.2 and 7.3). Those were obtained with Equations 4.3 and 4.4 (see Chapter 4). Tables 7.2 and 7.3 showed an unbalanced design as consequence of the omitted FTIR results with unacceptable residuals (see Chapter 4). For subjects with more than 2 replications, the second and subsequent replications were averaged. Tables 7.4 and 7.5 showed the summary statistics for $C_{\text {nose }}$ and $C_{\text {mouth }}$.

The summary statistics in Tables 7.4 and 7.5 showed the variability of human subjects' exposure. Human subject identified as Gray has the maximum concentration, median and standard deviation values for $C_{\text {nose }}(26.43,2.76$, and 8.33

ppm) and for $C_{\text {mouth }}(108.18,4.90$, and $24.74 \mathrm{ppm})$, respectively. This marked difference from the rest of the subjects will be analyzed later in this chapter. In addition, error bars were plotted on the average of the exposure data to indicate the confident interval that the means are likely to represent the true exposure values. 
Table 7.2 $C_{\text {nose }}$ for every human subject in ppm

\begin{tabular}{|c|c|c|c|c|c|c|c|c|}
\hline \multirow{2}{*}{$\begin{array}{r}V_{\text {face }}, \\
{[\mathbf{f p m}]}\end{array}$} & \multirow[b]{2}{*}{ Subject } & \multicolumn{6}{|c|}{$V_{\text {cross }},[\mathbf{f p m}]$} & \multirow[b]{2}{*}{ Mean } \\
\hline & & \multicolumn{2}{|c|}{14} & \multicolumn{2}{|c|}{46} & \multicolumn{2}{|c|}{63} & \\
\hline \multirow{10}{*}{100} & Orange & 0.0 & $0.1^{*}$ & 0.1 & 0.9 & 0.1 & 0.1 & \\
\hline & Red & 0.0 & 0.1 & 0.1 & $0.0 * *$ & 0.0 & 0.0 & \\
\hline & Yellow & 0.0 & $0.1^{*}$ & 0.1 & & 0.0 & $0.0^{*}$ & \\
\hline & Green & 0.0 & 0.0 & 0.2 & 0.1 & 0.0 & 0.9 & \\
\hline & Brown & 2.6 & 5.0 & 5.1 & 2.1 & 4.4 & 1.3 & \\
\hline & Gray & 26.1 & 7.2 & 11.9 & & 2.7 & & \\
\hline & Cyan & 0.0 & 0.0 & 0.3 & 0.1 & 0.0 & 0.3 & \\
\hline & Purple & 0.0 & 0.4 & 0.1 & 0.1 & 0.1 & 0.4 & \\
\hline & Black & 3.6 & 4.3 & 2.5 & 6.7 & 2.1 & & \\
\hline & Magenta & 0.1 & 0.0 & 0.2 & 0.1 & 0.2 & 0.1 & \\
\hline Mean & & 2.3 & & 1.5 & & 0.7 & & 1.5 \\
\hline \multirow{10}{*}{160} & Orange & 0.0 & 0.0 & 0.0 & 0.0 & 0.0 & 0.0 & \\
\hline & Red & 0.0 & 0.0 & 0.0 & 0.0 & 0.0 & 0.0 & \\
\hline & Yellow & 0.0 & 0.0 & 0.0 & 0.0 & 0.1 & 0.0 & \\
\hline & Green & 0.0 & $0.0^{*}$ & 0.0 & 0.1 & 0.0 & 0.0 & \\
\hline & Brown & 0.2 & 0.0 & 0.0 & 3.1 & 1.5 & 1.4 & \\
\hline & Gray & 2.8 & $6.1^{*}$ & 26.4 & 10.0 & 1.8 & $15.3^{*}$ & \\
\hline & Cyan & 0.1 & 0.1 & 0.1 & 0.0 & 0.1 & 0.1 & \\
\hline & Purple & 0.1 & 0.0 & 0.1 & 0.0 & 0.1 & $0.2^{* * *}$ & \\
\hline & Black & 0.0 & $8.1^{*}$ & 15.8 & 1.4 & 0.0 & $1.5^{*}$ & \\
\hline & Magenta & 0.0 & & 0.0 & & 0.1 & 0.0 & \\
\hline Mean & & 1.4 & & 3.0 & & 1.0 & & 1.8 \\
\hline \multirow{10}{*}{220} & Orange & 0.0 & $0.0^{*}$ & 0.0 & 0.0 & 0.0 & 0.0 & \\
\hline & Red & 0.0 & 0.0 & 0.0 & 0.0 & 0.0 & 0.0 & \\
\hline & Yellow & 0.0 & & 0.0 & 0.1 & 0.0 & 0.1 & \\
\hline & Green & 0.0 & 0.0 & 0.0 & $0.0^{*}$ & 0.0 & 0.0 & \\
\hline & Brown & 2.0 & 0.8 & 0.4 & 3.2 & 2.2 & 0.0 & \\
\hline & Gray & 2.2 & 0.1 & 3.3 & 7.1 & 0.3 & $0.4^{*}$ & \\
\hline & Cyan & 0.1 & 0.0 & 0.0 & 0.0 & 0.0 & 0.0 & \\
\hline & Purple & 0.1 & 0.3 & 0.0 & 0.0 & 0.0 & 0.2 & \\
\hline & Black & 2.2 & 2.1 & 4.3 & 0.3 & 0.3 & 1.7 & \\
\hline & Magenta & 0.1 & 0.0 & 0.1 & 0.1 & 0.0 & 0.2 & \\
\hline Mean & & 0.5 & & 0.9 & & 0.3 & & 0.6 \\
\hline Mean & & 1.4 & & 1.8 & & 0.6 & & 1.3 \\
\hline
\end{tabular}


Table 7.3 $C_{\text {mouth }}$ for every human subject in ppm

\begin{tabular}{|c|c|c|c|c|c|c|c|c|}
\hline \multirow{2}{*}{$\begin{array}{c}V_{\text {face }}, \\
{[\mathrm{fpm}]}\end{array}$} & \multirow[b]{2}{*}{ Subject } & \multicolumn{6}{|c|}{$V_{\text {cross, }}$ [fpm] } & \multirow[b]{2}{*}{ Mean } \\
\hline & & \multicolumn{2}{|c|}{14} & \multicolumn{2}{|c|}{46} & \multicolumn{2}{|c|}{63} & \\
\hline \multirow{10}{*}{100} & Orange & 0.3 & $0.0 *$ & 1.1 & 2.1 & 0.1 & 0.4 & \\
\hline & Red & 0.1 & 0.1 & 0.0 & $0.0^{* *}$ & 0.0 & 0.0 & \\
\hline & Yellow & 0.0 & $0.3^{*}$ & 0.5 & & 0.0 & $0.1^{*}$ & \\
\hline & Green & 0.2 & 0.0 & 0.5 & 0.6 & 0.1 & 3.7 & \\
\hline & Brown & 3.8 & 5.8 & 6.5 & 4.5 & 8.3 & 2.8 & \\
\hline & Gray & 11.8 & & 17.2 & & 108.2 & 8.3 & \\
\hline & Cyan & 0.1 & 0.0 & 1.4 & 0.1 & 0.2 & 0.6 & \\
\hline & Purple & 0.0 & 0.5 & 0.1 & 0.3 & 1.2 & 0.9 & \\
\hline & Black & 5.6 & 5.8 & 3.7 & 8.1 & 2.3 & 3.4 & \\
\hline & Magenta & 0.1 & 0.0 & 0.2 & 0.1 & 0.2 & 0.1 & \\
\hline Mean & & 1.7 & & 2.4 & & 6.7 & & 3.6 \\
\hline \multirow{10}{*}{160} & Orange & 0.1 & 0.0 & 0.1 & 0.0 & 0.1 & 0.1 & \\
\hline & Red & 0.0 & 0.0 & 0.1 & 0.0 & 0.0 & 0.0 & \\
\hline & Yellow & 0.3 & 0.1 & 0.0 & 0.1 & 0.1 & 0.2 & \\
\hline & Green & 0.0 & $0.0 *$ & 0.0 & 0.4 & 0.1 & 0.3 & \\
\hline & Brown & 0.4 & 0.8 & 7.7 & $7.3^{*}$ & 2.9 & 2.3 & \\
\hline & Gray & 4.4 & $8.2 *$ & 16.3 & & 4.7 & $12.9^{*}$ & \\
\hline & Cyan & 0.0 & 0.2 & 0.0 & 0.0 & 0.0 & 0.2 & \\
\hline & Purple & 0.2 & 0.0 & 0.1 & 0.0 & 0.0 & $0.0^{* * *}$ & \\
\hline & Black & 0.0 & $11.5^{*}$ & 23.2 & & 5.4 & 0.3 & \\
\hline & Magenta & 0.0 & & 0.0 & & 0.1 & 0.0 & \\
\hline Mean & & 2.1 & & 3.5 & & 1.8 & & 2.5 \\
\hline \multirow{10}{*}{220} & Orange & 0.0 & $0.0 *$ & 0.0 & 0.4 & 0.1 & 0.3 & \\
\hline & Red & 0.1 & 0.1 & 0.0 & 0.1 & 0.0 & 0.1 & \\
\hline & Yellow & 0.1 & & 0.0 & 0.1 & 0.0 & 0.0 & \\
\hline & Green & 0.0 & 0.0 & 0.1 & $0.0^{*}$ & 0.1 & 0.0 & \\
\hline & Brown & 3.7 & 1.3 & 1.2 & 6.0 & 4.4 & 0.0 & \\
\hline & Gray & 2.5 & 0.1 & 5.1 & 11.3 & 1.2 & $1.8^{*}$ & \\
\hline & Cyan & 0.1 & 0.0 & 0.0 & 0.0 & 0.0 & 0.0 & \\
\hline & Purple & 0.1 & 0.3 & 0.1 & 0.0 & 0.0 & 0.2 & \\
\hline & Black & 2.4 & 2.2 & 5.2 & & 0.5 & 2.0 & \\
\hline & Magenta & 0.1 & 0.0 & 0.1 & 0.1 & 0.1 & 0.1 & \\
\hline Mean & & 0.7 & & 1.5 & & 0.6 & & 0.9 \\
\hline Mean & & 1.5 & & 2.4 & & 3.1 & & 2.3 \\
\hline
\end{tabular}


Table 7.4 Human subjects' summary statistic for $C_{\text {nose }}$

\begin{tabular}{lccccccc}
\hline Subject & N & Mean & Median & StdDev & CV & Min & Max \\
\hline Orange & 20 & 0.1 & 0.0 & 0.2 & 2.5 & 0.0 & 0.9 \\
Red & 20 & 0.0 & 0.0 & 0.0 & 1.1 & 0.0 & 0.1 \\
Yellow & 18 & 0.0 & 0.0 & 0.1 & 1.3 & 0.0 & 0.2 \\
Green & 20 & 0.1 & 0.0 & 0.2 & 3.3 & 0.0 & 0.9 \\
Brown & 18 & 2.0 & 1.8 & 1.7 & 0.9 & 0.0 & 5.1 \\
Gray & 19 & 6.8 & 2.8 & 8.3 & 1.2 & 0.0 & 26.4 \\
Cyan & 18 & 0.1 & 0.0 & 0.1 & 1.2 & 0.0 & 0.3 \\
Purple & 20 & 0.1 & 0.1 & 0.1 & 1.0 & 0.0 & 0.4 \\
Black & 19 & 3.5 & 2.1 & 4.5 & 1.3 & 0.0 & 15.8 \\
Magenta & 16 & 0.1 & 0.1 & 0.1 & 0.7 & 0.0 & 0.2 \\
Total & 188 & 1.3 & 0.1 & 3.7 & 2.9 & 0.0 & 26.4 \\
\hline
\end{tabular}

Table 7.5 Human subjects' summary statistic for $C_{\text {mouth }}$

\begin{tabular}{lccccccc}
\hline Subject & N & Mean & Median & StdDev & CV & Min & Max \\
\hline Orange & 20 & 0.3 & 0.1 & 0.5 & 1.9 & 0.0 & 2.1 \\
Red & 20 & 0.0 & 0.0 & 0.0 & 0.8 & 0.0 & 0.1 \\
Yellow & 18 & 0.1 & 0.1 & 0.1 & 1.3 & 0.0 & 0.5 \\
Green & 20 & 0.3 & 0.1 & 0.8 & 2.6 & 0.0 & 3.7 \\
Brown & 19 & 4.1 & 3.8 & 2.7 & 0.7 & 0.0 & 8.3 \\
Gray & 18 & 13.2 & 4.9 & 24.7 & 1.9 & 0.1 & 108.2 \\
Cyan & 18 & 0.2 & 0.0 & 0.3 & 1.9 & 0.0 & 1.4 \\
Purple & 20 & 0.2 & 0.1 & 0.3 & 1.5 & 0.0 & 1.2 \\
Black & 17 & 5.5 & 3.4 & 6.6 & 1.2 & 0.0 & 23.2 \\
Magenta & 16 & 0.1 & 0.1 & 0.1 & 0.7 & 0.0 & 0.2 \\
Total & 186 & 2.3 & 0.1 & 8.8 & 3.8 & 0.0 & 108.2 \\
\hline
\end{tabular}




\subsubsection{Fluid dynamics considerations}

Hood face velocity $\left(V_{\text {face }}\right)$ and cross-draft velocity $\left(V_{\text {cross }}\right)$ are two competing external flows over the human body. However, to calculate the Reynolds number and determine the regime of the flow, an approach velocity was needed (see detailed explanation in Section 4.2 of Chapter 4). Approach velocity ranges between 25 and $97 \mathrm{fpm}$ for all human subjects (Appendix E) and it was determined as a function of $V_{\text {face }}$ and $V_{\text {cross }}$ (see Equation C.1 in Appendix C).

The width of the shoulder of each human subject was used as parameter to calculate the Reynolds numbers (Table 7.1). Reynolds numbers between 3000 and 18000 were found for all human subjects (Table 7.6). The effect of increasing $V_{\text {cross }}$ is more significant than the effect of increasing $V_{\text {face }}$ on a Reynolds number. Thus, higher Reynolds numbers were obtained with higher levels of $V_{\text {cross }}$ than with increasing levels of $V_{\text {face }}$. 
Table 7.6 Human subjects' Reynolds numbers

\begin{tabular}{|c|c|c|c|c|c|}
\hline \multirow{2}{*}{$\begin{array}{c}V_{\text {face }}, \\
{[\mathrm{fpm}]}\end{array}$} & \multirow{2}{*}{ Subject } & \multicolumn{3}{|c|}{$V_{\text {cross }},[\mathrm{fpm}]$} & \multirow[b]{2}{*}{ Mean } \\
\hline & & 14 & 46 & 63 & \\
\hline \multirow{10}{*}{100} & Orange & 4598 & 11436 & 14814 & 10282 \\
\hline & Red & 3887 & 9693 & 12572 & 8717 \\
\hline & Yellow & 4092 & 10257 & 13296 & 9215 \\
\hline & Green & 3967 & 9917 & 12916 & 8933 \\
\hline & Brown & 4047 & 10200 & 13242 & 9163 \\
\hline & Gray & 4047 & 10210 & 13255 & 9170 \\
\hline & Cyan & 3922 & 9896 & 12868 & 8895 \\
\hline & Purple & 4065 & 10215 & 13262 & 9180 \\
\hline & Black & 3980 & 9908 & 12900 & 8929 \\
\hline & Magenta & 4190 & 10511 & 13650 & 9450 \\
\hline Mean & & 4080 & 10224 & 13277 & 9194 \\
\hline \multirow{10}{*}{160} & Orange & 5727 & 12595 & 15995 & 11439 \\
\hline & Red & 4832 & 10651 & 13549 & 9677 \\
\hline & Yellow & 5118 & 11297 & 14377 & 10264 \\
\hline & Green & 4940 & 10945 & 13927 & 9937 \\
\hline & Brown & 5077 & 11228 & 14326 & 10211 \\
\hline & Gray & 5055 & 11233 & 14305 & 10198 \\
\hline & Cyan & 4917 & 10925 & 13900 & 9914 \\
\hline & Purple & 5046 & 11244 & 14315 & 10201 \\
\hline & Black & 4919 & 10929 & 13909 & 9919 \\
\hline & Magenta & 5220 & 11542 & 14730 & 10497 \\
\hline Mean & & 5085 & 11259 & 14333 & 10226 \\
\hline \multirow{10}{*}{220} & Orange & 6857 & 13733 & 17146 & 12579 \\
\hline & Red & 5779 & 11635 & 14528 & 10647 \\
\hline & Yellow & 6120 & 12295 & 15377 & 11264 \\
\hline & Green & 5911 & 11896 & 14921 & 10910 \\
\hline & Brown & 6066 & 12232 & 15324 & 11207 \\
\hline & Gray & 6054 & 12203 & 15299 & 11185 \\
\hline & Cyan & 5864 & 11870 & 14857 & 10864 \\
\hline & Purple & 6030 & 12197 & 15296 & 11174 \\
\hline & Black & 5869 & 11882 & 14864 & 10871 \\
\hline & Magenta & 6202 & 12556 & 15731 & 11496 \\
\hline Mean & & 6075 & 12250 & 15334 & 11220 \\
\hline Mean & & 5080 & 11244 & 14315 & 10213 \\
\hline
\end{tabular}




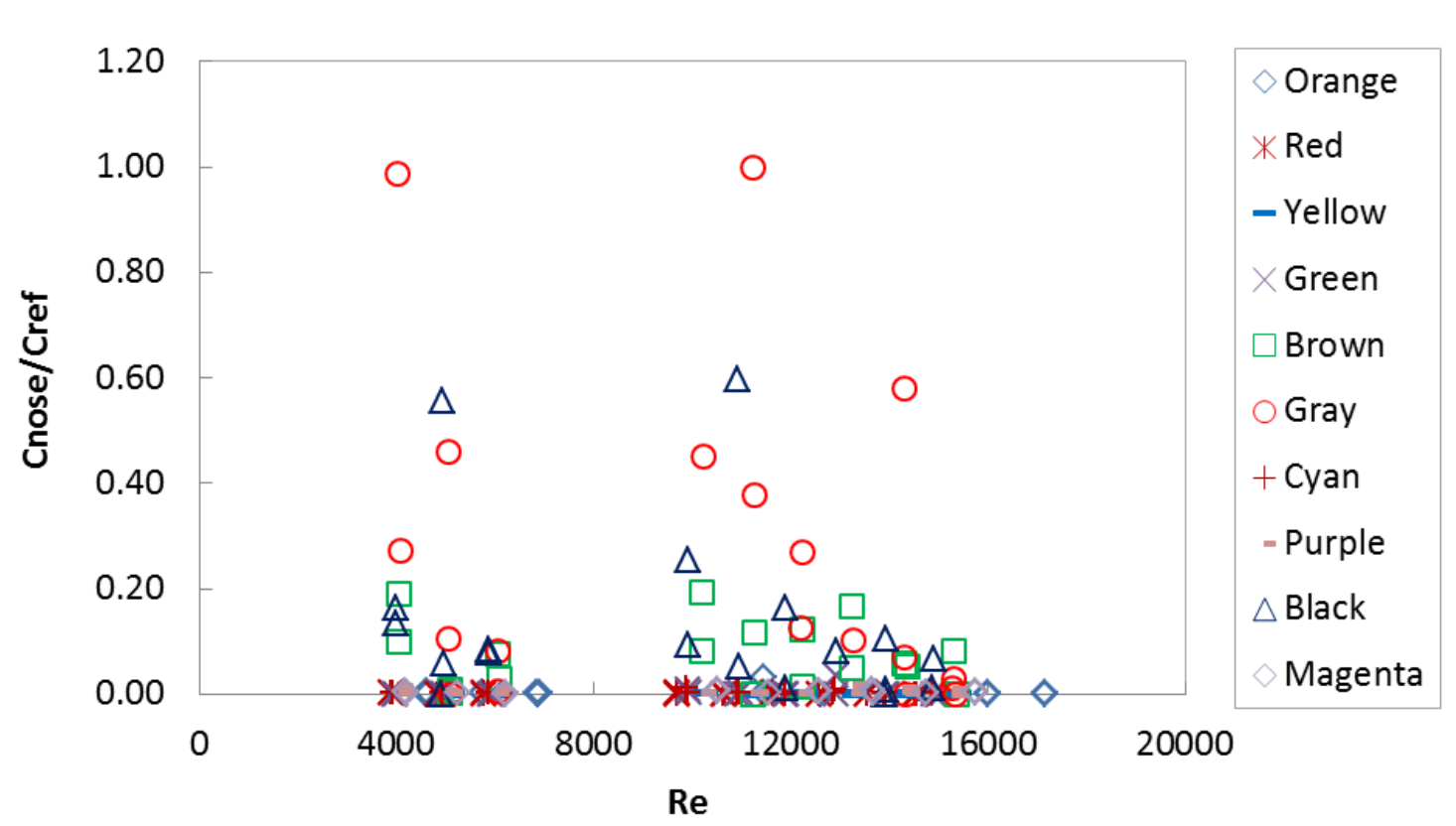

Figure 7.11 Effect of $R e$ on $C_{n o s e} / C_{r e f}$ for the human subjects, $C_{r e f}=26.4 \mathrm{ppm}$

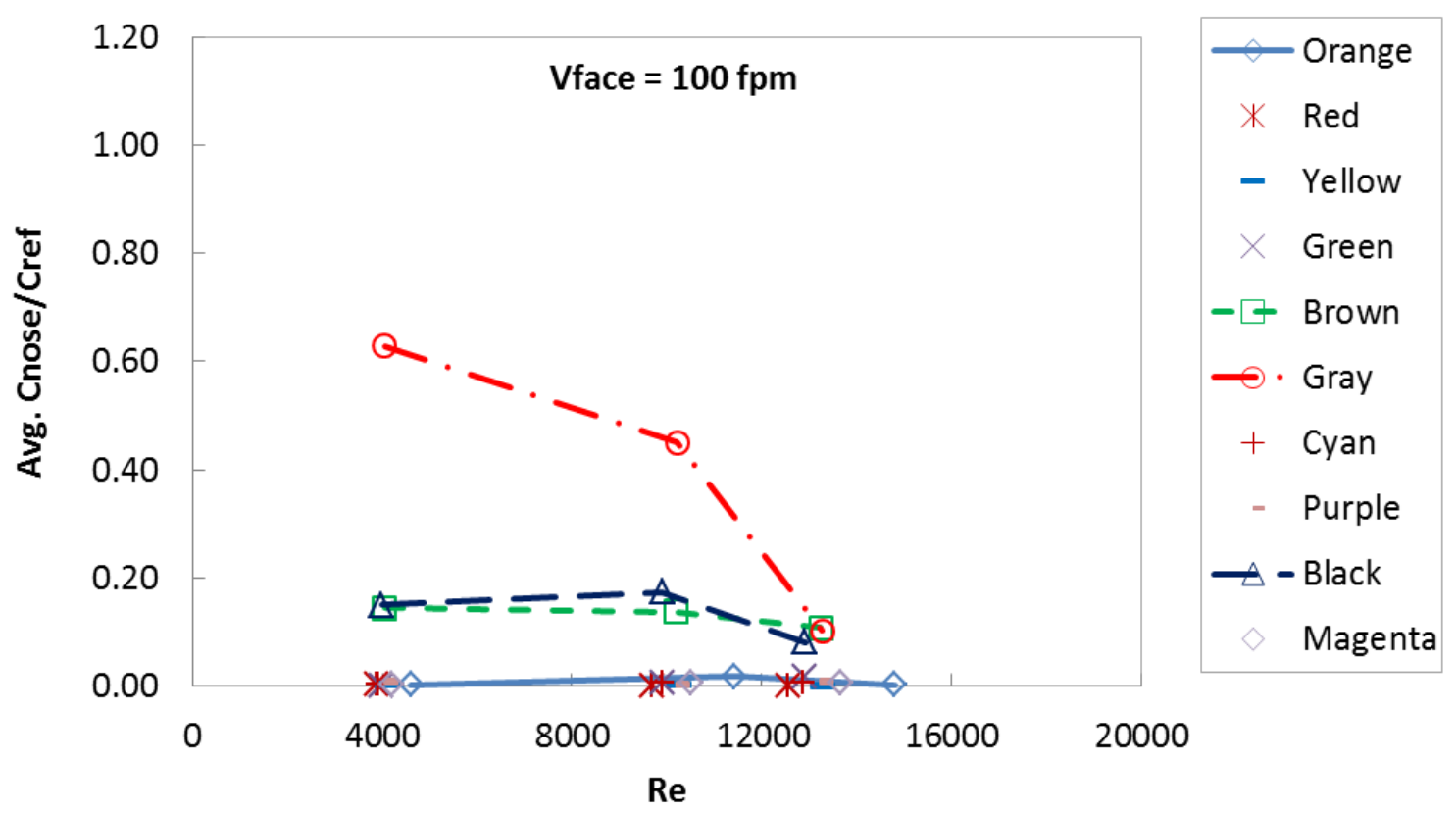

Figure 7.12 Human subjects' effect of $R e$ on average $C_{\text {nose }} / C_{\text {ref }}$ at $V_{\text {face }}=100 \mathrm{fpm}$,

$$
C_{r e f}=26.4 \mathrm{ppm}
$$




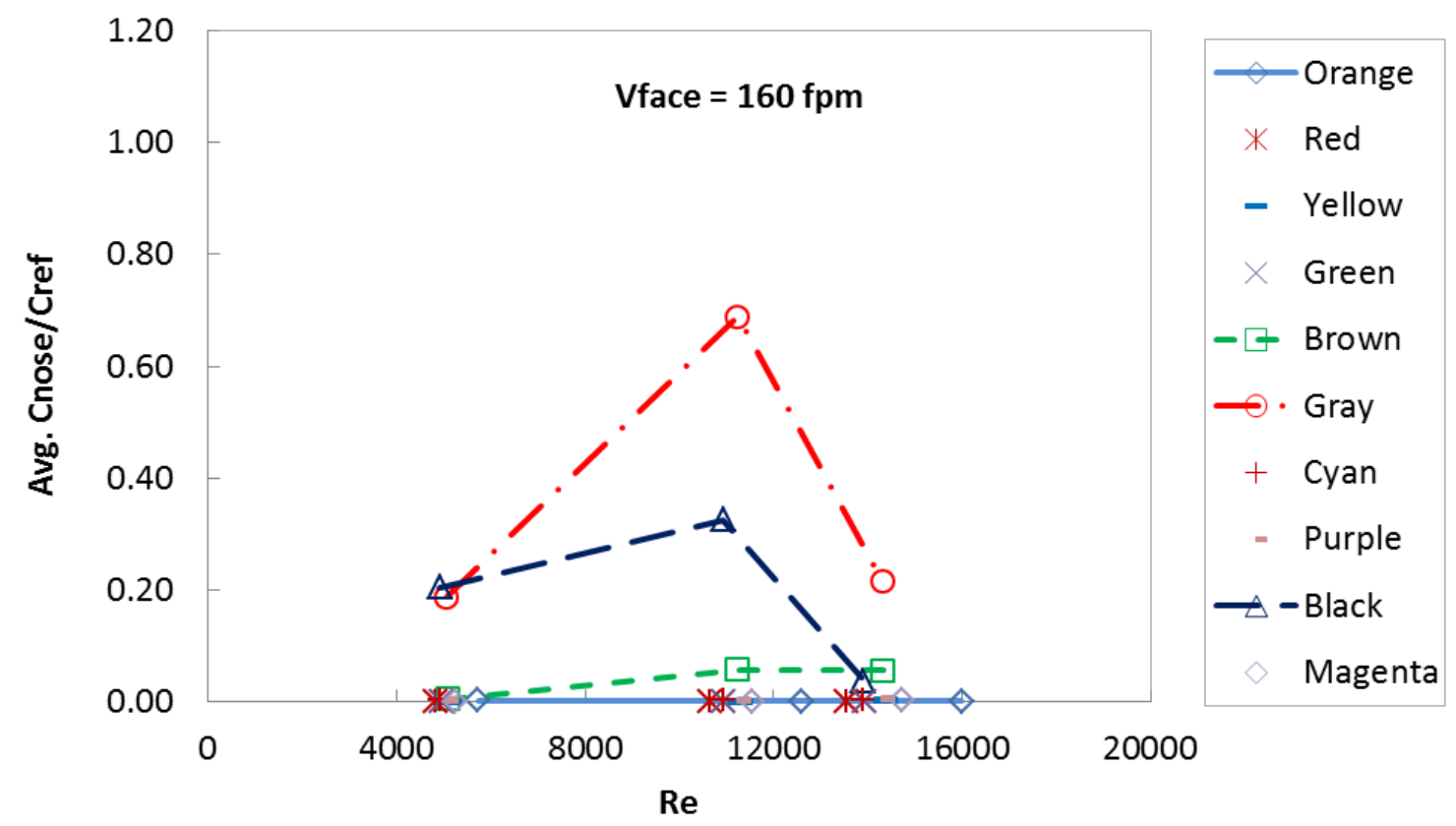

Figure 7.13 Human subjects' effect of $R e$ on average $C_{\text {nose }} / C_{\text {ref }}$ at $V_{\text {face }}=160 \mathrm{fpm}$, $C_{r e f}=26.4 \mathrm{ppm}$

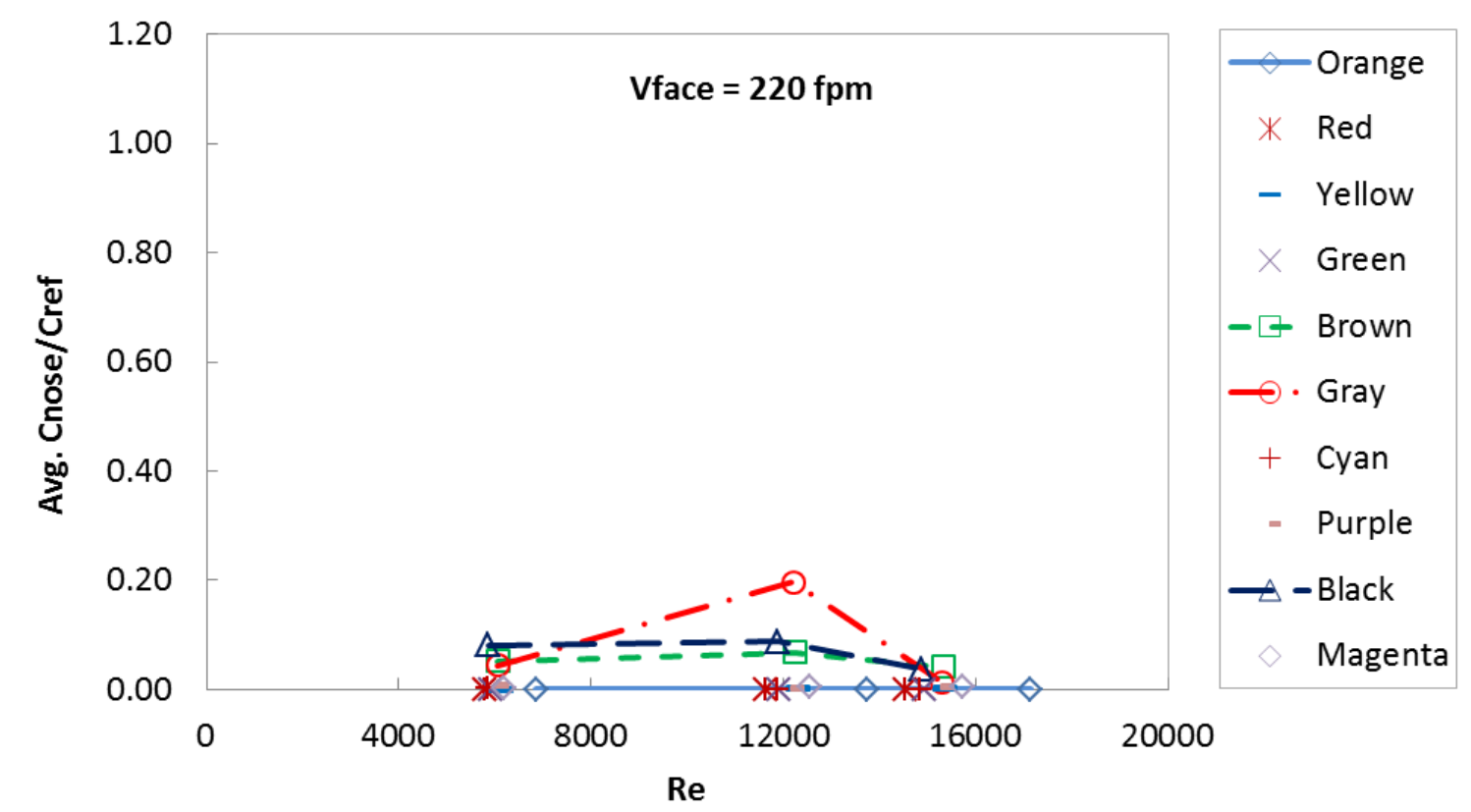

Figure 7.14 Human subjects' effect of $R e$ on average $C_{\text {nose }} / C_{\text {ref }}$ at $V_{\text {face }}=220 \mathrm{fpm}$,

$$
C_{r e f}=26.4 \mathrm{ppm}
$$


Subjects' ID Gray, Brown, and Black presented higher exposure than the other subjects, which may be due to differences in work practices and body dimensions (Figure 7.11). As shown in Figure 7.12, the dimensionless concentration at the nose $\left(C_{\text {nose }} / C_{r e f}\right)$ decreased as the Reynolds number increased, which is clearly observed for Gray, Brown, and Black subjects at $V_{\text {face }}=100 \mathrm{fpm}$. However, at $V_{\text {face }}=160 \mathrm{fpm}$ the dimensionless concentrations at the nose peaked at maximum values for subjects' ID Gray, Brown, and Black at around $R e=10000$ and then fell rapidly at higher Reynolds numbers (Figure 7.13). This finding agrees with Johnson and Flecher (1996) even though they used a fume hood. Similar patterns can be observed at $V_{\text {face }}=220 \mathrm{fpm}$ with lowest dimensionless concentrations for subjects' ID Gray, Brown, and Black (Figure 7.14). On the other hand, the reference concentration $\left(C_{r e f}\right)$ is the maximum exposure at the nose for $C_{\text {nose }} / C_{r e f}$ and the maximum exposure at the mouth for $C_{\text {mouth }} / C_{\text {ref }}$. 


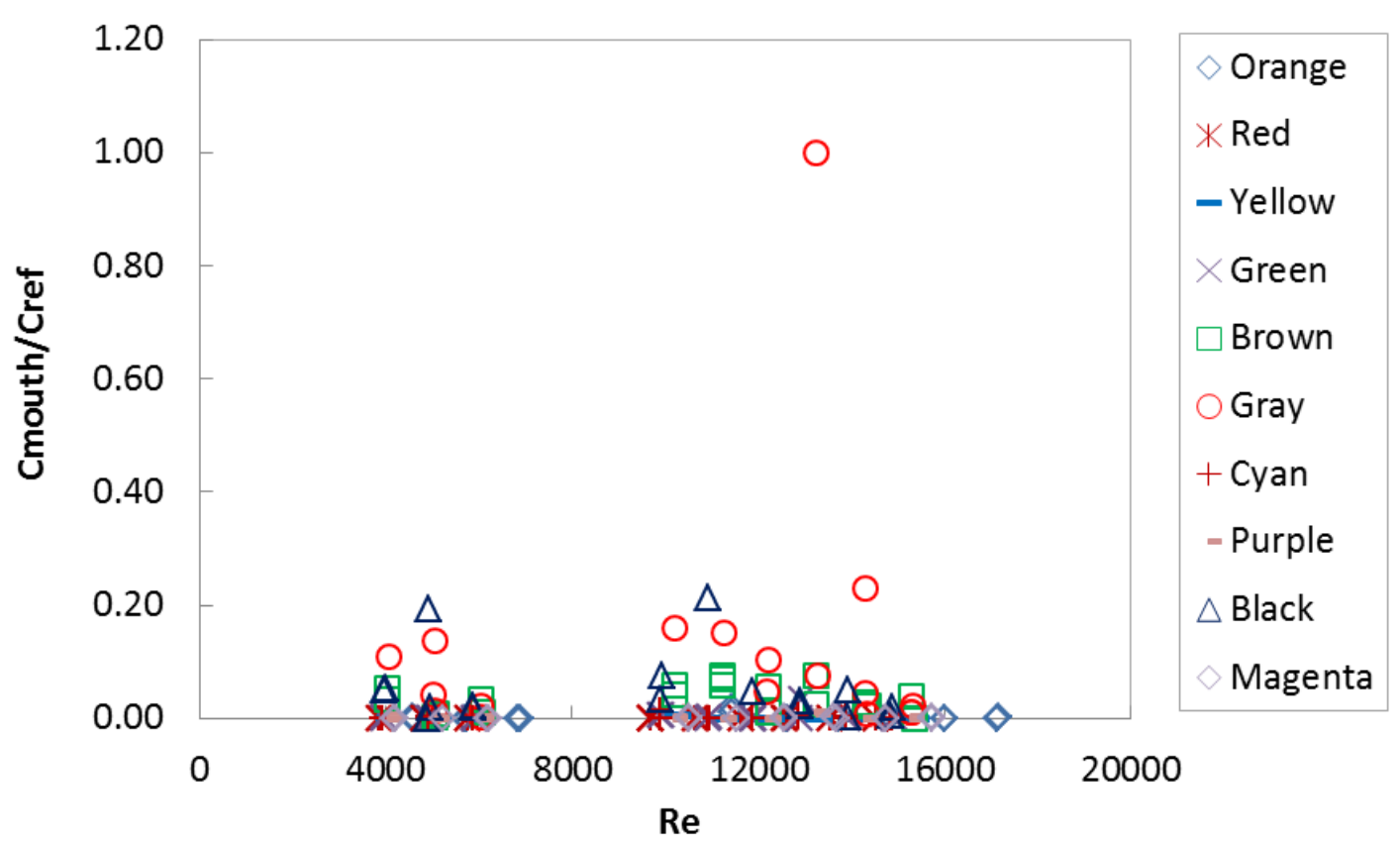

Figure 7.15 Effect of $\operatorname{Re}$ on $C_{\text {mouth }} / C_{r e f}$ for the human subjects, $C_{r e f}=108.2 \mathrm{ppm}$

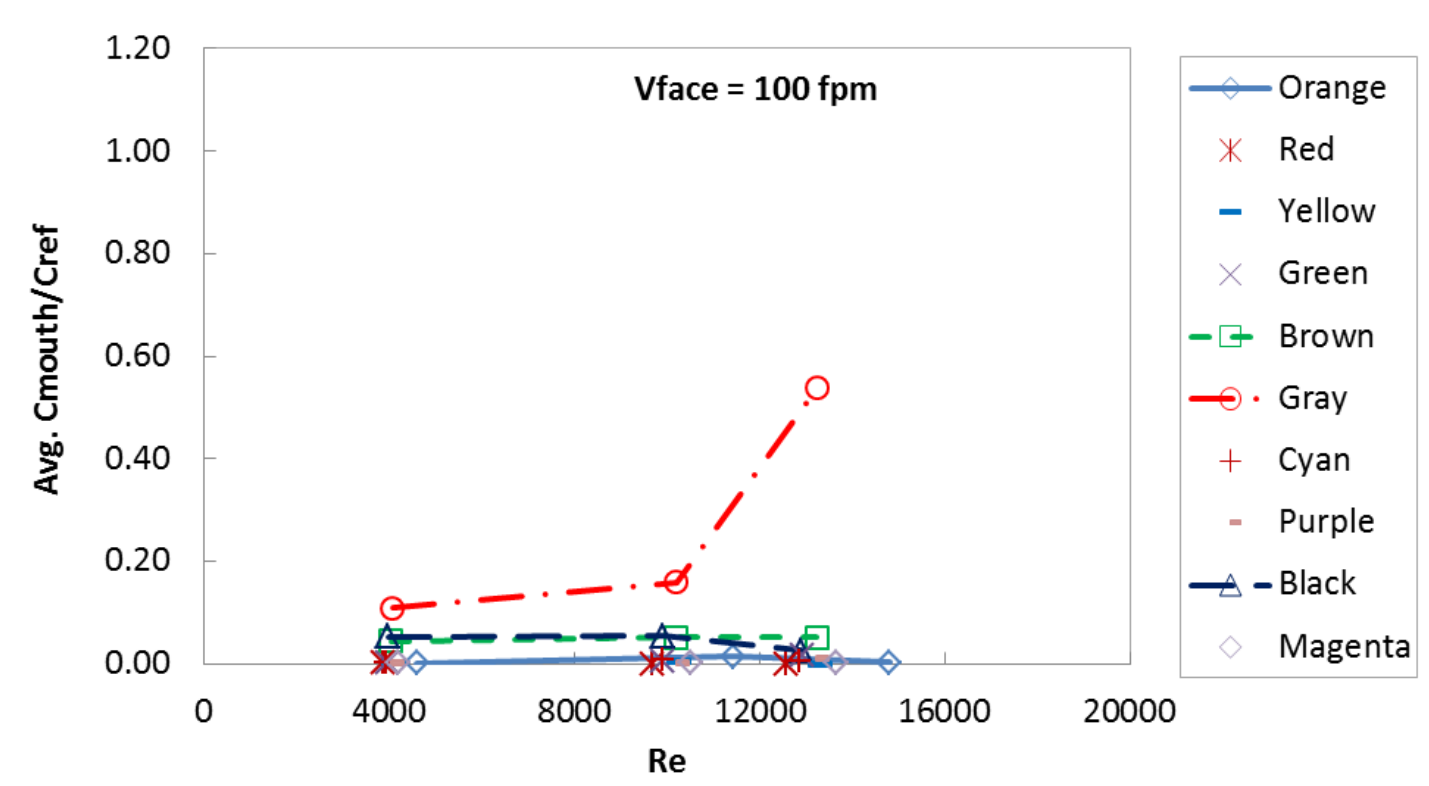

Figure 7.16 Human subject' effect of $R e$ on average $C_{\text {mouth }} / C_{\text {ref }}$ at $V_{\text {face }}=100 \mathrm{fpm}$, $C_{r e f}=108.2 \mathrm{ppm}$ 


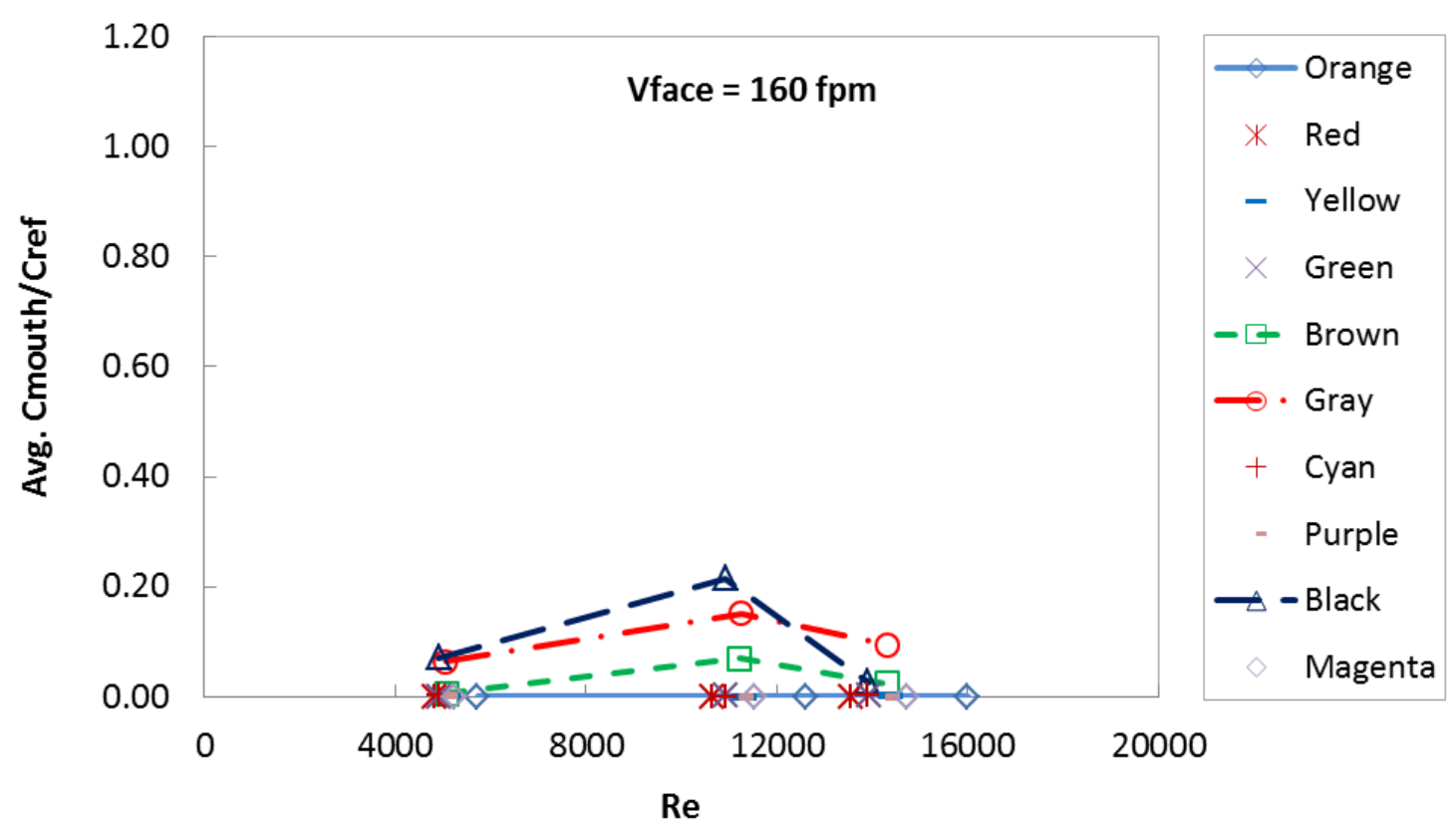

Figure 7.17 Human subject' effect of $R e$ on average $C_{\text {mouth }} / C_{\text {ref }}$ at $V_{\text {face }}=160 \mathrm{fpm}$, $C_{\text {ref }}=108.2 \mathrm{ppm}$

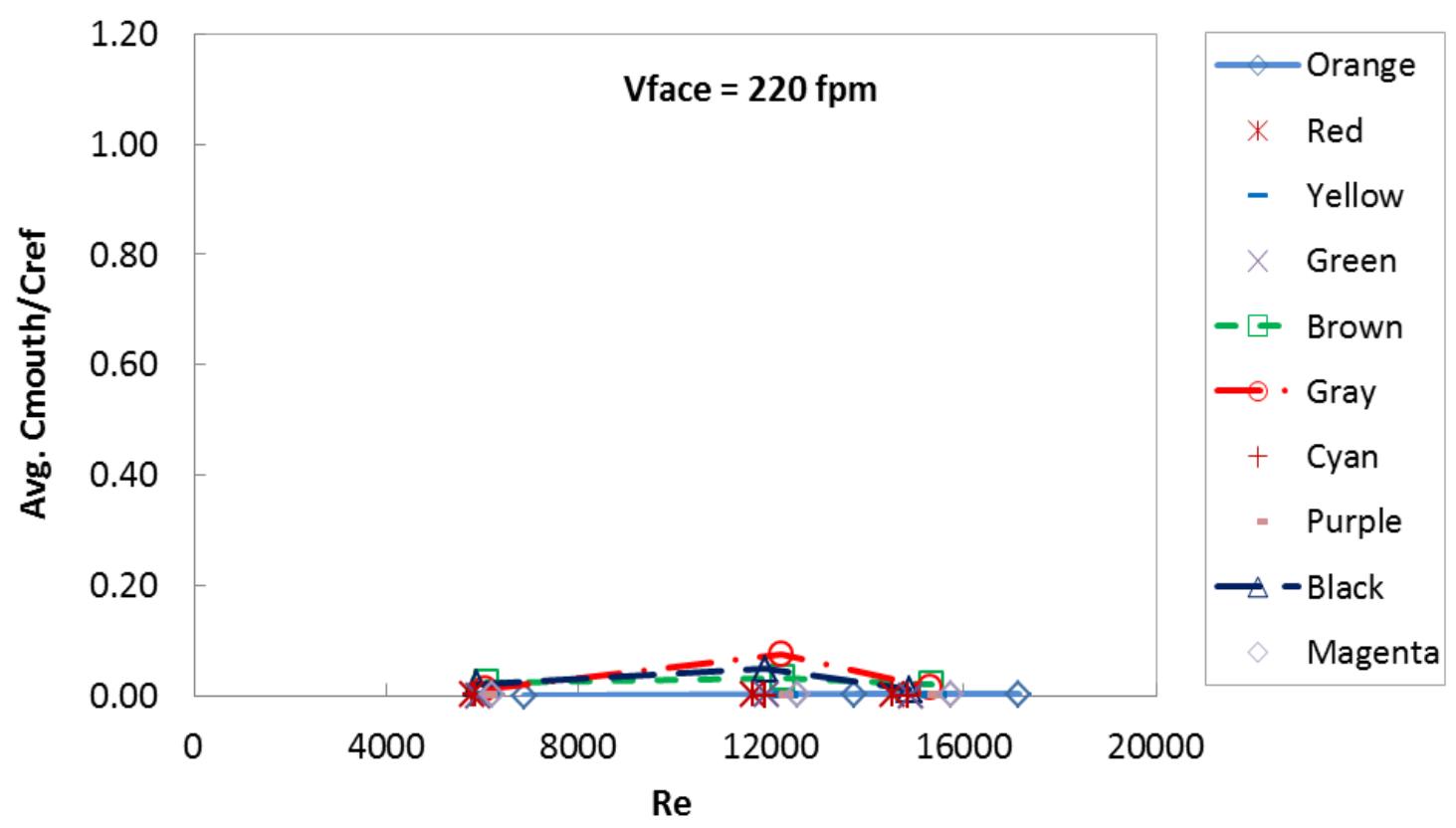

Figure 7.18 Human subject' effect of $R e$ on average $C_{\text {mouth }} / C_{\text {ref }}$ at $V_{\text {face }}=220 \mathrm{fpm}$, $C_{r e f}=108.2 \mathrm{ppm}$ 
Similar patterns of concentrations against $R e$ were expected for $C_{\text {nose }}$ and $C_{m o u t h}$ for all human subjects since the two locations are very near to each other. However, the actual results showed minor differences, such as the notably highest exposure (Gray) when compared to lower exposures for the other subjects (Figures 7.15 and 7.16). Differences in work practices may be the reason for the highest exposures. More specifically, it is likely that the distance between the breathing zone and the source varied for the subjects, as did the location of the head (see Figure 7.43 to 7.46 ). A detailed explanation will be given later in this chapter. On the other hand, the dimensionless concentration at the mouth $\left(C_{\text {mouth }} / C_{r e f}\right)$ showed the same pattern of behaviour than $\left(C_{\text {nose }} / C_{r e f}\right)$ when plotted against the Reynolds number at $V_{\text {face }}=160$ and $220 \mathrm{fpm}$ (Figures 7.17 and 7.18).

The temperature difference between the human subjects and their surroundings play a major part in the way heat is transported to the environment and on subjects' levels of exposure. For this study, heat was released from the subjects to the ambient air $\left(\Delta T_{\text {human }}>0\right)$ and in the direction of the suction flow into the enclosing hood. Heat can be transferred to the environment by natural, force or mixed convection (natural and force convection) depending on the Richardson number value. Richardson number is the ratio between buoyancy forces and inertial forces $\left(R i=G r / R e^{2}\right)$. In Appendix E, Table E.2 shows the Grashof numbers for this study and Table E.3 shows the vertical distance from the hood table to the human's top of the head $\left(H_{\text {human }}\right)$. 
Table 7.7 Human subjects' Richardson numbers

\begin{tabular}{|c|c|c|c|c|c|}
\hline \multirow{2}{*}{$\begin{array}{c}V_{\text {face }}, \\
{[\mathbf{f p m}]}\end{array}$} & \multirow{2}{*}{ Subject } & \multicolumn{3}{|c|}{$V_{\text {cross }},[\mathrm{fpm}]$} & \multirow[b]{2}{*}{ Mean } \\
\hline & & 14 & 46 & 63 & \\
\hline \multirow{10}{*}{100} & Orange & 22.19 & 3.47 & 1.90 & 9.19 \\
\hline & Red & 43.42 & 6.52 & 4.02 & 17.99 \\
\hline & Yellow & 43.05 & 6.81 & 4.09 & 17.98 \\
\hline & Green & 23.01 & 3.13 & 1.74 & 9.29 \\
\hline & Brown & 19.07 & 3.31 & 1.88 & 8.09 \\
\hline & Gray & 25.13 & 4.56 & 2.17 & 10.62 \\
\hline & Cyan & 18.06 & 3.82 & 1.81 & 7.90 \\
\hline & Purple & 17.85 & 2.57 & 1.73 & 7.38 \\
\hline & Black & 28.31 & 4.23 & 2.66 & 11.73 \\
\hline & Magenta & 33.51 & 5.39 & 2.53 & 13.81 \\
\hline Mean & & 27.36 & 4.38 & 2.45 & 11.40 \\
\hline \multirow{10}{*}{160} & Orange & 14.25 & 2.50 & 1.59 & 6.11 \\
\hline & Red & 29.70 & 5.55 & 3.30 & 12.85 \\
\hline & Yellow & 26.45 & 5.93 & 3.27 & 11.88 \\
\hline & Green & 10.84 & 2.56 & 1.46 & 4.95 \\
\hline & Brown & 11.35 & 2.56 & 1.47 & 5.13 \\
\hline & Gray & 13.01 & 3.55 & 1.77 & 6.11 \\
\hline & Cyan & 10.92 & 2.60 & 1.66 & 5.06 \\
\hline & Purple & 12.77 & 2.67 & 1.61 & 5.68 \\
\hline & Black & 18.64 & 3.68 & 2.29 & 8.20 \\
\hline & Magenta & 17.95 & 4.03 & 2.41 & 8.13 \\
\hline Mean & & 16.59 & 3.56 & 2.08 & 7.41 \\
\hline \multirow{10}{*}{220} & Orange & 8.62 & 2.46 & 1.51 & 4.20 \\
\hline & Red & 18.15 & 4.85 & 2.62 & 8.54 \\
\hline & Yellow & 18.23 & 4.81 & 3.10 & 8.71 \\
\hline & Green & 7.88 & 1.87 & 0.99 & 3.58 \\
\hline & Brown & 9.30 & 2.30 & 1.37 & 4.33 \\
\hline & Gray & 10.96 & 2.70 & 1.53 & 5.06 \\
\hline & Cyan & 8.64 & 2.17 & 1.27 & 4.02 \\
\hline & Purple & 10.23 & 2.30 & 1.43 & 4.65 \\
\hline & Black & 13.81 & 2.77 & 2.00 & 6.19 \\
\hline & Magenta & 14.05 & 3.50 & 1.93 & 6.49 \\
\hline Mean & & 11.99 & 2.97 & 1.78 & 5.58 \\
\hline Mean & & 18.65 & 3.64 & 2.10 & 8.13 \\
\hline
\end{tabular}




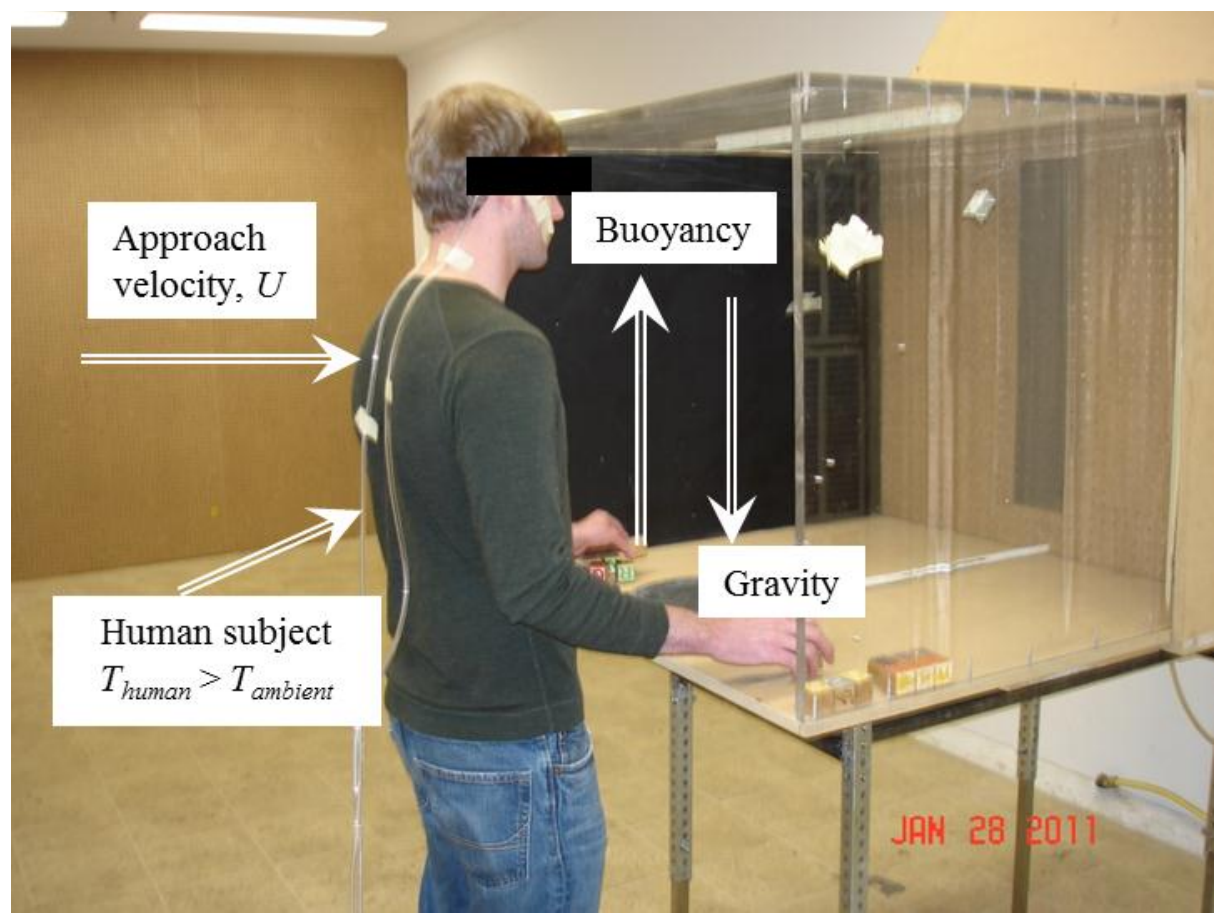

Figure 7.19 Approach velocity and buoyancy representations around a human subject

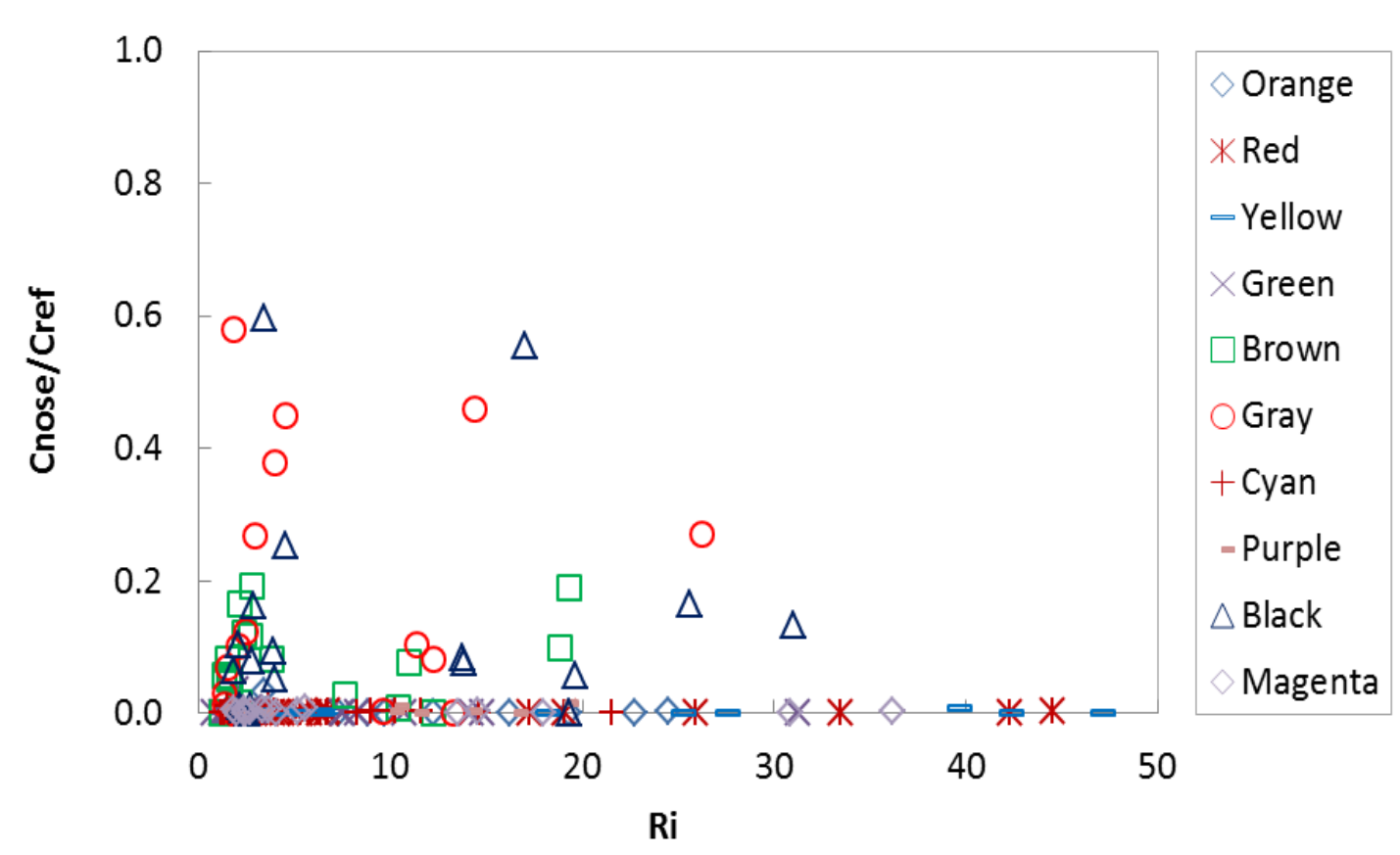

Figure 7.20 Human subjects' effect of $R i$ on $C_{n o s e} / C_{r e f}, C_{r e f}=26.4 \mathrm{ppm}$ (No highest exposure values) 


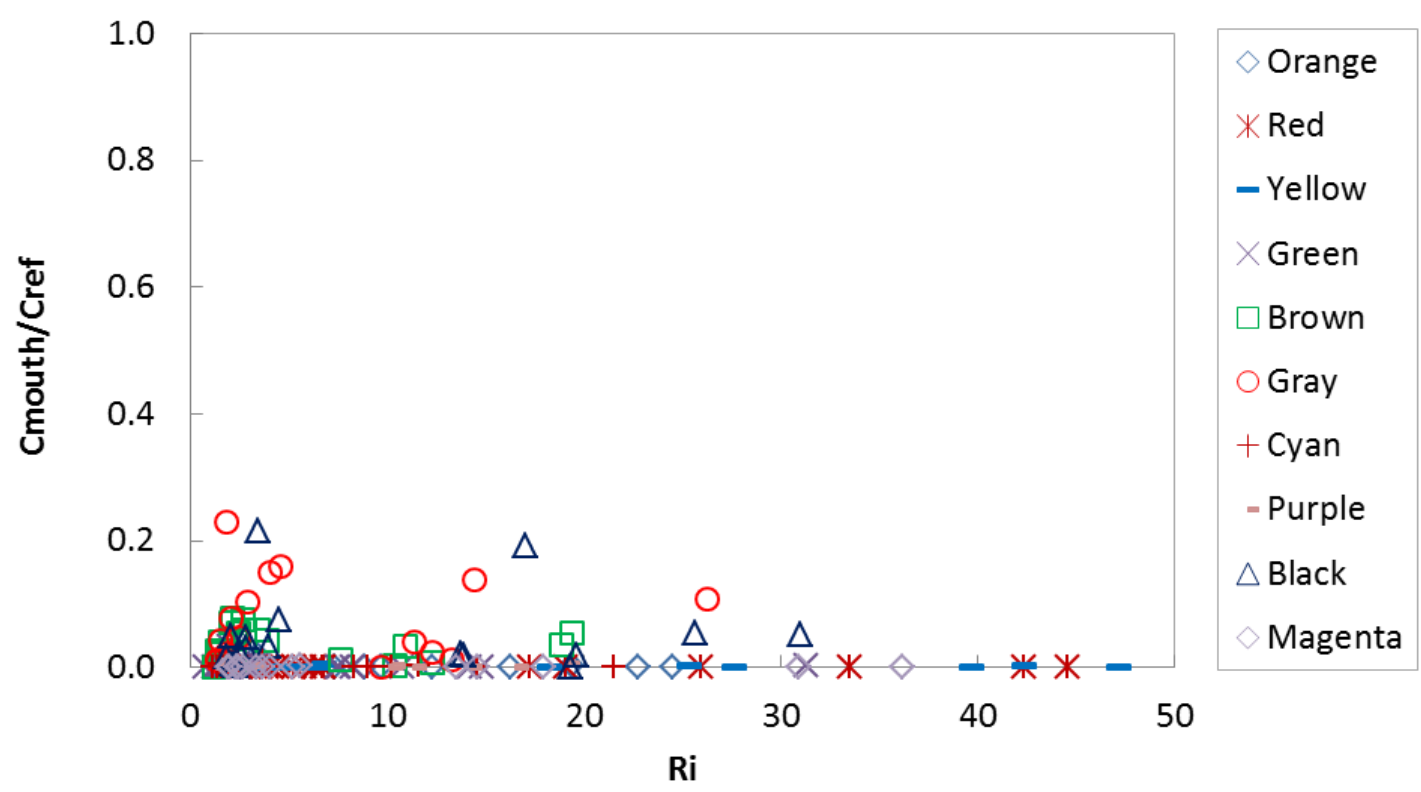

Figure 7.21 Human subjects' effect of $R i$ on $C_{\text {mouth }} / C_{r e f}, C_{r e f}=108.2 \mathrm{ppm}$ (No highest exposure value)

In this study, the approach velocity is horizontal and perpendicular to the buoyancy (Figure 7.19). Heat is transferred to the ambient mainly by mixed convection if the Richardson number is approximately between 0.53 and $16(0.53<$ $R i>16)$. Below this range force convection is important and free convection is negligible. Above this range buoyancy forces (free convection) are more relevant than forced convection (Oosthuizen and Madan, 1971; Brohus, 1997). In the present study, the predominant manner of the human subjects' heat transfer to their surroundings was through mixed convection (Table 7.7).

For the lowest cross-draft velocity $\left(V_{\text {cross }}=14 \mathrm{fpm}\right)$, the average $R i$ were 27.36 And 16.59 for $V_{\text {face }}=100$ and $160 \mathrm{fpm}$, which means that heat was released to the environment mainly through natural convection and force convection was 
negligible (Table 7.7). Thus the buoyancy force produced by the subjects' thermal load is more relevant than inertial force (forced convection) at low $V_{\text {cross. }}$. More clearly, it is suggested that buoyancy is more important than force convection at low Reynolds numbers $(R e<7000)$. However, buoyancy is still important at higher $V_{\text {cross }}\left(V_{\text {cross }}=46\right.$ and $63 \mathrm{fpm}$ ) or higher Reynolds numbers (see Tables 7.6 and 7.7) but at lower $R i$ values and in the mixed convection regime. This finding is in close agreement with previous research, such as for the numerical simulation of an enclosing hood (Karaismail, 2011), the simulation in a free stream airflow (Li et al, 2007), and the fume hood tests (Johnson et al; 1996). There is a tendency to increase exposure in the mixed convection heat transfer zone for subjects with the highest exposure (ID Gray, Brown, and Black) as can be seen in Figures 7.20 and 7.21 .

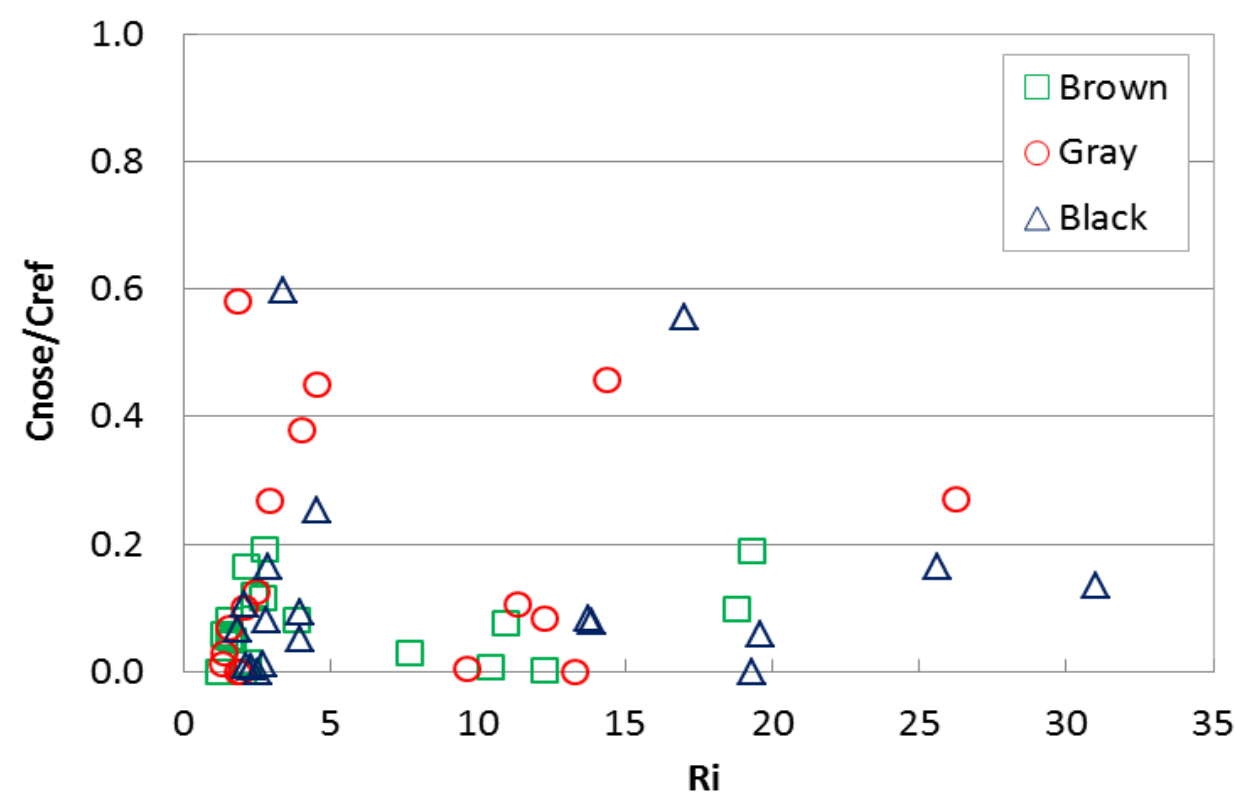

Figure 7.22 Effect of $R i$ on $C_{\text {nose }} / C_{r e f}$ for subjects Brown, Gray, and Black, $C_{r e f}=$ $26.4 \mathrm{ppm}$ (No highest exposure values) 


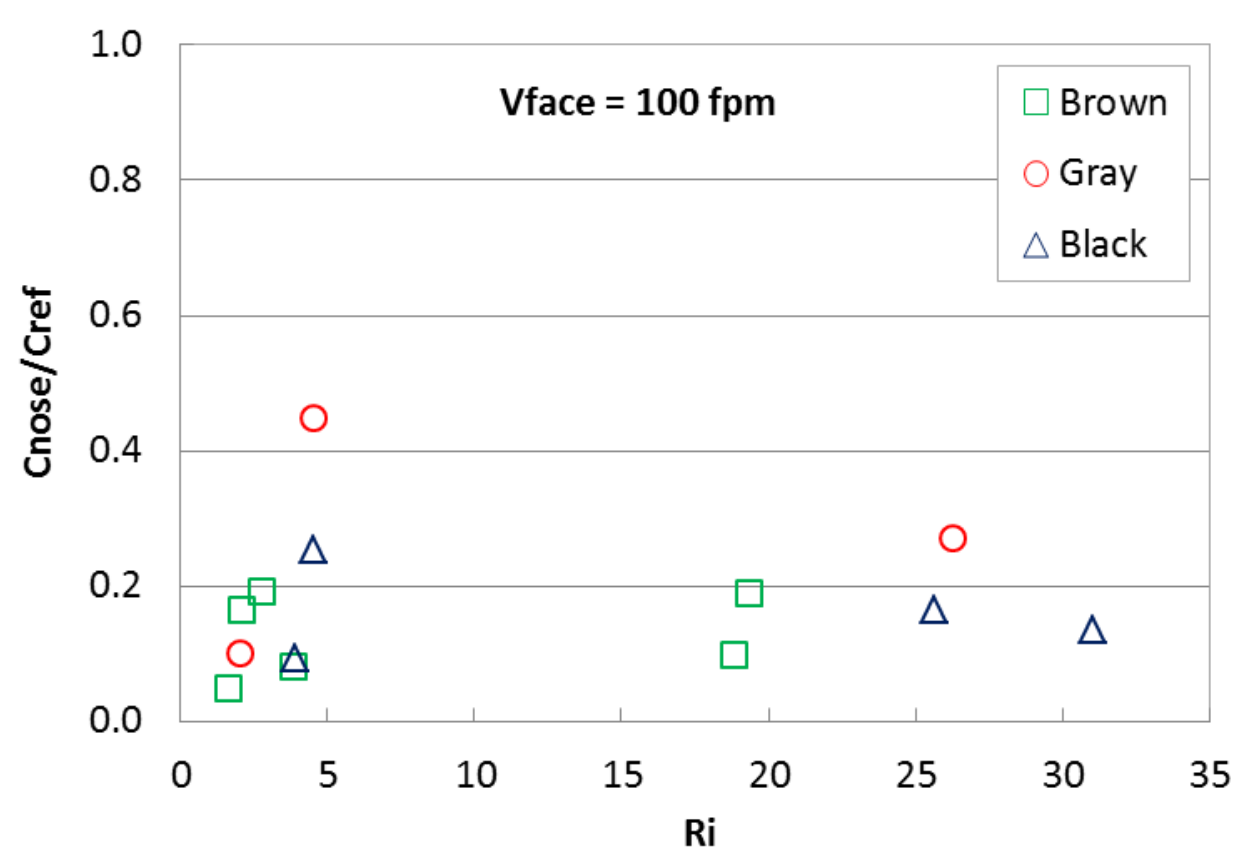

Figure 7.23 Effect of $R i$ on $C_{\text {nose }} / C_{\text {ref }}$ at $V_{\text {face }}=100 \mathrm{fpm}$ for human subjects, $C_{\text {ref }}=$ $26.4 \mathrm{ppm}$ (No highest exposure value)

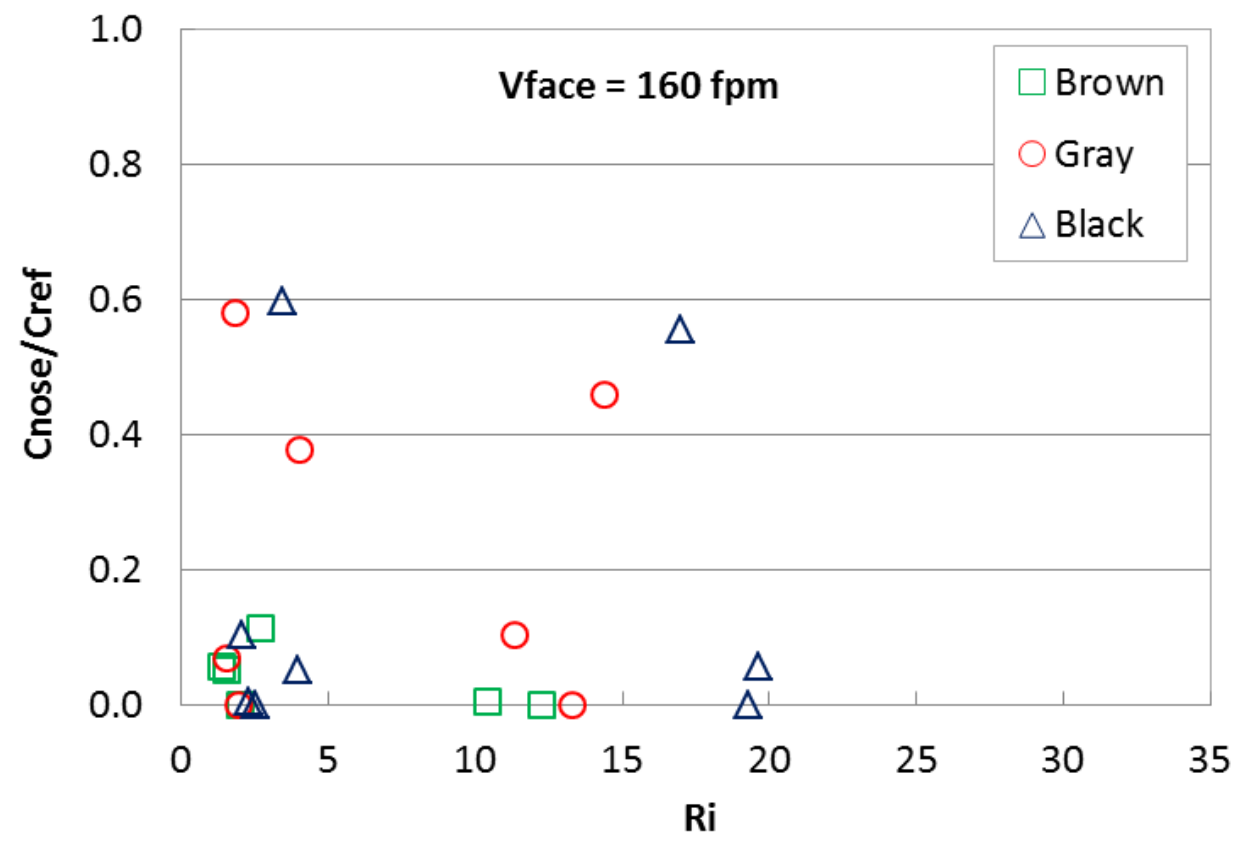

Figure 7.24 Effect of $R i$ on $C_{n o s e} / C_{r e f}$ at $V_{\text {face }}=160 \mathrm{fpm}$ for human subjects, $C_{\text {ref }}=$ 26.4 ppm (No highest exposure value 


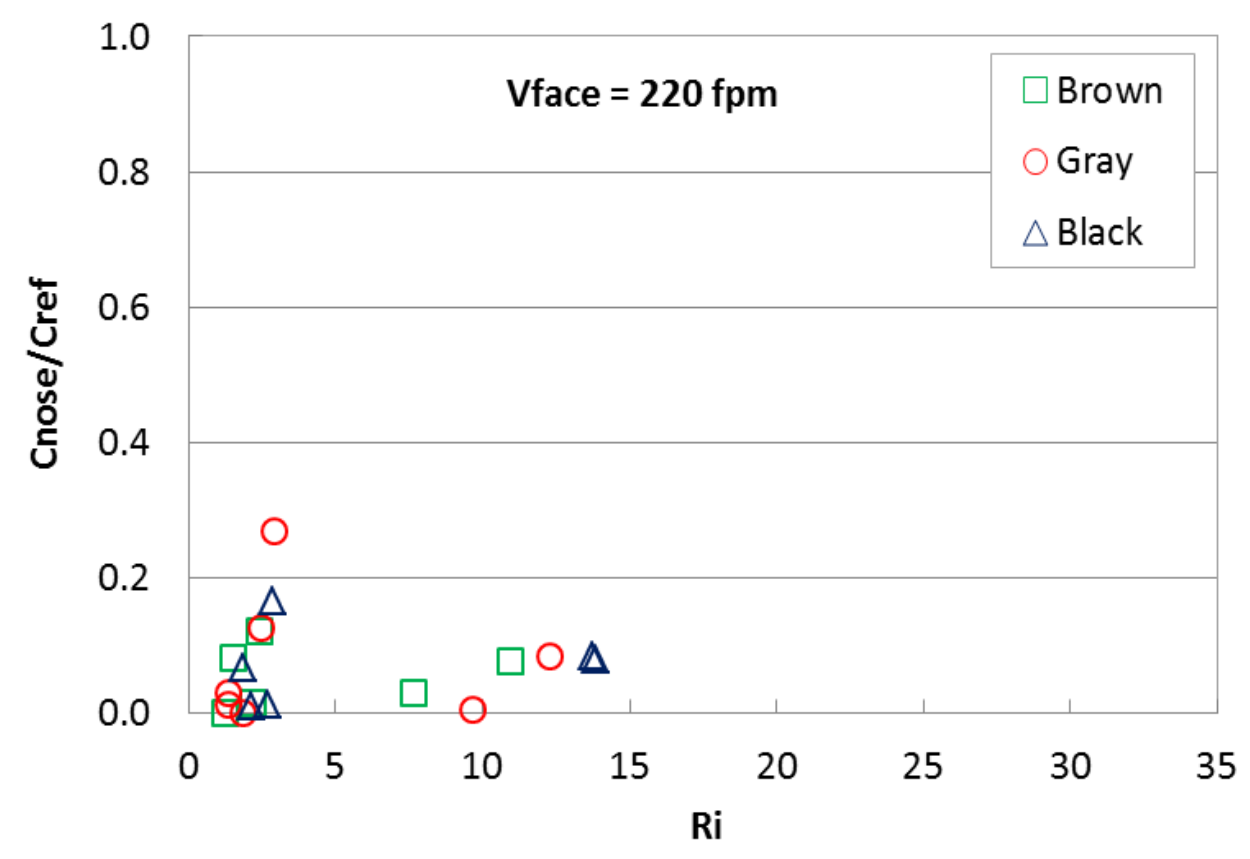

Figure 7.25 Effect of $R i$ on $C_{\text {nose }} / C_{\text {ref }}$ at $V_{\text {face }}=220 \mathrm{fpm}$ for human subject, $C_{\text {ref }}=$ $26.4 \mathrm{ppm}$ (No highest exposure value)

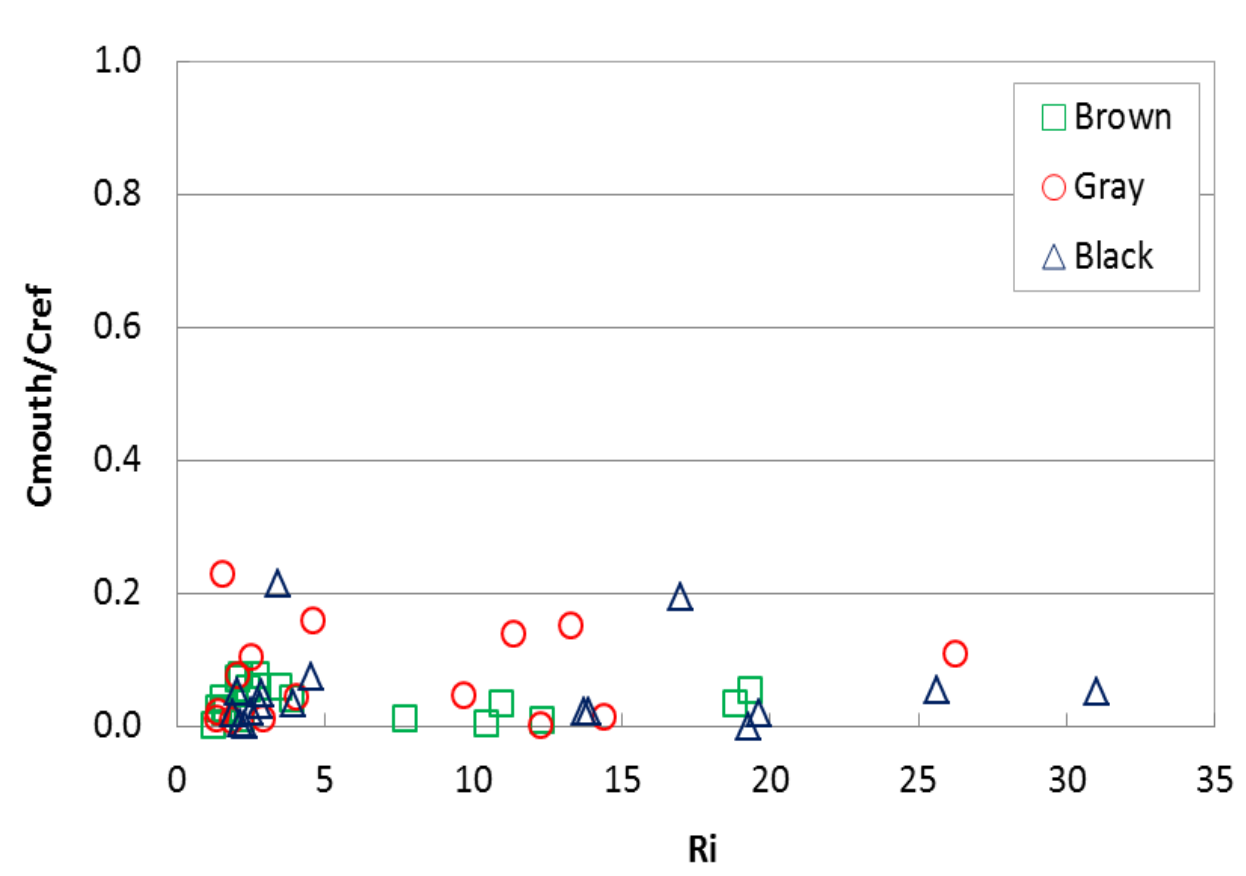

Figure 7.26 Effect of $R i$ on $C_{m o u t h} / C_{r e f}$ for subjects Brown, Gray, and Black, $C_{r e f}=$ $108.2 \mathrm{ppm}$ (No highest exposure value) 


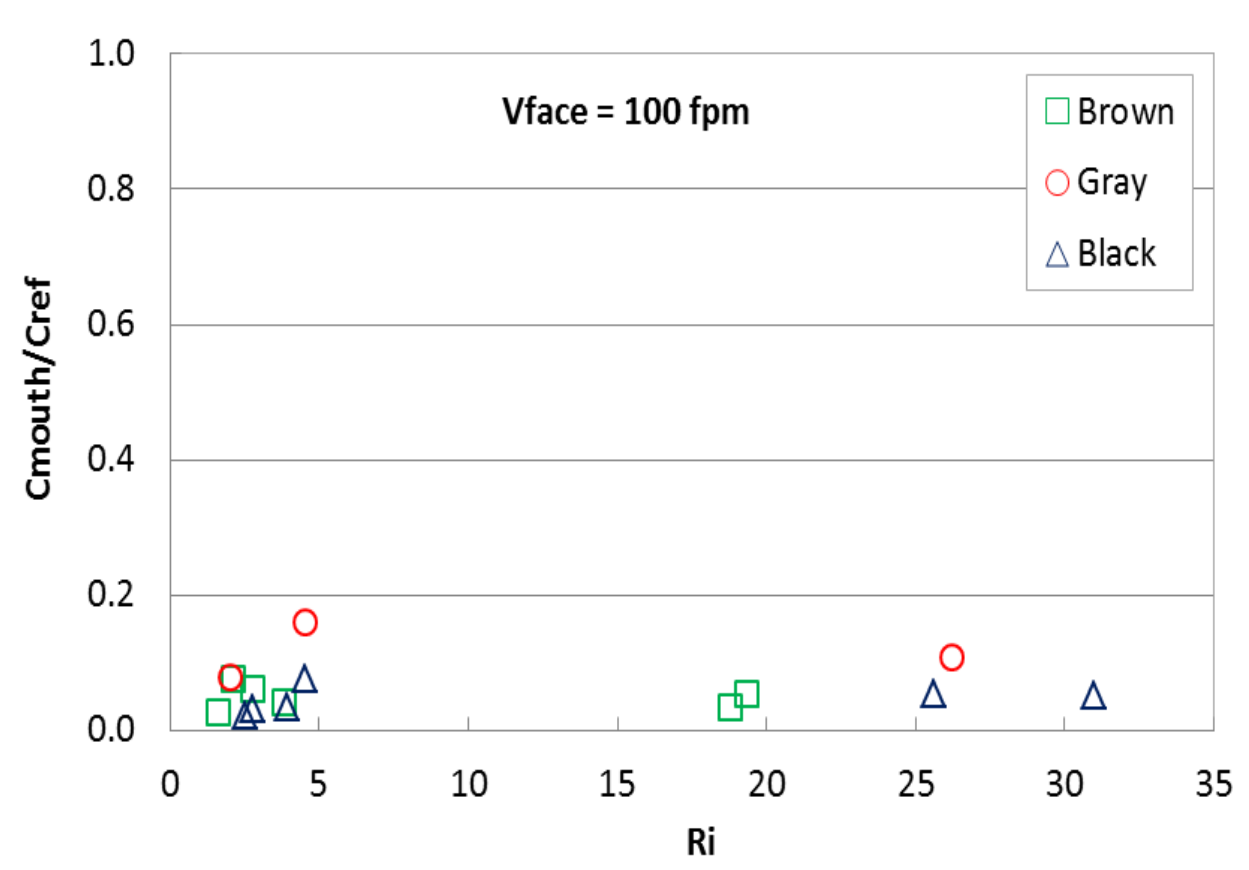

Figure 7.27 Effect of $R i$ on $C_{\text {mouth }} / C_{\text {ref }}$ at $V_{\text {face }}=100 \mathrm{fpm}$ for human subjects, $C_{\text {ref }}=$ $108.2 \mathrm{ppm}$ (No highest exposure value)

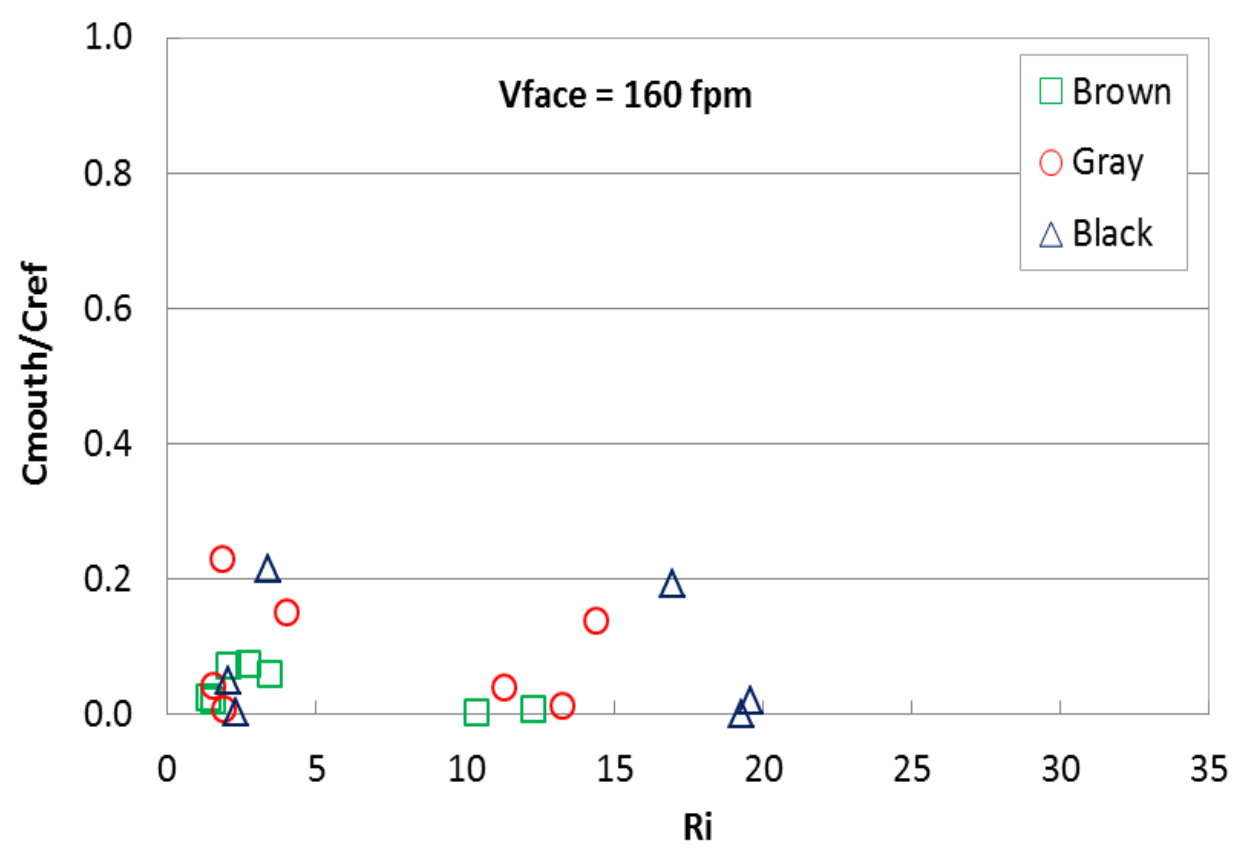

Figure 7.28 Effect of $R i$ on $C_{\text {mouth }} / C_{\text {ref }}$ at $V_{\text {face }}=160 \mathrm{fpm}$ for human subjects, $C_{\text {ref }}=$ $108.2 \mathrm{ppm}$ (No highest exposure value) 


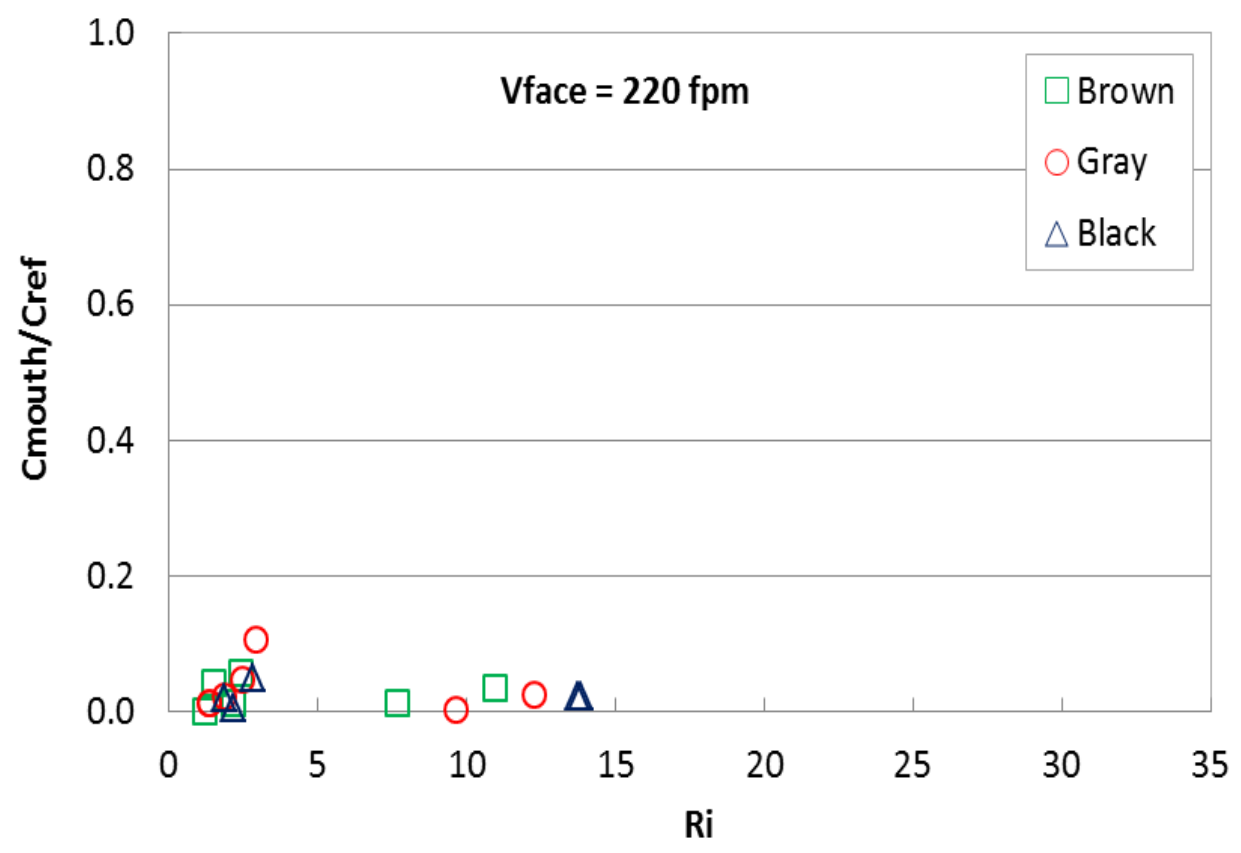

Figure 7.29 Effect of $R i$ on $C_{\text {mouth }} / C_{\text {ref }}$ at $V_{\text {face }}=220 \mathrm{fpm}$ for human subjects, $C_{\text {ref }}=$ $108.2 \mathrm{ppm}$ (No highest exposure value)

Only subjects with higher exposures (Brown, Gray, and Black) were plotted in Figures 7.22 to 7.25 . Since they had near zero exposures, the other seven subjects were omitted from these figures. Also higher exposure (1.0) was omitted. From Figures 7.22 to 7.25 , it appears that two regimes of $R i$ exist, the first between 1 and $5(1<R i<5)$ and the second regime for $R i$ greater than $10(R i>10)$. Higher exposure and mixed turbulence can be seen for the first regime (Figures 7.23 to 7.25) where a critical $R i\left(R i_{c r}\right)$ could exist roughly around $R i \sim 2.5$. Thus, when $R i<$ $R i_{c r}$ turbulence mixing occur and when $R i>R i_{c r}$ turbulence decays. For the second regime, it is suggested that $R i$ decreased as $V_{\text {face }}$ increased (Figures 7.23 to 7.25). Similar patterns can be seen in Figures 7.26 to 7.29 for $C_{\text {mouth }} / C_{r e f}$ again $R i$. 


\subsubsection{Effect of $V_{\text {face }}$ on $C_{\text {nose }}$ and $C_{\text {mouth }}$}

Earlier studies of the effect of hood face velocity $\left(V_{\text {face }}\right)$ on the performance of fume hoods found that using different human subjects of different body dimensions produced considerable variation in the results (Caplan and Knutson, 1982; Johnson and Fletcher, 1996). The same outcome was found in this study even though a benchtop enclosing hood was used and they used laboratory hoods, as it is shown in Figures 7.30 and 7.31 and Tables 7.2 and 7.3. Subjects ID Gray, Brown, and Black had exposure much higher than the others, which conceivable could be due to incorrect work practices in front of the plain hood (see sections 7.7.5 and 7.7.6 of this chapter). It is also observed that subject Gray had the highest concentration at the mouth $\left(C_{\text {mouth }}=108.18 \mathrm{ppm}\right)$ as shown in Figure 7.31.

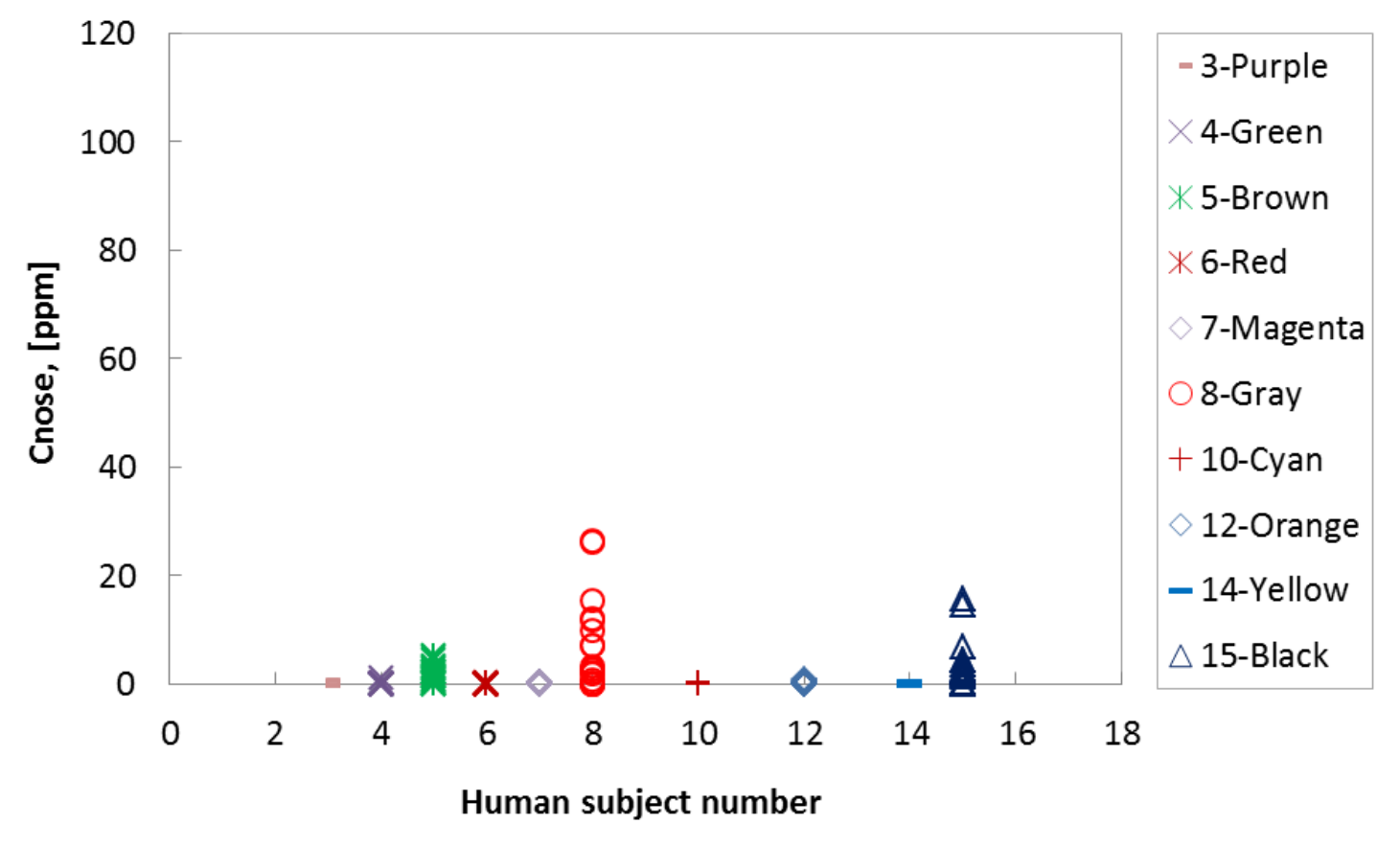

Figure 7.30 Comparison of $C_{\text {nose }}$ among the human subjects 


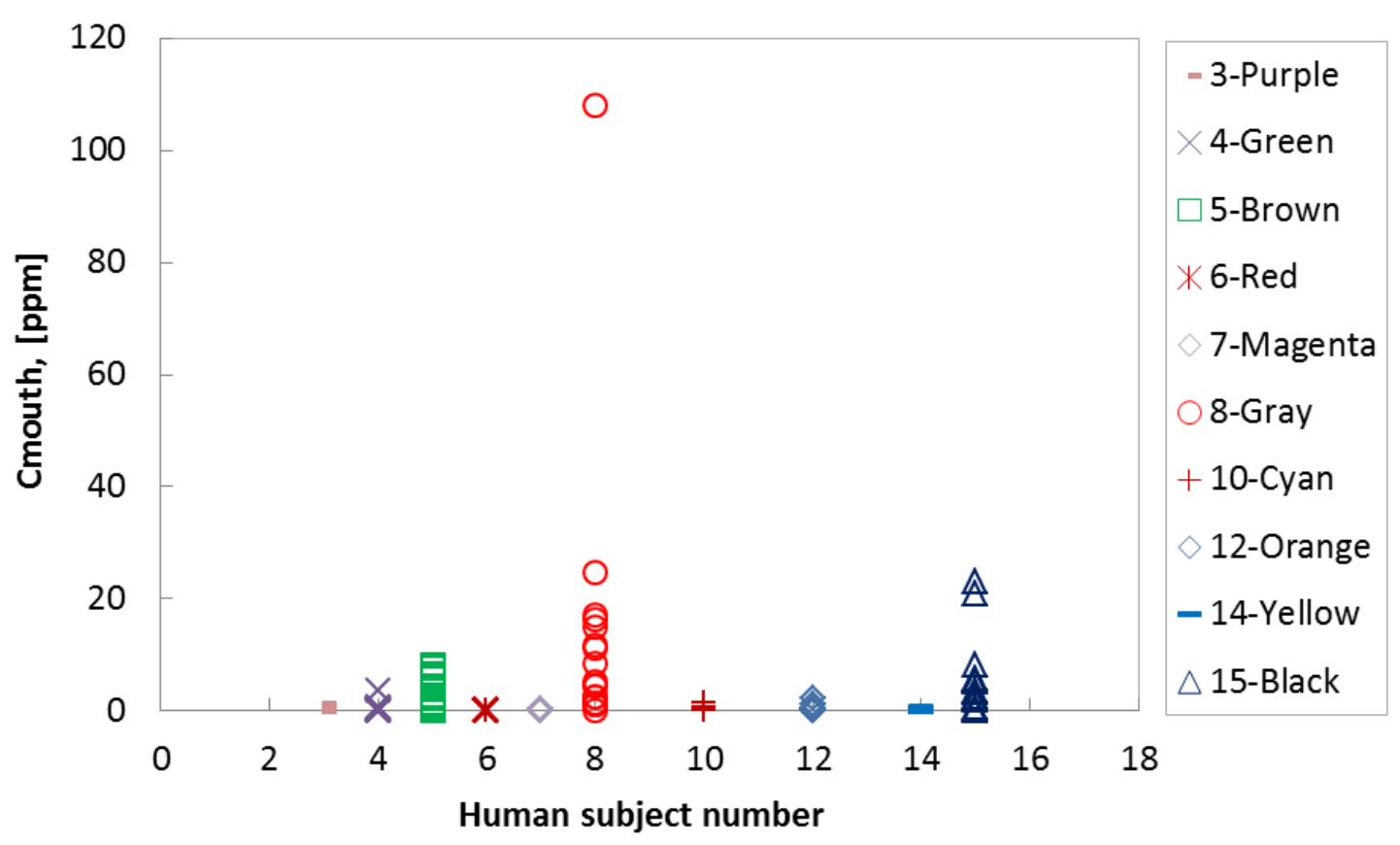

Figure 7.31 Comparison of $C_{\text {mouth }}$ among the human subject

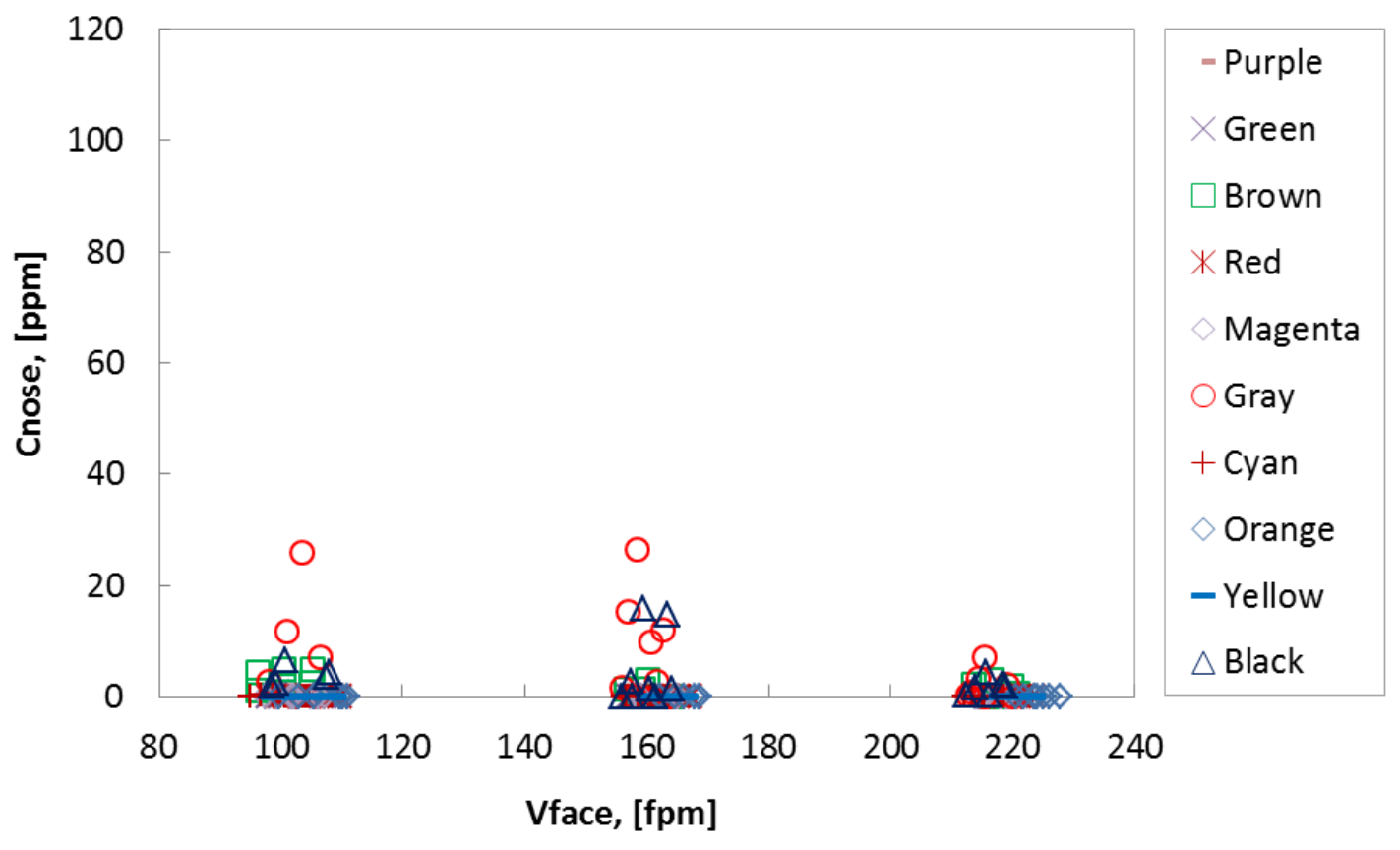

Figure 7.32 Effect of $V_{\text {face }}$ on $C_{\text {nose }}$ for the human subjects 


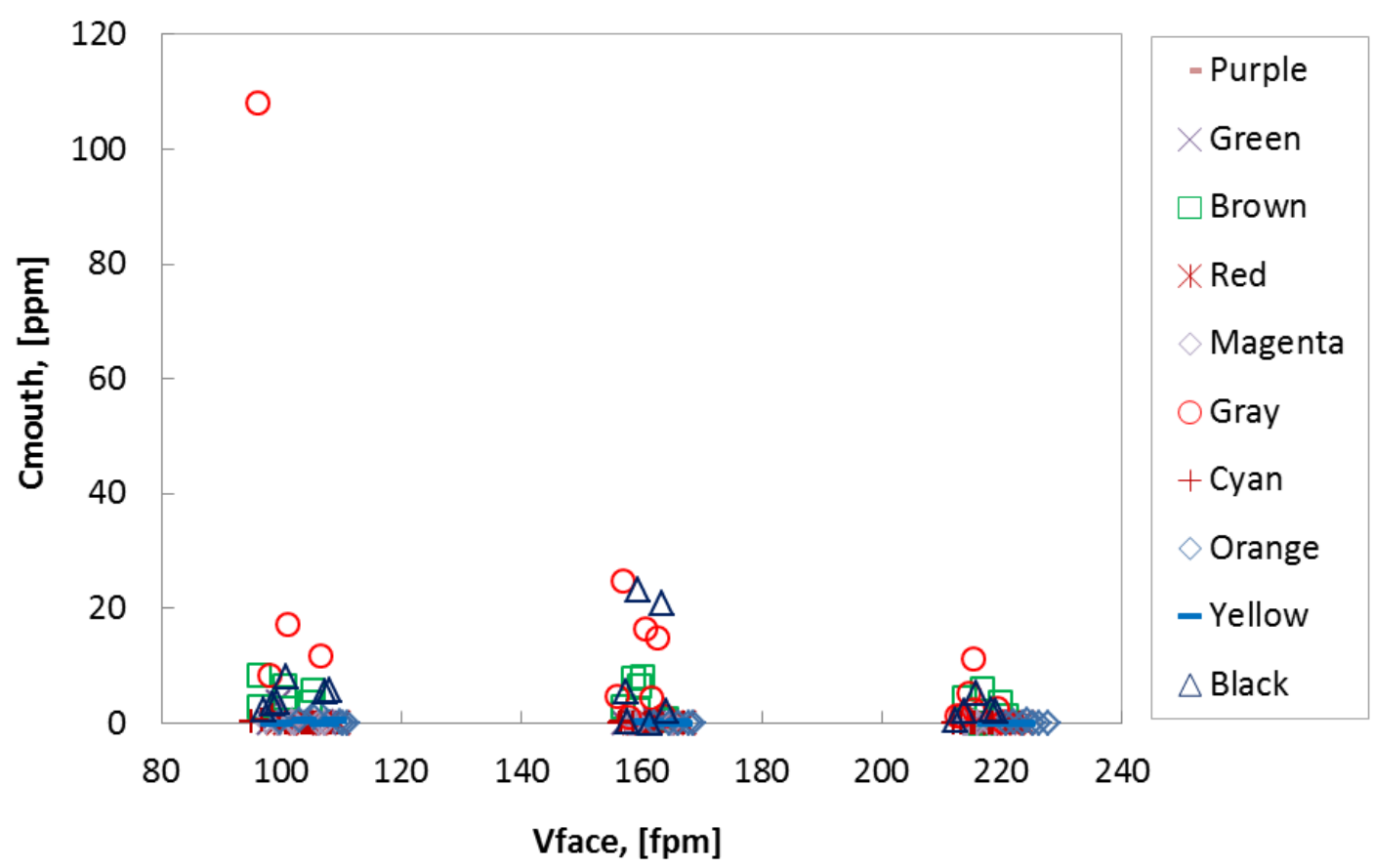

Figure 7.33 Effect of $V_{\text {face }}$ on $C_{\text {mouth }}$ for the human subjects

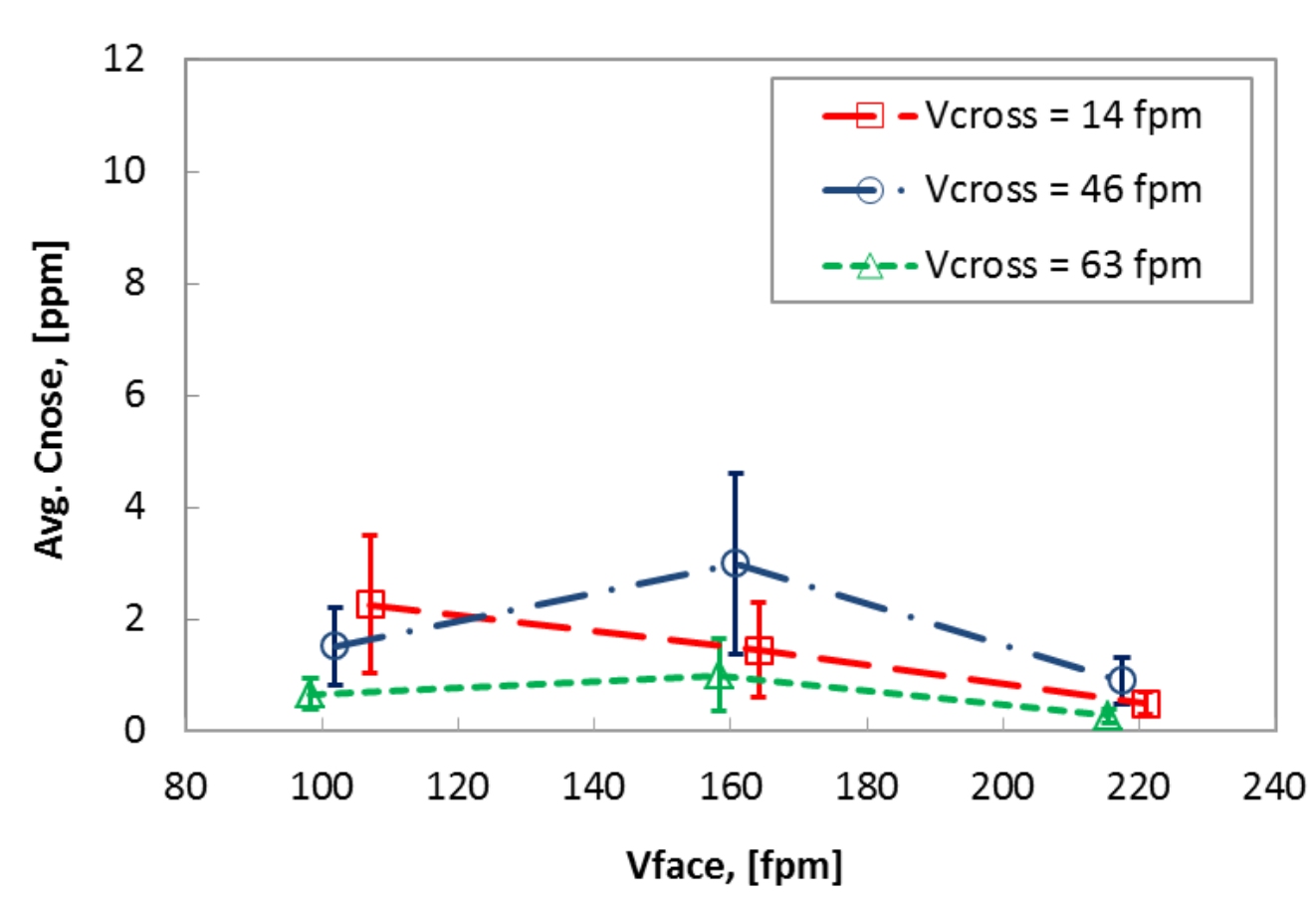

Figure 7.34 Effect of $V_{\text {face }}$ on average $C_{\text {nose }}$ for the human subjects 


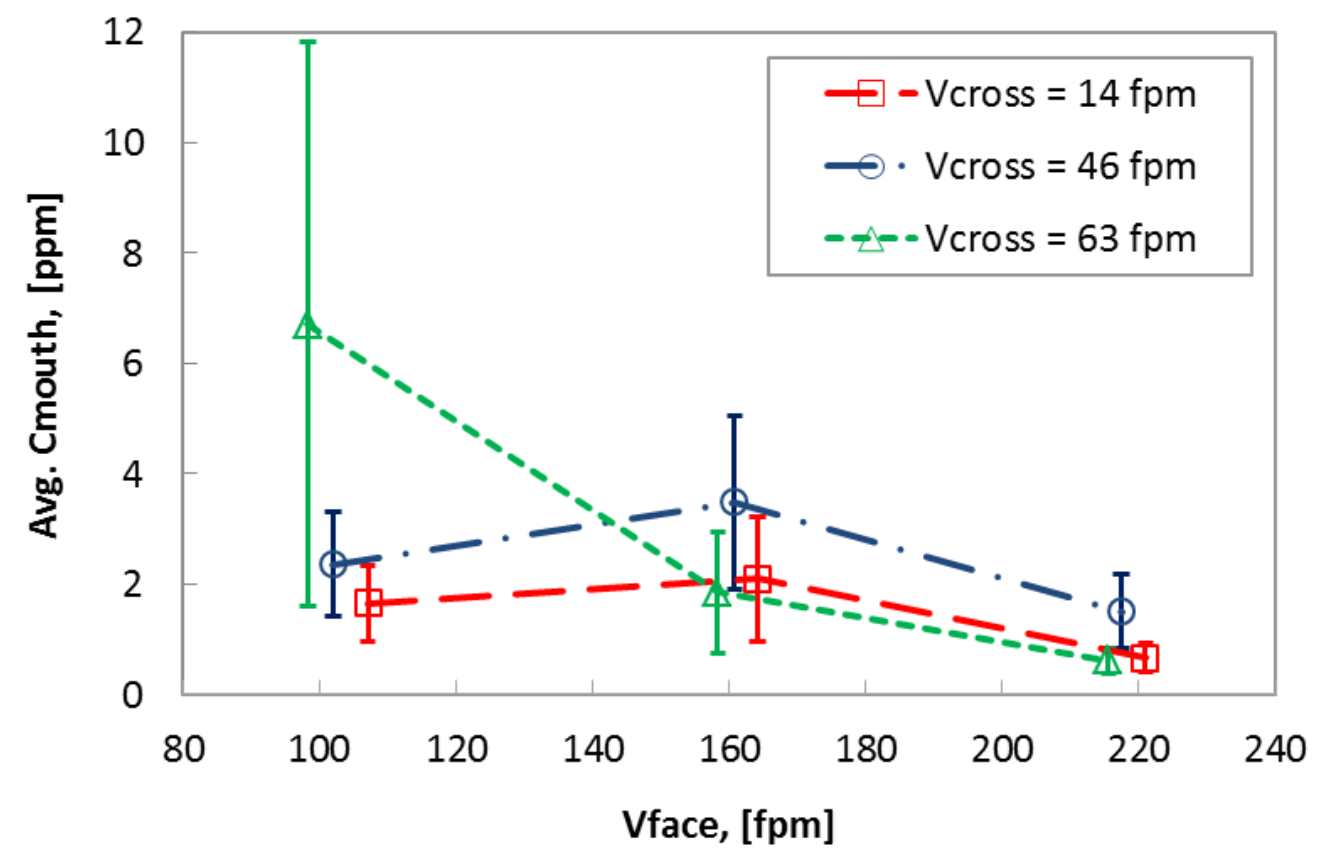

Figure 7.35 Effect of $V_{\text {face }}$ on average $C_{\text {mouth }}$ for the human subjects

The effects of $V_{\text {face }}$ on $C_{\text {nose }}$ and $C_{\text {mouth }}$ for the human subjects are presented in Figures 7.32 and 7.33. The clearness of the exposure patterns was highly affected by the highest exposure at the mouth. Thus, if this value of subject Gray is omitted, a more clear effect of $V_{\text {face }}$ on $C_{\text {nose }}$ and $C_{\text {mouth }}$ can be appreciated (see Figure E.1 and E.2 in Appendix E). For subjects Gray, Brown, and Black, it is shown that at $V_{\text {face }}=160 \mathrm{fpm}$, exposures peaked but then fell at higher face velocities (Appendix E). As expected human subject ID Gray had the highest standard deviation (see Tables 7.4 and 7.5) at the $C_{\text {nose }}$ and $C_{\text {mouth }}$ (8.33 and 24.74 ppm), and the highest mean and media values for $C_{\text {nose }}(6.8$ and $2.8 \mathrm{ppm})$ and $C_{\text {mouth }}$ (13.2 and $4.9 \mathrm{ppm}$ ) as shown in Tables 7.4 and 7.5. 
At $V_{\text {cross }}=46$ and $63 \mathrm{fpm}$, the average $C_{\text {nose }}$ for all human subjects presented maximum exposures at $V_{\text {face }}=160 \mathrm{fpm}$, which may be due to the recirculation of airflow on the wake of the human subjects and the thermal effects of the subjects' body heat (Figure 7.34). These results agree with Johnson and Fletcher (1996), Karaismail (2011), and Li et al. (2007) though different experimental conditions were used in these studies. However, a decreasing linear exposure was displayed at fixed $V_{\text {cross }}=14 \mathrm{fpm}$ with increasing $V_{\text {face }}$, which could be explained that at low cross-draft velocity $\left(V_{\text {cross }}=14 \mathrm{fpm}\right)$, buoyancy force is more relevant than inertial force (Table 7.7 and Figure 7.34) and higher exposures are expected (Karaismail, 2011; Li et al., 2007). For $C_{\text {mouth }}$, the pattern of the results is different mainly because other factors could also affect exposure (Figure 7.35).

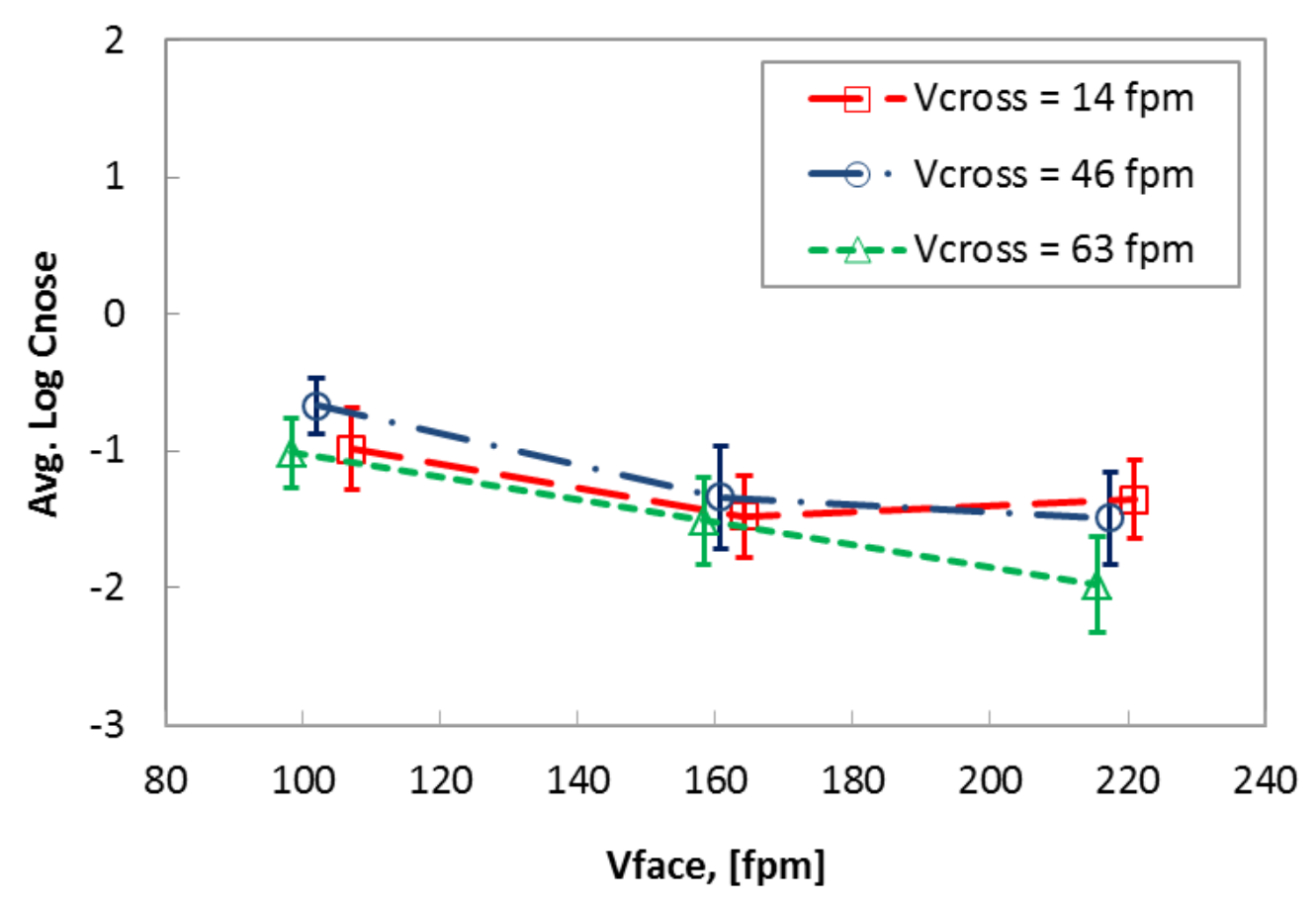

Figure 7.36 Effect of $V_{\text {face }}$ on average $\log C_{\text {nose }}$ for the human subjects 


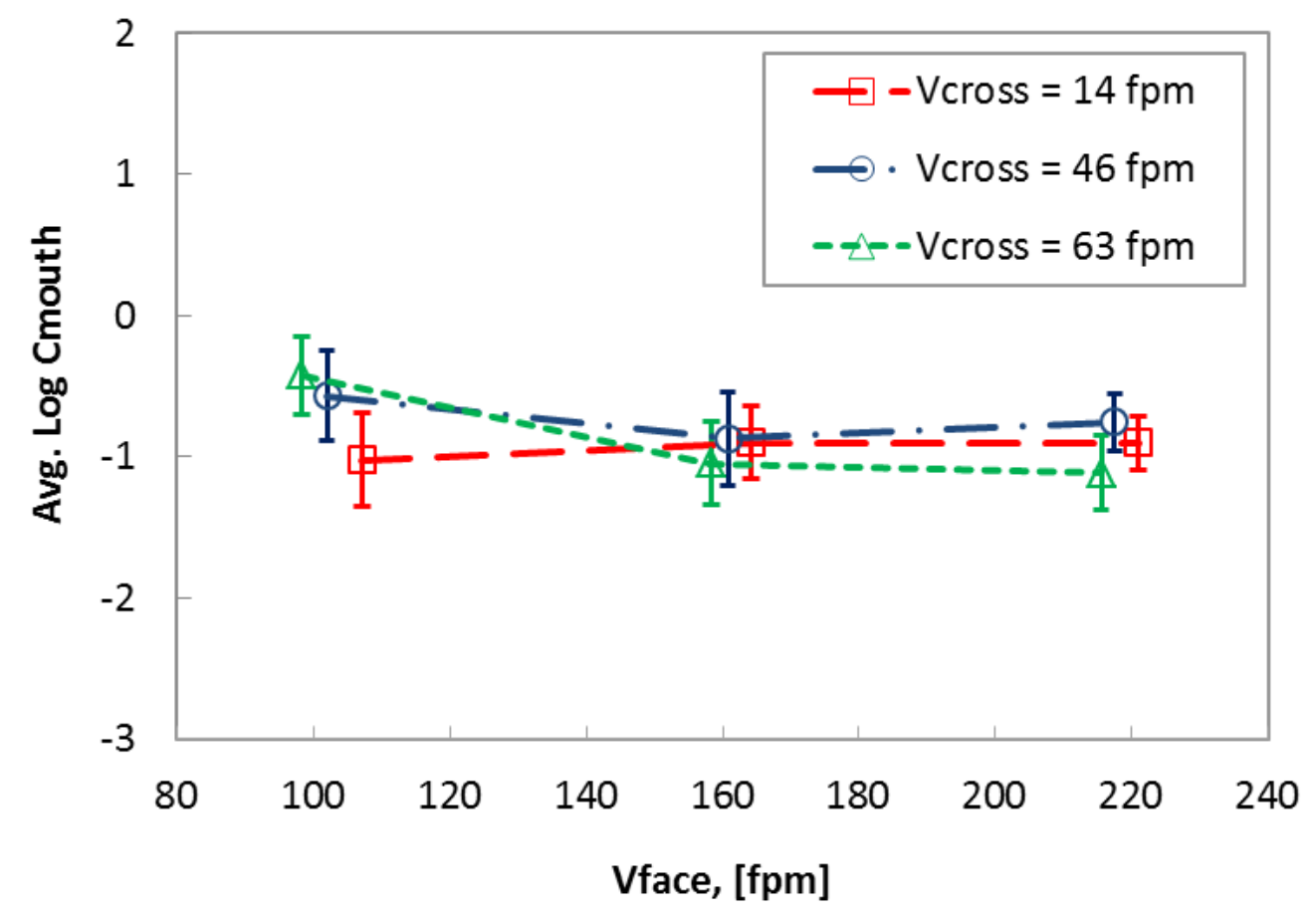

Figure 7.37 Effect of $V_{\text {face }}$ on average $\log C_{\text {mouth }}$ for the human subjects

Other factors could be important besides $V_{\text {face }}, V_{\text {cross }}$, and $\Delta T_{\text {human }}$. These factors included the body dimensions, work practices such as worker leaning inside the hood (face location), the distance between the source and the breathing zone, and body and hand movements among others (Johnson and Fletcher, 1996; Altemose et al., 1998; Ahn, 2008) as shown in Figures 7.30 to 7.37.

The variability of the data may be influenced by the factors mentioned above. For instance, subject Green shows the highest coefficient of variation (CV) for $C_{\text {nose }}$ and $C_{\text {mouth }}$ (3.29 and 2.59) even though subjects Gray, Brown, and Black have the highest standard deviation of the data at the nose $(8.33,1.67$, and 4.49 ppm) and mouth $(24.74,2.68$, and $6.62 \mathrm{ppm})$. This can be explained by the fact that 
$\mathrm{CV}$ is highly affected by the mean of the data, and for most human subjects this mean was below one, including values for subject Green. To reduce the data's variability and to obtain normal residuals, the exposures at the nose and mouth were logarithmically transformed, as shown in Figures 7.36 and 7.37.

\subsubsection{Effect of $V_{\text {cross }}$ on $C_{\text {nose }}$ and $C_{\text {mouth }}$}

Previous studies have experimentally investigated the effect of cross-draft velocity $\left(V_{\text {cross }}\right)$ on the containment ability of fume hoods (Altemose et al., 1998; Mikell and Hobbs, 1981; Johnson and Fletcher, 1996; Ahn, 2008). Cross-draft velocity, defined as the disturbance of face velocity $\left(V_{\text {face }}\right)$, can be generated by the location of the room air supply diffuser, exhaust air, doors opening, and people passing in front of the hood, among others. It is recommended that $V_{\text {cross }}$ should be less than one-fifth to two-thirds of the average $V_{\text {face }}$ (Altemose et al., 1998; Caplan and Knutson, 1982a). However, to the author's knowledge no study was carried out on the effect of $V_{\text {cross }}$ on the performance of benchtop enclosing hoods using human subjects. 


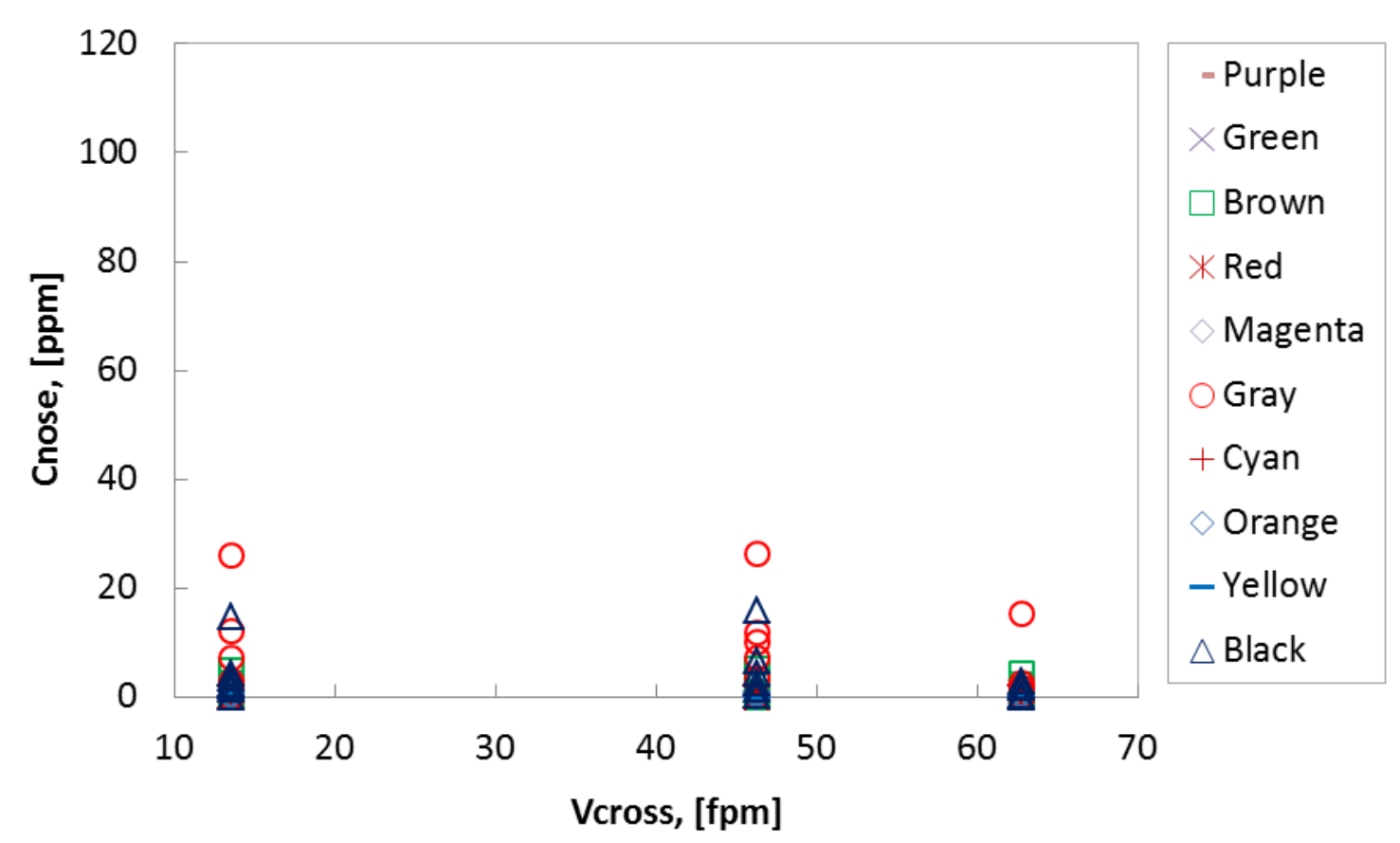

Figure 7.38 Effect of $V_{\text {cross }}$ on $C_{\text {nose }}$ for the human subjects

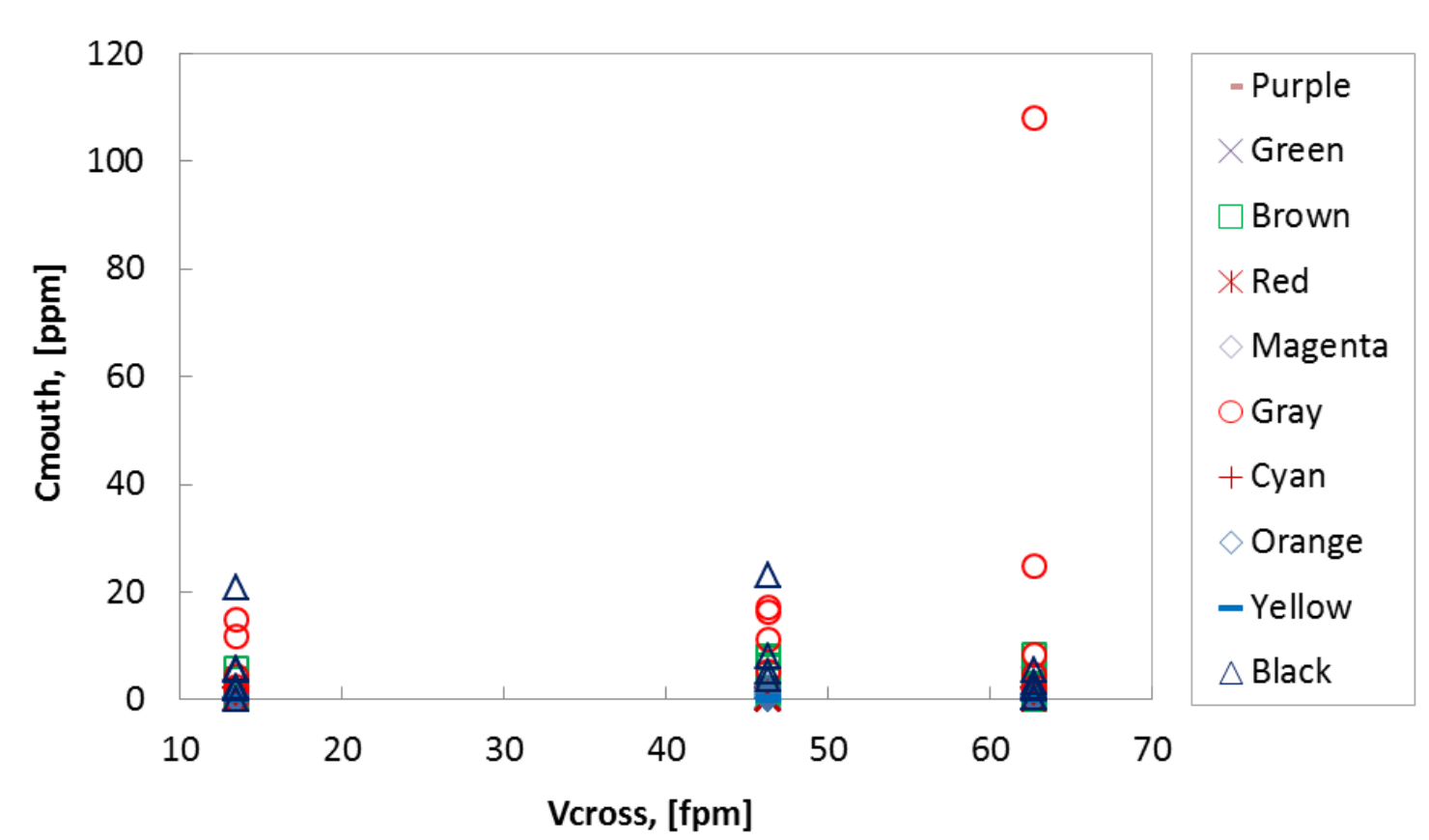

Figure 7.39 Effect of $V_{\text {cross }}$ on $C_{\text {mouth }}$ for the human subjects 
The effect of $V_{\text {cross }}$ on concentrations at the nose $\left(C_{\text {nose }}\right)$ and mouth $\left(C_{\text {mouth }}\right)$ for all levels of $V_{\text {face }}$ for each human subject are presented in Figures 7.38 and 7.39. The highest $C_{\text {mouth }}$ was for subject Gray (108.2 ppm). Subjects Brown and Black had the next higher exposure (Figures 7.38 and 7.39). Better scatter plots of the effect of $V_{\text {cross }}$ on $C_{\text {nose }}$ and $C_{\text {mouth }}$ can be seen in Figures E.3 and E.4 in Appendix E. The maximum exposure of seven of the ten human subjects tested (Orange, Red, Yellow, Green, Cyan, Purple, and Magenta) were below 1 ppm, a very low level of exposure. These results show that body dimensions and good work practices play a relevant role on a worker's exposure (see sections 7.7.5 and 7.7.6 of this chapter).

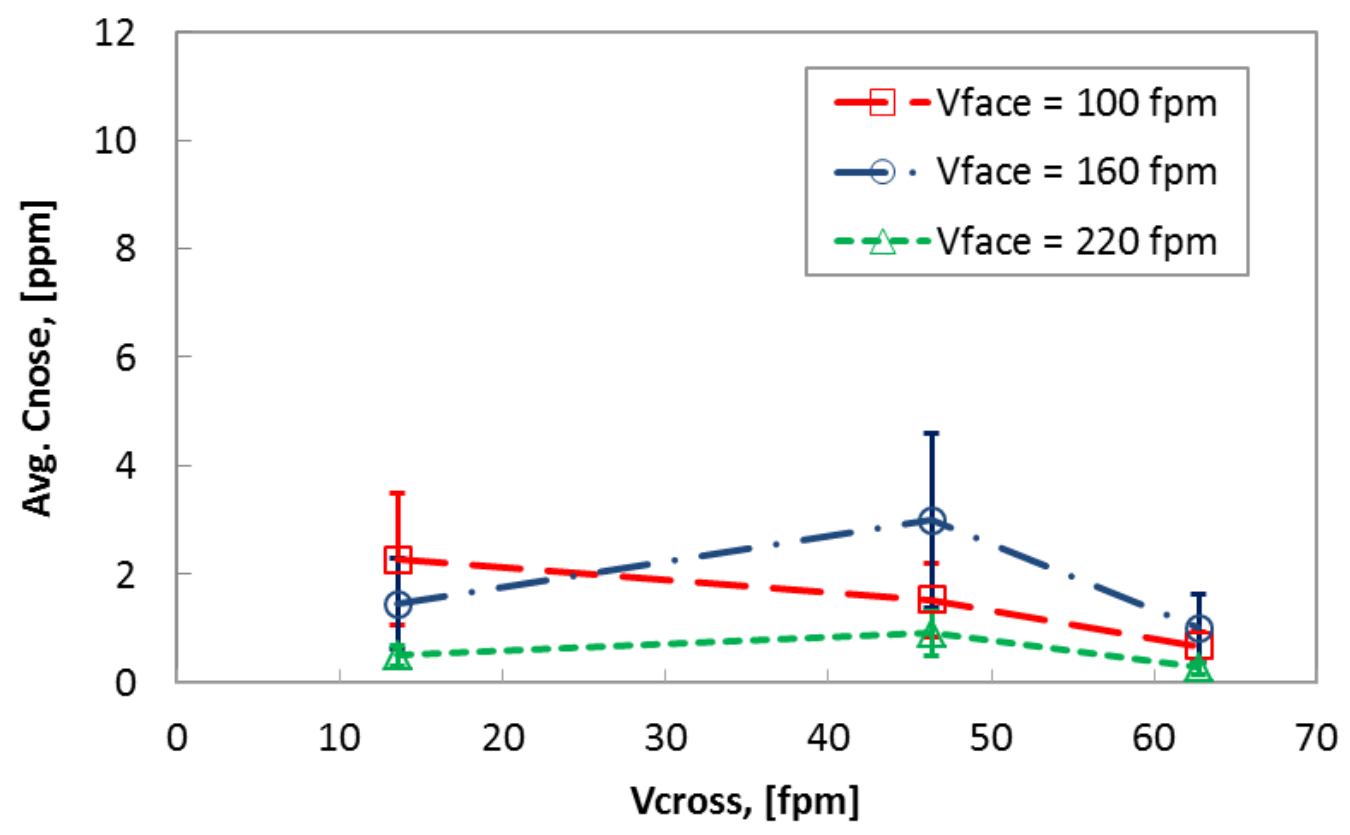

Figure 7.40 Effect of $V_{\text {cross }}$ on average $C_{\text {nose }}$ for the human subjects 


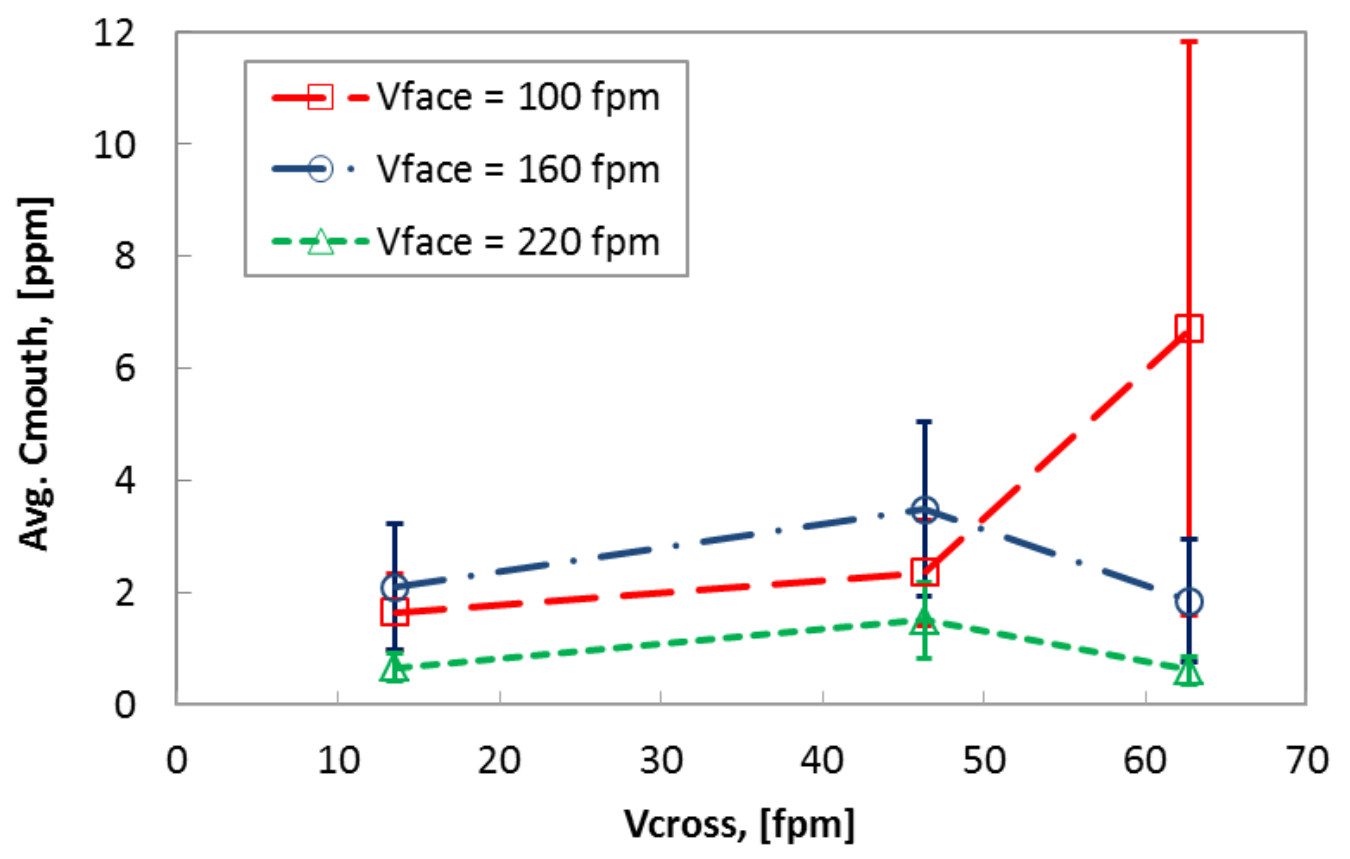

Figure 7.41 Effect of $V_{\text {cross }}$ on average $C_{\text {mouth }}$ for the human subjects

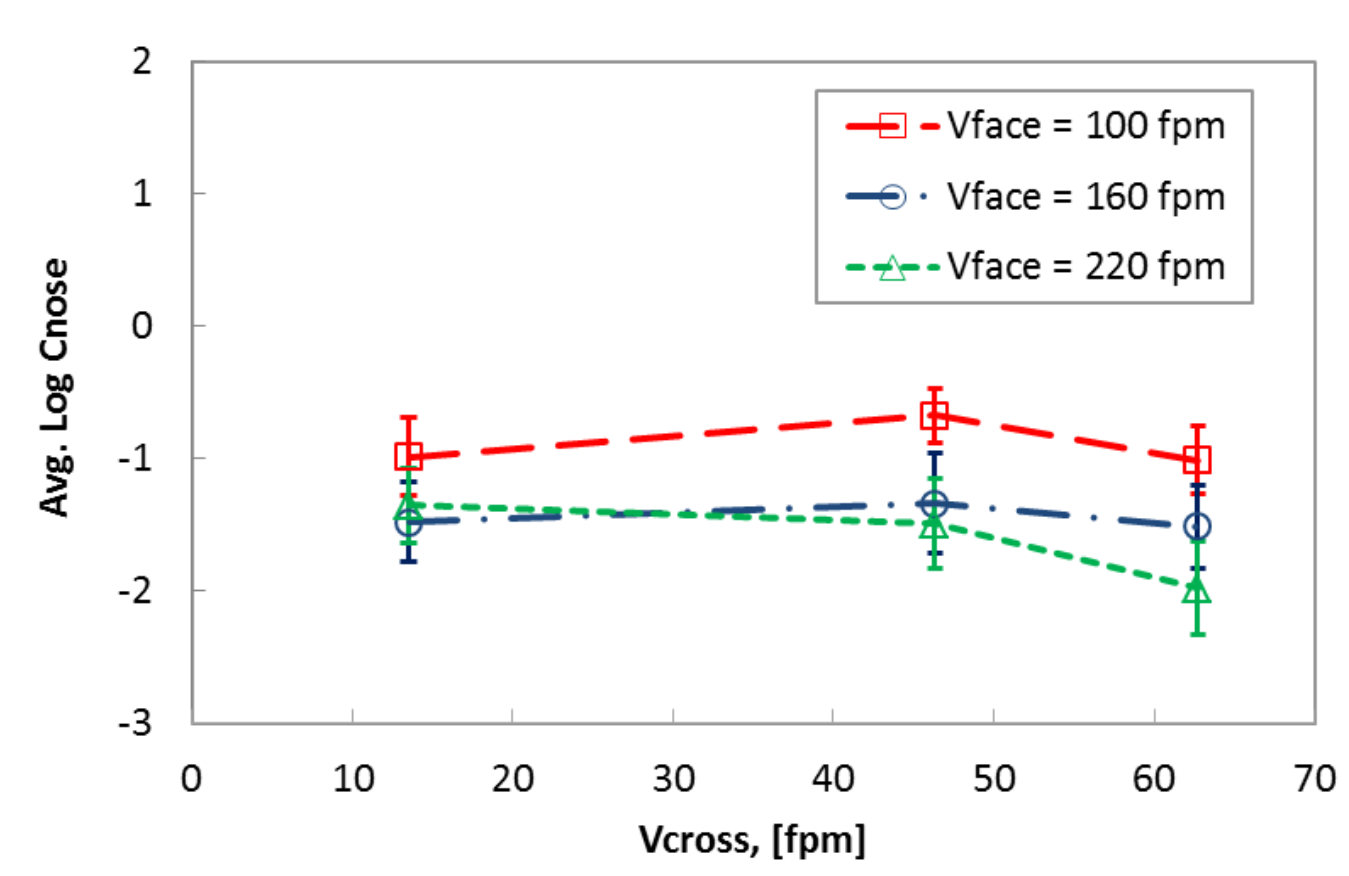

Figure 7.42 Effect of $V_{\text {cross }}$ on average $\log C_{\text {nose }}$ for the human subjects 


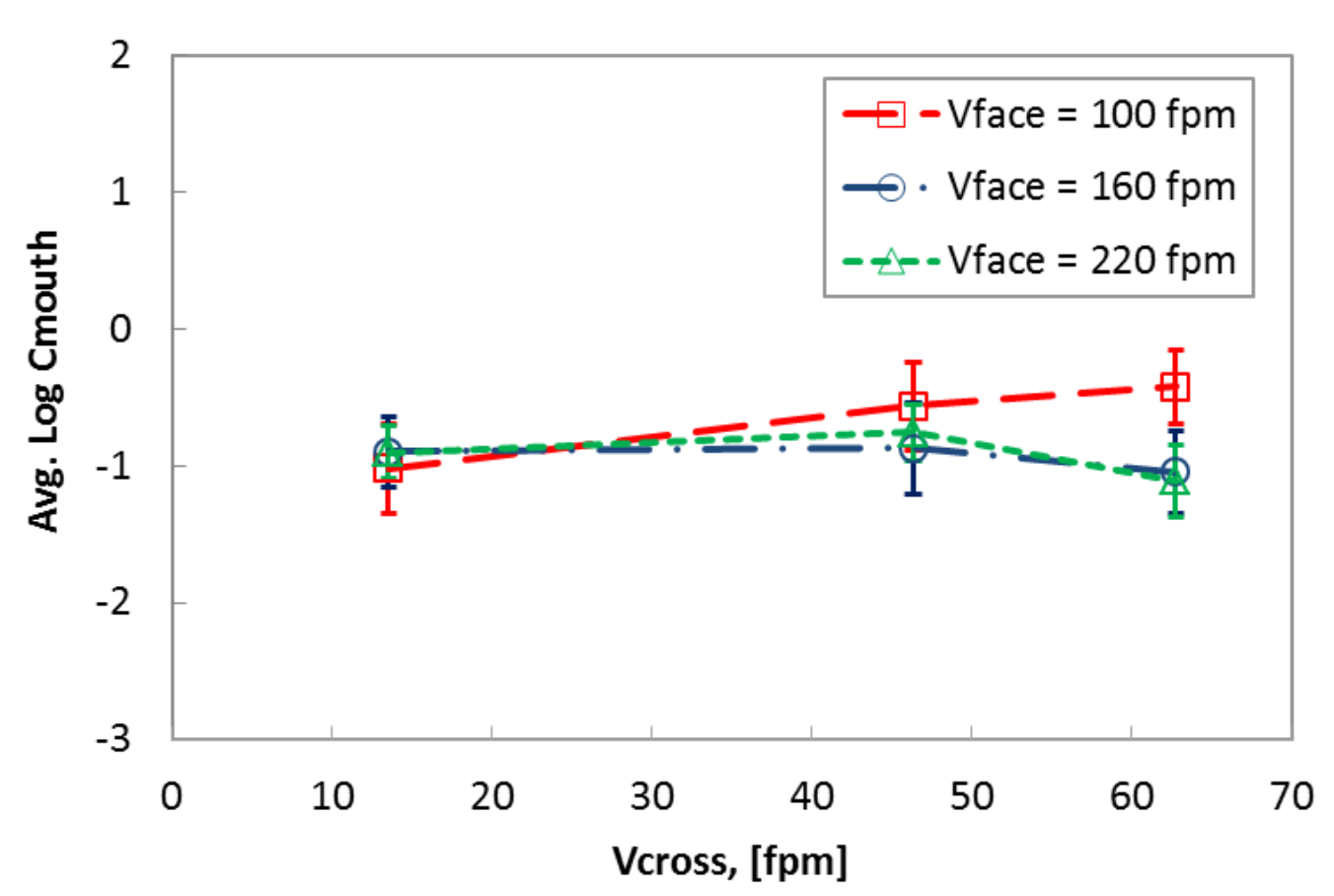

Figure 7.43 Effect of $V_{\text {cross }}$ on average $\log C_{\text {mouth }}$ for the human subjects

At $V_{\text {face }}=160$ and $220 \mathrm{fpm}$, the average $C_{\text {nose }}$ for all subjects increased as $V_{\text {cross }}$ increased, reaching peak values of 3 and $0.91 \mathrm{ppm}$ at $V_{\text {cross }}=46 \mathrm{fpm}$. Exposures then fell as $V_{\text {cross }}$ increased to $63 \mathrm{fpm}$ (Figure 7.40). However, at $V_{\text {face }}=$ $100 \mathrm{ppm}$, exposures followed a different pattern. It showed a maximum exposure greater than $2 \mathrm{ppm}$ at the lowest level of $V_{\text {cross }}(14 \mathrm{fpm})$ and then it decreased in an almost linear pattern to its lowest exposure $(0.67 \mathrm{ppm})$ at $V_{\text {cross }}=63 \mathrm{fpm}$ (Figure 7.40). Some of this exposure behavior could be explained by the fact that buoyancy force is more important at low Reynolds numbers (i.e., low $V_{\text {face }}$ and $V_{\text {cross }}$ values), as shown in Tables 7.6 and 7.7. Buoyancy force can transport contaminants from the source up to the subject's breathing zone. For this study, heat was released from 
the subject's body to the environment mostly through mixed convection. In other words, natural and force convection were relevant to exposures.

The average exposure at the mouth $\left(C_{\text {mouth }}\right)$ followed the same pattern as $C_{\text {nose }}$ at $V_{\text {face }}=160$ and $220 \mathrm{fpm}$ (Figure 7.41). However, at $V_{\text {face }}=100 \mathrm{fpm} \mathrm{a}$ completely different behavior is observed when exposure shows its highest value $(6.7 \mathrm{ppm})$ at $V_{\text {cross }}=63 \mathrm{fpm}$ (Figure 7.41). This shows the effect of subject Gray's highest exposure $(108.2 \mathrm{ppm})$ on the average value of $C_{\text {mouth }}$. On the other hand, an inverted-V shape relationship between exposure and free-stream velocity was shown in previous studies, which is in agreement with the present study even though those were in different experimental conditions (Johnson and Fletcher, 1996; El-Sotouhy, 2008). To reduce the exposure's variability and to improve the normality of residuals $\left(R_{a d j}^{2}=87.4 \%\right.$ for $C_{\text {nose }}$ and $R_{a d j}^{2}=86.5 \%$ for $C_{\text {mouth }}$ ), the $C_{\text {nose }}$ and $C_{\text {mouth }}$ were log-transformed (Figures 7.42 and 7.43). Though the exposures' curves show a more linear pattern, there is still a slightly inverted-V relationship at $V_{\text {cross }}=46 \mathrm{fpm}$ (Figure 7.42 and 7.43).

\subsubsection{Effect of humans' temperature on $C_{\text {nose }}$ and $C_{\text {mouth }}$}

Earlier experimental studies on fume hood and free-stream air (Johnson and Fletcher, 1996; Johnson et al., 1996) show the effects of temperature difference between the human subjects' bodies and the environment $\left(\Delta T_{\text {human }}\right)$ on exposure. In addition, free-stream and enclosing hood numerical studies (Li et al., 2007; Karaismail, 2011) have been done to investigate the effect of temperature difference on inhaled contaminants. However, no published experimental studies 
were found on the effect of $\Delta T_{\text {human }}$ on the performance of a benchtop enclosing hood.

In the present study, temperature data was collected from ten human subjects of different body dimensions who stood in front of the plain hood performing light work at selected combinations of $V_{\text {face }}$ and $V_{\text {cross }}$. Simultaneously, the temperature difference between the average body temperature and the dry bulb ambient temperature was computed (see Table 7.8) using Equation 4.2. The average of the cheek and back temperature (taken on clothes) was considered as the human subject temperature. For human subjects the $\Delta T_{\text {human }}$ ranged from 22.1 to 6.3 ${ }^{\circ} \mathrm{F}$ and the average was around $13^{\circ} \mathrm{F}$ (Table 7.8). 
Table 7.8 Human subjects' temperature differences with the ambient temperature $\left(\Delta T_{\text {human }}\right)$ in ${ }^{\circ} \mathrm{F}$

\begin{tabular}{|c|c|c|c|c|c|c|c|c|}
\hline \multirow{2}{*}{$\begin{array}{c}V_{\text {facee }}, \\
{[\mathbf{f p m}]}\end{array}$} & \multirow{2}{*}{ Subject } & \multicolumn{7}{|c|}{$V_{\text {cross }},[\mathrm{fpm}]$} \\
\hline & & \multicolumn{2}{|c|}{14} & \multicolumn{2}{|c|}{46} & \multicolumn{2}{|c|}{63} & Mean \\
\hline \multirow{10}{*}{100} & Orange & 13.3 & $16.4^{*}$ & 15.1 & 14.6 & 13.5 & 13.9 & 14.7 \\
\hline & Red & 17.1 & 18.2 & 17.1 & $16.3 * *$ & 16.6 & 17.6 & 16.9 \\
\hline & Yellow & 21.1 & $18.5^{*}$ & 19.3 & & 19.6 & $19.4^{*}$ & 19.4 \\
\hline & Green & 17.8 & 8.5 & 9.7 & 12.6 & 8.8 & 12.2 & 11.6 \\
\hline & Brown & 11.2 & 11.5 & 10.4 & 14.6 & 13.5 & 10.4 & 11.9 \\
\hline & Gray & 10.4 & 11.7 & 12.8 & & 10.8 & 9.7 & 11.1 \\
\hline & Cyan & 10.8 & 7.4 & 11.7 & 12.8 & 11.2 & 8.5 & 10.4 \\
\hline & Purple & 9.9 & 11.5 & 7.2 & 12.2 & 10.3 & 11.9 & 10.5 \\
\hline & Black & 16.0 & 13.3 & 12.6 & 14.6 & 13.7 & 15.3 & 14.3 \\
\hline & Magenta & 15.5 & 13.3 & 15.1 & 14.0 & 10.8 & 12.2 & 13.5 \\
\hline Mean & & 14.0 & & 13.8 & & 13.3 & & 13.7 \\
\hline \multirow{10}{*}{160} & Orange & 13.1 & 17.5 & 15.7 & 10.3 & 12.2 & 14.4 & 13.9 \\
\hline & Red & 20.9 & 16.4 & 17.6 & 16.2 & 17.8 & 14.8 & 17.3 \\
\hline & Yellow & 17.8 & 19.4 & 18.5 & 22.1 & 18.5 & 17.8 & 19.1 \\
\hline & Green & 6.7 & $11.1 *$ & 9.4 & 13.0 & 9.2 & 11.3 & 10.2 \\
\hline & Brown & 9.7 & 11.5 & 9.2 & $12.5^{* *}$ & 10.3 & 11.7 & 11.3 \\
\hline & Gray & 7.7 & $9.5 *$ & 10.4 & 13.7 & 8.5 & $10.4^{*}$ & 10.0 \\
\hline & Cyan & 8.1 & 9.2 & 9.7 & 10.6 & 10.3 & 10.8 & 9.8 \\
\hline & Purple & 13.0 & 10.6 & 12.4 & 12.1 & 10.4 & $12.5^{* *}$ & 12.0 \\
\hline & Black & 15.1 & $14.6^{*}$ & 13.3 & 15.5 & 16.0 & $13.8^{*}$ & 14.6 \\
\hline & Magenta & 12.1 & & 13.1 & & 12.6 & 13.0 & 12.7 \\
\hline Mean & & 12.7 & & 13.4 & & 12.7 & & 12.9 \\
\hline \multirow{10}{*}{220} & Orange & 13.5 & $13.1 *$ & 15.7 & 14.8 & 14.2 & 14.8 & 14.2 \\
\hline & Red & 15.5 & 17.1 & 19.3 & 16.0 & 14.8 & 14.9 & 16.3 \\
\hline & Yellow & 18.4 & & 21.1 & 18.0 & 21.1 & 18.4 & 19.4 \\
\hline & Green & 10.4 & 9.5 & 8.6 & $10.1 *$ & 9.7 & 6.3 & 9.3 \\
\hline & Brown & 14.6 & 10.3 & 11.9 & 13.1 & 13.0 & 10.4 & 12.2 \\
\hline & Gray & 12.1 & 9.5 & 9.9 & 11.7 & 8.5 & $10.2 *$ & 10.3 \\
\hline & Cyan & 10.1 & 9.4 & 9.9 & 10.1 & 9.9 & 8.5 & 9.6 \\
\hline & Purple & 13.3 & 13.7 & 13.3 & 11.5 & 12.2 & 12.1 & 12.7 \\
\hline & Black & 15.5 & 15.7 & 13.1 & 12.4 & 15.5 & 13.5 & 14.3 \\
\hline & Magenta & 13.7 & 12.8 & 13.0 & 14.0 & 12.1 & 11.3 & 12.8 \\
\hline Mean & & 13.1 & & 13.2 & & 12.4 & & 12.9 \\
\hline Mean & & 13.2 & & 13.4 & & 12.8 & & 13.2 \\
\hline
\end{tabular}




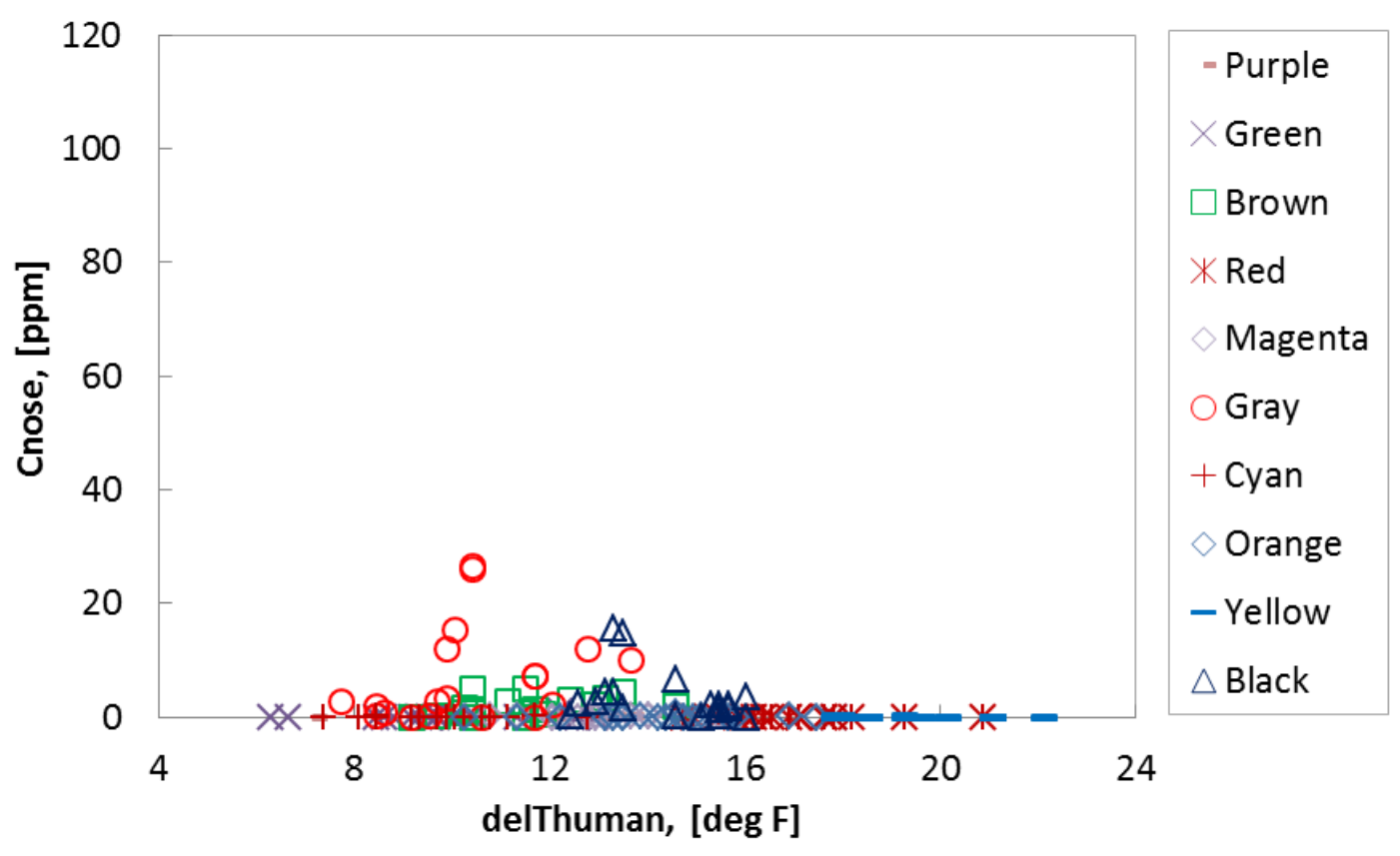

Figure $7.44 C_{\text {nose }}$ vs $\Delta T_{\text {human }}$ for the human subjects

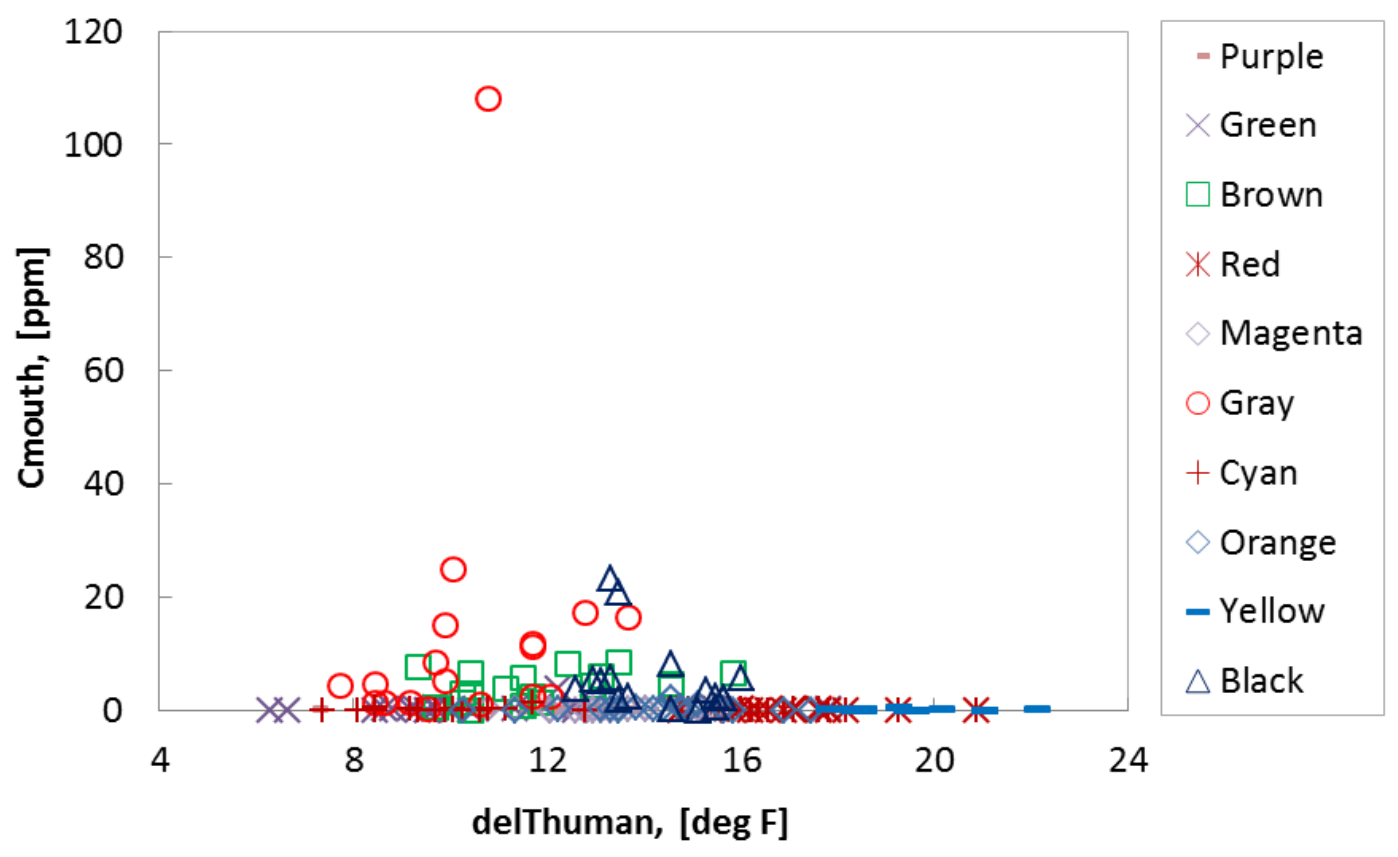

Figure $7.45 C_{\text {mouth }}$ vs $\Delta T_{\text {human }}$ for the human subjects 


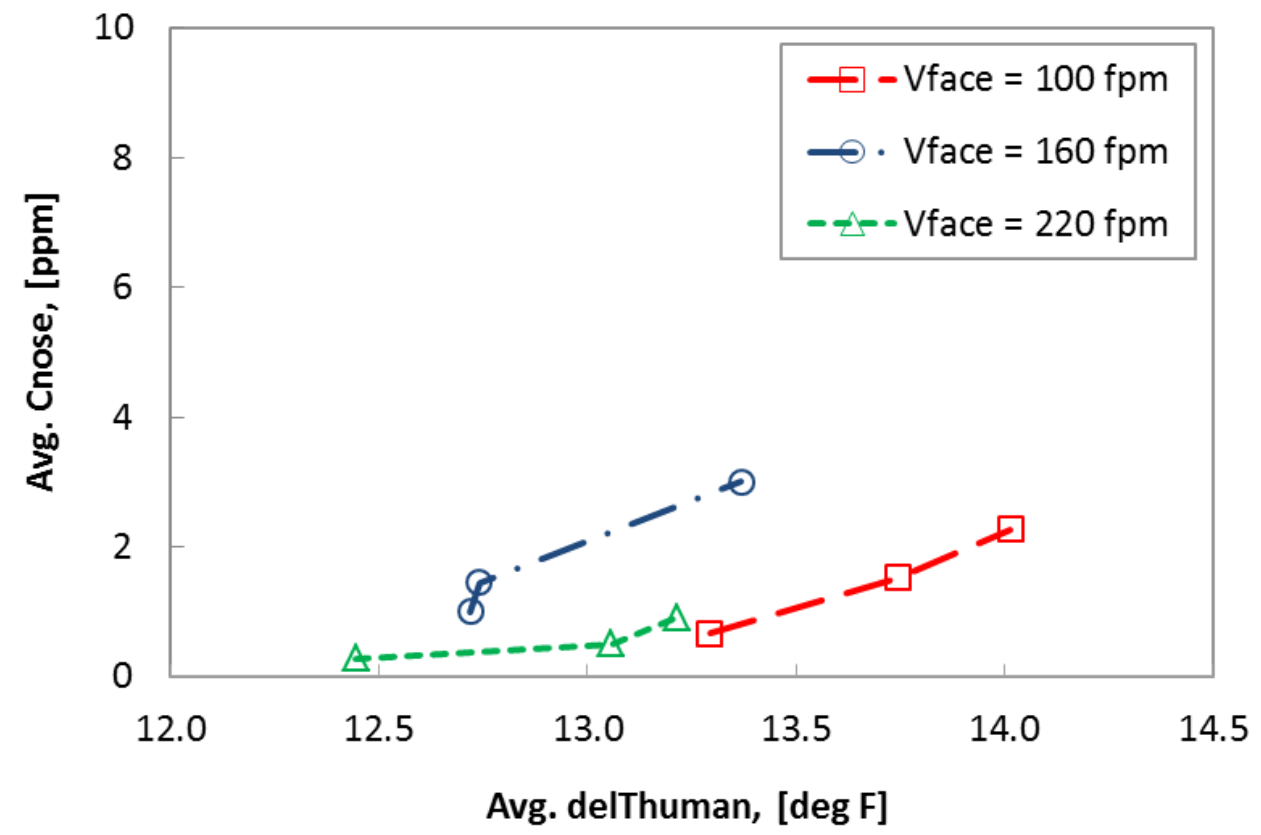

Figure 7.46 Effect of $\Delta T_{\text {human }}$ on average $C_{\text {nose }}$ for the human subjects

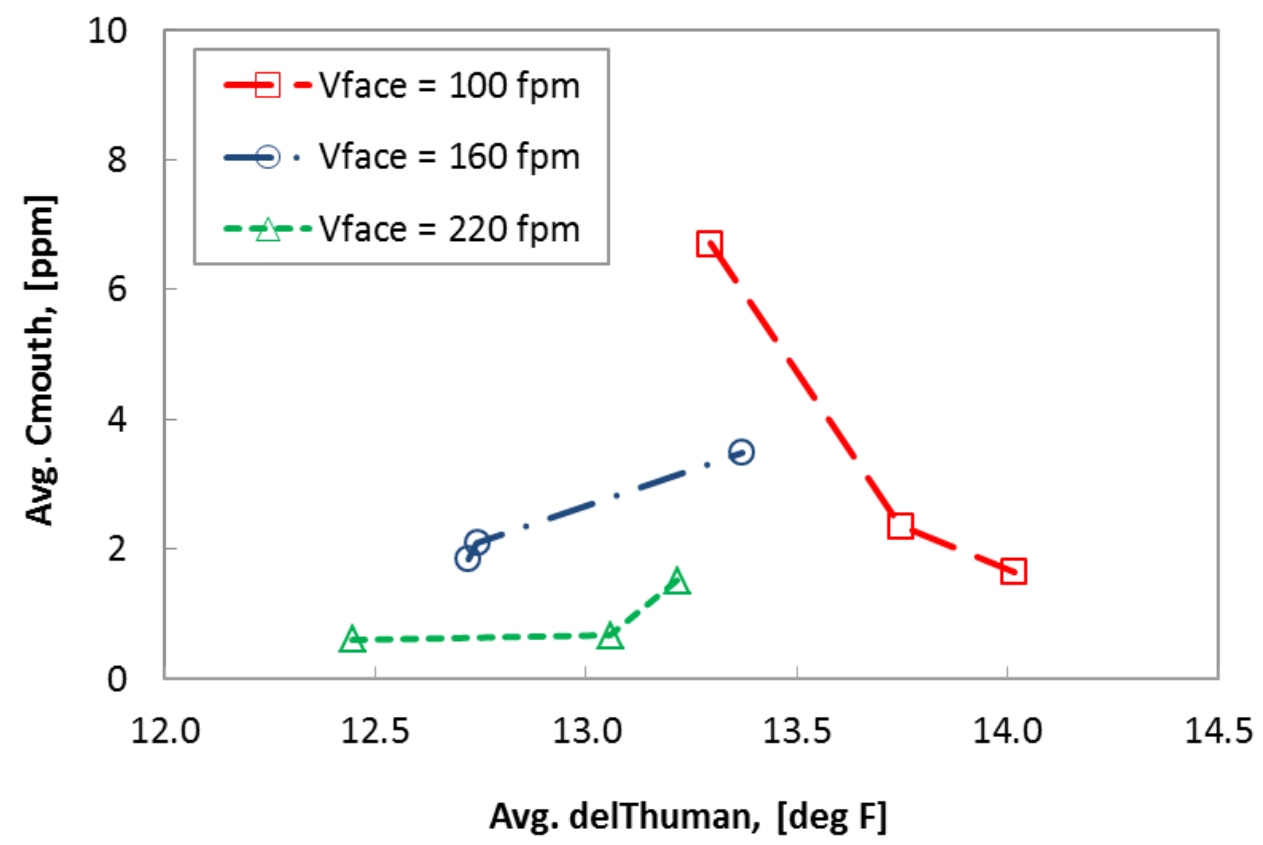

Figure 7.47 Effect of $\Delta T_{\text {human }}$ on average $C_{\text {mouth }}$ for the human subjects 
This $\Delta T_{\text {human }}$ (see Equation 4.2) causes the acceleration of the air near the subject's body, called the buoyancy driven force, at velocities between 40 and 56 fpm (Johnson and Fletcher, 1996; Johnson et al., 1996; Li et al., 2007; Karaismail, 2011; Murakami et al., 2000; Kilic and Sevilgen, 2008). Buoyancy is more relevant at low velocities and low Reynolds numbers, which produces higher Richardson numbers $(R i>1)$ such as those shown in Table 7.7. Buoyancy force may transport the contaminants from the lower part of the subject's body into the breathing zone. Scatter plots of the effect of $\Delta T_{\text {human }}$ on exposure for every human subject is presented in Figures 7.44 and 7.45. Most $\Delta T_{\text {human }}$ were between 8 and $16^{\circ} \mathrm{F}$.

Notably, the effect of $\Delta T_{\text {human }}$ on $C_{\text {nose }}$ is clearly shown in Figure 7.46. As $\Delta T_{\text {human }}$ increased, the exposure increased. It seems that there is a ratio of $2 \mathrm{ppm}$ of inhaled contaminants per $1^{\circ} \mathrm{F}$ of $\Delta T_{\text {human }}$ at $V_{\text {face }}=100$ and $160 \mathrm{fpm}$. However, at $V_{\text {face }}=220 \mathrm{fpm}$, lower increases in exposure were found as $\Delta T_{\text {human }}$ increased (see Figure 7.46). This shows that buoyancy effect on exposure is more important at low Reynolds numbers, as expected. Figure 7.47 showed a different pattern at $V_{\text {face }}=$ $100, C_{\text {mouth }}$ values decreased as $\Delta T_{\text {human }}$ increased. This behavior is clearly related to the higher exposure of subject Gray $\left(C_{\text {nose }}=108.2 \mathrm{ppm}\right)$ at $V_{\text {face }}=100$ and $V_{\text {cross }}$ $=63 \mathrm{fpm}$, which suggest that other factors can also be important, in addition $\Delta T_{\text {human }}$, on exposure. Factors such as the body dimensions and the distance between the contaminant source and the subject's breathing zone may also be important. Detailed explanation are given in sections 7.7.4, 7.7.5 and 7.7.6 of this chapter. 


\subsection{Discussion}

Previous experimental studies to test the performance of lab hoods or to determine exposures using human subjects were carried out by several authors (Johnson and Fletcher, 1996; Johnson et al., 1996; Altemose et al., 1998; Tan et al., 1999; Greenley et al., 2000). The effect of factors such as face velocity $\left(V_{\text {face }}\right)$, cross-draft velocity $\left(V_{\text {cross }}\right)$, and the temperature difference between the subject's body and the environment $\left(\Delta T_{\text {human }}\right)$ on human subjects' exposure were investigated. However, to the author's knowledge no studies have even been published on the effect of these factors on the effectiveness of a benchtop enclosing hood using several human subjects.

The present study provides evidence of the effect of these factors on the performance of a plain enclosing hood. Concentrations at the nose $\left(C_{\text {nose }}\right)$ showed a peak exposure at $V_{\text {face }}=160 \mathrm{fpm}$ and at $V_{\text {cross }}=46$ and $63 \mathrm{fpm}$, then exposure decreased as $V_{\text {face }}$ increased. This finding is in agreement with previous experimental studies (Johnson and Fletcher, 1996; El-Sotouhy, 2008), though they used a free-stream set-up. Numerical studies also found the same behavior in a freestream (Li et al., 2007) and in a simulated enclosing hood study (Karaismail, 2011). However, unlike $C_{\text {mouth }}, C_{\text {nose }}$ showed decreased pattern as $V_{\text {face }}$ increased at $V_{\text {cross }}=$ $14 \mathrm{fpm}$.

The fluid mechanics' theory of flow around a bluff body is of critical importance to understand many practical engineering applications ( $\mathrm{Hu}$ and Koochesfahani, 2011; Srinivas et al., 2009; Mills, 1999). Thus, human subjects 
standing in front of the enclosing hood, partially blocking the suction of air into the hood, can be deemed as bluff bodies. A fully turbulent flow over any bluff body is reached at Reynolds numbers greater than $2 \times 10^{5}$ (Hu and Koochesfahani, 2011; Srinivas et al., 2009; White, 2006; Mills, 1999). The maximum Reynolds number in this study is about 18000 , which is far below the turbulent regime. More clearly, the flow regime over the human body in this work is into the unstable and transitional regime. Most human subjects' Reynolds numbers were between 10000 and 14000, as can be seen in the scatter plot of Figure 7.11.

The results of this study provide evidence of the effect of $\Delta T_{\text {human }}$ on exposures (see Figure 7.46). It means as the average $\Delta T_{\text {human }}$ increases, the exposure increases. It can also be seen that small increases in exposure occur at $V_{\text {face }}=220 \mathrm{fpm}($ Figure 7.46), which confirm that there is a lower exposure at higher Reynolds numbers. Most notably, it was found that buoyancy effects were more important at low Reynolds numbers (Table 7.6), which agrees with previous studies of Li et al. (2007), Karaismail (2011), and Johnson and Fletcher (1996). Likewise, higher Richardson numbers $(R i>1)$ were obtained at low Reynolds numbers (Table 7.7), suggesting that natural convection was also important in heat transferred to the environment. Buoyancy forces can transport the contaminants at 40-52 fpm from the lower part of the body to the breathing zone.

Next, the adequacy of the sample size is evaluated and the human subjects study analyses of covariance are carried out to determine the statistical significance of the independent factors on exposure. In addition, protection efficiency was 
calculated to evaluate the performance of the tested enclosing hood. Other important factors, such as the effect of subjects' body dimensions, the distance of the contaminant source to the subjects' breathing zone, and the subjects' working posture are also considered.

\subsubsection{Analysis of covariance}

Earlier experimental studies with manikins (Guffey and Barnea, 1994; He, 2010) and one numerical study (Karaismail, 2011) established the importance of controlled independent factors such as face velocity $\left(V_{\text {face }}\right)$ and cross-draft velocity $\left(V_{\text {cross }}\right)$, on the performance of benchtop enclosing hoods. However, no experimental studies were found for plain enclosing hoods using human subjects. The present study tested the performance of a custom-made benchtop enclosing hood using ten human subjects of different body dimensions.

In addition to the controlled discrete variables of $V_{\text {face }}$ and $V_{\text {cross }}$, the human subjects (Subject) were also treated as a discrete variable. However, an uncontrolled and continuous variable was also considered, the temperature difference of the subjects' skin temperature and the temperature of the ambient air ( $\left.\Delta T_{\text {human }}\right)$, which was observed passively. It was also found that $\Delta T_{\text {human }}$ is independent of the other main factors (see Table E.4 in Appendix E).

The design of the experiments was a factorial completely randomized design with three levels of $V_{\text {face }}(100,160$, and $220 \mathrm{fpm})$ and three levels of $V_{\text {cross }}$ $(14,46$, and $63 \mathrm{fpm})$. A fixed model was chosen for this study due to the fact that there is a specific interest in the selected levels of $V_{\text {face }}$ and $V_{\text {cross }}$ (Montgomery, 
2009; Mason et al., 2003). The number of replications for each experimental trial was two for each human subject. However, due to the residual criterion for the FTIR (see Section 4.3in Chapter 4), exposure results were omitted in some cases and more than 2 replications resulted when several negative concentrations were kept and then replaced by a positive minimum value of 0.0001 in other cases (see Tables 7.2 and 7.3). As result, an unbalanced experimental design was created. It was analyzed with partial sums of squares (Type 3). The ANCOVA model with fixed effects can be recalled from Eq. 1.4 as,

$$
Y_{i j k l}=\mu+\alpha_{i}+\beta_{j}+\psi_{k}+\gamma x_{i j k l}+(\alpha \beta)_{i j}+\varepsilon_{i j k l}
$$

where $\mu$ is a constant, $\alpha$ represents the effect $V_{\text {face }}, \beta$ the effect of $V_{\text {cross }}, \psi$ the effect of human subjects, $x_{i j k l}$ the measurements of the covariate $\left(\Delta T_{h u m}\right)$ at the $i j k l$ run, $\gamma$ the regression analysis coefficient of the covariate, and $\alpha \beta$ the effect of the interaction between $V_{\text {face }}$ and $V_{\text {cross }}$. The experimental random error was represented for $\varepsilon$.

The dependent variables were $\log$-transformed $\left(\log C_{\text {nose }}\right.$ and $\left.\log C_{\text {mouth }}\right)$ to achieve a roughly linear statistical model and to produce more normal residuals. The adjusted coefficient of determination $\left(R_{a d j}^{2}\right)$ of the normality of residuals improve from $66.3 \%$ for $C_{\text {nose }}$ to $87.4 \%$ for $\log C_{\text {nose }}$ and from $36.7 \%$ for $C_{\text {mouth }}$ to 86.5\% for $\log C_{\text {mouth }}$ (see Figures E.7 and E.8 in Appendix E). In order to obtain the final statistical significance of the independent variables on exposure, a reduced ANCOVA model is presented in this study (Tables 7.9 and 7.10). As in previous 
manikin studies (Guffey and Barnea, 1994; He, 2010), the effect of hood face velocity on human subject exposures $\left(\log C_{\text {nose }}\right.$ and $\log C_{\text {mouth }}$ ) had a highly statistical significance $(\mathrm{p}<0.0001)$. However, $V_{\text {cross }}$ has no statistical significant effect on human subject exposures (Table 7.9 and 7.10), which agrees with the complex manikin study of the present work but disagrees with the results presented by He (2010). This may be due to the high variance between subjects.

Table 7.9 Log $C_{\text {nose }}$ ANCOVA for the human subjects

\begin{tabular}{lccccr}
\hline Source & df & Sums of Squares & Mean Square & F-ratio & \multicolumn{1}{c}{ Prob } \\
\hline Constant & 1 & 328.21 & 328.21 & 302.95 & $\bullet<0.0001$ \\
$V_{\text {face }}$ & 2 & 23.75 & 11.87 & 10.96 & $\bullet<0.0001$ \\
$V_{\text {cross }}$ & 2 & 5.17 & 2.59 & 2.39 & 0.0950 \\
$V_{\text {face }} V_{\text {cross }}$ & 4 & 3.42 & 0.85 & 0.79 & 0.5338 \\
Subject & 9 & 165.78 & 18.42 & 17.00 & $\bullet<0.0001$ \\
$\Delta T_{\text {human }}$ & 1 & 0.01 & 0.01 & 0.01 & 0.9092 \\
Error & 169 & 183.09 & 1.08 & & \\
Total & 187 & 376.90 & & & \\
\hline
\end{tabular}

Table 7.10 Log $C_{\text {mouth }}$ ANCOVA for the human subjects

\begin{tabular}{lccccr}
\hline Source & df & Sums of Squares & Mean Square & F-ratio & \multicolumn{1}{c}{ Prob } \\
\hline Constant & 1 & 133.16 & 133.16 & 168.93 & $\bullet<0.0001$ \\
$V_{\text {face }}$ & 2 & 14.72 & 7.36 & 9.34 & 0.0001 \\
$V_{\text {cross }}$ & 2 & 2.18 & 1.09 & 1.38 & 0.2537 \\
$V_{\text {face }} V_{\text {cross }}$ & 4 & 2.31 & 0.58 & 0.73 & 0.5708 \\
Subject & 9 & 128.63 & 14.29 & 18.13 & $\bullet<0.0001$ \\
$\Delta T_{\text {human }}$ & 1 & 1.17 & 1.17 & 1.48 & 0.2252 \\
$V_{\text {face }} * T_{\text {human }}$ & 2 & 11.86 & 5.93 & 7.52 & 0.0007 \\
Error & 165 & 130.06 & 0.79 & & \\
Total & 185 & 291.81 & & & \\
\hline
\end{tabular}


Human subjects significantly affect $(\mathrm{p}<0.0001)$ the performance of the plain enclosing hood as is shown in Tables 7.9 and 7.10. This could be due to different work practices in front of the enclosing hood or to different characteristic, such as adiposity, height, etc. On the other hand, the ANCOVA model shows that $\Delta T_{\text {human }}$ had no significant effect on human subject exposures ( $\left.\mathrm{p}>0.20\right)$, which is not in line with the results presented in Figure 7.46 where it is suggested that an increase in $\Delta T_{\text {human }}$ means a slight increase on exposure at the nose $\left(\log C_{\text {nose }}\right)$.

In addition, $\log C_{\text {nose }}$ and $\log C_{\text {mouth }}$ appear to be unaffected by the interaction between $V_{\text {face }}$ and $V_{\text {cross }}(\mathrm{p}>0.05)$ as is shown in Tables 7.9 and 7.10. However, exposure is affected by the interaction between $V_{\text {face }}$ and $\Delta T_{\text {human }}$ for $\log$ $C_{\text {mouth }}$ but not for $\log C_{\text {nose }}$. All other interactions showed no significant effects on human subject exposures, so they were omitted from the final models. A marginally better coefficient of determination was obtained for $\log C_{\text {mouth }}\left(R^{2}=\right.$ $55.4 \%)$ than for $\log C_{\text {nose }}\left(R^{2}=51.4 \%\right)$.

Human subject Gray showed the highest exposure at the mouth (108.2 ppm), which was much greater than the average $13.2 \mathrm{ppm}$. Therefore, analysis of covariance on $\log C_{m o u t h}$ excluding this uncommon exposure was carried out to elucidate how the significance of the main factors and their interactions were affected without this value. As shown in Table 7.11, there was no substantial change in the statistical significance of the independent factors and interactions after excluding this highest exposure value. 
Table 7.11 Log Cmouth ANCOVA for the human subjects without the highest exposure of subject ID Grey

\begin{tabular}{lccccr}
\hline Source & df & Sums of Squares & Mean Square & F-ratio & Prob \\
\hline Constant & 1 & 137.36 & 137.36 & 173.61 & $\bullet<0.0001$ \\
$V_{\text {face }}$ & 2 & 14.00 & 7.00 & 8.85 & 0.0002 \\
$V_{\text {cross }}$ & 2 & 2.21 & 1.11 & 1.40 & 0.2497 \\
$V_{\text {face }}{ }^{*} V_{\text {cross }}$ & 4 & 2.09 & 0.52 & 0.66 & 0.6201 \\
Subject & 9 & 124.59 & 13.84 & 17.50 & $\bullet<0.0001$ \\
$\Delta T_{\text {human }}$ & 1 & 1.13 & 1.13 & 1.43 & 0.2328 \\
$V_{\text {face }} \Delta T_{\text {human }}$ & 2 & 11.40 & 5.70 & 7.20 & 0.001 \\
Error & 164 & 129.76 & 0.79 & & \\
Total & 184 & 283.47 & & & \\
\hline
\end{tabular}

\subsubsection{Effect of human subjects' body dimensions}

Published numerical simulation studies have shown the effect of body size on worker's exposure in a free-stream airflow (Li et al., 2005) and in an enclosing hood (Karaismail, 2011). It was also experimentally observed that different human subjects of different body dimensions produce different "leakage" when standing in front of a laboratory fume hood (Caplan and Knutson, 1982). A rounded complex manikin produces better exposure results than either a block or simple geometrically formed manikin (Li et al., 2005; Karaismail, 2011). However, it is not clear that manikin and human subjects are interchangeable and manikin studies may give a false picture of the hood effectiveness (Caplan and Knutson, 1982; Johnson and Fletcher, 1996; Ljungqvist, 1987). Therefore, in the present study the effect of body dimensions on the performance of a benchtop enclosing hood was determined. 
Table 7.12 Log $C_{\text {nose }}$ ANCOVA for the human subjects' body dimensions

\begin{tabular}{lccccr}
\hline Source & df & Sums of Squares & Mean Square & F-ratio & \multicolumn{1}{c}{ Prob } \\
\hline Constant & 1 & 328.21 & 328.21 & 304.43 & $\bullet<0.0001$ \\
$V_{\text {face }}$ & 2 & 23.21 & 11.61 & 10.77 & $\bullet<0.0001$ \\
$V_{\text {cross }}$ & 2 & 5.18 & 2.59 & 2.40 & 0.0937 \\
$\Delta T_{\text {human }}$ & 1 & 0.02 & 0.02 & 0.02 & 0.8798 \\
Height & 3 & 44.90 & 14.97 & 13.88 & $\bullet<0.0001$ \\
Shoulder & 3 & 75.79 & 25.26 & 23.43 & $\bullet<0.0001$ \\
Weight & 3 & 45.45 & 15.15 & 14.05 & $\bullet<0.0001$ \\
Error & 173 & 186.51 & 1.08 & & \\
Total & 187 & 376.90 & & & \\
\hline
\end{tabular}

Table 7.13 Log $C_{\text {mouth }}$ ANCOVA for the human subjects' body dimensions

\begin{tabular}{lccccc}
\hline Source & df & Sums of Squares & Mean Square & F-ratio & Prob \\
\hline Constant & 1 & 133.16 & 133.16 & 178.09 & $\bullet<0.0001$ \\
$V_{\text {face }}$ & 2 & 17.73 & 8.87 & 11.86 & $\bullet<0.0001$ \\
$V_{\text {cross }}$ & 2 & 2.31 & 1.16 & 1.55 & 0.2163 \\
$\Delta T_{\text {human }}$ & 1 & 0.03 & 0.03 & 0.04 & 0.8352 \\
$V_{\text {face }} \Delta T_{\text {human }}$ & 2 & 14.26 & 7.13 & 9.53 & 0.0001 \\
Height & 3 & 10.01 & 3.34 & 4.46 & 0.0048 \\
$\Delta T_{\text {human }} *$ Height & 3 & 8.25 & 2.75 & 3.68 & 0.0134 \\
Shoulder & 3 & 19.27 & 6.42 & 8.59 & $\bullet<0.0001$ \\
Weight & 3 & 52.35 & 17.45 & 23.34 & $\bullet<0.0001$ \\
Error & 166 & 124.12 & 0.75 & & \\
Total & 185 & 291.81 & & & \\
\hline
\end{tabular}

Measures of the height, shoulder, weight, and heat perimeter were taken for each human subject who participated in this study (see Table 7.1 and Figures 7.1 to 7.10). Analysis of covariance (ANCOVA) for the log-transformed $C_{\text {nose }}$ and $C_{\text {mouth }}$ were carried out where $V_{\text {face }}, V_{\text {cross }}, \Delta T_{\text {human }}$, as well as head perimeter, subject height, shoulder width, and weight were considered. The subject dimensions were 
deemed as discrete variables. Partial (type 3) sums of squares were determined for the ANCOVA analyses.

This study results provide evidence that human subjects' body dimensions such as height, shoulder, and weight had highly significant effects $(\mathrm{p}<0.0001)$ on $\log C_{\text {nose }}$ (see Table 7.12). These results are in good agreement with previous numerical predictions by Karaismail (2011) done for the same experiments and Li et al. (2005) in a free stream airflow setup.

The dimension of head perimeter is almost about the same for all human subjects (Table 7.1) and therefore did not attain significance $(\mathrm{p}>0.05)$. In addition, $V_{\text {face }}$ shows to have a highly statistically significant effect on $\log C_{\text {nose }}(\mathrm{p}<0.0001)$ but neither $V_{\text {cross }}$ nor $\Delta T_{\text {human }}$ were now statistically significant $(\mathrm{p}>0.05$ ). Interactions between $V_{\text {face }}$ and $V_{\text {cross }}$ and all other interactions showed no significant effect $(p>0.05)$ on exposure. Therefore, a reduced ANCOVA model is presented in Table 7.12 without interactions.

In addition, the ANCOVA model for $\log C_{\text {mouth }}$ shows the same statistical significance for the factors as $\log C_{\text {nose }}$ with the exception in the model of two significant interactions ( $V_{\text {face }} * \Delta T_{\text {human }}$ and $\Delta T_{\text {human }} *$ height). All other interactions had no significant effect on exposures (Table 7.13). A moderately better coefficient of determination was obtained for $\log C_{\text {mouth }}\left(R^{2}=57 \%\right)$ than for $\log C_{n o s e}\left(R^{2}=\right.$ $50 \%)$. 


\subsubsection{Effectiveness of the enclosing hood}

As it was previously pointed out, no experimental study has been published to date to assess the performance efficiency (see Eq. 1.1) of a plain enclosing hood using human subjects. The only two experimental studies (Guffey and Barnea, 1994 and He, 2010) did establish the importance of $V_{\text {face }}$ and $V_{\text {cross }}$ on manikin's exposure but did not quantify the protection efficiency $\left(\eta_{\text {prot }}\right)$ of the enclosing hood. Protection efficiency measures the ability of the hood to reduce worker's exposure in relation to the quantity of airflow $(Q)$ used to it. High efficiency can result from either low concentration or lower $Q$ values to produce the same concentration. The present study shows the calculated average protection efficiency of the enclosing hood for all human subjects (Figure 7.48 and 7.49).

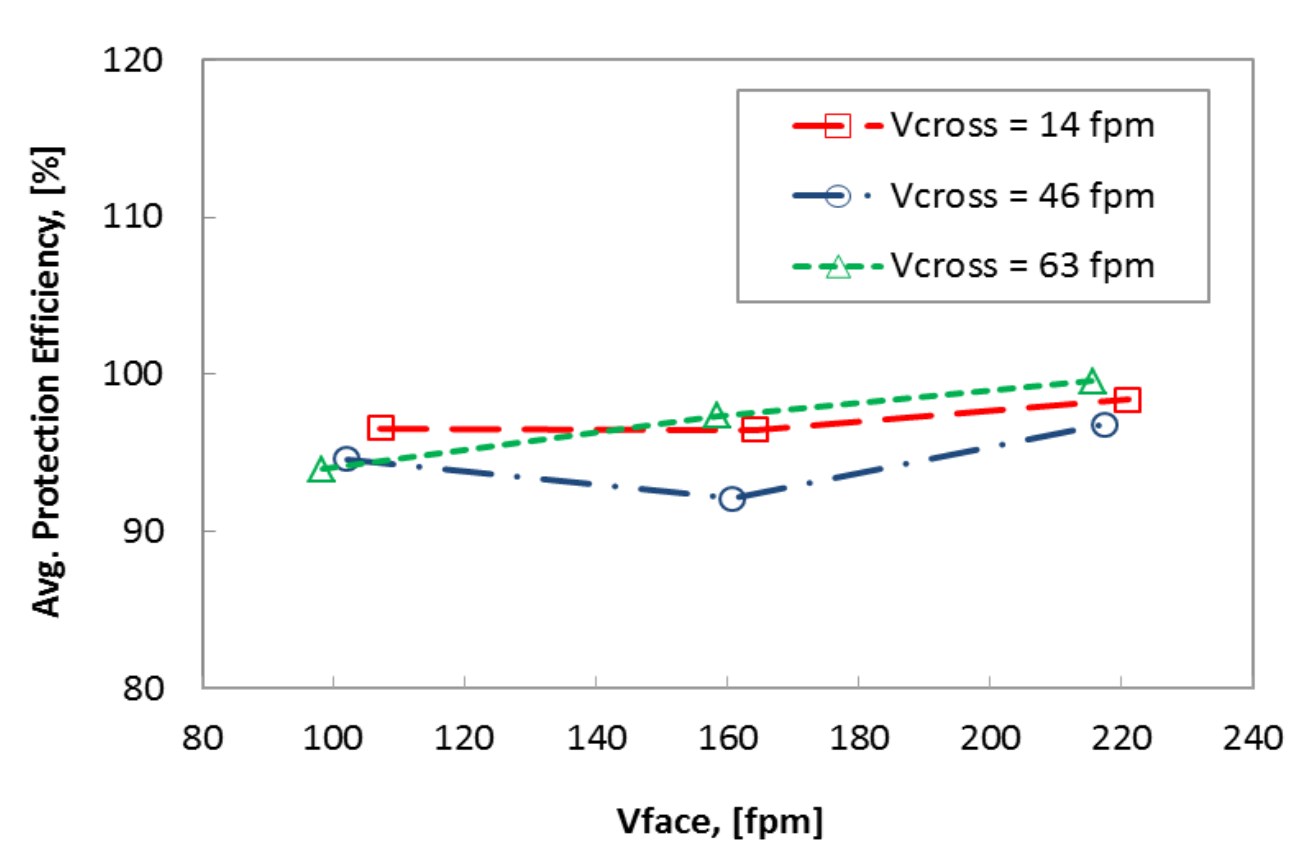

Figure 7.48 Effect of $V_{\text {face }}$ on the average protection efficiency at each level of $V_{\text {cross }}$ for the human subjects 
For enclosing hoods, one would expect $\eta_{\text {prot }}$ to initially increase with $Q$ then decrease as diminishing returns occur. At $V_{\text {face }}=100 \mathrm{fpm}$ (Figure 7.48), all protection efficiency appears to be near each other, which means that worker's exposure did not change significantly as $V_{\text {cross }}$ changes. For the intermediate $V_{\text {face }}$ value (160 fpm), the lowest $\eta_{\text {prot }}$ is presented for curves at $V_{\text {cross }}=14$ and $46 \mathrm{fpm}$. As $\eta_{\text {prot }}$ curves move from intermediate to higher $V_{\text {face }}(220 \mathrm{fpm})$, the enclosing hood gives a maximum protection to workers. In addition, protection efficiency seems to be unaltered at $V_{\text {face }}=220 \mathrm{fpm}$ and all levels of $V_{\text {cross }}$ (Figure 7.48). These results suggest that the point for diminishing effectiveness with $Q$ was not yet reached. Hence, even more airflow may further reduce exposure.

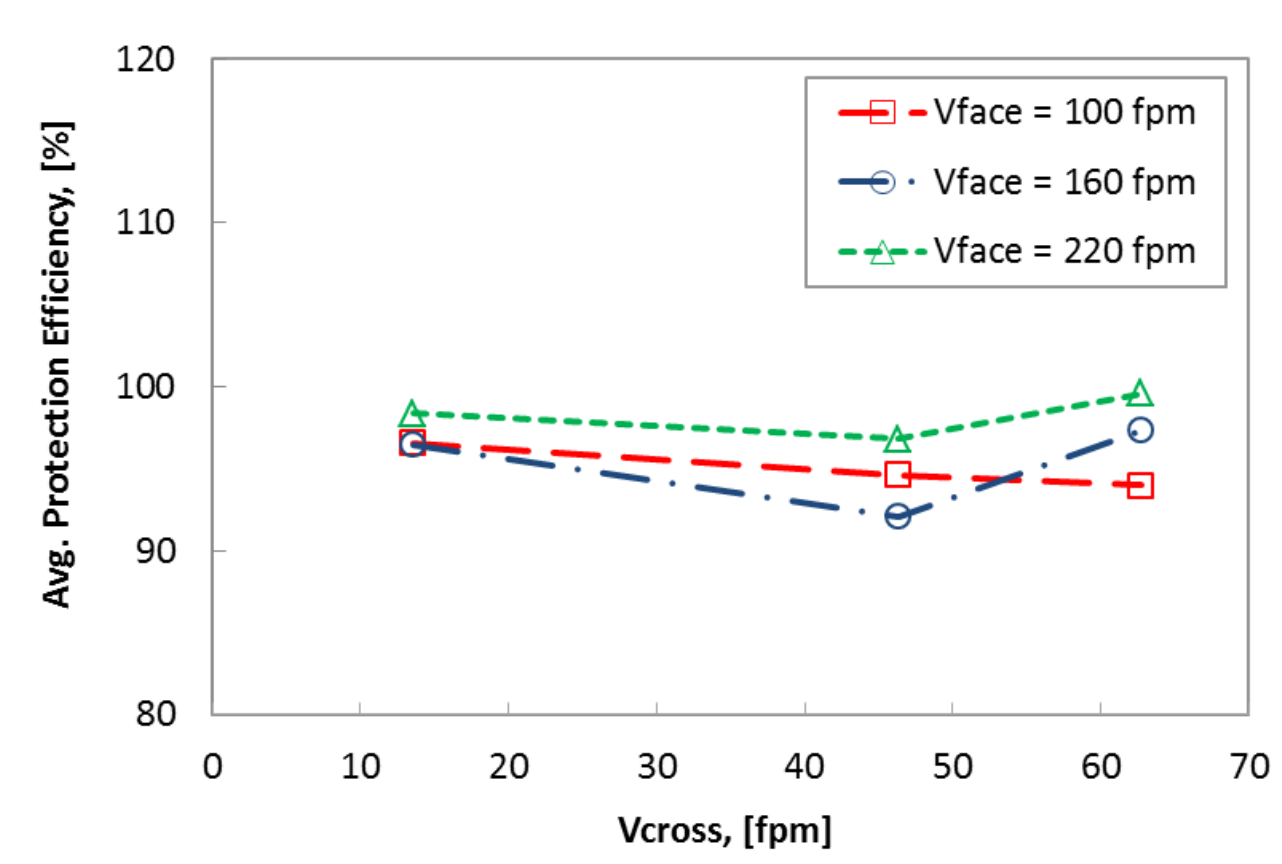

Figure 7.49 Effect of $V_{\text {cross }}$ on the average protection efficiency at each level of $V_{\text {face }}$ for the human subjects 
As shown in Figure $7.49, \eta_{\text {prot }}$ decreased slightly as $V_{\text {cross }}$ increased at $V_{\text {face }}$ $=100 \mathrm{fpm}$. However, as $V_{\text {cross }}$ increased to $63 \mathrm{fpm} \eta_{\text {prot }}$ increased slightly. Since $Q$ is constant in Figure 7.49 as $V_{\text {cross }}$ is incresed, this suggests that increased $V_{\text {cross }}$ improves $\eta_{\text {prot }}$ or at least does not affect it.

\subsubsection{Effect of face location on exposure}

Proper work practices can dramatically increase the effectiveness of fume hoods (Mikell and Hobbs, 1981; Mikell and Fuller, 1988; Johnson and Fletcher, 1996; Ivany et al., 1989). These correct work practices in lab fume hoods included keeping the contaminant source at least 6 in from the hood sash, the worker standing in front of the hood with his face outside of the sash and the sash being closed as much as possible. Exposure increases substantially in fume hoods if these recommendations are not followed, which represents bad work practices. However, no study was found about good or bad work practices in benchtop enclosing hoods using a human subject. Therefore, this study specifically investigated, using a human subject, how the worker's face location affects the performance of an enclosing hood.

Specific instructions were given to the human subject to keep the chosen face location during the experimental tests. Those were observed carefully throughout the experiments on a computer screen outside the wind tunnel. As shown in Figures 7.50, experiments were carried out with the human subject standing at almost 1 in from the table edge at waist level and the emitting source at 
a fixed location ( 2 in from the hood face). Thus, to determinee if the manikin's exposure pattern was also observed with a human doing a modest amount of hand movement inside the hood, two face working locations were investigated: the sideburn and the the back of the head (Figure 7.50).

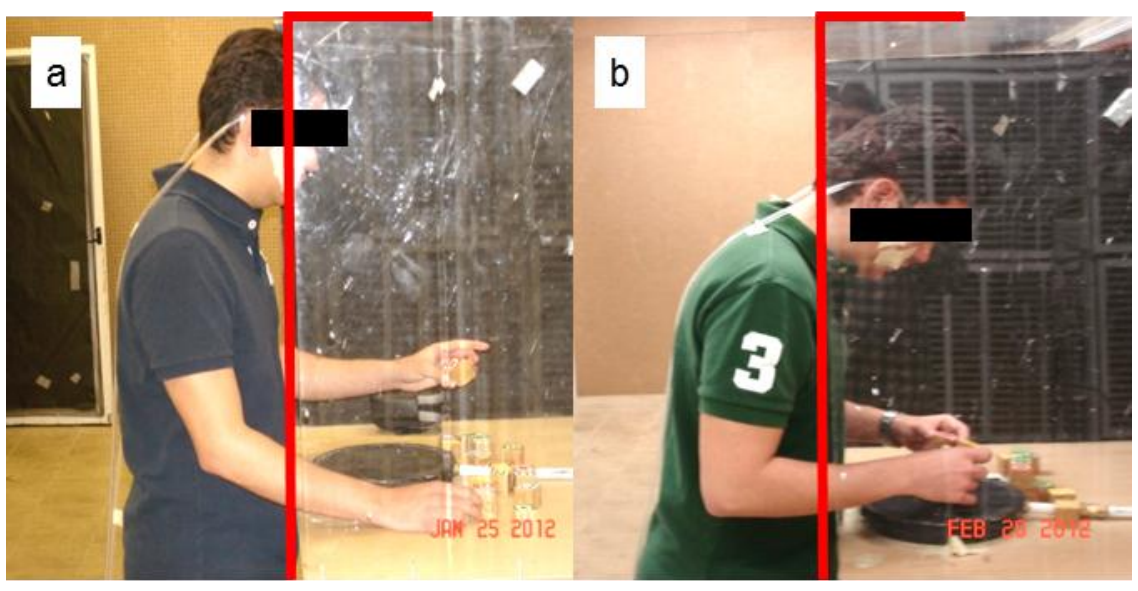

Figure 7.50 Human subject's face location a) sideburn b) back of the head

Table 7.14 Human subject's face location exposure

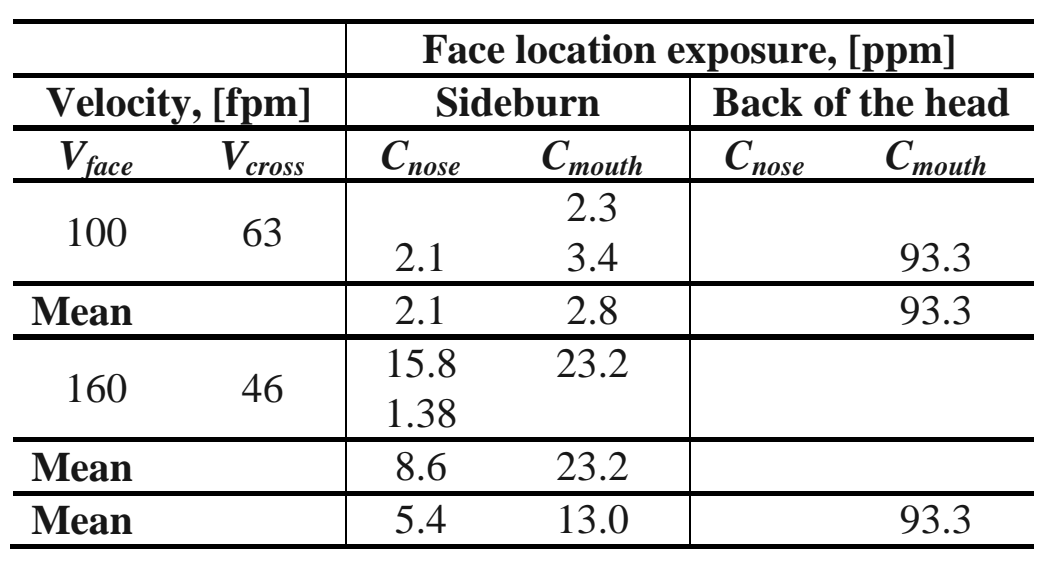


For the Sideburn face location the levels measured, average $C_{\text {nose }}=5.4 \mathrm{ppm}$ and average $C_{\text {mouth }}=13 \mathrm{ppm}$, were similar to those of the manikin at the Sideburn location (see Figure 7.50a and Table 7.14). When the human subject was tested with the back of the head at the face of the hood (Figure 7.50b), the highest exposure value was obtained $\left(C_{\text {mouth }}=93.3 \mathrm{ppm}\right)$ at $V_{\text {face }}=100 \mathrm{fpm}$ and $V_{\text {cross }}=63$ fpm (see Table 7.14). This means there was more than thirty times the value for the sideburn face location $\left(C_{\text {mouth }}=2.8 \mathrm{ppm}\right)$ at the same velocity combinations. Some values were omitted because their residuals were greater than the 0.02 criterion.

This high exposure at the back of the head location may explain the very high exposure of the human subject Gray $\left(C_{\text {mouth }}=108.2 \mathrm{ppm}\right)$ at the same $V_{\text {face }}=$ $100 \mathrm{fpm}$ and $V_{\text {cross }}=63 \mathrm{fpm}$. Human subject Gray (Figure 7.6) perhaps had a working posture similar to the back of the head face location (Figure 7.50b) when his highest exposure value was observed. Clearly, the location of the head relative to the hood face is very important to these results. It is not clear whether these effects is due to the airflow condition at the face of the hood or to the different distances to the source.

\subsubsection{Effect of the distance between the breathing zone and the source}

The effect of the distance between the breathing zone and the contaminant source is an important factor in a lab fume hood performance, as important as $V_{\text {face }}$ and $V_{\text {cross }}$ (Mikell and Hobbs, 1981; Mikell and Fuller, 1988; Johnson and Fletcher, 1996). For that reason, this study describes experiments using a human subject with different body's interventions (Figure 7.52). To the author's knowledge no 
previous published studies exist that investigated the effect of the distance of the breathing zone to the emission source produced by body's interventions on the performance of a benchtop enclosing hood.

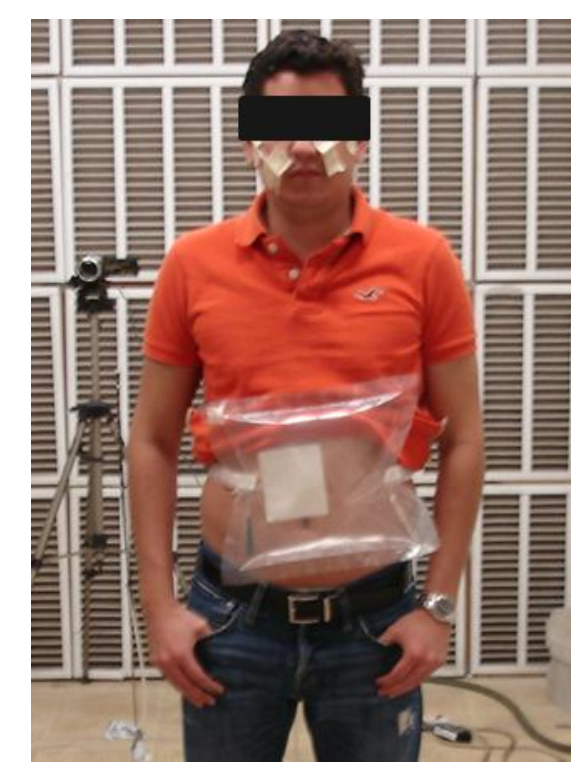

Figure 7.51 Human subject's padded belly

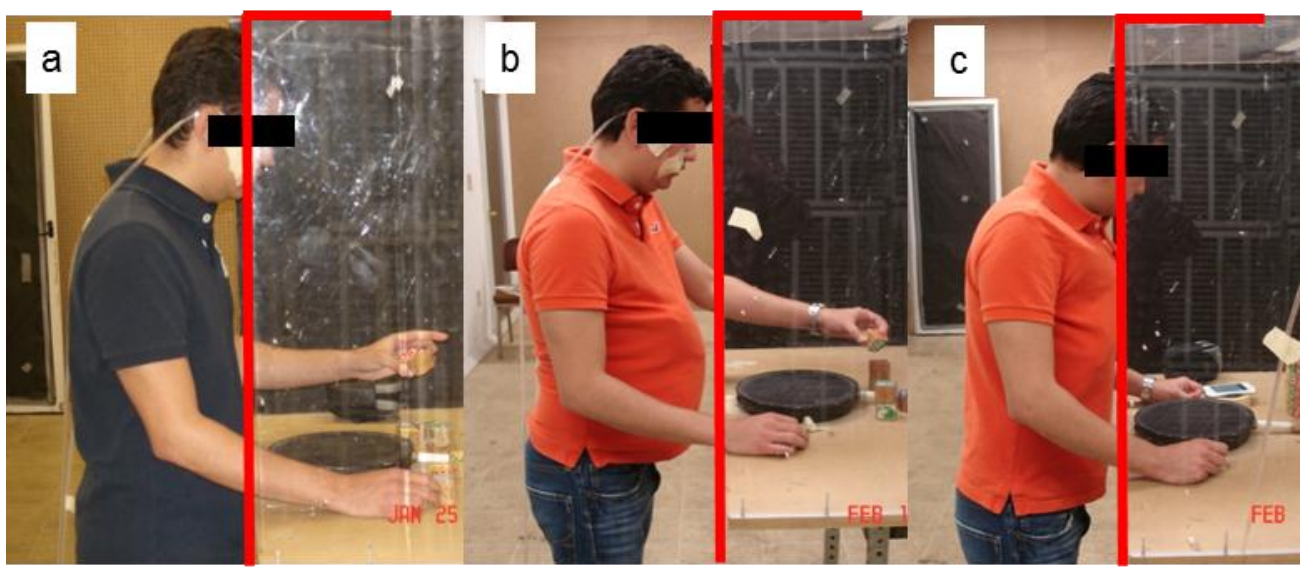

Figure 7.52 Human subject's intervention a) without padded belly b) padded belly c) ) padded chest 
Table 7.15 Human subject's intervention exposure

\begin{tabular}{|c|c|c|c|c|c|c|c|}
\hline & & \multicolumn{6}{|c|}{ Human subject intervention exposure, [ppm] } \\
\hline \multicolumn{2}{|c|}{ Velocity, [fpm] } & \multicolumn{2}{|c|}{ Without padded } & \multicolumn{2}{|c|}{ Padded belly } & \multicolumn{2}{|c|}{ Padded chest } \\
\hline$V_{\text {face }}$ & $V_{\text {cross }}$ & $C_{\text {nose }}$ & $C_{\text {mouth }}$ & $C_{\text {nose }}$ & $C_{\text {mouth }}$ & $C_{\text {nose }}$ & $C_{\text {mouth }}$ \\
\hline \multirow{2}{*}{100} & \multirow{2}{*}{63} & & 2.3 & 0.0 & 0.0 & 0.1 & 0.1 \\
\hline & & 2.1 & 3.4 & 0.0 & 0.0 & 0.9 & \\
\hline Mean & & 2.1 & 2.8 & 0.0 & 0.0 & 0.5 & 0.1 \\
\hline \multirow{2}{*}{160} & \multirow{2}{*}{46} & 15.8 & 23.2 & 0.0 & 0.0 & 0.1 & 0.1 \\
\hline & & 1.4 & & 0.0 & 0.0 & 0.1 & 0.2 \\
\hline Mean & & 8.6 & 23.2 & 0.0 & 0.0 & 0.1 & 0.1 \\
\hline Mean & & 5.4 & 13.0 & 0.0 & 0.0 & 0.3 & 0.1 \\
\hline
\end{tabular}

For all experiments, the human subject was standing at 1 in from the hood face and the contaminant source was fixed inside the hood at 2 in from the hood face edge. To simulate the subject's padded belly and padded chest, a sample bag was filled with 2.5 liters of air and then fixed to his belly and chest (see Figure 7.51 for the padded belly).This increased in 3.5 in width the human's belly and chest (see Figures 7.52b and 7.52c). For all experimental tests, the human subject's head was in the Sideburn posture. In addition, for each intervention, different sets of experiments were considered. Some values were omitted because their residuals were greater than the 0.02 criterion.

Three experimental human subject interventions were tested. The first and the second interventions were similar to those at the complex manikin experiments (Figures 7.52a and 7.52b). The third was a different intervention: a padded chest (Figure 7.52c). The distance between the belly with and without padding and the hood face was roughly 1 in. These experiments with a human subject represent an 
attempt to explore the effects of subject's body shape on the performance of the benchtop enclosing hood.

As shown in Table 7.15, there was no significant difference between human subject's and manikin's exposure when both were tested with and without a padded belly ( see Tables 6.23 and 7.15). When the human subject was tested with a padded belly (Table 7.15) there was a large reduction in exposure to negligible levels as compared to the tests without a padded belly (average $C_{\text {nose }}=5.4 \mathrm{ppm}$ and average $\left.C_{\text {mouth }}=13.0 \mathrm{ppm}\right)$. When a padded belly was used for the human subject (Figure 7.52b), belly forced him away from the hood face so that his breathing zone was outside the hood face. Thus, the effect of distance between the breathing zone and the source cannot be separate from the effect of padding or body shape on the plain hood's performance.

When a padded chest was used for the subject, the exposure was above zero with average $C_{\text {nose }}=0.3 \mathrm{ppm}$ and average $C_{\text {mouth }}=0.1 \mathrm{ppm}$, but still much lower than the results without the padded chest (Table 7.15). It is possible that the padded chest was somewhat blocking the upward airflow of contaminants from the lower part of the human subject to the breathing zone due to the buoyancy effect. In summary, a small increase in the distance between the subject breathing zone and the hood face produced a big difference on worker's exposure and in the effectiveness of a benchtop enclosing hood. It is also suggested that almost no exposure is obtained if the subject's breathing zone remains outside the hood face. 


\section{CHAPTER 8}

\section{COMPARISONS OF EXPOSURE FOR THE SIMPLE \\ MANIKIN, THE COMPLEX MANIKIN, AND THE HUMAN \\ SUBJECTS}

\subsection{Introduction}

Most previous experimental studies that have compared exposure in manikins and human subjects were carried out using a laboratory fume hood (Altemose et al, 1998; Johnson and Fletcher, 1996; Mikell and Hobbs, 1981; Greenley et al., 2000). The performance of a benchtop enclosing hood was also experimentally studied using a manikin (Guffey and Barnea, 1994; He, 2010). However, no comparisons were made with actual exposure to human subjects. In this study, results from previous chapters for a simple manikin, complex manikin and 10 human are compared and discussed.

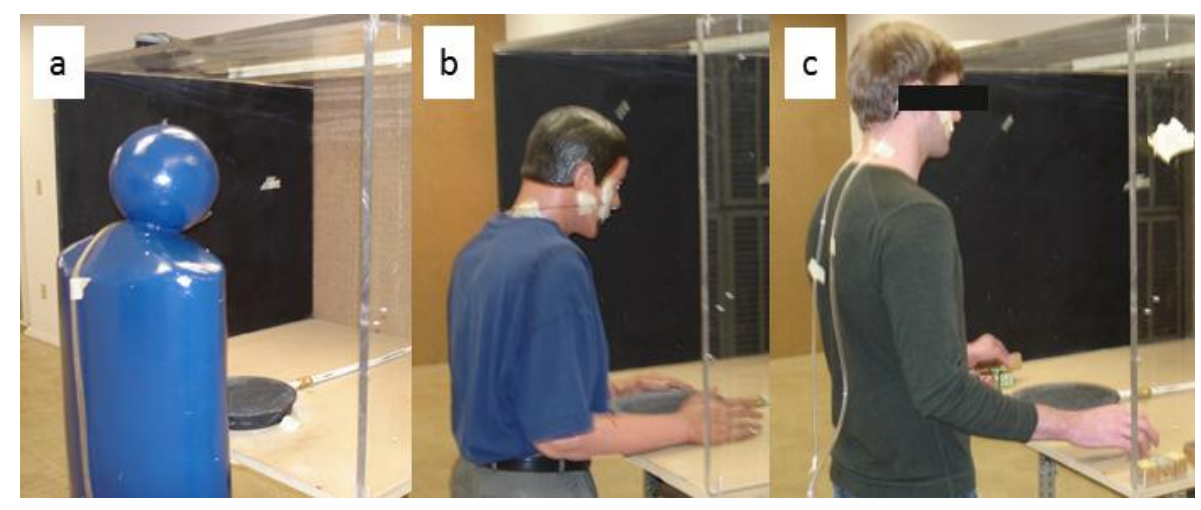

Figure 8.1 Subjects' working posture a) simple manikin b) complex manikin c) human subject 
As discussed in Chapters 5, 6, and 7, the experimental conditions were the same when testing with both manikins and with all human subjects. Both of the manikins and the human subjects stood in front of the enclosing hood in a working posture at side orientation to the wind tunnel airflow $\left(V_{\text {cross }}\right)$, as can be seen in Figure 8.1. The simple manikin and the complex manikin remained in static positions during all experimental tests. As it was detailed in previous chapters, the simple manikin was built of simple geometric forms, such as a sphere and cylinders, and had no hands. Conversely, the complex manikin had physical features and dimensions like a human being. Its hands were placed on both sides of the contaminant source. This complex manikin was heated and breathed. The human subjects were of different sizes, body dimensions, and ethnic backgrounds. They carried out a non-energetic task inside the hood: moving small children's blocks back and forth over the source of Freon 134a.

Good agreement on past studies of fume hood exposure was found between a 3-D heated manikin and a human subject (Johnson and Fletcher, 1996). However, there was not a consistent agreement on fume hood exposure to an unheated manikin and a human subject (Altemose et al., 1998). The effect of hood face velocity $\left(V_{\text {face }}\right)$ was a main factor on those studies. It was also experimentally proved in previous fume hood studies that there is a large difference in exposure levels between the manikins and the human subjects, which means that results of the former can give a false picture of the actual hood performance (Ljungqvist, 1987; Caplan and Knutson, 1982). 
In the present study, the effect of hood face velocity $\left(V_{\text {face }}\right)$ and cross-draft velocity $\left(V_{\text {cross }}\right)$ on concentrations at the nose and mouth $\left(C_{\text {nose }}\right.$ and $\left.C_{\text {mouth }}\right)$ were compared for the manikins and the human subjects to determine if either the simple or the complex manikin better represent human subject exposure when "working" in front of a benchtop enclosing hood.

\subsection{Results compared}

As can be observed in Figures 8.2 and 8.3, human subject IDs Gray, Black, and Brown experienced higher exposures than the other seven human subjects. Their exposures were similar to the exposures to the simple and the complex manikins (Figures 8.2 and 8.3). The remaining subjects experienced substantially lower exposures.

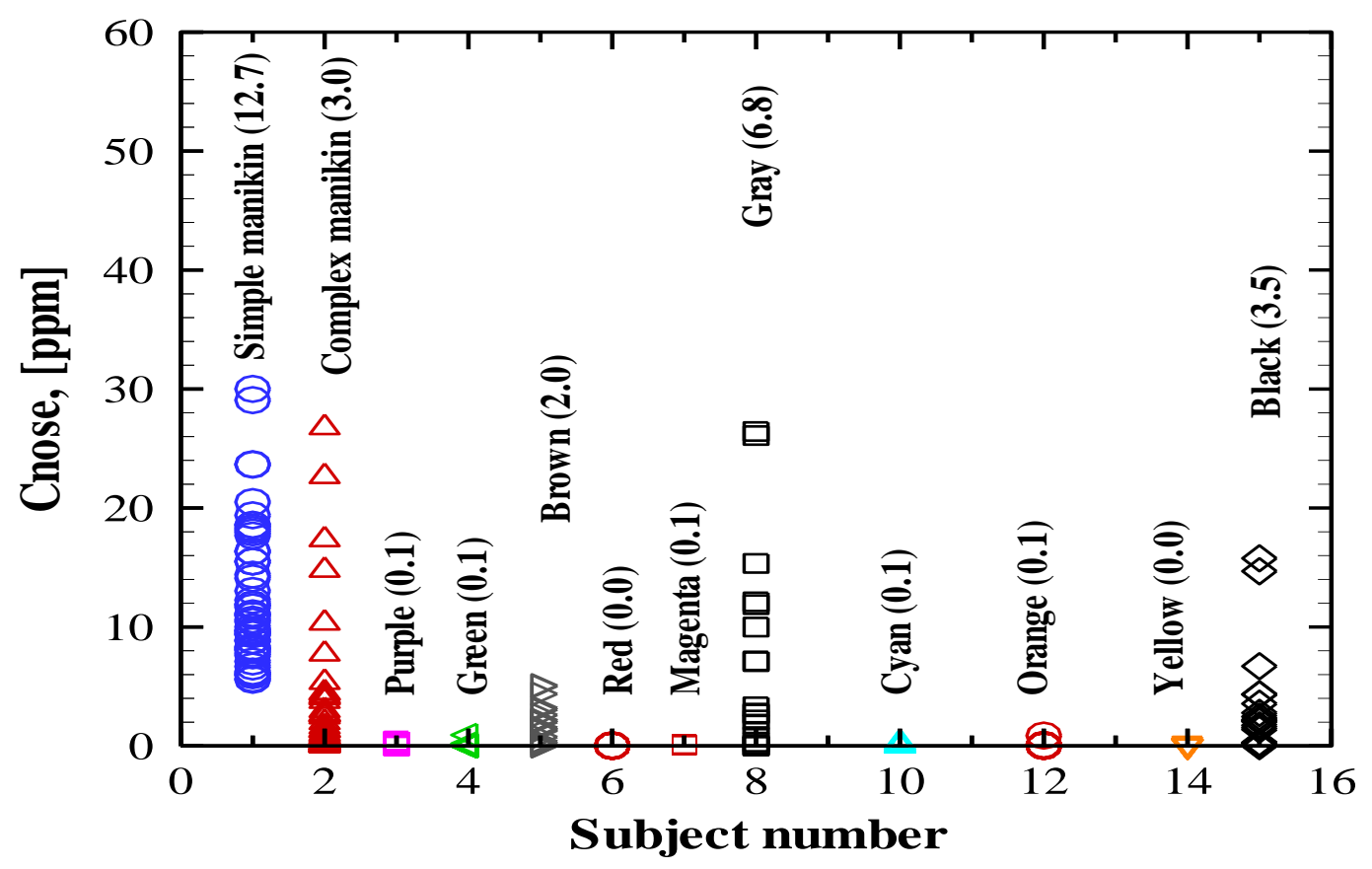

Figure $8.2 C_{\text {nose }}$ for both manikins and all 10 human subjects (average exposure in parenthesis) 


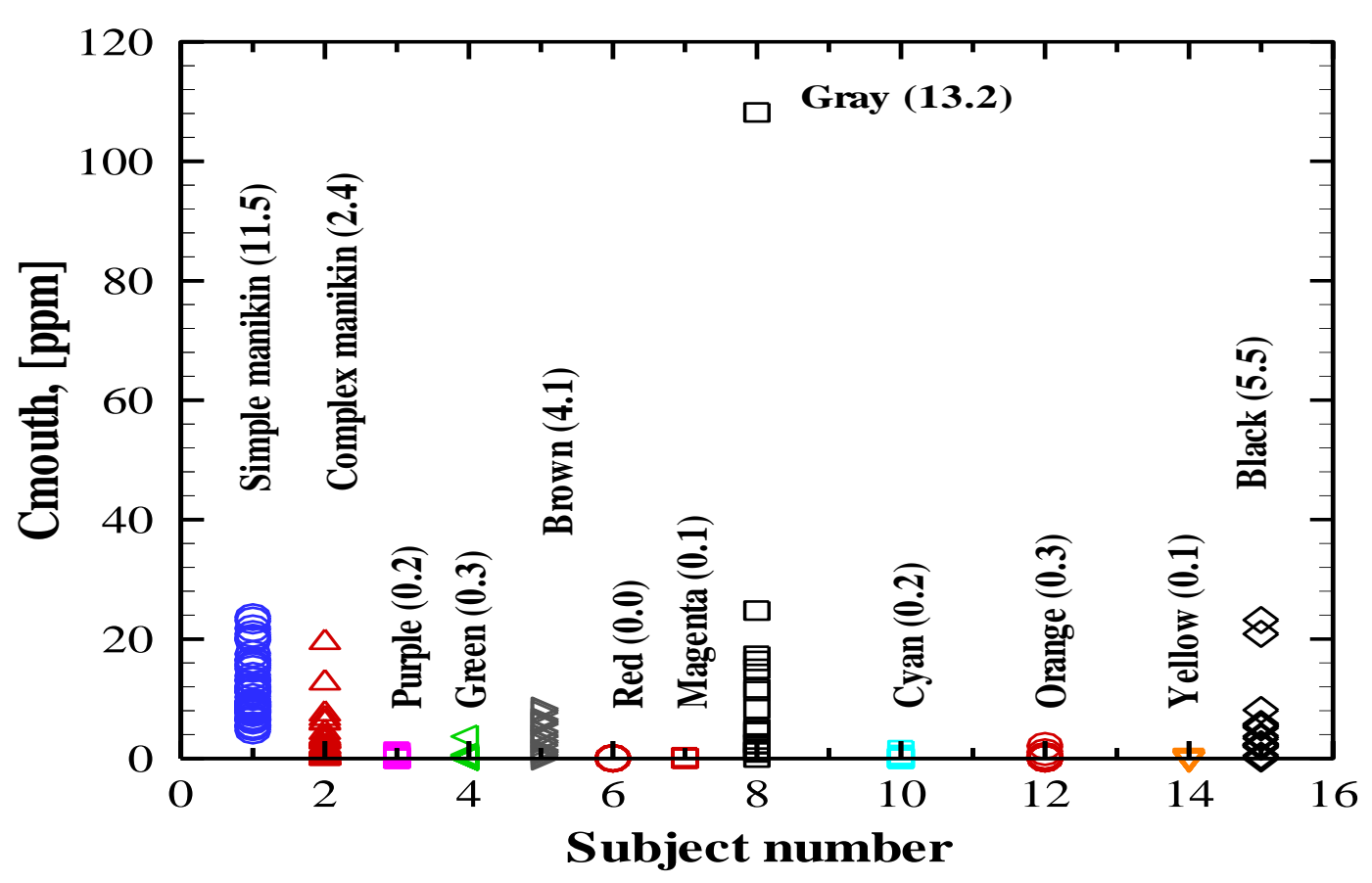

Figure $8.3 C_{\text {mouth }}$ for both manikins and all 10 human subjects (average exposure in parenthesis)

Table 8.1 Subjects' summary statistic for $C_{\text {nose }}$

\begin{tabular}{lccccccc}
\hline Subject & N & Mean & Median & StdDev & CV & Min & Max \\
\hline Simple manikin & 50 & 12.7 & 11.0 & 5.9 & 0.5 & 5.6 & 30.0 \\
Complex manikin & 54 & 3.0 & 0.8 & 5.5 & 1.8 & 0.0 & 26.8 \\
Purple & 20 & 0.1 & 0.1 & 0.1 & 1.0 & 0.0 & 0.4 \\
Green & 20 & 0.1 & 0.0 & 0.2 & 3.3 & 0.0 & 0.9 \\
Brown & 18 & 2.0 & 1.8 & 1.7 & 0.9 & 0.0 & 5.1 \\
Red & 20 & 0.0 & 0.0 & 0.0 & 1.1 & 0.0 & 0.1 \\
Magenta & 16 & 0.1 & 0.1 & 0.1 & 0.7 & 0.0 & 0.2 \\
Gray & 19 & 6.8 & 2.8 & 8.3 & 1.2 & 0.0 & 26.4 \\
Cyan & 18 & 0.1 & 0.0 & 0.1 & 1.2 & 0.0 & 0.3 \\
Orange & 20 & 0.1 & 0.0 & 0.2 & 2.5 & 0.0 & 0.9 \\
Yellow & 18 & 0.0 & 0.0 & 0.1 & 1.3 & 0.0 & 0.2 \\
Black & 19 & 3.5 & 2.1 & 4.5 & 1.3 & 0.0 & 15.8 \\
Total & 292 & 3.6 & 0.2 & 6.2 & 1.7 & 0.0 & 30.0 \\
\hline
\end{tabular}


Table 8.2 Subjects' summary statistic for $C_{\text {mouth }}$

\begin{tabular}{lccccccc}
\hline Group & N & Mean & Median & StdDev & CV & Min & Max \\
\hline Simple Manikin & 50 & 11.5 & 9.4 & 5.1 & 0.4 & 4.7 & 23.7 \\
Complex manikin & 51 & 2.4 & 1.3 & 3.4 & 1.4 & 0.1 & 19.4 \\
Purple & 20 & 0.2 & 0.1 & 0.3 & 1.5 & 0.0 & 1.2 \\
Green & 20 & 0.3 & 0.1 & 0.8 & 2.6 & 0.0 & 3.7 \\
Brown & 19 & 4.1 & 3.8 & 2.7 & 0.7 & 0.0 & 8.3 \\
Red & 20 & 0.0 & 0.0 & 0.0 & 0.8 & 0.0 & 0.1 \\
Magenta & 16 & 0.1 & 0.1 & 0.1 & 0.7 & 0.0 & 0.2 \\
Gray & 18 & 13.2 & 4.9 & 24.7 & 1.9 & 0.1 & 108.2 \\
Cyan & 18 & 0.2 & 0.0 & 0.3 & 1.9 & 0.0 & 1.4 \\
Orange & 20 & 0.3 & 0.1 & 0.5 & 1.9 & 0.0 & 2.1 \\
Yellow & 18 & 0.1 & 0.1 & 0.1 & 1.3 & 0.0 & 0.5 \\
Black & 17 & 5.5 & 3.4 & 6.6 & 1.2 & 0.0 & 23.2 \\
Total & 287 & 3.9 & 0.5 & 8.3 & 2.1 & 0.0 & 108.2 \\
\hline
\end{tabular}

Table 8.3 Subjects' body dimensions and exposure

\begin{tabular}{lccccc}
\hline Subject & Height, & Shoulder, & Weight, & \multicolumn{2}{c}{ Mean exposure, [ppm] } \\
\cline { 5 - 6 } & {$[$ in] } & {$[$ in] } & {$[\mathbf{l b}]$} & $\boldsymbol{C}_{\text {nose }}$ & $\boldsymbol{C}_{\text {mouth }}$ \\
\hline Simple manikin & 63 & 17.5 & & 12.7 & 11.5 \\
Complex manikin & 66 & 17.5 & & 3.0 & 2.4 \\
Green & 67 & 17.5 & 169.4 & 0.1 & 0.3 \\
Brown & 67 & 18.0 & 156.5 & 2.0 & 4.1 \\
Purple & 67 & 18.0 & 175.0 & 0.1 & 0.2 \\
Orange & 68 & 20.0 & 203.0 & 0.1 & 0.3 \\
Cyan & 68 & 17.5 & 180.0 & 0.1 & 0.2 \\
Black & 68 & 17.5 & 140.0 & 3.5 & 5.5 \\
Red & 70 & 17.0 & 160.0 & 0.0 & 0.0 \\
Yellow & 70 & 18.0 & 180.0 & 0.0 & 0.1 \\
Gray & 70 & 18.0 & 170.0 & 6.8 & 13.2 \\
Magenta & 71 & 18.5 & 183.0 & 0.1 & 0.1 \\
\hline
\end{tabular}

Human subject Gray presented an unusually high exposure (Figure 8.3) as compared to the other manikins and humans, which could be leaning forward so that his face was inside the hood. Human subjects' different body dimension is 
another important factor that affects exposure, which was also previously investigated (see Chapter 7). In addition, while the manikins remained static throughout the tests, the human subjects performed hand movements over the source, which may be another factor that explains exposure differences.

Maximum exposure values for the complex manikin and the human subject Gray are similar (27 and 26 ppm) but slightly below the simple manikin maximum exposure (30 ppm), as can be seen in Table 8.1. Human subject Purple, Green, Red, Magenta, Cyan, Orange, and Yellow had low concentrations (see Tables 8.1 and 8.2). Exposures lower than $1 \mathrm{ppm}$ for concentrations at the nose $\left(C_{\text {nose }}\right)$ were found for those human subjects (Table 8.1). Though human subjects body dimensions were found highly statistical significant on exposures, Table 8.3 showed no clear relationship between subjects' body dimensions and the average exposure.

In addition, the simple manikin has an over $300 \%$ higher mean exposure than the complex manikin and roughly $90 \%$ higher mean exposure than the human subject Gray for $C_{\text {nose }}$ (Table 8.1). However, for exposure at the mouth, the simple manikin has nearly 4 times the mean exposure of the complex manikin and $13 \%$ lower mean exposure than the human subject Gray (Table 8.2). On the other hand, error bars were plotted on the average exposure values of each subject to reflect the confident interval that the mean represents the true exposure value.

\subsubsection{Comparison of the effect of $V_{\text {face }}$ on exposure}

The effect of face velocity $\left(V_{\text {face }}\right)$ and cross-draft velocity $\left(V_{\text {cross }}\right)$ on the average concentrations at the nose $\left(C_{\text {nose }}\right)$ and mouth $\left(C_{\text {mouth }}\right)$ were compared for the 
simple manikin, the heated and breathing complex manikin, and the average of ten human subjects (Figures 8.4 and 8.9). It is clearly observed from these figures that the simple manikin exposure was greater than the complex manikin and the human subject's exposure (Figures 8.4 and 8.7). The relationship of $V_{\text {face }}$ and $V_{\text {cross }}$ to $C_{\text {nose }}$ and $C_{\text {mouth }}$ was also different for the simple manikin. The simple manikin exposure decreased almost linearly as $V_{\text {face }}$ increased (Figure 8.4 and 8.5). By contrast, the results of the complex manikin and the human subject exposure were similar, and both compare well with previous fume hood results by Johnson and Fletcher (1996). Thus, the heated and breathing complex manikin with human features offered much better results than a simple manikin when compared to actual human subjects' exposures.

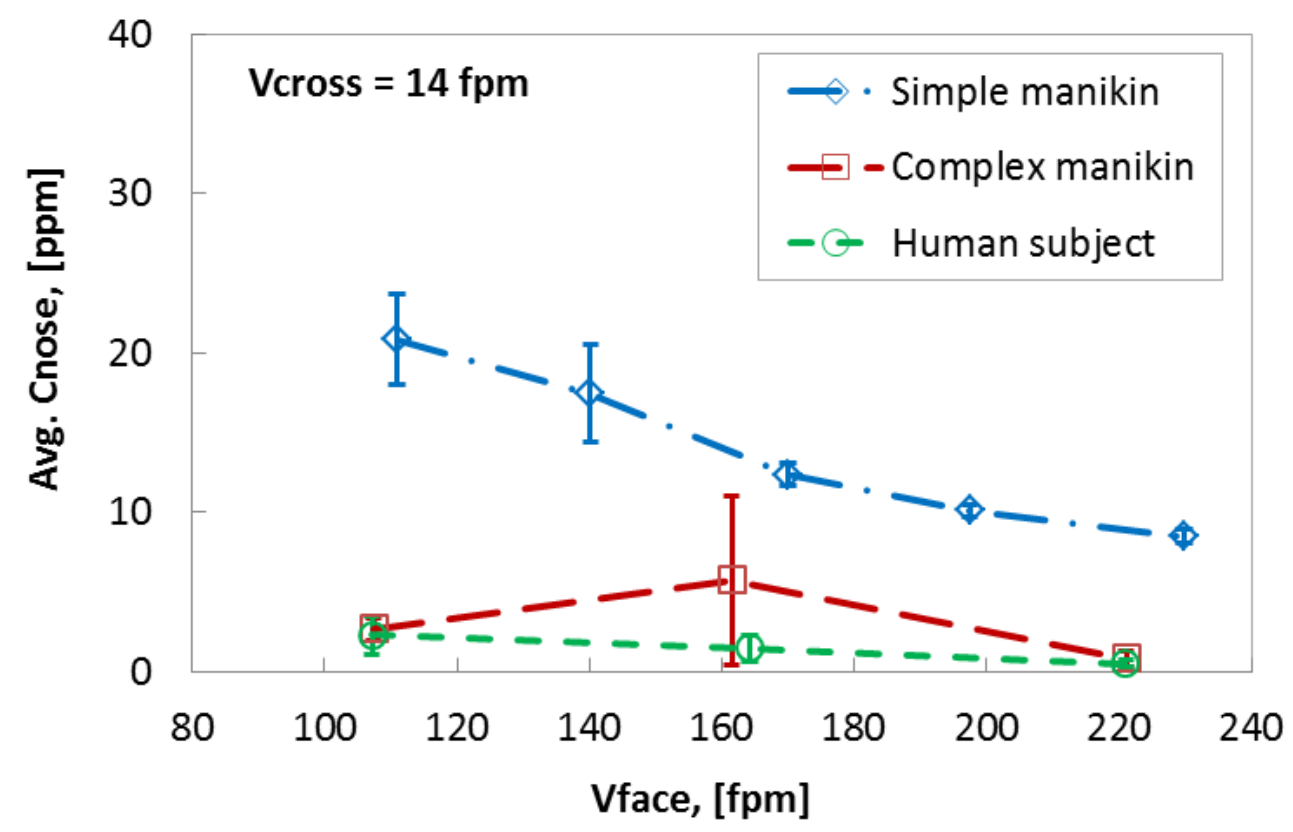

Figure 8.4 Comparison of the effect of $V_{\text {face }}$ on average $C_{\text {nose }}$ for all subjects at $V_{\text {cross }}$ $=14 \mathrm{fpm}$ 


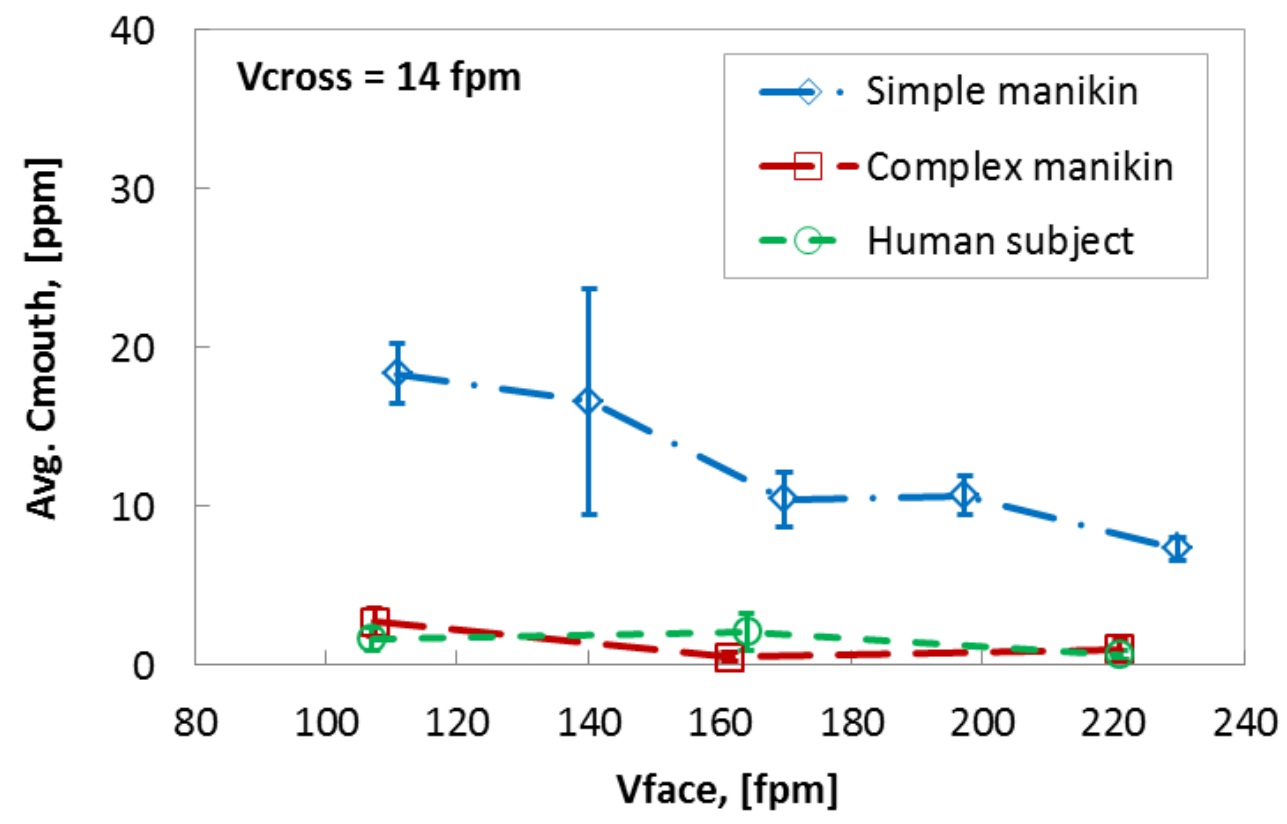

Figure 8.5 Comparison of the effect of $V_{\text {face }}$ on average $C_{\text {mouth }}$ for all subjects at $V_{\text {cross }}=14 \mathrm{fpm}$

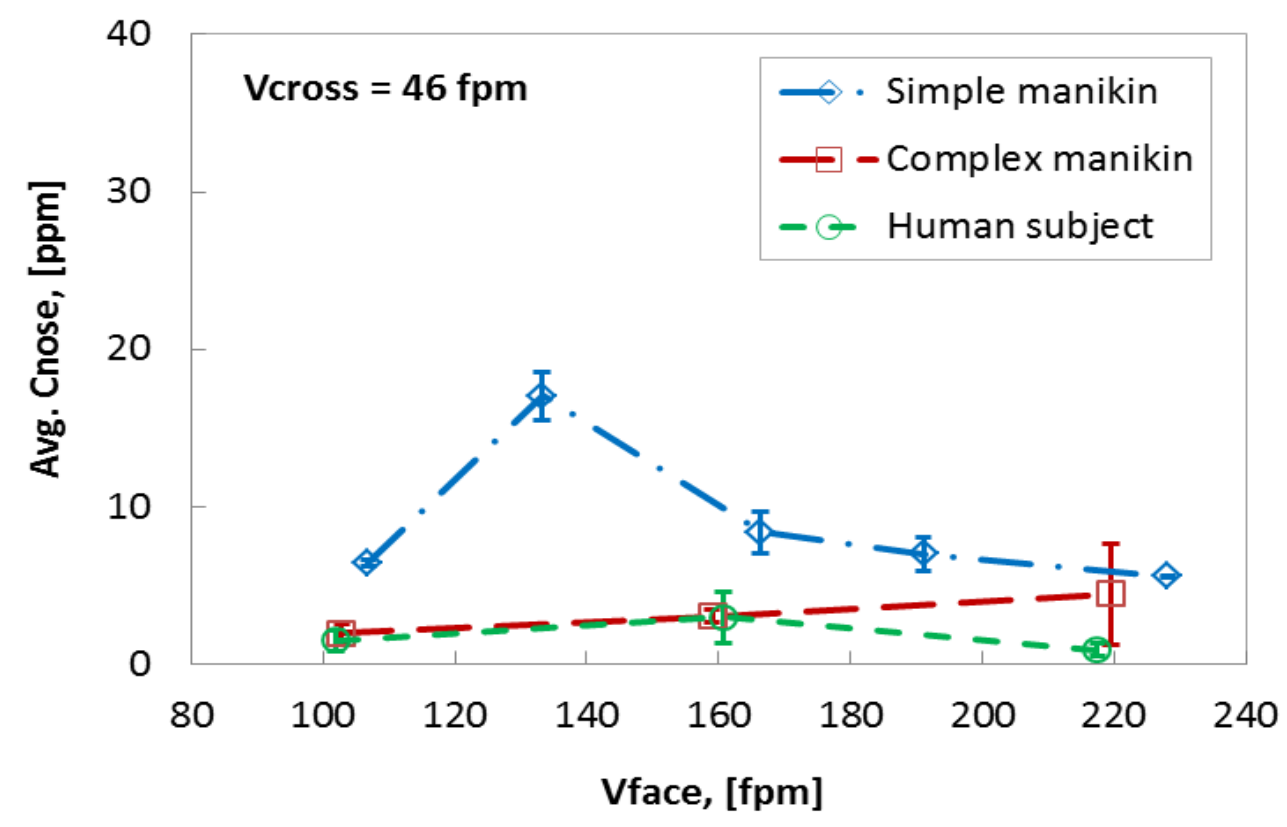

Figure 8.6 Comparison of the effect of $V_{\text {face }}$ on average $C_{\text {nose }}$ for all subjects at $V_{\text {cross }}$ $=46 \mathrm{fpm}$ 


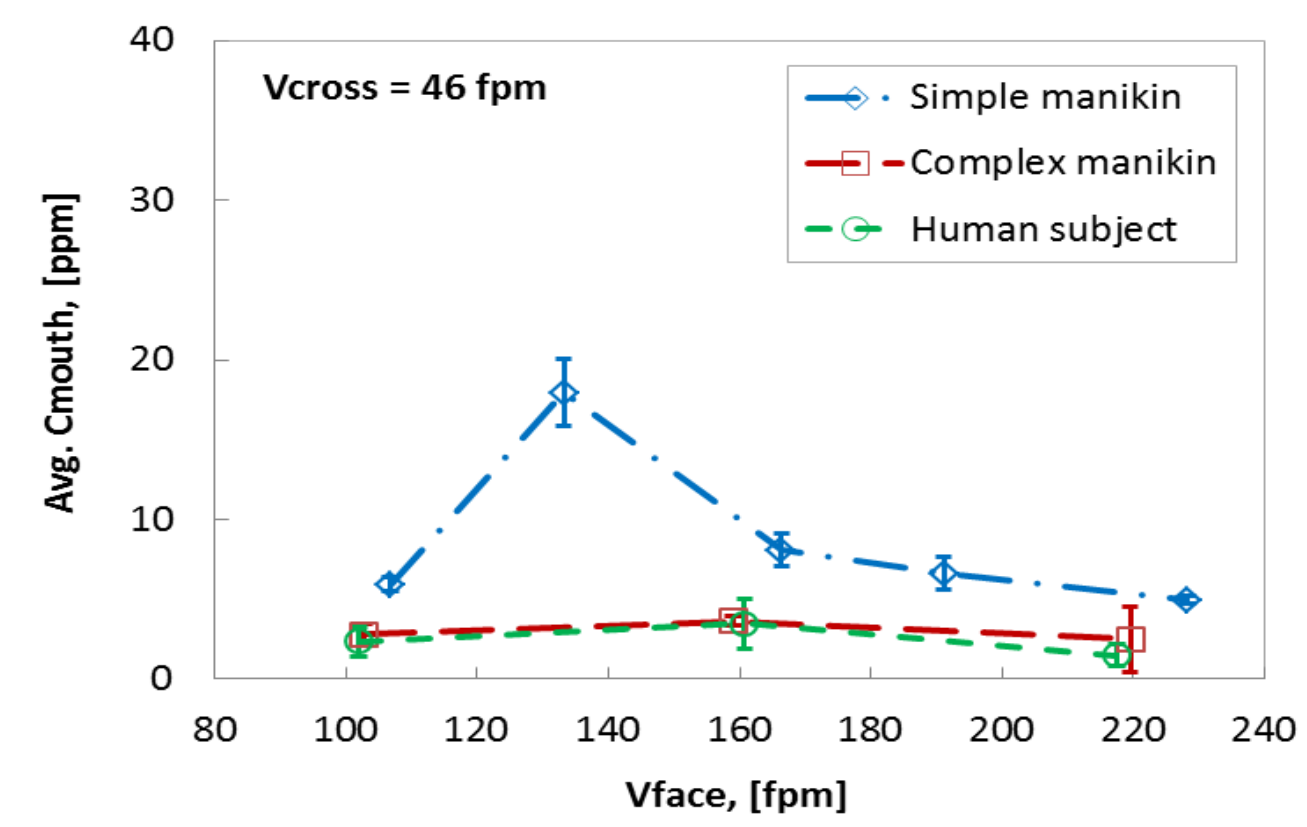

Figure 8.7 Comparison of the effect of $V_{\text {face }}$ on average $C_{\text {mouth }}$ for all subjects at $V_{\text {cross }}=46 \mathrm{fpm}$

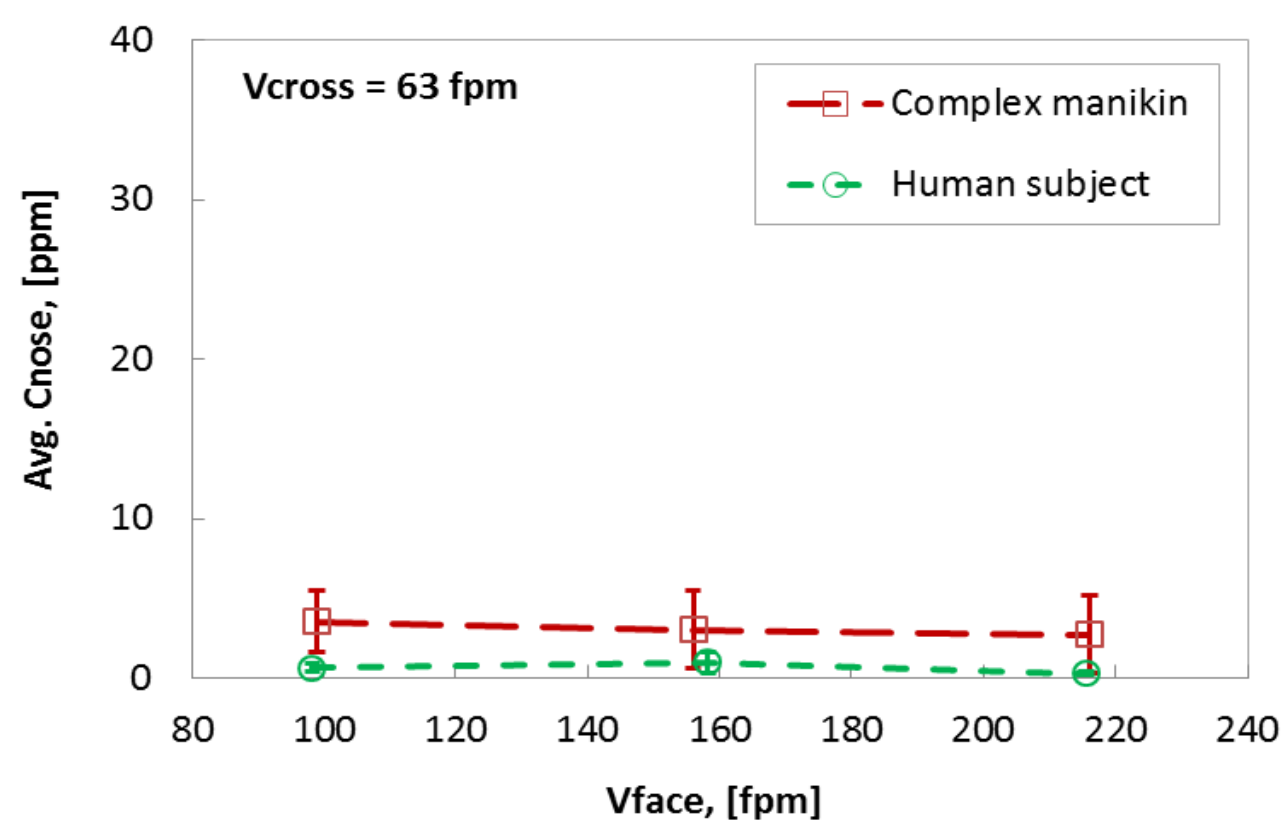

Figure 8.8 Comparison of the effect of $V_{\text {face }}$ on average $C_{\text {nose }}$ for all subjects at $V_{\text {cross }}$ $=63 \mathrm{fpm}$ (No simple manikin results) 


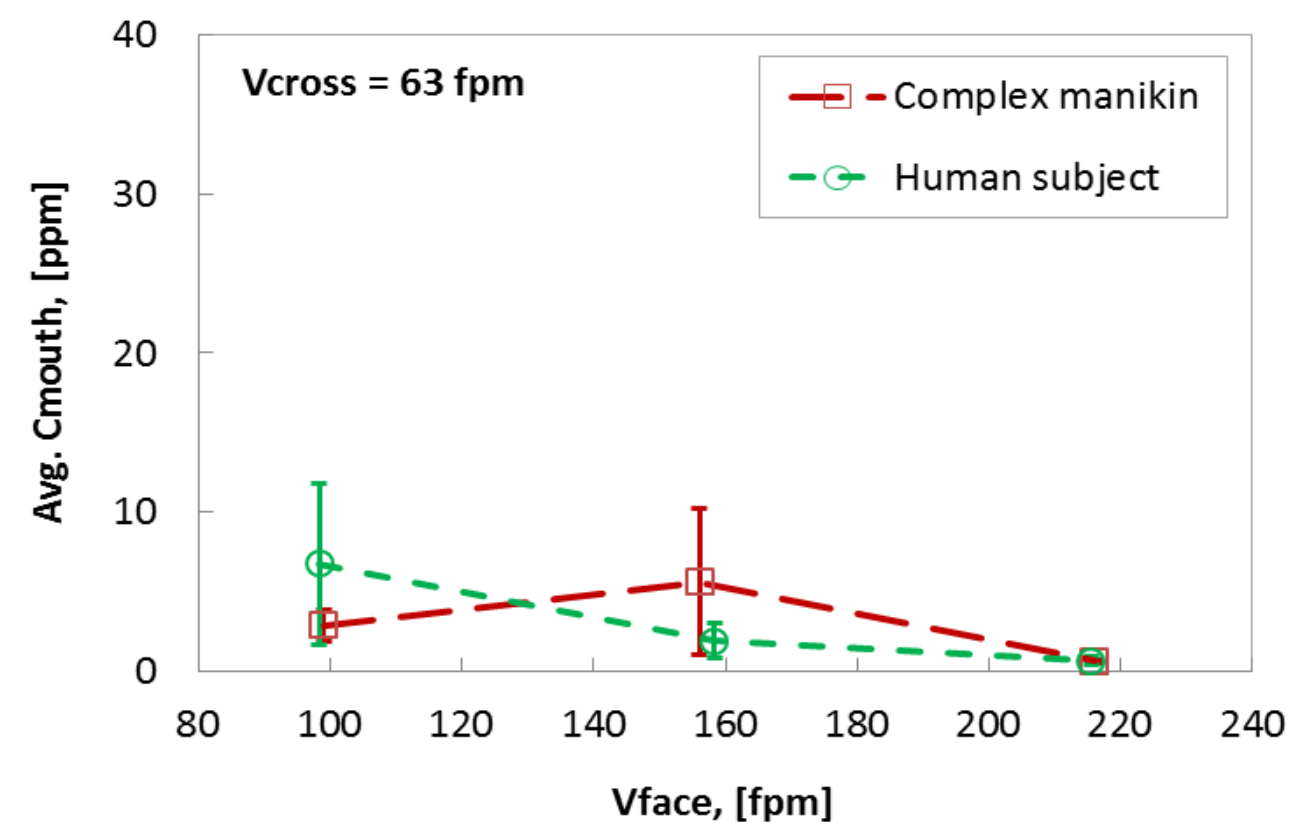

Figure 8.9 Comparison of the effect of $V_{\text {face }}$ on average $C_{\text {mouth }}$ for all subjects at $V_{\text {cross }}=63 \mathrm{fpm}$ (No simple manikin results)

At $V_{\text {cross }}=14 \mathrm{fpm}$ and $V_{\text {face }}=100$ and $220 \mathrm{fpm}$, the simple manikin exposure at the nose and mouth $\left(C_{\text {nose }}\right.$ and $\left.C_{\text {mouth }}\right)$ was roughly ten times higher than both the complex manikin and the human subjects' exposures (Figure 8.4 and 8.5). Even though a more narrow difference can be seen on $C_{\text {nose }}$ and $C_{\text {mouth }}$ at $V_{\text {cross }}=46$ fpm, the simple manikin's exposure was still higher than the complex manikin and the human subjects' exposures (Figure 8.6 and 8.7). This finding agrees well with previous simulation comparison (Karaismail, 2011) between the exposure of a simple manikin and a complex manikin for the same enclosing hood and conditions in the simulation. In addition, this also agrees with free stream airflow experiments by Li et al. (2005), when comparisons between a numerical simulated sharp body and a simulated rounded body manikin were carried out. 
At $V_{\text {cross }}=46 \mathrm{fpm}$, comparison of exposure results between the complex manikin and the human subjects almost overlap for $C_{\text {mouth }}$, which shows that the complex manikin represents the human exposure very well (Figure 8.7). At $V_{\text {cross }}=$ $63 \mathrm{fpm}$, the complex manikin and the human subjects also show similar $C_{n o s e}$ and $C_{\text {mouth }}$ values as previous $V_{\text {cross }}$ levels (Figures 8.8 and 8.9). The simple manikin was not tested at $V_{\text {cross }}=63 \mathrm{fpm}$. In summary, a complex manikin better represented the effect of $V_{\text {face }}$ on human subject's exposure than a simple manikin did.

\subsubsection{Comparison of the effect of $V_{\text {cross }}$ on exposure}

The relationship between $V_{\text {cross }}$ and exposure to the simple manikin, complex manikin, and human subjects are shown in Figures 8.10 and 8.15. The simple manikin also presented higher exposure at all levels of $V_{\text {cross }}$ than did the complex manikin and the average of ten human subjects. The simple manikin shows a higher exposure from $V_{\text {cross }}=14$ to $46 \mathrm{fpm}$ at each level $V_{\text {face }}$ (Figures 8.10 and 8.15). It can also be seen that the simple manikin's exposure in this range decreased as $V_{\text {face }}$ increased. However, the complex manikin and the human subject exhibited similar exposure with just small differences between them. At $V_{\text {cross }}=14$ and $46 \mathrm{fpm}$, the complex manikin and the human subject show almost the same exposure, but then slightly separated at $V_{\text {cross }}=63 \mathrm{fpm}$ (Figures 8.10 to 8.13). 


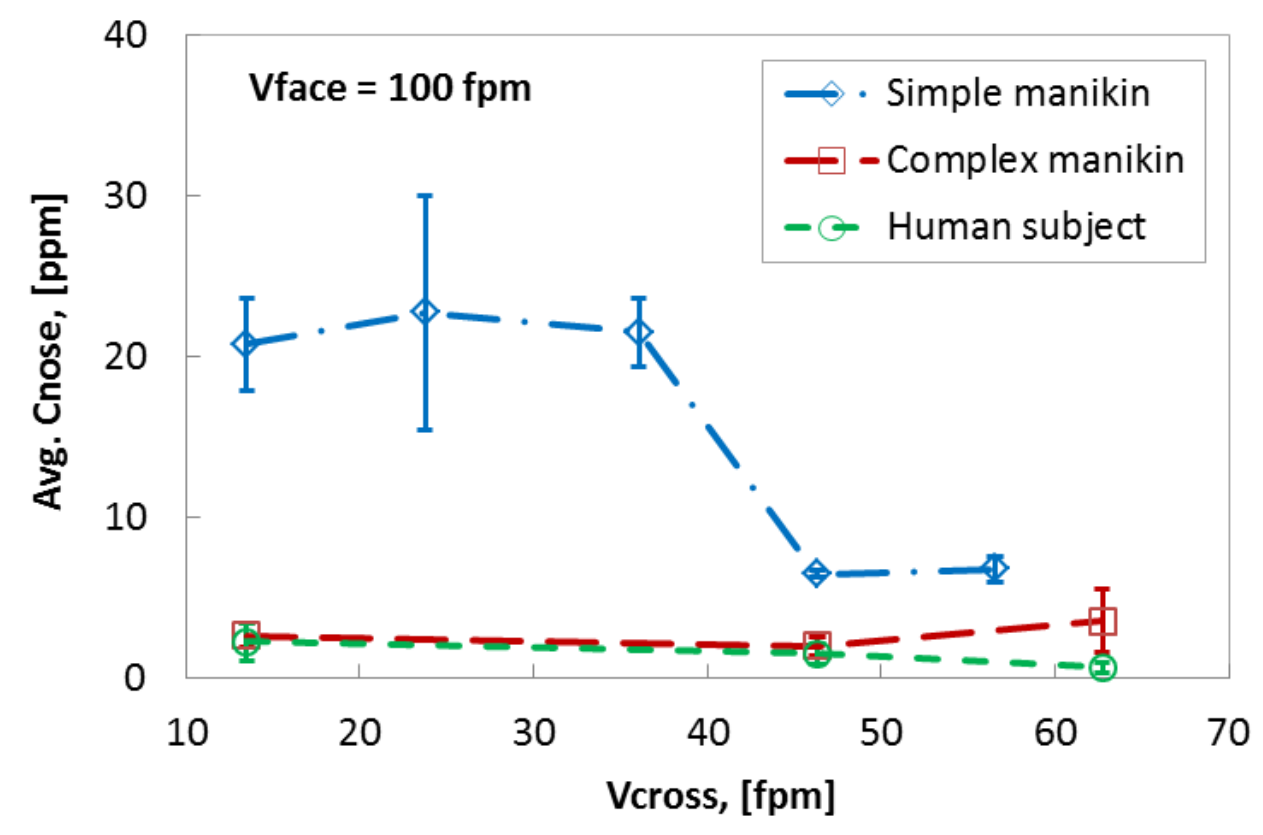

Figure 8.10 Comparison of the effect of $V_{\text {cross }}$ on average $C_{\text {nose }}$ for all subjects at $V_{\text {face }}=100 \mathrm{fpm}$

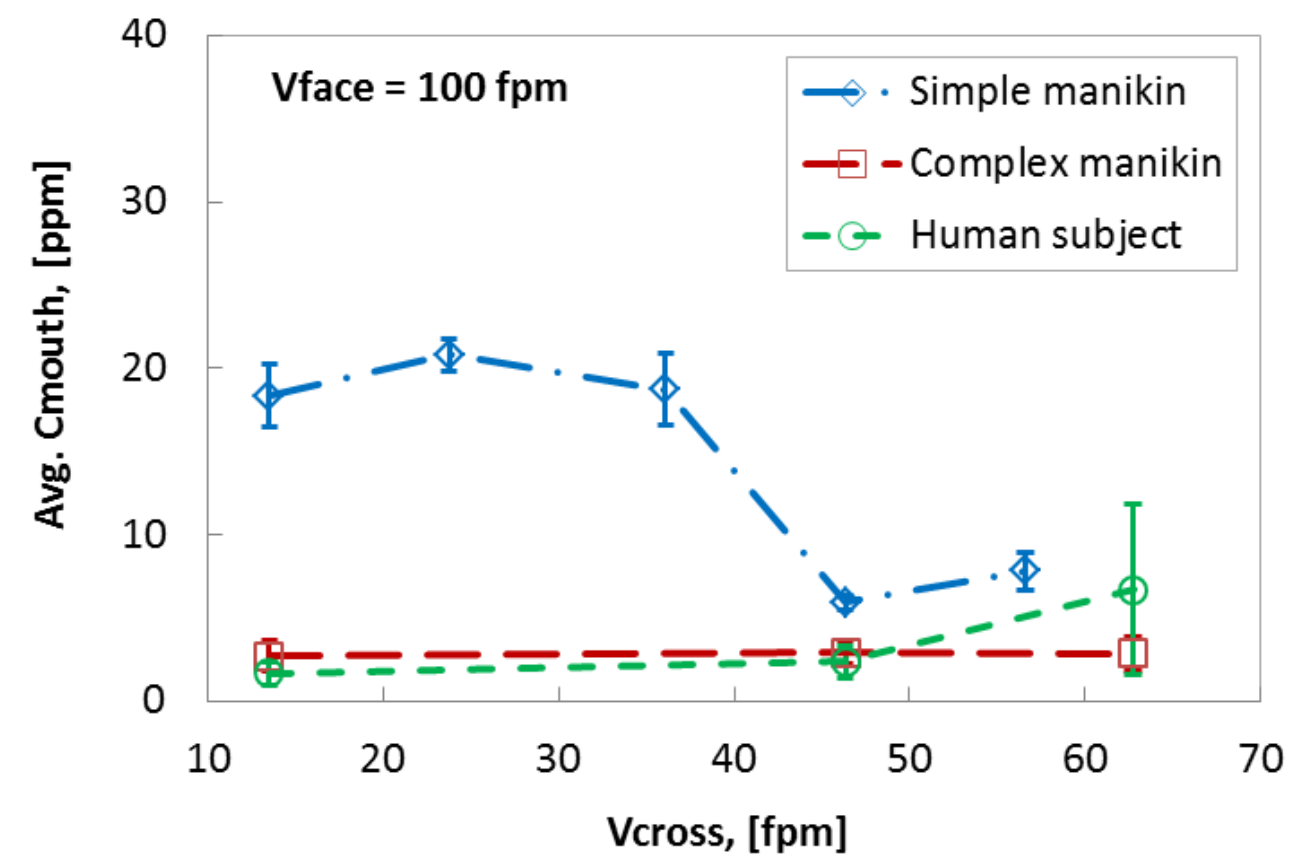

Figure 8.11 Comparison of the effect of $V_{\text {cross }}$ on average $C_{\text {mouth }}$ for all subjects at $V_{\text {face }}=100 \mathrm{fpm}$ 


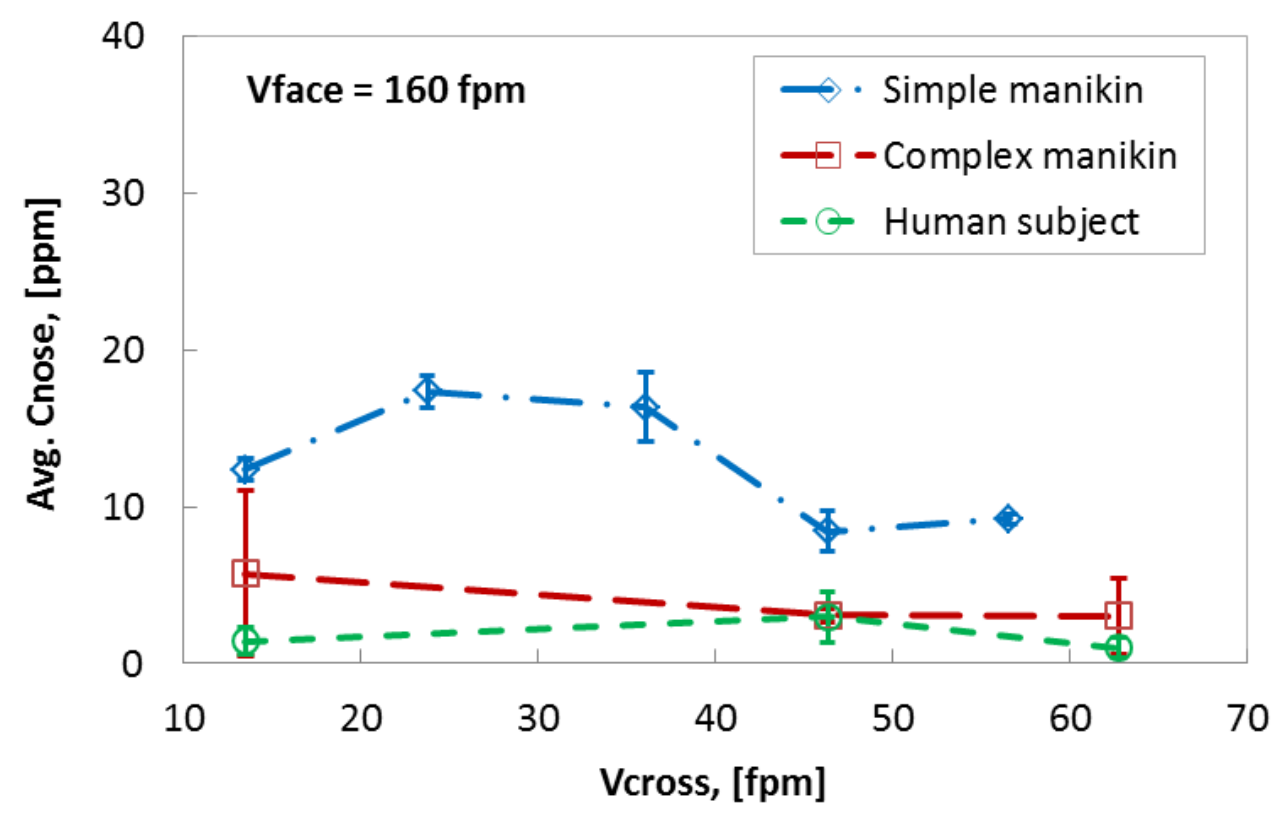

Figure 8.12 Comparison of the effect of $V_{\text {cross }}$ on average $C_{\text {nose }}$ for all subjects at $V_{\text {face }}=160 \mathrm{fpm}$

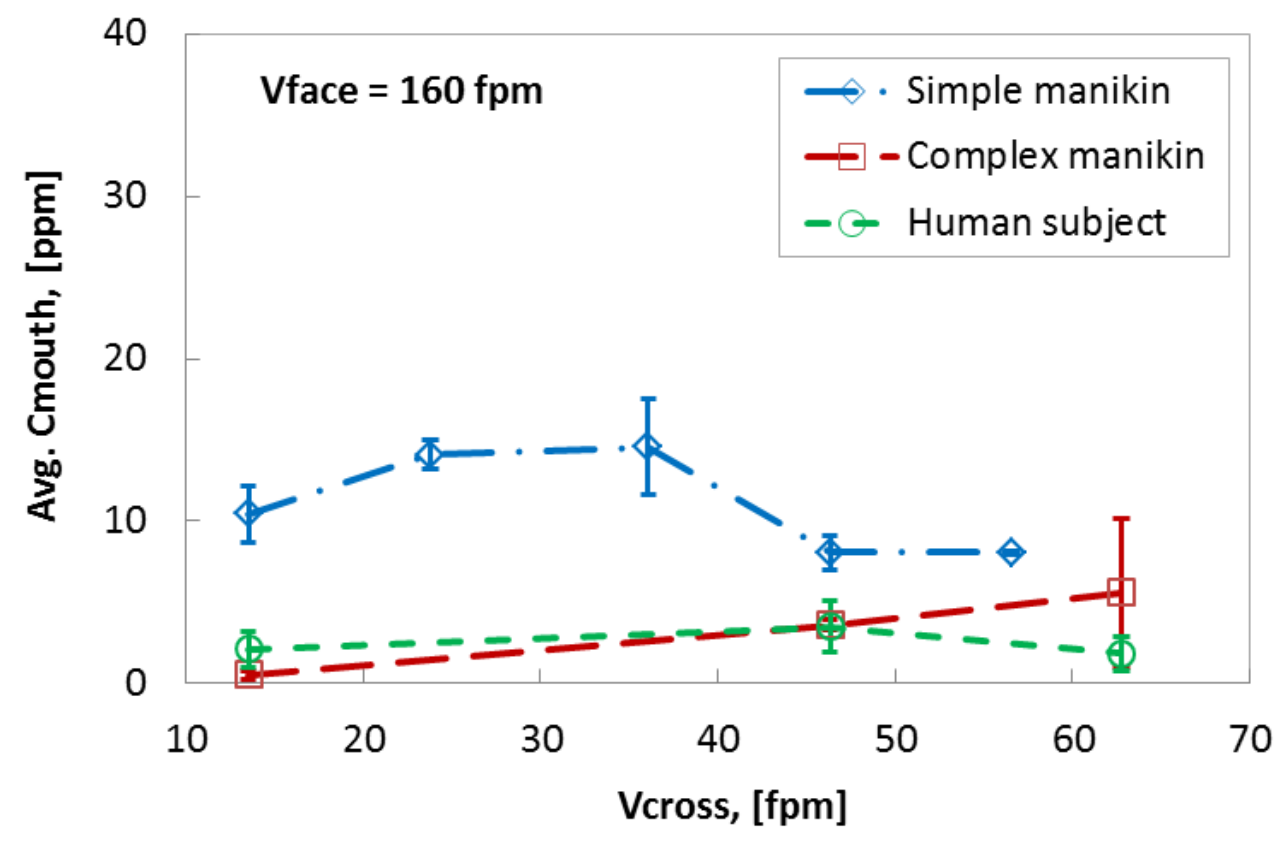

Figure 8.13 Comparison of the effect of $V_{\text {cross }}$ on average $C_{\text {mouth }}$ for all subjects at $V_{\text {face }}=160 \mathrm{fpm}$ 


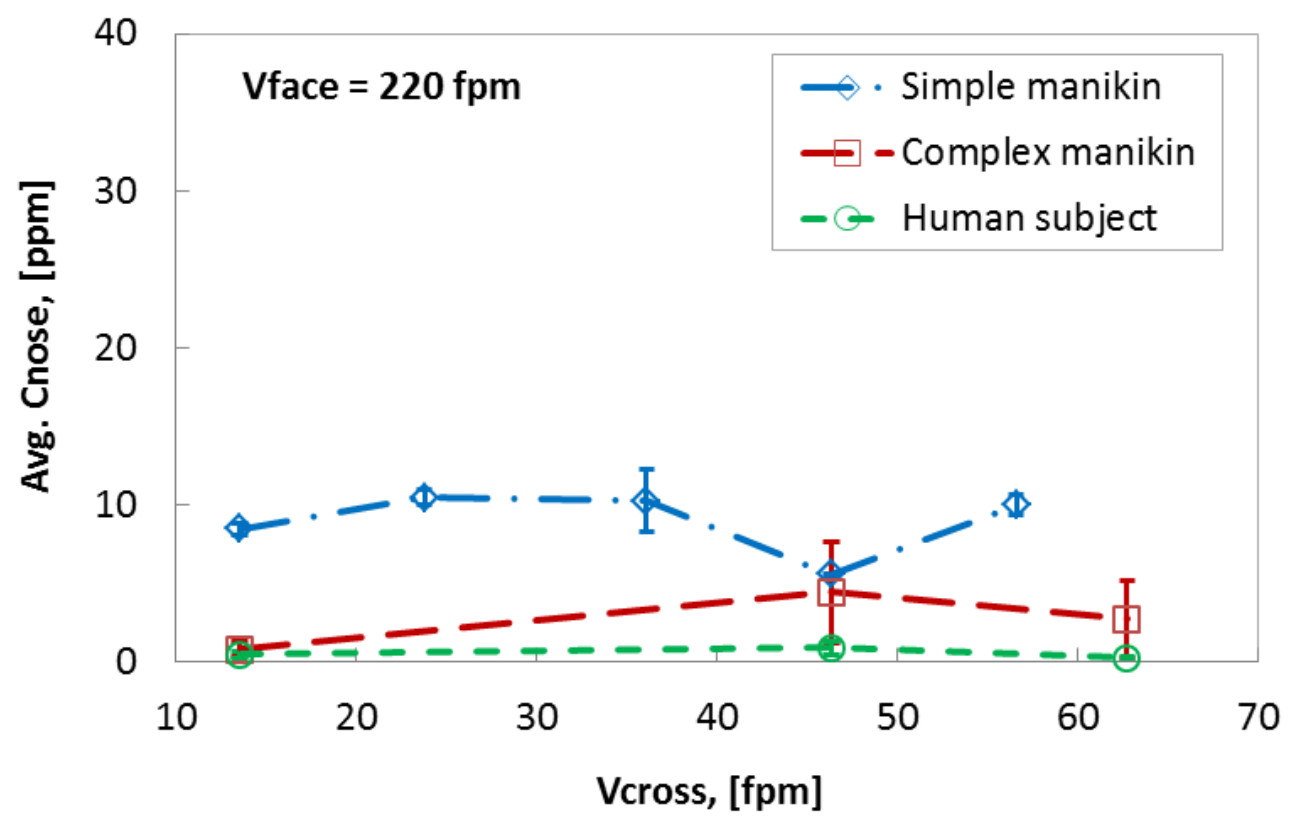

Figure 8.14 Comparison of the effect of $V_{\text {cross }}$ on average $C_{\text {nose }}$ for all subjects at $V_{\text {face }}=220 \mathrm{fpm}$

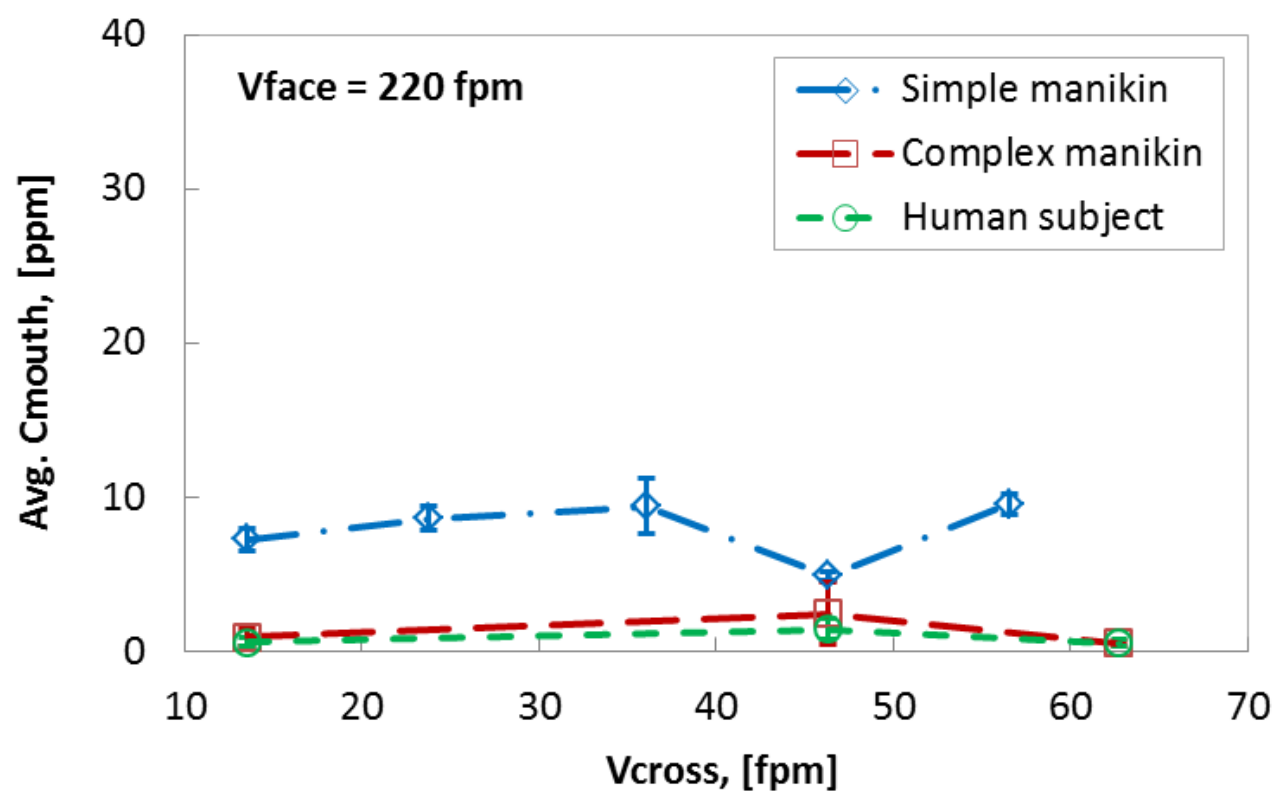

Figure 8.15 Comparison of the effect of $V_{\text {cross }}$ on average ${ }_{\text {Cmouth }}$ for all subjects at $V_{\text {face }}=220 \mathrm{fpm}$ 
Previous simulation studies (Karaismail, 2011; Li et al., 2005) pointed out that a simple representation of the body shape can lead to inaccurate results when compared to human subject's exposure. This statement was experimentally proven in the present study, where the simple manikin had much higher exposures than the complex manikin and the average of human subjects' exposures (Figure 8.10 to 8.15). The relationship of $C_{\text {nose }}$ and $C_{\text {mouth }}$ to $V_{\text {face }}$ and $V_{\text {cross }}$ also were different for the simple manikin than for human subjects and the complex manikin.

\subsection{Discussion}

Comparisons between tested exposures to a manikin and a human subject's exposures were carried out in early experimental fume hood studies (Johnson and Fletcher, 1996; Altemose et al., 1998). While a 3-D simulated heated manikin better represented a human's exposure (Johnson and Fletcher, 1996), an unheated simple manikin did not prove consistent agreement with a human's results (Altemose et al., 1998). Numerical studies of a benchtop enclosing hood and in a free-stream airflow (Karaismail, 2011; Li et al., 2005) showed that a manikin's body shape plays an important role in exposure. Particularly, a simple manikin presented higher exposure than a human-like complex manikin. However, no

studies were found that compared manikins to actual humans' exposure at a benchtop enclosing hood. In this study, comparisons of the exposure data of the simple and the complex manikin with those of the human subjects' were carried out to determine which best represent human subjects' exposure at an enclosing hood. 
This study found in all cases at all levels of $V_{\text {face }}$ and $V_{\text {cross }}$ (Figures 8.4 to 8.15) that the simple manikin presented higher exposures than the complex manikin and the average of ten human subjects. These results verify the simulation finding by Karaismail (2011), who compared the same simple manikin and the complex manikin's exposure in the same enclosing hood. Simulation comparison between a sharp body manikin and a rounded body manikin demonstrated that the former presented higher exposure than the rounded manikin ( $\mathrm{Li}$ et al., 2005). A good agreement in exposure was found when a three-dimensional heated manikin with a temperature of $30^{\circ} \mathrm{C}$ and a human subject were compared in fume hood tests (Johnson and Fletcher, 1996).

Most notably, the results of this study proved consistently that having a heated and breathing complex manikin with average human body dimensions in front of the enclosing hood better represented the actual human subjects' exposure (see Figures 8.4 to 8.15 ), bearing in mind the large differences between different human subjects. It is possible that if several manikins with a range of sizes and proportions similar to the ranges for the human subjects had been tested that the manikin results would have covered the entire range found for human subjects.

\subsubsection{Analysis of covariance}

The statistical analyses of covariance (ANCOVA) for both the manikins and the human subjects were performed for $\log C_{\text {nose }}$ and $\log C_{\text {mouth }}$. The subject numbers (SubjectNo) for the 10 human subjects, the simple manikin, and the complex manikin were deemed as independent factors, in addition to face velocity 
$\left(V_{\text {face }}\right)$, cross-draft velocity $\left(V_{\text {cross }}\right)$, and temperature difference $(\Delta T)$. All but $\Delta T$ were discrete variables. Partial sums of squares (Type 3) was considered for the model. The statistical model detailed in previous chapters will not be repeated here.

It can be seen in Tables 8.4 and 8.5 that $V_{\text {face }}$ for manikins and human subjects had a highly significant effect on $\log C_{\text {nose }}(\mathrm{p} \leq 0.0001)$ and $\log C_{\text {mouth }}(\mathrm{p}<$ 0.0079). The same highly significant effect on exposure $(\mathrm{p} \leq 0.0001)$ occurred when the 12 subjects (the simple manikin, the complex manikin, and the 10 different human subjects) were included as a factor in the ANCOVA model. All other factors showed non-significance, including the temperature difference $(\Delta T)$, as can be observed in Tables 8.4 and 8.5. As was discussed before, $\Delta T$ can affect worker's exposure due to buoyancy effect. However, it can be statistically unimportant when it is analyzed with all other factors. In addition, factors' interactions were omitted from the model when they were found to be nonsignificant $(\mathrm{p}>5 \%)$.

Table 8.4 $\log C_{\text {nose }}$ ANCOVA for both manikins and the human subjects

\begin{tabular}{lccccr}
\hline Source & df & Sums of Squares & Mean Square & F-ratio & \multicolumn{1}{c}{ Prob } \\
\hline Constant & 1 & 140.84 & 140.84 & 164.27 & $\leq 0.0001$ \\
$V_{\text {face }}$ & 4 & 26.01 & 6.50 & 7.58 & $\bullet \leq 0.0001$ \\
$V_{\text {cross }}$ & 5 & 4.65 & 0.93 & 1.09 & 0.3687 \\
SubjectNo & 11 & 179.90 & 16.35 & 19.08 & $\leq 0.0001$ \\
$\Delta T$ & 1 & 0.13 & 0.13 & 0.15 & 0.6971 \\
Error & 270 & 231.49 & 0.86 & & \\
Total & 291 & 669.18 & & & \\
\hline
\end{tabular}


Table 8.5 Log $C_{\text {mouth }}$ ANCOVA for both manikins and the human subjects

\begin{tabular}{lccccr}
\hline Source & df & Sums of Squares & Mean Square & F-ratio & \multicolumn{1}{c}{ Prob } \\
\hline Constant & 1 & 38.20 & 38.20 & 63.02 & $\bullet \leq 0.0001$ \\
$V_{\text {face }}$ & 4 & 8.57 & 2.14 & 3.53 & 0.0079 \\
$V_{\text {cross }}$ & 5 & 3.18 & 0.64 & 1.05 & 0.3886 \\
SubjectNo & 11 & 130.97 & 11.91 & 19.64 & $\leq 0.0001$ \\
$\Delta T$ & 1 & 0.71 & 0.71 & 1.17 & 0.2812 \\
Error & 265 & 160.65 & 0.61 & & \\
Total & 286 & 458.19 & & & \\
\hline
\end{tabular}

The results of Bonferroni post hoc tests for $\log C_{\text {nose }}$ indicated that the mean of the simple manikin differed significantly $(\mathrm{p}<0.05)$ of the mean of human subjects Purple, Green, Red, Magenta, Cyan, and Orange. All other human subjects showed no significant difference with the simple manikin (Table 8.6). On the other hand, six human subjects (Gray, Brown, Black, Purple, Magenta, and Yellow) presented no significant differences when compared with complex manikin. Complex manikin was significant different of human subjects Green, Red, Cyan, and Orange (Table 8.6). In addition, the means of human subjects Green, Brown, Gray, and Black presented higher significant differences when compared to other human subjects (Table 8.6).

For the Bonferroni post hoc tests of $\log C_{\text {mouth }}$, the mean of complex manikin and simple manikin differed significantly $(\mathrm{p}<0.05)$. Both manikins differed significantly of human subjects Purple, Green, Magenta, Orange, Red, Cyan, and Yellow (Table 8.7). Also, manikins were not significant different of subjects Gray, Brown, and Black. These subjects (Gray, Brown, and Black) show also significant differences with the rest of human subjects (Table 8.7). 
Table 8.6 Log $C_{\text {nose }}$ Bonferroni post hoc tests for both manikins and the human subjects

\begin{tabular}{lccc}
\hline Subjects' comparison & Difference & std. err. & Prob \\
\hline Simple manikin - Purple & 2.30 & 0.64 & 0.0246 \\
Simple manikin - Green & 4.18 & 0.59 & 0.0000 \\
Simple manikin - Red & 3.49 & 0.80 & 0.0013 \\
Simple manikin - Magenta & 2.36 & 0.69 & 0.0444 \\
Simple manikin - Cyan & 2.48 & 0.58 & 0.0019 \\
Simple manikin - Orange & 2.91 & 0.72 & 0.0045 \\
Complex manikin - Green & 3.00 & 0.33 & 0.0000 \\
Complex manikin - Red & 2.31 & 0.52 & 0.0008 \\
Complex manikin - Cyan & 1.30 & 0.32 & 0.0053 \\
Complex manikin - Orange & 1.73 & 0.44 & 0.0065 \\
Green - Purple & -1.88 & 0.30 & 0.0000 \\
Brown - Green & 2.83 & 0.31 & 0.0000 \\
Red - Purple & -1.20 & 0.35 & 0.0427 \\
Red - Brown & -2.15 & 0.36 & 0.0000 \\
Magenta - Green & 1.82 & 0.33 & 0.0000 \\
Gray - Purple & 1.13 & 0.30 & 0.0134 \\
Gray - Green & 3.02 & 0.30 & 0.0000 \\
Gray - Red & 2.33 & 0.38 & 0.0000 \\
Gray - Magenta & 1.20 & 0.33 & 0.0227 \\
Cyan - Green & 1.70 & 0.30 & 0.0000 \\
Cyan - Brown & -1.13 & 0.32 & 0.0258 \\
Cyan - Gray & -1.31 & 0.31 & 0.0016 \\
Orange - Green & 1.27 & 0.33 & 0.0090 \\
Orange - Brown & -1.56 & 0.32 & 0.0001 \\
Orange - Gray & -1.75 & 0.33 & 0.0000 \\
Yellow - Brown & -1.65 & 0.42 & 0.0067 \\
Yellow - Gray & -1.84 & 0.45 & 0.0037 \\
Black - Green & 2.91 & 0.33 & 0.0000 \\
Black - Red & 2.23 & 0.31 & 0.0000 \\
Black - Magenta & 1.09 & 0.32 & 0.0471 \\
Black - Cyan & 1.21 & 0.35 & 0.0379 \\
Black - Orange & 1.64 & 0.30 & 0.0000 \\
Black - Yellow & 1.73 & 0.35 & 0.0001 \\
\hline
\end{tabular}


Table 8.7 Log $C_{\text {mouth }}$ Bonferroni post hoc test for both manikins and the human subjects

\begin{tabular}{lccc}
\hline Subjects comparison & Difference & std. err. & Prob \\
\hline Complex manikin - Simple manikin & -1.19 & 0.33 & 0.0239 \\
Simple manikin - Purple & 2.79 & 0.54 & 0.0000 \\
Simple manikin - Green & 2.64 & 0.50 & 0.0000 \\
Simple manikin - Red & 3.44 & 0.68 & 0.0000 \\
Simple manikin - Magenta & 2.73 & 0.58 & 0.0003 \\
Simple manikin - Cyan & 2.56 & 0.49 & 0.0000 \\
Simple manikin - Orange & 2.80 & 0.61 & 0.0004 \\
Simple manikin - Yellow & 3.25 & 0.75 & 0.0015 \\
Complex manikin - Purple & 1.60 & 0.31 & 0.0000 \\
Complex manikin - Green & 1.45 & 0.28 & 0.0000 \\
Complex manikin - Red & 2.25 & 0.44 & 0.0000 \\
Complex manikin - Magenta & 1.54 & 0.35 & 0.0010 \\
Complex manikin - Cyan & 1.37 & 0.27 & 0.0001 \\
Complex manikin - Orange & 1.61 & 0.37 & 0.0012 \\
Complex manikin - Yellow & 2.06 & 0.51 & 0.0048 \\
Brown - Purple & 1.76 & 0.25 & 0.0000 \\
Brown - Green & 1.60 & 0.25 & 0.0000 \\
Red - Brown & -2.40 & 0.29 & 0.0000 \\
Magenta - Brown & -1.70 & 0.27 & 0.0000 \\
Gray - Purple & 2.14 & 0.26 & 0.0000 \\
Gray - Green & 1.99 & 0.25 & 0.0000 \\
Gray - Red & 2.79 & 0.32 & 0.0000 \\
Gray - Magenta & 2.08 & 0.28 & 0.0000 \\
Cyan - Brown & -1.52 & 0.26 & 0.0000 \\
Cyan - Gray & -1.91 & 0.26 & 0.0000 \\
Orange - Brown & -1.77 & 0.26 & 0.0000 \\
Orange - Gray & -2.15 & 0.28 & 0.0000 \\
Yellow - Brown & -2.21 & 0.35 & 0.0000 \\
Yellow - Gray & -2.60 & 0.38 & 0.0000 \\
Black - Purple & 1.54 & 0.27 & 0.0000 \\
Black - Green & 1.38 & 0.29 & 0.0002 \\
Black - Red & 2.18 & 0.27 & 0.0000 \\
Black - Magenta & 1.48 & 0.27 & 0.0000 \\
Black - Cyan & 0.30 & 0.0012 \\
Black - Orange & 0.26 & 0.0000 \\
Black - Yellow & 0.30 & 0.0000 \\
\hline
\end{tabular}




\section{CHAPTER 9}

\section{CONCLUSIONS AND RECOMMENDATIONS}

\subsection{Conclusions}

The effects of $V_{\text {face }}, V_{\text {cross }}$ and $\Delta T$ on the performance of a custom-made benchtop enclosing were experimentally investigated. In addition, factors such as the subjects' body dimensions and the distance between the subject and the hood face were also investigated.

This study provides evidence of the effects of $V_{\text {face }}$ and $V_{\text {cross }}$ on subjects' exposure. Face velocity was found to have a significant effect $(\mathrm{p}<0.05)$ on $\log$ transformed concentrations at the nose $\left(\log C_{\text {nose }}\right)$ and mouth $\left(\log C_{\text {mouth }}\right)$ of the simple manikin, on $\log C_{\text {mouth }}$ for the complex manikin, and on $\log C_{\text {nose }}$ and $\log$ $C_{\text {mouth }}$ for the human subjects. Cross-draft velocity had a highly significant effect (p $<0.0001)$ on $\log C_{\text {nose }}$ and $\log C_{\text {mouth }}$ for the simple manikin, and a barely significant effect $(\mathrm{p}<0.05)$ on exposure for the complex manikin $\left(\log C_{\text {mouth }}\right)$. However, $V_{\text {cross }}$ showed no significant effect $(\mathrm{p}>0.05)$ on the human subjects' exposures. Unlike the simple manikin, the interaction of $V_{\text {face }}$ and $V_{\text {cross }}$ presented no significant effects $(\mathrm{p}>5 \%)$ on exposure for the complex manikin or the human subjects. In general, exposure decreased as $V_{\text {face }}$ increased for all subjects.

The airflow regime near manikins and the human subjects was in the transitional and subcritical regime because the Reynolds numbers were far below the onset of turbulent regime $\left(<2 \times 10^{5}\right)$. It was also found that there is a 
considerable decrease of subjects' exposure at Reynolds numbers greater than 8000 and those exposures approach each other as Reynolds numbers increase.

Buoyancy became more important at low Reynolds numbers $(<7000)$ both the complex manikin and the human subjects. This agrees with previous numerical findings of Karaismail (2011) and Li et al. (2007). For most human subjects and the complex manikin, heat is released through mixed convection $(R i>0.53)$, which means that both natural and forced convection play an important role in heat released to the environment.

Evidence of the effect of $\Delta T_{\text {human }}$ on exposure was found for human subjects. Concentrations at the nose $\left(C_{\text {nose }}\right)$ increased as $\Delta T_{\text {human }}$ increased, and the higher exposure took place at the lowest $V_{\text {face }}(100 \mathrm{fpm})$. Even though the effect of $\Delta T_{\text {man }}$ and $\Delta T_{\text {human }}$ on exposure was statistically not significant for the complex manikin and the human subjects, the experimental results are suggestive indication of the $\Delta T_{\text {human }}$ contribution to the human subjects' exposure.

Based on protection efficiency results $\left(\eta_{\text {prot }}\right)$ the performance of the benchtop enclosing hood was outstanding for human and both manikins. In general, human subjects' protection efficiencies were above 95\%, showing a slight increase as $V_{\text {face }}$ increased. Notably, the results clearly suggest that $V_{\text {cross }}$ reduce $C_{\text {nose }}$ and $C_{\text {mouth }}$ at higher $V_{\text {cross }}(46$ and $63 \mathrm{fpm}$ ) for the simple manikin. Higher protection efficiency was found at $V_{\text {cross }}=46 \mathrm{fpm}$ and $V_{\text {face }}=100$ and $160 \mathrm{fpm}$ for the complex manikin. Human subjects show the lowest exposure and, therefore, the highest protection efficiency at $V_{\text {cross }}=63 \mathrm{fpm}$. Overall, the human subjects' protection 
efficiencies were roughly $15 \%$ higher than those of the simple manikin and somewhat similar to the complex manikin's protection efficiencies, respectively.

The thermocouple on the complex manikin's face shown significant effect on $\log C_{\text {nose }}(\mathrm{p}=0.04)$ but it was no significant on $\log C_{m o u t h}(\mathrm{p}>5 \%)$. The complex manikin with thermocouple had shown in most cases lower exposures than those of the complex manikin without thermocouple On the other hand, evidence was found of the effect on exposure of human subjects' body dimensions. The analysis of covariance (ANCOVA) indicated that subjects' different heights, shoulders, and weights had highly statistical significant effects $(\mathrm{p}<0.05)$ on exposures $\left(\log C_{\text {nose }}\right.$ and $\log C_{\text {mouth }}$. These findings agree with Li et al. (2005), confirming specifically which body dimensions affected exposure when human subjects were working in front of the enclosing hood.

The effect of face location in front of the enclosing hood on exposure was tested for the complex manikin and a human subject. It was clearly demonstrated with the tests' results that when the manikin's head was placed further inside the hood, the concentrations of contaminants increased considerably from the vertical face location $\left(C_{\text {mouth }}=0.9 \mathrm{ppm}\right)$ to at the ear face location $\left(C_{\text {mouth }}=17.9 \mathrm{ppm}\right)$. In addition, exposure increased radically from the sideburn $\left(C_{\text {mouth }}=2.8 \mathrm{ppm}\right)$ to the back of the head face location $\left(C_{\text {mouth }}=93.3 \mathrm{ppm}\right)$ for the human subject. It is suggested from the results that the most highly exposed subject Gray $\left(C_{\text {mouth }}=\right.$ $108.2 \mathrm{ppm}$ ) could be due to working with his head breaking the plane of the hood face. In other words, the distance between the breathing zone and the hood face and 
the source plays an important role on exposure, perhaps even more important than $V_{\text {face }}$ and $V_{\text {cross. }}$

The large effect on exposure of the distance between the subjects' breathing zone and the hood face was experimentally demonstrated. Negligible exposure was achieved when the breathing zone was a small distance outside the hood face. The complex manikin and a human subject were tested at the sideburn posture with and without a padded belly at 1 in from the hood face. For both subjects, the exposures were almost the same. Notably, the exposures dropped significantly to trivial values for the manikin and the human $\left(C_{\text {nose }}=0.01\right.$ and $\left.0.00 \mathrm{ppm}\right)$ when a padded belly was added, which pushed the subjects away from the hood face. The manikin's exposure was almost the same for greater separation (4 in) between the padded belly and the hood face. Thus, the results suggest that little exposure may occur when the subject's breathing zone remains outside the hood.

The comparisons of exposure between the simple manikin, the complex manikin, and the average of ten human subjects clearly suggest that the heated and breathing complex manikin better represented the human subjects' exposures. It was demonstrated that an unheated and breathless simple manikin built of simple geometric forms had substantially higher exposure than the complex manikin and the human subjects. However, it is possible that if manikins of different sizes and proportions similar to those of the human subjects had been tested, a more fairly comparison of exposures would have been obtained. 
When both manikins and human subjects were considered as a factor in the analysis of covariance (ANCOVA), they revealed a highly significant effect ( $\mathrm{p}<$ 0.0001) on exposure $\left(\log C_{\text {nose }}\right.$ and $\left.\log C_{\text {mouth }}\right)$. In addition, $V_{\text {face }}$ also had a statistically significant effect $(\mathrm{p}<0.05)$ on $\log C_{\text {nose }}$ and $\log C_{\text {mouth }}$, and all other factors and interactions show no significant effect on exposure. The Bonferroni test comparisons showed that both the simple and the complex manikin had no significant difference for $\log C_{\text {nose }}$ but they had significant difference ( $\mathrm{p}<5 \%$ ) for

$\log C_{m o u t h}$.It is also shown that higher exposure subjects (Gray, Black, and Brown) had significant differences with other lower exposure human subjects but no significant differences when compared with both manikins

\subsection{Recommendations for future work}

From the experience acquired due to a large number of experimental tests, the following recommendations can be suggested for future work.

1. Increase the number of levels for $V_{\text {face }}$ and $V_{\text {cross }}$ for the human subjects study and compare the results with those of the manikin study.

2. The effect of the complex manikin's arm and hand movements over the source on exposure should be investigated, if possible, and compared to the results of the human subjects.

3. The entire body of the complex manikin should be heated, including the arms, the hands, and the legs. The head, chest, and pelvis of the manikin were heated for the present study. 
4. The effect of source location inside the hood on exposure should be investigated.

5. In a realistic industrial workplace, workers wear glasses, helmets, goggles, and caps. The effect of a worker's apparel on exposure should be studied.

\subsection{Caveats}

1. Plastic sampling probes of $1 / 8$ " I.D. were used on the human subjects' faces. To avoid any doubt about the effect on the airflow pattern and exposure, sampling lines of smaller diameter should be utilized.

2. The simple manikin's sampling lines were glued to the outside surface of the head at nose and mouth locations. The sampling lines should go inside the manikin's body and come out at the nose and mouth face locations.

3. The complex manikin was partially heated (head, chest, and pelvis). The whole body could be heated.

4. A surface thermocouple was taped on the complex manikin's face to monitor his face temperature. A smaller thermocouple or another location should be used. 


\subsection{References}

Abrams, D. S., Reist, P. C., Dement, J. M. (1986). An Evaluation of the Effectiveness of a Recirculating Laboratory Hood. Am. Ind. Hyg. Assoc. J. 47(1): 22-26.

Ahn, K., Woskie, S., DiBerardinis, L., Ellenbecker, M. (2008). A Review of Published Quantitative Experimental Studies on Factors Affecting Laboratory Fume Hood Performance. Journal of Occupational and Environmental Hygiene, 5: 735-753.

Altemose, B., Flynn, M., Sprankle, J. (1998). Application of a Tracer Gas Challenge with a Human Subject to Investigate Factors Affecting the Performance of Laboratory Hoods. AIHA Journal 59:321-327.

American Conference of Governmental Industrial Hygienists (ACGIH). (2010).

Industrial Ventilation: A manual of Recommended Practice for Design. $27^{\text {th }}$ Edition. Cincinnati, $\mathrm{OH}$.

ASHRAE Fundamentals Handbook, (1993)

ASHRAE Fundamentals Handbook, (2001)

Brohus, H. (1997). Personal Exposure to Contaminant Sources in Ventilated Rooms. PhD Dissertation. Department of Building Technology and Structural Engineering. Aalborg University, Denmark.

Burgess, W., Ellenbecker, M., Treiman, R. (2004). Ventilation for Control of Work Environment. 2nd Edition, John Wiley \& Sons, Inc.

Caplan, K. J., Knutson, G. W. (1982). A Performance Test for Laboratory Fume Hoods. Am. Ind. Hyg. Assoc. J. 43(10): 722-737.

Caplan, K. J., Knutson, G. W. (1982a). Influence of Room Air Supply on Laboratory Hoods. Am. Ind. Hyg. Assoc. J. 43(10): 738-746.

Cohen, B.S., Harley, N.H., Lippmann, M. (1984). Bias in Air Sampling Techniques Used to Measure Inhalation Exposure. Am. Ind. Hyg. Assoc. J. 45(3): 187192.

DiBerardinis, L., First, M., Party, E., Smith, T., Warfield, C., Carpenter, J., Cook, J., Walters, D., Flynn, M., Galson, E., Greenley, P., Hitchings, D., Knutson, G., Price, J., Baum, J., Burton, J., Finucane, M., Ghidoni, D., Koenigsberg, 
J., Lyons, M., Memarzadeh, F., Norton, D., Schuyler, G., Zboralski, J., Barkley, W. (2003). Report of the Howard Hughes Medical Institute's Workshop on the Performance of Laboratory chemical Hoods. AIHA Journal 64: 228-237.

Dunnett, S. (1994). A Numerical Investigation into the Flow Field Around a Worker Positioned by an Exhaust Opening. Ann. Occup. Hyg. 38(5): 663686.

Elnahas, W.M. (2005). Effects of Heating, Breathing, Hair Style, Posture, and Air Velocity on Breathing Zone Concentrations for an AnthropometricallyCorrect Manikin in a Wind Tunnel. PhD Dissertation. Department of Industrial and Management Systems Engineering. West Virginia University, W. Va.

El-Sotouhy, A.R. (2008). Effects of Breathing, Posture, and Air Velocity on Breathing Zone Gas Concentrations for Human Subjects in a Wind Tunnel. PhD Dissertation. Department of Industrial and Management Systems Engineering. West Virginia University, W. Va.

Flynn, M., Ljungqvist, B. (1995). A Review of Wake Effects on Worker Exposure. Ann. Occup. Hyg. 39(2):211-221.

Flynn, M., Miller, C. (1991). Discrete Vortex Methods for the Simulation of Boundary Layer Separation Effects on Worker Exposure. Ann. Occup. Hyg. 35(1):35-50.

Fuller, F. (1990).Static and Dynamic Lab Hood Tests. Heating/Piping/Air Conditioning 62(3):87-89

Gasmet $^{\mathrm{TM}}$ Technology Oy, (2005). CALMET ${ }^{\mathrm{TM}}$ 2005-User's Guide and Reference Manual, Standard Version 1.2, Helsinki, Finland.

Greenley, P., Billings, C., DiBerardinis, L., Edwards, R., Barkley, E. (2000).

Containment Testing of Laboratory Hoods in the As-Used Condition. Applied Occupational and Environmental Hygiene 15(2): 209-216.

George, D., Flynn, M., Goodman, R. (1990). The Impact of Boundary Layer Separation on Local Exhaust Design and Worker Exposure. Appl. Occup. Environ. Hyg. 5(8): 501-509. 
Guffey, S.E., Flanagan, M.E., van Belle, G. (2001). Air Sampling at the Chest and Ear as Representative of the Breathing Zone. Am. Ind. Hyg. Assoc. J. 62:416-427.

Guffey, S.E., Barnea, N. (1994). Effects of Face Velocities, Flanges, and Manikin Position on the Effectiveness of a Benchtop Enclosing Hood in the Absence of Cross-Drafts. Am. Ind. Hyg. Assoc. J. 55(2):132-139.

He, X. (2010). Effects of Face Velocity, Cross-draft Velocity, and Interventions on the performance of a Benchtop Enclosing Hood. M.Sc. Thesis. Department of Industrial and Management Systems Engineering. West Virginia University, W. Va.

Hu, H., Koochesfahani, M. (2011). Thermal Effects on the Wake of a Heated Circular Cylinder Operating in Mixed Convection Regime. J. Fluid Mech. $685,235-270$.

Ingham, D., Yuan, Y. (1992). A Mathematical Model for the Air Flow Around a Worker Near a Fume Cupboard. Ann. Occup. Hyg. 36 (5): 441-453.

Ivany, R., First, M., DiBerardinis, L. (1989). A New Method for Quantitative, InUse Testing of Laboratory Fume Hoods. Am. Ind. Hyg. Assoc.J. 50:275280.

Johnson, A., Fletcher, B. (1996).The Effect of Operating Conditions on Fume Cupboard Containment. Saf. Sci. 24(1):51-60.

Johnson, A., Fletcher, B., Saunders, C. (1996). Air Movement Around a Worker in a Low-Speed Flow Field. Ann. Occup. Hyg. 40 (1): 57-64.

Karaismail, E. (2011). Transport Processes in Low Turbulent Flows Associated with Enclosing Hoods. PhD Dissertation. Mechanical and Aerospace Engineering Department. West Virginia University, W. Va.

Karaismail, E., Celik, I. (2010). On the Inconsistencies Related to Prediction of Flow into an Enclosing Hood Obstructed by a Worker. Journal of Occupational and Environmental Hygiene 7: 315-325.

Kim, T., Flynn, M. (1991a). Airflow Pattern Around a Worker in a Uniform Freestream. AIHA Journal 52(7):287-296.

Kim, T., Flynn, M. (1991b). Modeling Worker's Exposure from a Hand-Held Source in a Uniform Freestream. Am. Ind. Hyg. Assoc. J. 52(11): 458-463. 
Kim, T., Flynn, M. (1992). The Effect of Contaminant Source Momentum on a Worker's Breathing Zone Concentration in a Uniform Freestream. Am. Ind. Hyg. Assoc. J. 53(12): 757-766.

Kilic, M., Sevilgen, G. (2008). Modelling Airflow, Heat Transfer and Moisture Transport Around a Standing Human Body by Computational Fluid Mechanics. International Communications in Heat and Mass Transfer 35: 1159-1164.

Kroemer, K., Grandjean, E. (1997). Fitting the Task to the Human. Fifth Edition, Bristol, PA, Taylor \& Francis Inc.

Kulmala, I., Säämänen, A., Enbom, S. (1996). The Effect of Contaminant Source Location on Worker Exposure in the Near-Wake Region. Ann. Occup. Hyg., 40(5): 511-523.

Li, J., Yavuz, I., Celik, I., Guffey, S. (2005). A Numerical Study of Worker Exposure to a Gaseous Contaminant: Variations in Body Shape and Scalar Transport Model. Journal of Occupational and Environmental Hygiene 2: 323-334.

Li, J., Yavuz, I., Celik, I., Guffey, S. (2007). Predicting Worker Exposure-The Effect of Ventilation Velocity, Free-Stream Turbulence and Thermal Condition. Journal of Occupational and Environmental Hygiene 4: 864-874.

Ljungqvist, B. (1987). Air Movements - The Dispersion of Pollutants: Studies with Visual Illustrative Methods. ASHRAE Trans. 93(1): 1304-1317.

Martinelli, C.A., Harley, N.H., Lippmann, M., Cohen, B.S. (1983). Monitoring Real-time Aerosol Distribution in the Breathing Zone. Am. Ind. Hyg. Assoc. J. 44(4): 280-285

Maupins, K., Hitchings, D., (1998). Reducing Employee Exposure Potential Using the ANSI/ASHRAE 110 Method of Testing Performance of Laboratory Fume Hoods as a Diagnostic Tool. AIHA Journal 59:133-138.

Mason, R., Gunst, R., Hess, J., (2003). Statistical Design and Analysis of Experiments . 2nd Edition, Wiley-Interscience.

Mikell, W., Fuller, F. (1988).Good Hood Practices for Safe Hood Operation. J. Chem. Educ. 65(2):A36-A41. 
Mikell,W., and Hobbs, L. (1981). Laboratory Hood Studies. J. Chem. Educ. 58(5):A165-A169

Mills, A., (1999). Heat Transfer. $2^{\text {nd }}$ Edition, Prentice Hall, New Jersey.

Montgomery, D., (2009). Design and Analysis of Experiments. 7th Edition, New Jersey, John Wiley and Sons, Inc.

Montgomery, D., Peck, E., Vining, G., (2001). Introduction to Linear Regression Analysis. 3rh Edition, New York, John Wiley and Sons, Inc.

Moore, D., (1979). The Active Practice of Statistics. 1st Edition, New York, W. H. Freeman and Company.

Murakami, S., Kato, S., Zeng, J., (2000). Combined Simulation of Airflow, Radiation and Moisture Transport for Heat Release from a Human Body. Building and Environment. 35: 489-500.

National Institute of Occupational Safety and Health (NIOSH). The Industrial Environment - Its Evaluation and Control. Washington, DC: US Government Printing Office, 1973.

Neter, J., Wasserman, W., (1974). Applied Linear Statistical Models: Regression, Analysis of Variance, and Experimental Designs. Illinois, Irwin, Inc.

Oosthuizen, P., Madan, S. (1971). The Effect of Flow Direction on Combined Convective Heat Transfer from Cylinders to Air. Journal of Heat Transfer. 93 (2), 240-242.

OSHA Technical Manual: CPL2-2.20B, Chapter 1, Personal Sampling of Air Contaminants. OSHA, Cincinnati, OH, 1985.

Schlichting, B., (1949). Boundary Layer Theory. New York, McGraw-Hill, Inc.

Srinivas, A., Bharti, R., Chhabra, R., (2009). Mixed Convection Heat Transfer from a Cylinder in Power-Law Fluids: Effect of Aiding Buoyancy. Ind. Eng. Chem. Res. 48, 9735-9754.

Tan, Y., DiBerardinis, L., Smith, T., (1999). Exposure Assessment of Laboratory Students. Applied Occupational and Environmental Hygiene. 14(8): 530538. 
Tanabe, S., Kobayashi, K., Nakano, J., Ozeki, Y., Konishi M. (2002). Evaluation of Thermal Comfort Using Combined Multi-Node Thermoregulation (65MN) and Radiation Models and Computational Fluid Dynamics (CFD). Energy and Building. 34: 637-646.

Tseng, L., Huang, R., Chen, C., Chang, C. (2006). Correlation Between Airflow Patterns and Performance of a Laboratory Fume Hood. Journal of Occupational and Environmental Hygiene. 3: 694-706.

Van Der Wal, J.F., Moerkerken, A. (1984). The Performance of Passive Diffusion Monitors for Organic Vapours for Personal Sampling of Painters. Ann. Occup. Hyg. 28(1): 39-47.

Voelker, C., Hoffamann, S., Kornadt, O., Arens, E., Zhang, H., Huizenga, C. (2009). Heat and Moisture Transfer Through Clothing. Building Simulation - Eleven International IBPSA Conference, Glasgow, Scotland, July 2009.

Welling, I., Kulmala, I., Anderson, I., Rosen, G., Raisanen, J., Mielo, T., Marttinen, K., Saamanen, A., Neimela, R. (2001). Extent of the Reverse Flow Wake Region Produced by a Body in a Uniform Flow Field. Applied Occupational and Environmental Hygiene. 16(9): 900-904.

White, F. (2006). Viscous Fluid Flow. 3rh Edition, New York, McGraw Hill, Inc.

Young, D., Munson, B., Okiishi, T., Huebsch, W. (2007). A Brief Introduction to Fluid Mechanics. 4th Edition, John Wiley and Sons, Inc. 


\section{APPENDICES}

\section{APPENDIX A: Basic statistic relationships}

1) Coefficient of multiple determination $\left(R^{2}\right)$ :

$$
R^{2}=1-\frac{S S E}{S S T}
$$

2) Adjusted coefficient of multiple determination $\left(R_{A d j}^{2}\right)$ :

$$
R_{A d j}^{2}=1-\frac{(n-1)}{(n-p)} \frac{S S E}{S S T}
$$

Where,

$S S E=$ Sum of squares errors of the lineal model

$S S T=$ Total sum of squares of the linear model

$n$ = Sample size

$p=$ Number of parameters in the model including the constant term

3) t-test:

$$
t=\frac{b_{i}}{s . e_{i}}
$$

Where,

$b_{i}=$ Linear regression model coefficient

s. $e_{i}=$ Standard error for $b_{i}$

4) F-ratio:

$$
F_{\text {ratio }}=\frac{M S R}{M S E}=\frac{S S R / d f_{r}}{S S E / d f_{e}}
$$

Where,

$M S R=$ Mean square regression

$M S E=$ Mean square error

$S S R=$ Sum of square regression

$d f_{r}=$ Parameter degree of freedom

$d f_{e}=$ Error degree of freedom 


\section{APPENDIX B: Cross-draft velocity and face velocity equations}

Cross-draft velocity $\left(V_{\text {cross }}\right)$ :

$$
V_{\text {cross }}=-4.86005+0.0666345 * W T r p m
$$

Where:

$V_{\text {cross }}=$ Estimate wind tunnel cross-draft velocity, fpm

WTrpm $=$ Wind tunnel fan velocity, $\mathrm{rpm}$

Velocity pressure measurements:

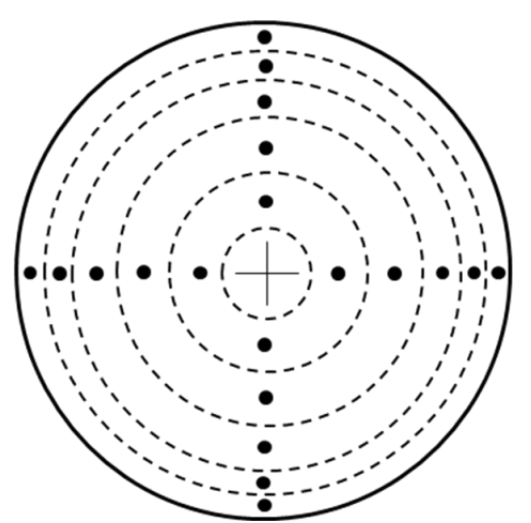

Figure B.1 Pitot traverse insertion depths for circular ducts (10 points)

Table B.1 Distance from the wall for every traverse insertion

\begin{tabular}{cc}
\hline $\begin{array}{c}\text { Number of } \\
\text { points }\end{array}$ & $\begin{array}{c}\text { Distance from the } \\
\text { wall* }\end{array}$ \\
\hline 1 & 0.019 \\
2 & 0.077 \\
3 & 0.153 \\
4 & 0.217 \\
5 & 0.361 \\
6 & 0.639 \\
7 & 0.783 \\
8 & 0.847 \\
9 & 0.923 \\
10 & 0.981 \\
\hline
\end{tabular}

* In fractions of a duct diameter (Source: Industrial Ventilation: A Manual of Recommended Practice for Design, 2010) 
Hood face velocity $\left(V_{\text {face }}\right)$ :

$$
\begin{gathered}
V_{i}=(4005) \sqrt{\frac{V P_{i}}{d f}} \\
\bar{V}=\frac{\sum_{i}^{n} V_{i}}{n}
\end{gathered}
$$

Where,

$V P_{i}=$ Velocity pressure at the $i$ traverse position in a duct cross-section, "wg $d f=$ Density factor $(d f=1$, when considering standard air $(70 \mathrm{~F})$, no moisture, and at sea level)

$V_{i}=$ Air stream velocity at the $i$ traverse position in a duct cross-section, fpm $\bar{V}=$ Average velocity in the duct, fpm

$$
Q=\bar{V} * A_{d u c t}
$$

Where,

$A_{d u c t}=$ Cross-sectional area of the duct, $\mathrm{ft}^{2}$

$D=$ Duct diameter $(7.875$ ')

$Q \quad=$ Estimate volumetric flow rate into the hood, acfm

$$
V_{\text {face }}=\frac{Q}{A_{\text {hood }}}
$$

Where,

$V_{\text {face }}=$ Estimate enclosing hood velocity face, $\mathrm{fpm}$

$A_{\text {hood }}=$ Enclosing hood face area, $\mathrm{ft}^{2}$ 


\section{APPENDIX C: Simple manikin}

Approach velocity $(U)^{*}$ linear model:

$$
U=-2.275+0.110 * V_{\text {face }}+1.193 * V_{\text {cross }}
$$

Table C.1 Approach velocities (fpm) for simple manikin experiments

\begin{tabular}{|c|c|c|c|c|c|c|}
\hline \multirow[b]{2}{*}{$V_{\text {face }},[\mathbf{f p m}]$} & \multicolumn{5}{|c|}{$V_{\text {cross }},[\mathbf{f p m}]$} & \multirow[b]{2}{*}{ Mean } \\
\hline & 14 & 24 & 36 & 46 & 57 & \\
\hline \multirow{3}{*}{100} & 26.04 & 37.80 & 52.28 & 64.74 & 76.65 & \multirow[b]{3}{*}{51} \\
\hline & 26.07 & 37.96 & 52.36 & 64.76 & 76.79 & \\
\hline & 26 & 38 & 52 & 65 & 77 & \\
\hline \multirow{3}{*}{140} & 29.23 & 41.13 & 55.66 & 67.63 & 79.69 & \multirow[b]{3}{*}{55} \\
\hline & 29.31 & 41.20 & 55.69 & 67.68 & 79.78 & \\
\hline & 29 & 41 & 56 & 68 & 80 & \\
\hline \multirow{3}{*}{160} & 32.43 & 44.37 & 58.97 & 71.15 & 83.35 & \multirow[b]{3}{*}{58} \\
\hline & 32.67 & 44.38 & 59.16 & 71.45 & 83.42 & \\
\hline & 33 & 44 & 59 & 71 & 83 & \\
\hline \multirow{3}{*}{190} & 35.56 & 47.44 & 61.72 & 73.97 & 86.49 & \multirow[b]{3}{*}{61} \\
\hline & 35.59 & 47.75 & 61.78 & 74.06 & 86.50 & \\
\hline & 36 & 48 & 62 & 74 & 86 & \\
\hline \multirow{3}{*}{220} & 39.08 & 50.81 & 65.54 & 78.08 & 89.46 & \multirow[b]{3}{*}{65} \\
\hline & 39.20 & 51.21 & 65.58 & 78.12 & 89.69 & \\
\hline & 39 & 51 & 66 & 78 & 90 & \\
\hline Mean & 33 & 43 & 59 & 71 & 83 & 58 \\
\hline
\end{tabular}

*Approach velocities were calculated by Karaismail (2011) in his numerical simulations of the benchtop enclosing hood at different combinations of $V_{\text {face }}$ and $V_{\text {cross. }}$ Therefore, a regression approach velocity $(U)$ equation with $R_{A d j}^{2}=99.2 \%$ was obtained using the numerical data of Karaismail (2011) for all studies in this work. 
Regression analysis for comparison of $C_{\text {nose }}$ and $C_{m o u t h}$ for the simple manikin study

Table C. $2 C_{\text {nose }}$ regression analysis for simple manikin

Dependent variable is: $C_{\text {nose }}$

$\mathrm{R}$ squared $=85.0 \% \quad \mathrm{R}$ squared $($ adjusted $)=84.7 \%$

$s=2.322$ with $50-2=48$ degrees of freedom

\begin{tabular}{lcccc}
\hline Variable & Coefficient & s.e. of Coeff & t-ratio & prob \\
\hline Constant & 0.351052 & 0.8184 & 0.429 & 0.6699 \\
$C_{\text {mouth }}$ & 1.0743 & 0.06515 & 16.5 & $0<0.0001$ \\
\hline
\end{tabular}

Residual plots for comparison of $C_{\text {nose }}$ and $C_{m o u t h}$

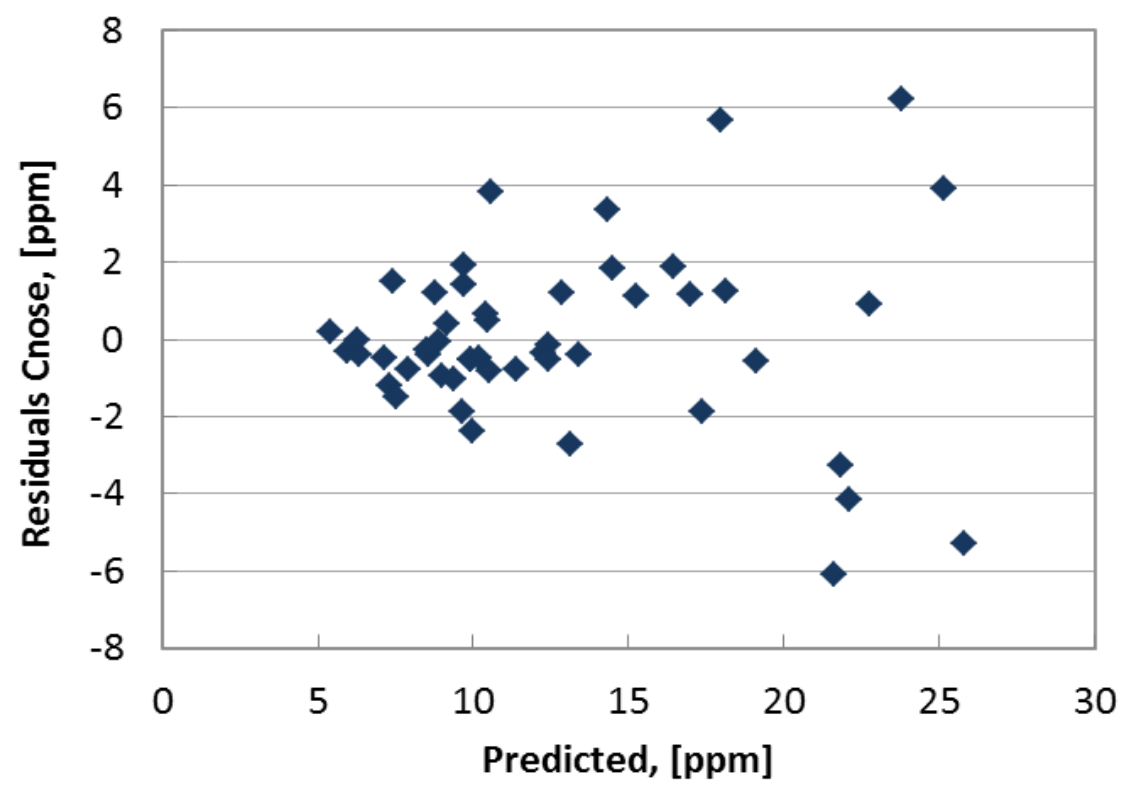

Figure C.1 Residuals $C_{\text {nose }}$ against Predicted $C_{\text {nose }}$ for the simple manikin 


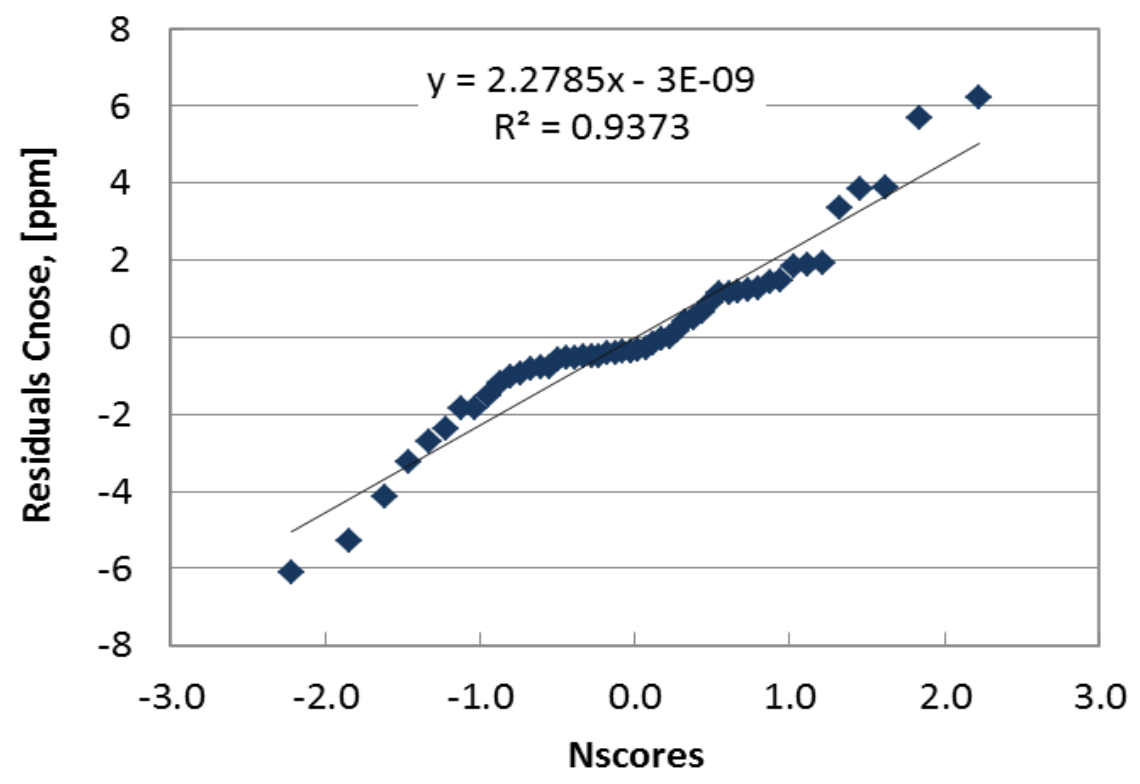

Figure C.2 Normal probability plot of Residuals $C_{\text {nose }}$ against Nscores for the simple manikin

Table C.3 Exhaust duct Reynolds number ( $R e=U D / v)$ for simple manikin study

\begin{tabular}{|c|c|c|c|c|c|c|}
\hline \multirow[b]{2}{*}{$V_{\text {face }},[\mathrm{fpm}]$} & \multicolumn{5}{|c|}{$V_{\text {cross }},[\mathbf{f p m}]$} & \multirow[b]{2}{*}{ Mean } \\
\hline & 14 & 24 & 36 & 46 & 57 & \\
\hline \multirow{3}{*}{100} & $1.71 \mathrm{E}+05$ & $1.65 \mathrm{E}+05$ & $1.62 \mathrm{E}+05$ & $1.65 \mathrm{E}+05$ & $1.60 \mathrm{E}+05$ & \multirow[b]{3}{*}{$1.65 \mathrm{E}+05$} \\
\hline & $1.72 \mathrm{E}+05$ & $1.67 \mathrm{E}+05$ & $1.63 \mathrm{E}+05$ & $1.65 \mathrm{E}+05$ & $1.62 \mathrm{E}+05$ & \\
\hline & $1.71 \mathrm{E}+05$ & $1.66 \mathrm{E}+05$ & $1.62 \mathrm{E}+05$ & $1.65 \mathrm{E}+05$ & $1.61 \mathrm{E}+05$ & \\
\hline \multirow{3}{*}{140} & $2.16 \mathrm{E}+05$ & $2.12 \mathrm{E}+05$ & $2.10 \mathrm{E}+05$ & $2.06 \mathrm{E}+05$ & $2.04 \mathrm{E}+05$ & \multirow[b]{3}{*}{$2.09 \mathrm{E}+05$} \\
\hline & $2.17 \mathrm{E}+05$ & $2.11 \mathrm{E}+05$ & $2.09 \mathrm{E}+05$ & $2.05 \mathrm{E}+05$ & $2.03 \mathrm{E}+05$ & \\
\hline & $2.16 \mathrm{E}+05$ & $2.12 \mathrm{E}+05$ & $2.09 \mathrm{E}+05$ & $2.06 \mathrm{E}+05$ & $2.04 \mathrm{E}+05$ & \\
\hline \multirow{3}{*}{160} & $2.61 \mathrm{E}+05$ & $2.57 \mathrm{E}+05$ & $2.56 \mathrm{E}+05$ & $2.55 \mathrm{E}+05$ & $2.55 \mathrm{E}+05$ & \multirow[b]{3}{*}{$2.58 \mathrm{E}+05$} \\
\hline & $2.64 \mathrm{E}+05$ & $2.57 \mathrm{E}+05$ & $2.58 \mathrm{E}+05$ & $2.59 \mathrm{E}+05$ & $2.55 \mathrm{E}+05$ & \\
\hline & $2.62 \mathrm{E}+05$ & $2.57 \mathrm{E}+05$ & $2.57 \mathrm{E}+05$ & $2.57 \mathrm{E}+05$ & $2.55 \mathrm{E}+05$ & \\
\hline \multirow{3}{*}{190} & $3.05 \mathrm{E}+05$ & $3.00 \mathrm{E}+05$ & $2.94 \mathrm{E}+05$ & $2.94 \mathrm{E}+05$ & $2.99 \mathrm{E}+05$ & \multirow[b]{3}{*}{$2.99 \mathrm{E}+05$} \\
\hline & $3.05 \mathrm{E}+05$ & $3.04 \mathrm{E}+05$ & $2.95 \mathrm{E}+05$ & $2.96 \mathrm{E}+05$ & $2.99 \mathrm{E}+05$ & \\
\hline & $3.05 \mathrm{E}+05$ & $3.02 \mathrm{E}+05$ & $2.95 \mathrm{E}+05$ & $2.95 \mathrm{E}+05$ & $2.99 \mathrm{E}+05$ & \\
\hline \multirow{3}{*}{220} & $3.54 \mathrm{E}+05$ & $3.47 \mathrm{E}+05$ & $3.48 \mathrm{E}+05$ & $3.52 \mathrm{E}+05$ & $3.40 \mathrm{E}+05$ & \multirow[b]{3}{*}{$3.49 \mathrm{E}+05$} \\
\hline & $3.56 \mathrm{E}+05$ & $3.53 \mathrm{E}+05$ & $3.49 \mathrm{E}+05$ & $3.53 \mathrm{E}+05$ & $3.43 \mathrm{E}+05$ & \\
\hline & $3.55 \mathrm{E}+05$ & $3.50 \mathrm{E}+05$ & $3.48 \mathrm{E}+05$ & $3.52 \mathrm{E}+05$ & $3.42 \mathrm{E}+05$ & \\
\hline Mean & $2.62 \mathrm{E}+05$ & $2.57 \mathrm{E}+05$ & $2.54 \mathrm{E}+05$ & $2.55 \mathrm{E}+05$ & $2.52 \mathrm{E}+05$ & $2.56 \mathrm{E}+05$ \\
\hline
\end{tabular}




\section{APPENDIX D: Anthropometrically-correct manikin}

Table D.1 Approach velocity (fpm) for complex manikin experiments

\begin{tabular}{|c|c|c|c|c|c|c|c|}
\hline \multicolumn{8}{|c|}{$V_{\text {cross }},[\mathbf{f p m}]$} \\
\hline \multirow{2}{*}{$V_{\text {face }},[\mathrm{fpm}]$} & \multicolumn{2}{|c|}{14} & \multicolumn{2}{|c|}{46} & \multicolumn{2}{|c|}{63} & \multirow[t]{2}{*}{ Mean } \\
\hline & 25.31 & 25.83 & 63.88 & 64.43 & 83.15 & 83.61 & \\
\hline \multirow{4}{*}{100} & 25.40 & 25.83 & 64.00 & 64.50 & 83.23 & 83.69 & \\
\hline & 25.74 & 25.94 & 64.02 & 64.66 & 83.40 & 83.75 & \\
\hline & & & 64.34 & 64.68 & 83.41 & & \\
\hline & 25.67 & & 64.31 & & 83.46 & & 57.82 \\
\hline \multirow{4}{*}{160} & 31.57 & 31.64 & 70.35 & 70.51 & 89.60 & 89.78 & \\
\hline & 31.57 & 31.72 & 70.36 & 70.76 & 89.73 & 89.83 & \\
\hline & 31.61 & & & & & & \\
\hline & 31.62 & & 70.49 & & 89.74 & & 63.95 \\
\hline \multirow{5}{*}{220} & 37.80 & 38.52 & 76.50 & 77.56 & 95.84 & 96.84 & \\
\hline & 37.80 & 38.69 & 76.69 & 77.58 & 95.92 & 96.89 & \\
\hline & 37.82 & 38.71 & 76.94 & 77.73 & 95.95 & 96.95 & \\
\hline & 37.84 & & 77.00 & & 95.97 & & \\
\hline & 38.17 & & 77.14 & & 96.34 & & 70.55 \\
\hline Mean & 31.82 & & 70.65 & & 89.85 & & 64.11 \\
\hline
\end{tabular}


Table D.2 Grashof number for complex manikin experiments

\begin{tabular}{|c|c|c|c|c|c|c|c|}
\hline \multirow{2}{*}{$\begin{array}{r}V_{\text {face }}, \\
{[\mathbf{f p m}]}\end{array}$} & \multicolumn{6}{|c|}{$V_{\text {cross }},[\mathrm{fpm}]$} & \multirow[b]{2}{*}{ Mean } \\
\hline & \multicolumn{2}{|c|}{14} & \multicolumn{2}{|c|}{46} & \multicolumn{2}{|c|}{63} & \\
\hline \multirow{5}{*}{100} & $1.58 \mathrm{E}+08$ & $1.16 \mathrm{E}+08$ & $1.95 \mathrm{E}+08$ & $1.32 \mathrm{E}+08$ & $1.74 \mathrm{E}+08$ & $1.32 \mathrm{E}+08$ & \\
\hline & $1.21 \mathrm{E}+08$ & $1.11 \mathrm{E}+08$ & $1.32 \mathrm{E}+08$ & $1.64 \mathrm{E}+08$ & $1.37 \mathrm{E}+08$ & $2.38 \mathrm{E}+08$ & \\
\hline & $1.11 \mathrm{E}+08$ & $8.45 \mathrm{E}+07$ & $1.21 \mathrm{E}+08$ & $1.32 \mathrm{E}+08$ & $5.28 \mathrm{E}+07$ & $1.95 \mathrm{E}+08$ & \\
\hline & & & $1.74 \mathrm{E}+08$ & $1.80 \mathrm{E}+08$ & $8.45 \mathrm{E}+07$ & & \\
\hline & $1.17 \mathrm{E}+08$ & & $1.54 \mathrm{E}+08$ & & $1.45 \mathrm{E}+08$ & & $1.39 \mathrm{E}+08$ \\
\hline \multirow{4}{*}{160} & $7.39 \mathrm{E}+07$ & $1.32 \mathrm{E}+08$ & $1.69 \mathrm{E}+08$ & $1.48 \mathrm{E}+08$ & $9.51 \mathrm{E}+07$ & $1.27 \mathrm{E}+08$ & \\
\hline & $1.53 \mathrm{E}+08$ & $1.74 \mathrm{E}+08$ & $1.32 \mathrm{E}+08$ & $1.64 \mathrm{E}+08$ & $1.58 \mathrm{E}+08$ & $1.11 \mathrm{E}+08$ & \\
\hline & $1.43 \mathrm{E}+08$ & & & & & & \\
\hline & $1.35 \mathrm{E}+08$ & & $1.53 \mathrm{E}+08$ & & $1.23 \mathrm{E}+08$ & & $1.37 \mathrm{E}+08$ \\
\hline \multirow{5}{*}{220} & $1.53 \mathrm{E}+08$ & $7.92 \mathrm{E}+07$ & $1.11 \mathrm{E}+08$ & $6.34 \mathrm{E}+07$ & $1.11 \mathrm{E}+08$ & $1.37 \mathrm{E}+08$ & \\
\hline & $9.51 \mathrm{E}+07$ & $1.32 \mathrm{E}+08$ & $2.01 \mathrm{E}+08$ & $1.48 \mathrm{E}+08$ & $1.11 \mathrm{E}+08$ & $8.98 \mathrm{E}+07$ & \\
\hline & $1.06 \mathrm{E}+08$ & $1.43 \mathrm{E}+08$ & $5.81 \mathrm{E}+07$ & $9.51 \mathrm{E}+07$ & $1.32 \mathrm{E}+08$ & $1.37 \mathrm{E}+08$ & \\
\hline & $1.64 \mathrm{E}+08$ & & $7.92 \mathrm{E}+07$ & & $1.74 \mathrm{E}+08$ & & \\
\hline & $1.24 \mathrm{E}+08$ & & $1.08 \mathrm{E}+08$ & & $1.27 \mathrm{E}+08$ & & $1.20 \mathrm{E}+08$ \\
\hline Mean & $1.26 \mathrm{E}+08$ & & $1.38 \mathrm{E}+08$ & & $1.32 \mathrm{E}+08$ & & $1.32 \mathrm{E}+08$ \\
\hline
\end{tabular}

Grashof number: $G r=g \beta \Delta T_{\operatorname{man}} H_{\text {man }}{ }^{3} / v^{2}$

$H_{\text {man }}$ : Vertical distance from the hood table to the manikin's top of the head

Distance from the floor to the hood table $=38.5 "$

Height of the complex manikin $=66 "$

$H_{\text {man }}=66-38.5=27.5 "$ 


\section{APPENDIX E: Human subjects}

Table E.1 Human subjects' approach velocity (fpm)

\begin{tabular}{|c|c|c|c|c|c|}
\hline \multirow{2}{*}{$\begin{array}{c}V_{\text {face }}, \\
{[\mathbf{f p m}]}\end{array}$} & \multirow{2}{*}{ Subject } & \multicolumn{3}{|c|}{$V_{\text {cross }},[\mathrm{fpm}]$} & \multirow[b]{2}{*}{ Mean } \\
\hline & & 14 & 46 & 63 & \\
\hline \multirow{10}{*}{100} & Orange & 25.99 & 64.64 & 83.73 & 58.12 \\
\hline & Red & 25.85 & 64.45 & 83.59 & 57.96 \\
\hline & Yellow & 25.70 & 64.42 & 83.50 & 57.87 \\
\hline & Green & 25.63 & 64.06 & 83.43 & 57.71 \\
\hline & Brown & 25.42 & 64.06 & 83.16 & 57.54 \\
\hline & Gray & 25.41 & 64.12 & 83.24 & 57.59 \\
\hline & Cyan & 25.34 & 63.92 & 83.12 & 57.46 \\
\hline & Purple & 25.53 & 64.15 & 83.28 & 57.65 \\
\hline & Black & 25.71 & 64.00 & 83.33 & 57.68 \\
\hline & Magenta & 25.60 & 64.22 & 83.40 & 57.74 \\
\hline Mean & & 25.62 & 64.20 & 83.38 & 57.73 \\
\hline \multirow{10}{*}{160} & Orange & 32.37 & 71.19 & 90.40 & 64.65 \\
\hline & Red & 32.13 & 70.82 & 90.09 & 64.35 \\
\hline & Yellow & 32.14 & 70.95 & 90.29 & 64.46 \\
\hline & Green & 31.91 & 70.70 & 89.96 & 64.19 \\
\hline & Brown & 31.88 & 70.51 & 89.97 & 64.12 \\
\hline & Gray & 31.74 & 70.55 & 89.83 & 64.04 \\
\hline & Cyan & 31.76 & 70.57 & 89.79 & 64.04 \\
\hline & Purple & 31.69 & 70.61 & 89.90 & 64.07 \\
\hline & Black & 31.78 & 70.60 & 89.84 & 64.07 \\
\hline & Magenta & 32.01 & 70.52 & 90.00 & 64.14 \\
\hline Mean & & 31.94 & 70.70 & 90.01 & 64.21 \\
\hline \multirow{10}{*}{220} & Orange & 38.76 & 77.62 & 96.91 & 71.10 \\
\hline & Red & 38.42 & 77.37 & 96.60 & 70.80 \\
\hline & Yellow & 38.43 & 77.21 & 96.57 & 70.74 \\
\hline & Green & 38.18 & 76.84 & 96.38 & 70.47 \\
\hline & Brown & 38.09 & 76.82 & 96.23 & 70.38 \\
\hline & Gray & 38.02 & 76.63 & 96.08 & 70.24 \\
\hline & Cyan & 37.88 & 76.68 & 95.96 & 70.17 \\
\hline & Purple & 37.87 & 76.60 & 96.06 & 70.17 \\
\hline & Black & 37.91 & 76.75 & 96.01 & 70.22 \\
\hline & Magenta & 37.90 & 76.72 & 96.12 & 70.25 \\
\hline Mean & & 38.15 & 76.92 & 96.29 & 70.45 \\
\hline Mean & & 31.90 & 70.61 & 89.89 & 64.13 \\
\hline
\end{tabular}


Table E.2 Human subjects' Grashof numbers

\begin{tabular}{|c|c|c|c|c|c|}
\hline \multirow{2}{*}{$\begin{array}{c}V_{\text {face }}, \\
{[\mathbf{f p m}]}\end{array}$} & \multirow{2}{*}{ Subject } & \multicolumn{3}{|c|}{$V_{\text {cross }},[\mathrm{fpm}]$} & \multirow[b]{2}{*}{ Mean } \\
\hline & & 14 & 46 & 63 & \\
\hline \multirow{10}{*}{100} & Orange & $4.69 \mathrm{E}+08$ & $4.54 \mathrm{E}+08$ & $4.18 \mathrm{E}+08$ & $4.47 \mathrm{E}+08$ \\
\hline & Red & $6.56 \mathrm{E}+08$ & $6.13 \mathrm{E}+08$ & $6.36 \mathrm{E}+08$ & $6.35 \mathrm{E}+08$ \\
\hline & Yellow & $7.21 \mathrm{E}+08$ & $7.16 \mathrm{E}+08$ & $7.23 \mathrm{E}+08$ & $7.20 \mathrm{E}+08$ \\
\hline & Green & $3.62 \mathrm{E}+08$ & $3.07 \mathrm{E}+08$ & $2.90 \mathrm{E}+08$ & $3.20 \mathrm{E}+08$ \\
\hline & Brown & $3.12 \mathrm{E}+08$ & $3.45 \mathrm{E}+08$ & $3.30 \mathrm{E}+08$ & $3.29 \mathrm{E}+08$ \\
\hline & Gray & $4.12 \mathrm{E}+08$ & $4.75 \mathrm{E}+08$ & $3.82 \mathrm{E}+08$ & $4.23 \mathrm{E}+08$ \\
\hline & Cyan & $2.78 \mathrm{E}+08$ & $3.74 \mathrm{E}+08$ & $3.00 \mathrm{E}+08$ & $3.17 \mathrm{E}+08$ \\
\hline & Purple & $2.95 \mathrm{E}+08$ & $2.68 \mathrm{E}+08$ & $3.05 \mathrm{E}+08$ & $2.89 \mathrm{E}+08$ \\
\hline & Black & $4.48 \mathrm{E}+08$ & $4.15 \mathrm{E}+08$ & $4.43 \mathrm{E}+08$ & $4.35 \mathrm{E}+08$ \\
\hline & Magenta & $5.88 \mathrm{E}+08$ & $5.96 \mathrm{E}+08$ & $4.71 \mathrm{E}+08$ & $5.52 \mathrm{E}+08$ \\
\hline Mean & & $4.54 \mathrm{E}+08$ & $4.56 \mathrm{E}+08$ & $4.30 \mathrm{E}+08$ & $4.47 \mathrm{E}+08$ \\
\hline \multirow{10}{*}{160} & Orange & $4.67 \mathrm{E}+08$ & $3.96 \mathrm{E}+08$ & $4.07 \mathrm{E}+08$ & $4.23 \mathrm{E}+08$ \\
\hline & Red & $6.93 \mathrm{E}+08$ & $6.29 \mathrm{E}+08$ & $6.06 \mathrm{E}+08$ & $6.43 \mathrm{E}+08$ \\
\hline & Yellow & $6.93 \mathrm{E}+08$ & $7.57 \mathrm{E}+08$ & $6.76 \mathrm{E}+08$ & $7.09 \mathrm{E}+08$ \\
\hline & Green & $2.64 \mathrm{E}+08$ & $3.07 \mathrm{E}+08$ & $2.83 \mathrm{E}+08$ & $2.85 \mathrm{E}+08$ \\
\hline & Brown & $2.93 \mathrm{E}+08$ & $3.22 \mathrm{E}+08$ & $3.02 \mathrm{E}+08$ & $3.06 \mathrm{E}+08$ \\
\hline & Gray & $3.33 \mathrm{E}+08$ & $4.49 \mathrm{E}+08$ & $3.62 \mathrm{E}+08$ & $3.81 \mathrm{E}+08$ \\
\hline & Cyan & $2.64 \mathrm{E}+08$ & $3.11 \mathrm{E}+08$ & $3.22 \mathrm{E}+08$ & $2.99 \mathrm{E}+08$ \\
\hline & Purple & $3.25 \mathrm{E}+08$ & $3.37 \mathrm{E}+08$ & $3.30 \mathrm{E}+08$ & $3.31 \mathrm{E}+08$ \\
\hline & Black & $4.51 \mathrm{E}+08$ & $4.40 \mathrm{E}+08$ & 4.44E+08 & $4.45 \mathrm{E}+08$ \\
\hline & Magenta & $4.93 \mathrm{E}+08$ & $5.37 \mathrm{E}+08$ & $5.22 \mathrm{E}+08$ & $5.17 \mathrm{E}+08$ \\
\hline Mean & & $4.28 \mathrm{E}+08$ & $4.48 \mathrm{E}+08$ & $4.25 \mathrm{E}+08$ & $4.34 \mathrm{E}+08$ \\
\hline \multirow{10}{*}{220} & Orange & $4.05 \mathrm{E}+08$ & $4.65 \mathrm{E}+08$ & $4.43 \mathrm{E}+08$ & $4.37 \mathrm{E}+08$ \\
\hline & Red & $6.06 \mathrm{E}+08$ & $6.56 \mathrm{E}+08$ & $5.52 \mathrm{E}+08$ & $6.05 \mathrm{E}+08$ \\
\hline & Yellow & $6.83 \mathrm{E}+08$ & $7.26 \mathrm{E}+08$ & $7.33 \mathrm{E}+08$ & $7.14 \mathrm{E}+08$ \\
\hline & Green & $2.75 \mathrm{E}+08$ & $2.64 \mathrm{E}+08$ & $2.21 \mathrm{E}+08$ & $2.53 \mathrm{E}+08$ \\
\hline & Brown & $3.42 \mathrm{E}+08$ & $3.45 \mathrm{E}+08$ & $3.22 \mathrm{E}+08$ & $3.36 \mathrm{E}+08$ \\
\hline & Gray & $4.02 \mathrm{E}+08$ & $4.02 \mathrm{E}+08$ & $3.57 \mathrm{E}+08$ & $3.87 \mathrm{E}+08$ \\
\hline & Cyan & $2.97 \mathrm{E}+08$ & $3.05 \mathrm{E}+08$ & $2.80 \mathrm{E}+08$ & $2.94 \mathrm{E}+08$ \\
\hline & Purple & $3.72 \mathrm{E}+08$ & $3.42 \mathrm{E}+08$ & $3.35 \mathrm{E}+08$ & $3.50 \mathrm{E}+08$ \\
\hline & Black & $4.76 \mathrm{E}+08$ & $3.90 \mathrm{E}+08$ & $4.43 \mathrm{E}+08$ & $4.36 \mathrm{E}+08$ \\
\hline & Magenta & $5.40 \mathrm{E}+08$ & $5.52 \mathrm{E}+08$ & $4.78 \mathrm{E}+08$ & $5.23 \mathrm{E}+08$ \\
\hline Mean & & $4.40 \mathrm{E}+08$ & $4.45 \mathrm{E}+08$ & $4.16 \mathrm{E}+08$ & $4.34 \mathrm{E}+08$ \\
\hline Mean & & $4.41 \mathrm{E}+08$ & $4.50 \mathrm{E}+08$ & $4.24 \mathrm{E}+08$ & $4.38 \mathrm{E}+08$ \\
\hline
\end{tabular}


Grashof number: $G r=g \beta \Delta T_{\text {human }} H_{\text {human }}{ }^{3} / v^{2}$

Distance from the floor to the hood table $=38.5 "$

Table E.3 Vertical distance from the hood table to the human's top of the head, $H_{\text {human }}$

\begin{tabular}{lcc}
\hline Subject & Height, [in] & $\boldsymbol{H}_{\text {human }},[$ in] \\
\hline Orange & 68 & 29.5 \\
Red & 70 & 31.5 \\
Yellow & 70 & 31.5 \\
Green & 67 & 28.5 \\
Brown & 67 & 28.5 \\
Gray & 70 & 31.5 \\
Cyan & 68 & 29.5 \\
Purple & 67 & 28.5 \\
Black & 68 & 29.5 \\
Magenta & 71 & 32.5 \\
\hline
\end{tabular}

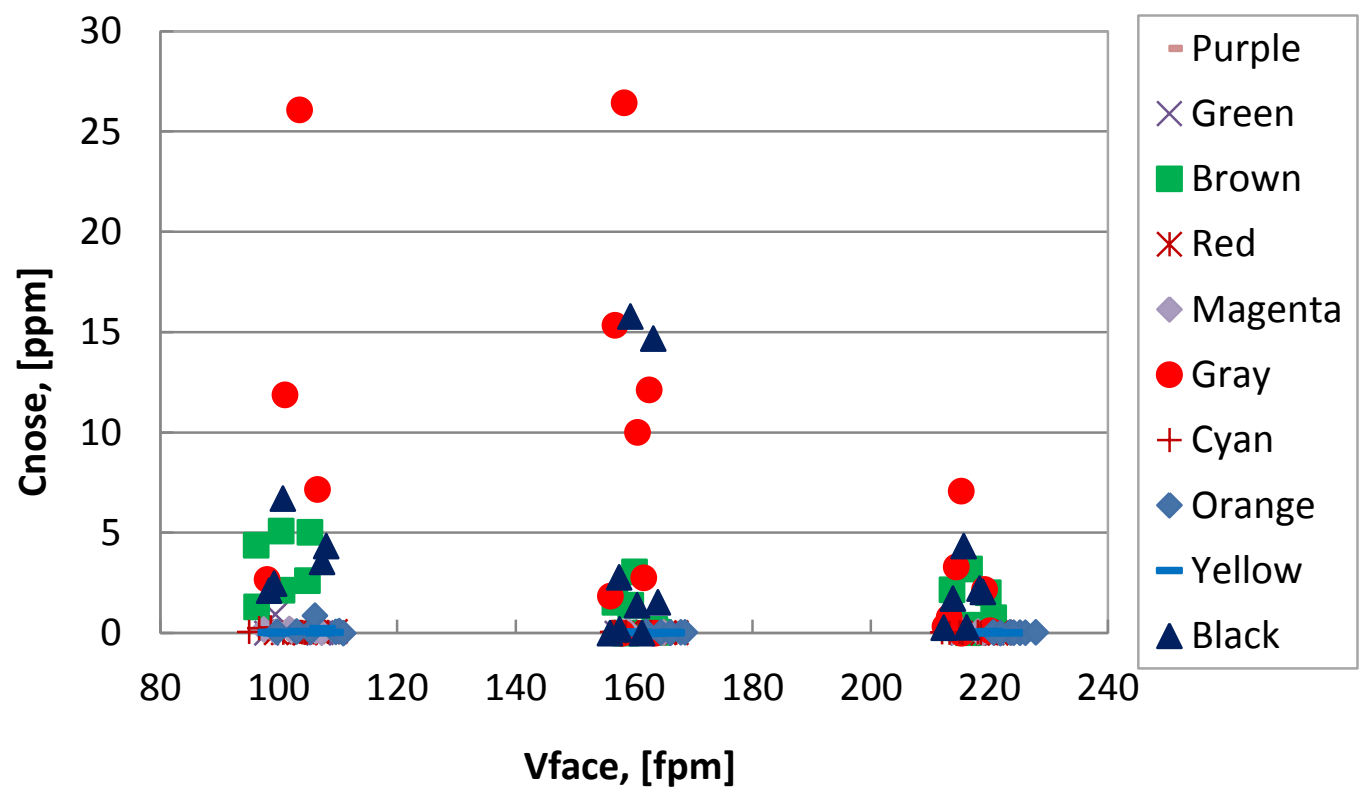

Figure E.1 Effect of $V_{\text {face }}$ on $C_{\text {nose }}$ without the highest concentration of subject ID Gray 


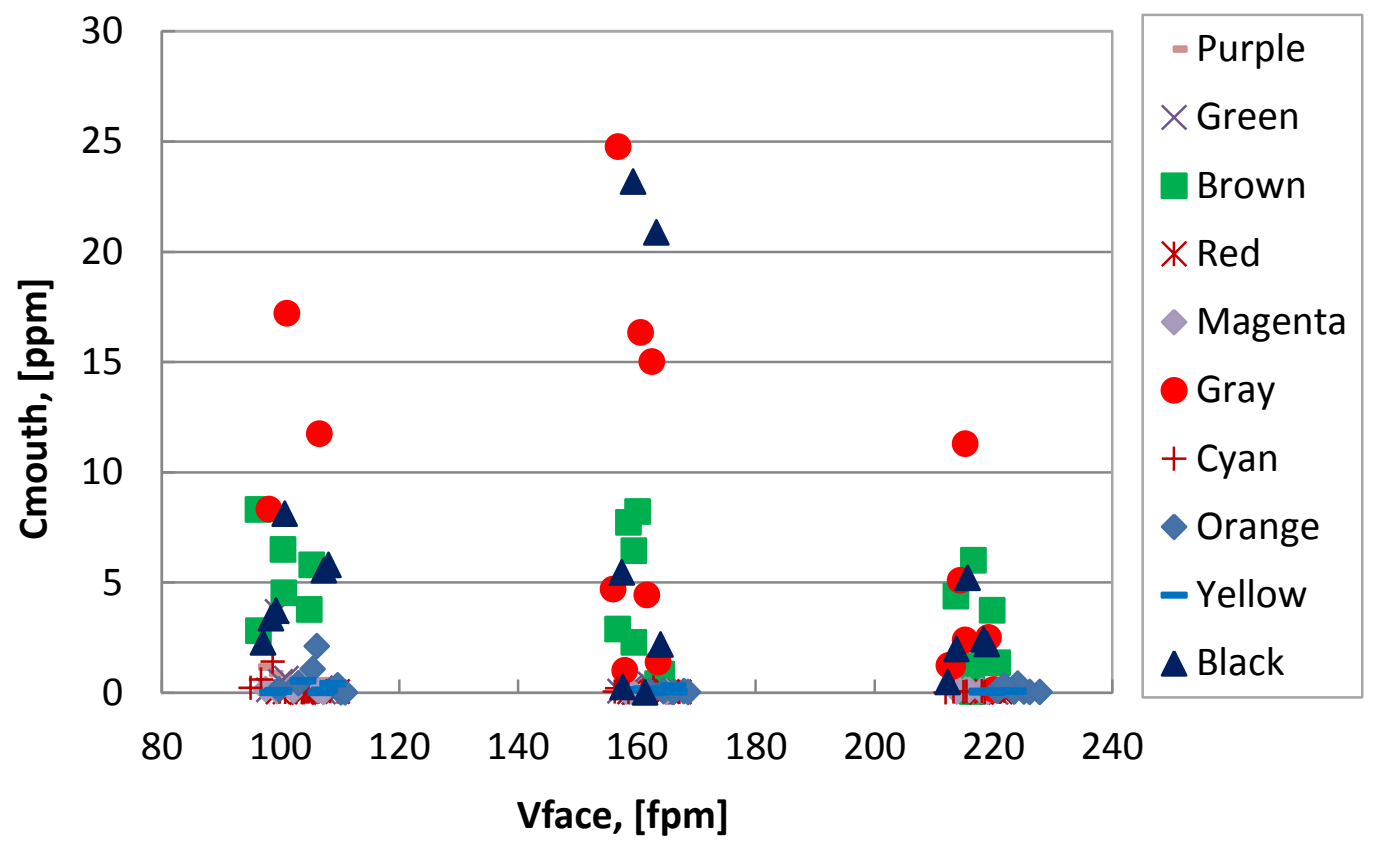

Figure E.2 Effect of $V_{\text {face }}$ on $C_{\text {mouth }}$ without the highest concentration of subject ID Gray

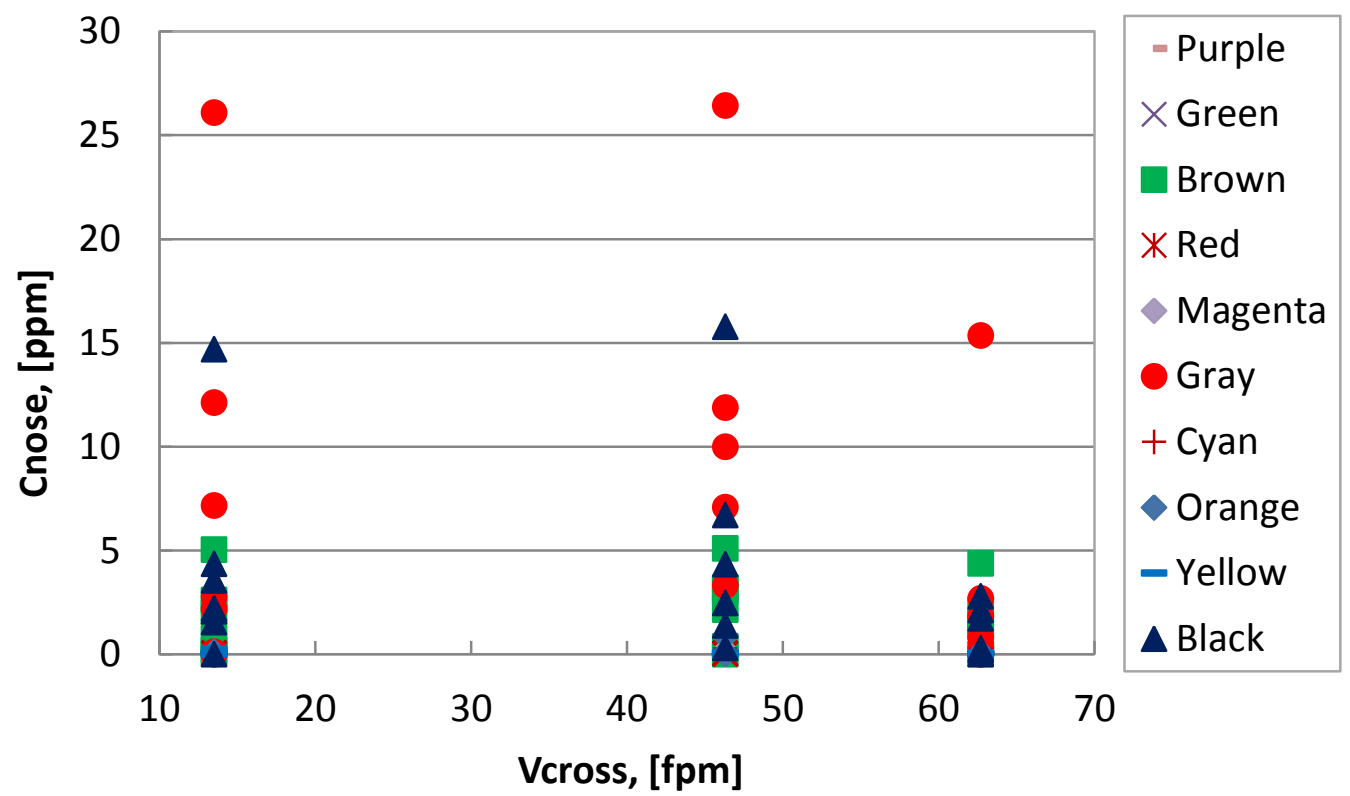

Figure E.3 Effect of $V_{\text {cross }}$ on $C_{\text {nose }}$ without the highest concentration of subject ID Gray 


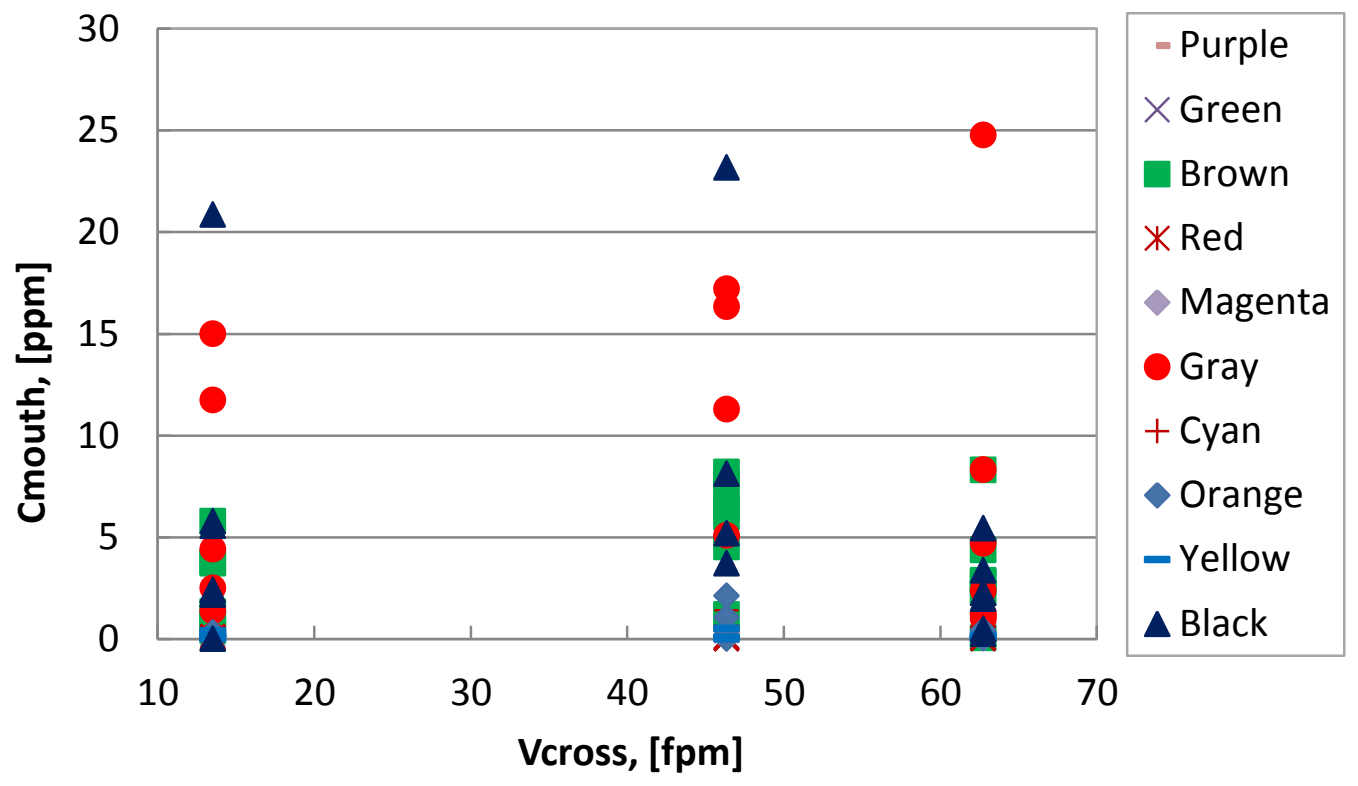

Figure E.4 Effect of $V_{\text {cross }}$ on $C_{\text {mouth }}$ without the highest concentration of subject ID Gray

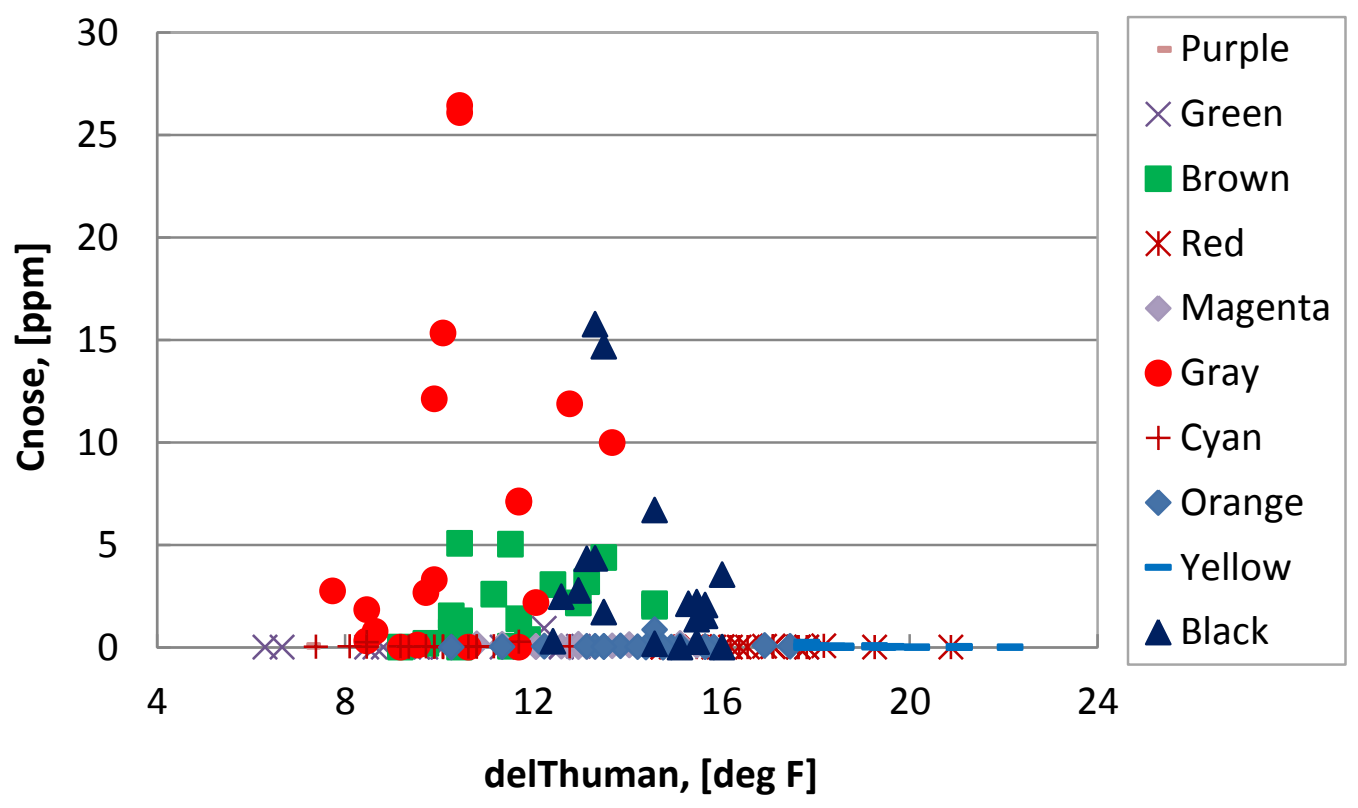

Figure E.5 Effect of $\Delta T_{\text {human }}$ on $C_{\text {nose }}$ without the highest concentration of subject ID Gray 


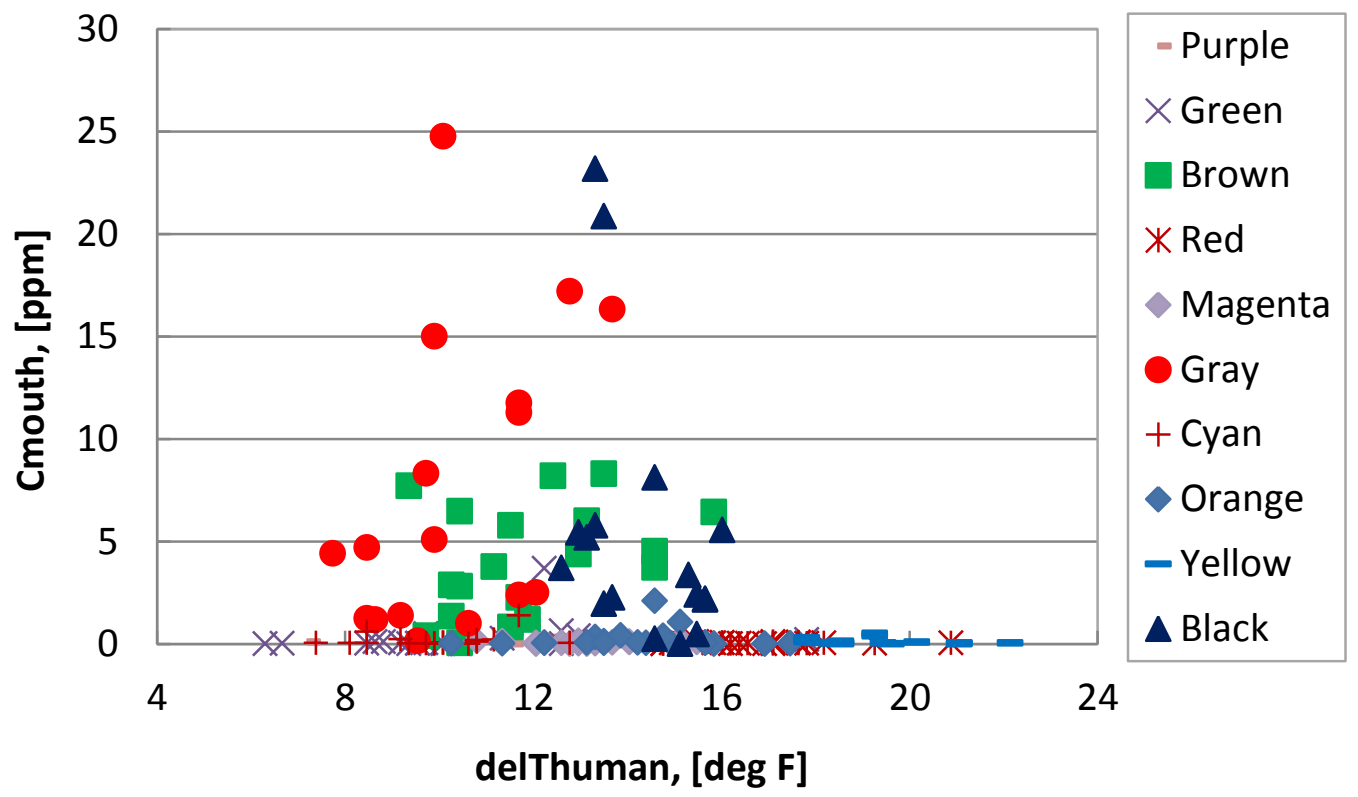

Figure E.6 Effect of $\Delta T_{\text {human }}$ on $C_{\text {mouth }}$ without the highest concentration of subject ID Gray

Table E.4 Linear regression of $\Delta T_{\text {human }}$ for human subjects

\begin{tabular}{|c|c|c|c|c|}
\hline \multicolumn{5}{|c|}{$\begin{array}{l}\text { Dependent variable is: } \Delta T_{\text {human }} \\
\mathrm{R} \text { squared }=1.2 \% \quad \mathrm{R} \text { squared (adjusted) }=0.1 \% \\
\mathrm{~s}=3.304 \text { with } 188-3=185 \text { degrees of freedom }\end{array}$} \\
\hline Variable & Coefficient & s.e. of Coeff & t-ratio & prob \\
\hline Constant & 14.540 & 0.948 & 15.30 & $<0.0001$ \\
\hline Vface & -0.007 & 0.005 & -1.38 & 0.1684 \\
\hline Vcross & -0.006 & 0.012 & -0.54 & 0.5920 \\
\hline
\end{tabular}

Note: Table E.4 showed than $\Delta T_{\text {human }}$ was not affected for other factors, such as $V_{\text {face }}$ and $V_{\text {cross. }}$ 


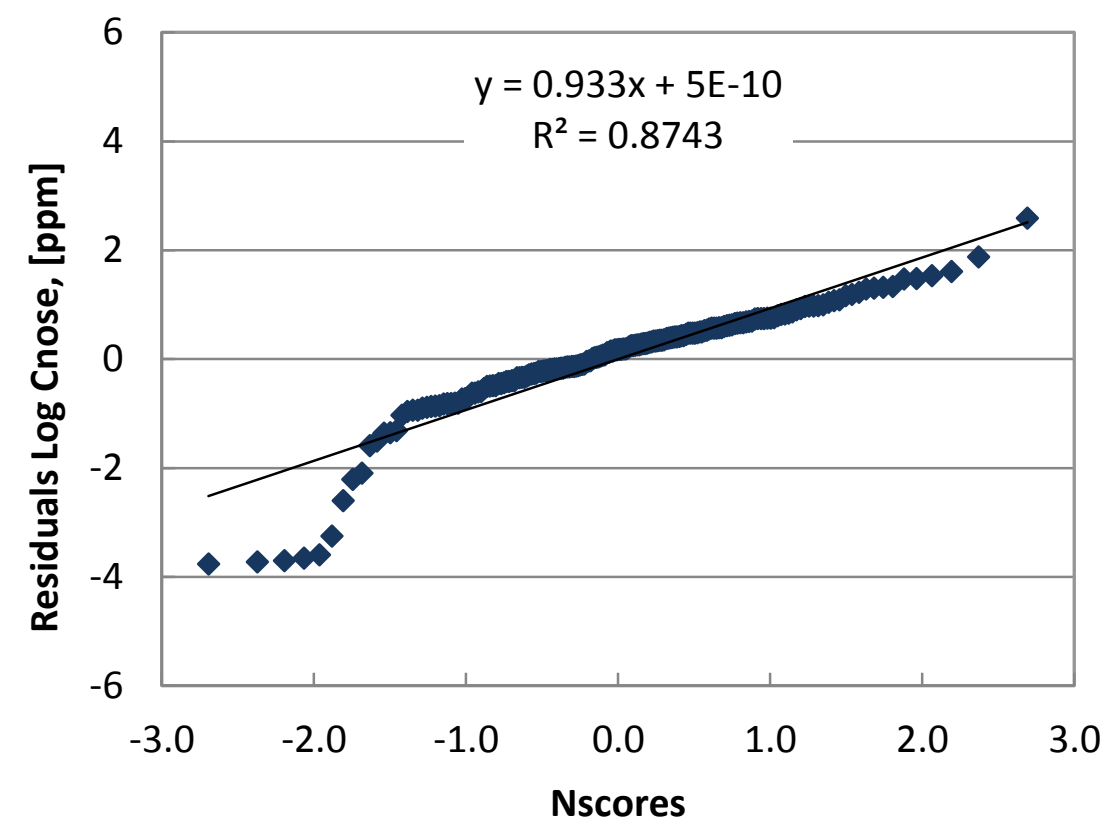

Figure E.7 Normal probability plot of Residuals $\log C_{\text {nose }}$ against Nscores for the human subjects $\left(R_{a d j}^{2}=87.4 \%\right)$

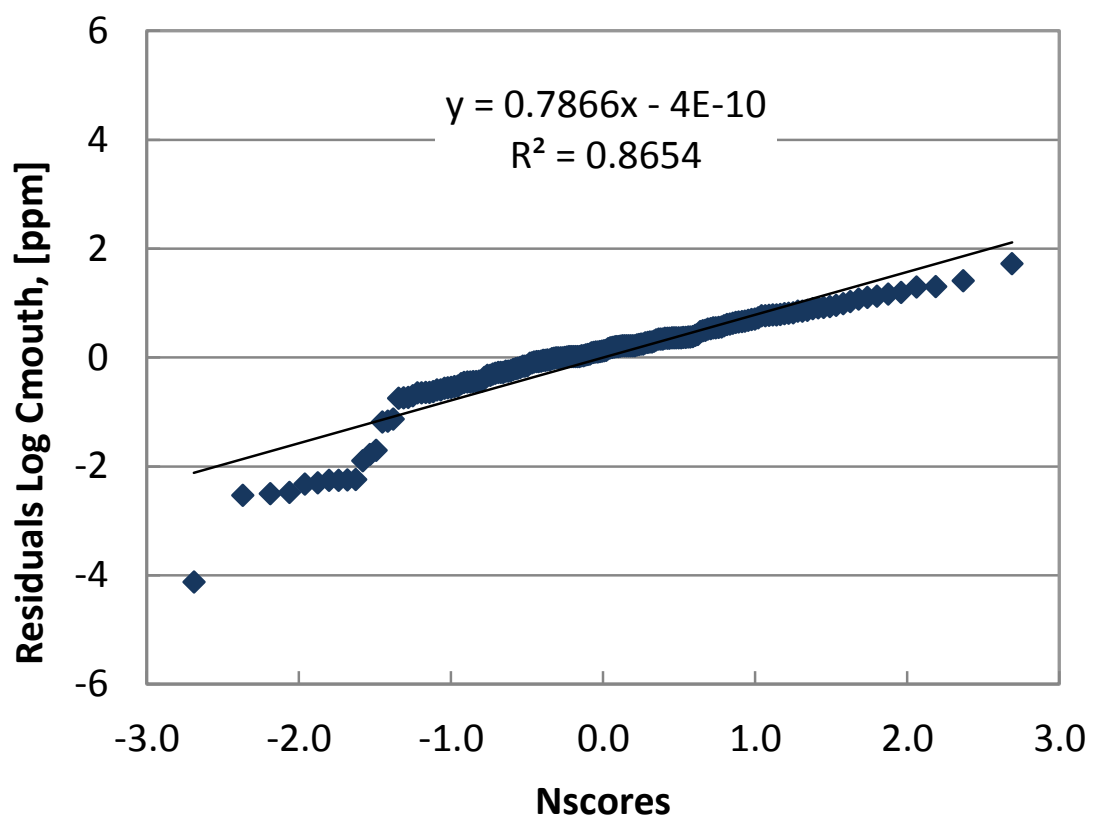

Figure E.8 Normal probability plot of Residuals $\log C_{\text {mouth }}$ against Nscores for the human subjects $\left(R_{a d j}^{2}=86.5 \%\right)$ 


\section{APPENDIX F: Calibration curve of Gasmet FTIR gas analyzer}

Calibration date: September 26, 2011

FTIR range for Freon 134a: 0 - 200 ppm

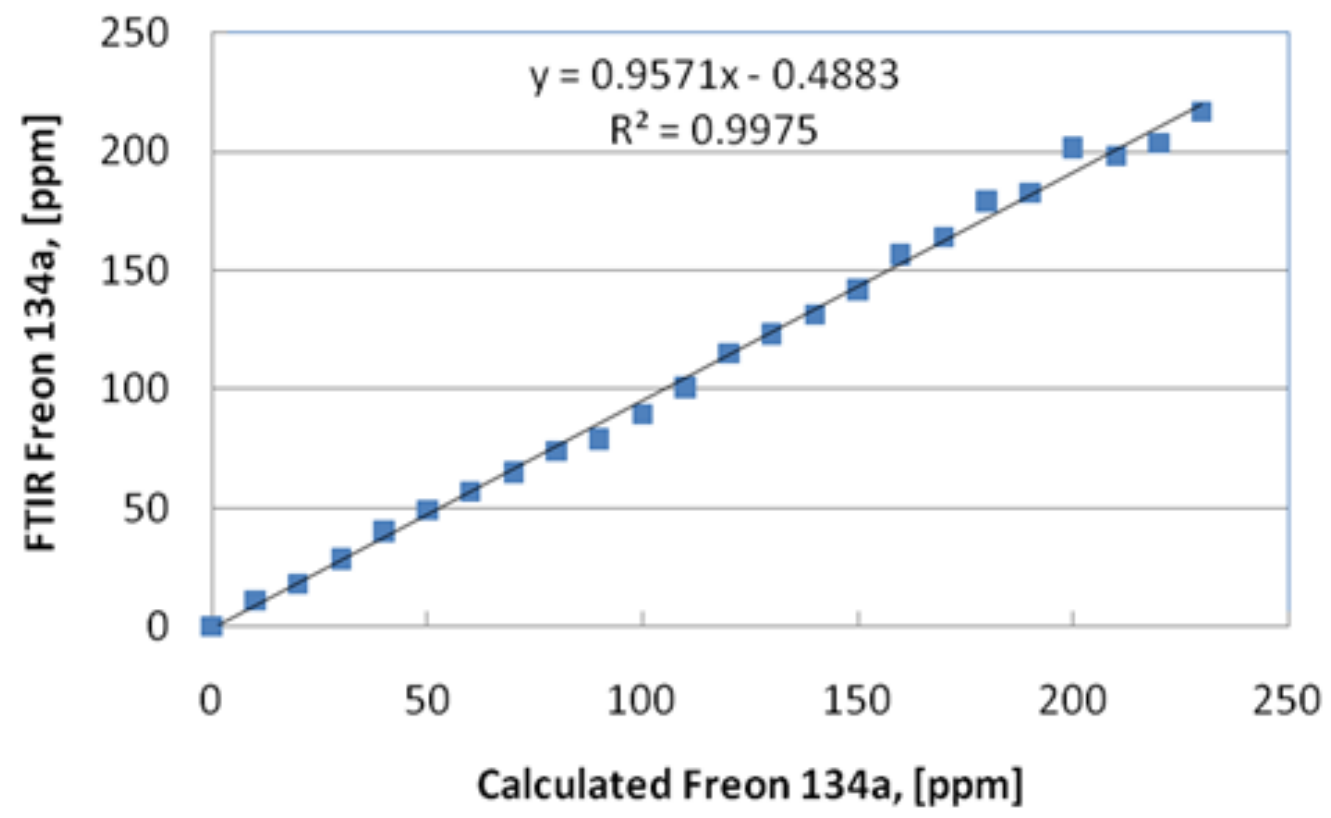

Figure F.1 Gasmet FTIR gas analyzer's calibration curve 


\section{APPENDIX G: Calibration of SKC ${ }^{\circledR}$ low flow sample pump}

Calibration date: February 8, 2011

Sample pump range: $50-200 \mathrm{ml} / \mathrm{min}$

All low flow sample pumps were set up at $200 \mathrm{ml} / \mathrm{min}$

For mouth location, there was a digital pocket sample pump

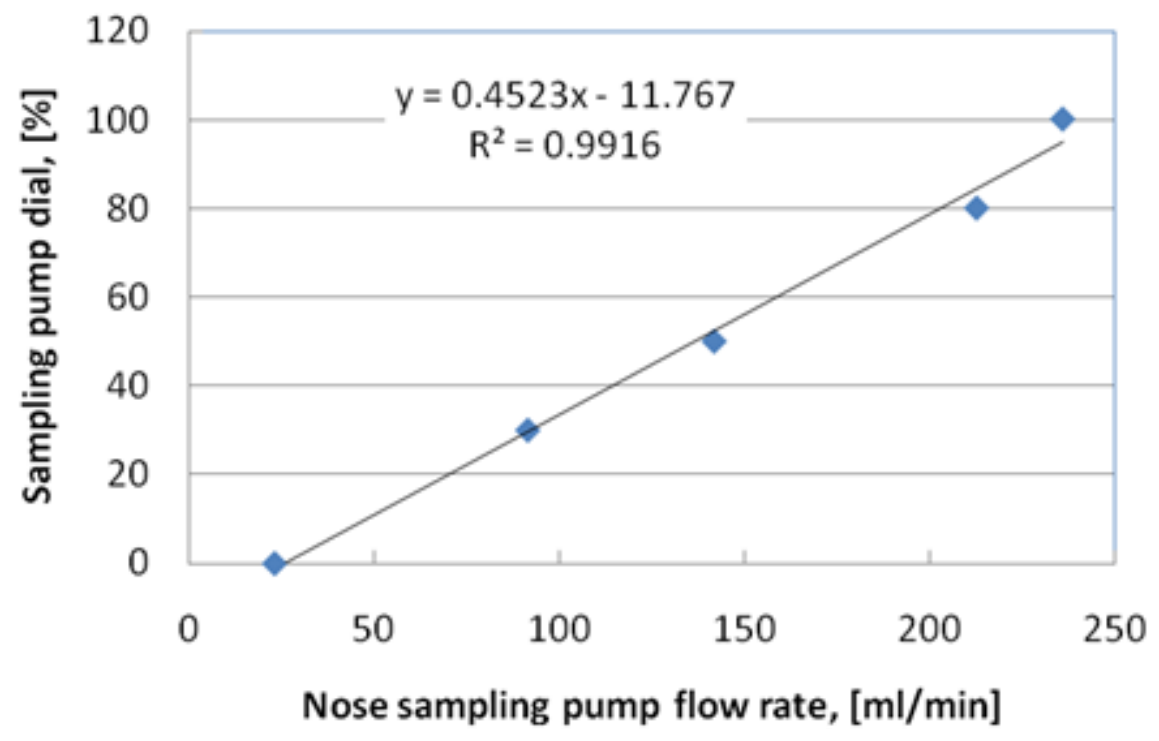

Figure G.1 SKC ${ }^{\circledR}$ sample pump's calibration curve 


\section{APPENDIX H: Calibration of Airflow PVM 100 micromanometer}

Pressure range : $0-14$ "wg

Pressure resolution: 0.001 "wg

Accuracy at $20^{\circ} \mathrm{C}: \pm 1 \%$ of reading

Calibration date: February 15, 2011

Table H.1 PVM ${ }^{\circledR} 100$ micromanometer's calibration data

\begin{tabular}{cccc}
\hline $\begin{array}{c}\text { Hook Gage } \\
\text { ["WG] }\end{array}$ & $\begin{array}{c}\text { PVM 100 } \\
\text { ["WG] }\end{array}$ & $\begin{array}{c}\text { Temp. } \\
\text { [F] }\end{array}$ & $\begin{array}{c}\text { Rod } \\
\text { [in] }\end{array}$ \\
\hline 0.000 & 0.009 & 73.0 & 1 \\
0.349 & 0.354 & 73.0 & 1 \\
0.702 & 0.701 & 74.0 & 1 \\
0.514 & 0.516 & 74.0 & 1 \\
1.039 & 1.030 & 74.0 & 1 \\
1.541 & 1.512 & 74.0 & 1 \\
2.041 & 2.028 & 76.0 & 1 \\
2.505 & 2.501 & 73.0 & 3 \\
3.019 & 3.004 & 74.0 & 3 \\
3.508 & 3.503 & 74.0 & 3 \\
4.013 & 4.003 & 74.0 & 3 \\
4.499 & 4.497 & 74.0 & 5 \\
5.013 & 5.008 & 74.0 & 5 \\
5.506 & 5.501 & 74.0 & 5 \\
6.020 & 6.006 & 74.0 & 5 \\
6.509 & 6.506 & 74.5 & 7 \\
7.014 & 7.004 & 74.5 & 7 \\
7.509 & 7.500 & 74.5 & 7 \\
8.015 & 8.018 & 74.5 & 7 \\
8.503 & 8.501 & 74.5 & 8 \\
9.030 & 8.998 & 74.5 & 8 \\
9.491 & 9.494 & 74.5 & 8 \\
\hline
\end{tabular}




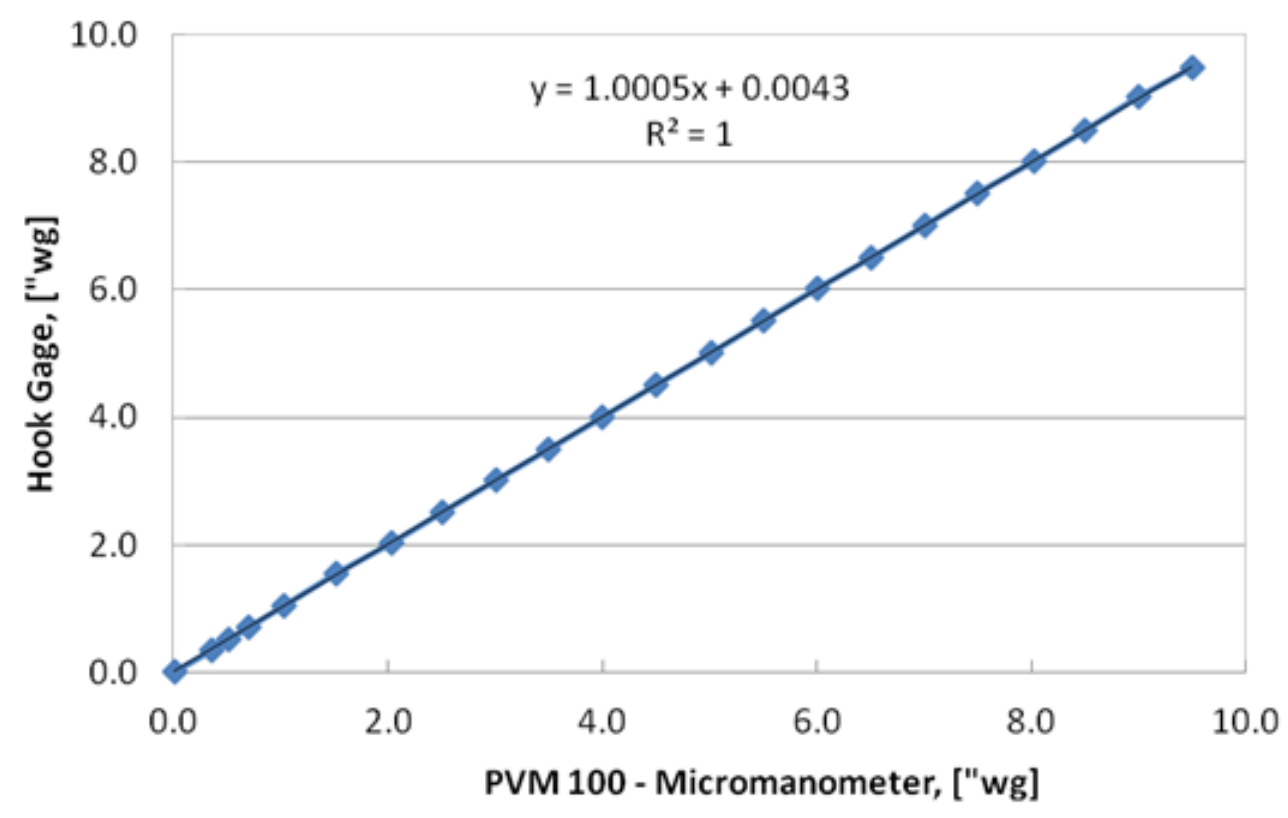

Figure H.1 PVM ${ }^{\circledR} 100$ micromanometer's calibration curve

\section{Regression analysis:}

Table H.2 Regression analysis of PVM ${ }^{\circledR} 100$ micromanometer's calibration data

Dependent variable is: Hook Gage

$\mathrm{R}$ squared $=100.0 \% \quad \mathrm{R}$ squared (adjusted) $=100.0 \%$

$\mathrm{s}=0.01007$ with $22-2=20$ degrees of freedom

\begin{tabular}{lcccc}
\hline Source & Sum of Squares & df & Mean Square & F-ratio \\
\hline Regression & 198.452 & 1 & 198.452 & $1.96 \mathrm{E}+06$ \\
Error & 0.00203 & 20 & 0.00010 & \\
Total & 198.454 & 21 & & \\
\hline Variable & Coefficient & s.e. of Coeff & t-ratio & prob \\
\hline Constant & 0.00428 & 0.00379 & 1.130 & 0.2720 \\
Micromanometer & 1.00054 & 0.00072 & $1.40 \mathrm{E}+03$ & $<0.0001$ \\
\hline
\end{tabular}




\section{APPENDIX I: Themometers calibration with a standard ASTM thermometer}

Feb. 14, 2012

5: $45 \mathrm{PM}$

Table I.1 Thermometers calibration with an ASTM thermometer

\begin{tabular}{ccccccc}
\hline Time, & \multicolumn{7}{c}{ Temperature, [deg C] } \\
\cline { 2 - 7 }$[\mathbf{m i n}]$ & Dry bulb & Wet Bulb & ASTM & Infrared & Thermocouple & Mean \\
\hline 1 & 23.7 & 23.1 & 23.3 & 23.6 & 23.2 & 23.4 \\
2 & 23.8 & 23.1 & 23.3 & 23.6 & 23.1 & 23.4 \\
3 & 24.0 & 23.2 & 23.3 & 23.6 & 23.1 & 23.4 \\
4 & 24.0 & 23.2 & 23.4 & 23.6 & 23.2 & 23.5 \\
5 & 23.9 & 23.1 & 23.4 & 23.6 & 23.1 & 23.4 \\
6 & 23.9 & 23.1 & 23.4 & 23.6 & 23.2 & 23.4 \\
7 & 23.9 & 23.1 & 23.4 & 23.6 & 23.2 & 23.4 \\
8 & 23.9 & 23.1 & 23.4 & 23.6 & 23.2 & 23.4 \\
9 & 23.9 & 23.1 & 23.4 & 23.6 & 23.2 & 23.4 \\
10 & 23.9 & 23.1 & 23.4 & 23.6 & 23.3 & 23.5 \\
\hline Mean & 23.9 & 23.1 & 23.4 & 23.6 & 23.2 & 23.4 \\
\hline
\end{tabular}

Notes:

- Wet bulb temperature was reading without put water in the sock

- The ASTM thermometer and the dry bulb and wet bulb thermometers were in vertical position, and at the same height and near the thermocouple on the back of the simple manikin.

- The lab heater was ON

- Measures with the IR thermometer were taken on the simple manikin's back close to the thermocouple

- Calibrations were carried out without $V_{\text {face }}$ and $V_{\text {cross }}$

- Thermometers' precision: Dry bulb: $+/-0.2^{\circ} \mathrm{C}$, ASTM : $0.1^{\circ} \mathrm{C}$, Infrared: +/$1^{\circ} \mathrm{C}$ 


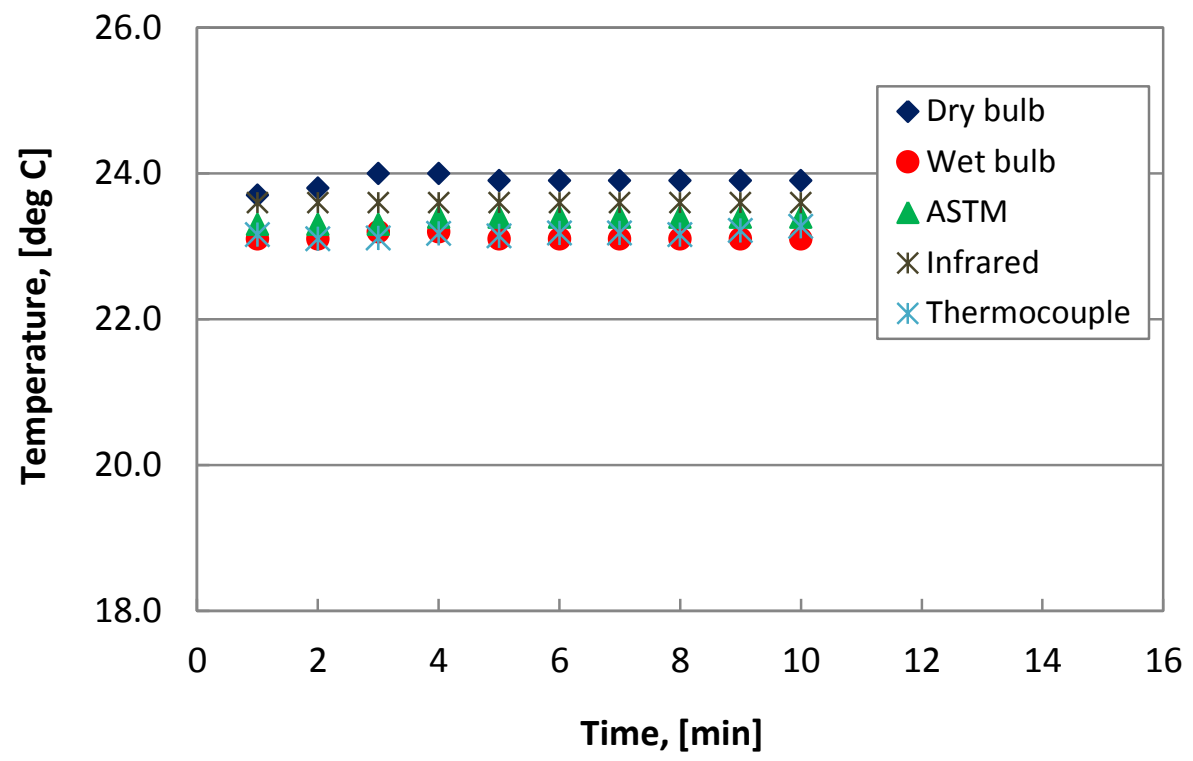

Figure I.1 Thermometer calibration with a ASTM thermometer 


\section{APPENDIX J: Hydraulic diameter $\left(D_{h}\right)$}

The hydraulic diameter can be calculated as,

$$
D_{h}=4 A / P
$$

Where,

$A=$ Cross-sectional flow area

$P=$ Wetted perimeter of the cross section

For the simple manikin study, the top view of the manikin is an ellipse

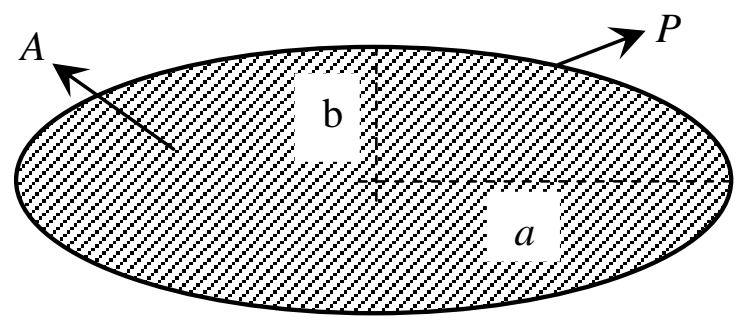

Figure J.1 Simple manikin cross-sectional flow area

Width of the manikin's shoulder $(D)$,

$D=2 a=17.5 ", \quad a=8.75$ in

$b=4 ”$

Then, the cross-sectional area and the perimeter are

$$
\begin{gathered}
A=\pi a b=109.96 \mathrm{in}^{2} \\
P \approx 2 \pi \sqrt{\frac{1}{2}\left(a^{2}+b^{2}\right)}=42.74 \mathrm{in}
\end{gathered}
$$

Then, the hydraulic diameter is

$$
D_{h}=10.29 \mathrm{in}
$$


At an approach velocity $(U)$ of $26.04 \mathrm{fpm}\left(V_{\text {cross }}=14 \mathrm{fpm}\right.$ and $V_{\text {face }}=100$ fpm), the Reynolds number based on the width of the manikin's shoulder $\left(\operatorname{Re}_{D}\right)$ and the Reynolds number based on the hydraulic diameter $\left(R e_{D_{h}}\right)$ are,

$$
\begin{gathered}
R e_{D}=4031 \\
R e_{D_{h}}=2370
\end{gathered}
$$

The numerical values of both Reynolds numbers $\left(R e_{D}\right.$ and $\left.R e_{D_{h}}\right)$ are different, which could affect the interpretation of the airflow regime and the way heat transfer was released from the subjects' body. The $D_{h}$ of simple and complex manikin were constant throughout the experiments. But for human subjects $R e_{D_{h}}$ and $R i$ will all be different because each human subject had its own $D_{h}$, which may be a factor in the variabilities observed in the measurements. All Reynolds numbers calculations in this work were based on the width of the shoulder $\left(R e_{D}\right)$ of both manikins and human subjects. 


\section{APPENDIX K: Thermocouples' temperature}

Complex manikin thermocouples' temperature:

TN : 932

Date : $7 / 27 / 2011$

Time : 11:13 AM

Table K.1 Thermocouples' temperature

\begin{tabular}{ccccc}
\hline & \multicolumn{3}{c}{ Thermocouples' temperature, $\left.{ }^{\mathbf{0}} \mathbf{C}\right]$} \\
\cline { 2 - 5 } Time, $[\mathbf{m i n}]$ & Face & Back & Ceiling & Sample wall \\
\hline 0 & 27.2 & 26.6 & 26.4 & 31.2 \\
1 & 27.2 & 26.6 & 26.4 & 31.3 \\
2 & 27.2 & 26.6 & 26.3 & 31.2 \\
3 & 27.2 & 26.6 & 26.4 & 31.2 \\
4 & 27.1 & 26.6 & 26.3 & 31.2 \\
5 & 27.2 & 26.5 & 26.3 & 31.1 \\
6 & 27.1 & 26.6 & 26.3 & 31.1 \\
7 & 27.1 & 26.6 & 26.3 & 31.1 \\
8 & 27.1 & 26.6 & 26.3 & 31.0 \\
9 & 27.1 & 26.5 & 26.3 & 31.0 \\
10 & 27.2 & 26.6 & 26.2 & 31.0 \\
11 & 27.1 & 26.5 & 26.3 & 30.9 \\
12 & 27.1 & 26.6 & 26.2 & 30.9 \\
13 & 27.1 & 26.5 & 26.2 & 30.9 \\
14 & 27.1 & 26.5 & 26.2 & 30.8 \\
15 & 27.1 & 26.5 & 26.2 & 30.8 \\
16 & 27.1 & 26.5 & 26.2 & 30.8 \\
17 & 27.1 & 26.5 & 26.2 & 30.8 \\
18 & 27.1 & 26.5 & 26.2 & 30.8 \\
19 & 27.0 & 26.4 & 26.1 & 30.7 \\
\hline
\end{tabular}

For Vface $=220 \mathrm{fpm}$ and Vcross $=63 \mathrm{fpm}$, thermocouples' temperature were recorded. During the 20 minutes experimental test, the temperature difference between the maximum and minimum value of the face location was $0.2{ }^{\circ} \mathrm{C}$. The same difference exists for the back location. Clearly, the temperature of the 
complex manikin's body does not change significantly throughout the experimental test.

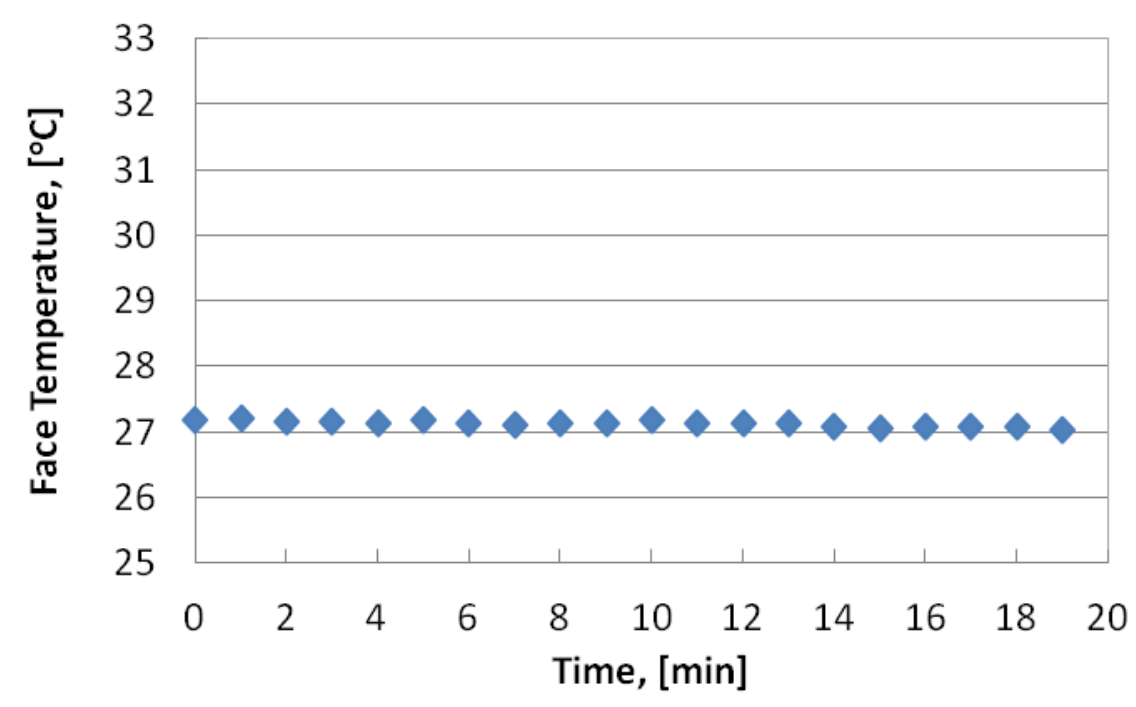

Figure K.1 Thermocouple's temperature at the face of the manikin 